Elizângela de Jesus Oliveira

(Organizadora)
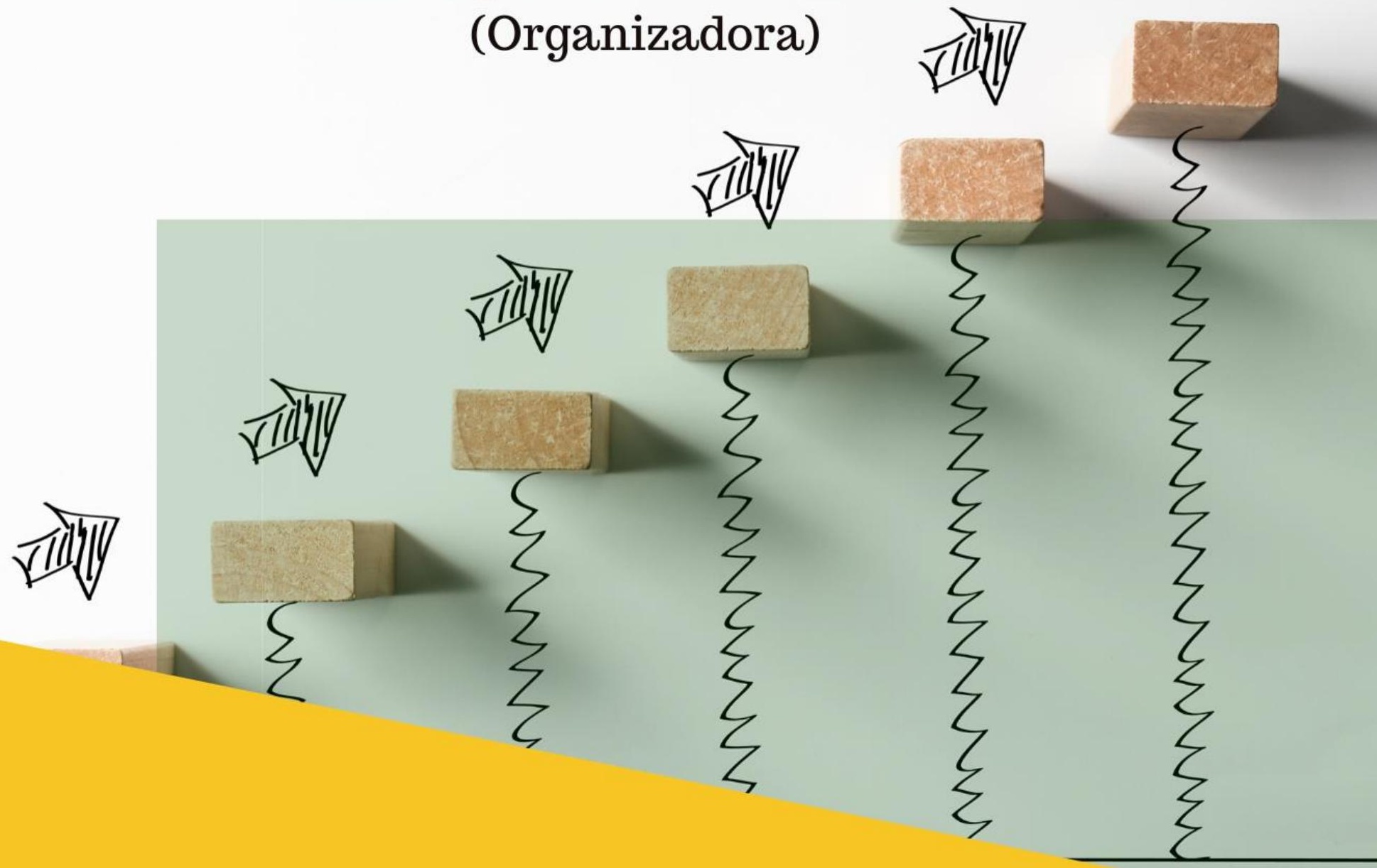

TÓpICOS EM

ADMINISTRAÇÃO

\title{
Volume 30
}

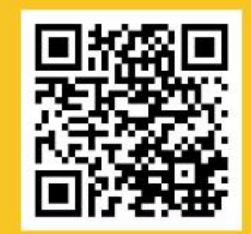


Elizângela de Jesus Oliveira

(Organizadora)

\section{Tópicos em Administração Volume 30}

1a Edição

Belo Horizonte

Poisson

2020 
Editor Chefe: Dr. Darly Fernando Andrade

\section{Conselho Editorial}

Dr. Antônio Artur de Souza - Universidade Federal de Minas Gerais

Ms. Davilson Eduardo Andrade

Dra. Elizângela de Jesus Oliveira - Universidade Federal do Amazonas

Msc. Fabiane dos Santos

Dr. José Eduardo Ferreira Lopes - Universidade Federal de Uberlândia

Dr. Otaviano Francisco Neves - Pontifícia Universidade Católica de Minas Gerais

Dr. Luiz Cláudio de Lima - Universidade FUMEC

Dr. Nelson Ferreira Filho - Faculdades Kennedy

Ms. Valdiney Alves de Oliveira - Universidade Federal de Uberlândia

Dados Internacionais de Catalogação na Publicação (CIP)

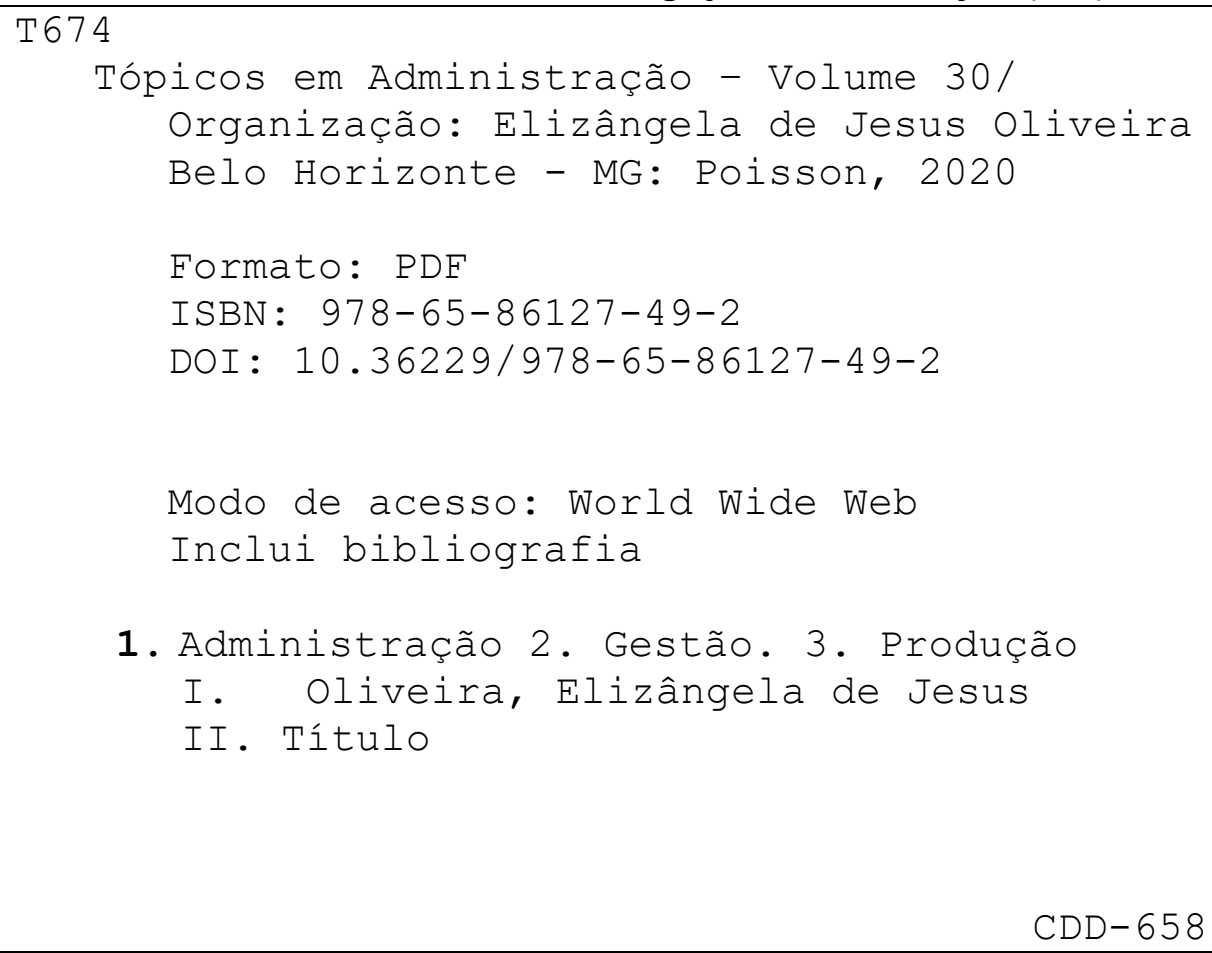

1. Administração 2. Gestão. 3. Produção

I. Oliveira, Elizângela de Jesus

II. Título

O conteúdo dos artigos e seus dados em sua forma, correção e confiabilidade são de responsabilidade exclusiva dos seus respectivos autores.

www.poisson.com.br

contato@poisson.com.br 


\section{SUMÁRIO}

Capítulo 1: How to avoid webrooming behavior improving consumer experience using their online touchpoints with brands. 8 Djonata Schiessl, Leticia Monteiro Pimentel, Demétrio de Mendonça Júnior, Helison Bertoli Alves Dias DOI: 10.36229/978-65-86127-49-2.CAP.01

Capítulo 2: Uma análise da importância de um modelo de negócio sistematizado para uma empresa do segmento têxtil 17

Poliana karina Faustino, Leandro Aparecido da Silva, Pablo Phorlan Pereira de Araujo, Salmo Batista de Araújo, Karla Dayane Bezerra Cruz, Tiago Douglas Cavalcante Carneiro

DOI: $10.36229 / 978-65-86127-49-2 . C A P .02$

Capítulo 3: 0 término da licença-maternidade e os desafios da Puérpera: Entrevistando trabalhadoras do comércio varejista no Sul do Brasil. 30

Helena Röpke, Simone Portella Teixeira de Mello, Elaine Garcia dos Santos

DOI: $10.36229 / 978-65-86127-49-2 . C A P .03$

Capítulo 4: Empoderamento Feminino: Estudo de caso em três Cooperativas de Crédito do Centro Oeste Mineiro 39

Hélia Geralda Siqueira, Marlene Catarina de Oliveira Lopes Melo

DOI: $10.36229 / 978-65-86127-49-2 . C A P .04$

Capítulo 5: Aspectos que influenciam a satisfação no trabalho: Estudo em uma empresa do comércio de autopeças 49

Regiane Aciléia Gonçalves Lopes, Claudelir Clein, Gilson Mussi dos Reis, Celito Nuernberg

DOI: $10.36229 / 978-65-86127-49-2 . C A P .05$

Capítulo 6: Estado da arte da produção científica dos artigos publicados no ENGEMA de 2014 a 2018. 59

Antônia Amanda Alves Pereira Moreira, Henrique César Melo Ribeiro, Magna da Silva Vilanova Castro, Matheus Morais Bruno, Rosany Corrêa

DOI: $10.36229 / 978-65-86127-49-2 . C A P .06$

Capítulo 7: Gestão ambiental e o papel social de uma cachaçaria artesanal no Piauí 70 Dalton Régis de Oliveira Soares, Jairo de Carvalho Guimarães

DOI: 10.36229/978-65-86127-49-2.CAP.07 


\section{SUMÁRIO}

Capítulo 8: Asseguração externa dos relatórios de sustentabilidade de empresas listadas na B3 2017 81

Heloisa Siqueira Lordello, Lygia Nathália Pereira da Silva

DOI: 10.36229/978-65-86127-49-2.CAP.08

Capítulo 9: Comércio internacional e desenvolvimento socioambiental: Um entendimento da temática em questão

Antônia Amanda Alves Pereira Moreira, Henrique César Melo Ribeiro, Rosany Corrêa, Magna da Silva Vilanova Castro, Matheus Morais Bruno

DOI: $10.36229 / 978-65-86127-49-2 . C A P .09$

Capítulo 10: Logística reversa do óleo de cozinha usado na cidade de Zé Doca-MA. 100 Neemias da Silva Nascimento, Francisco Sousa Costa, Stênio Lima Rodrigues, Marali Silva Santos, João Vitor de Oliveira Sousa, Ana Carla Cavalcante das Chagas

DOI: $10.36229 / 978-65-86127-49-2 . C A P .10$

Capítulo 11: Soluções tecnológicas para a segurança da navegação fluvial no Rio Negro 109

Celia Edi Lobo Silva, Jorge Gonçalves de Souza, Adão Marques dos Santos Cardoso, Paulo Ricardo de Oliveira Ramos

DOI: $10.36229 / 978-65-86127-49-2 . C A P .11$

Capítulo 12: Fatores limitantes para a inovação em micro e pequenas empresas no município de Zé Doca, Maranhão

Hugo da Costa Reis, Alexandre da Costa Reis, Stênio Lima Rodrigues, Marali Silva Santos, Ana Carla Cavalcante das Chagas, João Vitor de Oliveira Sousa

DOI: $10.36229 / 978-65-86127-49-2 . C A P .12$

Capítulo 13: A aplicação do Octógono da Inovação em uma organização pública 129

Ana Clara Cavalcanti de Miranda, Sérgio de Oliveira Lima, Millena de Carvalho da Cunha, Gesualdo Menezes Cavalcante, Alessandra Carla Ceolin

DOI: $10.36229 / 978-65-86127-49-2 . C A P .13$ 


\section{SUMÁRIO}

Capítulo 14: Contabilidade de custos e formação do preço de venda: Um estudo de caso em uma padaria.

Citania Aparecida Pilatti Bortoluzzi, Solange Chiossi, Tiago Francisco Camargo, Juliano Correa Daleaste, Ariberto Dalchiavon, Leossania Manfroi

DOI: $10.36229 / 978-65-86127-49-2 . C A P .14$

Capítulo 15: Índice de distorções financeiras do orçamento - IDFO: Uma proposta de ferramenta de avaliação da execução orçamentária municipal 154

Gustavo Silva de França, Marcos Paulo Andrade Silva, Silvana Maria de Jesus Vetter

DOI: $10.36229 / 978-65-86127-49-2 . C A P .15$

Capítulo 16: Educação financeira em ambientes colaborativos: 0 comportamento financeiro dos usuários de Coworking 165

Pedro Henrique da Silva Teles, Rebeca Sá do Nascimento Carrazzoni, Patrícia Lacerda de Carvalho DOI: $10.36229 / 978-65-86127-49-2 . C A P .16$

Capítulo 17: Compliance na iniciativa privada em Boa Vista Roraima 175

Eduardo Codevilla Soares, Aléxa Lauren Sousa Vasconcelos, Célia Dark Luzeiro Ribeiro

DOI: $10.36229 / 978-65-86127-49-2 . C A P .17$

Capítulo 18: 0 desempenho da exportação do açúcar no Porto de Santos e Paranaguá: E o advento do Apocalipse tecnológico, para os portuários em uma sociedade 5.0 185

Miriam Barbosa Soares

DOI: $10.36229 / 978-65-86127-49-2 . C A P .18$

Capítulo 19: Gestão e participação social na educação pública e conselhos gestores 194 Alexandre de Freitas Carneiro DOI: 10.36229/978-65-86127-49-2.CAP.19

Capítulo 20: Eficiência em licitações: Um estudo sobre o sistema compras WEB...... 206 Larissa Barbosa Ferreira de Souza, Flavio Pinheiro Martins, Luciana Romano Morilas DOI: $10.36229 / 978-65-86127-49-2 . C A P .20$ 


\section{SUMÁRIO}

Capítulo 21: Crescimento pró-pobre na Amazônia Legal: Uma análise para o decênio 2004-2014 com dados em painel.. 219

Luan Gomes de Oliveira, Abner Vilhena de Carvalho, Rhayza Alves Figueiredo de Carvalho, Jarsen Luis Castro Guimarães, Márcio Júnior Benassuly Barros, Mario Tanaka Filho, Rodolfo Maduro Almeida, Ednéa do Nascimento Carvalho

DOI: 10.36229/978-65-86127-49-2.CAP.21

Autores: 


\section{Capítulo 1}

How to avoid webrooming behavior improving consumer experience using their online touchpoints with brands

\section{Djonata Schiessl}

Leticia Monteiro Pimentel

Demétrio de Mendonça Júnior

Helison Bertoli Alves Dias

Abstract: The growing use of technology and the development of multiple sales channels offered consumers more options to purchase products. Technology has changed the way consumers go through the purchase journey as it helps them picturing the product in need and searching for the best option (pre-purchase) and also in the effective purchase and use of it (purchase and post-purchase). These changes in consumer journey brought forth new forms of consumption, such as the webrooming. The possibility to search in online channels and make the purchase in a physical store (webrooming) brings some problems to businesses with a focus on online channels, as it can decrease profits and sales. The objective of this research is to explore how brands can improve the consumer experience through the purchase journey and, in turn, reduce webrooming behavior. We contribute to retail literature highlighting triggers of the webrooming and showcasing propositions on how to reduce this behavior, through the improvement of consumerbrand touchpoints.

Keywords: Webrooming, customer journey, customer experience. 


\section{INTRODUCTION}

The increasing number of sales channels in recent years has changed the way consumers experience the purchase journey (Barwitz \& Maas, 2018; Lemon \& Verhoef, 2016). The technology was one of the most critical agents in these changes. It enabled brands to create websites and online stores, providing more touchpoints between consumers and brands. Further, it offered them more options to search and buy products. (Barwitz \& Maas, 2018; Pavlou, 2018).

According to Lemon \& Verhoef (2016), the consumer journey is characterized in three steps: prepurchase, purchase, and post-purchase. With more sales channels, consumers can switch between them during the purchase process (Pavlou, 2018). For instance, they can start this purchase process on the internet and finish it in an offline store, a behavior known as webrooming (Arora \& Sahney, 2018b). In other words, webrooming behavior happens when someone looks for products in online stores but decides to buy it on a physical store (Arora \& Sahney, 2018a). This choice of consumers to switch channels can have negative consequences for businesses selling products exclusively in online stores, resulting in a decrease in sales and profits (Arora \& Sahney, 2018b; Fernández, Pérez, \& Vázquez-Casielles, 2018).

Previous studies have mostly focused on consumer characteristics to explain the origins of webrooming behavior (Arora \& Sahney, 2017; Paper, Ho, \& Minh, 2016). Low trust in online stores, for example, lead them to look for products on the internet and buy it offline (Arora \& Sahney, 2018a). Other researchers showed that consumers who have a higher need to touch products before buying it are more prone to make purchases in physical stores (Fernandez et al., 2018).

However, an essential aspect of the buying journey has yet to be integrated into the webrooming framework: the consumer experience. It is present in all steps of the buying journey and can improve (or hinder) the consumer-brand relationship (Lemon \& Verhoef, 2016). Further, brands use their touchpoints to increase the experience and improve their relationship with consumers (Gregoire et al., 2017; Lemon \& Verhoef, 2016).

Given the relevance of the experience of buying journey and consequently to the webrooming behavior, we address in this work the relationship between them. We discuss the arguments made by Lemon \& Verhoef (2016) to explain how the experience generated within consumer-brand touchpoints in the journey can lead to behaviors of webrooming. We further make propositions regarding how brands can develop strategies to improve the experience and better control webrooming behavior.

In the next sessions, we will develop the theoretical background and our propositions regarding consumer journey touchpoints how they can generate webrooming behavior. We further discuss some possibilities for future research.

\section{CUSTOMER JOURNEY AND WEBROOMING}

The consumer journey is the entire process individuals make when acquiring a product, starting when they realize a specific need, including the purchase and use of a product which fills this need, and lasting until they discard it (Lemon \& Verhoef, 2016). Three steps compose buying journey: (i) prepurchase: when consumers search for options, assess their characteristics, and evaluate the best choice; (ii) purchase: the moment when they choose the product, order and pay for it and; (iii) postpurchase: the step in which consumers use the product, engage with the brand and may request post-purchase services (Lemon \& Verhoef, 2016).

Throughout this journey, touchpoints between brands and consumers can unfold, influencing their experience. These touchpoints emerge in the brand owned environment (e.g., advertisement and brand website) or they occur without the brand control, as consumers use its products in their daily life, interact with others regarding the brand in social media, and see the brand products in reviews websites (Lemon \& Verhoef, 2016).

Moreover, the experience can affect the loyalty consumers demonstrate to the brand (Daskalopoulou \& Skandalis, 2018; Kuehnl, Jozic, \& Homburg, 2019). Pleasant experiences (e.g., feeling the ease to search and buy a product on the brand website) lead them to demonstrate more brand loyalty. However, unsatisfactory experiences (e.g., Website not processing the consumer purchase of a product) contribute to individuals switching to other channels or brand competitors (George \& Wakefield, 2018; Kawaf, 2019). 
With the increasing use of technology, consumers have more options to search for products since more websites and online stores offering similar products are available (Anderl, Becker, von Wangenheim, \& Schumann, 2016; Ieva \& Ziliani, 2018). In this scenario, brands need to choose distinct strategies to attract them and maintain their loyalty (Anderl, Becker, et al., 2016; George \& Wakefield, 2018; Ieva \& Ziliani, 2018; Kawaf, 2019).

Past research has demonstrated that brands need to improve their touchpoints with consumers to increase the experience and, consequently, increase sales (Anderl et al., 2016; Lemon \& Verhoef, 2016). Some arguments in the literature showed that improve the experience to increase loyalty toward the brand (George \& Wakefield, 2018; Kawaf, 2019).

If a brand makes something wrong in the buying journey, it can affect consumer behavior in the sales channel (Halvorsrud, Kvale, \& Følstad, 2016; McColl-Kennedy, Zaki, Lemon, Urmetzer, \& Neely, 2019). Webrooming occurs when brands fail consumers during their purchase journey.

This behavior can be detrimental to brands that concentrate their business on online environments (Anantaram Balakrishnan, Sundaresan, \& Zhang, 2014). The failure caused by brands in the journey, more specifically in their touchpoints, affects the consumer relationship with the sales channel (George \& Wakefield, 2018; Kawaf, 2019). Thus they may choose another channel to close their purchases.

In this study, we will focus on sales made in websites and online stores as these internet sales channels have a significant impact on the economy (Statista, 2019), and especially because this is the environment where webrooming behavior emerges (Arora \& Sahney, 2017).

Looking at these previous researches that demonstrates the importance of experience in the buying journey (Lemon \& Verhoef, 2016), and how profound experience affect consumer relationship with brands (George \& Wakefield, 2018; Kawaf, 2019), we understand that profound experience (vs. high) generated in buying journey affect the webrooming behavior positively.

Webrooming will occur because the brand does not pay attention to the consumer journey, especially on consumer-brand touchpoints. It carries them to choose other options in this situation, another channel to buy the product.

Webrooming behavior generally occurs in pre-purchase and purchase stages, as consumers are just searching the best product, in that situation, it is easier for individuals to see the product on the internet and buy it in a physical store (Arora \& Sahney, 2017).

Sometimes people buy products just one time in their entire life (e.g., house), and for other products, purchases are more frequent (e.g., Pants) (Anderson, Foros, \& Kind, 2017). Bad experiences generated in post-purchase affect consumer behavior toward a brand if they need to repurchase the product. They consider other brand or channel in the subsequent purchase (Anderson et al., 2017; Lemon \& Verhoef, 2016).

Previous research in webrooming behavior demonstrated that consumers change their choice in prepurchase and purchase steps (Arora \& Sahney, 2017; Anantaram Balakrishnan et al., 2014; Fernández et al., 2018). As demonstrated by Kumar, Keller, \& Lemon (2016), all journey is relevant to improve their experience, Anderson et al. (2017) showed that consumers change their behavior if they need to buy the product just one time or more times. Looking at these results, we comprehend that Low experience (vs. high) in postpurchase step affect the webrooming behavior in next purchase positively.

Last researches did not explore the effect of repeated purchase on webrooming behavior (Arora \& Sahney, 2017; A Balakrishnan, Sundaresan, \& Zhang, 2014; Fernández et al., 2018), when consumers buy the product more than one time, their behavior will be affected by the experience generated in postpurchase, and it carries them to webrooming behavior in next purchase. To complement previous research, we propose that the experience generated in all stages of the buying journey leads to webrooming behavior.

As proposed by Lemon \& Verhoef (2016), the brand can use touchpoints with consumers to increase their loyalty and build a great experience for them. We propose that brands focusing on strategies through their touchpoints can reduce webrooming behavior. In the next session, we show some brand-consumer touch points that need to be improved to avoid this behavior. 


\section{TOUCHPOINTS}

In order to create an excellent experience, brands need to use touchpoints to do it (Lemon \& Verhoef, 2016). According to Lemon \& Verhoef (2016), there are four types of brand-consumer touchpoints: (i) the brand-owned; (ii) Partner owned; (iii) consumer-owned and; (iv) Social-owned. These different touchpoints impact them in different ways (Lemon \& Verhoef, 2016).

Touchpoints in offline or online stores have the same influences, but the types of touchpoints are different (Lemon \& Verhoef, 2016). For example, from an offline perspective, one brand-owned touchpoint is an ad in a press newspaper, and the same touchpoint in an online environment is an ad shown on Facebook.

We propose that low experience in online stores leads consumers to webrooming behavior. In this situation, the consumer sees a product on the internet and buy it in a physical store (Arora \& Sahney, 2017). We will demonstrate some brand-consumer touchpoints that brands can use to increase the experience and avoid webrooming. Some researches classified some touchpoints between the brand and consumers on the internet (Anderl, Becker, et al., 2016; Wolny \& Charoensuksai, 2014). In Table 1, we show possibles contact points between them.

Table 1 - Brand consumer touchpoints on the internet

\begin{tabular}{|c|c|c|c|c|}
\hline & Examples & Initiated By & Type of Touchpoint & Journey step \\
\hline Type-in & $\begin{array}{l}\text { The search box, shortcut, } \\
\text { bookmark }\end{array}$ & Consumer & Consumer-Owned & Prepurchase \\
\hline Search & Google & Consumer & External-Owned & Prepurchase \\
\hline Price comparison & Websites that aggregate prices & Consumer & $\begin{array}{l}\text { Partner- } \\
\text { owned/External } \\
\text { Owned }\end{array}$ & Prepurchase \\
\hline Display & $\begin{array}{l}\text { Advertising, in a website, or social } \\
\text { network }\end{array}$ & Brand & Brand-Owned & Prepurchase \\
\hline Retargeting & Personal Ad & Brand & $\begin{array}{l}\text { Brand- } \\
\text { Owned/Partner } \\
\text { Owned }\end{array}$ & Prepurchase \\
\hline Social Context & Online reviews, Brand communities & Consumer & Social-Owned & $\begin{array}{l}\text { Prepurchase/Po } \\
\text { stpurchase }\end{array}$ \\
\hline Newsletter & E-mail marketing & Brand & Brand-Owned & $\begin{array}{l}\text { Prepurchase/Po } \\
\text { stpurchase }\end{array}$ \\
\hline Social media & Twitter, Facebook, Instagram & Brand & Brand-Owned & $\begin{array}{l}\text { Prepurchase/Po } \\
\text { stpurchase }\end{array}$ \\
\hline Affiliate & $\begin{array}{l}\text { Digital influencers, or partner } \\
\text { websites }\end{array}$ & Brand/consumer & Partner-Owned & $\begin{array}{l}\text { Prepurchase/Po } \\
\text { stpurchase }\end{array}$ \\
\hline Referrer & $\begin{array}{l}\text { Partners that show your product } \\
\text { links in their websites }\end{array}$ & Brand/consumer & Partner-owned & $\begin{array}{l}\text { Prepurchase/Po } \\
\text { stpurchase }\end{array}$ \\
\hline Online store & $\begin{array}{l}\text { Own online store, Partner Online } \\
\text { Store }\end{array}$ & Brand/Partner & $\begin{array}{l}\text { Brand- } \\
\text { Owned/Partner } \\
\text { Owned }\end{array}$ & Purchase \\
\hline
\end{tabular}

Adapted from: (Anderl et al., 2016; Lemon \& Verhoef, 2016)

These are the essential touchpoints between brands and consumers on the internet environment (Anderl et al., 2016; Lemon \& Verhoef, 2016), brands need to use any touchpoint to improve the experience and avoid webrooming. We propose that a combination of fails made in touchpoints can lead consumers to this behavior.

The brand has control over the majority of touchpoints in an online environment and can explore all touchpoints to increase consumer experience and consequently avoid webrooming behavior (Anderl, Becker, et al., 2016; Anderl, Schumann, \& Kunz, 2016; Lemon \& Verhoef, 2016).

According to Lemon \& Verhoef (2016), brands can use different strategies to improve the experience. The structure and resources influence the number of touchpoints with consumers (Anderl, Becker, et al., 2016; Ieva \& Ziliani, 2018). Brands must highlight existing touchpoints to improve loyalty toward the brand (Lemon \& Verhoef, 2016). 
To better explore this touchpoint, we will use customer journey steps to make our prepositions. As demonstrated, low consumer experience conduct them to webrooming. The brand needs to make some fails in more of one touchpoint to motivate consumers to adopt this behavior (Lemon \& Verhoef, 2016).

\section{GENERAL MODEL}

Figure 1 pictures our general model to better understand the proposed antecedents of webrooming. The profound experience generated in any step lead consumers to switch from the online sales channel. Thus, brands can increase the experience in any step of the journey and avoid webrooming.

Figure 1: General Framework

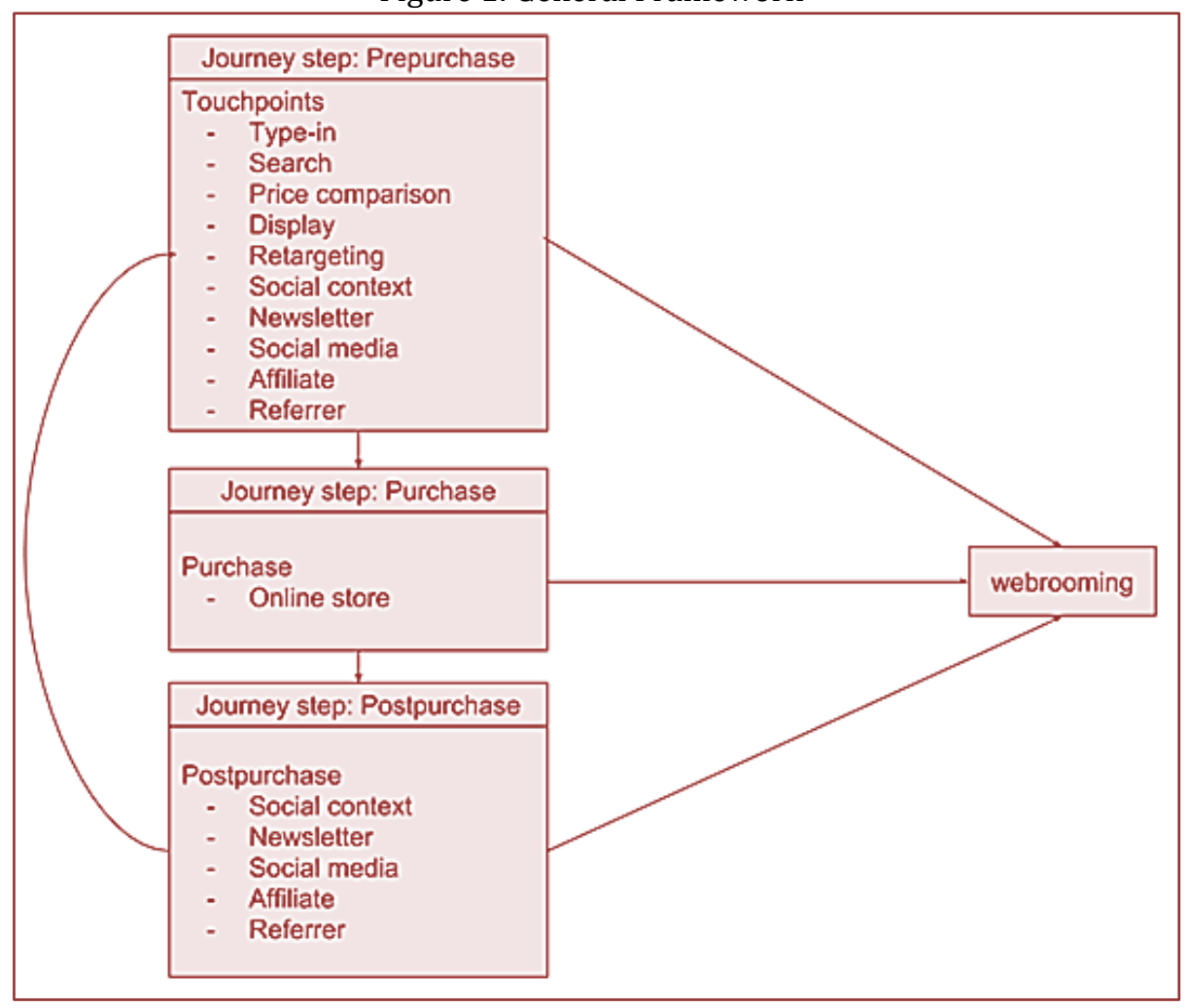

Figure 1 shows the relationship between buying journey steps and their impact on webrooming behavior. It is possible to see the elements that can influence consumer experience and touchpoints that need to be improved to avoid webrooming.

On the prepurchase step, consumers are searching for products, recognizing all brands, and considering all possibilities for the purchase (Lemon \& Verhoef, 2016). In this stage, brands must start the building of an excellent experience for them (Lemon \& Verhoef, 2016). Brands can make partners and improve the structure to offer sound options and increase consumer experience on prepurchase (Anderl, Becker, et al., 2016).

At the purchase stage, people are ordering and paying for it (Lemon \& Verhoef, 2016); in this step is necessary to them attempt to structure of the website and brand need to guarantee a good experience in this environment (Anderl, Becker, et al., 2016). For example, page load time affects their attitudes on websites (Rose, Lees, \& Meuter, 2011), consumers leave the page before they buy the product if the time of page load is high (Rose et al., 2011).

In the post-purchase stage, consumers are using the product, engaging with the brand and using some brand services (Lemon \& Verhoef, 2016), we propose that the promotion of a kind experience is essential to avoid webrooming behavior when they make a repeated purchase. 
The experience generated at one stage of the buying journey affects their behavior in the next purchase (Mattila \& Wirtz, 2000). Thus, postpurchase also has an essential role in preventing webrooming.

The stages of buying journey affect their experience and consequently affect webrooming behavior. Managers need to increase consumer experience, improving touchpoints to avoid these attitudes (Anderl, Schumann, et al., 2016; Lemon \& Verhoef, 2016).

The model showed in figure 1 helps us to better understand some antecedents of webrooming, in this case, using buying journey and experience generated on the internet (Anderl, Schumann, et al., 2016; Lemon \& Verhoef, 2016). Another relevant aspect is to understand the influence of any step of the journey (pre-purchase, purchase and post-purchase) on consumer behavior (Lemon \& Verhoef, 2016) and our propositions aim to explain these steps on the behavior of webrooming.

The objective of this model is to test the effect of low experience (vs. high) generated in any step of the journey, using touchpoints and the impact of poor experience on webrooming behavior.

In the next sessions, we discuss some implications of our propositions to theory and marketing practice, and some limitations and future research possibilities.

\section{GENERAL DISCUSSION}

Increasing the use of technology generates some changes in consumer behavior (van Noort \& van Reijmersdal, 2019). One perspective demonstrated by Lemon \& Verhoef (2016) is that the buying journey is affected by technology, and brands need to pay attention at this point because on the internet the touchpoints between brand and consumer are different.

As showed by Anderl, Schuman et al. (2016), the touchpoints on the internet affect consumer behavior and attitudes toward the brand. We propose that one of these behaviors can be webrooming when someone looks at a product on the internet and buy it in a physical store (Arora \& Sahney, 2017).

Past research has demonstrated some antecedents of webrooming behavior, Arora \& Sahney (2018b) showed that low trust on online stores leads them to behave in this manner, they also show that some consumers need to touch the product to buy it. Another antecedent explored by Arora \& Sahney (2017b) is that some consumers like to go to a physical store to buy.

Webrooming behavior is detrimental to brands selling in online environments, this, in turn, makes brand prone to use low prices to attract consumers, and with this strategy, brand profits are reduced (Anantaram Balakrishnan et al., 2014).

We also explored another antecedent that generates webrooming behavior, the experience generated on the buying journey. We proposed that profound experience in the journey because poor contact between brand and consumer touchpoints carries them to webrooming behavior. We explored the effect of lousy experience made in all buying journeys on webrooming behavior. Lemon \& Verhoef (2016) propose that the experience is generated on the whole journey because this reason is interesting to study the effect of the entire model shown in figure 1.

In their research Mattila \& Wirtz (2000) showed that experience generated in one stage of journey affect another step, we aim to explain if low experience generated in postpurchase step generate webrooming behavior in next purchase when they make repeated purchases. These results will show us what is necessary for to manager to focus on the three steps of the consumer journey because all of them are important (Lemon \& Verhoef, 2016).

All steps of the buying journey are essential, but some brand focus just in one or two stages. We intend to demonstrate the separated effects and show touchpoints that the brand needs to improve to increase consumer experience in any step and avoid webrooming behavior.

We propose that low experience generated in one step can affect the experience in a subsequent step. We intend to demonstrate that it is necessary to brand to have a balance between three steps. For example, if a brand has a good experience on the purchase step but a poor experience on the Prepurchase step, the effect can be carried to the purchase stage.

Understanding better webrooming antecedents managers can use some strategies to avoid this behavior that frequently happens on internet improving experience through consumer journey using online touchpoints (Arora \& Sahney, 2018b). In the next session, we demonstrate the managerial contributions of our research. 


\section{MANAGERIAL CONTRIBUTIONS}

With the increasing use of technology, some business focuses on online sells (Rowley, 2004) because this environment offers some advantages, like offer more information or, for instance, reduce the costs of a brand. (Rowley, 2004). The internet also offers more touchpoints between a brand and consumer (Anderl, Schumann, et al., 2016).

Besides, with the increasing use of technology, some consumer's behavior also changes (Anderl, Schumann, et al., 2016; Lemon \& Verhoef, 2016). One of these behavior is webrooming that frequently happens on the internet when they see the product in an online store and buy it in a physical store (Arora \& Sahney, 2017).

We proposed that this behavior occurs because of the profound experience generated in the buying journey. Lemon \& Verhoef (2016) showed that the experience is build using existing touchpoints between brand and consumer. We also show some of these touchpoints in our research.

If our prepositions are correct, managers can use our research to improve consumer experience using online touchpoints (Anderl, Becker, et al., 2016; Lemon \& Verhoef, 2016) and reduce webrooming behavior. The managers can use touchpoints in this research as a guide and map the touchpoints of their brands and work to improve them.

How was demonstrated by Anantaram Balakrishnan et al. (2014), webrooming behavior affects brand profits. After testing our prepositions, managers can develop touchpoints and improve the consumer experience, and they increase their profits.

They can use our research to identify what are the most critical steps of the journey to spend money on the most critical steps improving investment efficacy. The objective of exploring all steps is to demonstrate that it is necessary to create a balance and distribute resources between three steps.

\section{LIMITATIONS AND FUTURE RESEARCH}

We found two limitations to our work. The first one is that we just show some research possibilities; it is necessary to test these prepositions to contribute more with theory and managers. The second limitation is that we used just webrooming behavior to make our propositions. Other behaviors can happen because of profound experience, the showrooming. It happens when someone looks at the product on a physical store and buy it in the online store (Mehra, Kumar, \& Raju, 2013).

Next, studies need to verify if webrooming behavior is generated by low experience created in buying journey, we think that experimental methodology can be used to manipulate bad experiences in any online touchpoint and measure these effects on webrooming behavior.

There are some touchpoints between consumer and brand, how was demonstrated in box 1 . Next, researches can explore different combinations of these touchpoints to verify the best combination and offer some possibilities to brands to develop their strategies in buying a journey using resources better and avoiding webrooming behavior.

We show in our model three antecedents of webrooming behavior (Prepurchase, purchase, and postpurchase). We suggest that the next studies test it using a structural equation model to see the size of these antecedents in our general model.

In our research, we propose that low consumer experience affect positively webrooming behavior. Future researches can explore some mediators like psychological mechanisms that affect webrooming (Arora \& Sahney, 2018b) and some moderators like store characteristics or individual characteristics (Fernández et al., 2018).

Other research can explore the effect of low experience generated in a physical store on consumer showrooming behavior, what happens when someone looks at a product in a physical store and buy it an online store (Mehra et al., 2013), making our research we found some pieces of evidence that this behavior can occur in the physical environment. It is necessary to explore offline touchpoints and how they affect the experience in the offline store. 


\section{REFERENCES}

[1] Anderl, E., Becker, I., von Wangenheim, F., \& Schumann, J. H. (2016). Mapping the customer journey: Lessons learned from graph-based online attribution modeling. International Journal of Research in Marketing, 33(3), 457474. https://doi.org/https://doi.org/10.1016/j.ijresmar.2016.03.001

[2] Anderl, E., Schumann, J. H., \& Kunz, W. (2016). Helping Firms Reduce Complexity in Multichannel Online Data: A New Taxonomy-Based Approach for Customer Journeys. Journal of Retailing, 92(2), 185-203. https://doi.org/https://doi.org/10.1016/j.jretai.2015.10.001

[3] Anderson, S. P., Foros, Ø., \& Kind, H. J. (2017). Product Functionality, Competition, and Multipurchasing. International Economic Review, 58(1), 183-210. https://doi.org/10.1111/iere.12213

[4] Arora, S., \& Sahney, S. (2017a). Webrooming behaviour: a conceptual framework. International Journal of Retail and Distribution Management, 45(7-8), 762-781. https://doi.org/10.1108/IJRDM-09-2016-0158

[5] Arora, S., \& Sahney, S. (2017b). Webrooming behaviour: a conceptual framework. International Journal of Retail and Distribution Management, 45(7-8), 762-781. https://doi.org/10.1108/IJRDM-09-2016-0158

[6] Arora, S., \& Sahney, S. (2018a). Antecedents to consumers' showrooming behaviour: an integrated TAM-TPB framework. Journal of Consumer Marketing, 35(4), 438-450. https://doi.org/10.1108/JCM-07-2016-1885

[7] Arora, S., \& Sahney, S. (2018b). Consumer's webrooming conduct: an explanation using the theory of planned behavior. Asia Pacific Journal of Marketing and Logistics, 30(4), 1040-1063. https://doi.org/10.1108/APJML-082017-0185

[8] Balakrishnan, A, Sundaresan, S., \& Zhang, B. (2014). Browse-and-switch: Retail-online competition under value Uncertainty. Production and Operations Management, 23(7), 1129-1145. https://doi.org/10.1111/poms.12165

[9] Balakrishnan, Anantaram, Sundaresan, S., \& Zhang, B. (2014). Browse-and-switch: Retail-online competition under value Uncertainty. Production and Operations Management, 23(7), 1129-1145. https://doi.org/10.1111/poms.12165

[10] Barwitz, N., \& Maas, P. (2018). Understanding the Omnichannel Customer Journey: Determinants of Interaction Choice. Journal of Interactive Marketing, 43, 116-133. https://doi.org/10.1016/j.intmar.2018.02.001

[11] Daskalopoulou, A., \& Skandalis, A. (2018). Consumption field driven entrepreneurship (CFDE): How does membership in the indie music field shape individuals' entrepreneurial journey. European Journal of Marketing, 53(1), 63-82. https://doi.org/10.1108/EJM-06-2017-0424

[12] Fernández, N. V., Pérez, M. J. S., \& Vázquez-Casielles, R. (2018). Webroomers versus showroomers: Are they the same? Journal of Business Research, 92(August), 300-320. https://doi.org/10.1016/j.jbusres.2018.08.004

[13] George, M., \& Wakefield, K. L. (2018). Modeling the consumer journey for membership services. Journal of Services Marketing, 32(2), 113-125. https://doi.org/10.1108/JSM-03-2017-0071

[14] Gregoire, Y., Walkowiak, T., Voorhees, C. M., Bone, S., Fombelle, P. W., Gustafsson, A., \& Sousa, R. (2017). Service encounters, experiences and the customer journey: Defining the field and a call to expand our lens. Journal of Business Research, 79(April), 269-280. https://doi.org/10.1016/j.jbusres.2017.04.014

[15] Halvorsrud, R., Kvale, K., \& Følstad, A. (2016). Improving service quality through customer journey analysis. Journal of Service Theory and Practice, 26(6), 840-867. https://doi.org/10.1108/JSTP-05-2015-0111

[16] Ieva, M., \& Ziliani, C. (2018). The role of customer experience touchpoints in driving loyalty intentions in services. TQM Journal, 30(5), 444-457. https://doi.org/10.1108/TQM-11-2017-0141

[17] Kawaf, F. (2019). Capturing digital experience: The method of screencast videography. International Journal of Research in Marketing. https://doi.org/https://doi.org/10.1016/j.ijresmar.2018.11.002

[18] Kuehnl, C., Jozic, D., \& Homburg, C. (2019). Effective customer journey design: consumers' conception, measurement, and consequences. Journal of the Academy of Marketing Science. https://doi.org/10.1007/s11747018-00625-7

[19] Kumar, V., Keller, K. L., \& Lemon, K. N. (2016). Introduction to the Special Issue-Mapping the Boundaries of Marketing: What Needs to be Known. Journal of Marketing, 80(6), 1-5. https://doi.org/10.1509/jm.80.6.1

[20] Lemon, K. N., \& Verhoef, P. C. (2016a). Understanding Customer Experience Throughout the Customer Journey. Journal of Marketing, 80(6), 69-96. https://doi.org/10.1509/jm.15.0420

[21] Lemon, K. N., \& Verhoef, P. C. (2016b). Understanding Customer Experience Throughout the Customer Journey. Journal of Marketing, 80(6), 69-96. https://doi.org/10.1509/jm.15.0420

[22] Lemon, K. N., \& Verhoef, P. C. (2016c). Understanding Customer Experience Throughout the Customer Journey. Journal of Marketing, 80(6), 69-96. https://doi.org/10.1509/jm.15.0420 
[23] Mattila, A., \& Wirtz, J. (2000). The role of preconsumption affect in postpurchase evaluation of services. Psychology and Marketing, 17(7), 587-605. https://doi.org/10.1002/(SICI)1520-6793(200007)17:7<587::AIDMAR2>3.0.CO;2-3

[24] McColl-Kennedy, J. R., Zaki, M., Lemon, K. N., Urmetzer, F., \& Neely, A. (2019). Gaining Customer Experience Insights That Matter. Journal of Service Research, 22(1), 8-26. https://doi.org/10.1177/1094670518812182

[25] Mehra, A., Kumar, S., \& Raju, J. S. (2013). Competitive Strategies for Brick-and-Mortar Stores to Counter "Showrooming." Ssrn, (February 2019). https://doi.org/10.2139/ssrn.2200420

[26] Paper, C., Ho, E., \& Minh, C. (2016). The trend of showrooming and webrooming behaviors of the consumers in Ho Chi Minh City The trend of showrooming and webrooming behaviors of the consumers in Ho Chi Minh City, (April 2015).

[27] Pavlou, P. A. (2018). Consumer Acceptance of Electronic Commerce: Integrating Trust and Risk with the Technology Acceptance Model. International Journal of Electronic Commerce, 7(3), 101-134. https://doi.org/10.1080/10864415.2003.11044275

[28] Rose, G. M., Lees, J., \& Meuter, M. L. (2011). A refined view of download time impacts on e-consumer attitudes and patronage intentions toward e-retailers. International Journal on Media Management, 3(2), $105-111$. https://doi.org/10.1080/14241270109389953

[29] Rowley, J. (2004). Online branding. Online Information Review, 28(2), 131-138. https://doi.org/10.1108/14684520410531637

[30] Statista. (2019). Online shopping and buying-related activities performed by internet users in the United States as of March 2018. Retrieved February 3, 2019, from https://www.statista.com/statistics/868862/onlineshopping-buying-related-activities-internet-users/

[31] Van Noort, G., \& van Reijmersdal, E. A. (2019). Branded Apps: Explaining Effects of Brands' Mobile Phone Applications on Brand Responses. Journal of Interactive Marketing, 45, 16-26. https://doi.org/https://doi.org/10.1016/j.intmar.2018.05.003

[32] Wolny, J., \& Charoensuksai, N. (2014). Mapping customer journeys in multichannel decision-making. Journal of Direct, Data and Digital Marketing Practice, 15(4), 317-326. https://doi.org/10.1057/dddmp.2014.24 


\section{Capítulo 2}

Uma análise da importância de um modelo de negócio sistematizado para uma empresa do segmento têxtil

\section{Poliana karina Faustino}

Leandro Aparecido da Silva

Pablo Phorlan Pereira de Araujo

Salmo Batista de Araújo

Karla Dayane Bezerra Cruz

Tiago Douglas Cavalcante Carneiro

Resumo: Em um universo totalmente competitivo, empresas precisam inovar para que possam estabelecer um diferencial de mercado. Com a necessidade de atender as demandas, os empreendimentos procuram sempre manter um planejamento estratégico sistematizado, para que possa ter segurança, rapidez e organização na tomada de decisão. Desta forma, este estudo apresentou a seguinte problemática: Como aperfeiçoar um modelo de negócio empresarial através de uma ferramenta sistematizada? Para tanto, apresenta como objetivo geral elaborar um modelo de negócio sistematizado para uma empresa do segmento têxtil. Apresenta como objetivos específicos: identificar a percepção do gestor com relação à utilização do Sistema de Informação na gestão do negócio, averiguar junto ao gestor a viabilidade da utilização do modelo de negócio CANVAS em seu empreendimento e sugerir a implementação do Sistema de Informação Sebrae CANVAS para o aperfeiçoamento do modelo de negócio da organização. Com isso, o estudo conta com uma observação in loco, revisão bibliográfica para apresentar os conceitos, baseando-se nas obras de Turban e Volonino (2013), Veras (2017) entre outros. A pesquisa é exploratória, qualitativa, pois teve como base a revisão bibliográfica e informações cedidas pelo gestor da empresa. Os métodos utilizados permitiram a análise do planejamento estratégico da organização, indentificando a carência de ferramentas importantes. Acredita-se que o estudo proporcionou um feedback satisfatório, devido o fato do gestor confirmar seu interesse na implantação da ferramenta utilizada.

Palavras-chave: Planejamento estratégico; Sistema de Informação; Ferramenta CANVAS. 


\section{INTRODUÇÃO}

Devido ao mercado consumidor está cada vez mais exigente e competitivo, é necessário que as empresas planejem-se estrategicamente para reduzirem os seus riscos tornando-se mais eficazes, podendo assim proporcionar um diferencial competitivo com maior abrangência de consumidores. Esse método de planejar o futuro da organização traz uma maior segurança no momento de tomar decisões mais arriscadas, pois é com base no que foi planejado para o empreendimento que o gestor poderá analisar e tomar a decisão mais adequada para que não resulte em consequências não planejadas.

Os Sistemas de Informações estão cada vez mais ganhando espaço no cotidiano das empresas, auxiliando os gestores na tomada de decisão mais acertada. Com base em dados formalizados e alinhados nos computadores, obtêm-se informaç̧ões mais precisas e detalhadas, ocasionando uma organização necessária para a empresa com menos perda de dados por meio de papéis. Conforme Turban e Volonino (2013) as empresas devem está inovando sempre nos seus sistemas para que possam acompanhar o mercado, que encontra-se muito acirrado.

Veras (2016) salienta que o planejamento estratégico é uma avaliação de todos os ambientes da empresa, interno e externo, desde a missão até uma análise SWOT. É essencial que esse plano seja bem elaborado, conter clareza nas informações, ser simples e de fácil manuseio diário. Pensando nessa necessidade que muitos gestores possuem, criou-se a ferramenta CANVAS, por sentir a dificuldade que alguns gestores possuíam para desenvolver seu plano de negócio. A ferramenta auxilia na tomada de decisão do empreendimento para melhor alcance dos objetivos.

Com a ajuda do Sistema de Informação, o CANVAS está gradativamente ganhando mais espaço nas empresas. O SEBRAE (2015) desenvolveu uma ferramenta que permite qualquer pessoa possa criar ou modificar seu modelo de negócio. Está disponibilizado gratuitamente em seu site, e pode ser criada, modificada, compartilhada com outras pessoas e salva no sistema, o que torna mais dinâmica a criação do planejamento organizacional, proporcionando maior segurança, sem a necessidade de compra de cartazes para a sua elaboração, já que tudo é feito exclusivamente por meio de um sistema disponível na rede.

Diante todas as dificuldades já apresentadas, o estudo foi aplicado junto à empresa, a Tecelagem $\mathrm{S}$ Nogueira que atua no segmento têxtil. Instalada em Jardim de Piranhas/RN há 12 anos com a fabricação exclusiva dos panos de prato. Atualmente, a organização conta com 21 colaboradores de forma direta e 9 colaboradores indiretos (terceirizados). Pensando na importância da empresa possuir um planejamento eficaz para o alcance de metas sem correr riscos, elaborou-se a seguinte problemática para este estudo: Como aperfeiçoar um modelo de negócio empresarial através de uma ferramenta sistematizada? 0 intuito do estudo foi o de agregar e dispor de novos conhecimentos para a empresa afim de que o gestor possa desenvolver melhores planejamentos estratégicos para o sucesso do seu negócio.

Diante do problema, definiu-se como objetivo geral elaborar um modelo de negócio com base nas informações presentes na organização utilizando um Sistema de Informação. A partir de então, foi delineado as metas a serem alcançadas durante o estudo. Portanto, o primeiro objetivo específico foi identificar a percepção do gestor com relação à utilização do Sistema de Informação na gestão do negócio. O segundo foi averiguar junto ao gestor a viabilidade da utilização do modelo de negócio CANVAS em seu empreendimento, e por último, buscou-se implementar o Sistema de Informação utilizando a ferramenta SEBRAE CANVAS para o aperfeiçoamento do modelo de negócio organizacional.

\section{TIPOS DE SISTEMAS DE INFORMAÇÃO PARA O NEGÓCIO}

Com a competitividade no mercado consumidor as empresas possuem a necessidade de um planejamento eficaz para diferenciar-se das demais, superando suas expectativas e as dos clientes. Para isso, Audy e Brodbeck (2008) salientam que a empresa tem por obrigação um planejamento estratégico que auxilie na tomada de decisão para assim obter uma vantagem competitiva e que o uso da Tecnologia da Informação (TI) deve estar sempre focado para o futuro, na visão que a empresa possui. Sendo assim, a organização deve ter o cuidado sobre o planejamento e a TI para que os mesmos façam parte da empresa como parte de auxiliar nas decisões positivamente, pois assim como pode ajudar, poderá atrapalhar se usado inadequadamente (Stair \& Reynolds, 2006).

Conforme define Lopes (2017, p.171), "Os sistemas, do ponto de vista empresarial, podem ser classificados de acordo com a sua forma de utilização e o tipo de retorno dado ao processo de tomada de decisões." Percebe-se então que, a empresa antes de implantar um sistema, deve possuir o conhecimento sobre os tipos de sistemas, para que assim possa aderir ao mais adequado para o seu negócio. 
Assim como ressaltam Turban e Volonino (2013, p.349) “[...] são uma classe de Sistema de Informação que combina modelos e dados para solucionar problemas semiestruturados e não estruturados com envolvimento intensivo do usuário." Sendo assim, o SI necessita que o seu operador tenha alta disponibilidade de tempo para o seu manuseio, pois requer uma organização dos dados cautelosa para que possa transmitir uma solução rápida e eficaz.

\subsection{SISTEMA DE INFORMAÇÃO PARA ORGANIZAÇÃO DE DADOS E INFORMAÇÕES}

As informações geradas por meio dos dados informatizados proporcionam para a empresa a eficácia que os papéis não possuem. Stair e Reynolds (2006) ressaltam a importância do Sistema de Informação ao afirmar que o principal objetivo é fazer com que a empresa possa alcançar suas metas antes mesmo do tempo que seria estimado para isso, organizando e planejando com mais detalhes de forma eficiente. Compreende-se assim, que o estabelecimento que possui a TI como parte da organização dos seus dados e informações, dispõe de resultados mais precisos, rápidos, com a qualidade que a empresa necessita para transmitir as informações para as pessoas certas no momento adequado.

Para que as empresas possam tomar decisões importantes, é necessário obter as informações claras com o propósito de não deixar dúvidas no momento da resolução do problema. Assim, é de suma importância que na era da informação, as organizações possuam sistemas que auxiliem na tomada de decisão. A TI está cada vez mais revolucionando o mercado, que está sempre mais competitivo, e com isso, a informatização do negócio se torna fator fundamental para que a empresa se mantenha no mercado (Lopes, 2017). Antes de qualquer implantação na empresa, o gestor necessita elaborar um plano de negócio eficaz, para que não ocorra erros inesperados.

\subsection{PLANO DE NEGÓCIOS PARA O SUCESSO DA EMPRESA}

O planejamento estratégico é o caminho traçado pela empresa para sair de determinada situação para chegar em um futuro proveitoso. 0 início de um plano de negócios deve ser feito com base nas prioridades da empresa, o que a mesma prefere, pois no plano estratégico deve conter os objetivos que o gestor almeja para se obter sucesso no mercado (Veras, 2017).

A importância do gestor possuir o conhecimento do seu negócio, antes de tudo do que a sua empresa prioriza para que assim a mesma possa definir um plano eficaz, estabelecendo as estratégias de acordo com as suas necessidades e objetivos específicos. 0 planejamento estratégico mostra aos gestores uma direção, pensando na tomada de decisão futura, visando alcançar seus objetivos e evitar riscos (Mendonça et al., 2017). Sendo assim, o plano adequado para o empreendimento aumenta as chances de sucesso da mesma.

Pize (2017) aborda algumas dificuldades enfrentadas pelas organizações no momento de obter um planejamento adequado, como de revisão do planejamento, centralização nas decisões, erros cometidos sendo repetidos, falta de comunicação entre os demais membros da empresa. Com a visão do autor, é perceptível a dificuldade de alguns estabelecimentos em serem mais flexíveis à mudanças no momento de tomar decisões importantes.

Para que o gestor possa implantar um método seguro, é importante avaliar a possibilidade do Sistema de Informação mais adequado. Para que ocorra o equilíbrio da TI com as necessidades da empresa é necessário que haja um gerenciamento na TI, tornando os serviços disponíveis por ela um diferencial competitivo devido a segurança de informações para o gestor (Silva, Araújo \& Dornelas, 2018). Então, a tecnologia se torna uma peça chave para que o negócio ganhe os clientes e o mercado competitivo.Um modelo que apresenta-se prático, de fácil interpretação e compreensão é o modelo de negócios CANVAS.

\subsection{CANVAS DENTRO DAS EMPRESAS}

Empreender pode ser caro ou não, isso depende da criatividade do empreendedor. Afinal o século 21 está cheio de tecnologia, inovações e principalmente criatividade, o que gera uma vantagem competitiva considerável para o gestor enfrentar o mercado competitivo. Ser criativo requer responsabilidade e segurança na tomada de decisão, pois não é só pensar e fazer, e sim pensar e planejar antes de fazer. Está sempre buscando estratégias eficazes para o negócio será um auxílio no alcance de metas (Melo et al., 2017). 
Para ajudar o novo empreendedor a ter sucesso na sua jornada administrativa, Carmona (2017) ressalta que o CANVAS é muito importante para as empresas que estão iniciando no mercado, pelo fato de que o modelo apresenta visualmente o que seguirá, com informações íntegras, rápidas e organizadas. Sobre a visão holística do autor é importante observar o conjunto de detalhes importantes que a ferramenta possui para colaborar com a tomada de decisão da organização de forma simples e de fácil acesso, já que pode ser feito por meio de computador, até por meio de planilhas, o importante é organizar e ter controle das informações para a tomada de decisão mais acertada.

O CANVAS para integrar as empresas foi pensando para reduzir os altos custos de implantação de métodos eficazes para auxílio na tomada de decisão. Além de ser uma ferramenta eficaz nas análises, possui criatividade para a tomada de decisão de fácil compreensão (Pize, 2017). Por ser um modelo de planejamento estratégico de um custo benefício importante, também é de fácil introdução no ambiente interno do negócio. No momento inicial da empresa, principalmente de um Micro Empreendedor Individual (MEI), o capital é bem significativo, e para que o empreendedor não acumule muitas dívidas no início do empreendimento, o CANVAS é importante para auxiliá-lo na tomada de decisão.

O CANVAS em conjunto com a tecnologia podem proporcionar resultados rápidos e importantes para a empresa no momento da tomada de decisão, já que o seu acesso se tornou flexível aos novos meios de comunicação. A TI se tornou prioridade nos negócios e os softwares estão cada vez mais acompanhando as carências dos empreendimentos. Conforme Veras (2016) os sistemas com base em computadores pessoais foram primordiais para o início da gestão de projetos e recentemente com os avanços tecnológicos, o apoio dos aplicativos (app) em nuvem, e o app CANVAS, trouxeram a facilidade de novas experiências para os gestores.

Com o tempo, as coisas vão avançando e ficando tecnológicas, a necessidade de mudança aumenta gradativamente. Isso gera uma carência por modernizar e essa mudança requer melhorias que envolvem transformações em todos os processos da empresa (Muller, 2017). Essa melhoria só é considerada mudança quando ocorre o aperfeiçoamento em um produto, serviço ou nos processos pertencentes à organização.

0 modelo CANVAS sempre está se adequando ao novo mundo tecnológico. Devido às necessidades de mudanças nas empresas o modelo adaptou-se para que pudesse contribuir ainda mais com os negócios, só que agora de forma tecnológica. Para que o negócio seja diferente dos outros, é necessário haver um diferencial competitivo para o alcance e o desempenho máximo no mercado (Veras, 2016).

O modelo baseado em CANVAS foi desenvolvido em 2004 por Alexander Osterwalder na tese do seu doutorado, sob a orientação de seu professor Pigneur, com o objetivo de auxiliar no desenvolvimento da avaliação sobre o plano de negócio da empresa, que com pouco tempo acabou virando livro (Pontes, 2017).

Considerado uma ferramenta criativa para integrar os negócios, possui a inovação, flexibilidade, eficiência e vantagem competitiva no controle de informações, conseguindo traçar as metas do estabelecimento em um único método de planejamento de negócios. 0 modelo de negócio criado em 2004 é descrevido como um mapa visual por possuir análises de hipóteses fáceis para o futuro do negócio, possibilitando o gestor uma flexibilidade para realização das modificações necessárias (Biava, 2017).

O planejamento estratégico é uma junção do presente com o futuro da empresa, as metas do gestor planejadas de acordo com o que está acontecendo com seu negócio atualmente, visando evitar riscos futuros (Mendonça et al., 2017).

Devido a necessidade do seu uso, o CANVAS está sendo cada vez mais utilizado, principalmente em plataformas tecnológicas (Sistemas de Informação). O Serviço Brasileiro de Apoio às Micro e Pequenas Empresas (SEBRAE) apoia os empreendedores nas suas inovações e ajuda as empresas a crescer de forma simples. O SEBRAE (2015) disponibiliza a ferramenta para que os empreendedores usem de forma inovadora, criem e até repensem melhor sobre seu planejamento estratégico, podendo compartilhar, comentar e até avaliar o modelo estratégico com outros usuários.

No CANVAS é abordado os nove blocos para o planejamento estratégico da empresa. Para isso é importante que o gestor estabeleça suas prioridades e defina seus objetivos. Veras (2017) comenta que o empreendedor deverá fazer os seguintes questionamentos para um melhor planejamento: como vou fazer? 0 que será feito? Para quem? Quanto irá custar e quanto irei ganhar? Ao fazer essa análise e ter tudo definido, o gestor terá seu plano de negócio pronto, podendo haver modificações ao longo dos dias, sempre se adaptando de acordo com a necessidade da empresa. 
O acesso ao sistema do modelo de planejamento estratégico é gratuito, basta criar login (acesso a um sistema informatizado) e senha para que este possa acessar e criar o seu próprio modelo de negócio. A seguir será demonstrado o modelo estratégico disponibilizado no site do SEBRAE CANVAS.

A ilustração mostra as cinco dimensões utilizadas no momento da análise de maturidade. É perceptível que o sistema de informações está presente em todos os planejamentos estratégicos, pela sua forma tecnológica de segurança, rapidez e praticidade no seu manuseio que proporcionam ao gestor uma maior confiança em depositar seus dados e informações para que possam tomar uma decisão acertada (Campos, 2017).

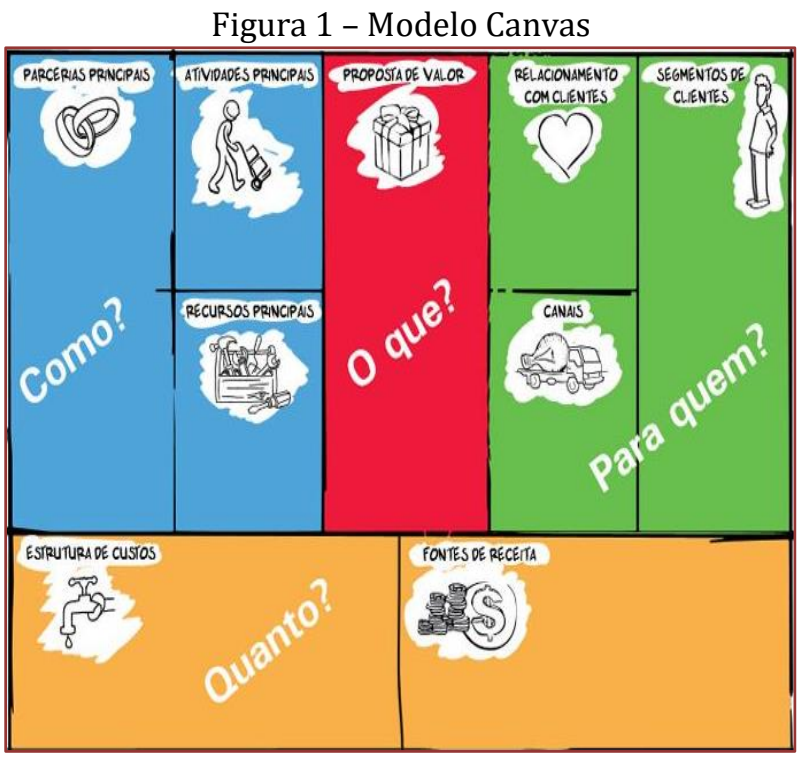

Fonte: adaptado de SEBRAE (2015)

A seguir apresenta-se o método utilizado para contemplação de todas as etapas do estudo.

\section{MÉTODO}

A respeito do problema, o estudo se enquadra como qualitativo por não ter como base os números para a representação das respostas, sendo assim, o pesquisador torna-se peça fundamental para a tradução e desenvolvimento da pesquisa. É o entendimento do sujeito sobre o objetivo e o subjetivo sem o uso de cálculos, apenas usando uma forma indutiva para analisar os dados coletados (Matias-Pereira, 2018).

A pesquisa caracteriza-se como exploratória que tem como intuito esclarecer conceitos de forma mais flexível, para que assim proporcione melhor entendimento, tendo no seu contexto entrevistas abertas para que o alvo das perguntas possa ficar à vontade no momento de responder. Com relação aos objetivos, caracteriza-se como uma pesquisa explicativa por procurar esclarecer problemas buscando uma explicação coerente para fácil entendimento, ocasionando em melhores resultados (Gil, 2012).

Ainda utilizou-se para o enriquecimento do estudo uma observação informal. Esta observação caracterizase por o pesquisador não precisar usar meios técnicos para alcance total dos objetivos, pois não possui um planejamento e controles anteriormente analisados (Matias-Pereira, 2018). A pesquisa foi realizada na empresa Tecelagem S Nogueira, que fica localizada no centro de Jardim de Piranhas/RN, esta atua no segmento têxtil. Ao longo da pesquisa foi desenvolvida uma entrevista com o gestor da empresa, colaborando com a coleta dos dados da pesquisa.

Para se obter as informações necessárias para a pesquisa, foi realizada uma primeira entrevista no dia 16 de maio de 2018 às 16:00, aplicou-se a ferramenta Sebrae CANVAS no dia 30 de outubro de 2018, com necessidade de apenas um dia para sua conclusão, para que assim fosse realizada uma segunda entrevista que ocorreu no dia 05 de novembro de 2018 às 9:00 com o gestor da empresa objeto de estudo. Andrade (2018) ressalta que a entrevista é eficaz se tiver boa coerência e bem elaborada, já que o pesquisador deve possuir o cuidado no momento de criar as questões a serem feitas e interpretadas de forma clara. Assim, a entrevista se torna peça chave para obtenção de informações importantes para o estudo. 


\section{ANÁLISE DOS RESULTADOS}

Foi realizada entrevistas com o gestor para obtenção dos resultados do estudo. Elaborou-se perguntas subjetivas para o empresário com o propósito de identificar um feedback positivo ou negativo diante de suas respostas. Em uma entrevista inicial que abordou questões sobre a utilização dos Sistemas de Informações. Um dos pesquisadores começou a entrevista com a seguinte pergunta: Como é realizado o controle da informação na organização? Em resposta o gestor relatou: "A forma de recebimento dos clientes das vendas é tudo anotado em blocos e a forma de pagamento dos funcionários, dos fornecedores que compro matéria prima tudo também é só em blocos, cadernos, anotado". Com isso foi identificada a carência de obtenção correta dos dados para obter uma informação coerente. Turban e Volonnino (2013) comentam que o Sistema de Informação possui um propósito de solução de problemas, respeitando a cultura da empresa.

Com isso foi perguntado: Qual a maior necessidade da empresa na organização das informações? O gestor respondeu da seguinte forma: "A falta de um Sistema de Informação para ter o controle de entradas e saídas dos pagamentos e armazenamento das informações". Neste momento o gestor afirmou a necessidade de um Sistema de Informação para a sua empresa, pois o mesmo possui um controle de informações ultrapassado e além disso, um pouco desorganizado já que as anotações, muitas são feitas em qualquer papel e o mesmo acaba perdendo os dados e informações importantes. Audy e Brodbeck (2008) afirma que o Sistema de Informação faz um alinhamento de todos os dados e informações para decisões seguras.

Tendo em vista a resposta, foi designada uma pergunta mais detalhada a respeito da forma de tomar a decisão. Com isso, fez a pergunta: Com base em quais critérios é tomada a decisão na empresa? A resposta do gestor foi clara: "Olho no bloco as informações e diante delas as decisões são tomadas". Diante dessa resposta, consegue-se constatar ainda mais a importância da implantação de Sistema de Informação, para que houvesse maior controle, qualidade, organização e segurança dos dados e informações para que a empresa não corresse riscos elevados de perdas de informações do financeiro, proporcionando ao gestor maior facilidade de controle de informações e segurança no armazenamento das mesmas. Rainer e Cegielski (2011) ressalta que os sistemas fornecem apoio às decisões com base em análises mais complexas em computadores.

Com o andamento da entrevista, uma pergunta foi primordial para que identificasse o grau do conhecimento do gestor, portanto o questionamento foi: Qual o seu conhecimento acerca do Sistema de Informação? Com essa indagação o empresário justificou-se: "Tenho um vago conhecimento sobre planilhas, eu não sei manusear, mas estou aberto para aprender". A resposta foi fundamental para que o estudo fosse cauteloso de acordo com as carências da empresa e do gestor para que não houvesse altos riscos no início de um novo método de controle de informações no negócio. Segundo Baltzan e Phillips (2012) o sistema sozinho não é útil, necessitando de uma pessoa capacitada para gerenciar de forma correta.

Sendo assim, a entrevista continuou com maior necessidade de se coletar informações com maior precisão sobre o tema em estudo. Com isso foi necessária fazer a pergunta: Qual a importância de um Sistema de Informação para a sua empresa? Foi respondido: "Acho muito importante para ter um controle rápido, organizado e seguro das informações". Neste momento, o empresário mostrou que estava ciente da importância de um Sistema de Informação ser implantado na sua empresa, tendo em vista o reconhecimento da alta necessidade de controle dos dados de seus clientes e fornecedores. Mannino (2008) afirma que com o banco de dados a empresa possui o acesso de informações importantes que ficam armazenadas com segurança e que no momento certo são recuperadas.

Procurando compreender a maior dificuldade de armazenamento das informações por meio de um Sistema de Informação, fez-se a seguinte indagação: Quais as dificuldades enfrentadas pela empresa na implantação de um Sistema de Informação? Diante deste questionamento o gestor pensou nas diversas necessidades da empresa e respondeu: "Não sei mexer e precisa de uma pessoa que saiba mexer em sistemas de informação". Pelo fato de o empresário não possuir o manuseio adequado para controlar as informações no sistema, propôs-se que o gestor inicialmente contrata-se uma pessoa específica para manusear as informações da empresa de forma segura, que resultou no consentimento do mesmo. Conforme Rainer e Cegielski (2011) é complicado manter o método de desenvolvimento das informações, por isso requer responsabilidade.

É fundamental que o empreendimento se adeque às suas novas adaptações aos poucos, para que não haja perdas de dados no momento de inovar no controle de informações. Com base nisto, a pergunta executada teve a seguinte necessidade de esclarecer: Qual o meio de Sistema de Informação mais adequado para se 
implantar em curto prazo na empresa? Por quê? A resposta foi a seguinte: "Planilhas, pois já tenho no computador e é mais fácil de manusear e eu já tenho uma noção". A forma mais rápida de organização de informações escolhida pelo empresário no momento possui significado positivo pelo fato de ser um meio barato e seguro de controle da empresa. Para Baltzan e Phillips (2012) devido à alta demanda de informações, não se pode confiar em relatórios manuais, sendo o sistema um colaborador importante para a tomada de decisão.

Como o mercado consumidor está mais exigente, as empresas estão sempre procurando inovar e ter seu destaque perante seus clientes e fornecedores. Explicando ao gestor todo o envolvimento de um Sistema de Informação dentro de uma organização, foi perguntado: As estratégias que um Sistema de Informação proporciona para a empresa seriam um diferencial competitivo? Por quê? Tendo como base sua experiência de mercado, foi esclarecido da seguinte maneira: "Sim, porque a empresa que possui um sistema possui um maior controle de informações e gera uma maior segurança para o cliente". Desta forma ficou claro que o cliente sente maior segurança de comprar em uma empresa que possua maior organização, no controle de informações principalmente. Conforme Audy e Brodbeck (2008) um planejamento estratégico eficaz é um instrumento importante, juntamente com os sistemas para auxiliar na tomada de decisão.

Com a perspectiva de mudanças, conseguiu-se observar o interesse da parte do gestor em mudar seus métodos de controle de informações com isso foi indagado: Você acredita que uma empresa sistematizada possui maior abrangência no mercado? Por quê? Após a explicação melhor da pergunta, o gestor respondeu: "Sim, pois possui um controle das informações de toda a empresa e com base nelas saberá se terá capacidade de atender as demandas". Com a respectiva afirmação, pode-se concluir que o gestor possui o conhecimento de que uma empresa com controle de informações possui uma capacidade maior de atender o mercado, pois com as informações rápidas e claras, é possível uma maior precisão na resposta para o cliente. Turban e Volonino (2013) salientam que as empresas necessitam se adequar aos novos sistemas para obter vantagem competitiva.

Para finalizar a entrevista, foi primordial executar uma pergunta a respeito do futuro do empreendimento. Com isso, fez-se o questionamento: Quais seus planos futuros em relação aos tipos de Sistemas de Informação para a sua empresa? A questão foi solucionada da seguinte forma: "Pretendo implantar os principais tipos de sistemas para que possa me ajudar no controle de toda a empresa para que eu tome uma decisão com maior certeza". Diante da resposta, é importante observar o avanço do estudo realizado, as melhorias principalmente no pensamento do gestor em relação ao armazenamento dos dados e informações da empresa. Segundo Mannino (2008) o banco de dados é vital para a empresa que possui sistemas pela facilidade em recuperar e a manutenção das informações.

Em um segundo momento, com uma entrevista abordando questões sobre à ferramenta CANVAS. 0 gestor foi indagado com a seguinte pergunta: Como você faz para alcançar os objetivos da empresa? 0 mesmo respondeu: "Devido eu ter pouco estudo, acabo fazendo os planos com base na minha experiência de comércio, só na minha cabeça, mas sei que esse método não é o certo, o que torna meu planejamento um pouco errado." Percebe-se que o gestor possui um planejamento antigo e perigoso pelo fato de não haver um estudo sobre as necessidades reais da empresa, juntamente com a carência dos consumidores.

Veras (2016) ressalta que para um planejamento eficaz, é necessário passar pela determinação de objetivos, como alcançar as metas e elaborar o plano de ação. Diante do pensamento do autor é perceptível que há a importância de haver um estudo minucioso para o plano de sucesso.

Seguindo com as perguntas, foi realizada a indagação: Quais os critérios que você usa para basear os planos de administração da empresa? Obteve-se a resposta: "Me baseio pelo o comercio atual, a demanda do meu produto. Com isso, vou vendo o que posso fazer para melhorar as vendas. Na parte da produção, deixo o controle de qualidade por conta do meu gerente e com base no que ele me diz eu tomo uma decisão." É perceptível que o empreendedor faz seu planejamento estratégico com base no achismo, no que o mesmo ver diariamente e é informado pelo gerente.

É importante ressaltar que é um sistema de planejamento com riscos, já que pode ocorrer ruídos na comunicação do colaborador com o gestor, além do mercado está em constante mudanças que por isso necessita de estudos cautelosos. Mendonça et al. (2017) afirma que existe uma técnica para o planejamento estratégico e que o mesmo não pode ser feito com base em achismo. Na perspectiva do autor, é notável que para todo empreendimento, o estudo do mercado e da empresa em si é primordial para obter vantagem competitiva, então, não se pode tomar decisões sem antes haver todo um conhecimento adequado do segmento. 
Seguindo com a entrevista, perguntou-se: Você considera o planejamento de administração da empresa eficaz? "Não como deveria ser. Sei que para se ter um bom negócio devo melhorar algumas coisas que vejo que está errado mas as vezes vou deixando de lado. Meus planos são muitos por impulso, penso que vai dar certo e tento, sem me planejar e sei que isso é errado para a minha empresa." Neste momento o gestor reconhece que sua forma de planejar suas metas é perigoso por ser muito por impulso e achismo. 0 reconhecimento de que algo seja feito errado é importante para que possa corrigir e adequar da forma correta para a empresa.

Segundo Carmona (2017) elaborar um cronograma, conferir tudo em detalhes e criar uma mente inovadora que ver o futuro da empresa em pouco tempo é mais fácil. Nesta visão, percebe-se que os gestores veem um planejamento de forma demorada, mas proporciona feedback importante para que o estabelecimento alcance o resultado esperado há um curto prazo.

Com a apresentação adequada da ferramenta ao gestor e a explicação devida sobre a sua importância, perguntou-se: Você acredita que o auxílio da ferramenta CANVAS pode ajudar nas suas tomadas de decisões? "Sim. Após o conhecimento dele vi que é algo simples de se utilizar, que torna uma maior segurança na minha tomada de decisão, devido verificar o plano atual do meu negócio e fazer um maior planejamento." É importante observar o resultado do estudo na empresa, que apesar de pouco tempo, vêse uma diferença do interesse do empreendedor de adequar suas necessidades a sua tomada de decisão para que possa ser feita de forma correta e com segurança.

Veras (2017) lembra que a principal função do CANVAS é toda a coleta de informação do negócio e a sua representação adequada. Isso proporciona para empresa uma maior organização de seus objetivos e diante da ferramenta pode verificar o que realmente pode abranger.

No decorrer das indagações, a autora fez o seguinte questionamento: 0 modelo de negócio CANVAS seria adequado para auxiliar na gestão de sua empresa? "Sim. Depois que vi que é simples e de fácil acesso, pode melhorar muito a organização da minha empresa. Percebi que uma coisa tão simples e fácil pode me ajudar bastante a ganhar mais espaço no mercado." Neste ponto é possível verificar a importância do estudo em uma microempresa que possui um plano antigo de atingir metas e arriscado e que com uma simples ferramenta demostrada pode melhorar muito o desempenho do planejamento estratégico e aumentar a qualidade da tomada de decisão.

Para Pontes (2017) o CANVAS organiza as grandes ideias e disponibiliza a visualização de pontos importantes para empresa. Sendo assim, permite ao gestor verificar possíveis oportunidades que antes não eram perceptíveis, um fator bastante significativo para o empreendimento se manter perante os concorrentes e aumentar seu índice de procura por seus produtos.

No decorrer da entrevista, teve a importância de fazer a pergunta: Você acredita que um sistema computacional poderia facilitar na administração do seu negócio? "Sim. O sistema é importante porque organiza com maior segurança e tem uma maior facilidade de ver as informações." É perceptível o feedback que foi obtido com o estudo in locus, que proporcionou ao gestor um valor agregado maior, uma melhor obtenção de resultados que anteriormente o seu negócio não possuía de forma adequada para auxiliá-lo na tomada de decisão.

Segundo Turban e Volonino (2013) um Sistema de Informação em tempo real possui acesso rápido às informações, ocasionando em uma decisão segura. 0 sistema oferece a praticidade que toda empresa precisa para o auxílio na tomada de decisão, pois todos os dados e informações já estão prontas, o que acarreta em um planejamento mais preciso e eficaz.

Com todas as explicações antes e durante a entrevista, perguntou-se: Após conhecer o sistema CANVAS, você gostaria de utilizá-lo para a administração do seu negócio? "Sim. Gostei dessa maneira de planejar, fácil, com segurança e sem custos, já que o Sebrae tem disponível de graça." É importante verificar que muitas empresas ainda não possui um planejamento adequado pensando por pensar no custo que irá ter. Ao se deparar com a informação que o Sebrae dispõe da ferramenta de graça, percebe-se que a sua adesão se torna mais fácil, o que proporciona grande importância para a organização.

Segundo Veras (2017) a ferramenta auxilia o gestor por ser mais informal, que identifica os principais pontos do negócio e é usada diariamente. Assim, o CANVAS oferece a praticidade e segurança que necessita no momento de tomar uma decisão, proporcionando a qualidade ideal das informações coletadas para não correr riscos.

Para finalizar a entrevista com o gestor da empresa em estudo, foi feita a seguinte indagação: Na sua percepção, qual o tempo necessário para utilizar o modelo CANVAS no seu negócio? "Em pouco tempo. 
Meus filhos estão organizando a empresa atualmente e essa forma de planejar será importante nessa organização. As informações serão passadas para eles, devido a minha dificuldade de mexer em tecnologia. Será de grande importância tomar minhas decisões de forma mais segura." 0 gestor não possui o manuseio adequado dos novos meios de melhorar a tomada de decisão. É perceptível o seu interesse de melhorar a qualidade e segurança das decisões, disponibilizando para que seus filhos possam manusear com base nas informações do empreendedor.

Para Biava (2017) o CANVAS é uma excelente ferramenta pelo de fato simplificar as informações que o gestor necessita. Nota-se que o modelo de negócio é essencial para facilitar mensagens dentro e fora da empresa. É importante ressaltar a importância da entrevista para a conclusão do estudo. Com base nela, observa-se o avanço da pesquisa e o valor agregado que proporciona a empresa, aumentando seu poder de tomada de decisão mais acertada para o mercado consumidor que está altamente competitivo.

A ferramenta escolhida para ser utilizada na pesquisa dentro da empresa em estudo foi o Modelo de Negócios CANVAS, onde está representado todo o planejamento da empresa para o alcance de suas metas no mercado consumidor. O CANVAS possui a característica de fácil manuseio onde aumenta as chances do gestor está modificando de acordo com suas necessidades e tomadas de decisão.

A simplicidade de elaborar um plano de negócio de vantagem competitiva faz com que as empresas procurem aderir cada vez mais rápido para que auxilie na tomada de decisão à curto prazo. Esta ferramenta proporciona para o empreendimento maior segurança em todas as áreas pelo fato de conter todas as informações necessárias para o negócio (Mendonça et al., 2017). A seguir será explicado o modelo CANVAS desenvolvido junto a empresa objeto de estudo.

Os parceiros chaves são os fornecedores de matéria prima para a empresa. Neste caso, o empreendimento é do segmento têxtil, que possui a necessidade de manter o controle ideal com os fornecedores citados, sempre mantendo a negociação da qualidade oferecida e preços, pois para a satisfação total do consumidor, o gestor prioriza a qualidade desde o início da produção ao produto final e para isso é de suma importância manter fornecedores de confiança e qualidade. Rodrigues (2018) explica que os parceiros chave é uma relação da empresa com fornecedores e parceiros que se torna parte fundamental para que o negócio se desenvolva de forma adequada para que alcance o sucesso.

Figura 2 - Canvas desenvolvido para Tecelagem S Nogueira

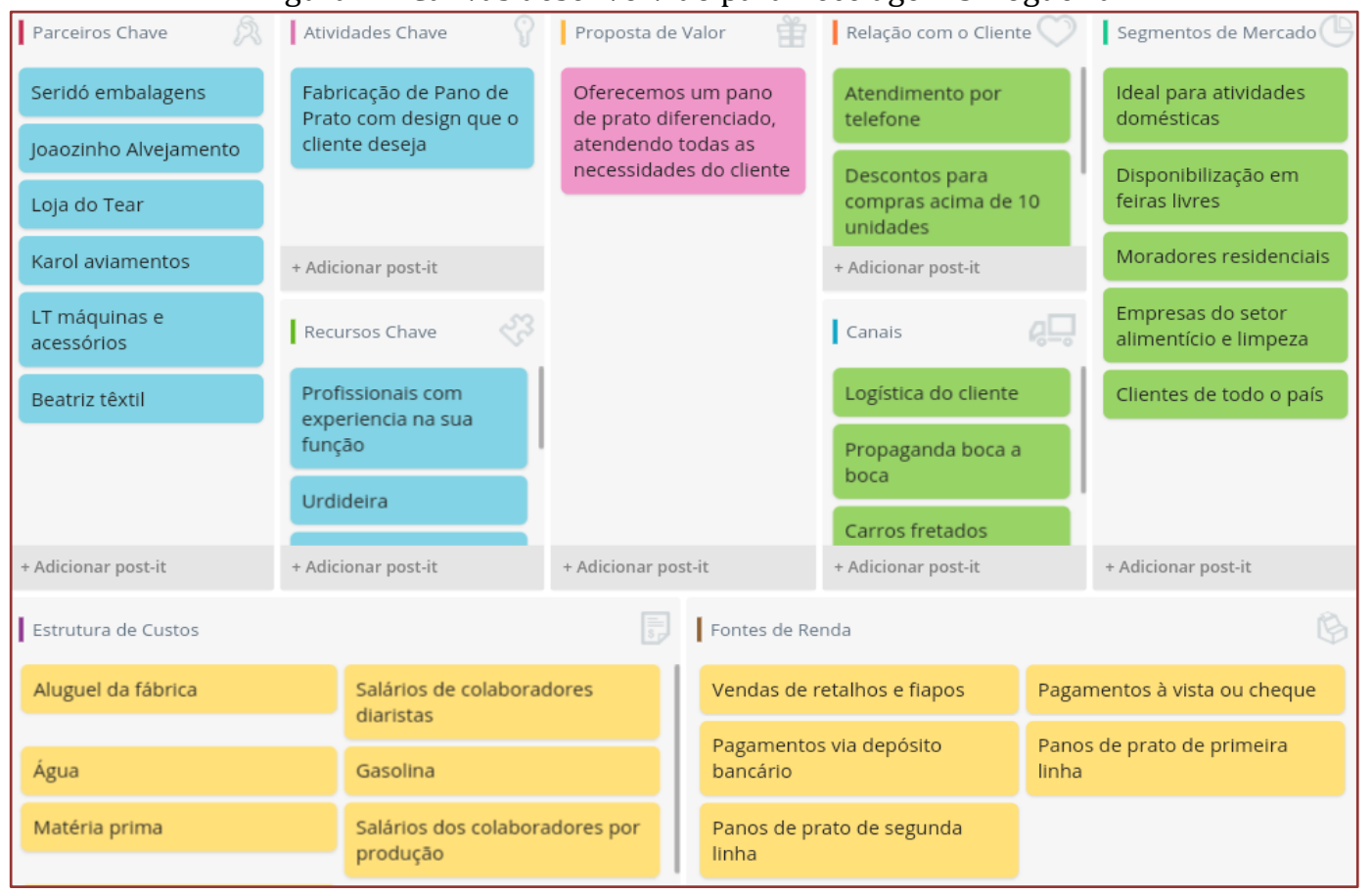

Fonte: elaborado pelos autores, 2018

As atividades chaves é o que a empresa tem para oferecer para o cliente (Melo et al., 2017). É a forma pela qual o gestor procura oferecer ao mercado de maneira diferenciada que traga uma vantagem competitiva, que ocasionará no alcance maior das metas. Os recursos chave são os equipamentos necessários para a 
produção do produto, juntamente com os colaboradores qualificados para o manuseio adequado no processo de produção. São os ativos essenciais para que o negócio prospere no mercado consumidor (Pontes, 2017).

A proposta de valor é a missão da empresa, o que a organização tem a oferecer para o cliente de forma diferenciada dos concorrentes. Rodrigues (2018) comenta que essa etapa é um conjunto de tudo que o empreendimento disponibiliza para um público alvo no mercado.

0 relacionamento com o cliente é um dos principais pontos de atenção que a empresa deve observar. É a interação do empreendimento com o cliente, as vendas, informações trocadas, ou seja, é o método usado pela organização para manter o contato com o cliente (Melo et al., 2017). É de suma importância que o gestor fique atento nessa área para que evite riscos futuros pois os consumidores estão cada vez mais exigentes, além de saberem a importância que possuem para o negócio obter sucesso. Por isso, o atendimento e benefícios estão cada vez mais na lista de exigências dos clientes atuais.

Biava (2017) ressalta que os canais é a forma como a empresa consegue se comunicar com os consumidores, transmitindo o objetivo do negócio para o mercado consumidor. Sendo assim, os canais é a forma pela qual o produto consegue chegar ao seu destino final por meio de comunicação que o empreendimento proporciona. 0 empreendimento que foi alvo do estudo possui logística comum, mas possui a carência no setor do marketing. A empresa não possui um plano de marketing para oferecer seu produto para novos clientes. A forma que os consumidores e novos fornecedores conseguem encontrar o produto do estabelecimento é por via da propaganda boca a boca, o que ocasiona em um déficit neste setor da organização.

Pontes (2017) salienta que o segmento de mercado é onde a empresa quer atingir, para qual público o produto irá satisfazer as necessidades, criando valores. Neste contexto, é a preocupação da empresa com o destino do seu produto. É o público alvo que o gestor deseja atingir. Pode ser um segmento focado em somente uma área ou como na empresa objeto de estudo, ser destinado à vários tipos de segmentos, despertando o interesse de diversas pessoas.

Na visão de Rodrigues (2018) a estrutura de custos é o conjunto de todos os custos envolvidos de todas as etapas do processo que o produto leva para que chegue até o cliente. No caso da empresa objeto de estudo, a mesma ainda possui a carência de uma sede própria para a finalização do produto. Os custos variáveis possui um controle adequado e satisfatório já que é frequentemente supervisionado.

Conforme Melo et al. (2017) a fonte de renda é o valor que a empresa consegue receber por está entregando o seu produto ao seu cliente, a forma que o consumidor irá pagar por esse produto. 0 empreendimento alvo da pesquisa possui um controle importante nas fontes de renda já que todo o material que não é utilizado para a produção do pano de prato que seria descartado, é vendido de forma mais barata para que não ocorra prejuízos. Isso proporciona para o negócio um feedback de suma importância com relação a renda, meio ambiente - já que a maioria dos produtos que não teria utilização para a empresa são vendidos, o que gera maior satisfação da empresa e clientes.

As observações foram iniciadas primeiramente conhecendo as instalações físicas da empresa, verificou-se que a parte de controle dos pagamentos dos clientes estava com um déficit elevado, ocasionando em perdas de dados para o gestor. Foi possível descobrir que o setor Financeiro e de Recursos Humanos é coordenado pelo próprio gestor e os demais setores são coordenados pelo gerente da empresa.

Diante do conhecimento aprofundado sobre a empresa, detectou-se que o gestor tomava suas decisões e fazia seu planejamento estratégico com base no achismo. Foi explanado o método ideal e seguro para que o empresário fizesse seu plano de negócios sem custo, o que proporcionou em um interesse significativo pela ferramenta indicada, o CANVAS. 0 recurso foi logo abordado em detalhes para que o mesmo compreendesse cada etapa com clareza para não obter riscos futuros. A ferramenta foi aplicada à empresa para obtenção de um feedback positivo perante a visão do gestor, que ocasionou em uma satisfação nítida do mesmo.

Conforme Turban e Volonino (2013) ressaltam que o planejamento estratégico é uma série de processos que conserva a empresa, mantendo-a saudável. Na perspectiva dos autores, o empreendimento que possui o plano de negócios adequado, disponibiliza uma melhor gestão com colaboradores e clientes, maior tranquilidade em traçar as metas, proporcionando um negócio com menos riscos e sem conflitos.

Por fim, foi realizada entrevistas para que obtivesse-se os resultados sobre a realização do estudo na empresa. Foram realizadas maiores observações em todos os setores para que a autora pudesse agregar maior valor à organização, já que o mercado está cada vez mais competitivo ocasionando em uma maior 
atenção nos setores pertencentes a instituição e atualidade das necessidades do mercado para assim atender com maior eficiência.

\section{CONCLUSÃO}

0 mercado consumidor encontra-se cada vez mais competitivo, exigindo gradativamente maiores esforços das empresas para que possa atender todas as necessidades conforme o cliente deseja. Para que o gestor possa atender as demandas de forma adequada é essencial que o mesmo procure inovar, agregar valor ao seu empreendimento, para que as decisões sejam tomadas com precisão. É importante que haja uma flexibilidade para aderir novos métodos de auxílio na tomada de decisão, pois é significativo no momento da empresa enfrentar a concorrência. Com base nesses fatos, levantou-se o questionamento de como aperfeiçoar um modelo de negócio empresarial através do Sistema de Informação, visando o significado que um planejamento certo acarreta para a organização.

Tendo em vista a relevância desse estudo, deu-se como objetivo geral elaborar um modelo de negócio sistematizado para uma empresa do segmento têxtil, propondo um planejamento estratégico adequado para o alcance de metas. Para que o objetivo fosse atingido, procurou-se um aprofundamento do tema em pesquisas bibliográficas e uma aplicação prática na empresa objeto do estudo.

Diante do primeiro objetivo específico que foi identificar a percepção do gestor com relação à utilização do Sistema de Informação na gestão do negócio, observou-se que o gestor não havia conhecimento sobre como armazenar os dados corretamente e utilizá-los adequadamente para que fosse realizado um planejamento estratégico adequado, o que proporcionava muitas dúvidas no momento de tomar decisões. Verificou-se que todas as resoluções de problemas eram feitas com base em "achismo" e informações registradas em papéis variados o que acarreta grande perigo para a organização, ocasionando em falhas no momento da tomada de decisão, podendo haver perca de clientes.

De acordo com o segundo objetivo específico que buscava averiguar junto ao gestor a viabilidade da utilização do modelo de negócio CANVAS em seu empreendimento, onde foi identificado o interesse do comerciante em aprofundar mais o conhecimento sobre a ferramenta para que fosse implantado na organização. Perante a posição do gestor a respeito de usar o método adequado para o seu planejamento, foi perceptível a mudança de pensamento do mesmo, pois mesmo com pouco tempo de explicação e demonstração, obteve-se o entusiasmo de aderir ao CANVAS para que suas decisões fossem tomadas com mais certeza, diminuindo o grau de risco no seu negócio.

Conforme o terceiro objetivo específico que foi a implementação do Sistema de Informação Sebrae CANVAS para o aperfeiçoamento do modelo de negócio na organização, identificou-se através da entrevista com o gestor que o mesmo possui o interesse de implantar a ferramenta. 0 gestor relatou que a ferramenta é de suma importância para auxiliar na decisão correta e que isso é um grande benefício para a sua empresa que antes não possuía o seu conhecimento, mas confirmou que está disposto, juntamente com seus filhos, de aprofundar o estudo sobre o modelo disponível pelo Sebrae. 0 empresário salientou que como é de fácil acesso e gratuito, seus filhos por possuírem um melhor entendimento sobre Sistemas de Informação, irão implementar o novo método para que a organização apresente melhores resultados.

A respeito do Sistema de Informação para que o gestor possa utilizar de forma adequada na empresa, sugeriu-se haver um conhecimento mais detalhado do mesmo sobre o manuseio adequado dos sistemas para que possa fazer o registro das informações no computador, mas foi ressaltado pelo empresário que de início o procedimento de armazenagem correta será realizado pelo seu filho, e após será contratada uma pessoa capacitada para executar a função.

O empreendimento apresentava o grande risco de percas de informações constantemente devido não terem um armazenamento correto de dados e informações, impossibilitando o gestor de tomar decisões corretas diariamente. Apresentou-se a forma adequada de armazenamento e explicada passo a passo como seria feito todo o processo. Com a implantação do sistema certo na organização, o comerciante terá mais confiança e precisão nas suas decisões, eliminando possíveis dúvidas já que o sistema esclarece de forma rápida, segura e clara todas as informações que anteriormente estavam com falhas no seu armazenamento para que assim possa alcançar os objetivos empresariais.

Conforme a averiguação da possibilidade de utilizar o modelo de negócio, diante do interesse do gestor em aderir à ferramenta, sugere-se que para obter um planejamento estratégico eficaz para a sua empresa o mesmo utilize o modelo de negócio BMC, pois é de fácil introdução no seu negócio, além de ser competente nas resoluções de problemas, já que com base nele pode-se haver um plano de negócio mais 
seguro devido está sempre verificando e modificando possíveis estratégias, de acordo com as mudanças e exigências do mercado consumidor.

Segundo a implementação do Sistema de Informação Sebrae CANVAS, sugeriu-se que para a implantação correta da ferramenta para a empresa, o filho do gestor fizesse um estudo no que ainda possui dúvidas sobre o modelo, já que o mesmo possui informações importantes para a organização e requer bastante cuidado em seu manuseio para que não ocorra danos e percas de dados do método de planejamento estratégico.

A nova proposta de um plano eficaz para o negócio, proporcionou um fator bastante importante para o gestor, devido o mesmo não possuir informações de forma adequada para que seu planejamento pudesse ter um feedback positivo. Como a forma de planejar estava com riscos, o estudo acarretou em novos conhecimentos para o empresário que o fez possuir maior interesse e concordar em implantar um método eficaz para se tomar decisão de forma segura, o que ocasiona em maior satisfação do cliente, fornecedores e colaboradores.

No decorrer da construção deste trabalho foram enfrentadas algumas limitações para a sua conclusão. Começando no lócus da pesquisa, que foi direcionado somente para o setor administrativo, não aprofundando nos demais setores no que seria possível detectar outros problemas para que assim possíveis soluções fossem apresentadas. Para a aplicação da pesquisa, somente uma empresa foi estudada o que limitou a temática abordada, impossibilitando de se fazer possíveis comparações com demais empreendimentos do mesmo segmento, para melhor obtenção dos resultados.

A coleta de dados possuiu a carência de que o comerciante não tinha conhecimento sobre o método eficaz para auxiliar na tomada de decisão, que proporcionou em uma maior explicação de uma forma em que o mesmo pudesse entender e confiar em abrir sua organização para a pesquisa, no que após acarretou na captação de informações importantes por meio de entrevistas com o gestor somente sobre o assunto abordado na pesquisa, privando o mesmo de tentar resolver outros possíveis problemas das demais áreas da organização. Perante os resultados obtidos durante a pesquisa, concluiu-se que todos os objetivos foram alcançados, proporcionando para o estudo um fator satisfatório.

\section{REFERÊNCIAS}

[1] Andrade, M. (2018). Introdução à metodologia do trabalho científico: elaboração de trabalhos na graduação. São Paulo: Atlas.

[2] Andrade, M. (2018). Introdução à metodologia do trabalho científico: elaboração de trabalhos na graduação. São Paulo: Atlas.

[3] Audy, J., \& Brodbeck, Â. (2008). Sistemas de Informação: planejamento e alinhamento estratégico nas organizações. Porto Alegre: Bookman.

[4] Baltzan, P., \& Phillips, A. (2012). Sistema de informação. (R. Dubal, Trad.) São Paulo: AMGH.

[5] Biava, J. (2017). A metodologia CANVAS e suas variações para o deesenvolvimento do empreendedorismo. TCC (Graduação), Unesc, Curso de Administração, Criciúma.

[6] Campos, F. (2017). Elaboração dos planos de gestão e de marketing de um aplicativo de busca de eventos. TCC (Graduação), UFRJ, Curso de Engenharia de Produção, Rio de JAneiro.

[7] Carmona, D. (2017). Visionários: Desenvolva um novo olhar sobre o seu negócio, inove e se destaque no mercado! São Paulo: Gente.

[8] Gil, A. (2012). Métodos e técnicas de pesquisa social. São Paulo: Atlas.

[9] Lopes, B. (2017). Gestão do conhecimento e inovação. Belo Horizonte: Poisson.

[10] Mannino, M. (2008). Projeto, desenvolvimento de aplicações \& administração de banco de dados. (B. Honorato, D. Prairo, L. Moura, \& S. Sonoe, Trads.) São Paulo: AMGH.

[11] Matias-Pereira, J. (2018). Manual de metodologia da pesquisa científica. São Paulo: Atlas.

[12] Melo, J. (2017). Percepção contribuição do Business Model CANVAS em empresas de tecnologia. FSA, 14(5), 73-96.

[13] Mendonça, S. (2017). O planejamento estratégico como ferramenta: um estudo sobre a eficiência das micro e pequenas empresas brasileiras. Administração de Empresas em Revista, 16(17), 50-68. 
[14] Muller, L. (2017). Proposta de modelo de processo como apoio a coleta de ideias para inovação de produtos: estudo de caso em empresa de tecnologia da informação. TCC (Graduação), Universidade Tecnológica Federal do Paraná, Curso de Tecnologia em Análise e Desenvolvimento de Sistemas, Pato Branco.

[15] Pize, A. (2017). Planejamento e alinhamento estratégico de projetos: um guia prático aplicando os modelos Spcanvas e Psacanvas. Rio de Janeiro: Brasport.

[16] Pontes, J. (2017). Contribuições do Business Model CANVAS para a avaliação de desempenho organizacional. Dissertação (Mestrado), Faculdade de Ciências Aplicadas, Curso de Engenharia da Produção e de Manufatura, Limeira.

[17] Rainer, R., \& Cegielski, C. (2011). Introdução aos sistemas de informação. (D. Vieira, Trad.) Rio de Janeiro.

[18] Rodrigues, L. (2018). Business Model Canvas: Uma análise da ferramenta aplicada ao desenvolvimento de modelos de negócios criativos. Especialize On-Line Ipog, 1(15), 1-21.

[19] Sebrae. (2015). Sebrae Canvas. Acesso em 2018, disponível em http://www.sebraecanvas.com

[20] Silva, H., Araújo, M., \& Dornelas, J. (2018). Determinantes da não utilização de frameworks de gestão e/ou governança de TI. Gestão \& Tecnologia, 18(2), 274-299.

[21] Stair, R., \& Reynolds, G. (2006). Princípios de sistemas de informação: uma abordagem gerencial. (F. Silva, G. Mega, \& I. Sucupira, Trads.) São Paulo: Thomsom.

[22] Turban, E., \& Volonino, L. (2013). Tecnologia da informação para gestão: em busca do melhor desempenho estratégico e operacional. (A. Evers, Trad.) Porto Alegre: Bookman.

[23] Veras, M. (2016). Gestão dinâmica de projetos: Life Cycle Canvas. Rio de Janeiro: Brasport.

[24] Veras, M. (2017). Negócio baseado em projetos. Rio de Janeiro: Brasport. 


\section{Capítulo 3}

O término da licença-maternidade e os desafios da Puérpera: Entrevistando trabalhadoras do comércio varejista no Sul do Brasil

\section{Helena Röpke}

Simone Portella Teixeira de Mello

\section{Elaine Garcia dos Santos}

Resumo: Este estudo discute implicações da licença-maternidade e retorno da mulher ao trabalho. Teve como objetivo analisar a trajetória gravídico-puerperal de trabalhadoras do comércio varejista de Pelotas/RS. Traça-se o perfil sóciodemográfico de trabalhadoras em empresas de micro, pequeno, médio e grande porte. Descreve-se carreira profissional, relações de trabalho e direitos trabalhistas, período gestação/maternidade, implicações da maternidade na vida familiar e desafios/problemas diante do retorno ao trabalho. A pesquisa é qualitativa, exploratória, usa-se entrevistas via técnica de Snowball. Resultados revelam idade entre 22 a 40 anos, ensino médio completo, casadas e solteira, filhos frequentam creches, renda familiar de dois a três salários mínimos. 0 desafio maior no retorno ao trabalho é o deslocamento com a criança, acordar cedo e pouco tempo para estar com o bebê. É essencial que existam incentivos para dar estabilidade na fase gravídico-puerperal, de modo que não sejam vistas com limitações/empecilho para a empresa.

Palavras-chave: Puérpera. Mulher trabalhadora. Licença-Maternidade. Gênero. 


\section{INTRODUÇÃO}

A inserção da mulher no mercado de trabalho é marco recente na história brasileira e teve crescimento notável no país a partir dos anos 70, quando começaram a alcançar atividades jamais idealizadas. A partir de então, a figura feminina vem ganhando espaço, principalmente pelas constantes lutas sociais por igualdade de direitos e respeito, demonstrando a grande força e resistência que elas têm e merecem, ao exercerem diversos papéis fundamentais dentro da sociedade, como por exemplo, o dom da reprodução humana (BRUSCHINI, 2007).

Contudo, a descoberta de uma gravidez até o nascimento do bebê é uma fase de transições na vida de qualquer mulher, em especial quando a mulher trabalha. Além das mudanças físicas, representa toda uma reestruturação do modo de vida e costumes, seguidas por novas experiências, diferentes responsabilidades, incontáveis sensações e emoções, das quais passam a tornar-se mais e mais evidentes a cada dia dessa nova fase maternal (BARRETTO; OLIVEIRA, 2010).

0 problema é recorrente e é preciso ser mais explorado, especialmente em estudos que tratam de trabalhadoras no comércio varejista, que são escassos na literatura. Essas mulheres têm condições de trabalho adversas, com uma carga horária de trabalho maçante e lidam diretamente com uma diversidade de clientes e empregadores, realizando sua jornada de trabalho basicamente em pé. A fase gravídicopuerperal dessas mulheres precisa ser explorada, para se tecer novas contribuições sobre o tema.

Sendo assim, o objetivo deste estudo é analisar a trajetória gravídico-puerperal de trabalhadoras de empresas do comércio varejista da cidade de Pelotas/RS. Para tanto, inicialmente se traçou o perfil sociodemográfico dessas mulheres, descreve-se a carreira profissional dessas, assim como as relações de trabalho e os direitos trabalhistas vivenciados. Os relatos da gestação/maternidade também estão presentes na narração dessas, assim como as implicações da maternidade na vida familiar e os desafios e/ou problemas diante do retorno ao trabalho.

\section{REFERENCIAL TEÓRICO}

Ao longo da história, em todo o mundo, as mulheres percorreram constantes e duras trilhas, tiveram que passar por cima de muitos rótulos e reivindicar diversos direitos. Conforme Santos e Sacramento (2011), a educação para elas era minimizada, insuficiente e restrita, seu comportamento era moldado e vigiado pela sociedade.

No Brasil, percebe-se que as diferenças de gênero estão fortemente enraizadas na sociedade, como algo denso e difícil de ser removido, praticamente a toda hora, seja em algum momento do dia a dia, ou através dos noticiários deparamo-nos com fatos dramáticos e assustadores envolvendo violência, tortura, opressão, desrespeito e descaso principalmente com pessoas do sexo feminino (ARAÚJO, 2005). A temática patriarcal tem grande influência nessa instrução sociocultural brasileira, uma vez que nos tempos atuais permanece a crença ou estigma vinda de tempos remotos da história, de que o homem, pai de família, tem o papel mais forte e de maior importância dentro de sua linhagem.

Segundo Bruschini (2007), na metade dos anos 70, a mulher passou a ter maior ascendência no mercado de trabalho brasileiro, motivada principalmente pelo alargamento da economia e os processos acelerados de industrialização e urbanização. Apesar das modificações do mercado, o crescimento e a maior aceitação da inserção da mulher nas mais diversas funções e atividades profissionais, muitas delas ainda se deparam com empecilhos em suas carreiras, na maioria dos casos apenas por pertencerem ao gênero tido como frágil. Estas barreiras costumam distanciar a mulher do que realmente ela pode ser, significar e alcançar ao desenvolver seu trabalho (COUTINHO; DIOGO, 2006).

Há uma série de direitos legais da gestante e daquela que teve o bebê com idade até seis meses, intitulada puérpera, um adjetivo que se origina do latim puer, que quer dizer criança, mais o verbo que também se origina do latim parěre, que significa parir ou dar à luz (PUÉRPERA, 2019). Conforme Godoy et al. (2011), os direitos legais da grávida ou da mãe de um RN objetivam transmitir à mulher e mesmo ao casal o entendimento de que o desenvolvimento da gravidez e do puerpério não é apenas de responsabilidade da família, mas sim de toda a sociedade, haja vista que o nascimento de uma criança implica em questões muito além das trabalhistas.

Os direitos das gestantes no Brasil datam da década de 40, a partir da Consolidação das Leis do Trabalho (CLT), À época era assegurado à gestante o direito de sair do trabalho para no mínimo seis consultas médicas e demais exames complementares. 
Ela também tem direito de mudar de função ou setor em seu trabalho diante de sua situação gestacional e mesmo ao término da licença, quando de seu retorno ao trabalho (CLT, 1999). Mais recentemente, após a licença-maternidade de 120 dias a mulher também tem direitos assegurados por lei para cuidados com o RN, estabilidade no emprego até que o bebê complete cinco meses e ao aleitamento. Para tanto, a mulher tem o direito a ser dispensada do trabalho duas vezes ao dia por pelo menos 30 minutos para amamentar até o bebê completar seis meses de idade. Um avanço é que se admite, por força da lei, que os intervalos sejam unidos de modo que a mulher que esteja amamentando possa chegar uma hora mais tarde ao trabalho ou sair uma hora mais cedo desse (BRASIL, 2016).

A partir de 2008, com a lei 11.770, a duração da licença maternidade pôde ser estendida por 60 dias desde que a empresa onde a trabalhadora esteja empregada faça parte do Programa Empresa Cidadã (BRASIL, 2008). Primeiramente, o Programa foi criado para prorrogar a licença-maternidade por meio de concessão de incentivo fiscal às empresas inscritas no citado programa. Mediante a inserção no programa, a empresa poderá descontar o valor pago a tal título do Imposto de Renda devido, vedado o lançamento dessa cifra como despesa operacional.

Aos poucos as mulheres se uniram, lutaram por melhorias e conquistaram direito a licençamaternidade, flexibilidade de horário, pausa para amamentação e outros grandes feitos que amparam a mulher na área profissional (NORONHA; VOLPATO, 2006). Muitas vezes a inserção feminina em uma organização através de processos seletivos já é tida como uma eventual "primeira barreira" para a mulher. Mesmo com a maior transparência e naturalidade possível, dificilmente um profissional responsável por funções gerenciais ou de alto cargo na empresa, não cogitará ou, por vezes, demonstrará na entrevista, alguma alusão ao receio de investir tempo e dinheiro em oportunidade e qualificação para a mulher entrevistada, como o risco dessa colaboradora constituir uma família, engravidar e por consequência vir a se afastar da empresa em algum momento (LIMA et al. 2013).

Por outro lado, uma "segunda barreira", cerca outra categoria do sexo feminino, à das mulheres que já se encontram atuantes no mercado de trabalho e decidem e/ou planejam tornarem-se mães, ou ainda, caem na ocorrência inesperada de uma gestação. No período gravídico a trabalhadora não está mais só, e passa a carregar consigo não apenas uma vida, mas a encarar uma série de mudanças biológicas e hormonais, bem como uma enorme carga de variações sentimentais sucessivas aos ambientes internos e externos. Todas essas transformações passam a interferir na vida e saúde da grávida bem como limitar suas atividades profissionais (PUSTIGLIONE, 2017).

No comércio varejista, por exemplo, há demanda de atividades que exigem um bom condicionamento físico. As trabalhadoras, principalmente vendedoras, costumam passar longos períodos de pé, aguardando a entrada de clientes. Muitas delas precisam carregar peso, subir escadas até o estoque de mercadorias várias vezes ao dia, ou escalar prateleiras para alcançar produtos que agradem ao público do empreendimento. Isso também revela para a mulher em período gestacional um fator de maior desgaste e risco muitas vezes, já que elas sofrem com aumento de peso, inchaço ou desconfortos que as impedem de realizar certas funções.

A questão emocional da separação entre mãe e bebê e de não conseguir acompanhar o crescimento do filho, é preocupação de muitas mulheres que retornam ao mercado de trabalho. Por vezes, elas precisam ficar longos períodos do dia fora de casa e vêem seus filhos relativamente pouco, o que não as permite acompanhar em demasiado o crescimento, desenvolvimento e primeiras evoluções como a fala, primeiros passos, novas descobertas e outros. Garcia e Viecili (p. 277, 2018) constataram que neste momento da volta ao trabalho: [...] "é necessário um novo esforço de adaptação, que tende a ser tão intenso quanto o primeiro - o momento do nascimento do bebê, e algumas vezes acaba trazendo sofrimento.

Para a trabalhadora que volta às atividades profissionais pós licença-maternidade, uma das maiores inquietações, costuma ser também o suporte, abrigo, e assistência social a criança. Algumas mães possuem boas configurações parentais e optam por entregar o cuidado com o filho a um familiar. Outras necessitam de apoio social para que o filho se adapte em creches, o que nem sempre é tarefa fácil. Muitas mães não têm escolha, aporte familiar ou financeiro para pagar uma creche. Grande parte não se sente segura em deixar o filho na supervisão de terceiros e preferem deixar a carreira profissional de lado e destinar atenção para o bebê (BELTRAME; DONELLI, 2012).

A posição de mãe, esposa, dona do lar e profissional, evidencia outra dificuldade no retorno da mulher as atividades de carreira. Muitas vezes estas se sentem sobrecarregadas tendo que dividir o tempo entre diferentes tarefas/cuidados bem como elaborar diferentes estratégias para que tudo se encaixe. E é também neste momento que várias mulheres optam por abrir mão da realização profissional para atender arduamente os demais compromissos, com destaque principal para a maternidade (CAVALCANTI; BAÍA, 2017). 


\section{METODOLOGIA}

A trajetória dessa pesquisa se deu de maneira exploratória, que visa principalmente o detalhamento e maior investigação acerca de determinado assunto ainda não completamente esclarecido (BEUREN, 2006). Essa perspectiva também objetiva atingir os motivos ou encontrar o estopim de determinadas atitudes e condutas das pessoas (GIL, 2018).

Como o foco de análise foi discutir e problematizar a fase da mulher desde a gestação até o retorno ao trabalho, sua fase puérpera, optou-se por desenvolver a pesquisa numa perspectiva qualitativa. A partir de então os relatos são tratados por meio de análise de conteúdo (BARDIN, 2011). Além disso, os argumentos relatados pelas respondentes são triangulados com a literatura pertinente.

A amostra se deu por conveniência ou por acessibilidade. Gil (2010), destaca que essa classificação é usual, de uso frequente com elementos pré-disponíveis. 0 público-alvo foram quatro mulheres que atravessaram o período gestacional trabalhando, com vínculo empregatício, em empresas comerciais, do segmento do varejo na cidade de Pelotas/RS. A situação trabalhista atual também foi considerada e entrevistou-se mulheres em diferentes situações: trabalhando, demitida quando do retorno da licença, e duas que pediram demissão pós-licença maternidade por motivos particulares. A amostra considerou ainda as empresas que essas mulheres trabalhavam, respectivamente empresas de porte micro (até 9 colaboradores), pequeno (10 a 49 funcionários), médio (até 99 empregados) e grande porte (100 pessoas ocupadas ou mais) (SEBRAE, 2013).

Outro aspecto considerado foi o fato de não haver tempo hábil para desenvolver uma pesquisa com mais mulheres. Optou-se então, por aprofundar a análise decorrente das entrevistas, trazendo à tona as peculiaridades observadas. Além disso, optou-se por dar nomes fictícios às quatro entrevistadas, foram inspiradores, pois representam mulheres fortes e guerreiras. De certa forma, as quatro entrevistadas também foram à luta para tentar mudar a batalha cotidiana que é a vida de uma mulher e de uma recente mãe voltando ao mercado de trabalho ou saindo dele. Esses nomes foram capturados da obra "Lute como uma Garota: 60 feministas que mudaram o mundo" (BARCELLA; LOPES, 2018). Os nomes são: Clarice, Francisca, Wilma e Leila. De certa forma conhecer um pouco da biografia dessas feministas foi fonte de inspiração para a posterior análise das entrevistadas. A seguir apresenta-se o quadro 1, que sintetiza o explicado anteriormente.

Quadro 1 -Entrevistadas quanto à situação trabalhista.

\begin{tabular}{|c|c|c|}
\hline \multicolumn{1}{|c|}{ CODINOME } & PORTE DA EMPRESA & SITUAÇÃO TRABALHISTA \\
\hline Clarice & Micro & Demitiu-se \\
\hline Francisca & Pequena & Demitiu-se \\
\hline Wilma & Média & Trabalhando \\
\hline Leila & Grande & Demitida \\
\hline
\end{tabular}

Fonte: Dados da Pesquisa, 2019.

As entrevistadas foram encontradas a partir da técnica metodológica de Snowball (bola de neve), essa técnica é uma ferramenta não probabilística, utilizada em pesquisas sociais onde os participantes iniciais de um estudo indicam novos participantes que por sua vez indicam novos participantes e assim sucessivamente, até que seja alcançado o objetivo proposto, o ponto de saturação (BALDIN; MUNHOZ, 2011). A coleta de dados se valeu de entrevistas (Duarte, 2004; Manzini, 2004) semiestruturadas, quando as respondentes foram submetidas a uma série de questões tanto abertas quanto fechadas. 0 roteiro da entrevista foi concebido a partir de revisão de literatura sobre o tema. 0 quadro 2 sintetiza o framework de pesquisa (MARTINS, 2018). 0 questionário foi composto 35 questões e os resultados são apresentados a seguir. 
Quadro 2 - Framework de pesquisa

Traçar o perfil sociodemográfico (idade, renda familiar, escolaridade, estado civil, filhos) Questões 17

Descrição carreira profissional, situação atual de trabalho, segmento mercado, tempo certo para engravidar, realização profissional, Questões 8-11 Conhecer as relações de trabalho e os direitos. Tempo afastamento do trabalho antes do parto, reação chefia frente à gravidez, período de licença maternidade, informações sobre direitos/deveres de gestante, licença e pós-licença, período de estabilidade pós-gestação previsto em lei, retorno ao trabalho/carga horária/funções/turno, amamentação/ pausas previstas em lei, demissão, motivo saída do trabalho, auxilio disponibilizado pelo empregador, relacionamento com colegas, relacionamento com líderes/chefes/supervisores de trabalho, trabalho antes e depois da licença, Questões 12-26

Relatar a gestação/maternidade. Planejamento/Desejo da gravidez, auxílio psicológico enquanto trabalha, Questões 27-29.

Explicar as implicações da maternidade na vida familiar.

Cuidado com o(a) filho, participação do companheiro nos cuidados com a criança, participação da família nos cuidados com a criança quando mãe no trabalho, Questões 30-32.

Identificar os desafios e/ou problemas diante do retorno ao trabalho.

Conciliação trabalho/cuidado filhos(as), fator desgastante no retorno ao trabalho pós-licença maternidade, preparo emocional para voltar ao trabalho, Questões 33-35 durante/após licença maternidade, quem cuida do filho

Dados básicos como: idade, renda familiar mensal escolaridade, estado civil, se possuí filhos, quantidade de filhos e idade dos filhos.

BRUSCHINI, Maria Cristina Aranha. Trabalho e gênero no Brasil nos últimos dez anos. Cadernos de Pesquisa, v. 37, n. 132, set/dez. 2007.

GODOY, Maria Beatriz de. et. al. Situação trabalhista da mulher no ciclo grávido-puerperal. Revista Investigação e Educação em Enfermagem, ed. 29, n. 1, 2011. Colômbia. MARQUES, Teresa Cristina Novaes. A regulação do trabalho feminino em um sistema político masculino, Brasil: 1932-1943. Estudos Históricos Rio de Janeiro, v. 29, n. 59, p. 667-686, set/dez. 2016.

VILLELA, Wilza Vieira. Ser mulher, gestar e parir: sentidos em transição e desafios para o setor saúde. Revista Ciência \& Saúde Coletiva. v. 23 n.11, Rio de Janeiro: nov. 2018.

GALON, Sabrina Zanotti. Como as mulheres gerenciam os múltiplos papéis no período pós-licença maternidade? Dissertação. Programa de Pós-Graduação em Administração da Fundação Instituto Capixaba de Pesquisas em Contabilidade, Economia e Finanças (FUCAPE), Vitória, 2014.

GARCIA, Carla Fernandes; VIECILI, Juliane Viecili. Implicações do retorno ao trabalho após licençamaternidade na rotina e no trabalho da mulher. Fractal: Revista de Psicologia, v. 30, n. 2, p. 271-280, mai/ago. 2018.

GALON, Sabrina Zanotti. Como as mulheres gerenciam os múltiplos papéis no período pós-licença maternidade? Dissertação Programa de Pós-graduação em Administração da Fundação Instituto Capixaba de Pesquisas em Contabilidade, Economia e Finanças (FUCAPE). Vitória, 2014.

Fonte: Dados da pesquisa.

\section{RESULTADOS}

A escritora, advogada, tradutora, contista, cronista e jornalista Clarice Lispector marcou diversas gerações enriquecendo a literatura nacional e internacional. Lispector serviu de inspiração para dar o nome fictício à primeira entrevistada, Clarice, uma bela mulher de 40 anos, branca, cabelos claros, traços delicados e estilo clássico de se vestir, assim como a escritora. Clarice teve dois filhos homens, também passou por altos e baixos em sua vida, enfrentou uma separação, passou por momentos de solidão e incertezas, mas conta que superou as dificuldades, não se deixando sucumbir ao desânimo.

A outra entrevistada foi Francisca. A inspiração do nome se baseia em Francisca Senhorinha da Motta Diniz, que viveu no século XIX no Brasil. Ela foi uma importante escritora, educadora e jornalista brasileira que através da criação do próprio jornal abordou temas polêmicos e importantes que envolviam a mulher e o mundo feminista como pauta. A entrevistada é mãe e esposa, possuí 32 anos, pele clara, cabelos volumosos, corpulenta, bastante comunicativa e espontânea. Assim como a jornalista citada, Francisca teve duas filhas e é engajada nas causas feministas, em suas redes sociais sempre manifesta posicionamento favorável ao feminismo, gosta de ler e opinar a respeito de assuntos que remetam à liberdade, igualdade e defesa da mulher, e isso foi ratificado quando da entrevista. 
A terceira entrevistada remete à trajetória de Wilma Rudolph (1940-1994), uma atleta velocista que conquistou importantes feitos nos esportes olímpicos. Além de ter sido uma corredora veloz, ainda inspirou mulheres pelo mundo na luta por espaço feminino no esporte. Espelhada na atleta norteamericana, a entrevistada Wilma é uma mulher negra de 30 anos, cabelos curtos e cacheados, que pouco sorri, parecendo de personalidade forte, independente e um tanto sofrida. A conversa com Wilma confirma esse comportamento. Ela não tem vida fácil, é determinada, trabalhadora, tenta sempre se reinventar e alcançar suas metas, assim como Rudolph foi à sua época. Para ela não foi difícil retornar ao trabalho após o término da licença maternidade.

A próxima entrevistada teve seu nome inspirado na brasileira Leila Diniz (1945-1972), que era atriz e ex-professora, marcando sua época por ser considerada uma afronta à sociedade repressora, vista como vedete, era mulher irreverente, ousada e de personalidade forte, opinava sobre temas polêmicos e quebrou tabus impostos para a mulher na época. Essa personalidade "segura de si" serviu de fonte para designar essa quarta integrante desse estudo, apontada apenas como Leila. Trata-se de uma mulher esguia, dona de bonitos traços, longos cabelos escuros, estatura média, de origem indígena, com uma pele peculiar. Jovem, 22 anos e estilo despojado de vestir-se. Além da beleza, há outras similaridades entre essas duas mulheres, Leila, assim como Diniz, teve uma filha, é mulher forte, desinibida e não tem medo de expor seu ponto de vista por vezes polêmico quando questionada sobre diferentes assuntos. Trabalhou poucos dias pós licença-maternidade e foi demitida. Não esconde ter passado por um período conturbado ao conciliar a realização profissional com a realização do sonho de ser mãe. Para ela, sua demissão foi consequência de se tornar mãe.

Os resultados mostraram que a faixa etária destas mulheres entrevistadas é de 22 a 40 anos de idade, todas possuem o ensino médio completo, três são casadas, mas Wilma que é solteira. Estudos como os de Parada e Tonete (2009) e Caetano, Netto e Manduca (2011) revelam que desde as últimas décadas diversas mudanças no papel da mulher frente a sociedade, trabalho, família e modo de vida vem ganhando espaço. Uma das diferenças observadas engloba o número cada vez mais crescente de mulheres que optam pela concepção de seus primogênitos em idades mais avançadas como, por exemplo, com mais de 35 anos, mesmo enfrentando maiores riscos e tendo que tomar maiores cuidados.

Leila possui uma filha, já as demais possuem dois filhos(as) cada, além disso, suas rendas familiares são maior parte constituídas por dois salários mínimos regionais, com ressalva à Clarice com três salários. Sobre a reação das chefias com a notícia da gravidez, para Clarice e Francisca pareceram normais, para Wilma se mostraram felizes e para Leila suas chefias não gostaram. Sobre o suporte da empresa em relação a informações sobre benefícios, direitos e deveres de gestante, licença-maternidade e pós-licença, apenas Leila recebeu orientações da empresa, as demais adquiriram referências através de outros meios de informação. Convém destacar que a mulher gestante tem direito a licença maternidade, assim como quando do retorno só pode ser totalmente desvinculada da empresa que atua quando seu bebê completar cinco meses de idade.

Tanto Clarice como Francisca demitiram-se, Leila foi demitida e Wilma segue trabalhando. Para Carrara, Nunes e Sarsur (2014) existe uma série de fatores que podem influenciar a saída de um colaborador da empresa, tais como: mudanças e a sazonalidade do negócio; o corte de investimentos em desenvolvimento das pessoas em momentos de crise; a lentidão dos líderes na tomada de decisão; a complacência que algumas lideranças têm com o baixo nível de desempenho; a demora dos líderes na comunicação de decisões e de fatos relevantes; e, o receio dos gestores quanto ao confronto no trabalho. Uma delas atualmente trabalha como autônoma, o que tem sido frequente. Conforme a Pesquisa Nacional por Amostra de Domicílio (Pnad) IBGE (2018), o número de trabalhadores autônomos no país teve crescimento considerável e chegou a um total de 24 milhões até o primeiro trimestre de 2019. Observa-se ainda que há uma tendência de divisão social relativa ao salário. Estudos como os de Beltrame e Donelli (2012) destacam que as mulheres com salários mais baixos suportam as multitarefas do lar e do trabalho, visando à necessidade de terem um salário e manutenção das condições de vida. Por outro lado, as mulheres com salários mais altos ou com suporte do cônjuge/família são mais autônomas, podendo sair do emprego por terem certa condição econômica favorável e passarem um tempo sem precisar de um emprego, de modo a viverem e se dedicarem exclusivamente ao filho e às tarefas fora do âmbito empregatício.

Todas acreditam que profissionalmente tiveram seus filhos no período certo, contudo, nenhuma delas obteve realização profissional no comércio varejista da cidade. Relatam que ao regressar ao trabalho, continuaram em horário integral. 
Nenhuma notou tratamento diferente se relacionado aos colegas quando do retorno da licença. Quanto ao trato dos superiores diretos e aumento da quantidade de trabalho, apenas Leila sentiu diferença e aumento da carga de trabalho, respectivamente.

As mães entrevistadas tiveram suas gestações planejadas ou desejadas e conseguiram trabalhar até poucos dias do parto, com exceção de uma das gestações de Francisca que não foi planejada e nessa ela precisou se afastar no sexto mês de gravidez. Contudo, o planejamento nem sempre acontece. 0 estudo de Prietschet al. (2011) revela que a cada ano, ao menos 80 milhões de mulheres em todo o mundo experimentam a situação de ter uma gravidez não planejada, o que parece impactante. Wilma estava emocionalmente preparada para retomar as atividades e nenhuma precisou de auxílio psicológico. Entretanto, o estudo de Garcia e Viecili (2018) revela que esse período carrega consigo diferentes impactos, e uma grande necessidade de adaptação em diferentes aspectos como, por exemplo, o lado econômico da família. Também é comum puérperas apresentem depressão pós-parto, condição clínica de profunda tristeza que acontece logo após o nascimento do bebê e segundo o estudo de Schmidt, Piccoloto e Müller (2005, p. 61) se manifesta por um conjunto de sintomas como "irritabilidade, choro, sentimentos de desamparo e desesperança, falta de energia e motivação, desinteresse sexual, transtornos alimentares e do sono, ansiedade, sentimentos de incapacidade de lidar com novas solicitações".

Todas, em algum momento fizeram uso de creches para deixarem seus filhos enquanto trabalhavam. Negam que o cuidado com o filho seja atribuição apenas da mulher. Para que elas possam trabalhar em relação à participação dos pais nas atividades com os filhos, as entrevistadas consideram satisfatória e/ou cooperativa. Para Arruda e Lima (2013), a figura paterna no cuidado com os filhos vem ganhando novos traços na sociedade moderna, os papéis estão se invertendo e a rotina exigindo flexibilidade não apenas da mãe, mas tornando também fundamental a inserção do homem-pai na participação efetiva nas tarefas do dia-a-dia. Assim o pai em muitos casos deixa de fazer o papel secundário e assume o papel de protagonista junto à mãe na criação dos filhos e realização de afazeres. Isso ratifica o que salienta Crepaldi et al. (2006) quando destacam que a cultura de nossa sociedade vem passando constantemente por modificações, e com o decorrer dos anos o pai não é necessariamente o responsável pelo sustento da casa, sendo parte fundamental nas responsabilidades da casa e no envolvimento com os filhos, tendo papel protagonista junto com a mãe.

Com relação à participação da família, apenas Francisca classifica como razoável, as demais informam que a família ajuda, coopera e é participativa. Sobre o fator mais desgastante pós licençamaternidade e a volta à vida profissional duas mães acreditam ser o deslocamento com a criança ou com os objetos pessoais, para Wilma acordar cedo é o maior desgaste. Para Leila é o pouco tempo para estar com a filha. A família é um conjunto de elementos interligados, quando algo se modifica em um destes elementos, este tende a influenciar ou interferir no comportamento dos demais (SANTOS, 2013).

O sentido do trabalho e da maternidade por vezes é conflitante. Os relatos ratificam isso.

\section{CONSIDERAÇÕES FINAIS}

Diante dos resultados obtidos, entende-se que é imprescindível que haja mais informações repassadas aos empresários e donos de empresas do comércio da cidade, bem como existam mudanças, incentivos e medidas a fim de reforçar e transmitir maior suporte e estabilidade na fase gravídicopuerperal, para que as mulheres-mães-trabalhadoras que buscam engravidar ou que, estão na fase de cuidado com o bebê ou retorno ao trabalho, não sejam vistas mais como qualquer tipo de limitação, desvantagem ou empecilho para a empresa seja na realização, desenvolvimento de atividades ou carreira profissional dessa mulher.

Quanto às limitações do estudo ressalta-se o tamanho da amostra, que limita generalizações. Sugere-se a realização de estudos com amostras mais generosas e em outros segmentos de mercado. Cada uma das entrevistadas enfrenta diferentes medos, incertezas, dores e obstáculos e a área profissional não precisa ser mais um agravante nesse contexto.

\section{REFERÊNCIAS}

[1] Araújo, Alice Braga de. Gravidez não planejada e suas implicações: intervenções em atenção primária à saúde. Minas Gerais. 2017. Disponível em: https://www.nescon.medicina.ufmg.br/biblioteca/imagem/Alice-BragaAraujo.pdf. Acesso em: 10 mai. 2019.

[2] Araújo, Maria de Fátima. Diferença e igualdade nas relações de gênero: revisitando o debate. Psicologia Clínica Online, vol. 17, n. 2, p. 41- 52. Rio de Janeiro,2005. Disponível em: http://pepsic.bvsalud.org/pdf/pc/v17n2/v17n2a04.pdf. Acesso em: 30 mar. 2019. 
[3] Arruda, Sérgio Luiz Saboya; Lima, Manuela Caroline Ferreira. O novo lugar do pai como cuidador da criança. Estudos Interdisciplinares em Psicologia. v 4, n. 2, p. 201-216, Londrina. dez. 2013. Disponível em: http://www.uel.br/revistas/uel/index.php/eip/article/viewFile/18198/14471. Acesso em: 10 ago. 2019.

[4] Baldin, Nelma; Munhoz, Elzira Bagatin. I Seminário Internacional de Representações Sociais, Subjetividade e Educação - Sirsse. Snowball (Bola de Neve): Uma Técnica Metodológica para Pesquisa em Educação Ambiental Comunitária. Paraná, 2011. Disponível em: https://educere.bruc.com.br/CD2011/pdf/4398_2342.pdf. Acesso em: 01 out. 2019.

[5] Barcella, Laura; LOPES, Fernanda. Lute como uma garota: 60 feministas que mudaram o mundo. São Paulo: Cultrix, 2018.

[6] Bardin, Laurence. Análise de conteúdo. Ed. 70, São Paulo: 2011.

[7] Barretto, Ana Paula Valasques; Oliveira, Zulmerinda Meira. O SER Mãe: Expectativas de Primigestas. Rev.Saúde.com, Bahia, $2010 . \quad$ Disponível em: http://periodicos2.uesb.br/index.php/rsc/article/view/162/125. Acesso em: 06 mar. 2019.

[8] Beltrame, Greyce Rocha; Donelli, Tagma Marina Schneider. Maternidade e carreira: desafios frente à conciliação de papéis. Revista interdisciplinar de Psicologia e Promoção da Saúde, Aletheia. Canoas. mai/dez. 2012. Disponível em: http://pepsic.bvsalud.org/pdf/aletheia/n38-39/n38-39a17.pdf/. Acesso em: 29 mai. 2019.

[9] Brasil. [Constituição (1988)]. Constituição da República Federativa do Brasil. Disponível em: https://www2.senado.leg.br/bdsf/bitstream/handle/id/518231/CF88_Livro_EC91_2016.pdf. Acesso em: 26 ago. 2019.

[10] Brasil. LEI n ${ }^{\circ}$ 11.770, de 9 de setembro de 2008. Licença Maternidade. Presidência da República Casa Civil. 2008. Disponível em http://www.planalto.gov.br/ccivil_03/_Ato2007-2010/2008/Lei/L11770.htm. Acesso em 10 jan. 2020.

[11] Bruschini, Maria Cristina Aranha. Trabalho e gênero no Brasil nos últimos dez anos. Cadernos de Pesquisa, v. 37, n. 132, set/dez. 2007. Disponível em: http://www.scielo.br/pdf/cp/v37n132/a0337132.pdf. Acesso em: 31 nov.2019.

[12] Caetano, Laíse Conceição; Netto, Luciana; Manduca, Juliana Natália de Lima. Gravidez Depois dos 35 Anos: Uma Revisão Sistemática da Literatura. Revista Mineira de Enfermagem- Reme. v.15. n. 4. Minas Gerais: out/dez. 2011. Disponível em: file:///C:/Users/helen/Downloads/v15n4a15.pdf. Acesso em: 27 jun. 2019.

[13] Carrara, Tânia Maria Paiva; Nunes, Simone Costa; Sarsur, Amyra Moyzes. Fatores de retenção, permanência e desligamento de talentos e de performers. Race. Revista de Administração Contabilidade e Economia. v. 13, n. 3, set/dez 2014.

[14] CLT. Consolidação das Leis de Trabalho. Art. 373. Decreto Lei 5452/43. 1999. Disponível em https://www.jusbrasil.com.br/topicos/10724675/artigo-373-do-decreto-lei-n-5452-de-01-de-maio-de-1943. Acesso em jun, 2019.

[15] Cavalcanti, Natália C. Silva Barros; Baía, Deylane Corrêa Pantoja. Ser mãe no mundo do trabalho: notas sobre os desafios da reinserção de mulheres no mercado de trabalho após a experiência de maternidade. Seminário Internacional Fazendo Gênero $11 . \quad$ Florianópolis, $2017 . \quad$ Disponível em: http://www.en.wwc2017.eventos.dype.com.br/resources/anais/1499457316_ARQUIVO_Sermaenomundodotrabalho .pdf. Acesso em: 27 set. 2019.

[16] Crepaldi, Maria Aparecida; Andreani, Grace; Hammes, Patrícia Simone; Ristof, Clarissa Dionísio; Abreu, Sandra Ribeiro de. A Participação do Pai nos cuidados da Criança, Segundo a Concepção de Mães. Revista Psicologia em Estudo, v. 11, n. 3, p. 579-587. Florianópolis-SC. set/dez. 2006. Disponível em: http://www.scielo.br/pdf/pe/v11n3/v11n3a13.pdf. Acesso em: 01 ago. 2019.

[17] Diogo; Maria Fernanda; Coutinho, Maria Chalfin. A dialética da inclusão/exclusão e o trabalho feminino. Revista Interações, v. 11, n. 21, p. 121-124, jan./jun. 2006. Disponível em: http://pepsic.bvsalud.org/pdf/inter/v11n21/v11n21a07.pdf. Acesso em: 31 mar.2019.

[18] Duarte, Rosália. Entrevistas em pesquisas qualitativas. Revista Educar. Curitiba, n. 24. Universidade Federal do Paraná UFPR: 2004. Disponível em: https://revistas.ufpr.br/educar/article/view/2216/1859. Acesso em: 18 abr. 2019.

[19] Galon, Sabrina Zanotti. Como as mulheres gerenciam os múltiplos papéis no período pós-licença maternidade? Dissertação. PPGA da Fundação Instituto Capixaba de Pesquisas em Contabilidade, Economia e Finanças (FUCAPE), Vitória, 2014.

[20] Garcia, Carla Fernandes; Viecili, Juliane. Implicações do retorno ao trabalho após licença-maternidade na rotina e no trabalho da mulher. Fractal: Revista de Psicologia, v. 30, n. 2, p. 271-280, Santa Catarina. mai/ago. 2018. Disponível em: http://www.scielo.br/pdf/fractal/v30n2/1984-0292-fractal-30-02-271.pdf. Acesso em: 20 mai. 2019. [21] Gil, Antonio. Carlos. Como elaborar projetos de pesquisa. 5 ed. São Paulo: ATLAS, 2010.

[22] _ Métodos e técnicas de Pesquisa Social. 6 ed. São Paulo: Atlas, 2018.

[23] Godoy, Maria Beatriz et al. Situação trabalhista da mulher no ciclo grávido-puerperal. Revista Investigação e Educação em Enfermagem, v. 29, n. 1, p. 47-53. Colômbia: 2011. Disponível em: http://www.scielo.org.co/pdf/iee/v29n1/v29n1a06.pdf. Acesso em: 15 abr. 2019. 
[24] IBGE, Instituto Brasileiro de Geografia e Estatística -Projeção da População 2018: número de habitantes do país deve parar de crescer em 2047. Jul. 2018. Disponível em: https://agenciadenoticias.ibge.gov.br/agencia-sala-deimprensa/2013-agencia-de-noticias/releases/21837-projecao-da-populacao-2018-numero-de-habitantes-do-paisdeve-parar-de-crescer-em-2047. Acesso em: 10 set. 2019.

[25] Lima, Gustavo Simão et al. O Teto de Vidro das Executivas Brasileiras. Revista Pretexto. v. 14, n. 4. out/dez. 2013. Disponível em: http://www.fumec.br/revistas/pretexto/article/view/1922. Acesso em: 21 out. 2019.

[26] Marques, Teresa Cristina Novaes. A regulação do trabalho feminino em um sistema político masculino, Brasil: 1932-1943. Estudos Históricos Rio de Janeiro, v. 29, n. 59, p. 667-686, set./dez. 2016. Disponível em: http://www.scielo.br/pdf/eh/v29n59/0103-2186-eh-29-59-0667.pdf. Acesso em: 18 abr. 2019.

[27] Martins, Ricardo. A importância de um framework (modelo analítico) na pesquisa. fev. 2018. Disponível em: https://ideiasricardomartins.wordpress.com/2018/02/17/a-importancia-de-um-framework-modelo-analitico-napesquisa/ . Acesso em: 10 set. 2019.

[28] Manzini, Eduardo José. II Seminário Internacional Sobre Pesquisa E Estudos Qualitativos. Entrevista SemiEstruturada: Análise de Objetivos e de Roteiros. 2004, São Paulo. Disponível em: https://www.marilia.unesp.br/Home/Instituicao/Docentes/EduardoManzini/Manzini_2004_entrevista_semiestruturada.pdf. Acesso em: 18 abr. 2019.

[29] Noronha, Elisiani Cristina de Souza Freitas; Volpato, Terezinha Gascho. A Trajetória Educacional e Profissional da Mulher Administradora. Revista Pretexto, v. 7, n. 2. Belo Horizonte. 2006. Disponível em: http://www.fumec.br/revistas/pretexto/article/view/432. Acesso em: 07 out. 2019,

[30] Parada, Cristina Maria Garcia De Lima; Tonete, Vera Lúcia Pamplona. Experiência da gravidez após os 35 anos de mulheres com baixa renda. Escola Anna Nery. Revista de Enfermagem. v.13, n. 2, p. 385-392. abr/jun. Rio de Janeiro: 2009. Disponível em: http://www.scielo.br/pdf/ean/v13n2/v13n2a21. Acesso em: 22 jun. 2019.

[31] Puérpera. In: Dicio, Dicionário Online de Português. Porto: 7Graus, 2019. Disponível em: https://www.dicio.com.br/puerpera/. Acesso em: 02 nov. 2019.

[32] Pustiglione, Marcelo. Trabalhadoras gestantes e lactantes: impacto de agentes de risco ocupacional (ARO) no processo de gestação, no concepto e no lactente. Revista Brasileira de Medicina do Trabalho. v.15, n. 3. São Paulo, 2017 Disponível em: file://C:/Users/helen/Downloads/v15n3a14.pdf. Acesso em: 07 nov. 2019.

[33] Prietsch, Silvio Omar Macedo et al. Gravidez não planejada no extremo Sul do Brasil: prevalência e fatores associados. Caderno de Saúde Pública. v. 27, n.10. Rio de Janeiro, 2011. Disponível em: https://www.scielosp.org/toc/csp/2011.v27n11/. Acesso em: 17 ago. 2019.

[34] Beuren, Ilse Maria (Org.) Como Elaborar Trabalhos Monográficos em Contabilidade: teoria e prática. São Paulo: Atlas, 2006.

[35] Santos, Ramaiane Costa; Sacramento, Sandra Maria Costa Pereira do. O Antes e o Depois das Principais Conquistas Femininas. Revista Anagrama: Revista Científica Interdisciplinar da Graduação. v.1, n. 5. São Paulo. Set./Nov. 2011. Disponível em: http://www.revistas.usp.br/anagrama/article/view/35598/38317. Acesso em: 25 set. 2019.

[36] Santos, Mariana Monteiro Silva. Os efeitos do divórcio nas famílias com filhos pequenos. Psicologia. PT. 0 Portal dos Psicólogos. Salvador, 2013. Disponível em: https://www.psicologia.pt/artigos/textos/TL0342.pdf. Acesso em: 01 out. 2019.

[37] SEBRAE. Serviço Brasileiro de Apoio às Micro e Pequenas Empresas. Anuário do trabalho na micro e pequena empresa 2013. $\quad$ v. 5, p. 17. São Paulo. 2013. Disponível em: http://www.sebrae.com.br/Sebrae/Portal/Anexos/Anuario do Trabalho Na Micro e Pequena Empresa_2013. pdf. Acesso em: 5 mai. 2019.

[38] Schmidt, Eluisa Bordin; Piccoloto, Neri Mauricio; Müller, Marisa Campio. Depressão pós-parto: fatores de risco e repercussões no desenvolvimento infantil. Universidade de São Francisco, Programa de Pós-Graduação Stricto Sensu em Psicologia. v. 10, n. 1, p. 61-68, jan./jun. São Paulo: 2005 . Disponível em: http://www.scielo.br/pdf/pusf/v10n1/v10n1a08.pdf. Acesso em: 14 ago. 2019.

[39] Villela, Wilza Vieira. Ser mulher, gestar e parir: sentidos em transição e desafios para o setor saúde. Revista Ciência \& Saúde Coletiva.v. $23 \mathrm{n}$. 11, Rio de Janeiro: nov. 2018. Disponível em: http://www.scielo.br/scielo.php?script=sci_arttext\&pid=S1413-81232018001103478. Acesso em: 18 abr. 2019. 


\section{Capítulo 4}

\section{Empoderamento Feminino: Estudo de caso em três Cooperativas de Crédito do Centro Oeste Mineiro}

\section{Hélia Geralda Siqueira \\ Marlene Catarina de Oliveira Lopes Melo}

Resumo: As mulheres tem percorrido longo caminho na busca de igualdade na sociedade e no mercado de trabalho. Apesar de existirem muitas mulheres ocupando cargos de diretoras e presidentes em organizações, a proporção ainda é baixa em relação ao universo masculino, apontando para o frágil empoderamento das mulheres também nas organizações. Nesse contexto, objetivou-se analisar como mulheres de três cooperativas de crédito, localizadas em Minas Gerais, percebem o empoderamento feminino nas cooperativas, bem como as facilidades e as dificuldades encontradas. Para a coleta de dados foi enviado um questionário aberto composto por 21 perguntas às gerentes, diretoras e conselheiras fiscais e administrativas das três cooperativas pesquisadas. Do total de 30 questionários enviados, 10 foram respondidos.0s dados foram tratados por meio da análise de conteúdo. Os resultados apontam que as mulheres pesquisadas demonstraram possuir confiança em si mesmas, construindo suas carreiras baseadas na capacitação e no profissionalismo. Encontram facilidades em administrar a carreira profissional com a vida pessoal. Por serem do gênero feminino, não sentem ter dificuldades em exercer nenhum cargo, encarando os problemas como desafios, embora indicam a existência de diferenciação de salários para o mesmo cargo por causa do gênero.

Palavras-chave: Cooperativas de Crédito. Empoderamento Feminino. Mulheres em Cargos de Liderança. 


\section{INTRODUÇÃO}

Tem sido longo o caminho percorrido pelas mulheres na busca de igualdade na sociedade e no mercado de trabalho. Apesar de existirem muitas mulheres ocupando cargos de diretoras e presidentes em organizações no mundo afora, elas são, ainda, em número reduzido e com baixa proporcionalidade em relação ao universo masculino, apontando para o frágil empoderamento das mulheres também nas organizações.

A definição da palavra empoderamento, segundo kleba e Wendausen (2009) aborda exatamente o encorajamento, uma vez que o termo implica atribuir poderes a alguém, transferir poderes de decisão a empregados individuais e a equipes.

Segundo Younger, Brockbancke Ulrich (2013), o empoderamento das mulheres é a sua capacidade para provocar uma mudança econômica por si mesma, visando promover a participação das mesmas em pé de igualdade perante os homens, contribuindo para o seu fortalecimento econômico e social, quando estas iniciam um negócio para geração de renda ou mesmo para expandir seu empreendimento existente.

Lisboa (2007) analisa o empoderamento da mulher na perspectiva feminista e o considera como novo conceito de poder nas relações de gênero que reconhece e valoriza as mulheres e que, segundo Costa (2004) numa visão mais otimista, assume formas democráticas, construindo novos mecanismos de tomada de decisões de responsabilidades compartilhadas.

É notória a expansão do cooperativismo, todavia, o número de mulheres em cargos de decisão nas cooperativas não tem acompanhado o ritmo de crescimento do cooperativismo. Em decorrência dos baixos índices de participação feminina no cooperativismo, a ACI (1995) desde o final do século passado vem desenvolvendo ações objetivando discutir processos que evidenciem a igualdade entre homens e mulheres.

Mais de duas décadas depois, os mesmos planos permanecem atuais, visto que, ainda que tenham sido alcançados avanços no período, a mudança de padrões culturais tarda a se concluir. A pesquisa Gender equality and women's empowerment in co-operatives _ a literature review, desenvolvida por Duguid e Weber (2016), aponta não haver conexão definitiva entre participação e empoderamento feminino envolvendo cooperativas, porque elas tendem a refletir as mesmas relações de poder existentes na sociedade na qual está inserida.

Dados divulgados pelo Banco Central do Brasil (BACEN, 2017) apontam um crescimento tímido da participação feminina em cargos de diretoria e presidência nas cooperativas, sendo 15\% de mulheres nas singulares, em todo o país, $13 \%$ no Conselho de Administração e $22 \%$ no Conselho Fiscal.

Ressalta-se que, mesmo que as conquistas femininas venham ocorrendo de forma "gradual e progressiva, ainda existe um teto de vidro impedindo que as mulheres atinjam os níveis de empoderamento nos espaços de decisão, públicos e privados" (ALVES, 2014, p. 1).

Visando melhor compreender como este processo vem acontecendo, este estudo tem como objetivo analisar como mulheres de três cooperativas de crédito, localizadas em Minas Gerais, percebem o empoderamento feminino nas cooperativas, bem como as facilidades e as dificuldades encontradas.

O Cooperativismo e suas formas são atividades muito antigas. A convivência era garantia de sobrevivência. As pessoas tendem a se unir em torno de crenças e valores e vivem em comunidades, agregando-se em grupos menores ou maiores formando cidades, buscando se manterem. Portanto, o cooperativismo é uma forma de somar capacidade dentro de um mundo de concorrência. É uma forma de preservar a força econômica e de vida dos indivíduos de um mesmo padrão e tipo, com objetivos comuns e com as mesmas dificuldades (SANTOS, 1998).

O cooperativismo de crédito surgiu em Rochdale (Inglaterra), no ano de 1844, por meio da cooperativa dos probos tecelões de Rochdale, por causa da precisão de melhor qualidade de vida e busca de resolução as questões de desemprego e fome. Desse modo, o cooperativismo começou a colaborar para a política de desenvolvimento nacional, encorajando nascimento e crescimento das micro, pequenas e médias empresas e assessorando as atuais (FRANCISCO; AMARAL; BERTUCCI, 2012). 
Para Pinheiro (2006, p. 7), as cooperativas de crédito:

[...] são instituições financeiras constituídas sob a forma de sociedade cooperativa, tendo por objetivo a prestação de serviços financeiros aos associados, [...] além de outras operações específicas e atribuições estabelecidas na legislação em vigor.

Buscando os objetivos propostos para esta pesquisa foi realizado um estudo de caso em três cooperativas de crédito do Centro Oeste Mineiro, definidas como C1, C2, C3 para preservar a identidade das mesmas.

Este esudo se justifica pelas contribuições sociais, organizacionais e acadêmicas. Os resultados da pesquisa podem contribuir para a formulação de políticas visando a inserção da mulher nas esferas de decisão, bem como analisar o empoderamento feminino em cooperativas de crédito. No campo acadêmico é justificado pela existência de poucos estudos nessa temática.

Este artigo está estruturado na introdução, seguido do referencial teórico sobre os temas empoderamento feminino e cooperativismo de crédito, metodologia, contextualização do estudo, apresentação e análise de dados, considerações finais e referências usadas.

\section{REFERENCIAL TEÓRICO}

Neste estudo o referencial teórico baseia-se principalmente em dois temas principais: o empoderamento feminino e o cooperativismo de crédito.

\subsection{EMPODERAMENTO FEMININO}

A palavra empoderamento possui significados distintos, em algumas situações, o termo expressa sentido de emancipação, controle e busca de poder social ou político, em outras, percebem-se pessoas obtendo controle sobre suas próprias vidas e planejando seu futuro, como forma de mudança desejada (DEERE; LEÓN, 2002). Nas palavras de Lisboa (2007, p. 7),

empoderamento é o mecanismo pelo qual as pessoas, as organizações e as comunidades tomam controle de seus próprios assuntos, de sua própria vida, de seu destino, tomam consciência da sua habilidade e competência para produzir, criar e gerir.

Costa (2004) e Lisboa (2007) mencionam que o termo empoderamento chama a atenção para o conceito de 'poder' enquanto relação social. Assim, o 'poder' pode ser fonte de opressão, autoritarismo, abuso e dominação, como pode ser fonte de emancipação, reconhecimento e valorização trazendo à tona uma nova concepção de poder, assumindo formas democráticas, construindo novos mecanismos de responsabilidades coletivas, de tomada de decisões e responsabilidades compartilhadas.

De acordo com Deere e León (2002), o empoderamento da mulher precisa partir da sensibilização, no sentido de fortalecer a conscientização no que diz respeito à discriminação de gênero e para que se estabeleça uma nova concepção da mulher em relação à auto percepção negativa relativa à sua capacidade e seus direitos. Importa lembrar, entretanto, que o empoderamento não é um processo com um começo bem delineado e um final com experiências iguais para todas as mulheres, pois não existem fórmulas ou projetos, receitas ou modelos prescritos que ensinem a mulher a se empoderar. Ele é moldado para cada indivíduo, com base em suas experiências individuais, seus contextos e suas histórias, ocorrendo, assim, de acordo com a posição de subordinação de cada um nos níveis pessoal, familiar e profissional.

De acordo com Batliwala (1997), os objetivos do empoderamento feminino é desafiar a concepção patriarcal (dominação do homem e subordinação da mulher), transformar as bases e instituições que reforçam e eternizam a discriminação de gênero e a desigualdade social (a família, a raça, a classe, a religião, os processos educativos, as instituições, os sistemas, as práticas de saúde, as leis e os códigos civis e os processos políticos) e capacitar as mulheres com condições financeiras mais precárias, para que tenham acesso e controle da informação e dos recursos materiais. 
Ainda nesta perspectiva, Prá (2006, p. 40-41) reforça a análise do empoderamento no contexto das relações de poder na sociedade:

Fortalecer ou empoderar se refere a permitir que a pessoa assuma o comando de sua própria vida. No caso das mulheres, o empoderamento insiste na importância de aumentar seu poder e controle sobre as decisões e problemáticas que determinam a sua vida. 0 empoderamento da mulher se refere ao poder e às relações dentro da sociedade que se entrecruzam com o gênero, a classe social, a raça, a cultura e a história. 0 poder está identificado com a equidade e a igualdade da mulher e do homem, no que se refere ao acesso aos recursos e vantagens.

Sobre a questão da igualdade apresentada no Fórum Econômico Mundial (FEM, 2005), foram expostas cinco dimensões importantes do empoderamento e oportunidade das mulheres levando em consideração os padrões de desigualdades entre homens e mulheres, a saber: participação econômica, oportunidade econômica, empoderamento político, avanço educacional e saúde e bem-estar.

A participação econômica refere-se não só à participação quantitativa de mulheres no mercado de trabalho, mas também à sua remuneração em termos igualitários (FEM, 2005). Na média, a mulher ganha $76 \%$ do salário dos homens. Nos cargos de gerência e direção, essa proporção vai para 68\%. Quanto mais alto o cargo e a escolaridade, maior a desigualdade de gênero (ALMEIDA, 2017).

Com o avanço da mulher no mercado de trabalho, elas respondem atualmente por $43,8 \%$ de todos os trabalhadores brasileiros. Mas a participação vai caindo conforme aumenta o nível hierárquico. Elas representam 37\% dos cargos de direção e gerência. No topo, nos comitês executivos de grandes empresas, elas não atingem 10\% no Brasil (ALMEIDA, 2017).

Já o empoderamento político refere-se não só à representação numérica de mulheres em estruturas de tomada de decisão, tanto formais quanto informais, mas também ao seu direito à voz na formulação de políticas que afetam a sociedade na qual estão inseridas (FEM, 2005).

No que se refere ao avanço educacional, esse é, sem dúvida, o pré-requisito fundamental para o empoderamento das mulheres em todas as esferas da sociedade (FEM, 2005). As estatísticas mostram que, na média da população, a escolaridade feminina é maior. A mulher tem oito anos de estudo, e o homem, 7,6 anos (ALMEIDA, 2017). Sem educação de qualidade e conteúdo comparável ao recebido por meninos e homens, as mulheres não conseguem acesso a empregos bem pagos do setor formal, nem avanços na carreira, participação e representação no governo e influência política (FEM, 2005).

Todavia, a crença por parte das mulheres de romper as barreiras para ter acesso ao exercício do poder se estabelece como um dos principais desafios ao processo de empoderamento, uma vez que, ao longo dos séculos, esse poder cabia aos homens, tanto na esfera pública quanto na familiar. Essas posições de poder diferenciadas foram perpetuadas, cultural e institucionalmente. Às mulheres restava a possibilidade de utilizar estratégias de influência às quais podiam recorrer quando precisavam exercer o poder (MARTINS, 2003). Neste sentido, a subordinação de gênero foi introjetada pelas mulheres e é ponto crítico para as transformações do empoderamento.

De acordo com Deere e Leal (2002), o empoderamento da mulher precisa partir da sensibilização, no sentido de fortalecer a conscientização no que diz respeito à discriminação de gênero e para que se estabeleça uma nova concepção da mulher em relação à autopercepção negativa relativa à sua capacidade e seus direitos. Importa lembrar, entretanto, que o empoderamento não é um processo com um começo bem delineado e um final com experiências iguais para todas as mulheres, pois não existem fórmulas ou projetos, receitas ou modelos prescritos que ensinem à mulher a se empoderar. Ele é moldado para cada indivíduo, com base em suas experiências individuais, seus contextos e suas histórias, ocorrendo, assim, de acordo com a posição de subordinação de cada um nos níveis pessoal, familiar e profissional.

\subsection{COOPERATIVISMO DE CRÉDITO}

0 termo cooperação deriva do latim 'cooperari', denotando a ideia de se trabalhar em conjunto com outra pessoa, por meio de uma associação cooperativa que permita a resolução de problemas de caráter social, por meio de transações econômicas. Nesse modelo, o principal é a união de esforços em prol de um objetivo comum (PINHO, 1966), no qual a soma das forças resulta na superação dos obstáculos, permitindo alcançar melhores resultados. 
O movimento cooperativo é detentor de uma história profunda, ilustre e intelectual. No decorrer das últimas dez gerações, a temática relativa ao cooperativismo vem sendo difundida em várias partes do mundo, apresentando sempre uma preocupação com os valores cooperativos (KLAES, 2005).

0 Brasil desde cedo investiu nesta conduta cooperativista. A legislação brasileira é pródiga em emissão de leis que autorizam a criação de cooperativas. Todavia, em alguns governos o desenvolvimento desta atividade foi mais incentivado, em comparação a outros (CENZI, 2009).

Fruto do trabalho do padre jesuíta Teodoro Amstadt, em 1902 surgiu no Brasil a primeira cooperativa de crédito. Amstadt, quando percorria a área de colonização alemã do estado do Rio Grande do Sul (RS), levava a doutrina do cooperativismo junto com o seu trabalho missionário. Essa iniciativa incentivou a criação da primeira cooperativa de crédito brasileira, na qual foi fundamentada no padrão agrícola alemão. Este foi, inicialmente, o responsável pela evolução do movimento de crédito, que se alargou por todo o país. A princípio, este movimento cooperativista teve destaque apenas no estado gaúcho; posteriormente observou-se o seu desenvolvimento, também nas regiões sul e sudeste do Brasil. A sua principal característica consistia na aceitação de todas as variedades econômicas na composição do seu quadro social (ETGETO et al., 2005).

As cooperativas de créditos são regulamentadas, pela Resolução № 4.434, de 05 de agosto de 2015, que traz em seu texto a normatização para a sua constituição, autorização para o seu funcionamento, incluindo as alterações estatutárias e o seu cancelamento de concessão para funcionamento.

Os cooperados são ao mesmo tempo donos e usuários da cooperativa, participando de sua gestão e usufruindo de seus produtos e serviços. Nas cooperativas de crédito, os associados encontram os principais serviços disponíveis nos bancos, como conta corrente, aplicações financeiras, cartão de crédito, empréstimos e financiamentos. Os associados têm poder igual de voto independentemente da sua cota de participação no capital social da cooperativa. 0 cooperativismo não visa lucros, os direitos e deveres de todos são iguais e a adesão é livre e voluntária (BACEN, 2017, p. 1).

As cooperativas de créditos destacam-se no mercado, disponibilizando os mesmos serviços e produtos bancários de forma mais vantajosa, satisfazendo as necessidades dos cooperados. Além das taxas mais atrativas, nas cooperativas de crédito os associados têm direito à participação nas sobras, pois há uma divisão de rendimentos com os associados no final do período. Este grande diferencial favorece o destaque das cooperativas de crédito no mercado econômico, bem como o seu segmento (CUNHA; OLIVEIRA; GOZER, 2016).

Percebe-se assim, que as cooperativas de crédito têm como prioridade principal garantir uma melhor qualidade de vida às pessoas, favorecendo o desenvolvimento das famílias. Ou seja, independente do crédito, há um posicionamento humano, social e educativo. Essa é a causa da essência do cooperativismo de crédito, em que há uma firme e ativa participação dos sócios, permitindo o funcionamento de um sistema descentralizado em operação de forma democrática (KLAES, 2005).

Assim, tem sido exigido dos novos profissionais deste século XXI conhecimentos mais amplos, em que a utilização do cérebro seja maior que a força bruta. É preciso que ocupem cargos de tomada de decisão; por vezes, participação ativa nos negócios como assessores e deixar de lado as atividades obsoletas de tarefas rotineiras. 0 conhecimento empregue ao trabalho humano é uma verdade incontestável e pode ser considerado excluído do mercado aquele que não acompanhar essas novas exigências (KLAES, 2005).

Neste contexto, desde 1995, em virtude da comemoração do seu centenário, a ACI ao estabelecer os princípios de regimento para o seu funcionamento já trazia em seu texto a necessidades de seus associados visarem à busca pela educação, treinamento e informação, contribuindo assim com o desenvolvimento do cooperativismo. Além disso, esse organismo máximo do cooperativismo mundial, estabelecendo as diretrizes para o seu funcionamento, conceitua sobre o controle democrático dos seus membros, favorecendo assim a igualdade de gêneros em todas as competências cooperativistas. Homens e mulheres com os mesmos direitos - tanto políticos como econômicos na tomada de decisões (ACI, 1995). 


\section{METODOLOGIA}

A abordagem utilizada nesta pesquisa foi qualitativa. Para Minayo (2001) a pesquisa qualitativa trabalha com o universo de significados, motivos, aspirações, crenças, valores e atitudes, o que corresponde a um espaço mais profundo das relações, dos processos e dos fenômenos que não podem ser reduzidos á operacionalização de variáveis. Quanto aos fins, o tipo de pesquisa utilizado foi descritivo. De acordo com Gil (2008), as pesquisas descritivas mostram características de uma determinada experiência, fenômeno ou população.

0 método utilizado foi o estudo de caso, realizado em três cooperativas de crédito do centro oeste mineiro, filiadas ao Sicoob Central Cecremge com sede em Belo Horizonte. As três cooperativas possuem mais de 20 anos de existência, aqui referenciadas como C1, C2 e C3, no intuito de preservar suas identidades, e tem sede em Itaúna, Divinópolis e Cláudio, respectivamente, além de pontos de atendimento em diversas cidades nos seus entornos.

As cooperativas de crédito, objeto deste estudo são todas de livre admissão, o que as tornam bastante atrativas e competitivas para as comunidades onde estão inseridas.

Essas três instituições financeiras oferecem um grande leque de produtos e serviços a seus cooperados, onde eles são ao mesmo tempo usuários e sócios, e é este um dos diferenciais em relação aos bancos comerciais.

A missão das três cooperativas pesquisadas é de gerar soluções financeiras adequadas e sustentáveis, por meio do cooperativismo, aos associados e às suas comunidades, conforme preconizado pelo sistema Sicoob.

A unidade de análise desta pesquisa foi o empoderamento feminino nas cooperativas de crédito.

Como sujeitos da pesquisa, foram selecionadas mulheres cooperativistas que exercem cargos de gerentes, diretoras e conselheiras administrativas ou fiscais nas três cooperativas pesquisadas. Foram escolhidas, porque o objetivo da pesquisa é entender o processo de empoderamento feminino nas cooperativas de crédito, suas percepções sobre o processo, facilidades e dificuldades vivenciadas para atingirem cargos mais elevados em suas cooperativas. Também utilizou-se do critério de acessibilidade e saturação. Segundo Glaser e Strauss (1967) a saturação indica o momento de interromper a captação de informações (obtidas junto a uma pessoa ou grupo), pertinentes à discussão de uma determinada categoria dentro de uma investigação. Para os autores trata-se de uma confiança empírica de que a categoria está saturada, levando-se em consideração uma combinação de critérios: os limites empíricos dos dados, a integração dos dados com a teoria, que, por sua vez tem uma determinada densidade e a sensibilidade teórica de quem analisa os dados.

Para a coleta de dados foi enviado um questionário aberto composto por 21 perguntas às gerentes, diretoras e conselheiras fiscais e administrativas das três cooperativas pesquisadas. Todas as pesquisadas foram informadas de que as respostas seriam utilizadas apenas para fins acadêmicos e que teriam suas identidades preservadas. Do total de 30 questionários enviados, 10 foram respondidos.

Os dados foram tratados por meio da análise de conteúdo. Segundo Bardin (2008) a análise de conteúdo configura-se como um conjunto de técnicas de análise das comunicações, que utiliza procedimentos sistemáticos e objetivos de descrição do conteúdo das mensagens.

\section{APRESENTAÇÃO E ANÁLISE DOS DADOS}

Uma análise da inserção da mulher nas estruturas funcionais das cooperativas mostra que a C1 tinha 135 funcionários, sendo 89 mulheres; a C2 tinha 188 funcionários sendo 98 mulheres e a C3 tinha 107 funcionários sendo 67 mulheres, ou seja, as mulheres juntas representavam 69(sessenta e nove) por cento do quadro das cooperativas. Na alta direção a participação feminina é bem pequena, notando-se apenas uma diretora e uma conselheira. A nível de gerência nota-se uma maior participação das mulheres, atingindo a marca de $50 \%$ do total dos gerentes.

Do universo pesquisado, foram analisados os dados dos 10 questionários respondidos, sendo 2 questionários da C1, 3 questionários da C2 e, 5 da C3.

0 perfil das pesquisadas quanto à faixa etária, escolaridade, estado civil, cargo e tempo de serviço são apresentados no quadro 1 : 
Quadro 1 - Perfil do grupo pesquisado

\begin{tabular}{|c|c|c|c|c|c|}
\hline Pesquisada & Faixa Etária & Estado Civil & Formação & Cargo & $\begin{array}{c}\text { Tempo de } \\
\text { serviço }\end{array}$ \\
\hline P1 & 31 a 40 & casada & Pós-Graduação & $\begin{array}{c}\text { Gerente } \\
\text { Administrativa }\end{array}$ & 19 anos \\
\hline P2 & 41 a 50 & casada & Pós-Graduação & $\begin{array}{c}\text { Diretora } \\
\text { Administrativa }\end{array}$ & 17 anos \\
\hline P3 & 31 a 40 & casada & Pós-Graduação & Gerente de RH & 5 anos \\
\hline $\mathrm{P} 4$ & 31 a 40 & casada & Mestrado & Conselheira Fiscal & 17 anos \\
\hline P5 & 31 a 40 & casada & Pós-Graduação & Gerente de Agencia & 19 anos \\
\hline P6 & 20 a 30 & casada & Pós-Graduação & Gerente de Negócios & 6 anos \\
\hline P7 & 41 a 50 & Solteira & Pós-Graduação & Gerente comercial & 03 anos \\
\hline P8 & 31 a 40 & Casada & Pós-Graduação & Gerente de Negócios & 01 ano \\
\hline P9 & 31 a 40 & Casada & Pós-Graduação & Gerente de Negócios & 08 anos \\
\hline P10 & Acima de 51 & Casada & Superior Incompleto & Gerente de Negócios & 07 anos \\
\hline
\end{tabular}

Conforme demonstrado no quadro 1, uma das pesquisadas está na faixa etária entre 20 a 30 anos, 6 estão entre 31 a 40 anos, 2 estão entre 41 a 50 e 1 está acima de 51 anos. Com relação ao grau de escolaridade 8 têm Pós-Graduação, 1 mestrado e 1 possui o curso superior incompleto. Quanto ao estado civil 9 são casadas e 1 solteira. Pelo quadro 1 percebe-se que as pesquisadas são qualificadas, fato ressaltado nas respostas, onde a maioria acredita que qualificação e capacitação são fundamentais para o crescimento profissional.

Indagadas sobre o que as levou a procurar trabalho na cooperativa, uma não respondeu, três disseram que foram convidadas em função da experiência, e as demais por gostar e acreditar no cooperativismo, gostar do clima organizacional, pelos serviços diferenciados prestados pela cooperativa e possibilidade de crescimento pessoal e profissional.

[...] crescimento pessoal e profissional, clima organizacional, ter a tranquilidade de oferecer produtos e serviços de qualidade a preço justo para os cooperados. (P9)

Percebe-se que sentir-se bem no trabalho, gostar do que fazem, acreditar no sistema cooperativista e a possibilidade de crescimento pessoal e profissional são fatores determinantes para que elas buscassem no cooperativismo de crédito a sua colocação profissional.

Das entrevistadas, quatro responderam que foram admitidas direto no cargo que ocupam e $60 \%$ tiveram progressão, sendo que uma começou como estagiária até chegar ao cargo de gerente.

Fui admitida como assistente de gerência, após nove meses, fui promovida a gerente de negócios. (P6)

A maioria respondeu que se sente realizada no trabalho. As justificativas para a realização profissional foram formação afim aos serviços efetuados, oportunidade de crescimento, profissionalismo e ética dentro das instituições, muito embora ainda almejem cargos mais elevados.

Muito feliz e satisfeita porque minha formação profissional é em Recursos Humanos e ter a oportunidade de trabalhar na área de formação é ótimo. (P3)

Embora elas tenham respondido que se sentem realizadas, quase todas (9) ainda almejam crescer, querem ocupar cargos mais elevados.

Questionadas se o fato de ser mulher as impediam de desempenhar alguma tarefa, ou se percebiam alguma diferença nas divisões de tarefas entre homens e mulheres, todas responderam que ser mulher não as impediam de nada e também não percebiam diferença na divisão de tarefas. Apenas duas ressaltaram que faltam mulheres no alto escalão, que não veem mulheres nos conselhos e diretoria. Mesmo não percebendo diferenças na divisão de tarefas e nem impedimento por serem mulheres, duas delas reclamam que faltam mulheres nos cargos de conselheiras e diretoras.

Em relação a sentirem dificuldades em ocupar posições de poder, cinco pesquisadas responderam afirmativamente. E se justificaram: por não se sentir capaz, mas também pelo preconceito, pela progressão da mulher ser mais lenta, pelo fato de mulheres no mesmo cargo terem salário menor e pelo fato de que as mulheres chegam no máximo ao cargo de gerente. Quatro disseram que não sentiam dificuldades, e uma não respondeu. 
As respostas das pesquisadas deixam claro que há diferenças para homens e mulheres nos cargos de decisão. Fica claro que os homens atingem o poder mais rápido e a mulher alcança a progressão funcional e hierárquica mais lentamente, chegando mais facilmente apenas, até o cargo de gerente. Tais resultados indicam a existência do teto de vidro para as mulheres no campo do cooperativismo. Por teto de vidro entende-se a existência de uma barreira invisível ou dissimulada para a promoção a cargos e representações hierárquicas elevadas.

Quando perguntadas se a criação familiar influenciou no seu desenvolvimento profissional; a maioria respondeu que sim; iniciaram o trabalho precocemente, foram incentivadas a estudar e ter independência, não ter a vida que a mãe teve.

Sim, por meus pais não terem estudado incenivou que eu estudasse e trabalhasse muito e pelo melhor (P8)

0 fator cultural refere-se ao poder e as relações dentro da sociedade que se entrecruzam com o gênero, a classe social, a raça, a cultura e a história. Neste contexto, percebe-se que a família atua como fio condutor no processo de empoderamento das pesquisadas trazendo em sua história trabalho, exemplo e conquistas (MELO; LOPES, 2012).

Questionadas se a cultura brasileira dificulta o sucesso profissional das mulheres, todas responderam que sim, que a cultura é machista, há desigualdade salarial, cargos altos são para os homens, falta de oportunidades, preconceito e até mesmo as questões legais de licença maternidade. Apesar de todos os avanços obtidos pelas mulheres, ainda há um certo machismo embutido na cultura brasileira.

[...] As mulheres ganham $30 \%$ a menos que os homens. Mesmo quando desempenham a mesma função. Cargos de chefia e liderança são mais ocupados pelos homens (P10)

As facilidades que tiveram para alcançar o cargo foram: experiência anterior, credibilidade, estudo, dedicação, capacitação, competência, tempo de casa. Complementa ainda, que as mulheres, por apresentarem uma capacidade intensa de relacionamento, tem mais facilidades de exercer essa função. Neste contexto é criado um novo perfil de gestão, capaz ainda, de favorecer o crescimento da presença feminina nos cargos de chefia (MELO, 2002).

Experiência anterior em banco comercial. (P9)

Elas não veem dificuldades, mas sim como desafio, por exemplo, assumir uma agencia nova, problemas funcionais. Segundo Machado (2002) a capacidade profissional está vinculada a realização de várias tarefas e funções simultaneamente nas organizações.

Assumir uma agência nova é um desafio e não uma dificuldade. (P6)

Quando perguntadas se a cooperativa é um espaço masculino ou feminino, quatro responderam que é um espaço para ambos os sexos. Mas a maioria aponta que é um espaço feminino para cargos operacionais, mas a questão de gênero pesa quando se trata dos cagos mais elevados.

É um espaço feminino. Sendo a maioria dos funcionários do sexo feminino. (P5)

Na visão das respondentes não existem estratégias para uma mulher alcançar um cargo na cooperativa. Vale o currículo da pessoa, competência, conhecimento, liderança, mas predominando o relacionamento interpessoal, comprometimento.

Ter habilidade comercial, autonomia e competência. (P1).

Ao final, ao serem questionadas se tinham algo a acrescentar, a maioria não se manifestou, três acham que as mulheres têm condições de ocupar cargos mais elevados, existe esta lacuna, principalmente no cargo de Presidente. Apenas uma acha que o sistema é para todos e que a ocupação de cargos depende somente da competência e do comprometimento, além da diferenciação salarial para o mesmo cargo. 


\section{CONSIDERAÇÕES FINAIS}

O objetivo da pesquisa foi analisar como mulheres de três cooperativas de crédito, localizadas em Minas Gerais, percebem o empoderamento feminino nas cooperativas, bem como as facilidades e as dificuldades encontradas.

As mulheres pesquisadas demonstraram possuir confiança em si mesmas, construindo suas carreiras baseadas na capacitação e no profissionalismo. Encontram facilidades em administrar a carreira profissional com a vida pessoal. Por serem do gênero feminino, não sentem ter dificuldades em exercer nenhum cargo, encarando os problemas como desafios, embora indicam a existência de diferenciação de salários para o mesmo cargo por causa do gênero.

Quanto ao empoderamento feminino em cargos de níveis mais elevados, ficou claro que isso ainda está um pouco distante da realidade atual. Da totalidade pesquisada, apenas duas alcançaram os cargos de diretora e conselheira, as demais, embora possuam bastante tempo de casa, capacitação, formação acadêmica, comprometimento e bom relacionamento interpessoal, ainda permanecem em cargos gerenciais.

Para a realização da pesquisa, foram encontradas algumas limitações. Os resultados podem ter sido comprometidos em função da pequena amostra estudada, visto que foram pesquisadas 3 cooperativas em apenas 3 cidades, numa região bastante ampla e somente em cooperativas de crédito.

Para estudos futuros sugere-se que a pesquisa seja feita em mais cooperativas de crédito e mais cidades da região. Considerando que as cooperativas, objeto deste estudo tem seu quadro funcional composto por sessenta e nove por cento do gênero feminino, o empoderamento feminino praticamente inexiste.

Diante de tal constatação, caberia um estudo mais aprofundado junto às mulheres cooperadas, buscando compreender o motivo pelo qual as mesmas não se candidatam aos cargos eletivos de conselheiras administrativas ou fiscais visto que são elas que podem almejar estes cargos. Da mesma forma, buscar fatores que as impedem de atingir os cargos de diretoria, posto que, embora a grande maioria delas tenha qualificação profissional e acadêmica e longo tempo no exercício do cargo de gerente, ainda permanecem fora dos cargos de direção. Outrossim, seria conveniente fazer um estudo baseado na ótica masculina, das razões da pequena participação feminina na alta direção das cooperativas.

Em síntese, analisar o fenômeno do teto de vidro nas organizações cooperativas, ou seja, buscar compreender a situação da permanência da mulher em posições inferiores de poder na hierarquia organizacional, favorecendo a discrepância entre homens e mulheres nos cargos mais elevados e assim contribuir para políticas e práticas estimuladoras do empoderamento feminino.

\section{REFERÊNCIAS}

[1] Aliança Cooperativa Internacional - ACI. Dados das cooperativas. 1995. Disponível em: http://www.portaldocooperativismo.coop.br/Cooperativismo. Acesso em: 13 nov. 2018.

[2] Almeida, Cassia. Mulheres estão em apenas 37\% dos cargos de chefia nas empresas. 2017. Disponível em: < https://oglobo.globo.com/economia/mulheres-estao-em-apenas-37-dos-cargos-de-chefia-nas-empresas-

21013908\#ixzz58znaceOs>. Acesso em: 06 Mar. 2018.

[3] Alves, José Eustáquio Diniz. 08 de março e o empoderamento das mulheres brasileiras. EcoDebate, 2014. Disponível em: <https://www.ecodebate.com.br/2014/03/07/o-8-de-marco-e-o-empoderamento-das-mulheresbrasileiras-artigo-de-jose-eustaquio-diniz-alves/>. Acesso em 02 Mar. 2018.

[4] Batliwala, S. El significado delempoderamiento de lasmujeres: nuevos conceptos desde laacción. In: León, Magdalena. Poder y empoderamiento das mujeres. TM Editores, Santa Fe de Bogotá, 1997, pp. 187-211.

[5] Banco Central do Brasil. Bacen 2017. Cooperativa de crédito. 2017. Disponível em: <http://www.bcb.gov.br/pre/composicao/coopcred.asp>. Acesso em 04 jan. 2018

[6] Bardin, L. análise de Conteúdo. Lisboa. Edição. 70, 2008.

[7] Cenzi, Nerii Luiz. Cooperativismo: desde as origens ao projeto de Lei de Reforma do Sistema Cooperativo Brasileiro, Curitiba, Jeruá, 2009.

[8] Costa, A. A. Gênero, poder e empoderamento das mulheres. A química das mulheres, Salvador, março 2004.

[9] Cunha, Pedro Vinicius Silva; Oliveira, Willer Carlos de; Gozer, Isabel Cristina. Análise De Desempenho Das Cooperativas De Crédito Do Estado De Santa Catarina: Aplicação Do Sistema Pearls. Revista de Ciências Empresariais da UNIPAR, v. 17, n. 1, 2016. 
[10] Deere, C. D.; Léon, M. O empoderamento da mulher: direitos à terra e direitos de propriedade na América Latina. Porto Alegre: UFRGS, 2002.

[11] Duguid, Fiona; Weber, Nadya. Gender equality and women's empowerment in co-operatives. A literature review. International Co-operative Alliance. 2016. Disponível em: <http://www.sicoobexecutivo.com.br/ns/wpcontent/uploads/2016/10/WomenCoops-Literature-Review-Oct6.pdf>. Acesso em: 01 mar. 2018.

[12] Etgeto, Anderson Augusto et al. Os princípios do cooperativismo e as cooperativas de crédito no Brasil. Revista de Ciências Empresariais, 2005, 4. ed. p.9.

[13] FEM - Fórum Econômico Mundial. Empoderamento de mulheres: avaliação das disparidades globais de gênero. Genebra, 2005.

[14] Francisco, J. R. S.; Amaral, H. F.; Bertucci, L. A. Risco de crédito em cooperativas: uma análise com base no perfil do cooperado. Sociedade, contabilidade e gestão, v. 7, n. 2, 2012.

[15] Gil, A. C. Como elaborar projetos de pesquisa. São Paulo: Atlas, 2008.

[16] Glaser, B. G.; Strauss, A. L. The Discovery of Grounded Theory. Strategies for Qualitative Research. New York: Aldine. (1967).

[17] Klaes, Luiz Salgado et al. Cooperativismo e ensino a distância. Florianópolis, 2005.

[18] Kleba, M.E; Wendausen, A. Empoderamento: processo de fortalecimento dos sujeitos nos espaços de participação social e democratização política. Saúde soc., São Paulo, v. 18, n. 4, p. 733-743, dez. 2009.

[19] Lisboa, T. K. Empoderamento de mulheres e participação na gestão de políticas públicas. 2007. Disponível em:<http://www.sociologia.ufsc.br/npms/teresa_kleba_lisboa.pdf>. Acesso em: 23 dez. 2017.

[20] Machado, H. P. V. Identidade empreendedora de mulheres no Paraná. Tese (Doutorado). Programa de PósGraduação em engenharia de produção. Universidade Federal de Santa Catarina. UFSC, 2002.

[21] Martins, Clitia Helena Backx. Trabalhadores na reciclagem do lixo: dinâmicas econômicas, socioambientais e políticas na perspectiva de empoderamento. 2003. [s.n] Tese (doutorado) - Programa de Pós-Graduação em Sociologia, Universidade Federal do Rio Grande do Sul, 2003.

[22] Melo, M. C. O. L (Coord). A gerência feminina em empresas do setor industrial mineiro: inserção, vivência e desafios. 2002. 196f. (Relatório de Pesquisa) - Núcleo de Relações de Trabalho e Tecnologias de Gestão - Nurteg, Universidade Federal de Minas Gerais, Centro Nacional de Desenvolvimento Cientifico e Tecnologia - CNPQ, Belo Horizonte, 2002.

[23] Melo, M. C. O.; Lopes, A. L. M. Empoderamento de mulheres gerentes: a construção de um modelo teórico de análise. Revista Gestão e Planejamento, v. 12, n. 3, p. 648-667, set./dez., 2012.

[24] Minayo, M. C. S. Pesquisa social: teoria, método e criatividade. Petrópolis: Vozes, 2001.

[25] Pinheiro, M. Cooperativas de Crédito: história da evolução normativa no Brasil. 5 ed. Brasília, 2006.

[26] Pinho, Diva Benevides. A doutrina cooperativa nos regimes capitalista e socialista. 2. ed. São Paulo: Pioneira, 1966. $161 \mathrm{p}$.

[27] Prá, Jussara Reis. Políticas públicas, direitos humanos e capital social. In: BAQUERO, M.; Cremonese, D. (Org.). Capital social: teoria e prática. Editora Unijui. Ijuí, 2006.

[28] Santos, A. C. L. Cooperativismo: entre os princípios teóricos e o desenvolvimento viável: um estudo de caso. 90 f. Dissertação (Mestrado em Desenvolvimento e Meio Ambiente) - Universidade Federal do Ceará, Fortaleza. 1998.

[29] Younger, D U. J; Brockbank, W.; Ulrich, M. Seis competências para o futuro da área de recursos humanos: RH de dentro para fora. Porto Alegre: Bookman, 2013. 


\section{Capítulo 5}

\section{Aspectos que influenciam a satisfação no trabalho: Estudo em uma empresa do comércio de autopeças}

\section{Claudelir Clein \\ Gilson Mussi dos Reis \\ Celito Nuernberg}

Regiane Aciléia Gonçalves Lopes

Resumo: 0 capital humano de uma organização vem sendo tomado como um dos focos principais em questões estratégicas, observando-se que é através dele que as empresas possuem maiores chances de crescimento e desenvolvimento. Desta forma, optou-se como objetivo, verificar por meio da Escala de Satisfação no Trabalho (EST), qual é o índice de satisfação dos colaboradores de uma empresa que atua no ramo de venda de autopeças. Portanto, considerando a EST, o estudo foi baseado em cinco dimensões da satisfação no trabalho: a satisfação com os colegas, com o salário, com a chefia, com a natureza do trabalho e com as promoções. Como todos os estudos científicos requerem utilizar-se de uma metodologia específica, este utilizou uma pesquisa bibliográfica descritiva e estudo de caso tendo como base o método indutivo. Sendo assim, foi realizada uma pesquisa com abordagem qualiquantitativa que permitiu verificar quais os índices de satisfação no trabalho, coletando-se os dados através de questionário aplicado aos colaboradores. Os resultados demonstram que os colaboradores encontram-se satisfeitos, entretanto, foram colocados enfoco alguns pontos de indiferença referentes ao plano de carreira e à política em relação às tarefas desenvolvidas, necessitando-se de estratégias de gestão que viabilizem atingir maiores níveis de satisfação no trabalho.

Palavras-chave: Satisfação no trabalho; Colaboradores; Organização. 


\section{INTRODUÇÃO}

Em nenhuma outra época nas organizações, as pessoas foram tão valorizadas como atualmente em relação às suas habilidades e competências (Marquardt \& Engel 1993; Sant'anna et al., 2005). E juntamente neste contexto a satisfação no trabalho é uma temática que vem ganhando espaço nos diferentes tipos de negócios no mercado. Com o passar do tempo muitas pesquisas mostram os benefícios que uma organização pode ter proporcionando que seus colaboradores sintam-se satisfeitos e motivados. Através deste estudo, percebeu-se que os colaboradores tornam-se mais produtivos e interativos com a empresa, bem como, possuem maior facilidade para atingir metas e obter resultados positivos quando estão satisfeitos no trabalho.

Fu (2014) e Silva et al (2017) relatam que a diminuição da satisfação no trabalho pode influenciar nos índices de produtividade, nos custos com a assistência médica, no absenteísmo e na rotatividade, já que existente uma relação considerável e correlata entre componentes do contexto organizacional e satisfação. Ou seja, uma empresa onde não investe no bem estar de seus colaboradores e não se preocupa em fornecer um ambiente de trabalho adequado pode ter um aumento nos seus custos operacionais.

As organizações vivem uma constante disputa por clientes, nichos de mercados e inovações em um parâmetro nunca visto antes. Com isso, são levadas também a competirem por um dos principais recursos disponíveis: o capital humano (Bartlett \& Ghoshal 1987; Sant'anna et al. 2005). Pode-se inferir que o capital humano se tornou uma das peças chave para uma organização obter sucesso. Todavia, se faz necessário que a empresa busque conhecer os colaboradores visando planos de melhorias contínuos que atendam seus anseios e proporcionem um ambiente de trabalho produtivo e saudável.

Sendo assim, o presente trabalho tem como objetivo, verificar qual o índice de satisfação no trabalho. Sendo obtidos os dados por meio de questionário aplicado na matriz da empresa localizada no município de Toledo - PR, e na filial localizada no município de Francisco Beltrão - PR. Para tanto, buscou-se responder a seguinte problemática: qual o nivel de satisfação dos colaboradores que atuam na comercialização de peças automotivas?

Para mensurar os níveis de satisfação, utilizou-se da ferramenta EST (Escala de Satisfação no Trabalho). A mesma é uma medida multidimensional construída e validada com o objetivo de identificar o grau de satisfação do colaborador através de cinco dimensões do trabalho, sendo elas: satisfação com os colegas, com o salário, com a chefia, com a natureza do trabalho e as promoções. (SIQUEIRA, 2008).

Para tanto, além desta introdução, o trabalho apresenta-se dividido em cinco partes. Na seção dois, expressa sobre o comportamento organizacional, satisfação e motivação dos colaboradores. Em seguida, na seção três, apresenta-se a metodologia onde são descritos os propósitos e os caminhos metodológicos utilizados na pesquisa. A apresentação e análise dos resultados são apresentadas na seção quatro. A quinta e última seção demonstra as considerações finais relativas ao estudo proposto.

\section{COMPORTAMENTO ORGANIZACIONAL}

O comportamento organizacional consiste no estudo regrado das ações e atitudes das pessoas que compõem uma organização. O mesmo procura utilizar evidências científicas obtidas sob condições controladas, medidas e interpretadas para a atribuição de causa e efeito. 0 estudo do comportamento organizacional pode contribuir de forma positiva não somente para uma organização, mas para os profissionais que nela atuam (ROBBINS, 2007).

São grandes os benefícios oriundos do estudo do comportamento organizacional, embora os resultados não serem imediatamente visíveis. Neste contexto, o estudo e a aprendizagem do comportamento organizacional possibilitam quatro vantagens: o desenvolvimento das habilidades; crescimento pessoal; melhoria da eficácia organizacional; apuro e refinamento do bom senso (DUBRIN, 2006).

Dentro o âmbito do comportamento organizacional é possível citar uma variável importante: o clima organizacional, o mesmo está diretamente ligado com o capital humano que compõe uma organização. São as pessoas que contribuem com o clima para que seja favorável, facilitando assim o alcance de objetivos almejados (Araujo \& Garcia, 2010). Para tanto, o clima existente em uma organização pode influenciar diretamente no comportamento humano. 
Neste sentido, o clima organizacional reflete a qualidade do ambiente de trabalho constatado pelas pessoas. 0 mesmo é fortemente influenciado pela cultura da empresa. (Schein, 1985; Lacombe, 2011). A cultura contempla o que é prezado pela empresa, estilos de liderança, os procedimentos e rotinas, as definições de sucesso onde tornam uma organização única em meio a tantas opções (CAMERON \& QUINN, 2006; SILVA et al. 2017).

A cultura organizacional norteia através de seus valores e crenças, qual o comportamento que um indivíduo deve adotar dentro de uma organização (Hartnell, Ou \& Kinicki, 2011; Silva et al., 2017). Diante deste contexto, tendo observado quanto ao comportamento organizacional, cabe dar sequência no referencial teórico considerando quanto à satisfação e motivação de colaboradores.

\subsection{SATISFAÇÃO E MOTIVAÇÃO DE COLABORADORES}

De acordo com Hauff et al., (2015) e Silva et al., (2017) a satisfação no trabalho é uma variável de relevância no âmbito organizacional. A mesma é resultante da percepção que o colaborador tem sobre seu trabalho, envolvendo os aspectos afetivos que ele considera satisfatórios ou não (ANDRADE et al., 2017; LOCKE, 1976; MARTINS \& SANTOS, 2006; SILVA et al., 2017).

Para Tamayo (2001); Warr (2007); Silva et al., (2017), a satisfação estabele uma relação com inúmeros aspectos presentes no ambiente organizacional, relacionados à remuneração, relação com os colegas e superiores, carreira, clima organizacional, autonomia e conteúdo do trabalho, segurança no trabalho, posição alcançada pelo trabalho realizado, justiça percebida pelo colaborador. Sendo assim, a insatisfação do colaborador pode desenvolver para a empresa certos efeitos que merecem atenção como alguns custos organizacionais. Por exemplo: o absenteísmo e a rotatividade (WAGNER \& HOLLENBECK, 2006).

Entretanto observa-se que o fornecimento de treinamento, variedade, independência e controle elevam em maioria a satisfação dos colaboradores. O quanto os indivíduos apreciam o contexto social em que trabalham também apresenta uma correlação com a satisfação. Colaboradores satisfeitos e comprometidos apresentam menores taxas de rotatividade, absenteísmo e comportamentos desviantes, demonstrando maior desempenho. Por terem o foco de manter demissões e faltas em níveis baixos os gestores devem ter atitudes que gerem iniciativas relacionadas ao ambiente de trabalho (ROBBINS, 2010).

Percebe-se que a satisfação está interligada com algumas variáveis, por exemplo, a motivação que o colaborar possui referente ao seu trabalho que exerce influência no que diz respeito à sua produtividade. Mas o que seria a motivação? De acordo com Vergara (2007) a motivação é uma força, uma energia, algo que nos impulsiona em prol de um objetivo. A mesma é intrínseca, ou seja, nasce de dentro para fora, do nosso interior.

Convém desta forma, considerar que Maslow (1943) demonstra as necessidades humanas organizadas em uma pirâmide de importância no comportamento humano. A base da pirâmide refere-se às necessidades mais baixas e recorrentes chamadas primárias e, no topo, às secundárias onde são as mais sofisticadas e intelectualizadas. É possível observar através da Figura 1.

Figura 1 - Hierarquia das necessidades humanas segundo Maslow.

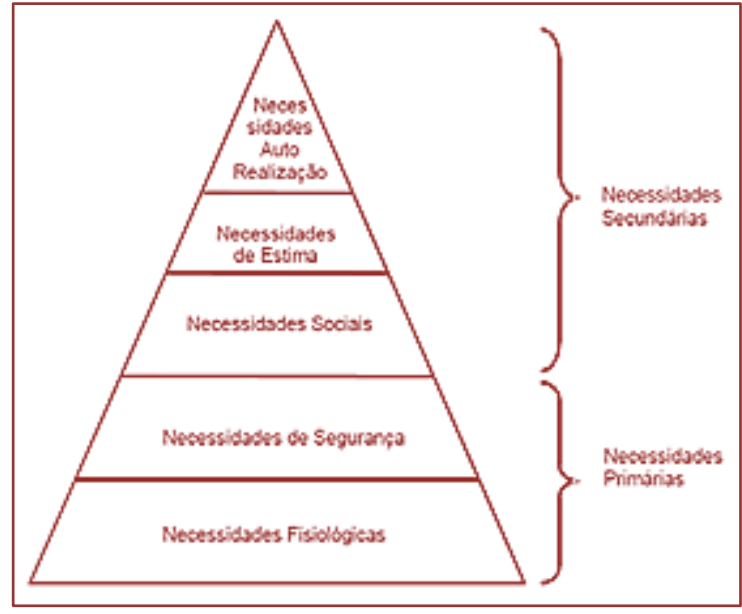

Fonte: Faculdade de são Luiz França (2017). 
As necessidades fisiológicas constituem a parte mais baixa das necessidades humanas. São necessidades inatas, como a fome, sede, sono etc. Sua principal característica é a premência: se alguma dessas necessidades não está satisfeita domina a direção do comportamento da pessoa (MASLOW, 1943; CHIAVENATO, 2008).

Já o segundo nível condiz com as necessidades de segurança que levam a pessoa a se proteger de qualquer perigo real ou imaginário. É de grande valia, pois as pessoas têm uma relação de dependência com a organização, onde as relações gerenciais autoritárias ou as decisões erradas podem provocar incerteza e/ou insegurança quanto à permanência das pessoas no trabalho. As necessidades sociais (terceiro nível) são de participação, aceitação por parte dos colegas, troca de amizades, afeto e de amor. São visíveis no comportamento quando as necessidades mais baixas se encontram levemente satisfeitas. A necessidade social quando não atendida torna a pessoa resistente, antagônica e hostil com relação ás pessoas que o cercam (MASLOW, 1943; CHIAVENATO, 2008).

Maslow (1943) apud Chiavenato (2008) ainda discorrem sobre a satisfação da necessidade de estima que conduz a sentimentos de autoconfiança, valor, força, prestígio, poder, capacidade e utilidade. A sua frustração pode trazer sentimentos de inferioridade, fraqueza, dependência e desamparo, podendo acarretar em desânimo ou atividades compensatórias.

A necessidade de autorrealização está no topo da pirâmide, a mesma se refere ao potencial e desenvolvimento contínuo do indivíduo ao longo de toda a vida. Quanto mais a pessoa obtém retornos de satisfação mais importantes se tornam e reforçarão a sua busca. (MASLOW, 1943; CHIAVENATO, 2008).

Conforme abordado por Maslow e Chiavenato, pode-se perceber que todo o ambiente que envolve uma organização poderá influenciar na satisfação, motivação e no desempenho produtivo do colaborador. Fazse necessário comentar as palavras de Gurgel (2001), o qual relata que a produtividade ocorre por meio da fixação de recursos e da sua aplicação no trabalho. Isso requer a presença de pessoas, tecnologia e conhecimento ampliado dos recursos financeiros. Porém, depende unicamente da tarefa de administrar, gerenciar, deixar o trabalho produtivo e o trabalhador realizado e feliz, tornando o trabalho mais atrativo aos seres humanos.

A produtividade é consequência, vem por último. É resultante da produção de equipes capacitadas, apaixonadas, ferramentas adequadas, recursos, conhecimento, visão, tecnologia, gestão e satisfação com o trabalho (GURGEL, 2001).

\section{0 PROCEDIMENTOS METODOLÓGICOS}

Este trabalho utilizou uma pesquisa bibliografica descritiva e estudo de caso tendo como base o método indutivo, uma vez que o mesmo consiste em enumerar os enunciados sobre o fenômeno que será pesquisado. Através da observação, procura-se encontrar algo que está geralmente presente na sua ocorrência (ANDRADE, 2007).

A coleta de dados se deu por meio da aplicação de questionário estruturado com base Escala de Satisfação no Trabalho - EST, sendo uma medida multidimensional que possui o objetivo de avaliar o grau de satisfação do colaborador frente a cinco dimensões do seu trabalho: a satisfação com os colegas, com o salário, com a chefia, com a natureza do trabalho e com as promoções.

Para obter as informações necessárias para este estudo, o questionário foi aplicado em uma reunião realizada pelo gestor da filial em Francisco Beltrão - PR, onde todos puderam responder tranquilamente, e assim que foram respondidos aconteceu o recolhimento dos mesmos. Todos que compõem a empresa puderam participar da pesquisa, inclusive os gestores.

Já em Toledo - PR, foi obtida a colaboração da empresa onde os questionários foram mandados por malote através da filial de Francisco Beltrão, com as recomendações de aplicação, abrangendo também, todos os níveis hierárquicos da empresa. Foram aplicados sessenta questionários em Francisco Beltrão e trinta e seis em Toledo, totalizando um público de respondentes de noventa e seis trabalhadores. 


\section{0 APRESENTAÇ̃̃O E ANÁLISE DOS RESULTADOS}

Com o presente estudo verificou-se através das análises dos resultados os níveis de satisfação dos colaboradores em cinco dimensões do trabalho sendo: satisfação com os colegas; com o salário; com a chefia; a natureza do trabalho e as promoções. Portanto, na aplicação da EST, buscou-se primeiramente saber sobre o nível de satisfação com colegas de trabalho, em que foram feitos alguns questionamentos conforme pode ser observado na Figura 1.

Figura 1 - Satisfação com os Colegas.



Fonte: Pesquisa do autor $(2017$.

Apurado a primeira dimensão referente à satisfação com os colegas de trabalho, obteve-se um resultado de 5,42, considerando-se a média dos questionamentos que a compõem. Ou seja, a mesma se enquadra nos parâmetros de satisfação.

Desta forma, entende-se que o resultado positivo apontado pelos colaboradores é fator impulsionador de motivação, o que contribui para possível aumento da produtividade no ambiente laboral. Outro ponto a se enfatizar, é que na medida em que uma relação fraterna com os colegas de trabalho se estabelece, aumenta a sinergia da equipe mantendo um bom clima organizacional (ROBBINS, 2010).

Em contrapartida verifica-se que considerando uma escala de 5 a 7, o resultado da dimensão se encontra com nível frágil de satisfação (5,42). De acordo com Likert (1971) e Lacombe (2011) o grau de satisfação interno da empresa está diretamente interligado com a motivação, lealdade, colaboração e aos relacionamentos entre as pessoas, identificação com a empresa, facilidade de se comunicar internamente, integração da equipe, dentre outras.

Sendo assim, infere-se que se torna importante realizar trabalhos direciondos às equipes no trabalho, como por exemplo, práticas de comunicação que proporcionem fortalecer os relacionamentos não só entre colaboradores do mesmo departamento como em relação aos outros que integram a empresa.

Dando sequência a aplicação da EST, buscou-se levantar informações quanto à satisfação com o salário, possuindo enfoque de como o colaborador se encontra satisfeito perante o quanto recebe mensalmente, comparando-se com o quanto trabalha, com a capacidade profissional, custo de vida, bem como os seus esforços na realização do trabalho, sendo os resultados expostos na Figura 2.

Figura 2 - Satisfação com o Salário.

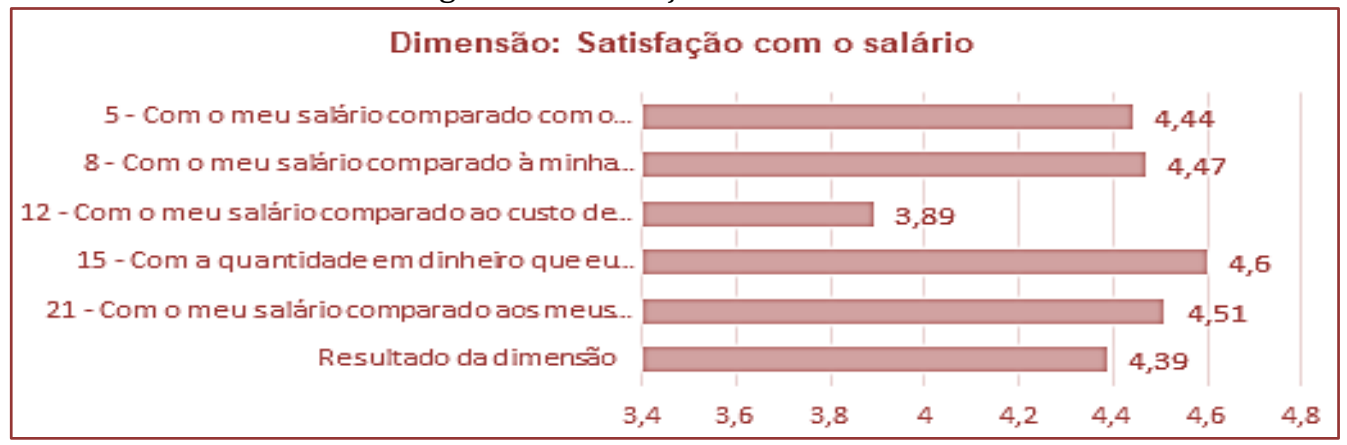

Fonte: Pesquisa 2017. 
A dimensão referente à satisfação com o salário resultou em uma escala de 4,39. Analisando a Figura 2 de um modo geral, constata-se que os colaboradores estão em um estado de indiferença.

Na medida em que os colaboradores se encontram indiferentes diante à função que realizam na empresa como consequência do seu salário, podem apresentar menor desempenho em suas atividades. Isso pode incluir o atendimento ao cliente, a diminuição do interesse nos objetivos da organização e outros aspectos inerentes ao trabalho. 0 índice de rotatividade também pode ser influenciado, considerando que o indivíduo pode não estar disposto a permanecer na empresa onde o salário não é atrativo e os benefícios são reduzidos ou inexistentes.

Desta forma, neste parâmetro sobre satisfação com o salário, denota-se a importância de rebuscar os fatores da pirâmide das necessidades de Maslow, focando no segundo nível, onde se refere à segurança. Um dos aspectos integrantes desta categoria é a remuneração (salário e benefícios), e uma vez que esta necessidade é suprida o indivíduo se sente seguro para buscar outros níveis de satisfação e realização. No entanto, quando isso não ocorre podem ser desenvolvidos sentimentos negativos como a insatisfação. (MASLOW, 1943; CHIAVENATO, 2008).

Posteriormente, questionou-se em relação à satisfação com a chefia. Neste quesito foi avaliado o quanto o colaborador está satisfeito com a capacidade profissional e de organização do chefe, com o interesse que o mesmo tem pelo trabalho dos subordinados, bem como, o entendimento na comunicação entre ambos. Sendo assim, demonstra-se os dados obtidos nesta dimensão através da Figura 3.

Figura 3 - Satisfação com a Chefia.

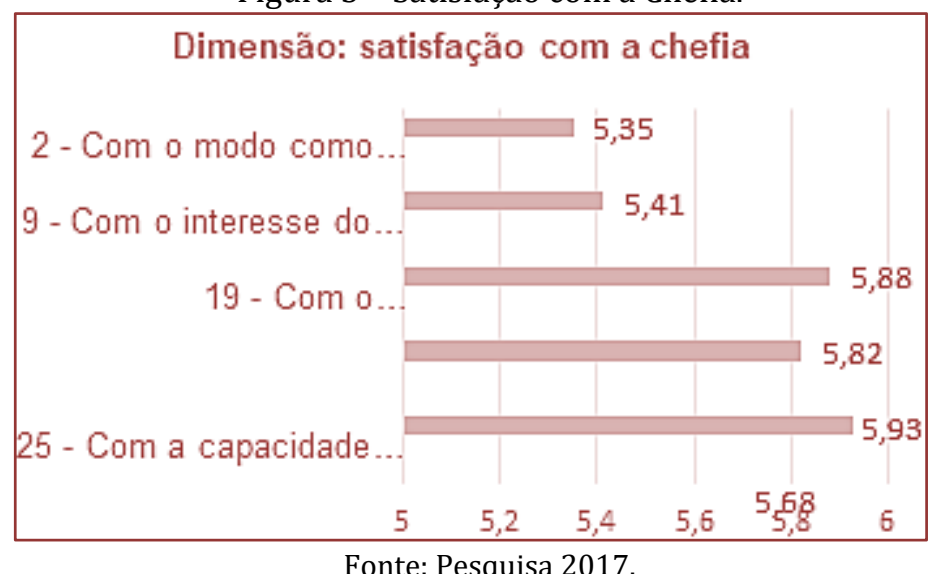

A apuração geral da escala satisfação com a chefia foi de 5,68, como se pode notar na Figura 3, encontrando-se nos parâmetros de satisfação, considerando que a escala de satisfação é de 5 a 7.

Identifica-se de acordo com o resultado obtido, que não existe uma percepção classificada como de alta satisfação. Neste aspecto tornam-se necessários cuidados que visem manter elevado nível de satisfação, tendo como pressuposto que quando o colaborador se encontra pouco satisfeito com a forma de trabalho e com o pouco interesse do seu chefe, pode agir com descaso diante de suas funções. Em vista disso, foi possível compreender quanto à satisfação com a chefia que o contato direto com seus subordinados serve como aspecto determinante, onde, se positivo, a empresa terá mais facilidade de obter resultados almejados. Entretanto, se for negativo, pode dificultar o alcance dos objetivos estabelecidos (ROBBINS, 2010).

0 próximo passo foi verificar o índice de satisfação com o trabalho, possuindo foco no interesse das tarefas, com a variância que existe entre elas e com a qualidade de vida no trabalho. Evidenciou-se o nível de satisfação com trabalho conforme os resultados expostos na Figura 4. 
Figura 4 - Satisfação com a Natureza do Trabalho.

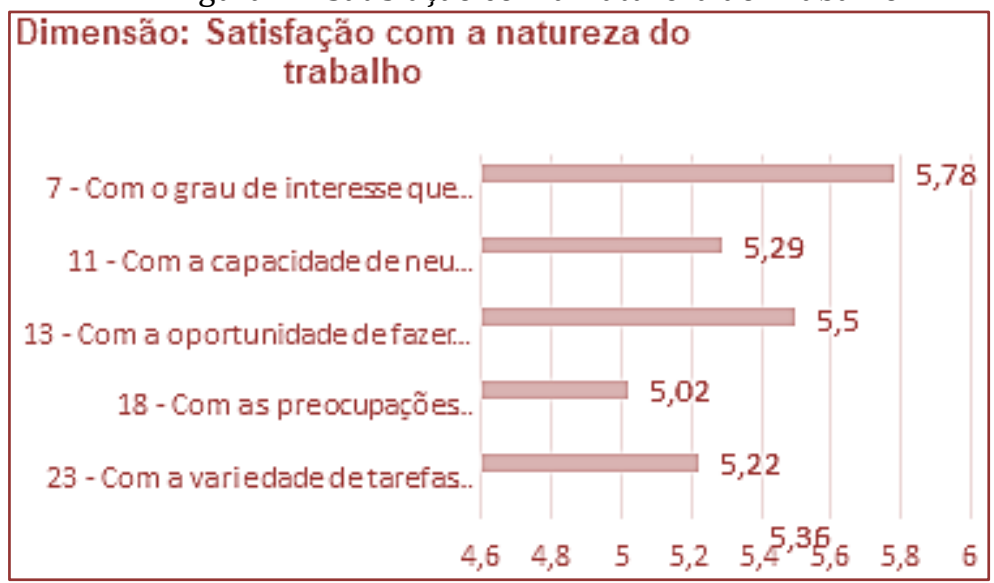

Fonte: Pesquisa 2017.

0 resultado da dimensão é de 5,36, o que se encaixa no padrão de satisfaçã, porém, estando baixo. Com isso, há necessidade de averiguar que alguns dos fatores que norteiam a queda da satisfação no trabalho podem estar vinculados ao esforço dos empregadores em aumentar a produtividade sem demonstrar preocupação com a motivação de seus colaboradores enquanto sobrecarga de trabalho e prazos menores ou inatingíveis para a realização das tarefas. A insatisfação no trabalho e o estresse podem gerar na empresa efeitos que não devem ser descuidados, tais como: o aumento da rotatividade, do absenteísmo, os custos de assistência medida e a agressividade no ambiente de trabalho (ROBBINS, 2007).

A última dimensão analisada corresponde às promoções no trabalho, compreendendo-se como uma via de mão dupla, isto é, o colaborador irá buscar se perceber que a empresa oferece oportunidades, e a empresa irá promovê-las se existir engajamento no desempenho das atividades e no alcance dos objetivos estabelecidos. Na Figura 5 são exibidos os resultados da dimensão satisfação com as promoções.

Figura 5 - Satisfação com as Promoções.

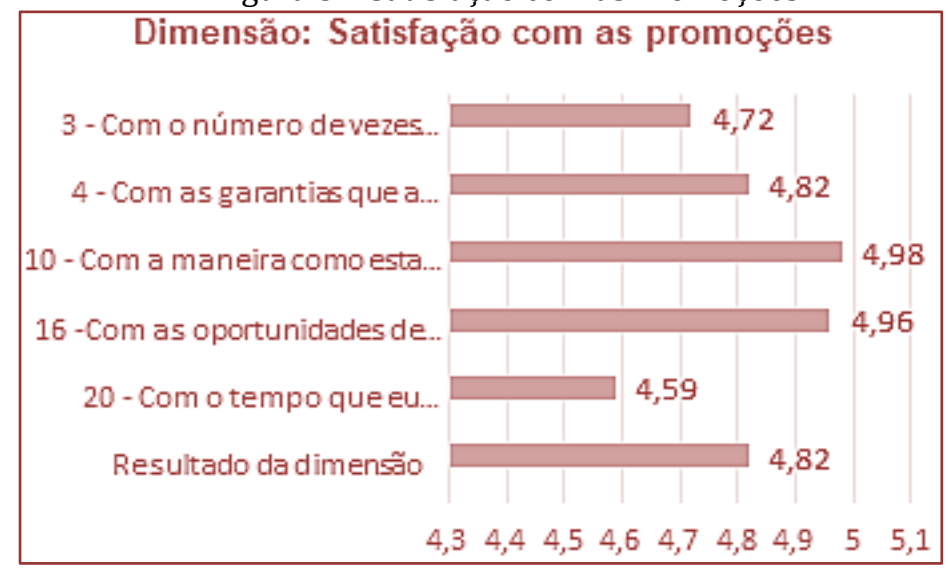

Fonte: Pesquisa 2017.

A computação da dimensão no âmbito universal foi de 4,82. Detecta-se que os colaboradores não estão satisfeitos com as possibilidades que a empresa oferece de promoção. Entretanto, nesta questão temos duas diretrizes em que a primeira se resume na busca do conhecimento e de qualificação por parte dos colaboradores, e de contrapartida o devido reconhecimento da empresa.

Destarte, o colaborador deve ter em mente que para atingir cargos mais altos é preciso buscar desenvolver seus conhecimentos, habilidades e atitudes dentro da empresa. Contudo, a empresa como meio de auxiliar o monitoramento e possibilidades de qualificações dos seus colaboradores, poderia desenvolver um plano de carreira especificando as qualificações necessárias para cada cargo, sendo assim, uma forma de motivar seus colaboradores a buscarem maior desenvolvimento pessoal e profissional. 


\subsection{COMPARAÇõES ENTRE AS MÉDIAS DAS DIMENSÕES}

Primeiramente, para que se possa apresentar com clareza a comparação entre a média das dimensões e demonstrar o caráter científico em que se baseou este estudo, expõe-se que se considera como escore médio os valores de 5 a 7, onde se enquadram nos parâmetros de satisfação. Valores entre 1 e 3,9 tendem a indicar insatisfação. Já os valores que se enquadram entre 4 e 4,9 informam um estado de indiferença dos colaboradores perante a dimensão em questão (SIQUEIRA, 2008).

Partindo para a comparação entre os resultados gerais, conforme pode ser observado através do Quadro 1 , o escore médio de todas as dimensões englobadas na pesquisa ficou entre 4,39 (classificado como indiferença) e 5,68 (enquadrando-se como satisfação).

Quadro 1 - Escore Médio.

\begin{tabular}{|l|c|}
\multicolumn{1}{|c|}{ DIMENSÕES } & RESULTADOS \\
\hline Satisfação com os colegas & 5,42 \\
\hline Satisfação com o salário & 4,39 \\
\hline Satisfação com a chefia & 5,68 \\
\hline Satisfação com a natureza do trabalho & 5,36 \\
\hline Satisfação com as promoções & 4,82 \\
\hline
\end{tabular}

Fonte: Pesquisa 2017.

Visando ter uma noção da importância de cada dimensão para os resultados esperados em relação à satisfação de forma completa, buscou-se verificar a influência que uma ou mais dimensões exercem sobre as demais ou numa outra em específico.

Como percebido que o maior grau de satisfação se deu com o chefe imediato $(5,68)$, e que o menor se refere à satisfação com o salário $(4,39)$, cabe destacar que o valor em retribuição ao emprego da força laboral determinante em termos de influência no índice de satisfação com o trabalho. Se considerado a satisfação com o salário, identifica-se que assim como no que se refere às promoções no trabalho, os índices se apresentam fragilizados. Esses índices podem contribuir para que os colaboradores adotem um comportamento descomprometido com a empresa sem se importar em atingir metas, podendo ocorrer uma diminuição da produtividade.

Portanto, é possível constatar que pode ser o momento da empresa optar por um plano de carreira vinculado a um auxílio qualificação em instituições de ensino superior ou nível técnico profissionalizante, promovendo treinamentos que gerem oportunidades e levem ao desenvolvimento dos seus colaboradores.

Deste modo, infere-se que é improvável tratar da satisfação dos colaboradores de forma individual analisando somente um aspecto do local de trabalho, pois se o mesmo não estiver satisfeito com uma das dimensões surtirá efeito nas outras Da mesma forma, se o nível de satisfação for mais alto a tendência é que os índices aumentem em todos os aspectos. Sendo assim, pode-se entender também que a satisfação com a natureza do trabalho pode interferir na satisfação com o salário, Neste sentido, o colaborador pode se sentir injustiçado com o quanto recebe analisando as tarefas que executa, podendo ser um fato desencadeador da intenção em sair da organização.

De acordo com Robbins (2010) quando um colaborador está satisfeito com o seu local de trabalho, o mesmo poderá desenvolver um comportamento proativo ajudando os colegas, tornando a relação mais afetiva, se colocando à disposição e ainda estar propenso a falar bem da empresa onde trabalha.

\section{CONSIDERAÇÕES FINAIS}

Cada vez mais fica perceptível a importância do estudo da satisfação no trabalho. Observa-se que o capital humano passou a ter grande relevância nas organizações, sendo tomado como um dos pontos cruciais em um mercado competitivo.

Desta forma, as pessoas se tornam um ponto chave para obter vantagem competitiva. Então, as empresas que procuram investir nos seus colaboradores possuem chances de conquistar uma fatia maior no mercado. Entretanto, a satisfação precisa ser monitorada, ou seja, um aspecto de constantes melhorias. 
Com a realização deste estudo, por meio da escala de satisfação no trabalhoo (EST), foi possível constatar que os colaboradores em partes estão satisfeitos, sendo as dimensões de maior satisfação as que envolvem os colegas, a chefia e a natureza do trabalho. Já quanto às dimensões focadas no salário e nas promoções, os colaboradores encontram-se indiferentes.

Por conseguinte, também se verificou com o presente trabalho algumas das principais causas que interferem negativamente no alcance da satisfação do colaborador. Nesse contexto observou-se que a falta de reconhecimento, um clima desfavorável, um local de trabalho desagradável, a inflexibilidade, as poucas ou nulas oportunidades de crescimento profissional, salários baixos e a falta de um plano de carreira para os colaboradores influenciam diretamente para gerar a insatisfação.

A satisfação no trabalho pode aumentar e muito a capacidade produtiva do colaborador e com isso a empresa poderá utilizar da melhor forma essa produtividade para atingir os seus objetivos. Mas para que isso ocorra, algumas coisas devem ser implantadas ou melhoradas na empresa, tais como: monitorar os índices de satisfação; proporcionar um ambiente agradável de trabalho; oferecer feedback; reconhecer os colaboradores que se destacam no trabalho; ser empáticos com os trabalhadores; implantar uma política salarial equilibrada com o cargo e as funções que os colaboradores exercem; incentivar a prática de exercícios, bem como, implantar a ginástica laboral para mantê-los mais dispostos; estimular a relação entre os colaboradores mantendo-os unidos e focados nos objetivos; oferecer benefícios e premiações quando uma meta é alcançada.

Por fim, conclui-se que os gestores e diretores precisam estar atentos no que se refere às dimensões de satisfação no trabalho, aspecto fundamental para o crescimento e sucesso da organização. Portanto, compreende-se que os colaboradores devem ser tratados nas organizações como seres humanos que possuem uma essência e não somente como números, sendo merecedores de reconhecimento e valorização.

\section{REFERÊNCIAS}

[1] Andrade, M. M. de. Introdução à Metodologia do Trabalho Científico: Elaboração de Trabalhos na Graduação. 8ae ed. São Paulo: Atlas, 2007.

[2] Andrade, T., Costa, V. F, Estivalete, V. de F. B., \& Lengler, L. (2017). Comportamento de cidadania organizacional: Um olhar à luz dos valores e da satisfação no trabalho. Revista Brasileira de Gestão de Negócios, 19(64), 236-262. http://dx.doi.org/10.7819/rbgn.v19i64.2899.

[3] Araújo, L. C. G; Garcia, A. A.. Gestão de Pessoas. São Paulo: Atlas, 2010.

[4] Bartlett, C. A.; Ghoshal, S. The myth of the generic manager: new personal competencies for new management roles. California Management Review, v. 40, n. 1, p. 93-116, 1987.

[5] Cameron, K. S., \& Quinn, R. E. (2006). Diagnosing and changing organizational culture - Based on the competing values framework. San Francisco, CA: Jossey-Bass.

[6] Chiavenato, I. Recursos Humanos: O Capital Humano das Organizações. 8 ed. 4 reimpressão - São Paulo: Atlas, 2008.

[7] Dubrin, A. J. Fundamentos do Comportamento Organizacional. São Paulo: Pioneira Thomson Learning, 2006.

[8] Fu, W. (2014). The impact of emotional intelligence, organizational commitment, and job satisfaction on ethical behavior of Chinese employees. Journal of Business Ethichs, 122(1), 137-144. http://dx.doi.org/10.1007/s10551-013-1763-6.

[9] Gurgel, A. O. C. RH Positivo - Novo mundo do trabalho. Rio de janeiro: Qualitymark, 2001.

[10] Hartnell, C. A., Ou, A. Y., \& Kinicki, A. (2011). Organizacional culture and organizational effectiveness: A metaanalytic investigation of the competing values framework's theorical suppositions. Journal of Applied Psychology, 96(4), 677-694. http://dx.doi.org/10.1037/a0021987.

[11] Hauff, S., Richter, N. F., \& Tressin, T. (2015). Situational job characteristics and job satisfaction: The moderating role of national culture. International Business Review, 24(4), 710-723. http://dx.doi.org/10.1016/j.ibusrev.2015.01.003.

[12] Locke, E. A. (1976). The nature and causes of job satisfaction. In M. D. Dunnette (Ed.), Handbook of industrial and organizational psychology (pp. 1297-1349). Chicago: Rand McNally.

[13] Marquardt, M. J.; Engel, D. W. Global human resource development. Englewood Cliffs: Prentice-Hall, 1993.

[14] Robbins, S. P. Fundamentos do Comportamento Organizacional. São Paulo: Pearson Prentice Hall, 2007. 
[15] Comportamento Organizacional. 14aㅡ ed. São Paulo: Pearson Prentice Hall, 2010.

[16] Siqueira, M. M. M. (2008). Satisfação no trabalho. In M.M.M Siqueira (Org.), Medidas do comportamento organizacional: Ferramentas de diagnóstico e de gestão (pp. 265-274). Porto Alegre: Artmed.

[17] Tamayo, A. (2001). Prioridades axiológicas, atividade física e estresse ocupacional. Revista de Administração Contemporânea, 5(3),127-147. http://dx.doi.org/10.1590/S1415- 65552001000300007.

[18] Vergara, S. C. Gestão de Pessoas. 6ª ed. São Paulo: Atlas, 2007.

[19] Wagner III, J. A \& Hollenbeck, J. R. Comportamento Organizacional. Trad. Cid Knipel Moreira. São Paulo: Saraiva, 2006.

[20] Warr, P. (2007). Work, happiness, and unhappiness. Mahwah, NJ: Lawrence Erlbaum. 


\section{Capítulo 6}

Estado da arte da produção científica dos artigos publicados no ENGEMA de 2014 a 2018

\section{Antônia Amanda Alves Pereira Moreira \\ Henrique César Melo Ribeiro \\ Magna da Silva Vilanova Castro \\ Matheus Morais Bruno \\ Rosany Corrêa}

Resumo: A principal finalidade da ciência é perceber e entender os fenômenos da natureza. A produção científica é um meio de buscar novos conhecimentos e soluções para os problemas que permeiam o dia-a-dia das pessoas, proporcionando a satisfação das necessidades humanas. 0 presente estudo tem como principal objetivo, investigar o perfil e as características da produção científica do congresso ENGEMA durante o quinquênio 2014 a 2018. A metodologia adotada para a realização da pesquisa se constitui como uma pesquisa quantitativa com forma de análise bibliométrica. Ao analisar os dados obtidos é possível notar a grandeza e importância do evento para o Brasil. Em cinco anos foram 1.626 artigos científicos publicados com 5.120 participações nos trabalhos apresentados no congresso das mais variadas regiões do país. Portanto, conclui-se que através do congresso e seus achados os temas voltados para a sustentabilidade passaram as ser debatidos de forma abrangente através dos artigos publicados e do espaço de debate que o evento proporciona no decorrer de suas edições e assim as pessoas passam a adquirir uma consciência ambiental necessária na atualidade.

Palavras-Chave: Estado da Arte. Produção Científica. Engema. 


\section{INTRODUÇÃO}

A principal finalidade da ciência é perceber e entender os fenômenos da natureza. Ela é considerada instrumento indispensável na incessante busca de respostas, seus registros são essenciais para conservação e preservação de resultados, observações, cálculos, teorias, etc., possibilitando, assim, a crítica, aceitação ou não, e aperfeiçoamentos posteriores. A comunicação desses registros é ação ainda mais importante, condição pela qual se possibilita o alcance público, permitindo, assim, a apropriação desses por outros indivíduos e, consequentemente, a geração de mais conhecimentos (DROESCHER; SILVA, 2014).

A produção científica é um meio de buscar novos conhecimentos e soluções para os problemas que permeiam o dia-a-dia das pessoas, proporcionando a satisfação das necessidades humanas, principalmente aquelas relacionadas ao mundo moderno e tecnológico, trazendo assim desenvolvimento para a ciência bem como para toda a sociedade. Nesse sentido, a pesquisa é uma prática que deve ser inserida e implementada na convivência do profissional desde o seu ingresso na graduação, e a universidade bem como os professores tem um papel muito importante nesse processo (CORRÊA; RIBEIRO, 2017; SANTOS, 2011).

No Brasil, com a expansão dos cursos de pós-graduação em administração e o exercício de maior pressão pela Coordenadoria de Aperfeiçoamento do Ensino Superior (CAPES) foram estimulados mais ainda à produção acadêmica e sua divulgação sistemática em periódicos de excelência e abrangência nacional. Fortalecendo esse avanço surge o Encontro Nacional de Gestão Empresarial e Meio Ambiente [ENGEMA], evento anual dedicado a incentivar a produção científica em gestão ambiental empresarial (JABBOUR; SANTOS, BARBIERI, 2008).

O ENGEMA vem sendo realizado pela FGV/Eaesp e pela FEA/USP, desde o final da década de 1980, contando com a participação de outras renomadas instituições de pesquisa. 0 objetivo do evento é o intercâmbio, a divulgação de práticas de gestão ambiental e o estimulo de produção de novos conhecimentos e novas abordagens administrativas que contribuam para a proteção do meio ambiente e para a melhoria da qualidade de vida das populações. 0 número de trabalhos tem crescido a cada edição, o que reflete um aumento da produção e interesse pelos temas relacionados com a gestão socioambiental (KRUGLIANSKAS et al.,2008; STREIT; GUARNIERI;GOMES,2016).

Em uma breve busca pela produção científica em Administração veiculada em revistas e eventos científicos brasileiros, os mais importantes, nos últimos anos, chama-nos a atenção à pequena, porém crescente, produção de estudos bibliométricos sobre os mais diferentes assuntos (TEIXEIRA; IWAMOTO; MEDEIROS, 2013). É sabido que dentre as formas de trabalhar a produção científica existe, a forma qualitativa, chamada epistemologia e uma forma quantitativa, chamada bibliometria que trata dos aspectos quantitativos da construção do conhecimento (MELLO et al.,2015).

A principal diferença entre os subcampos está no objeto de estudo, o que gera variáveis observáveis e métodos diferenciados, isso de acordo com o objetivo em questão. A bibliometria volta-se para a produção existente entre livros, documentos e periódicos (VANTI, 2002). Com seu surgimento entre os 1920 e 1930, solidificou-se na aplicação de técnicas estatísticas e matemáticas, inicialmente foi conhecida como bibliografia estatística até o momento em que a diferença essencial entre os dois conceitos pudesse ser identificada: enquanto na bibliometria prevalecem os métodos quantitativos, na bibliografia estatística prevalecem os discursivos (ARAÚJO, 2006).

Mediante as informações citadas anteriormente esse estudo se justifica, pela necessidade de investigar o perfil e as características da produção científica do congresso ENGEMA durante o quinquênio 2014 a 2018 e uma vez que contribui para o evento no que tange a sua influência e participação na evolução da produção científica do país, também somando ao acervo bibliográfico da pesquisa acadêmica nacional e internacional. Tais justificativas levam a seguinte questão de pesquisa: Qual o perfil e as características da produção científica do congresso ENGEMA durante o quinquênio 2014 a 2018? Procurando responder a referida indagação o presente estudo tem como principal objetivo, investigar o perfil e as características da produção científica do congresso ENGEMA durante o quinquênio 2014 a 2018.

A metodologia adotada para a realização da pesquisa se constitui como uma pesquisa quantitativa com forma de análise bibliométrica através do estudo dos artigos publicados durante o quinquênio 2014 a 2018 no ENGEMA. O presente estudo visa contribuir para a pesquisa científica do assunto em questão, servindo assim de base para futuras pesquisas mais aprofundadas sobre a temática e também para mostrar a relevância do ENGEMA para a produção científico-acadêmica de acordo com perfis e características estudados. 
Além desta seção, o presente trabalho possui mais quatro partes. A seção seguinte compete ao referencial teórico, posteriormente serão apresentados à metodologia, seguida da análise e discussão dos dados coletados e, por fim, as considerações finais desse estudo.

\section{REFERÊNCIAL TEÓRICO}

Esta sessão abordará temas importantes nos quais envolvem Produção Científica, Encontro Internacional sobre Gestão Ambiental e Meio Ambiente (ENGEMA), Bibliometria e as Leis Bibliométricas, abordando conceitos e teorias para fins de estudo, procurando dar as bases que sustentarão ao processo de pesquisa.

\subsection{PRODUÇÃO CIENTÍFICA}

O grau de desenvolvimento de um país é obtido por diversos fatores, dentre os vários fatores se destaca a produção científica que é revelada pela sua representação junto à comunidade científica mundial, que acompanha a preocupação e comprometimento dos governos com o crescimento científico e tecnológico da nação. Por esta razão toda pesquisa deve ter por objetivo principal a divulgação de seus resultados junto à comunidade científica, uma vez que os índices de publicação científica são fatores determinantes tanto para o crescimento do país como para o próprio pesquisador (BARBOSA; RAMOS; CíRIACO, 2009).

A produção científica é uma investigação feita com o objetivo expresso de obter conhecimento específico e estruturado sobre um determinado tema. 0 pesquisador, indivíduo que realiza a produção, deve ter como foco de análise um objeto ou assunto bem delimitado, concentrando todo seu esforço na solução do problema proposto. Em suma, a produção científica é o fundamento de toda e qualquer ciência e a principal maneira de conferir se um estudo ou trabalho foi motivo de pesquisa é verificar se ela provocou avanços (BARBOSA; RAMOS; CÍRIACO, 2009).

A experiência da escrita é algo que cada pessoa carrega consigo, mas no ambiente acadêmico, lugar onde os estudantes já estão determinados a um objetivo observa-se que a preparação e a dedicação completa requerem a especialização, pesquisa e atualização, buscando o aprofundamento do que se já estudou em sala de aula e instigando o acadêmico a ser um sujeito produtor de conhecimentos, revelar-se, não apenas ser um anônimo leitor, mas sim um visível escritor, produtor de conhecimentos e não somente um reprodutor dos mesmos (STOCKMANNS; PEREIRA, 2017).

A realização de pesquisas proporciona algo muito além da mera cópia e do repasse de conhecimentos já existentes, é através da pesquisa que se constrói novos conhecimentos, descobre-se a verdade sobre determinados fatos e buscam-se soluções para resolução de problemas, contribuído assim para o crescimento das várias ciências, bem como para o desenvolvimento da sociedade (SANTOS, 2011).

Começar uma vida de produção científica e intelectual exige a tomada de atitudes como perseverança, disciplina e muita curiosidade sobre o objeto de estudo. Em todos os estudos e pesquisas o que deve prevalecer é a coerência. Partindo do simples para o complexo, o pesquisador deverá ser capaz de fazer conclusões de fácil interpretação e entendimento, pois afirmações não comprovadas levam ao descrédito de quem as formulou (BARBOSA; RAMOS; CÍRIACO, 2009).

Nos últimos anos os cientistas brasileiros têm tido uma preocupação demasiada quanto à produção acadêmica, leia-se publicação de artigos. Isso tem acontecido devido à pressão dos órgãos que regulam e credenciam a ciência e tecnologia no Brasil. Um dos fatores que corrobora para esse processo é a falta de uma política de integração e troca de conhecimento entre universidade e empresa. 0 Brasil apesar de ter uma produção científica elevada, ocupando a $13^{a}$ posição na participação das publicações internacionais, a proteção das propriedades intelectuais é pouco significativa, representando apenas $0,1 \%$ das proteções mundiais (NUNES et al.,2013).

Observando o lado empresarial os balanços da produção científica na área de administração começaram a ser produzidos e divulgados antes da década de 90 , cabendo o pioneirismo às pesquisas de Siqueira (1988) e de Machado-da-Silva, Cunha e Amboni (1990), realizadas nas áreas de recursos humanos e organizações, respectivamente, e divulgados no EnANPAD (Encontro da Associação Nacional de PósGraduação em Administração) e posteriormente surgem outros congressos, dentre eles o Encontro Nacional de Gestão Empresarial e Meio Ambiente [ENGEMA] (JABBOUR; SANTOS; BARBIERI, 2008; STREIT; GUARNIERI;GOMES,2016). 


\subsection{BIBLIOMETRIA E AS LEIS BIBLIOMÉTRICAS}

Existem diversas formas de mensurar e avaliar a disseminação do conhecimento científico e o fluxo de informações, com destaque para a bibliometria, a cienciometria, a informetria e a webometria. (VANTI, 2002). A bibliometria, forma de análise desse estudo nasceu nos anos sessenta do século XX e foi assim nomeada por Pritchard (1969) e, por ter caráter quantitativista, orientou a formulação de leis matemáticas, cujo objetivo é o de mensurar a produção científica (TEIXEIRA; IWAMOTO; MEDEIROS, 2013).

Os estudos bibliométricos ou cientométricos têm como origem os esforços de Hulme (1923), Lotka (1926) e outros, os quais acreditavam que a geração de conhecimento é materializada por meio da produção científica. (LUNDEBERG, 2006). De forma precisa a pesquisa bibliométrica é um recurso essencial para avaliar a difusão da produção acadêmica e científica (FRANCISCO, 2011; KOCH et al., 2017).

A bibliometria faz uso de várias leis e princípios empíricos que usam métodos matemáticos e estatísticos, que instituem regras de busca e classificação na pesquisa científica. Dentre as principais leis bibliométricas podem-se citar as de Bradford, de Lotka e de Zipf (GUEDES; BORSCHIVER, 2005; VANTI, 2002). A Lei de Lotka ou Lei dos Quadrados Inversos assinala a medição da produtividade científica de autores, por meio de um modelo de distribuição tamanho/frequência dos diferentes autores em um conjunto de documentos (FRANCISCO, 2011).

A lei de Bradford (1934) ou Lei de Dispersão proporciona a medição da produtividade dos periódicos, estabelecendo o núcleo e as áreas de dispersão sobre um assunto em um mesmo conjunto de periódicos, e a lei de Zipf (1949) ou Lei do Mínimo Esforço, consiste em mensurar a frequência de ocorrência das palavras nos textos, gerando uma lista ordenada de termos de uma disciplina ou assunto. (ARAÚJO, 2006; VANTI, 2002).

Essas leis bibliométricas têm sido utilizadas em pesquisas de diferentes campos do conhecimento, onde também se inserem as áreas gerenciais como, por exemplo, Administração, Economia e Contabilidade (ARÁÚJO; OLIVEIRA, SILVA, 2008). Apesar de o termo bibliometria ser muito utilizado no Brasil, nota-se através dos estudos que se sabe pouco sobre a relevância e o rigor a serem aplicados nesses estudos. Os estudos bibliométricos podem colaborar na tarefa de sistematizar as pesquisas realizadas num determinado campo de saber e endereçar problemas a serem investigados em pesquisa futuras (CHUEKE; AMATUCCI, 2015).

Na atualidade a bibliometria tem seguido dois caminhos distintos: um, dando continuidade ao enfoque original, persegue a trilha do aperfeiçoamento das leis de mensuração e, outro, que questiona a validade dos estudos exclusivamente quantitativos (ARAÚJO, 2006). A aplicação das técnicas bibliométricas em estudos científicos é difundida entre pesquisadores de diversas áreas de conhecimento. Essas técnicas permitem desvelar as tendências de diferentes áreas, arranjos entre pesquisadores, instituições e proficuidade das temáticas e suas indagações, subsidiando as novas produções (KOCH, 2017).

\subsection{ENCONTRO INTERNACIONAL SOBRE GESTÃO AMBIENTAL E MEIO AMBIENTE (ENGEMA)}

O Encontro Internacional sobre Gestão Empresarial e Meio Ambiente (ENGEMA) é um evento anual de âmbito internacional realizado pela Faculdade de Economia, Administração e Contabilidade da Universidade de São Paulo (FEAUSP). Considerado um dos principais eventos científicos de sustentabilidade da América Latina, seu objetivo definido é a realização do intercâmbio, a divulgação de práticas de gestão socioambiental e o estímulo à produção de novos conhecimentos e abordagens administrativas que contribuam com as estratégias de negócios e ao mesmo tempo com o desenvolvimento sustentável (ALVES et al.,2014).

Os trabalhos selecionados para o evento tratam com propriedade temas atuais, contribuindo dessa forma para enriquecer o repertório de conhecimento sobre a gestão ambiental concernente a diferentes problemas e setores econômicos. Gestão de energias renováveis, gestão de resíduos; contabilidade ambiental, indicadores de sustentabilidade ambiental, responsabilidade socioambiental, técnicas de manejo sustentável e tecnologia social são alguns exemplos de temas aceitos em suas categorias. 0 evento também busca a interação público/privada que compete na busca por melhores soluções para os problemas ambientais (KRUGLIANSKAS et al.,2008).

0 evento conta com uma programação variada que compreende a apresentação e o debate sobre pesquisas, trabalhos práticos e propostas em uma série de temas relacionados à sustentabilidade. 0 ENGEMA é promovido pelo Departamento de Administração da Faculdade de Economia, Administração e 
Contabilidade da Universidade de São Paulo (FEA/USP), com apoio da Fundação Instituto de Administração (FIA) (ENGEMA, 2018).

Buscando incentivar a produção científica de qualidade, o ENGEMA conta com o apoio de vários periódicos, que oferecem processos de fast track para os melhores trabalhos apresentados no evento (de acordo com classificação Qualis-CAPES em 2017): RAUSP Management Journal (Qualis A2), Revista de Administração da UFSM - REA (Qualis B1), Revista de Gestão - REGE (Qualis B1), Revista de Gestão Social e Ambiental - RGSA (Qualis B1), Latin American Journal of Management for Sustainable Development (Qualis B2), Revista de Gestão Ambiental e Sustentabilidade - GEAS (Qualis B2) e Revista Organizações e Sociedade (Qualis B4) (de acordo com classificação Qualis em 2017) (ENGEMA,2018).

0 fortalecimento de fóruns de debate específicos em gestão ambiental empresarial, tal como o ENGEMA, contribui para o aumento do número de artigos registrados nos periódicos em administração (JABBOUR; SANTOS; BARBIERI, 2008). Dentre os estudos publicados destacam-se os do campo bibliométrico, que vem apresentando um crescente desenvolvimento sobre os mais diversos assuntos variados, inclusive na área socioambiental na qual trata o referido evento (TEIXEIRA; IWAMOTO; MEDEIROS, 2013).

\section{METODOLOGIA}

A pesquisa utilizou-se da abordagem quantitativa. Por pesquisa quantitativa entende-se aquela investigação que se apoia predominantemente em dados estatísticos. (GUNTHER, 2006). Ainda sobre o estudo quantitativo entende como "tudo pode ser quantificável, o que significa traduzir em números opiniões e informações para classificá-las e analisá-las" (SILVA; MENEZES, 2005).

Sua natureza demonstrar aspectos quantitativo-descritivos, uma vez que consiste em fazer investigações de pesquisa empírica cuja principal finalidade é o delineamento das características de fatos, a avaliação de programas, o isolamento de variáveis principais e também se utilizará de aspectos exploratórios cujo objetivo é a formulação de questões ou de um problema, com tripla finalidade: desenvolver hipóteses, aumentar a familiaridade do pesquisador com um ambiente, fato ou fenômeno, para a realização de uma pesquisa futura mais precisa ou modificar e clarificar conceitos (MARCONI; LAKATOS, 2003).

É importante salientar que mediante um vasto acervo bibliográfico disponível através dos anais de muitas edições do congresso ENGEMA, o referido estudo optou por delimitar seu campo de pesquisa ao quinquênio referente aos anos 2014, 2015, 2016, 2017 e 2018, em busca de uma análise recente mais detalhada e elaborada dos perfis e características da produção científica do evento.

\subsection{PROCEDIMENTOS METODOLÓGICOS}

Seu procedimento é um estudo Bibliométrico dos perfis e as características da produção científica do congresso ENGEMA durante o quinquênio 2014 a 2018 através de dados e documentos bibliográficos coletados nos anais de cada uma dessas edições e tabulados e, posterirormente, analisados para fins de contribuição acadêmica nacional e internacional. 0 estudo bibliométrico ou blibliometria pode ser definido como o estudo dos aspectos quantitativos da produção, disseminação e uso de informação registrada. A bibliometria desenvolve padrões e modelos matemáticos para mensurar esses processos, usando seus resultados para elaborar previsões e apoiar tomadas de decisão (CHAPULA, 1998).

\subsection{PROCEDIMENTOS DE COLETA DE DADOS}

Seu procedimento de coleta de dados será pautado na duplicidade da coleta e análise de documentos, esses que se referem a artigos submetidos ao ENGEMA no quinquênio 2014 a 2018 . A coleta é a etapa da pesquisa em que se inicia a aplicação dos instrumentos elaborados e das técnicas selecionadas, pretendendo-se efetuar a coleta dos dados previstos. São vários os procedimentos para a realização da coleta de dados, que variam de acordo com as circunstâncias ou com o tipo de investigação, em linhas gerais, as técnicas de pesquisa. 0 presente estudo optou pela Coleta Documental.

Documentos são quaisquer suportes que contenham informações registradas, formando uma unidade, que possam servir para consulta, estudo ou prova. Incluem impressos, manuscritos, registros audiovisuais e sonoros, imagens, sem modificações, independentemente do período decorrido desde a primeira Publicação. Uma vez adquiridos os dados, o passo seguinte é a análise e interpretação dos mesmos, constituindo-se ambas no núcleo central da pesquisa. Análise é a divisão do tema em partes, determinação 
das relações existentes entre elas, seguidas do entendimento de toda sua organização (MARCONI, LAKATOS, 2003).

\subsection{PROCEDIMENTOS DE ANÁLISE DE DADOS}

Seu procedimento de análise de dados foi baseado na coleta e análise documental através do método bibliométrico dos perfis e as características da produção científica do congresso ENGEMA durante o quinquênio 2014 a 2018. A pesquisa teve início no mês de dezembro de 2017 se estendendo até maio de 2018 com a fase da escrita até a metodologia do estudo. Em junho do mesmo ano foi iniciado à apuração dos dados, através dos anais disponíveis em cada ano do congresso, foram baixados todos os artigos separando os mesmos em pastas com o nome da área temática até o ano de 2017.

Na sequencia uma tabela no Excel foi criada para a posterior análise dos dados coletados, onde no primeiro momento foram separados os artigos por ano dentro das suas áreas temáticas e no segundo momento foi tabulado o ano de cada artigo, seguido do nome dos autores, a quantidade de autores por artigo, as Instituições de Ensino Superior e suas regiões.

Em janeiro de 2019 o mesmo processo foi realizado para a inclusão dos dados colhidos através dos anais de 2018 finalizando assim o preenchimento das tabelas do Excel. Após preenchimento de dados nas tabelas a análise dos dados foi feita manualmente através da função cont.se do Excel, e assim foram contados os números de artigos por ano e a área de atuação, seguindo das autorias e por fim as IES e suas regiões. A escolha do arranjo das seções da análise dos dados do presente estudo foi espelhada e adaptada do modelo de Corrêa, Ruiz e Ribeiro (2013) referente ao artigo The International Journal of Conflicts Management: Uma Análise da Produção Acadêmica à Luz da Bibliometria de 2003 a 2012.

\section{ANÁLISE E DISCURSÃO DOS RESULTADOS}

Nesta seção são apresentadas as descrições obtidas através dos dados encontrados nos anais do ENGEMA, a partir do qual foi possível fazer-se uma análise e discursão referente ao perfil e as características da produção científica do referido congresso, durante o quinquênio 2014 a 2018, buscando contribuir para a produção científica do mesmo.

\subsection{NÚMERO DE ARTIGOS POR ANO E ÁREA DE ATUAÇÃO}

Os trabalhos apresentados no ENGEMA são organizados por Áreas de Atuação, assim todos os trabalhos devem ser enviados com sua área já definida. Em sua última edição o evento contou com 18 áreas de atuação diferentes. De forma geral, o objetivo das áreas de atuação é relatar a gestão socioambiental em empresas mediante diversos cenários.

Durante o período estudado houve uma variação nas áreas de atuação do ENGEMA, como é possível visualizar na tabela a seguir:

Através da tabela identifica-se que as áreas de atuação do ENGEMA se modificaram durante o período estudado. No primeiro ano de estudo (2014) o congresso abriu apenas 9 áreas, uma quantidade relativamente inferior ao último ano de estudo (2018), o qual apresentou 18 áreas de atuação, nesse ano foram criadas 3 novas áreas (cidades sustentáveis e inteligentes smart cities, estudos da Amazônia e gestão de pessoas e sustentabilidade). 
Tabela 1: Número de artigos por ano e área de atuação

\begin{tabular}{|c|c|c|c|c|c|c|}
\hline Áreas de Atuação & 2014 & 2015 & 2016 & 2017 & 2018 & Total/Área \\
\hline Cidades Sustentáveis e Inteligentes Smart Cities & - & - & - & - & 31 & 31 \\
\hline Educação e Sustentabilidade & - & - & - & 24 & 21 & 45 \\
\hline Empreendedorismo e Negócios de Impacto & - & - & - & 15 & 9 & 24 \\
\hline Estratégia para a Sustentabilidade & 33 & 41 & 40 & 28 & 24 & 166 \\
\hline Estudos da Amazônia & - & - & - & - & 7 & 7 \\
\hline Estudos Organizacionais em Sustentabilidade & - & - & - & 10 & 8 & 18 \\
\hline Finanças Sustentáveis & - & - & - & 9 & 3 & 12 \\
\hline Gestão Ambiental & 33 & 46 & 44 & 30 & 25 & 178 \\
\hline Gestão de Pessoas e Sustentabilidade & - & - & - & - & 8 & 8 \\
\hline $\begin{array}{l}\text { Indicadores e Modelos de Mensuração da } \\
\text { Sustentabilidade }\end{array}$ & 42 & 34 & 50 & 16 & 24 & 166 \\
\hline Inovação Sustentável & 28 & 28 & 20 & 24 & 23 & 123 \\
\hline Marketing e Sustentabilidade & - & - & - & 22 & 11 & 33 \\
\hline Operações Sustentáveis & 50 & 45 & 40 & - & 25 & 160 \\
\hline Reporte e Comunicação da Sustentabilidade & - & - & - & 18 & 11 & 29 \\
\hline Responsabilidade Social Coorporativa & 36 & 21 & 40 & 13 & 17 & 127 \\
\hline Sustentabilidade e Políticas Públicas & 25 & 31 & 33 & 32 & 34 & 155 \\
\hline Sustentabilidade na Economia e na Contabilidade & - & - & - & 19 & 11 & 30 \\
\hline Abordagens Economicas da Sustentabilidade & 17 & 16 & 14 & - & - & 47 \\
\hline Outros Temas Correlatos & 95 & 90 & 72 & - & 10 & 267 \\
\hline Total & 359 & 352 & 353 & 260 & 302 & 1.626 \\
\hline
\end{tabular}

O aumento no número de áreas de atuação do evento impactou em específico na área de atuação outros temas correlatos. Durante os anos de 2014 a 2016, o número de publicações aceitas para essa área era uma média de aproximadamente 86 artigos por ano. Com a abertura de novas áreas em 2017, esta área foi excluída do evento, no entanto em 2018 a mesma retornou, porém com um número bem inferior aos anos passados.

Ao analisar-se a evolução das áreas temáticas do ENGEMA neste período constatou-se que a área temática "outros temas correlatos" tinha uma grande quantidade de artigos aceitos durante os anos de 2014 a 2016, toda via no ano de 2018 o evento contou com novas áreas que supriram parte da necessidade que os artigos qualificados como outros temas correlatos demonstravam durante os anos estudados.

Sendo assim, foram analisados 1.626 artigos científicos, totalizando uma média de 325,2 artigos por edição, tomando como base os anos de 2014 a 2018. As edições com maior número de publicações foram realizadas nos anos de 2014, 2015 e 2016, com respectivamente 359, 352 e 353 artigos publicados nos anais. Dessa forma, 2017 foi o ano com o menor número, 260 artigos, em 2018 houve uma elevação no número de artigos e áreas temáticas em relação a 2017.

\subsection{AUTORIA}

A análise das autorias evidenciou destaque na produção científica publicada no ENGEMA, cuja pesquisa conta com dois autores.

Tabela 2: Autores por publicação

\begin{tabular}{|c|c|c|c|c|c|}
\hline Autores por Publicação & 2014 & 2015 & 2016 & 2017 & 2018 \\
\hline Um Autor & 29 & 32 & 20 & 17 & 23 \\
\hline Dois Autores & 109 & 98 & 107 & 73 & 85 \\
\hline Três Autores & 85 & 79 & 89 & 63 & 77 \\
\hline Quatro Autores & 67 & 67 & 66 & 62 & 59 \\
\hline Cinco Autores & 69 & 76 & 71 & 45 & 58 \\
\hline Total & 359 & 352 & 353 & 260 & 302 \\
\hline
\end{tabular}

Na tabela acima, é apresentado o número de autores por publicação. Totalizando uma média de 71,8 artigos no ano de 2014, 70,4 artigos em 2015, 70,6 artigos em 2016, 52 artigos em 2017 e finalizando os anos de estudo com uma média de 60,4 artigos publicados em 2018. 
Tomando como base essas médias, identificou-se que a maioria dos artigos submetidos nos anos de estudo desta pesquisa foi produzido por dois autores. Sendo que de um total de 1626 artigos publicados durante o período estudado, os artigos produzidos por apenas dois autores corresponderam a aproximadamente 24,5\%. Quanto aos artigos publicados por outro número de autores, houve pouca variação, sendo as publicações de um único autor as que tiveram menor número de artigos aceitos no congresso.

Seguindo a tabela abaixo, tem-se o Top 10 dos autores do ENGEMA durante os anos de 2014 a 2018, ou seja, são apresentados os autores mais produtivos com o maior número de publicações aceitas no congresso durante os anos estudados. 0 critério de desempate adotado foi à ordem alfabética.

Tabela 3: Top 10 de autores 2014 a 2018

\begin{tabular}{|c|c|c|c|c|}
\hline Posição & Nome & IES & Publicações & Ano da publicação \\
\hline $1^{0}$ & Clandia Maffini Gomes & UFSM & 14 & $2014-2015-2016-2017-2018$ \\
\hline $2^{\circ}$ & Dusan Schreiber & FEEVALE & 14 & $2014-2015-2016-2017-2018$ \\
\hline $3^{\circ}$ & Sady Mazzioni & UNOCHAPECÓ & 13 & $2014-2015-2016-2017-2018$ \\
\hline 4 은 & Ana Paula Perlin & UFSM & 12 & $2014-2015-2016-2017-2018$ \\
\hline 50 & Artur Gomes de Oliveira & UFC & 12 & $2014-2015-2016-2017$ \\
\hline 60 & Mônica Mota Tassigny & UNIFOR & 12 & $2014-2015-2016-2017$ \\
\hline 70 & Dafne Oliveira Carlos de Morais & FGV & 11 & $2014-2015-2016-2017-2018$ \\
\hline $8^{\circ}$ & Denise Barros de Azevedo & UFMS & 11 & $2014-2015-2016-2017-2018$ \\
\hline 9은 & Fabricia Silva da Rosa & UFSC & 11 & $2014-2015-2017-2018$ \\
\hline $10^{\circ}$ & João Alexandre Paschoalin Filho & UNINOVE & 11 & $2014-2015-2017-2018$ \\
\hline
\end{tabular}

Fonte: Dados da pesquisa

Observando a tabela, é identificado que os autores que empataram no primeiro lugar no top 10, foram Clandia Maffini Gomes e Dusan Schreiber, ambos com 14 artigos publicados durante os cinco anos retratados no estado da arte desta pesquisa. A produção destes autores consistiu em pelo menos um artigo publicado por ano, ou seja, os mesmos publicaram em todos os anos do congresso nos últimos cinco anos.

Ainda observando os dados do Top 10, constata-se que houve uma grande produtividade de uma parcela da população de autores, uma vez que no Top 10 não se observa uma grande variação no número de publicações individuais, considerando que o ENGEMA permite apenas três publicações por ano de cada autor ou co-autor. Desta forma, é importante ressaltar a significativa participação de todos os autores do congresso, que com seus estudos, contribuíram para a relevância deste congresso, no entanto devido ao número elevado não foi possível apresentar a todos.

A tabela a seguir exibe o número total de autores em cada edição do congresso nos últimos cinco anos.

Tabela 4: Número de Autores por Ano
\begin{tabular}{|c|c|c|c|c|}
2014 & 2015 & 2016 & 2017 & 2018 \\
\hline 1.115 & 1.111 & 1.120 & 824 & 950 \\
\hline \multicolumn{5}{|c|}{ Total de 5.120 autores } \\
\hline
\end{tabular}

Fonte: Dados da pesquisa

Ao observar a tabela 04, identifica-se que houve variação na quantidade de autores durante o período. Na edição de 2017, houve uma queda de 296 autores em relação à edição anterior, não somente no número de autores, mas também no número de artigos apresentados no congresso (mostrado na tabela 02), fato curioso uma vez que neste ano foram criadas quatro novas áreas temáticas no evento. Em 2018 houve um aumento no número de autores, embora este número ainda fique abaixo dos demais encontrados nos anos anteriores, exceto do ano de 2017.

Ao se observar a tabela 04, visualiza-se que houve um total de 5.120 autorias durante o período de análise, ou seja, foram encontradas 5.120 participações nos trabalhos apresentados no congresso, sendo realizadas por diferentes autores, nas quais alguns destes tiveram o privilégio de mais de uma participação. 


\subsection{INSTITUIÇÕES DE ENSINO SUPERIOR E REGIÕES}

A tabela abaixo apresenta os dados referente às Instituições de Ensino Superior identificadas no ENGEMA. A mesma evidencia as dez instituições que mais publicaram no período estudado.

Tabela 5: Top 10 instituições de ensino superior

\begin{tabular}{|c|c|c|c|c|c|c|c|c|}
\hline Posição & IES & 2014 & 2015 & 2016 & 2017 & 2018 & Total & Região \\
\hline $1 \underline{a}$ & USP & 32 & 16 & 32 & 11 & 5 & 96 & Sudeste \\
\hline $2^{\underline{a}}$ & UNINOVE & 28 & 26 & 22 & 5 & 11 & 92 & Sudeste \\
\hline $3^{\mathrm{a}}$ & UFC & 7 & 13 & 11 & 15 & 20 & 66 & Nordeste \\
\hline $44^{\mathrm{a}}$ & UNIR & 14 & 14 & 12 & 10 & 11 & 61 & Norte \\
\hline $5 \underline{a}$ & UFSC & 11 & 14 & 17 & 9 & 7 & 58 & Sul \\
\hline $6^{\mathrm{a}}$ & UNIFOR & 9 & 12 & 17 & 10 & 10 & 58 & Nordeste \\
\hline $7 \underline{a}$ & UFSM & 18 & 7 & 8 & 9 & 15 & 57 & Sul \\
\hline $8^{\underline{a}}$ & FURB & 12 & 11 & 13 & 8 & 0 & 44 & Sul \\
\hline 9aa & USCS & 17 & 9 & 4 & 4 & 0 & 34 & Sudeste \\
\hline $10^{\underline{a}}$ & UFCG & 13 & 8 & 8 & 1 & 2 & 32 & Nordeste \\
\hline \multicolumn{2}{|c|}{ Total } & 161 & 130 & 144 & 82 & 81 & 598 & $\mathrm{X}$ \\
\hline
\end{tabular}

Fonte: Dados da pesquisa

Acima identifica-se que nos anos de 2014, 2015, 2016, 2017 e 2018, as dez instituições representaram, respectivamente, as seguintes porcentagens com relação ao total dos artigos publicados em cada ano, 44,8\%, 36,9\%, 40,8\%, 31,5\% e 26,8\%, ou seja, apenas este Top 10 representa uma média anual de 38,16\% dos artigos publicados anualmente.

Ainda foi possível constatar que ao final dos cinco anos de estudo as instituições do top 10, representaram $36,8 \%$ de todos os estudos publicados no ENGEMA, nos últimos cinco anos. Isso demonstra que poucas instituições publicam muito e muitas instituições publicam pouco, identificando assim, uma das leis que alicerçam a bibliometria, a lei de Lotka.

Quanto às regiões, observa-se uma forte presença das instituições da região Sudeste, Nordeste e sul, comparado à região Norte e, principalmente, a Centro-Oeste, que não teve nenhuma instituição de ensino superior retratada no top 10 acima, no entanto, é importante ressaltar que todas as instituições participantes do congresso tiveram grande influência na relevância do evento.

\section{CONSIDERAÇ̃̃ES FINAIS}

A pesquisa científica é uma atividade desenvolvida por investigadores visando novas descobertas, ao adquirir novos achados ela contribui para a qualidade de vida intelectual, para o desenvolvimento de novas tecnologias e métodos, para o aprimoramento de estudos já realizados, de modo geral, ela contribui para a evolução da espécie humana. Investir na pesquisa científica é fundamental para que uma nação se desenvolva, pois o conhecimento concebido torna-se pressuposto norteador para a experiência cotidiana.

O congresso ENGEMA desde o final da década de 1980 vem contribuindo para o fomento da pesquisa e no decorrer dos anos vem apresentando crescentes avanços através da qualidade de pesquisas inovadoras que surgem em cada edição. Ao analisar o quinquênio do congresso é possível notar a grandeza e importância do evento para o Brasil. Em cinco anos foram 1.626 artigos científicos publicados com 5.120 participações nos trabalhos apresentados no congresso das mais variadas regiões do país.

É sabido que produzir não é uma tarefa fácil, a pesquisa é árdua e exaustiva, ao pesquisar se faz necessário planejamento, conhecimento e adequação às normas científicas, contudo, ela é enriquecedora para quem produz e para quem consome. Investigando o estado da arte da produção científica tomando por base os perfis e características dos artigos publicados no ENGEMA de 2014 a 2018 é notado um alto desenvolvimento no aprimoramento das técnicas científicas, estudos com temáticas diferenciadas e modernas envolvendo a Gestão Ambiental e Meio Ambiente.

Por vivemos em tempos onde a preocupação ambiental é um assunto de relevância devido às poluições, as queimadas, o aquecimento global, o calor em excesso e muitos outros fatores naturais que causam a poluição do planeta, conclui-se que através do congresso e seus achados os temas voltados para a sustentabilidade passaram as ser debatidos de forma abrangente através dos artigos publicados e do 
espaço de debate que o evento proporciona no decorrer de suas edições e assim as pessoas passam a adquirir uma consciência ambiental necessária na atualidade.

A contribuição desse estudo se da através da iniciativa e colaboração na construção de um artigo que servirá como base para futuras pesquisas mais aprofundadas sobre a temática e também para mostrar a relevância do ENGEMA para a produção científico-acadêmica de acordo com perfis e características estudados e apresentados através do estado da arte da produção científica disponível no congresso.

A limitação desta pesquisa foi à insipiência de estudos análogos a este, considera-se esse estudo pioneiro, contudo, ressalta-se que tanto a questão como também o objetivo de investigar o perfil e as características da produção científica do congresso ENGEMA durante o quinquênio 2014 a 2018 foram respondidos e alcançados respectivamente.

Sugere-se para que a comunidade acadêmica invista em pesquisas semelhantes a esta e que um artigo mais detalhado seja feito analisando minuciosamente cada tópico da análise deste estudo, acrescida da análise dos temas do evento a fim de catalogar e buscar um cruzamento de informações para um aprimoramento dessa pesquisa.

\section{REFERÊNCIAS}

[1] Alves, Juliani Karsten Alves; Chechim, Jessica; Manfio, Fernanda Cargnin Manfio; Madruga, Sergio Rossi. Estudo bibliométrico: Análise dos autores participantes do Encontro Nacional Sobre Gestão Empresarial (Engema). São Paulo, p. 1-12, 2014.

[2] Araújo, C. A. Bibliometria: Evolução histórica e questões atuais. Em Questão: Revista da Faculdade de Biblioteconomia e Comunicação da UFRGS. Porto Alegre, v. 12, n. 1, p. 11-32, 2006.

[3] Aráújo, Elisson Alberto T.; Oliveira, Victor do Carmo; Silva, Wendel Alex Castro. Estudo Bibliométrico da Produção Científica sobre Contabilidade Gerencial. Faculdade Novos Horizontes, p.1-17,2008.

[4] Barbosa, Elvina Maria de Sousa; Ramos, Joelson; Ciríaco, Maria do Socorro S. Despertando para a produção intelectual: A importância da pesquisa científica. Universidade Estadual do Piauí - Uespi. Teresina, p. 1-14, 2009.

[5] Corrêa, Rosany; Ribeiro, Henrique César Melo. Comportamento e particularidades da produção científica dos artigos divulgados na Revista Geas no quadriênio 2012-2015. Amazônia, Organizações e Sustentabilidade, v. 6, n.1, p. 63-87, 2017.

[6] Corrêa, Rosany; Ruiz, Mauro Silva; Ribeiro, Henrique César Melo. The International Journal of Conflicts Management: Uma Análise da Produção Acadêmica à Luz da Bibliometria de 2003 a 2012. Revista de Administração, Contabilidade e Sustentabilidade, v.3, n. 4, p. 1-19, 2013.

[7] Chapula, Cesar A. Macias. O papel da informetria e da cienciometria e sua perspectiva nacional e internacional. Ci. Inf. Brasília, v. 27, n. 2, p. 134-140, 1998.

[8] Chueke, Gabriel Vouga; Amatucci, Marcos. O que é bibliometria? Uma introdução ao Fórum. Revista eletrônica de negócios internacionais. São Paulo, v.10, n. 2, p. 1-5, 2015.

[9] Droescher, Fernanda Dias; Silva, Edna Lucia da. O pesquisador e a produção científica. Perspectivas em Ciência da Informação, v.19, n.1, p.10-189, 2014.

[10] Francisco, E. R. Exploração do acervo à luz da bibliometria, geoanálise e redes sociais. Rae-eletrônica, v. 51, n. 3, p. 280-306, 2011.

[11] Guedes, V. F. S., Borschiver, S. Bibliometria: Uma ferramenta estatística para a gestão da informação e do conhecimento, em sistemas de informação, de comunicação e de avaliação científica e tecnológica. Anais... Encontro Nacional de Ciências da Informação, Salvador, p.1-18, 2005.

[12] Gunther,Hartmut. Pesquisa Qualitativa Versus Pesquisa Quantitativa: Esta É a Questão?. Psicologia: Teoria e Pesquisa. Brasília, v. 22 , n. 2, p. 201-210, 2006.

[13] Jabbour, C. J. C.; Santos F. C. A.; Barbieri, J. C. Gestão ambiental empresarial: Um levantamento da produção científica brasileira divulgada em periódicos da área de administração entre 1996 e 2005. Revista de Administração Contemporânea, v. 12, n. 3, p. 689-715, 2008.

[14] Koch, Leani Lauermann; Lappe, Larissa; POLI, Odilon Luiz; Mazzioni, Sady; Jacoski, Claudio Alcides. Análise bibliométrica da produção científica sobre políticas públicas para inovação. Anais... I Congresso Internacional de Desempenho do Setor Público. Florianópolis, p. 1-20, 2017.

[15] Kruglianskas, Isak; Oliveira, José Antônio Puppim de; Barbieri, José Carlos; Dziedzic, Maurício. Edição especial: Os melhores artigos do Ix Engema. Revista de Gestão Sócio e Ambiental, v.2, n.1,p.1-2,2008. 
[16] Ludenberg, J. Bibliometrics as a research assessment tool - impact beyond the impact factor. Karolinska Institutet, (2006). Disponível em < http://diss.kib.ki.se/2006/91-7140-965-3/thesis.pdf >. Acesso em: 26/06/2018.

[17] Marconi, Marina de Andrade, Lakatos, Eva Maria. Fundamentos da Metodologia Científica. 5. ed. São Paulo : Atlas, p. 165-167,187-188,2003.

[18] Mello, Ivan Ribeiro; Barbosa, Karla Marisa Fernandes; Dantas, José Alves; Botelho, Ducineli Régis. 25 Anos de Publicação em Auditoria: Análise Bibliométrica com Ênfase na Lei de Lotka,Lei de Zipf e Ponto de Transição (T) de Goffman. 6ํㅡㄹ Congresso Ufsc de Controladoria e Finanças. Santa Catarina, p.1-18, 2015.

[19] Nunes, Maria Augusta Silveira Netto; Cazella, Sílvio César ; PIRES, Edilson Araújo ;Russo, Suzana Leitão. Discussões sobre produção acadêmico-científica \& tecnológica: Mudando paradigmas. Revista Geintec. São Cristóvão, v. 3, n. 2, p.205-220, 2013.

[20] Santos, Edilza de Almeida. Produção Científica: Uma Análise de sua Contribuição na Formação Acadêmica e Profissional dos Discentes de Ciências Contábeis da Uefs. Ferreira de Santana, p.1-16, 2011.

[21] Silva, E. L. da; Menezes, E. M. Metodologia da pesquisa e elaboração de dissertação. 4. ed.,Florianópolis: UFSC,p.20, 2005.

[22] Stockmanns, Jussara Isabel; Pereira, Viviane Aparecida Traversin. A escrita acadêmica: Desafios do ato de escrever na educação superior. VI Seminário Internacional sobre Profissionalização Docente - Sipd /Cátedra Unesco, p.1-10, 2017.

[23] Streit, Jorge Alfredo Cerqueira; Guarnieri, Patricia; Gomes, Ricardo Corrêa. A produção científica do Encontro Internacional sobre Gestão Empresarial e Meio Ambiente (Engema) sobre "Sustentabilidade e Políticas Públicas" nas edições de 2010 a 2015: Uma revisão da literatura. Encontro Nacional Sobre Gestão Empresarial (Engema). São Paulo p.1-15, 2016.

[24] Teixeira, Maria Luisa Mendes; Iwamoto, Helga Midori; Medeiros, Ana Lúcia. Estudos bibliométricos (?). Em administração: discutindo a transposição de finalidade. Administração: Ensino e Pesquisa Rio de Janeiro, v. 14 n. 3 p. 423-452, 2013.

[25] Vanti, N. A. P. Da bibliometria à webometria: Uma exploração conceitual dos mecanismos utilizados para medir o registro da informação e a difusão do conhecimento. Ciência da Informação, v. 31, n.2, p. 152-162, 2002. 


\section{Capítulo 7}

Gestão ambiental e o papel social de uma cachaçaria artesanal no Piauí

\section{Dalton Régis de Oliveira Soares \\ Jairo de Carvalho Guimarães}

Resumo: 0 objetivo da pesquisa é descrever como uma cachaçaria pode obter lucro, promovendo o desenvolvimento sustentável, gerando impacto social na região de atuação. Esta medida só é possível com um sistema equilibrado entre a economia, a sociedade e o ecossistema. Foi feita uma entrevista com o gestor da Cachaçaria Lira com o propósito descrever o processo produtivo, buscando desvelar como é mantido o padrão de qualidade dos produtos atuando de maneira sistemática na preservação ambiental, por meio da reutilização dos resíduos de produção. Foi possível concluir que em indústrias artesanais é possível implementar medidas de preservação ambiental, contribuindo para o desenvolvimento sustentável regional, sem abrir mão do fator econômico que move uma organização com fins lucrativos.

Palavras-chave: Cachaçaria. Produção artesanal. Desenvolvimento sustentável. Qualidade. 


\section{INTRODUÇÃO}

A partir do processo de industrialização, inicialmente concebido como consequência da Revolução Industrial, muitos tipos de produtos foram padronizados e comercializados, em uma velocidade nunca vista antes pela humanidade. Porém, este progresso acelerado e a rapidez com que as comunicações avançaram exigiram das empresas uma reflexão ecológica, fruto das exigências de uma sociedade antenada com a necessidade de um cuidado efetivo com o Meio Ambiente, afinal, fonte dos recursos que provêm os insumos das organizações, de um modo geral. Com efeito, a noção de que o gerenciamento adequado da utilização dos recursos naturais e os desdobramentos imediatos no ciclo produtivo precisou ser repensada.

Com o passar dos anos, a necessidade de um conceito de Gestão Ambiental foi sendo necessário para administrar os recursos naturais que, outrora, eram vistos como ilimitados. Esse conceito segundo Bruns (2009, p. 26) está assim delineado:

A Gestão Ambiental visa ordenar as atividades humanas para que estas originem o menor impacto possível sobre o meio. Esta organização vai desde a escolha das melhores técnicas até o cumprimento da legislação e a alocação correta de recursos humanos e financeiros.

Segundo Godard (1997), a Gestão Ambiental deve sempre se manter em uma estratégia de desenvolvimento a longo prazo. Isso significa que deve existir uma visão da matéria consumida para além do uso cotidiano, descartando ou reutilizando o material de forma que não polua o Meio Ambiente e que se consiga consumir os recursos naturais sem perda para o Meio Ambiente.

As normas de gestão e de qualidade ambiental também passam a ser editadas, com vistas à criação de padrões de segurança e proteção ambiental e à implantação de controles para a gestão de resíduos. Para a integridade dos produtos na produção e no consumo, para a garantia de saúde de funcionários, para a minimização de riscos e perdas com acidentes, para a gestão de passivos ambientais e para a prevenção e gestão de crises. Da mesma forma, sistemas de auditoria ambiental passam a ser concebidos e implantados nas empresas como forma de assegurar e demonstrar o cumprimento das políticas e objetivos ambientais destas (JUCHEM, 1995). Pertshi (2006, p. 2) pontua que:

a gestão ambiental representa na atualidade uma importante estratégia de longevidade das empresas em seus negócios, tendo em vista que as pressões de toda a sociedade bem como dos próprios consumidores só fazem aumentar perante tantos discursos do ecologicamente correto.

Dessa forma, para que alguém possa formar uma empresa que consiga ter potencial para prosperar ao longo dos anos, o exercício da cidadania é uma peça fundamental para assegurar tal condição. Assim, as indústrias tiveram que agir, investindo em soluções tecnológicas, criando materiais biodegradáveis, aperfeiçoando as técnicas para cultivar matérias-primas a longo prazo, para assegurar que a produção perdure por tempo indeterminado.

Para falar de desenvolvimento sustentável no mundo de uma forma simples e direta, podem-se contar com alguns conceitos. Existe uma rede de relações que envolve o desenvolvimento sustentável que reconhece a necessidade de considerar os aspectos sociais do ambiente e as suas relações entre a economia, o ambiente e o desenvolvimento, a adoção das perspectivas locais e globais, a promoção da solidariedade internacional, entre outros (SCOULLOS, 1995).

Diante do exposto, pode-se perceber que a sociedade poderia estar mais consciente de suas demandas e ações, ou seja, tudo o que pensam em fazer poderiam priorizar o Meio Ambiente, sob pena de os recursos provenientes da natureza não suportarem as necessidades imediatas. Cita-se o exemplo da água potável, tendo em vista que estudos mostram que cerca de 1,5 bilhão de pessoas não têm acesso à água de boa qualidade (UN STATISTICS DIVISION, 2008).

Por outro lado, o Meio Ambiente tem se tornado prioridade para o empreendedor. Segundo Mendes (2011), o empreendedor é aquele que corre atrás das oportunidades, e para ele considerar algo como uma oportunidade, precisa haver três critérios, que são: inovação, tomada de risco e proatividade. Segundo Teixeira (2012), o empreendedor é um criador de valor, assumindo riscos e juntando matérias-primas em um único local para produção, implementando potencialmente uma inovação.

Para alguém que pretende se tornar empreendedor, o gerenciamento dos recursos naturais, além de permitir a conquista de um mercado lucrativo quando bem utilizados, tal gestão também pode ser considerada um exercício pleno da cidadania, pela qual o indivíduo é capaz de analisar a realidade a que 
está sujeito, avaliando de forma crítica as situações que o cercam e adotando mecanismos de mitigação de eventuais danos decorrentes da produção. A partir dessa experiência, a pessoa é capaz de se posicionar, apresentando seu ponto de vista, com base em argumentos que resultam da análise do que acontece (KOCH, 1993).

Com isso, o empreendedor se torna bem mais competente a partir do momento em que tem em mente uma maneira ótima de direcionar os recursos disponíveis para o preparo do seu produto final, com qualidade e sem desperdício. 0 objetivo deste estudo é descrever o papel da Gestão Ambiental de uma indústria produtora de cachaça artesanal em relação à sustentabilidade.

A Cachaçaria Lira, localizada na cidade de Amarante, PI, externa uma preocupação em desenvolver atitudes sustentáveis, necessárias não apenas para assegurar a perpetuação do negócio, mas, sobretudo, para orientar e esclarecer às pessoas que é possível obter lucro sem devastar o Meio Ambiente, contribuindo, desta forma, com o processo de sustentabilidade nas relações societárias. Neste aspecto, a compreensão acerca do Desenvolvimento Sustentável é imperiosa para avaliar o nível de atuação direta que a empresa realiza com vistas a manter equilibrada a relação economia x sociedade x Meio Ambiente.

\section{DESENVOLVIMENTO SUSTENTÁVEL}

Devido aos grandes desequilíbrios ecológicos ocorridos desde a Revolução Industrial, as empresas precisaram criar uma forma de desenvolvimento que proporcionasse uma considerável produção com a coleta de matéria-prima em excesso, sem qualquer preocupação com possíveis danos ao Meio Ambiente. Mas, investigando uma organização do Século XXI, inserida num ambiente de alta competitividade e num rigoroso cenário sob a atmosfera globalizante, seria possível desenvolver um projeto sustentável e relativamente barato com as condições de uma cidade piauiense por mais de cem anos? Trata-se de questão a ser analisada, tendo em vista que muitas das atuais ações empresariais convergem para o desequilíbrio ambiental.

Mesmo quando não se falava muito sobre Gestão Ambiental naquela época, já existia no Piauí algumas empresas que já se preocupavam com sua matéria-prima a ponto de preservar seu ambiente para assegurar que haveria material para o futuro. Segundo MOFFATT (2007), o desenvolvimento sustentável é justamente amparar o processo produtivo a longo prazo. Segundo Bañon Gomis et al. (2011), o desenvolvimento sustentável tem o compromisso de tentar conseguir um equilíbrio entre sociedade, Meio Ambiente e economia, evitando problemas por consequência de suas formas habituais de agir.

Entretanto, a falta de especificidade e as pretensões totalizadoras têm tornado o conceito de desenvolvimento sustentável difícil de ser classificado em modelos concretos e operacionais e analiticamente precisos. Por isso, ainda é possível afirmar que não se constitui num paradigma no sentido clássico do conceito, mas uma orientação ou um enfoque, ou ainda uma perspectiva que abrange princípios normativos (JACOBI, 1997; RUSCHEINSKY, 2004; GUIMARÃES, 2001).

Deste modo, inicia-se um tipo de relação entre o consumo e a produção de recursos naturais, focado na busca do equilíbrio. HART (1996 apud HOURNEAUX et al., 2004), por sua vez, fala do processo de sustentabilidade como sendo dividido em três estágios fundamentais: a prevenção da poluição, a zeladoria de produtos e a utilização de tecnologias limpas, assim promovendo um ambiente sustentável. Dessa forma, é possível identificar quando uma empresa está sendo responsável ou não com seus recursos naturais e humanos na região onde está instalada.

Os recursos naturais são finitos e estão diminuindo paulatinamente. Fauna e flora estão se esvaindo em decorrência da ação do homem. Outro tema também discutido é a diminuição da água potável existente no mundo que, devido às ações diretas que o ser humano impõe, está comprometendo as gerações futuras. Em uma indústria de bebidas como a Cachaçaria Lira, a água é fundamental para sustentar as plantações de cana-de-açúcar.

O desenvolvimento sustentável é um processo de aprendizagem social de longo prazo, que por sua vez, é direcionado por políticas públicas orientadas por um plano de desenvolvimento nacional. Assim, a pluralidade de atos sociais e interesses presentes na sociedade colocam-se como um entrave para as políticas públicas voltadas ao desenvolvimento sustentável (BEZERRA; BURSZTYN, 2000).

Algumas práticas de desenvolvimento sustentável se forem adotadas pela sociedade, e principalmente, pelo governo, farão grande diferença no Meio Ambiente. Uma delas é a reciclagem que, segundo Shibao, Moori e Santos (2010), trata-se de um conjunto de técnicas para reaproveitar o que seriam resíduos em 
uma produção, em outro tipo de produção paralela. Dessa forma, diminui-se a necessidade de resíduos jogados no Meio Ambiente.

Por muitas vezes, reciclagem pode ser confundido com o de reutilização. Esse conceito para Rosa, Fraceto e Moschini-Carlos (2012, p. 347-348) está assim definido: “[...] reutilização é o consumo de itens que possam ser usados novamente, como produtos com refil ou garrafas retornáveis. Trata-se do aproveitamento do produto, podendo este ser um pouco modificado, mas sem ser descaracterizado".

Portanto, pode-se perceber que algumas empresas atualmente estão se preocupando mais com Meio Ambiente, adotando práticas saudáveis para a sua preservação. Esse processo está em fase de crescimento, pois ainda são poucas as empresas que implementam ações efetivas neste segmento.

Atualmente, pode-se dizer que a maioria dos países, independentemente da situação econômica, possui algum tipo de legislação ambiental. Contudo, boa parte do conjunto potencial de relações sociedade/natureza não é considerada nos processos de formulação de políticas públicas (GONÇALVES; ALVES, 2003).

Alguns pontos turísticos, por serem ligados diretamente a recursos naturais como os rios e as florestas, estão diretamente conectados ao bem-estar ambiental da região. Existem muitos pontos turísticos naturais no Estado do Piauí, como a praia do Coqueiro em Luís Correia e o Parque Nacional de Sete Cidades, em Piracuruca.

A melhor forma de preservação desses equipamentos naturais seria a conscientização da população, sempre lembrando que esses pontos só existem porque se trabalho a questão da preservação ambiental. Um dos papéis da Gestão Ambiental é atuar para assegurar que os recursos sejam preservados, permitindo que os turistas retornem às regiões, usufruindo das riquezas e belezas naturais, sem afetar o ecossistema da região.

Como se pode perceber, os pontos turísticos devem ser preservados, embora os recursos arrecadados com esse turismo não sejam inteiramente utilizados para a preservação do Meio Ambiente. Cabe apenas a algumas poucas empresas que precisam de material primário, plantados em locais específicos, melhorar a Gestão Ambiental e garantir a colheita de uma boa matéria-prima a longo prazo, como é o caso da Cachaçaria Lira.

\section{GESTÃO AMBIENTAL NO BRASIL}

Com o passar dos anos, o governo teve que intervir para que o Meio Ambiente não tivesse tantas perdas e, neste sentido, começam a surgir dispositivos legais para inibir o uso inadequado dos recursos naturais. Isso acaba submetendo as empresas aos órgãos públicos: leis protetoras, normas e penalizações para aqueles que cometem atos ilegais ou inadequados.

Segundo Barbieri (2016), com a Gestão Ambiental, mudam as relações entre a sociedade e a natureza. A GA visa ao uso de práticas que garantam a conservação e a preservação da biodiversidade, a reciclagem das matérias-primas e a redução do impacto ambiental das atividades humanas sobre o Meio Ambiente.

Segundo Barbosa (2006), faz parte também de conhecimentos associados à Gestão Ambiental algumas técnicas para a recuperação de áreas degradadas, analisando padrões para reflorestamento com espécies nativas, visando diminuir o esforço de recuperação as áreas degradadas.

No bojo destas mudanças no país, desenvolvem-se formas diferentes de gestão pública dos municípios e de todos seus cidadãos, isto é, uma "nova" gestão do poder local que "[...] não se resume à gestão pública ou governo municipal; é bem mais amplo; constituiu-se de diversas forças nas áreas política, econômica, social e cultural" (OLIVEIRA, 2004, p. 89).

\section{OS PRIMÓRDIOS DA GESTÃO AMBIENTAL NO BRASIL}

Em termos cronológicos, as origens da participação remetem à Grécia antiga com participação direta dos políticos (cidadãos) na pólis (cidade), principalmente na cidade de Atenas onde, por cerca de dois Séculos, existiu a democracia direta. Isto é, não havia representantes ou políticos, mas somente os cidadãos decidindo livremente sobre ações políticas (SOUZA, 2008).

Mas é no Século XIX que os processos participativos emergem mais fortemente como resultado da Revolução Industrial, possibilitando a formação de um proletariado urbano que, após muitas lutas, 
assegurou seu direito de participação e ampliou consideravelmente o número de pessoas a gozar deste direito (DALLARI, 1984).

O conceito de Gestão Ambiental ganhou um viés claramente tecnocrático mesmo depois da Conferência de Estocolmo, em 1972. Até a década de 1980, assimilando gradualmente desde então a contribuição das ciências sociais às ciências "naturais" ou "exatas" (VIEIRA; WEBER, 1997; RIBEIRO, 2000).

No processo de redemocratização do Brasil, a Gestão Ambiental teve suas bases formadas. Todavia, a sociedade não era considerada um participante da gestão. Assim, os anos 90 no país correspondem à institucionalização da consulta a população dentro dos marcos da democracia, ao mesmo tempo em que:

[...] são caracterizados por uma inflexão nas relações entre o Estado e os setores da sociedade civil comprometidos como projeto participativo democratizante, onde estes últimos substituem o confronto aberto da década anterior por uma aposta na possibilidade de uma atuação conjunta com o Estado (DAGNINO, 2004, p. 99).

Com o passar dos anos, a sociedade começa a sentir a necessidade de conseguir gerir melhor os recursos de sua região, de forma sustentável, para conseguir deixar os mesmos recursos para as gerações futuras. Porém, apenas a vontade da população não tem tanto efeito sem uma política socioambiental.

\section{A GESTÃO MUNICIPAL E SUA PARTICIPAÇÃO NO PROCESSO DE CONSCIENTIZAÇÃO COLETIVA}

A Gestão Municipal tem tentado fazer seu papel para a formação significativa na formação, execução e acompanhamento dos projetos ambientais e suas políticas. Analisando a transformação do município brasileiro ao longo da história e utilizando o município de Itapecerica da Serra (SP) como estudo de caso, BALDUSCO (2006, p. 284) identifica que um município bem gerido deve basear-se em articulações do poder municipal com a iniciativa privada e comunidade: "[...] a participação é um dos elementos necessários para legitimação das intervenções", portanto, "[...] a democratização das decisões é fundamental para transformar o planejamento da ação municipal em algo compartilhado e assumido pelos cidadãos".

No Brasil, a participação popular é entendida como processo de "[...] esforços organizados para aumentar o controle sobre os recursos e as instituições que controlavam a vida em sociedade" (GONH, 2001, p. 50) e figura como elemento central desde a Constituição Federal de 1988.

Durante muitos anos, o Brasil passou por uma série de mudanças na área ambiental devido às ações cometidas pela sociedade na natureza: a caça ilegal de animais, desmatamentos, queimadas e destruição da camada de ozônio na atmosfera, poluição marítima (MENDONÇA, 1994).

Para Dias (2000), cuidar do ambiente é tarefa diária para todos, além de estar sempre atualizado sobre informações sobre as questões que envolvem o Meio Ambiente, tendo em vista que tal atitude caracteriza, também, um elemento do composto cidadania. Contudo, a participação das empresas também se torna muito importante, haja vista que o processo de industrialização tem se acelerado e as consequências deste progresso influencia diretamente na utilização dos recursos naturais.

Portanto, viabilizar soluções factíveis para os dilemas ambientais é um grande desafio para as organizações, não apenas porque impõe a reserva de recursos financeiros para a adoção de medidas de prevenção, mas porque o tecido societário tem atuado fortemente em defesa das causas ambientais, impondo às organizações a mudança de paradigma e o repensar de estratégias que mitiguem os danos ambientais.

Neste sentido, a Gestão Ambiental emerge como um meio eficaz para a realização de ações que contemplem, concomitantemente, os interesses econômicos, sociais e ambientais.

\section{A GESTÃO AMBIENTAL SOB O PONTO DE VISTA EMPRESARIAL}

Ao longo dos anos, grandes avanços tecnológicos vêm sendo feitos para melhorar a eficiência de tempo de produção e aproveitamento completo dos recursos naturais, com o resultado disso indiretamente, se minimiza os efeitos negativos ao Meio Ambiente pelo qual muitas empresas têm feito.

Camargo, apud Novaes (2002), afirma que os últimos dois Séculos têm vivido sob a tríade da liberdade, da igualdade e da fraternidade. À medida que caminhamos para o Século XXI, é preciso tomar como 
inspiração um quarto elemento, indispensável à preservação ambiental e à garantia de vida das próximas gerações: a sustentabilidade.

A sustentabilidade se torna, portanto, ponto de partida e de chegada para amalgamar os fatores que compõem o processo de "reflexão-na-ação" e "reflexão-sobre-ação" que, tomando os ensinamentos de Schön (2000), pressupõe a busca da solução dos problemas reais por meio da colaboração entre os atores envolvidos.

Este sistema reflexivo se torna fundamental para compreender a dinâmica dos problemas que envolvem o sistema produtivo, principalmente nos dias atuais, quando se percebe a alavancagem de novos produtos e serviços, muitos dos quais com forte utilização de recursos naturais, gerando degradação ambiental e repercussões negativas para o composto societário (BARBIERI, 2016).

Nesse sentido, o desenvolvimento dessas e outras tecnologias deverá servir a metas de equilíbrio com o Meio Ambiente e de complemento as capacidades inovadoras de cada país em desenvolvimento. MEYER (2000) enfoca que, sob esta ótica, o conceito de desenvolvimento sustentável apresenta pontos básicos que devem considerar, de maneira harmônica, o crescimento econômico, maior percepção com os resultados sociais decorrentes e equilíbrio ecológico na utilização dos recursos naturais.

Notar essa necessidade ecológica e econômica é difícil, pois muitas empresas apenas fazem essa mudança quando sentem no bolso o preço de suas escolhas erradas, e deve haver uma boa visão a longo prazo para perceber isso há mais de um Século atrás. Ou seja, tudo que disser respeito à sustentabilidade precisa compor o arsenal estratégico das organizações.

Nesse contexto, na medida em que uma empresa desenvolve e aplica adequadamente a Gestão Ambiental sinaliza um indicativo de que tem compromisso não apenas com o aspecto econômico, mas sobretudo com os fatores social e ambiental, razão pela qual a Cachaçaria Lira, ao longo dos anos, tem incorporado à sua estratégia de perpetuação e crescimento os elementos que constituem as boas práticas de sustentabilidade no processo produtivo.

\section{METODOLOGIA}

A metodologia científica compreende o conjunto de etapas ordenadamente dispostas a serem executadas na investigação de um fenômeno. A pesquisa possui natureza descritiva e propõe a abordagem qualitativa, utilizando-se da entrevista com o principal gestor da empresa.

As pesquisas exploratórias são feitas em áreas onde ainda existe pouca ou nenhuma exploração, proporcionando uma visão primária de determinado evento, buscando mostrar padrões em vez de testar hipóteses (COLLIS; HUSSEY, 2005, p.24). A abordagem quantitativa usa métodos estatísticos para apontar precisamente quantificação de dados. Geralmente utilizada em pesquisas descritivas para descobrir e classificar relações entre eventos ou para pesquisas conclusivas (OLIVEIRA, 1997).

A pesquisa tem abordagem qualitativa, de natureza descritiva e exploratória e utiliza-se do Estudo de Caso como técnica capaz de validar os achados. Foram utilizados como fontes para consubstanciar o estudo: documentos, entrevista e registros fotográficos, permitindo amalgamar o método utilizado em direção ao objetivo traçado.

Segundo Manzini (2004) existe a entrevista estruturada, semiestruturada e não-estruturada. Nesse trabalho, foi feita uma entrevista não-estruturada (questões abertas), assim permitindo obter, com riqueza de detalhes, como ocorre o processo de fabricação e de que maneira a empresa desenvolve as suas práticas sustentáveis.

Esse Estudo de Caso foi realizado na Cachaçaria Lira, com o objetivo de descrever se as suas teorias de Gestão Ambiental realmente vêm sendo colocadas em prática. A pesquisa compreendeu duas etapas: uma pesquisa teórica, com base nas informações sobre a Gestão Ambiental e uma pesquisa de campo, descrevendo como a Cachaçaria Lira mantém as suas práticas sustentáveis - por meio da eficaz Gestão Ambiental - com concomitante manutenção da qualidade do produto final.

A partir dos dados coletados com um dos principais envolvidos em todo processo produtivo e com mais informações técnicas, foi verificado se tudo que foi dito realmente acontece na realidade. Haroldo Lira é descente do fundador da cachaçaria e atualmente é o principal responsável pelo funcionamento da empresa, acompanhando sempre de perto cada passo do processo de fabricação. 
A partir das informações coletadas foram analisadas para se confirmar que realmente existe Gestão Ambiental sendo realizada na Cachaçaria Lira, se está sendo eficaz e se está tendo retorno para o meio ambiente, para a sociedade e economicamente também.

\section{CACHAÇARIA LIRA: HISTÓRIA, INICIATIVAS, REPERCUSSÕES}

A Cachaça Lira tem ganhado grande notoriedade dentro do cenário regional devido à sua Gestão Ambiental, a qual utiliza os recursos naturais necessários para produção de forma sustentável com o Meio Ambiente desde os primeiros dias de fundação, demonstrando que tal atitude permitiu que se tornasse um destaque no mercado, mesmo em uma cidade pequena e com baixo desenvolvimento na época, como Amarante, Estado do Piauí.

A Vila de Amarante foi uma das várias cidades brasileiras que herdaram, nomes de cidades portuguesas: Amarante de São Gonçalo, importante região do país colonizador. Esse povoado piauiense conseguiu desenvolver um grande processo de navegação a vapor. Com isso, a vila se tornou oficialmente uma cidade, uma pela Resolução Provincial no 734 no dia 04 de agosto de 1871.

Alguns anos após a oficialização da cidade de Amarante, nasceu Francisco José Lira, em 1864, o qual começou a produzir cachaça em 1889. Graças à sua capacidade empreendedora, conseguiu vencer os desafios da seca de 1915 que devastou o sertão nordestino. Fundou o Sítio Floresta, onde conseguiu racionalizar os recursos naturais criando, assim, meios de sustentabilidade ambiental.

Além de a produção ser feita lá, o sítio também é considerado um dos pontos turísticos da cidade em função de suas belezas naturais, as quais o grupo empresarial fez questão de preservar, não apenas face à prioridade de garantir os recursos naturais necessários ao processo produtivo, mas em elevada parte por conta da atratividade que o ambiente proporciona, sempre atraindo pessoas para conhecer toda a estrutura do local.

Figura 1: Moinho da Cachaçaria Lira construído no começo do Século XX

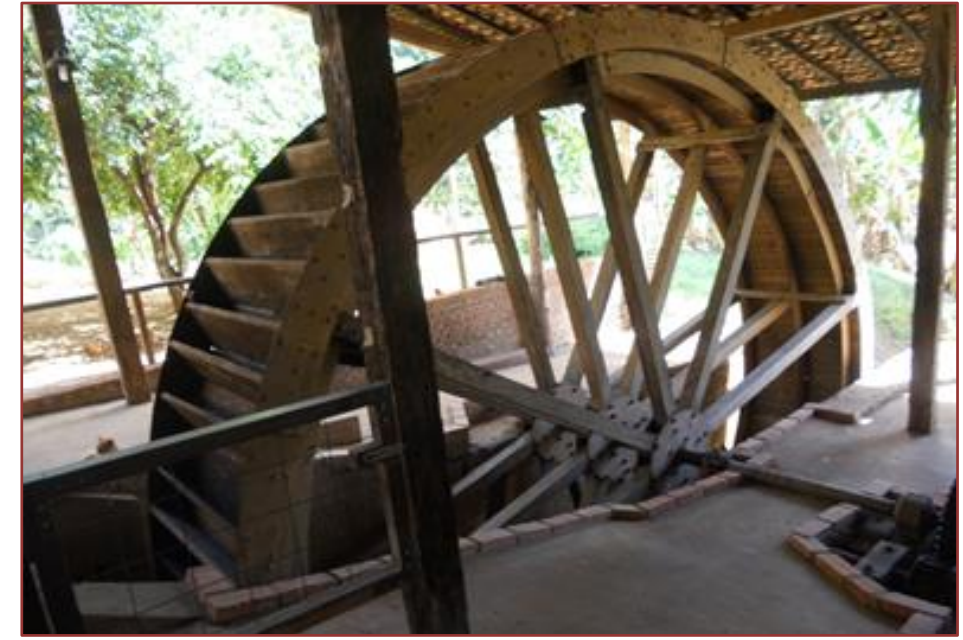

Fonte: Dados da pesquisa, 2018.

Segundo Brundtland (1987) a compatibilidade de forma intrínseca é o caminho que deve ser percorrido para se alcançar o desenvolvimento sustentável. De acordo com esse conceito, é possível entender como um empreendimento pode se tornar tão antigo e firme no mercado local com uma história quase tão grande quanto a da própria cidade.

Os descendentes da família Lira preservaram o negócio através da ética, rigor e outras lições que aprenderam com o fundador do empreendimento, pelo então Coronel Francisco José Lira. Aliando tradição e o avanço tecnológico, trouxe uma qualidade do produto ao nível dos padrões internacionais de qualidade dando tanto orgulho à família que colocaram seu próprio nome nessa empresa.

Essa empresa consegue preservar durante muitos anos o ambiente em que retiram todas as suas matérias-primas, por isso, esse negócio é um modelo no que se refere a Gestão Ambiental, a fim de melhorar a qualidade de seus produtos e garantir sua obtenção de matéria-prima de forma sustentável. 
Naquela época, poucas pessoas tinham interesse e informações, para saber que os recursos não eram ilimitados.

Figura 2: Placa de proteção ao meio ambiente erguida no Sítio Floresta

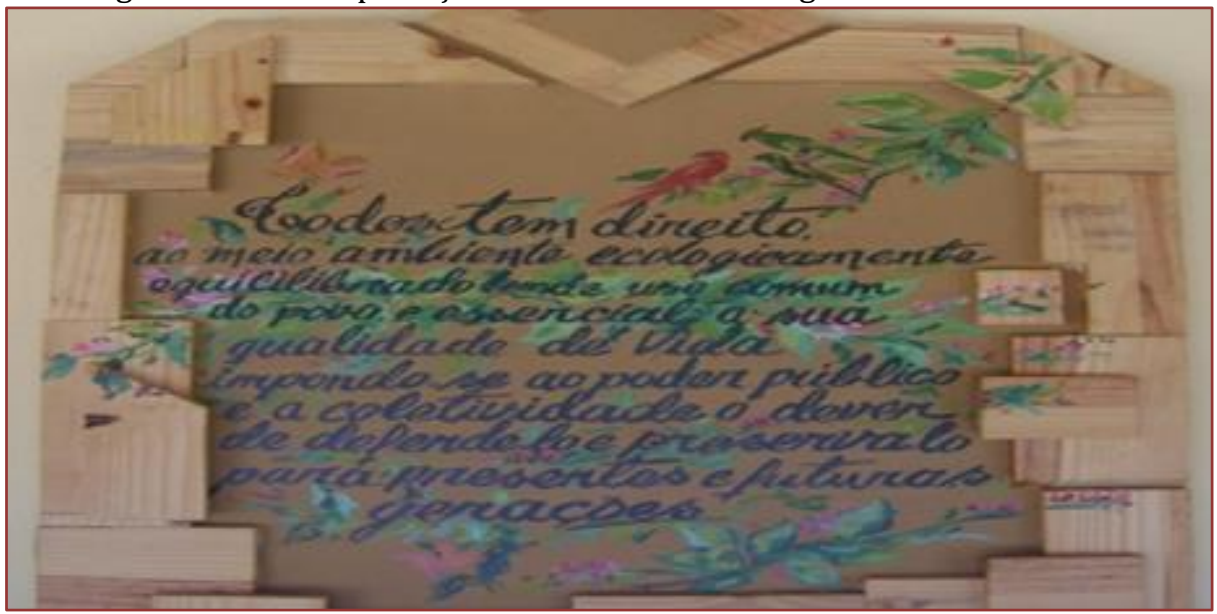

Fonte: Dados da pesquisa, 2018.

O Sítio Floresta produz as bebidas na época de seca, graças à ajuda da tecnologia atual. Embora possa parecer fácil, fabricar um produto e conviver com o Meio Ambiente em harmonia é extremamente difícil nos dias de hoje, pois muitos fabricantes ainda não conseguem usufruir dos recursos naturais de forma sustentável. Por isso, é importante entender como uma empresa do próprio Piauí conseguiu fazer isso sem precisar afastar-se da realidade local.

No processo de produção a cana-de-açúcar (em apenas 17 hectares em 2014) é plantada e colhida com a supervisão do engenheiro agrônomo do local, certificando-se da distância entre as canas e o jeito certo para colher, utilizando técnica de corte que não prejudique a colheita seguinte.

Figura 3: Cana-de-açúcar cortada do jeito certo para produção

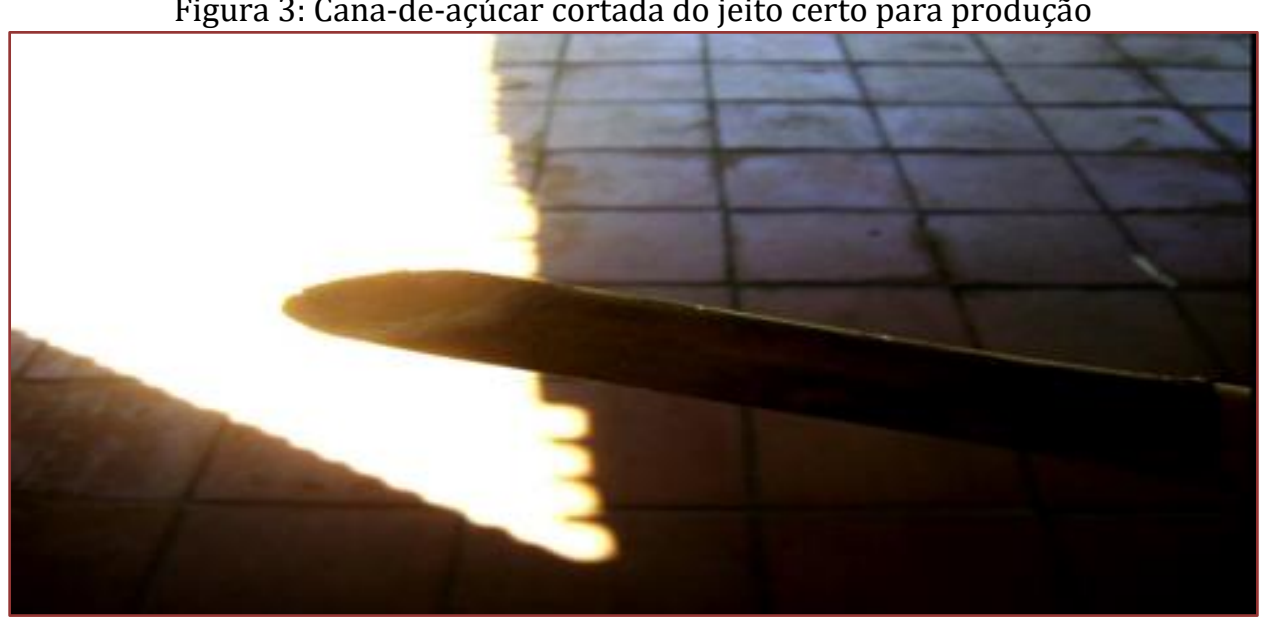

Fonte: Dados da pesquisa, 2018.

Logo após a colheita, a cana-de-açúcar é moída e o caldo da cana, caso contenha alguma impureza, não é utilizado na produção. Em seguida é levado ao processo de fermentação. Esse processo é feito em dornas de aço inox, a fermentação é feita sem acrescentar aditivos químicos, esse processo tem duração de 24 a 30 horas. Nessa etapa, o caldo da cana é transformado em vinho por causa da sacarose e leveduras alcoólicas (Sacharomyces Cerevisiae), de linhagem que existe no próprio sítio.

Logo depois, o vinho da cana é destilado em um alambiquei de cobre, onde somente 15\% do vinho da cana continua na produção. A chamada "cabeça" e a "calda", que é a parte que faz mais prejudiciais à saúde, por conter uma quantidade mais de metanol, ácidos voláteis, aldeídos e álcoois superiores. 
A parte que não é aproveitada na produção (cachaça de cabeça e calda), como não pode ser usada para consumo, é reaproveitada para produção de combustível para máquinas e veículos que participam da produção e locomoção da matéria-prima. Adicionalmente, o álcool tem menor quantidade de gases que desenvolvem o efeito estufa, pois não utiliza combustíveis fósseis.

No Brasil, o uso de álcool como combustível vem crescendo e isso ajuda a diminuir principalmente a quantidade de monóxido de carbono, óxidos de enxofre, compostos orgânicos tóxicos como o benzeno e compostos de chumbo, melhorando a qualidade do ar (UNICA, 2006).

Segundo o principal responsável pela produção Haroldo Lira, a etapa do envelhecimento é feita em tonéis de Castanheira (madeira considerada "carvalho brasileiro") com capacidade de armazenamento de 700 litros, onde ficam por um tempo mínimo de 12 meses. Isso faz com que a cachaça aprimore seu sabor, aroma, brilho, maciez e cor antes do engarrafamento, mantendo as características de um produto artesanal, produzida com os mais altos padrões de higiene e qualidade. Por isso consegui importar seu produto para países da América do Sul como Argentina e europeus como a Alemanha.

Depois de toda essa produção, sobram alguns resíduos, que são devidamente reaproveitados, os resíduos são:

- Ponta da cana que é utilizada na alimentação de animais;

- Bagaço da cana, utilizada como alimento para os animais, adubação, além de servir como combustível para a caldeira;

- Vinhoto, utilizado também para adubação e alimentação de animais;

- Cabeça e calda da cachaça, utilizada na fabricação de combustível.

Os problemas resultantes da má utilização dos resíduos poderiam gerar grandes impactos ao Meio Ambiente, pois além da fábrica se localizar em um lugar onde não se tem quase nenhum tipo de preocupação com o Meio Ambiente, tem por perto os rios Parnaíba, Mulato e Canindé, o que, ao longo de tantos anos, já poderia ter tornado a água de algum desses rios, inconsumível.

Pensando também em turismo ecológico, o Sítio Floresta está construindo um açude que utiliza a mesma água que é transposta do Rio Mulato e utilizada para mover o moinho que tem mais de cem anos do local que será aberto ao público como uma Reserva Particular do Patrimônio Natural.

Conversando com Haroldo Lira, engenheiro agrônomo e responsável técnico da produção, é possível confirmar a consolidação da empresa e o orgulho em não gerar nenhum tipo de resíduo, pensando na parte econômica, social e ecológica para promover uma melhor Gestão Ambiental. A adubação da cana-deaçúcar é plantada e adubada com esterco orgânico. Outra característica citada por ele é a atenção à biodiversidade para que o cultivo da matéria-prima da cachaça não seja afetado pela monocultura.

\section{CONSIDERAÇÕES FINAIS}

De acordo com os dados apresentados, é possível perceber que não é necessário sair do Piauí para encontrar empresas que conseguem proteger o Meio Ambiente, por isso é necessário que outras empresas que ainda não conseguem fazer um produto sem conseguir reciclar, ou pelo menos diminuir seus impactos ao Meio Ambiente possam pensar em um jeito melhor de aprimorar sua produção com o objetivo de garantir matéria-prima para o futuro, além de garantir às futuras gerações um estado com muitas belezas naturais e com natureza preservada.

Preservar o ambiente é um investimento não só para produção, mas também para o turismo e para a saúde das pessoas que trabalham no local, que podem ter um trabalho bem mais produtivo, além de assegurar que o lugar poderá se manter por mais muitos anos.

A entrevista foi feita apenas com Haroldo Lira, principal responsável pela produção, por isso sugere-se que novas pesquisas sejam implementadas a fim de que outros achados possam contribuir para o fortalecimento da consciência ambiental e da percepção de que uma ação isolada não resolve os dilemas ambientais. Muitas outras perspectivas podem ser obtidas em campo no ambiente da Cachaçaria Lira e, por esta razão, propõe-se que pesquisadores, acadêmicos em geral e especialistas possam desenvolver novos estudos e conhecimentos que fomentem movimentos de ações efetivas em busca de um Meio Ambiente saudável e sustentável. 


\section{REFERÊNCIAS}

[1] Baldusco, L. F. Gestão metropolitana e o papel do município periférico: Itapecerica da Serra. 2006. Disponível em: <http://www.dominiopublico.gov.br/download/texto/cp031213.pdf>. Acesso em: 07 Ago. 2017.

[2] Barbieri, J. C. Gestão ambiental empresarial: conceitos, modelos e instrumentos. 4. ed. São Paulo: Saraiva, 2016.

[3] Barbosa, L. M. Manual Para Recuperação de Áreas Degradadas do Estado De São Paulo: Matas Ciliares do Interior Paulista. São Paulo: Instituto de Botânica, 2006.

[4] Bañón Gomis, A. J.; Guillén Parra, M.; Hoffman, M. W.; Mcnulty, R. E. (2011). Rethinking the Concept of Sustainability. Business and Society Review. Vol. 116, Issue: 2, pp. 171-191.

[5] Bezerra, M. C. L.; Bursztyn, M. (cood.). Ciência e Tecnologia para o desenvolvimento sustentável. Brasília: Ministério do Meio Ambiente e dos Recursos Naturais Renováveis: Consórcio Cds/ Unb/ Abipti, 2000.

[6] Brundtland, G. H. Our Common Future (The Brundtland Report), In: Oxford University Press, 1987.

[7] Bruns, G. B. Afinal, o que é gestão ambiental? Ambiente Brasil. 2009. Disponível em: < http://www.ambientebrasil.com.br/composer.php3?base=./gestao/index.html\&conteud >. Acesso em: 18 jul. 2018.

[8] Cachaçaria Lira, História de Amarante. Disponível em: < http://www.cachacalira.com.br/pt/historiaamarante.php>. Acesso em 30 de dez. 2018.

[9] Camargo, A. Governança para o Século 21. In: TRIGUEIRO, A. Meio Ambiente no Século 21: 21 especialistas falam da questão ambiental nas suas áreas de conhecimento. Rio de Janeiro: Sextante, 2003.

[10] Cavalcanti, C. (Org.). Desenvolvimento e natureza: estudos para uma sociedade sustentável. São Paulo: Cortez, 2003.

[11] Collis, J.; Hussey, R. Pesquisa em Administração. Um guia prático para alunos de graduação e pós-graduação. 2aㅡ. Ed. Porto Alegre: Bookman, 2005.

[12] Dagnino, E. ¿Sociedade civil, participação e cidadania: de que estamos falando? In: Mato, D. (Coord.). Políticas de ciudadania y sociedad civil en tiempos de globalización. Caracas: Faces, Universidad Central de Venezuela, 2004.

[13] Dallari, D. A. Ambientalismo e participação na contemporaneidade. Direito de participação. In: Soorentino, M. (Coord.). São Paulo: Educ/Fapesp, 2001.

[14] Dias, G. F. Educação ambiental. 6. ed. São Paulo: Gaya, 2000.

[15] Godard, O. A gestão integrada dos recursos naturais e do meio ambiente: conceitos, instituições e desafios de legitimação. In: Vieira, P. F. ; Weber, J. Gestão de recursos naturais renováveis e desenvolvimento: nossos desafios para a pesquisa ambiental. São Paulo: Cortez, 1997.

[16] Gonçalves, D. B.; Alves, J. C. A legislação ambiental e o desenvolvimento sustentável no complexo agroindustrial canavieiro da bacia hidrográfica do rio MogiGuaçú. In: Seminário Economia do Meio Ambiente: Regulação Estatal E Auto-Regulação Empresarial Para O Desenvolvimento Sustentável, 3, 2003, Campinas. Anais. São Paulo: Unicamp, 2003. p. 1-24.

[17] Gonh, M. G. Conselhos gestores e participação sociopolítica. São Paulo: Cortez, 2001.

[18] Guimarães, R. A ética da sustentabilidade e a formulação de políticas de desenvolvimento. In: Viana, G. et al. (Org.) O desafio da sustentabilidade. São Paulo: Fundação Perseu Abramo, 2001.

[19] Hart, S. L. Beyond greening: strategies for a sustainable world. Harvard Business Review, Jan-Feb 1997, p. 67-76.

[20] Hourneaux, F.; Barbosa, M.; Katz, S. A gestão ambiental nas indústrias brasileiras. Anais do Seminário em Administração da Fea-Usp, São Paulo, SP, Brasil, 7, 2004.

[21] Jacobi, P. Meio ambiente urbano e sustentabilidade: alguns elementos para a reflexão. In: Cavalcanti, C. (Org.). Meio ambiente, desenvolvimento sustentável e políticas públicas. São Paulo: Cortez Editora, 1997.

[22] Juchem, P. A. Gestão e auditoria ambiental. Curitiba: Fae 1995.

[23] Koch, I. G. V. Argumentação e linguagem. 3. ed. São Paulo: Cortez, 1993.

[24] Manzini, E. J. Entrevista: definição e classificação. 4 transparência. P\&b, 39 cm x 15 cm. Marília: Unesp, 2004.

[25] Marconi, M. D. A.; Lakatos, E. M. Técnicas de pesquisa: planejamento e execução de pesquisas, amostragens e técnicas de pesquisas, elaboração, análise e interpretação de dados. 3. ed. São Paulo: Atlas, 1996. 
[27] Mendes, M. T. T. Educação empreendedora: uma visão holística do empreendedorismo na educação. 2011. Dissertação (Mestrado em Ciências da Educação) Universidade Católica Portuguesa, Lisboa, 2011. 288p.

[28] Mendonça, F. A. Geografia e meio ambiente. 2. ed. São Paulo, Contexto, 1994.

[29] Meyer, M. M. Gestão ambiental no setor mineral: um estudo de caso. 2000. Dissertação. (Mestrado em Engenharia da Produção) - Universidade Federal de Santa Catarina, Florianópolis.

[30] Moffatt, I. Environmental space, material flow analysis and ecological footprinting. In: Atkinson, G.D.; Dietz, S.; Neumayer, E. (Eds.). Handbook of Sustainable Development. Cheltenham and Northampton: Edward Elgar Publishing, 2007. p. 319-344.

[31] Oliveira, S. L. Tratado de metodologia científica. São Paulo: Pioneira. 1997.

[32] Oliveira, F. M. Desafios da participação popular no poder local. In: Fundação Konrad Adenauer. Participação cidadã: novos conceitos e metodologias. Fortaleza: Expressão Gráfica e Editora, 2004 p. 87-100.

[33] Pertshi, I. K. Gestão ambiental na hotelaria: um estudo da aplicação de indicadores ambientais. Rio Grande do Sul. Seminário de Pesquisa em Turismo do MERCOSUL. 2006.

[34] Ribeiro, M. Ecologizar pensando o ambiente humano. 2. ed. Belo Horizonte: Rona, 2000.

[35] Ronstadt, R. C. Entrepreneurship. Dover: Lord Publishing, 1984.

[36] Rosa, A. H.; Fraceto, L. F.; Moschini-Carlos, V. (Org.). Meio ambiente e sustentabilidade. Porto Alegre: Bookman, 2012.

[37] Ruscheinsky, A. Sustentabilidade: uma paixão em movimento. Porto Alegre: Sulina, 2004.

[38] Schön, Donald A. Educando o profissional reflexivo: um novo design para o ensino e a aprendizagem. Porto Alegre: Artmed, 2000.

[39] Scoullos, M. Towards an environmental education for sustainable development. In United Nations Educational, Scientific, and Cultural Organization (Unesco), Interregional Workshop on Re-orienting Environmental Education for Sustainable Development, June, 26-30, 1995.(Annex 6, pp. 1-10). Athens: Unesco, 1995.

[40] Shibao, F., Moori, R., \& Santos, M.. A logística reversa e a sustentabilidade empresarial. Anais dos Seminários em Administração, São Paulo, SP, Brasil, 13, 2010.

[41] Souza, M. L. Mudar a cidade: uma introdução crítica ao planejamento e à gestão urbanos. 5. ed. Rio de Janeiro: Bertrand Brasil, 2008.

[42] Teixeira, C. M. M. Educação para o Empreendedorismo: um estudo sobre o Projeto Nacional de Educação para o Empreendedorismo In: Faculdade de Psicologia e de Ciências da Educação, Faculdade de Economia, Coimbra: 2012.

[43] Unica - União da Agroindústria Canavieira de São Paulo. Disponível em: <http://www.unica.com.br/portalunica>. Acesso em: 12 jun. 2018.

[44] Unitad Nations Statistics Division. Millennium Development Goals Indicators. 2008. Disponível em: <http://mdgs.un.org/unsd/mdg/default.aspx. >. Acesso em: 07 Ago. 2017.

[45] United Nations Statistics Division. 2008. Millennium Development Goals Indicators Disponível em: <http://mdgs.un.org/unsd/mdg/default.aspx>. Acesso em: 05 Ago. 2017.

[46] Vieira, P.; Weber, J. (Orgs.) Gestão de recursos naturais renováveis e desenvolvimento. Novos desafios para a pesquisa ambiental. 3. ed. São Paulo: Cortez, 1997. 


\section{Capítulo 8}

\section{Asseguração externa dos relatórios de sustentabilidade de empresas listadas na B3 2017}

\section{Heloisa Siqueira Lordello \\ Lygia Nathália Pereira da Silva}

Resumo: Relatórios de sustentabilidade divulgam informações sobre os impactos de uma organização - sejam positivos ou negativos - sobre o meio ambiente, a sociedade e a economia. Há uma recomendação por parte do GRI para que as empresas procedam a verificação externa desses relatórios de sustentabilidade. Essa asseguração pode ser realizada de acordo com diversas normas, dentre elas a ISAE 3000, que será analisada neste estudo. Alguns autores chamam a atenção para a importância do fornecimento de uma declaração de garantia nos relatórios de sustentabilidade, pois gera maior confiabilidade do que quando tal garantia não é fornecida Dessa forma este artigo tem como objetivo geral investigar o processo de asseguração externa das informações de sustentabilidade por empresas listadas na iniciativa "Relate ou Explique para os Objetivos de desenvolvimento Sustentável (ODS)” da B3. Como suporte teórico são apresentados os modelos de relatórios de sustentabilidade com ênfase no GRI e a norma de asseguração dos relatórios de sustentabilidade - ISAE 3000. A pesquisa é qualitativa, bibliográfica e documental. A amostra foi composta por 113 empresas do Relate ou explique da B3 do ano base 2017, das quais 95 publicaram o relato de sustentabilidade com diversas denominações. Os resultados mostram que apesar da GRI recomendar a realização de uma verificação externa nos relatórios, apenas 41\% das empresas pesquisadas submeteram seus relatórios a verificação externa de acordo com a ISAE 3000. Das empresas que submetem seus relatórios a asseguração em conformidade com a ISAE 3000, 85\% optaram pela garantia limitada.

Palavras-chave: Asseguração externa. Relatórios de sustentabilidade. ISAE 3000. 


\section{INTRODUÇÃO}

De acordo com o Global Reporting Institute - GRI, o relatório de sustentabilidade auxilia as organizações a estabelecerem metas, aferir seu desempenho e gerir mudanças com vistas a tornar suas operações mais sustentáveis. Relatórios de sustentabilidade divulgam informações dos impactos causados pelas atividades das organizações ao meio ambiente, a sociedade e a economia; assim, eles dão forma concreta às questões abstratas, ajudando as organizações a compreender e gerir melhor os efeitos do desenvolvimento da sustentabilidade sobre suas atividades e estratégias (GRI, 2019).

De acordo com uma pesquisa sobre Relatórios de Responsabilidade Corporativa da KPMG em 2017 93\% das 250 maiores corporações do mundo relatam seu desempenho em sustentabilidade (GRI, 2019). No Brasil em 2012 a B3, que é uma das principais empresas de infraestrutura de mercado financeiro no mundo com atuação em ambiente de bolsa e de balcão, lançou a iniciativa "Relate ou Explique para os Objetivos de Desenvolvimento Sustentável (ODS)"; que tem como objetivo estimular a transparência das estratégias e ações das companhias listadas em relação aos 17 Objetivos de Desenvolvimento Sustentável - ODS estabelecidos pela ONU. É uma recomendação de adesão voluntária da nossa Bolsa às empresas listadas para estimular a publicação de informações ESG (Environmental, Social e Governance) e, desde então, todo ano é publicado o resumo dessas práticas das empresas listadas respondentes. Desta forma a B3 passa a entender melhor como as empresas que são a liderança do mercado brasileiro estão trabalhando com a agenda de sustentabilidade $(B 3,2019)$.

Nos trabalhos de asseguração dos relatórios de sustentabilidade, podem ser utilizadas diferentes normas internacionais, como o Relatório de Sustentabilidade Padrão da GRI, os Padrões Prestação de Contas da Assurance Standard - AS (AA1000) e a Norma Internacional de Asseguração de Garantia - International Standard on Assurance Engagements (ISAE 3000). A norma ISAE 3000 foi aprovada pelo International Auditing and Assurance Standards Board - IAASB em 2003. Foram estabelecidos, nesta Norma, os princípios básicos e procedimentos fundamentais para trabalhos de asseguração que não tenham referência a auditorias ou revisões de informação financeira histórica (JUNIOR; BEST e COTTER, 2014). De acordo com os resultados de uma pesquisa global efetuada pelo IAASB em 2008, a norma ISAE 3000 estava sendo aplicada na prática em todo o mundo sem grandes dificuldades.

No entanto, alguns países como a Alemanha e a Holanda possuem normas específicas para esses tipos de trabalho. Por sua vez, a Federação dos Peritos Contábeis Europeus (Fédération des Experts Comptables Européens - FEE) estudou o assunto e emitiu um extenso documento, resumindo as práticas que vinham sendo seguidas em quatro países europeus (Suécia, França, Holanda e Alemanha). Devido ao processo de garantia dos relatórios de sustentabilidade ser relativamente novo e não é regulamentado na maioria dos países, existem diferentes tipos de entidades que prestam serviços de garantia utilizando diferentes escopos, metodologias e declarações de garantia (IBRACON, 2012).

Junior; Best e Cotter (2014) ressalta que uma vez que, a garantia de relatórios de sustentabilidade ainda não é regulamentada na maioria dos países, empresas poderiam buscar apenas uma declaração para ser incluída nos seus relatórios de sustentabilidade, independentemente da qualidade do processo de garantia realizada. Hodge, Subramaniam \& Stewart (2009) verificou que o fornecimento de uma declaração de garantia nos relatórios de sustentabilidade gera maior confiabilidade do que quando tal garantia não é fornecida.

No Brasil foi elaborada a Norma Trabalho de Asseguração Diferente de Auditoria e Revisão NBC TO 3000 de acordo com a sua equivalente internacional da IFAC a ISAE 3000, que foi aprovada pelo Conselho Federal de Contabilidade por meio da Resolução CFC no 1.160/2009; mesmo passando por alterações no ano de 2015, que deram nova redação à NBC TO 3000, a norma se manteve (CONSELHO FEDERAL DE CONTABILIDADE, 2019). Assim, este trabalho parte da seguinte questão:

As empresas listadas na iniciativa "Relate ou Explique para os Objetivos de desenvolvimento Sustentável (ODS)" da B3 elaboram asseguração externa de seus relatos de sustentabilidade?

Sendo assim, o objetivo geral do estudo é investigar o processo de asseguração externa das informações de sustentabilidade por empresas listadas na iniciativa "Relate ou Explique para os Objetivos de desenvolvimento Sustentável (ODS)" da B3.

Para sua concretização descrevem-se os seguintes objetivos específicos: a) identificar os modelos de informações divulgados pelas empresas da amostra; b) apurar o tipo de asseguração externa que as companhias da amostra têm se submetido. 


\section{REVISÃO DA LITERATURA}

A fundamentação teórica apresenta o conceito de contabilidade ambiental, modelos de relatórios de sustentabilidade e Global Reporting Initiative - GRI. Descreve sobre a Asseguração dos Relatórios de Sustentabilidade e discorre sobre a ISAE 3000. Por fim expõe o Relate ou Explique para os Objetivos de Desenvolvimento Sustentável (ODS) da B3.

\subsection{CONTABILIDADE AMBIENTAL}

Segundo Tinoco e Kraemer (2011) devido ao crescimento da preocupação ambiental, divulgados nos meios de comunicação, os gestores empresariais e os contadores começaram a visualizar nos sistemas de gestão e de contabilidade formas de controle dos impactos de suas atividades nos meios temas ambientais, ecológicos e sociais; dando início a Contabilidade Ambiental. Porém os autores reforçam "essa contabilidade é ainda muito pouco utilizada nas empresas, mesmo no contexto mundial".

De acordo com Bergamini Jr. (1999, p. 3) a "contabilidade financeira ambiental tem o objetivo de registrar as transações da empresa que impactam o meio ambiente e os efeitos das mesmas que afetam, ou deveriam afetar, a posição econômica e financeira dos negócios da empresa". Desta forma a contabilidade ambiental produz informação relevante não apenas aos usuários internos, mas para a toda sociedade que absorve os impactos gerados pelas atividades das empresas, investidores e demais partes interessadas.

\subsection{RELATÓRIOS DE SUSTENTABILIDADE}

Relatórios de sustentabilidade devem divulgar informações sobre os impactos de uma organização sejam positivos ou negativos - sobre o meio ambiente, a sociedade e a economia. Ajudando as organizações a compreender e gerir melhor os efeitos do desenvolvimento da sustentabilidade sobre suas atividades e estratégias (GRI, 2019).

A pesquisa de Calixto (2013) analisou comparativamente as informações socioambientais divulgadas por companhias de capital aberto latino-americanas estabelecidas na Argentina, Brasil, Chile, México e Peru. Os resultados demonstram que a maioria das companhias de capital aberto não disponibiliza informações socioambientais nos seus relatórios anuais ou em relatórios específicos sobre o tema. Entretanto, as organizações estabelecidas no Brasil são as que mais destacam o tema nos seus relatórios. As empresas utilizam o relatório anual como principal forma de divulgação seguido do relatório de sustentabilidade, divulgado como parte do relatório anual ou como uma publicação específica.

De acordo com Ribeiro (2010, p. 108) atualmente existem diversas instituições que desenvolvem modelos de relatórios, direcionadores e procedimentos para a divulgação de informações de natureza ambiental. Explica ainda o motivo que mais impulsiona as empresas a optar por elaborar seus relatórios são os prêmios outorgados por essas instituições. A autora destaca algumas das principais instituições: Coalition for Environmentally Responsible Economics (CERES); Global Environmental Management Initiative (GEMI); Japan Federantion of Economic Organizations (Keidanren); Responsable Care Program; Business Charter for Sustainable Development (ICC); Global Reporting Initiative (GRI); Global Compact; e AccountAbility 1000 (AA1000).

\subsection{GLOBAL REPORTING INITIATIVE (GRI)}

A Global Reporting Initiative (GRI) é uma organização internacional independente que auxilia empresas, governos e outras organizações a compreender e divulgar os impactos de suas ações sobre pontos relevantes, tais como direitos humanos, alterações climáticas, sustentabilidade, e muitos outros. Sua criação teve início em 1997 com as organizações sem fins lucrativos norte americanas Coalition for Environmentally Responsible Economics (CERES) e o Instituto Tellus, com o apoio do Programa das Nações Unidas para o Meio Ambiente (United Nations Environment Programme - UNEP). Em 1999 foi lançada um esboço da versão das Diretrizes para Relatórios de Sustentabilidade. No ano de 2002, na Cúpula Mundial para o Desenvolvimento Sustentável em Joanesburgo, a segunda versão foi lançada e as diretrizes GRI foram mencionadas no Plano de Implementação assinado por todos os membros presentes. Na sequência tornou-se uma instituição permanente e mudou seu secretariado para Amsterdã, Holanda (GRI, 2019). 
Segundo Vellani (2011), os relatórios gerados com base no modelo GRI revelam informações das companhias sobre as demonstrações contábeis (desempenho econômico), pareceres de auditoria, comunicados da administração, recursos humanos (desempenho social) e ecossistemas (desempenho ecológico).

Apesar das organizações elaborarem seus relatos de sustentabilidade com base nas diretrizes GRI, algumas dessas empresas não alcançam níveis aceitáveis de conformidade com os padrões (FREITAS, SANTOS e CRISÓSTOMO, 2019). Em outubro de 2016 a GRI lançou o modelo de relatório GRI Standard em substituição a versão G4. Torna-se relevante notar que apesar de sua adoção ser exigida a partir de 30 de junho de 2018, muitas empresas relatoras optaram por adotar esse modelo no ano de 2017. Ressalta-se também que esse novo modelo GRI Standard oferece às empresas recomendações mais claras sobre os requisitos para elaboração de seus relatórios e continua a oferecer a opções "de acordo Essencial" ou "de acordo Abrangente" (SOLUTA, 2019).

Os relatórios de sustentabilidade devem apresentar um conteúdo padrão geral que se aplica a qualquer organização relatora. Dependendo da opção “de acordo" escolhida, a organização irá identificar os conteúdos que serão relatados; a "opção Abrangente" apresenta diversos indicadores de Governança, Ética e Integridade que as organizações relatoras podem escolher reportar integralmente. Caso contrário podem escolher a "opção Essencial", desta forma existindo maior flexibilidade e veracidade das informações relatadas (GRI, 2019).

No Brasil, a antiga BM\&FBOVESPA, agora B3, em parceria com a Global Reporting Initiative - GRI, iniciou um trabalho de pesquisa com as empresas listadas questionando se elas publicavam algum tipo de relatório sobre sustentabilidade ou similar; que divulgassem onde este se encontrava disponível e, ainda, caso não, o fizessem, explicassem o motivo da não elaboração, assim começou o "Relate ou explique". "Após a divulgação do comunicado externo 017 2011-DP, que instituiu o relate ou explique, a instituição administradora do mercado de capitais brasileiro passou a acompanhar a adesão das empresas à política de divulgação pública de informações" (CHAVES, FLORES e SANTOS, 2018, p.450).

Ainda no começo da iniciativa os idealizadores do Relate ou explique perceberam que não adiantaria apenas recomendar e, sim que, deveriam implementar ações de apoio, desta forma, anualmente eram feitos workshops que tinham como alvo habilitar e incentivar que as organizações apresentassem seus relatos de sustentabilidade; principalmente as empresas que ainda não haviam apresentado algum relato ou aquelas que em suas explicações evidenciavam que não possuíam a sustentabilidade em sua estratégia de negócio (FAVARETTO, 2016).

\subsection{ASSEGURAÇÃO DOS RELATÓRIOS DE SUSTENTABILIDADE}

Como forma de aumentar a credibilidade e a qualidade das informações apresentadas em seus relatos, as empresas passaram assegurar seus relatórios através de auditorias externas; independentemente do modelo de relato de sustentabilidade, foram estabelecidos diversos critérios para normatizar a avaliação dos relatórios, sendo as principais a AA1000 AS e a ISAE 3000 (GRI, 2019).

A AA1000 Assurance Standard, AA1000AS (2008), é uma normatização dos trabalhos que asseguram a credibilidade, a qualidade do desempenho sustentável e elaboração de relatórios de sustentabilidade. Argumenta-se, ainda, que a garantia com base no uso das duas normas: a AA1000AS, para os prestadores de garantia fora da profissão contábil e a ISAE 3000 para os profissionais contábeis, é suscetível de produzir resultados realçados (IANSEN-ROGERS; OELSCHLAEGEL, 2005). No entanto neste artigo iremos nos ater a norma ISAE 3000.

A GRI, apesar de recomendar o uso de verificação externa para relatórios de sustentabilidade, não expressa esse ponto como uma exigência. A GRI usa o termo "verificação externa" para se referir a atividades que resultem em conclusões publicadas sobre a qualidade do relatório e das informações (qualitativas ou quantitativas) nele contidas (GRI, 2019).

\subsection{INTERNATIONAL STANDARD ON ASSURANCE ENGAGEMENTS - ISAE 3000}

A norma ISAE 3000 foi aprovada pelo International Auditing and Assurance Standards Board (IAASB) em 2003 e produziu efeitos a partir de janeiro de 2005. A referida norma fornece diretrizes que dão orientações na abordagem e procedimentos a serem considerados no desenvolvimento desses tipos de 
projetos, para que estejam de uma forma sistemática e consistente com os standards profissionais de auditoria e seus códigos de conduta (GOMES e EUGÉNIO, 2015).

De acordo com Simnett (2012) um serviço de asseguração limitada é aquele em que o praticante reduz o risco do contrato para um nível que é aceitável nas circunstâncias do trabalho, mas onde o risco é maior do que para um serviço de asseguração razoável. Assim, o conjunto de procedimentos realizados em um serviço de asseguração limitada é limitado em comparação com aquelas que são consideradas necessárias em um serviço de asseguração razoável. A definição proposta de um serviço de asseguração limitada, no entanto, também explica que, em tais compromissos, o conjunto de procedimentos realizados é planejado para obter um nível de garantia que é, no julgamento profissional do praticante, significativa aos usuários previstos.

No que respeita aos níveis de garantia, a norma ISAE 3000 prevê uma escolha entre garantia razoável e limitada. A norma sugere que diferentes partes de um relatório podem aplicar diferentes níveis de garantia, o que reflete maior ou menor profundidade nos procedimentos de verificação. Isto significa que, nas indicações das conclusões, os prestadores de garantia devem indicar pormenorizadamente qual partes da auditoria atingiu confiabilidade razoável e que oferecem confiabilidade apenas limitada. No entanto, isto pode se mostrar confuso para os leitores, sobretudo para não especialistas. Por esta razão, os peritos da Federation Comptables Europeens (FEE, 2006), comentando sobre a proposta IFAC, considera que asseguração limitada sobre um documento inteiro em um processo de auditoria pode melhor atingir o objetivo de uma maior clareza (MANETTI E BECATTI, 2009).

Segundo a norma NBC TO 3000 do CFC

a. Trabalho de asseguração razoável é o trabalho de asseguração no qual o auditor independente reduz o risco do trabalho para um nível aceitavelmente baixo nas circunstâncias do trabalho como base para a sua conclusão. A conclusão do auditor independente é emitida de forma que o possibilite expressar sua opinião sobre o resultado da mensuração ou avaliação de determinado objeto de acordo com os critérios aplicáveis.

b. Trabalho de asseguração limitada é o trabalho de asseguração no qual o auditor independente reduz o risco do trabalho a um nível que é aceitável nas circunstâncias do trabalho, mas onde o risco é maior do que o risco para o trabalho de asseguração razoável como base para emissão de uma conclusão na forma que expresse se, com base nos procedimentos executados e nas evidências obtidas, algum assunto tenha chegado ao conhecimento do auditor independente de forma a levá-lo a acreditar que a informação do objeto esteja distorcida de forma relevante. A natureza, a época e a extensão dos procedimentos executados em trabalho de asseguração limitada são restritas (menos extensos) quando comparados com o que são necessários em trabalho de asseguração razoável, mas são planejados para obter um nível de segurança que seja, no julgamento profissional do auditor independente, significativo. Para que seja significativo, o nível de segurança obtido pelo auditor deve ser capaz de aumentar a confiança dos usuários previstos sobre a informação do objeto a um nível que seja claramente mais do que irrelevante (ver itens A3 a A7).

Pastre, Zaro e Alberton (2013) realizaram um estudo que buscou evidenciar quais os critérios e princípios que norteiam os auditores no Brasil na emissão dos relatórios de asseguração constantes. A amostra utilizou relatórios de sustentabilidade de 26 empresas que integrantes da carteira de 2013 do Índice de Sustentabilidade Empresarial - ISE B3. Os autores verificaram que apenas 18 empresas adotaram práticas de asseguração e que as verificações foram efetuadas por intermédio de auditoria externa independente ou pela contratação de empresa de consultoria especializada. Outro dado obtido através do estudo foi que existe uma forte tendência de escolha por empresas de auditoria externa (71\%) sendo 100\% big four, o restante submete à averiguação de consultorias especializadas e ou utilizam ambas as metodologias. Em relação aos normativos, os utilizados são a NBC TO 3000, AA1000SA e GRI 3.1, sendo a mais utilizada a NBC TO 3000 por 74\% das empresas da amostra. De Almeida (2014) analisou qual a estrutura dos relatórios de asseguração emitidos para informações de sustentabilidade da empresa Petrobrás no período de 2005 a 2012. 
A principal conclusão do artigo foi que a estrutura dos relatórios de asseguração mais recentes segue as seguintes normativas: NBC TO 3000 e ISAE 3000, sendo as assegurações realizadas por empresas de auditoria externa, e que os critérios adotados para avaliação das informações apresentadas pela empresa nos anos de 2007-2011 o GRI-G3.1, e embora em 2012 não tenha possuído um tópico específico para os critérios adotados, cabe destacar que o relatório de asseguração aponta o uso do GRI-G3.1.

\section{PROCEDIMENTOS METODOLÓGICOS}

Este estudo tem caráter qualitativo, pois esse tipo de abordagem pode proporcionar uma compreensão aprofundada dos fenômenos sociais do que a investigação quantitativa. (MAJOR \& VIEIRA, 2009). Minayo (2011) ressalta que a pesquisa qualitativa trabalha com o universo de significados, aspirações, crenças, valores e atitudes; o que corresponde a um espaço mais profundo das relações dos processos e dos fenômenos que não podem ser reduzidos a operacionalização de variáveis.

O estudo tomou como base para seleção da amostra as companhias listadas no arquivo "Banco de dados das respostas 2017" da iniciativa "Relate ou Explique para os Objetivos de desenvolvimento Sustentável (ODS)" da B3. Quanto aos procedimentos técnicos empregados na coleta de dados, apoiou-se nos seguintes mecanismos: pesquisa bibliográfica e documental, por meio da análise de conteúdo. Essa técnica aproveita os registros feitos por outros pesquisadores como fonte para construir uma nova plataforma teórica (SEVERINO, 2008).

Posteriormente foi efetuada a busca dos informes ambientais diretamente nos websites das companhias pesquisadas. Segundo Gil (2012) essa modalidade de pesquisa vale-se de conteúdos que ainda não receberam tratamento analítico ou que podem ser reelaborados de acordo com os objetos da pesquisa.

\subsection{COMPOSIÇÃO DA AMOSTRA}

A população da pesquisa selecionou do arquivo "Banco de dados das respostas 2017" disponível no website da B3 "Relate ou Explique para os Objetivos de desenvolvimento Sustentável (ODS)" apenas as companhias que responderam "Sim" (elabora relatório de sustentabilidade ou integrado levando em conta os ODS) ou que na coluna "Busca ativa" possuíam alguma informação de endereço eletrônico, totalizando 113 empresas, apresentadas no Quadro 1.

Quadro 1 - Empresas Analisadas

\begin{tabular}{|l|l|l|l|l|}
\multicolumn{1}{c|}{ AES ELPA } & \multicolumn{2}{c|}{ BRF SA } & \multicolumn{1}{c|}{ GOL } & \multicolumn{1}{c|}{ PARANAPANEMA } \\
\hline AES TIETE E & CACHOEIRA & AUTOBAN & INVEPAR & PORTOBELLO \\
\hline AFLUENTE T & CCR SA & CPFL ENERGIA & ITAPEBI & PETROBRAS BR \\
\hline ALGAR TELEC & CELUL IRANI & CPFL RENOVAV & ITAUUNIBANCO & PETROBRAS \\
\hline ALIANSCE & CEMIG DIST & CPFL GERACAO & ITAUSA & RAIZEN ENERG \\
\hline AMBEV S/A & CEMIG GT & TRAN PAULIST & JSL & AES SUL \\
\hline AMPLA ENERG & ELETROBRAS & DOHLER & KLABIN S/A & RIO GDE ENER \\
\hline ANIMA & CELESC & DOMMO & KROTON & SANTOS BRP \\
\hline B2W DIGITAL & CEG & DURATEX & LIGHT S/A & SAO CARLOS \\
\hline B3 & COELBA & ECON & LIGHT & SIERRABRASIL \\
\hline BBSEGURIDADE & CEMIG & ECORODOVIAS & LOCALIZA & SUL AMERICA \\
\hline BRADESCO & COELCE & ENERGIAS BR & LOJAS AMERIC & SUZANO HOLD \\
\hline BRASIL & COSERN & ESCELSA & LOJAS RENNER & SUZANO PAPEL \\
\hline BANRISUL & CEEE-D & EBE & M.DIASBRANCO & TELEF BRASIL \\
\hline PINE & CEEE-GT & ELEKTRO & MAGNESITA SA & TERMOPE \\
\hline SANTANDER BR & MELHOR SP & ELETROPAULO & MINERVA & TIM PART S/A \\
\hline BANSANTANDER & COPEL & EMBRAER & MRV & TRIUNFO PART \\
\hline BNDESPAR & PAUL F LUZ & ENERGISA & MULTIPLAN & VALE \\
\hline BOMBRIL & CPFL PIRATIN & ENGIE BRASIL & NATURA & VIAVAREJO \\
\hline BRADESCO LSG & SABESP & ESTACIO PART & NEOENERGIA & WEG \\
\hline BRADESPAR & CIELO & FER HERINGER & ODONTOPREV & WHIRLPOOL \\
\hline BRASKEM & ECOVIAS & FIBRIA & OI & \\
\hline BRB BANCO & ECOPISTAS & FLEURY & OGX PETROLEO & \\
\hline
\end{tabular}


O Quadro 1 expõe apenas o "Nome de Pregão" das empresas selecionadas para a amostra, tendo em vista que a denominações sociais das companhias são extensas e essa denominação atende futuras checagens.

\subsection{COLETA DE DADOS}

Para este estudo foram consultadas informações ambientais divulgadas voluntariamente pelas empresas em seus websites. Das companhias listadas pela B3 Relate ou Explique para os ODS no arquivo "Banco de dados das respostas 2017" 14\% não possuem nenhum tipo de informação de sustentabilidade disponível no ano de 2017. Conforme pode ser observado na Figura 1.

Figura 1 - Informações sobre Sustentabilidade



Fonte: Elaborado pelas autoras, 2019.

A Figura 1 demonstra que ainda existe um percentual significativo da amostra que não divulga nenhum tipo de informação sobre impacto de suas atividades (em números absolutos correspondem a 18 empresas da amostra).

\subsection{LIMITAÇÃO DO ESTUDO}

A pesquisa está limitada as informações de sustentabilidade disponibilizados voluntariamente pelas empresas da amostra em seus websites. As informações analisadas referem-se aos relatos elaborados no ano base de 2017 bem como relatórios de asseguração externa que os acompanham.

Os relatos de sustentabilidade são documentos voluntários emitidos pelas organizações, por entender que as partes interessadas buscam informações adicionais, não apresentadas nos relatos obrigatórios.

\section{ANÁLISE DOS RESULTADOS}

Os resultados serão expostos com base nas investigações elaboradas nos informes ambientais apresentados voluntariamente pelas empresas da amostra. Uma vez encontrada alguma informação sobre sustentabilidade observou-se diferentes nomenclaturas de apresentação dos relatos, pode-se inferir diferença também nos relatos apresentados, conforme pode ser observado na Figura 2.

Figura 2 - Tipo de Apresentação da Informação Divulgada

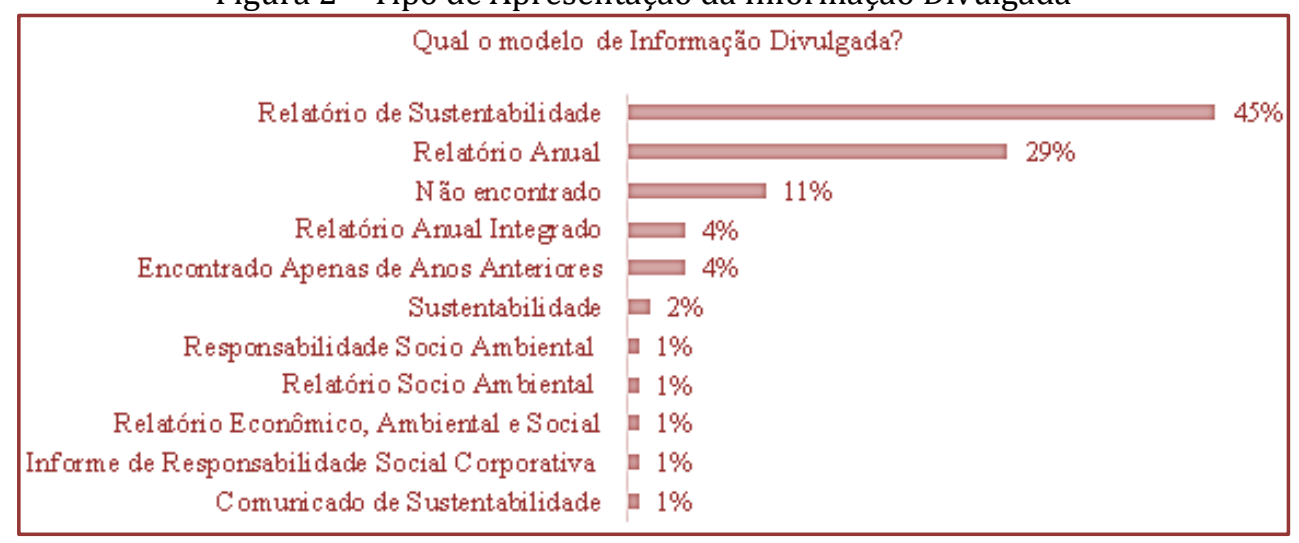

Fonte: Elaborado pelas autoras, 2019. 
A Figura 2 identifica as nomenclaturas designadas aos diversos formatos de Relatório de Sustentabilidade, sendo a mais utilizada "Relatório de Sustentabilidade" seguida por "Relatório Anual". Esta informação ainda que pareça irrelevante, define muito das informações que serão apresentadas nestes relatos. Outros dados relevantes que podem ser visualizadas na Figura 2 são: a quantidade de empresas que não divulgam nenhum tipo de informação ambiental "Não encontrado" (11\%) e de empresas que haviam divulgado informações "apenas em anos anteriores" ao ano de 2017 (representando 4\%) totalizando assim $15 \%$ da amostra estudada.

Outra informação obtida através do exame dos informes ambientais das organizações da amostra, das empresas que elaboravam algum tipo de relatório, se este seria com base no modelo da Global Reporting Initiative - GRI. A Figura 3 os relatórios de sustentabilidade elaborados de acordo com o modelo GRI.

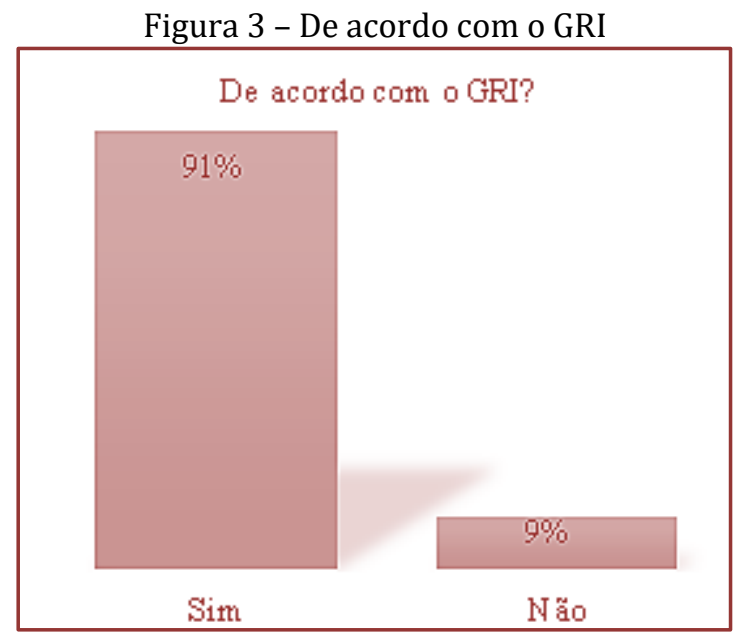

Fonte: Elaborado pelas autoras, 2019.

A Figura 3 demonstra que das empresas que publicam alguma informação sobre Sustentabilidade (Figura 1), 91\% utilizam o modelo GRI para elaborar seus relatórios. E conforme exposto na Fundamentação teórica, a Global Reporting Initiative em outubro de 2016 lançou uma nova versão de modelo de relatório, o GRI Standards, que muitas companhias adotaram logo em 2017, apresentado na Figura 4.

Figura 4 - Modelo de Relatório Padrão GRI

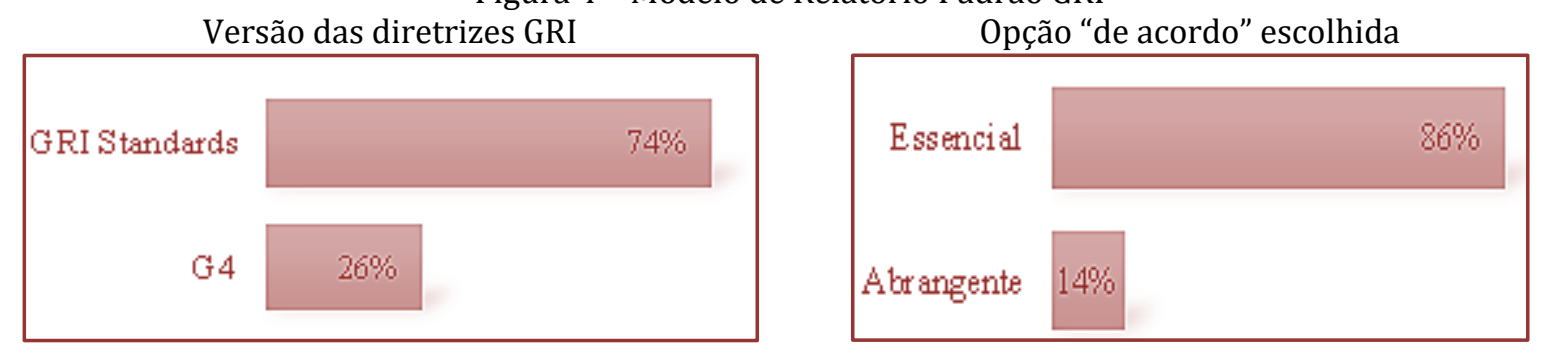

Fonte: Elaborado pelas autoras, 2019.

Torna-se relevante perceber que na escolha do modelo exibido na Figura 4 apenas 14\% optaram pelo modelo Abrangente. Apesar da nova versão do padrão GRI propor instruções mais claras sobre os requisitos, a grande maioria das empresas (86\%) opta pelo modelo Essencial, ainda que o modelo Abrangente possua uma a apresentação mais ampla e aprofundada, expondo todos os indicadores sobre a governança, estratégia, ética e integridade da entidade.

Embora a GRI recomende o uso de verificação externa, essa recomendação não constitui um requisito para que o relatório esteja "de acordo" com as Diretrizes, portanto, ainda que as empresas publiquem alguma informação sobre sustentabilidade, no padrão GRI ou não, uma parte considerável não realiza a asseguração externa de seus relatos, exibido na Figura 5. 


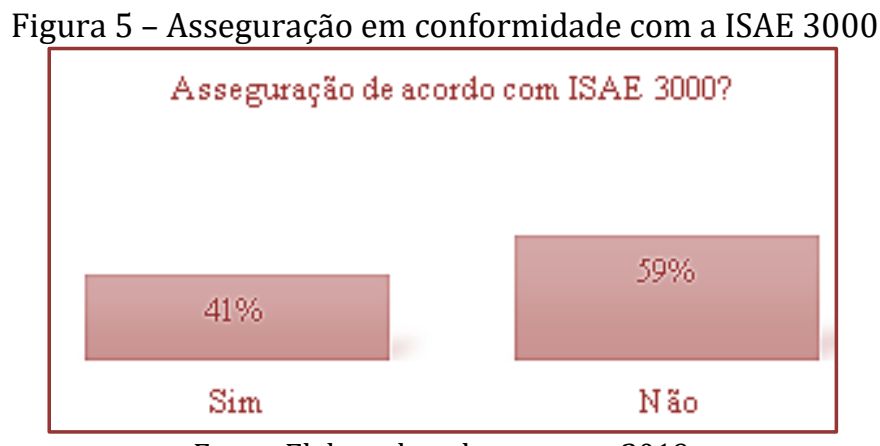

Fonte: Elaborado pelas autoras, 2019.

Pode ser observado na Figura 5 que apenas $41 \%$ das organizações realizaram asseguração externa de acordo com o ISAE 3000, cabe ressaltar que esta norma fornece diretrizes e padrões sobre procedimentos desenvolvidos, que de maneira sistemática, servem de auxílio e respaldo para os profissionais de auditoria.

\section{CONSIDERAÇÕES FINAIS}

0 presente estudo teve como objetivo investigar se as empresas listadas na iniciativa "Relate ou Explique para os Objetivos de desenvolvimento Sustentável (ODS)" da B3 elaboram asseguração externa de seus relatos de sustentabilidade. Para atingir seu intuito, precisou alcançar os seguintes objetivos específicos: a) identificar os modelos de informações divulgados pelas empresas da amostra; b) apurar o tipo de asseguração externa que as companhias da amostra têm se submetido.

Os resultados mostram que $85 \%$ das empresas que divulgam informações ambientais são nos formatos de Relatório de Sustentabilidade e Anual (em torno de 74\%). Em relação ao modelo utilizado 91\% das companhias da amostra elaboraram seus relatos de acordo com as diretrizes GRI, sendo a nova versão GRI Standards a mais utilizada. A GRI oferece duas opções de apresentação de relatório: essencial ou abrangente. Observou-se que $86 \%$ das empresas optaram pelo modelo essencial, apesar do modelo abrangente incluir informações sobre governança, estratégia, ética e integridade da companhia. Nos resultados da pesquisa de Calixto (2013), o relatório mais utilizado era o relatório anual seguida dos relatórios de sustentabilidade, o que se apresenta de forma contrária.

Pastre, Zaro e Alberton (2013) analisaram que 70\% das empresas da carteira ISE da B3 em 2012 adotam práticas de asseguração. Em relação aos normativos os utilizados pelas empresas são a NBC T0 3000, AA1000SA e GRI 3.1 sendo a mais utilizada a NBC - TO - 3000 por $74 \%$ das empresas. A GRI recomenda que realize uma verificação externa, no entanto apenas $41 \%$ das empresas pesquisadas submeteram seus relatórios a verificação externa com a ISAE 3000, essa distorção nos resultados encontrados pode ser explicada devido as empresas participantes da carteira do ISE cumprirem uma série requisitos para integrar essa carteira, diferente das empresas da amostra deste estudo. Observou-se ainda que das empresas que submetem seus relatórios a asseguração em conformidade com a ISAE 3000, 85\% optaram pela garantia limitada.

0 estudo contribui com a literatura do assunto, pois pode compreender como as empresas brasileiras listadas na B3 relatam suas informações ambientais e como procedem a asseguração externa (ISAE 3000). Em virtude de a amostra utilizada ser superior comparada a estudos anteriores, se entende a possibilidade de generalizar os resultados para a população.

Uma das sugestões para pesquisas futuras é verificar junto empresas que apresentaram a opção abrangente do GRI Standard os motivos dessa opção. Também analisar quais as informações adicionais geradas por esse modelo que agregaram valor para a empresa e os usuários das informações. 


\section{REFERÊNCIAS}

[1] B3. Sustentabilidade nas empresas Relate ou Explique. Disponível em: <http://www.b3.com.br/pt_br/b3/sustentabilidade/nas-empresas/relate-ou-explique/> Acesso em: 29 jul. 2019.

[2] Bergamini JR, Sebastiao. Contabilidade e risco ambientais. In: Contabilidade e risco ambientais. BNDES, 1999.

[3] Calixto, Laura. A divulgação de relatórios de sustentabilidade na América Latina: um estudo comparativo. Revista de Administração, v. 48, n. 4, p. 828-842, 2013.

[4] Chaves, Vinicius Figueiredo; da Silva Flores, Nilton Cesar; SANTOS, Roberta Maria Costa. Relate ou explique: o papel indutor da sustentabilidade empresarial pela instituição administradora do mercado de valores mobiliários brasileiro. Revista Internacional Consinter de Direito, ano IV, n. VII, p. 439-454, 2018.

[5] Conselho Federal de Contabilidade. Princípios Fundamentais de Contabilidade. Resolução 2015 / NBC T0 3000, 25 de novembro $2015 . \quad$ de 2019 em: <http://www1.cfc.org.br/sisweb/sre/detalhes_sre.aspx?Codigo=2015/NBCTO3000>. Acesso em: 29 jul. 2019.

[6] De Almeida, Janaina Borges. Asseguração de relatórios de sustentabilidade: o caso Petrobrás. 2014.

[7] Favaretto, Sonia Consiglio. Capital Aberto. Relate ou Explique para Relatório de Sustentabilidade ou Integrado: um case brasileiro de sucesso 2016. Disponível em: <https://capitalaberto.com.br/canais/b3/relate-ouexplique-para-relatorio-de-sustentabilidade-ou-integrado-um-case-brasileiro-de-sucesso/>. Acesso em: 29 jul. 2019.

[8] Freitas, Maria Rafaela Oliveira; Santos, Sandra Maria; Crisóstomo, Vicente Lima. Nível de abrangência da informação ambiental divulgada nos relatórios de sustentabilidade de empresas brasileiras com potencial de impacto ao meio ambiente. Revista Contabilidade e Controladoria, v. 10, n. 3, 2019.

[9] Gil. Antonio Carlos. Metodologia do Ensino Superior. 4 ed. São Paulo: Atlas, 2012.

[10] Gomes, Sónia Ferreira; Eugénio, Teresa Cristina Pereira; BRANCO, Manuel Castelo. Sustainability reporting and assurance in Portugal. Corporate Governance, v. 15, n. 3, p. 281-292, 2015.

[11] GRI. Empowering Sustainable Decisions. Disponível em:<https://www.globalreporting.org/>. Acesso em: 29 jul. 2019.

[12] Hodge, Kristy; Subramaniam, Nava; Stewart, Jenny. Assurance of sustainability reports: Impact on report users' confidence and perceptions of information credibility. Australian accounting review, v. 19, n. 3, p. 178-194, 2009.

[13] Iansen-Rogers, Jennifer; Oelschlaegel, Jeanette. Assurance Standards briefing AA1000 assurance standard and ISAE3000. AccountAbility and KPMG Sustainability, Amsterdam, The Netherlands, 2005.

[14] Ibracon. Comunicado Técnico IBRACON № 07/2012. Disponível em: <www.ibracon.com.br/ibracon/Portugues/downloadFile.php?parametro>. Acesso em: 10 mai. 2019.

[15] Junior, Renzo Mori; BEST, Peter J.; Cotter, Julie. Sustainability reporting and assurance: a historical analysis on a world-wide phenomenon. Journal of Business Ethics, v. 120, n. 1, p. 1-11, 2014.

[16] Major, Maria João; Vieira, Rui. "Contabilidade e controlo de gestão: teoria, metodologia e prática." Escolar Editora (2009).

[17] Manetti, Giacomo; Becatti, Lucia. Assurance services for sustainability reports: Standards and empirical evidence. Journal of Business Ethics, v. 87, n. 1, p. 289-298, 2009.

[18] Minayo, Maria Cecília de Souza Pesquisa social: teoria, método e criatividade (33a ed.). Petrópolis, RJ: 2013.

[19] Pastre, Franciele; ZARO, Elise Soerger; ALBERTON, Luiz. Asseguração dos relatórios de sustentabilidade das empresas que compõem a carteira do índice de sustentabilidade empresarial 2013. Revista de Contabilidade do Mestrado em Ciências Contábeis da UERJ, v. 20, n. 1, 2016.

[20] Ribeiro, Maísa de Souza. Contabilidade ambiental. 2.ed. Rio de Janeiro: Saraiva, 2010.

[21] Severino, Antônio Joaquim. Metodologia do trabalho científico. 23.ed. São Paulo: Cortez, 2008.

[22] Simnett, Roger. Assurance of sustainability reports: Revision of ISAE 3000 and associated research opportunities. Sustainability Accounting, Management and Policy Journal, v. 3, n. 1, p. 89-98, 2012.

[23] Soluta. Relatórios de Sustentabilidade e as normas GRI. Disponível em: <http://www.soluta.eco.br/2018/12/19/relatorios-de-sustentabilidade-e-as-normas-gri/>. Acesso em: 29 jul. 2019.

[24] Tinoco, João Eduardo Prudêncio; Kraemer, Maria Elisabeth Pereira. Contabilidade e gestão ambiental. 3. ed. São Paulo: Atlas, 2011.

[25] Vellani, Cassio Luiz. Contabilidade e responsabilidade social: integrando desempenho econômico, social e ecológico. São Paulo: Atlas, 2011. 


\section{Capítulo 9}

\section{Comércio internacional e desenvolvimento socioambiental: Um entendimento da temática em questão}

Antônia Amanda Alves Pereira Moreira

Henrique César Melo Ribeiro

Rosany Corrêa

Magna da Silva Vilanova Castro

Matheus Morais Bruno

Resumo: O fenômeno globalização ocasionou grandes transformações nos últimos anos no cenário econômico nacional e internacional. Frente à globalização e a expansão do comércio internacional, o mercado passou a estar cada vez mais exigente e o consumidor adquiriu novas preocupações, uma delas é a preocupação socioambiental que fez com que as empresas passassem a aderir novas mudanças de atitude. 0 presente estudo tem como objetivo principal entender a relação existente entre comércio internacional e desenvolvimento socioambiental mediante informações coletadas em estudos bibliográficos disponíveis na literatura nacional. A metodologia adotada para a realização da pesquisa se constitui como uma pesquisa bibliográfica com abordagem qualitativa. No atual estágio de globalização, inúmeros requisitos ambientais e sociais foram e estão em definição. Trata-se de um momento que exige grande conscientização e intensa participação os setores envolvidos nesse processo e portando, constatou-se que o comércio internacional apresenta uma relação estreita com o meio ambiente e o ser humano, e está relação assegura o funcionamento do sistema econômico de um país, fomentando assim o crescimento das nações.

Palavras-Chave: Comércio Internacional. Desenvolvimento Socioambiental. Entendimento. 


\section{INTRODUÇÃO}

O fenômeno globalização ocasionou grandes transformações nos últimos anos no cenário econômico nacional e internacional (DAVANZO et al.,2017). A globalização é o processo de aproximação entre as diversas sociedades, seja no âmbito econômico, social, cultural ou político e o principal destaque dado por ela está na integração de mercado existente entre os países. A globalização é um fenômeno cujos reflexos são nitidamente sentidos nas mais variadas áreas do conhecimento humano. Notadamente nas relações comerciais exteriores, as quais passaram a compreender novos mecanismos e instrumentos (BERTO, 2003, CAMPOS; CANAVEZES, 2007).

Entre as atividades econômicas, o comércio é a que considera de forma mais intensa o relacionamento humano. 0 processo de troca, a essência da atividade comercial não envolve somente a transferência de mercadoria. Implica também o intercâmbio de ideias, experiências sensações e sonhos. Seu ambiente é dinâmico e faz parte do cotidiano das pessoas e se faz necessário frisar que o comércio garante o processo produtivo e gera riquezas para a sociedade uma vez que trabalha para aumentar a eficiência na cadeia de distribuição de produtos, obtém ganhos de escala e permite que o mercado cresça através das suas interações sejam elas, internas ou externas (RATT0, 2009).

0 comércio internacional referente à interação externa é a troca de bens e serviços através de fronteiras internacionais ou territórios, desde o início da ciência econômica, ele é tratado como a alternativa ideal para que os países aproveitem melhor os seus fatores produtivos (CASSANO, 2002). O comércio internacional de um país é um importante gerador de divisas nas relações comerciais com países estrangeiros. Além disso, o comércio responde por parte substancial da entronização de divisas no balanço de pagamento, sobretudo em períodos de baixa mobilidade de capitais (BELLUZO; ALMEIDA, 2002 apud FILHO; LOPREATO, 2016).

Frente à globalização e a expansão do comércio internacional, o mercado passou a estar cada vez mais exigente e o consumidor adquiriu novas preocupações, uma delas é a preocupação socioambiental que fez com que as empresas passassem a aderir novas mudanças de atitude. Até pouco tempo atrás os pressupostos da reponsabilidade socioambiental se resumiam em doações e campanhas comunitárias por parte das organizações, atualmente os pressupostos estão voltados para a criação de medidas que proporcionem qualidade de vida dentro e fora das organizações de forma humana, ética e ecologicamente responsável. E assim a empresa social e sustentável passa a ser sinônimo de bons negócios (TACHIZAWA; POZO, 2007).

Mediante as informações citadas anteriormente esse estudo se justifica, visando analisar a relação existente entre comércio internacional e desenvolvimento socioambiental mediante informações coletadas em estudos bibliográficos disponíveis na literatura nacional e também como forma de contribuição para a pesquisa bibliográfica nacional sobre a temática proposta uma vez que a mesma tem chamado atenção de pesquisadores timidamente. E assim chegasse a seguinte questão de pesquisa: Como se apresenta a relação existente entre comércio internacional e desenvolvimento socioambiental mediante informações coletadas em estudos bibliográficos disponíveis na literatura nacional?

A fim de responder essa indagação o presente estudo tem como principal objetivo, entender a relação existente entre comércio internacional e desenvolvimento socioambiental mediante informações coletadas em estudos bibliográficos disponíveis na literatura nacional. A metodologia adotada para a realização da pesquisa se constitui como uma pesquisa bibliográfica com informações coletadas no acervo bibliográfico nacional. 0 presente trabalho visa contribuir para a pesquisa científica do assunto em questão, servindo assim de base para futuras pesquisas mais aprofundadas sobre a temática e também para mostrar a importância da relação existente entre comércio internacional e desenvolvimento socioambiental.

A estrutura do trabalho está organizada em quatro seções. A primeira inclui a seção introdutória com a questão e objetivo de pesquisa. Na próxima seção são contemplados os procedimentos metodológicos. Logo após evidencia-se a revisão teórica, que aborda sobre Comércio Exterior e Comércio Internacional, Desenvolvimento Socioambiental e a Relação entre eles. A última seção se destina as considerações finais, descrevendo também as limitações e sugestões para futuras pesquisas.

\section{PROCEDIMENTOS METODOLÓGICOS}

A pesquisa demonstrará sua natureza exploratória uma vez que irá buscar auxiliar e compreender melhor uma situação para a elaboração de novas ideias, unificação de novos conceitos e ampliação de novos 
conhecimentos, envolvendo leitura de sondagem, tendo em vista localizar as informações, uma vez que já se tem conhecimento de sua existência. Parte-se do princípio de que um capítulo ou tópico trata de assunto que nos interessa, mas pode omitir o aspecto relacionado diretamente com o problema que nos preocupa (GIL, 1987; MARCONI; LAKATOS, 2003).

Ele irá optar ainda pela abordagem qualitativa, uma vez que o estudo qualitativo se aplica ao estudo da história, das relações, das representações, das crenças, das percepções e das opiniões, produtos das interpretações que os humanos fazem a respeito de como vivem, constroem seus artefatos e a si mesmos, sentem e pensam. Esse tipo de pesquisa reforça que o estudo compreende a logica interna de grupos, instituições e atores (MINAYO, 2006; VERGARA 2008). Seu procedimento será um estudo bibliográfico da relação existente entre comércio internacional e desenvolvimento socioambiental mediante informações coletadas em estudos bibliográficos disponíveis na literatura nacional utilizando-se de artigos, monografias, teses, livros, dentre outros meios disponíveis para finalidade de estudo.

Entende-se por pesquisa bibliográfica aquela que é feita com o intuito de levantar um conhecimento disponível sobre teorias, a fim de analisar, produzir ou explicar um objeto sendo investigado. A pesquisa bibliográfica visa então analisar as principais teorias de um tema, e pode ser realizada com diferentes finalidades (KAIMEN; CHIARA et al., 2008).

\section{REVISÃO TEÓRICA}

Este capítulo então apresenta um panorama das inúmeras facetas dos temas nos quais envolvem: Comércio Exterior e Comércio Internacional, Desenvolvimento Socioambiental e a Relação entre eles abordando conceitos e teorias para fins de estudo, procurando dar as bases que sustentarão o processo de pesquisa.

\subsection{COMÉRCIO EXTERIOR E COMÉRCIO INTERNACIONAL}

Desde os tempos dos antigos os povos do oriente médio começaram a desenvolver atos de troca de mercadorias entre os mesmo, configurando os primórdios do que chamamos hoje de comércio exterior. 0 Brasil há tempos pretérito esteve à margem do comércio exterior. Desde seu "descobrimento" quando o país se torna uma colônia de Portugal, firma um pacto colonial onde as trocas comerciais se resumiam ao envio de matérias primas para a metrópole e a compra de mercadorias manufaturadas provenientes da mesma (SZEZERBICKI et al.,2009).

Posteriormente as trocas internacionais só passaram a acontecer com a vinda da corte portuguesa para o Brasil no início do séc. XIX. Mesmo assim, os produtos comercializáveis sempre foram de origem agrícola, já que a indústria brasileira só se desenvolveria muito tempo depois. 0 comércio exterior é fundamental para a manutenção da economia e o desenvolvimento de um país, essa ferramenta foi implementada a partir da proclamação da independência que ocorreu em 1822. (SZEZERBICKI et al.,2009).

Na última década as exportações brasileiras apresentaram um crescimento significativo e uma mudança na sua estrutura. Esse crescimento e essa mudança verificada na estrutura estão relacionados ao processo de crescimento econômico, à expansão do comércio mundial e às estratégias comerciais que foram seguidas pela economia brasileira no passado. A partir do fim da década de 1980, os formuladores da política econômica brasileira começaram a introduzir algumas medidas de livre comércio, a fim de tornar a economia brasileira mais competitiva e moderna (HIDALGO; FEISTEL, 2012).

O Comércio Exterior trata das regras internas de cada país relacionadas ao Comércio Internacional, e também da padronização e da regularização dos produtos que são importados e exportados, com os procedimentos legislativos, administrativos, tributários e aduaneiros necessários para o cumprimento desses processos. Alguns dos principais órgãos que controlam o Comércio Exterior são o MDIC (Ministério do Desenvolvimento, Indústria e Comércio Exterior) e o SISCOMEX (Sistema Integrado do Comércio Exterior) (HORA, 2018).

A dinâmica do comércio exterior vai muito além do simples processo de compra e venda de mercadorias entre residentes e não residentes. Ela pode representar um elemento-chave sobre as condições de desenvolvimento de determinadas economias nacionais ou regiões. Uma região sujeita à influência do exterior pode utilizar-se do comércio com este, particularmente na sua capacidade de exportar, como um instrumento para o crescimento econômico, desde que tal atividade sirva de suporte para a expansão da região exportadora (MUNDURUCA; SANTANA, 2012). 
A expansão das exportações é capaz de exercer um efeito multiplicador sobre as atividades do mercado interno não exportador, impactando no setor terciário da economia local por meio da criação de demanda por serviços e, por conta disso, incrementando os níveis de renda e de emprego da população. As exportações, portanto, seria assim um indutor do crescimento econômico do país ou região, sobretudo em economias pequenas (MUNDURUCA; SANTANA, 2012).

0 comércio internacional por sua vez, refere-se às regras internacionais aplicadas a todos os países de forma homogênea, a fim de facilitar as negociações comerciais. São normas aplicadas a produtos e serviços e até os movimentos de capital. Essas regras são estabelecidas por meio de acordos entre os países e blocos econômicos, ou por intervenção de órgãos internacionais confiáveis como, por exemplo, a OMC (Organização Mundial do Comércio), a OCDE (Organização para a Cooperação do Desenvolvimento Econômico) ou a CCI (Câmara do Comércio Internacional) (HORA, 2018).

No decorrer do desenvolvimento do Comércio Internacional o fenômeno globalização foi fundamental para o avanço do que é caracterizado pela unificação do mercado em escala mundial, abrangendo a área de atuação das empresas num único mercado: o mercado global. Tal mercado é desenvolvido a cada dia através do desenvolvimento constante que ocorre nas operações de troca entre os países. Uma das organizações responsáveis por tais avanços é a OMC (Organização Mundial do Comércio) que vêm eliminando gradativamente as barreiras do livre comércio, a fim de estimular as empresas nas trocas internacionais (RIGHETTI; MICHEL, 2007).

o Comércio Internacional tem papel importante no desenvolvimento econômico e social de uma nação, ao que tange a um melhor padrão de vida de toda a população, e não simplesmente ao crescimento das indústrias de forma desatrelada aos fenômenos sociais. Estes fenômenos sociais promovem o crescimento da renda per capita da população decorrente do avanço eminente do Comércio Internacional (RIGHETTI; MICHEL, 2007).

Na medida em que o comércio internacional avança a sociedade capitalista contemporânea enfrenta importantes desafios para a construção de um modelo de desenvolvimento mais sustentável do ponto de vista econômico e socioambiental. Para lidar com os desafios, nessa trajetória de mudanças, muitos conceitos, práticas e estratégias vem sendo desenhadas pela gestão privada e pública na busca de uma maior eficiência e eficácia nas suas políticas sinalizando o surgimento de novos padrões na governança global (WISNIEWSKI; BOLLMANN, 2012).

\subsection{DESENVOLVIMENTO SOCIOAMBIENTAL}

No contexto das poderosas mudanças econômicas, políticas, culturais e ambientais que as sociedades contemporâneas vêm experimentando nas últimas décadas, o conceito "desenvolvimento" vem sofrendo sucessivas redefinições epistemológicas, ligadas a igualmente mutantes agendas político-econômicas. Apropriada e redefinida pelo movimento ambientalista a partir da década de 1970, a palavra "desenvolvimento", adjetivada pelo complemento "sustentável", significou crescimento econômico e ampliação da produção industrial durante as décadas de 1970 e 1980 (FONSECA, 2005).

A partir dos acontecimentos políticos econômicos internacionais do princípio dos anos 1990 e seus desdobramentos belicosos, o conceito "desenvolvimento" vem sendo entendido como: "equidade social", "erradicação da pobreza" e "participação popular", entre outros (FONSECA, 2005). O termo socioambiental por sua vez, refere-se aos problemas e processos sociais, tendo em conta sua relação com o meio ambiente. Trata-se da sociedade com o meio ambiente e da responsabilidade dos indivíduos por suas ações que afetam o ambiente (AURÉLIO, 2019).

Assim como o conceito de desenvolvimento, a organização da vida produtiva dos homens passou por diferentes estágios (comunismo primitivo, escravismo, feudalismo, mercantilismo, capitalismo que vigora até então). E, cada um desses estágios foi marcado por distintas formas de relação entre os homens e a natureza. Em formas de organização econômico-social pré-capitalista, na passagem do estado de animal ao de ser social, o homem buscava transformar a natureza, por meio do trabalho, para satisfazer suas necessidades de sobrevivência, criando objetos, instrumentos, produtos com valor-de-uso. 0 que permitiu essa transformação da natureza pelo homem foi sua capacidade teleológica, ou seja, a capacidade do homem de prefigurar o resultado de sua ação (NUNES, 2013).

A partir do desenvolvimento do mundo capitalista, onde a temática da globalização trouxe níveis de informação, avanços tecnológicos, bem como práticas de comercialização além das fronteiras dos países, mais problemas emergiram produzindo consequências em todo o processo. Uma nova ligação envolvendo 
teoria e prática torna-se necessária. Relações harmoniosas entre os seres humanos e destes com o meio ambiente são importantes a fim de atenuar a degradação do meio ambiente, bem como novos padrões de comportamento precisam ser postos em ação (FERNANDES; VASCOLCELOS; JUNIOR, 2014).

0 mundo vem passando, nos últimos anos, por profundas transformações de ordem econômica, política e social que, entre outras características, tem influenciado diretamente e indiretamente no papel do Estado e das empresas, bem como no relacionamento destes com a sociedade. Faz-se necessário a mudança paradigmática e um posicionamento crítico por parte da sociedade. Dessa forma, os negócios de hoje tem de lidar com uma economia cada vez mais globalizada, com a revolução tecnológica, uma proliferação de fontes de informações, um enorme crescimento no porte e no escopo dos negócios internacionais e sinais de crescentes danos ecológicos e desigualdades sociais (FERREIRA; GUERRA, 2012).

Um dos maiores desafios da humanidade neste século XXI é o da problemática ambiental. O quadro socioambiental atual demonstra que, a cada dia, os impactos causados pela ação do homem no meio ambiente e na sociedade são cada vez mais objetos de atenção, interesse e de cuidados. Diante desse cenário de risco global, faz-se necessário superar o reducionismo econômico que tem pautado os modelos de desenvolvimento atuais. 0 fortalecimento do debate ambiental vem provocando o aumento de pressões políticas, sociais e econômicas sobre os setores empresariais para que estes modifiquem seu modo de se relacionar com o meio ambiente, demonstrando um maior comprometimento socioambiental através de medidas de gestão e controle ambiental com ênfase em estratégias preventivas (SILVA; LIMA, 2013).

Com as organizações formando um campo extremamente fértil para a compreensão das dimensões possíveis do homem do século XXI, juntamente a sua vida girando em torno do trabalho e com as empresas ocupando um papel nervoso na vida de todos. A empresa tornou-se a instituição fonte de riquezas e cultura por excelência, destinada a resolver a maioria dos problemas com que defrontamos hoje. Desde modo, a complexidade das organizações impõe novas formas de gestão. Essa nova realidade faz com que as empresas invistam em outros atributos além de econômicos, tais como produtos ambientalmente corretos, relacionamento ético com todas as partes interessadas e ainda a valorização ligada à segurança e saúde dos funcionários, preservação ambiental e melhoria no cenário social (FERREIRA; GUERRA, 2012).

A responsabilidade socioambiental que faz parte do desenvolvimento socioambiental visa, portanto, criar uma harmônica relação entre a sociedade e as empresa que fazem parte do comércio nacional e internacional, onde estas passam a conceder meios para que a sociedade se desenvolva, seja nos aspectos sociais propriamente ditos, seja nos aspectos ambientais e até mesmo em termos econômicos, já que há geração de emprego "in loco" e geração de renda até mesmo através da criação de cooperativas. Nesse sentido, a relação entre sociedade e empresa funciona de forma positiva, pois além de promover ações através de projetos com benfeitorias, criam canais de comunicação com seu entorno a fim de escutar as críticas e sugestões da sociedade, objetivando a busca constante pela melhoria contínua dos processos nas organizações (LACERDA; MOURA, 2016).

\subsection{RELAÇÃO: COMÉRCIO INTERNACIONAL E DESENVOLVIMENTO SOCIOAMBIENTAL}

A sociedade vem tonando-se cada vez mais exigente no que diz respeito à observação de critérios ambientais na produção, visto que os problemas ambientais vêm se tornando mais críticos, com o esgotamento de matérias primas, a situação do abastecimento de água e a questão da destinação de resíduos e a preservação de bens culturais. Assim, as variáveis ambientais adquiriram considerável valor de mercado na economia globalizada, com maior procura por produtos ambientalmente corretos. A economia global de mercado, como existe atualmente, não protege o meio ambiente e não beneficia metade da população mundial. Um desafio básico é a criação de sistemas globais de governança que harmonizem o mercado de forma mais efetiva com a proteção ambiental e por consequência a vida humana (DRUMMOND, 2012).

O conceito de Responsabilidade Socioambiental tem como premissa o reconhecimento de que as decisões e os resultados das atividades das companhias alcançam um universo de agentes sociais muito mais amplo do que o composto por seus sócios e acionistas. Muitas das decisões e atividades dos negócios se refletem na comunidade local, meio ambiente e outros aspectos da sociedade. Em princípio, as empresas são responsáveis pelas consequências de suas operações, incluindo impactos diretos assim como externalidades a afetar terceiros, em toda a sua cadeia produtiva e no ciclo de vida dos produtos (ROBLES; BORGE; MACHADO, 2010).

A Responsabilidade Socioambiental guarda uma relação direta e progressiva com a o Desenvolvimento 
Sustentável e consequentemente com a Sustentabilidade. As empresas que trabalham dentro do padrão da Responsabilidade Socioambiental necessariamente são empresas sustentáveis ou que estão caminhando fortemente nessa direção, pois atuam de acordo com o tripé que norteia o desenvolvimento sustentável e a sustentabilidade: o ambiente, a sociedade e a economia (LIMA, 2015).

Nessa perspectiva, a responsabilidade socioambiental se apresenta como um tema cada vez mais importante no comportamento das organizações, exercendo impactos nos objetivos, estratégias e no próprio significado da empresa. As transformações socioeconômicas dos últimos anos têm afetado profundamente o comportamento de empresas até então acostumadas à pura e exclusiva maximização do lucro. Adotar posturas éticas e compromissos sociais com a comunidade pode ser um diferencial competitivo e um indicador de rentabilidade no longo prazo (GRAH B. et al.,2009).

As empresas ainda têm certa resistência em investir no setor ambiental, porém a gestão ambiental afeta a organização como um todo, podendo trazer diversos benefícios, apesar destes não serem imediatos. Entretanto, o tema está em foco e investir no meio ambiente pode auxiliar no desenvolvimento da empresa gerando benefícios comuns com a preservação do meio ambiente e por resultado, auxiliando na qualidade da vida humana (GRAH B. et al.,2009).

As questões ambientais estabelecem comportamentos e exigências que podem influir na produção e no comércio de várias maneiras. Os aspectos ambientais dos processos de produção, além de repercutirem indiretamente na competitividade industrial, podem condicionar a própria localização da indústria, em termos espaciais. Já os aspectos ambientais dos produtos em si podem, por sua vez, ter influência direta no comércio quando se levam em conta, por exemplo, custos de adequação a regulamentos e normas, ou a preferência de consumidores por produtos ambientalmente corretos, tanto plano nacional como no internacional. Os países e o setor produtivo estão caminhando para a completa internalização dos custos da proteção ambiental, implicando mudança nos padrões de produção e consumo e, consequentemente, de comércio (FILHO N.; COELHO, 2002).

Uma característica básica das relações internacionais nos últimos anos consiste na preocupação com a dimensão ambiental do desenvolvimento econômico. 0 assunto está presente em inúmeras arenas, tais como os debates a respeito do controle do efeito estufa e da preservação da biodiversidade. Mais recentemente, verifica-se que o foco das atenções está privilegiando uma nova temática: as relações entre o comércio internacional e o meio ambiente. A relevância que o tema está adquirindo deriva do papel central que as transações comerciais desempenham no cenário internacional, aliado ao fato de envolverem a intensa utilização dos recursos naturais (GUIMARÃES, 1994).

As questões socioambientais passaram a ser consideradas entre os determinantes da competitividade dos países e de suas empresas no comércio internacional. Por exemplo, a poluição gerada por uma empresa que não ultrapassar o território de um país seria um problema interno desse país. Porém, no comércio internacionalizado com baixas proteções tarifárias, esse problema torna-se uma fonte de competitividade, pois a empresa poderá praticar preços menores do que as que não geram poluição por investirem no seu combate (CAJAZEIRA; BARBIERI, 2007).

0 mesmo vale para as práticas de responsabilidade social, principalmente, as relacionado com o trabalho, próprias ou terceirizado. Daí a importância e a necessidade das normas e regulamentos técnicos estabelecendo exigências sobre essas matérias relacionadas com o comércio internacional. Caso contrário, estaria validando práticas socioambientais predatórias (CAJAZEIRA; BARBIERI, 2007).

No atual estágio de globalização, inúmeros requisitos ambientais e sociais foram e estão em definição. Trata-se de um momento que exige grande conscientização e intensa participação os setores envolvidos nesse processo. Como subsídio para debate, formulação e implementação de políticas, regulamentos, normas e procedimentos ambientais, que busquem favorecer o desenvolvimento socioambiental perante a comercialização internacional em beneficio de todos os seres humanos e do crescimento das nações de forma consciente (FILHO N.; COELHO, 2002).

\section{CONSIDERAÇÕES FINAIS}

O objetivo dessa pesquisa foi entender a relação existente entre comércio internacional e desenvolvimento socioambiental mediante informações coletadas em estudos bibliográficos disponíveis na literatura nacional. Portanto, constatou-se que o comércio internacional apresenta uma relação estreita com o meio ambiente e o ser humano, e está relação assegura o funcionamento do sistema econômico de um país, fomentando assim o crescimento das nações, intensificando a competitividade global e 
possibilitando a aquisição de mercadorias escassas em determinados locais. Entretanto na medida em que se tira do meio ambiente para produzir e comercializar através das relações internacionais se faz necessário o cuidado com meio no qual o homem é dependente.

A comercialização internacional depende da produção empresarial que por sua vez depende do ser humano e do que é extraído no meio ambiente, portanto, uma relação de inteira dependência que foi intensificada ao longo dos tempos devido à globalização e a mudança de pensamentos e necessidades humanas. 0 homem da atualidade em sua diversidade de papéis, enquanto consumidor, empresário, colaborador de uma empresa dentre outros se preocupa em adquirir bens, atingir resultados, agir de forma responsável para com o outro e cuidar do futuro do planeta.

Além de mostrar a importância da relação existente entre comércio internacional e desenvolvimento socioambiental uma vez que ambos apresentam relação de estreita dependência, pôde-se perceber através dos achados que empresas ainda precisam evoluir muito no que se refere ao pensamento e sua responsabilidade socioambiental que está intimamente ligada a reponsabilidade da empresa com a sociedade, com o meio ambiente de forma legal e econômica, criando as melhores alternativas para gerar com sustentabilidade e ética.

Através desse estudo pôde assim estabelecer que exista uma relação existente entre o comércio internacional e o desenvolvimento socioambiental uma vez que analisou, discutiu sua relação e mostrou sua importância. Mediante os achados, faz-se necessário reafirmar o que é citado na pesquisa de Roque (2010) onde em suas considerações discorre que, "os estudos sobre o comércio exterior e relações internacionais, apesar de sempre existirem, ainda necessitam de mais discussões e se é necessário que os profissionais atuantes dessa área estejam sempre atualizados nas novas regras de relações comerciais e nas mudanças de mercado, tanto interno quanto externo, mudanças estas, que os órgãos governamentais interferem significativamente". Entretanto, é possível afirmar que os caminhos até então percorridos apontam para o progresso.

A limitação desta pesquisa foi à insipiência de estudos análogos a este, pois embora seu campo de pesquisa possa aparentemente parecer amplo, ele se apresenta com informações escassas sobre a referida temática que vem sendo pesquisada timidamente ao longo dos anos, contudo, ressalta-se que tanto a questão como também os objetivos do estudo foram respondidos e alcançados respectivamente.

A contribuição dessa pesquisa está na colaboração para com a bibliografia da literatura nacional uma vez que apresenta um vigoroso e novo entendimento sobre o entendimento da à relação existente entre comércio internacional e desenvolvimento socioambiental comprovando assim sua importância de modo que futuras pesquisas mais aprofundadas sobre a temática sejam realizadas partindo desta. Sugere-se a comunidade acadêmica que invista em pesquisas semelhantes sobre o tema em questão a fim de cruzar informações e potencializar este trabalho. Sugere ainda que seja realizado um estudo multicaso de abordagem qualitativa propondo investigar a relação existente entre comércio internacional e desenvolvimento socioambiental em empresas que realizam comercializações internacionais de uma determinada região.

\section{REFERÊNCIAS}

[1] Aurélio, Dicionário online de Português. Conceito da palavra socioambiental. Disponível em: < https://www.dicio.com.br/socioambiental/>. Acesso em: 10/02/2019.

[2] Berto, Ándré Rogério. Barreiras ao comércio internacional. Congresso virtual brasileiro de administraçãoCovinbra 04, p.1-14, 2003.

[3] Cajazeira, Jorge Emanuel dos Reis; Barbieri, José Carlos. Normas internacionais de gestão socioambientais e comércio internacional: Uma análise do posicionamento dos países na normalização global para consolidar a sua estratégia comercial. Revista de Gestão Social e Ambiental- RGSA. São Paulo, v. 1, n. 3, p. 3-20,2007.

[4] Campos, Luís; Canavezes Sara. Introdução a Globalização. Instituto Bento Jesus Caraça Departamento de Formação da Cgtp-IN, p.1-165, 2007.

[5] Cassano, Francisco Américo. A teoria econômica e o comércio internacional. Revista Pesquisa \& Debate-P\&D. São Paulo, v. 13, n. 121, p. 112-128, 2002.

[6] Davanzo, Jean Naves; Oliveira, Felipe Flausino de; Fonseca, Alan Sales; Júnior, Pedro dos Santos Portugal; Portugal, Nilton dos Santos. O comércio internacional e a política protecionista brasileira: Uma análise no período recente. Simpósio de Excelência em Gestão e Tecnologia- Xvi Seget, p.1-12,2017. 
[7] Drummond, Maria Claudia B.O. Comércio internacional e desenvolvimento sustentável. Boletins do Legislativo, p.1-11. Disponíveis em <www.senado.gov.br/senado/conleg/boletim_do_legislativo.html>. Acesso em: $06 / 12 / 2018$.

[8] Fernandes, Vivian Duarte Couto; Vasconcelos, Andréa Costa van Herk; Junior, Valdir Machado Valadão. Gestão socioambiental em ongs: Um olhar a partir do desempenho empresarial e suas percepções como stakeholders de outras organizações. Revista Metropolitana de Sustentabilidade - RMS. São Paulo, v. 4, n. 2, p. 25-46, 2014.

[9] Ferreira, B. S. ;Gurerra, J. A. de P. Responsabilidade socioambiental: um olhar sistêmico em uma organização estatal. 8o Congresso Brasileiro de Sistemas. Revista Gestão \& Conhecimento. Ed. Especial, p.160-180, 2012.

[10] Filho, Luís Abel da Silva; Copreato, Francisco Luiz Cazeiro. Comércio internacional brasileiro: Considerações para os setores industriais e de commodities. Revista Espacios.Caracas, v. 38, n. 09, p.10, 2017.

[11] Filho, Nilton Fornasari; Coelho, Luciano Rodrigues. Aspectos ambientais do comércio internacional. Federação das Indústrias do Estado de São Paulo - Fiesp,Centro das Indústrias do Estado de São Paulo - Ciesp. p.1$129,2002$.

[12] Fonseca, Denise Pini Rosalem da. Discutindo os termos de uma equação de congruência: cultura e desenvolvimento sustentável. In: Gomes, Maria de Fátima Cabral e Pelegrino, Ana Izabel de Carvalho (Orgs.). Política de habitação popular e trabalho social. Rio de Janeiro: DP\&A Editora, p.115-128, 2005.

[13] Gil, Antonio Carlos. Métodos e técnicas da pesquisa social. 2. ed. São Paulo:Atlas,p.44-71, 1987.

[14] Grah, B. et al. A Atuação da Responsabilidade Social e Gestão Ambiental: Estudo de Caso em uma Prestadora de Serviço de Comércio Exterior. In: 3o Congresso UFSC de controladoria e finanças. Florianópolis, p.1-15, 2009.

[15] Guimarães, Paulo Cesar Vaz. Comércio internacional e desenvolvimento sustentável: Condicionantes para a ação empresarial. Revista de Administração de Empresas-Rae. São Paulo, v. 34, n. 5, p. 6-12, 1994.

[16] Hidalgo, Álvaro Barrantes; Feistel, Paulo Ricardo. Mudanças na Estrutura do Comércio Exterior Brasileiro: uma Análise sob a Ótica da Teoria de Heckscher-Ohlin. Estudos Econômicos -Revistas USP. São Paulo, v. 43, n.1, p.79$108,2013$.

[17] Hora, Fernanda Alzira Pereira. Diferença entre Comércio Internacional e Comércio Exterior. Matéria do site Portogente, disponível em < https://portogente.com.br/portopedia/102850-diferenca-entre-comercio-internacional-ecomercio-exterior>. Acesso em: 05/11/2018.

[18] Kaimem, Maria Júlia Giannasi; Chiara, Ivone Guerreiro Di; Carelli, Ana Esmeralda; Cruz, Vilma Aparecida Gimenes da. Normas de documentação aplicadas a área da saúde. E- Papers, Rio de Janeiro, p.15-26, 2008.

[19] Lacerda, Adriana dos Santos; Moura, Denise de. A responsabilidade socioambiental como estratégia de competitividade para as organizações da contemporaneidade. XII Congresso Nacional de Excelência em Gestão, Issn 1984-9354, p.1-16, 2016.

[20] Lima, Luiz Eduardo Corrêa. Responsabilidade Socioambiental: um conceito que veio para ficar. Site: Professor Luiz Eduardo, 2015. Disponível em:< https://www.profluizeduardo.com.br/2015/05/16/responsabilidadesocioambiental-um-conceito-que-veio-para-ficar/>. Acesso em: 10/02/2019.

[21] Marconi, Marina de Andrade, Lakatos, Eva Maria. Fundamentos da Metodologia Científica. 5. ed. São Paulo : Atlas, p. 22-225,2003.

[22] Minayo, M.C.S. Contradições e consensos na combinação de métodos quantitativos e qualitativos. In: 0 desafio do conhecimento: pesquisa qualitativa em saúde. 9 ed. São Paulo : Hucitec, p.54-76,2006.

[23] Munduruca, Danilo Felipe Viana; Santana, José Ricardo de. Comércio Exterior como Estratégia de Crescimento Econômico: Uma Proposta de Priorização de Produtos Exportáveis para a Economia Sergipana. Documentos Técnico-Científicos. v. 43, n. 03, p.612-630, 2012.

[24] Nunes, Letícia Soares. A questão socioambiental e a atuação do assistente social. Textos \& Contextos (Porto Alegre), v. 12, n. 1, p. 196 - 212, 2013.

[25] Ratto, Luiz. Comércio: Um mundo de negócios. 2.ed. 1 reimpr. Rio de Janeiro, Senac Nacional, p.12, 2009.

[26] Righetti, Renato César; Michel, Murillo. O comércio internacional como fonte geradora de desenvolvimento econômico e social do país. Revista científica eletrônica de administração - ISSN: 1676-6822, Ano VII .n 12 , Periódicos Semestral, p.1-6, 2007.

[27] Robles, Leo Tadeu; Borger, Fernanda Gabriela; Machado, Tania Regina de Oliveira. A Responsabilidade Socioambiental como Componente da Logística Integrada: O Caso da Exportação do Complexo Soja pela Bunge Alimentos S/A. XXXIV Encontro da Anpad. Rio de Janeiro, p.1-16, 2010.

[28] Roque, Leibi. Comércio internacional: um estudo das principais dificuldades encontradas pelas empresas brasileiras no comércio exterior. Revista Conteúdo. Capivari, v.1, n.3, p.20-30, 2010. 
[29] Silva, Danielly Ferreira; Lima, Gustavo Ferreira da Costa. Empresas e meio ambiente: contribuições da legislação ambiental. Revista Internacional Interdisciplinar- interthesis. Florianópolis, v.10, n.2, p. 334-359, 2013.

[30] Szezerbicki, Arquimedes da Silva; Diniz, Conrado de Mello; Gurski, Fábio; Sandrino, Samuel. Comércio exterior brasileiro. Cescage, p.1-10, 2009.

[31] Tachizawa, Takeshy; Pozo, Hamilton. Gestão socioambiental e desenvolvimento sustentável: Um indicador para avaliar a sustentabilidade empresarial. Revista Eletrônica de Prodema-Rede. Fortaleza,v.1,n.1,p.35-54, 2007.

[32] Vergara, Sylvia Constant. Relatórios de pesquisa em administração. 8. Ed. São Paulo: Atlas,p.45, 2008.

[33] Wisniewski, Marina Luiza Gaspar; Bollmann, Harry Albert. A responsabilidade socioambiental no contexto das relações entre mercado, estado e sociedade: Contribuições da constituição brasileira de 1988. Revista de Desenvolvimento Regional- Redes. Santa Cruz do Sul, v. 17, n. 1, p. 115 - 140 , 2012. 


\section{Capítulo 10}

Logística reversa do óleo de cozinha usado na cidade de Zé Doca - MA

\section{Neemias da Silva Nascimento}

Francisco Sousa Costa

Stênio Lima Rodrigues

Marali Silva Santos

João Vitor de Oliveira Sousa

Ana Carla Cavalcante das Chagas

Resumo: Logística Reversa (LR) é uma subárea da Logística Empresarial que possui as responsabilidades de planejamento, operação e controle dos fluxos materiais e de informações. A LR tem se tornado um importante campo de estudo ao longo das ultimas décadas. Os objetivos da pesquisa foram conhecer a percepção de duas empresas pesquisadas quanto a implementação/utilização da LR e identificar os motivos que as levam a implementar as práticas de LR. A metodologia adotada foi de estudo de caso múltiplo, com abordagem exploratória, os dados foram obtidos por meio de duas entrevistas realizadas com auxilio de um questionário semiestruturado, com questões abertas e fechadas. Depois de coletado os dados das empresas, fez-se uma análise comparativa entre as mesmas Os resultados apontaram a descrição da empresa; conhecimento em LR; conhecimento dos riscos do descarte; e a intenção de compra e implementação da LR. Ambas as empresas demonstraram ter sensibilidade com o meio ambiente e com a necessidade emergente implementar práticas de LR.

Palavras-Chave: reuso; sustentabilidade; meio ambiente. 


\section{INTRODUÇÃO}

O conceito de logística reversa (LR) vem sendo construído ao longo dos anos, já que é um processo dinâmico, que insere um conjunto de conhecimentos, habilidades e atitudes a serem desenvolvidos de acordo com as exigências legais e práticas sociais de um país (MARCHI, 2011). Para Gonçalves e Marins (2006) a definição que melhor se adequa para logística reversa é o que é definido pela Reverse Logistics Executive - RLEC, que reconhece como um processo de planejamento, implementação e controle, do fluxo de matérias-primas, da produção e do produto acabado (e seu fluxo de informação), do ponto de consumo até a origem, com o fim de recapturar valor ou oferecer um destino ecologicamente adequado.

Diante da definição do que é a LR, torna-se claro como se dá a compreensão da mesma quando se trata no contexto do uso do óleo de cozinha. Para que o retorno do óleo de cozinha como matéria-prima seja possível, é preciso a adoção de uma série de procedimentos inter-relacionados, entre eles: acondicionamento, coleta, armazenagem e movimentação até o local de produção (GODOY et al., 2010).

Segundo Pitta Junior et al. (2009), devido a um crescente interesse profissional e de pesquisadores, quanto a valorização econômica da cadeia produtiva e diminuição de custos dos produtos finais almejados, na relação entre a matéria prima virgem e a reciclada (por exemplo, a soja e o óleo de cozinha reutilizado, respectivamente), a LR surge como uma forma de solucionar duas dificuldades: a de preservação ao meio ambiente e diminuição de custos, e consequente a isso valorização da empresa em questão, diante ao público consumidor.

Muitas vezes o ciclo convencional do resíduo de óleo advém em seu início na plantação da oleaginosa, em seguida a extração do óleo, as adequações para o consumo humano (caracterização físico química, purificação para a retirada de impurezas, etc.), por fim o produto está pronto para a venda. Tal ciclo tem uma característica aberta, visto que não ocorre volta do produto até o produtor.

0 problema perante esse ciclo começa quando o resíduo de óleo gerando não tem mais utilidades alimentícias, visto que para uma parte populacional a educação ambiental e a conscientização não são uma realidade, o que nesse caso gera um descarte irregular de resíduos. Sempre que o resíduo é descartado de maneira irregular, acaba gerando alguns problemas específicos, dentre eles destaca-se a impermeabilização do solo, ou seja, não ocorre o ciclo natural da água, prejudicando o ciclo de vida das plantas, que necessitam de absorver a água presente no solo. Quando esse resíduo é despejado na água, o problema é parecido, sendo o óleo menos denso que a água, acaba gerando uma camada superficial e impendido a entrada de luz e oxigênio, afetando cadeia alimentar aquática.

Na ausência de estudos voltados a LR na cidade de Zé Doca, esta pesquisa vem estudar tal problemática quanto no município, desta forma, buscando investigar a destinação dos resíduos de óleos gerados por pequenas empresas.

O presente trabalho tem por objetivos: conhecer a percepção das empresas pesquisadas quanto a implementação ou utilização da LR e identificar que motivos levariam as empresas a implementar práticas de LR em seus estabelecimentos.

O estudo se configurou como um estudo de caso múltiplo em duas empresas. Os procedimentos metodológicos utilizados consistiram em uma entrevista simples, onde se adquiriu as informações necessárias para o reconhecimento da utilização ou não da logística reversa nas empresas estudadas. Após realizadas as entrevistas, fez-se uma análise e um traçado de perfil individual das empresas, a partir daí fez-se um comparativo nos resultados adquiridos, tanto entre as empresas quanto com a bibliografia.

Segundo o Serviço Brasileiro de Apoio às Micro e Pequenas Empresas (SEBRAE), as MPEs, são a grande maioria dos estabelecimentos comerciais brasileiros (em torno de $99 \%$ ), portanto merecem especial atenção na realização de pesquisas cientificas que venham disseminar boas práticas e necessidades de melhorias nesse segmento (SEBRAE, 2017).

Tendo em vista que a importância das MPEs para a economia do que se, verifica-se a necessidade de pesquisas que identifiquem gargalos e apontem soluções para este segmento. A pesquisa aqui proposta segue essa linha de raciocínio e proporcionará um instrumento de diagnóstico, com a viabilidade e os benefícios que adoção de práticas de LR podem proporcionar para essas empresas.

0 presente artigo, além desta introdução, tem uma estrutura dividida em mais quatro seções. Na segunda estão as discussões entre autores onde se aborda assuntos como a logística reversa o óleo de cozinha, assim como a Política Nacional de Resíduos Sólidos - PNRS. Na terceira são apresentados os procedimentos metodológicos utilizados para a realização da pesquisa. Na quarta, encontra-se os resultados apoiados na bibliografia. Por último, na quinta seção, apresenta-se as considerações finais. 


\section{REFERENCIAL TEÓRICO}

\subsection{LOGÍSTICA REVERSA DE ÓLEO DE COZINHA}

Segundo a SABESP (2014), se descartado de forma irregular em suas diversas formas, o resíduo de óleo de cozinha quando passa pelo caminho da encanação, se acumula nas encanações que por consequência retém outros materiais sobre si.

Os óleos comestíveis são os mais utilizados diariamente e os mais presentes na vida dos consumidores. Segundo Castellanelli (2007) e Paraíso (2008), em especial aos utilizados para fins de fritura, é notável que o conhecimento e a informação não se fazem presente, a consequência disso é o que muitas vezes é feito posteriormente ao uso de tais produtos, que tendem a ser despejados em rios, riachos, vasos sanitários e pias, o destino final desses resíduos, por intermédio de tubulações, chega a ser inclusive os oceanos, o que acaba gerando "[...] o encarecimento dos processos das Estações de Tratamento além de acarretar na poluição do meio aquático [...]".

Ainda segundos autores, ainda existem outras problemáticas ambientais geradas, já que o óleo possui uma baixa densidade em relação a água tende a não se misturar a mesma, o que acaba gerando uma espécie de superfície, gerando bloqueio da oxigenação e dificuldade na entrada de luz, tal fato compromete a cadeia alimentar e a vida no ecossistema aquático, causando desequilíbrio.

Desta maneira, surge a necessidade de adoção de estratégias em prol de informar a população sobre os malefícios que estas atitudes provocam e a maneira correta de se dispor tal resíduo. Aproveitar, tratar ou destinar os resíduos sólidos e líquidos urbanos é uma responsabilidade da qual a sociedade não tem como se esquivar. Sendo uma questão de cidadania propor alternativas para que estes rejeitos causem o menor impacto possível ao meio ambiente (CASTELLANELLI, 2007).

Os resíduos de óleo de cozinha gerados, segundo Pitta Junior et al. (2009), têm a possibilidade de servir como matéria prima para a produção "[...] de diversos produtos, tais como biodiesel, tintas, óleos para engrenagens, sabão, detergentes, entre outros [...]".

Segundo Senado Notícias (2018), a Política Nacional de Resíduos Sólidos (Lei 12.305), sanção que entrou em rigor na data de 02 de agosto de 2010, e que é regulamentada pelo Decreto 7.404 de 23 de dezembro de 2010, afirma que "[...] as pessoas físicas e jurídicas passaram a ser responsáveis pela geração e pelo gerenciamento dos resíduos sólidos (BRASIL, 2010)".

A definição dada pela PNRS sobre logística reversa se encontra no Capítulo II, Art. 3oㅡ,

XII, onde é reconhecido como um "[...] instrumento de desenvolvimento econômico e social caracterizado por um conjunto de ações, procedimentos e meios destinados a viabilizar a coleta e a restituição dos resíduos sólidos ao setor empresarial, para reaproveitamento, em seu ciclo ou em outros ciclos produtivos, ou outra destinação final ambientalmente adequada (BRASIL, 2010).

0 notável é que nem na definição de logística reversa e na PNRS estão incluídos o resíduo de óleo de cozinha. Porém, ainda segundo Senado Notícias (2018) o Projeto de Lei (PLS 75/2017) busca considerar e incluir os resíduos de óleo de cozinha como relevantes para que assim possam-se buscar destinos mais efetivos e ambientalmente mais sustentáveis.

Surge a seguinte questão: por quais motivos o óleo de cozinha deixa de ser recolhido em grande escala e retornado ao ciclo logístico direto? Assim, é possível afirmar que se precisa de uma análise das práticas utilizadas pelas empresas coletoras do produto no momento do descarte dos consumidores e nas legislações referentes aos resíduos, já que esses são os fatores de maior influência nas práticas de logísticas reversas (PITTA JUNIOR, 2009).

No Brasil, segundo Santos (2009), anualmente são descartados em torno de "[...] 9 bilhões de litros de óleo de cozinha por ano [...]", porém, apenas uma pequena parcela de $2,5 \%$ é reciclada de fato, "[...] ou seja, separado, coletado, filtrado e reinserido na cadeia produtiva. E para atender a diversos seguimentos da indústria [...]", em São Paulo 1 milhão de litros de resíduos ao mês são reciclados. Mesmo sendo um valor tão alto, "[...] representa menos que 5\% de todo o descarte, ou seja, 95\% ainda não é reciclado [...]".

É bem notável a carência de projetos que estimulem de forma efetiva a cadeia logística do óleo de cozinha, tanto de quem compra e/ou fornece/vende. Mesmo assim, é possível ver iniciativas que buscam contribuir ambientalmente e buscar benefícios tanto para empresa quanto para a população.

Uma das alternativas de aproveitamento do resíduo de óleo seria a produção de biodiesel, que relativamente seria bem mais sustentável, já que produzir biodiesel a base de grandes cultivos de soja, por 
exemplo, acaba por ser um impasse, visto que muda o destino de alimentação para combustível uma boa alternativa é que a própria empresa geradora de resíduo usufrua do biodiesel a base do próprio resíduo (OLIVEIRA et al., 2014).

Um exemplo de sucesso, segundo a BiodiselBR (2015), no reuso do óleo de cozinha residual em um ciclo fechado dentro da própria empresa é a MC Donald's que no ano de 2015 os caminhões da rede chegaram a rodar em torno de 5 milhões de $\mathrm{km}$ (com biodiesel produzido a partir do óleo residual da própria rede), o equivalente a 125 voltas completas na terra.

Essa iniciativa além da contribuição financeira, contribuiu também ambientalmente para uma diminuição de $26 \%$ de gás carbônico na cadeia de abastecimento dos restaurantes, o que seria em torno de 4,37 milhões de toneladas de gás carbônico (GLOBO RURAL, 2010; BIODISELBR 2015).

\section{METODOLOGIA}

A então pesquisa se caracteriza por um estudo de caso qualitativo, que segundo Prodanov e Freitas (2013), "[...] consiste em coletar e analisar informações sobre determinado indivíduo, uma família, um grupo ou uma comunidade, a fim de estudar aspectos variados de sua vida, de acordo com o assunto da pesquisa".

Para Yin (2005), seria de forma empírica uma investigação que procura saber de um fenômeno contemporâneo dentro do seu próprio contexto real sem a intervenção do investigador, "quando os limites entre o fenômeno e o contexto não estão claramente definidos", parte-se do princípio de que os dados coletados fornecem muitas informações sobre o que se estuda.

Foram escolhidas apenas duas empresas, destas se extraiu o máximo de informações possíveis que melhor representasse as demais, o critério utilizado na escolha foi a relevância destas, na cidade. Por ser uma pesquisa precursora sobre o assunto, a investigação tem por característica ser exploratória, visto que busca conhecer e entender mais sobre a logística reversa do óleo de cozinha em Zé Doca - MA.

Segundo Prodanov e Freitas (2013), uma pesquisa exploratória configura-se por se encontrar na fase preliminar e em como finalidade proporcionar mais informações sobre o assunto que se pretende investigar, possibilitando sua definição e seu delineamento, isto é, facilitar a delimitação do tema da pesquisa; orientar a fixação dos objetivos e a formulação das hipóteses ou descobrir um novo tipo de enfoque para o assunto. Assume, em geral, as formas de pesquisas bibliográficas e estudos de caso.

A cidade de Zé Doca está situada na região do Alto Turi, no estado do Maranhão, região esta que possui uma grande quantidade de estabelecimentos de lanches que necessitam do uso contínuo do óleo de cozinha, que por consequência gera uma grande quantia de resíduos desse produto, diante de tal surge/surgiu a necessidade de conhecer sobre que o é feito com esses resíduos depois de cumpridos com suas finalidades. As empresas estão localizadas na referida cidade, a empresa 01 é uma lanchonete que oferece como produto principal coxinha, além de outros produtos que em sua grande maioria das vezes são servidos como acompanhamento.

A empresa 02 tem seus produtos variados, desde lanche até refeição, e sua principal são os produtos, que atendem um público interessado em uma comida mais saudável, com baixa utilização ou isento de óleo de cozinha.

Os participantes da pesquisa que se submeteram as entrevistas tiveram acesso a um termo de consentimento onde continham todas as informações em relação ao que seria feito com os dados obtidos e sobre a preservação do sigilo das empresas, ambas as empresas não tiveram resistência em assinar os termos.

Feito a coleta dos dados, considerou-se as seguintes categorias: descrição da empresa, conhecimento em LR, conhecimento dos riscos do descarte e intenção de compra e implementação da LR. Após essa etapa, realizou-se uma analise comparativo entre as empresas. 


\section{APRESENTAÇÃO E DISCUSSÃO DOS RESULTADOS}

\subsection{CARACTERIZAÇÃO DAS EMPRESAS}

\subsubsection{DESCRIÇÃO EMPRESA 01 - EMPRESA DE LANCHES}

A empresa 01 é uma lanchonete situada na cidade de Zé Doca - MA, na região do Alto Turi, que atua na venda de coxinha como produto principal, além de outros que em sua grande maioria são oferecidos como acompanhamento.

Sua atuação no mercado é de três anos, porém, especificamente na cidade de Zé Doca o tempo são de apenas dois anos. A quantidade de empregados que atuam no funcionamento da empresa são sete funcionários, distribuídos entre cozinheiros, entregadores e caixas.

Em relação à reciclagem de resíduos de óleos utilizados pela empresa, constatou-se que não são descartados no meio ambiente e que todos são doados para terceiros, para que possam ser reciclados, na produção de sabão. A utilização mensal, em média, de óleo, para a produção de coxinha, é em torno de 20 litros.

\subsubsection{CONHECIMENTO EM LOGÍSTICA REVERSA}

Ao tratar sobre os benefícios possíveis em que a logística reversa poderia proporcionar, obteve-se como resposta que a ajuda ao meio ambiente era um ponto crucial na contribuição da preservação ambiental, visto que o descarte irregular acarreta diversos problemas. 0 que se pode notar é que os fatores influenciadores dessa ação foi a preocupação em contribuir ao meio ambiente e possíveis futuras punições legais a empresa.

Para saber sobre responsabilidade compartilhada a resposta obtida foi de que o termo era desconhecido, porém relatou uma parceria com a delegacia de polícia local, onde garrafas pet's são doadas para fins produtivos, de onde se resultam vassouras.

\subsubsection{CONHECIMENTO DOS RISCOS DO DESCARTE}

Quanto ao que poderia acontecer em relação a certos riscos de descartes irregulares do óleo de cozinha e gorduras poderia gerar, a breve resposta foi de que conhecia e estava ciente quanto ao assunto, além de afirmar que tal ato pode ocasionar a poluição do meio ambiente. Sobre possíveis utilizações do resíduo de óleos e gorduras gerados depois que a função alimentícia não fosse mais possível, a resposta obtida foi de que há o desconhecimento sobre tal.

\subsubsection{INTENÇÃO DE COMPRA E IMPLEMENTAÇ̃̃O DA LOGÍSTICA REVERSA}

Sobre a intenção de consumo e até percepções em relação a produtos que passaram no processo de logística reversa, o obtido foi de que a opção "com certeza compraria" foi a que melhor se encaixava no grau de intenção.

Além disso, foi relatado que o próprio estabelecimento faz uma parceria com terceiros para a produção de sabão líquido a partir dos resíduos de óleo que são doados, tais são representantes de uma casa de apoio para reabilitação de alcoólatras.

A empresa já recicla através da parceria com terceiros, recolhendo de maneira espontânea, regular e mais sustentável o óleo de cozinha, sabendo disso se buscou saber sobre as possibilidades da implementação da logística reversa no negócio por meios legais, a resposta obtida foi que "sim, com certeza!".

Buscou-se saber também sobre o grau de interesse em relação a reciclagem do óleo de cozinha, depois de ter se tornado resíduo, a reposta mais adequada obtida foi a de que "já recicla", apesar de que o processo de reciclagem ocorre por meio de terceiros. 


\subsubsection{DESCRIÇÃO EMPRESA 02 - LANCHONETE FITNESS}

A segunda empresa é caracterizada como micro e pequena empresa, atuante, também, no ramo de alimentação na venda de lanche, porém, além de lanche oferece também refeição, seu principal diferencial é o de produtos fitness, situado em Zé Doca - MA, na região do Alto do Turi.

Está no mercado há mais de dois anos. Já as dificuldades encontradas pela empresa na hora de oferecer seus produtos estão na parte da entrega do mesmo, o motivo para tal: determinados endereços que acabam dificultando; e a infraestrutura da cidade onde está alocada a empresa, que em determinados momentos não contribui.

A quantidade de colaboradores atuantes é de cinco ao todo. Sobre o que acontece com os resíduos do óleo, se este é submetido a algum processo de reciclagem, a resposta foi negativa, ou seja, na empresa não há nenhum tipo de reciclagem do óleo, e o quanto de resíduo é produzido mensalmente também, a justificativa está justificado no produto: uma alimentação mais saudável. Ou seja, não tendo a necessidade de fazer muito uso do óleo de cozinha, a média de uso mensal está em torno de 3 litros.

\subsubsection{CONHECIMENTO EM LOGÍSTICA REVERSA}

Apenas o termo "logística reversa" é desconhecido aos proprietários do estabelecimento. Já em relação a responsabilidade compartilhada o termo já é conhecido, e o que consideram ser, também, é o compartilhamento de responsabilidades entre os funcionários.

\subsubsection{CONHECIMENTO DOS RISCOS DO DESCARTE}

Em relação aos riscos do descarte irregular do óleo de cozinha e gorduras, constatou- se que o conhecimento sobre o assunto era pouco, porém afirmou que o reuso do mesmo, para fins alimentícios não é aconselhável. Quanto as possibilidades do reuso do óleo ou da gordura para alguma utilidade que não fosse o descarte, a reposta foi de que com esse resíduo existe a possibilidade de produzir sabão.

\subsubsection{INTENÇÃO DE COMPRA E IMPLEMENTAÇÃO DA LOGÍSTICA REVERSA}

0 grau de interesse, caso fosse exposto a tal, de compra de um produto que já estivesse passado por todo um processo de logística reversa, a alternativa que melhor se adequou foi a de "com certeza compraria".

Quanto a implementação da LR, o que se obteve foi novamente uma negativa justificada pelo uso mínimo do óleo de cozinha, visto que devido a isso a implementação para o óleo, não tem qualquer necessidade, porém, caso fosse necessário, a implementação seria uma opção. A mesma negativa aconteceu quando questionado sobre o grau de interesse em reciclar os resíduos do óleo de cozinha, a opção que melhor se adequou foi a de "nenhum interesse".

\subsection{ANÁLISE COMPARATIVA DOS DADOS}

\subsubsection{COMPARAÇÃO DESCRITIVA DAS EMPRESAS}

Ambas as empresas são micro e pequenas empresas que estão em Zé Doca - MA, com uma média de 2 anos, atuam no ramo da alimentação, especificamente no de lanche, com exceção da empresa 02 que além de lanche oferece refeições.

Das dificuldades encontradas a empresa 02 ressalta a infraestrutura da cidade e a localização de alguns endereços, o que afeta no serviço delivery, já a empresa 01, não relatou nenhum problema sobre tal, pois não faz uso do serviço de entregas. Nota-se uma discrepância considerável entre as empresas em relação ao consumo do óleo de cozinha, justificado pelo produto que oferecem.

\subsubsection{PERCEPÇÃO SOBRE A LOGÍSTICA REVERSA DAS EMPRESAS}

Quanto ao entendimento sobre logística reversa, ambas afirmaram que desconheciam o termo e não tinham entendimento algum sobre, o que dá a razão a Gonçalves e Chaves (2014), que afirmam sobre o desconhecimento, tanto da população quanto de empresas, em relação a informações sobre o assunto. 
Porém, quando questionado quais os benefícios possíveis na adoção de tal, a empresa 02 não declarou algo jus ao questionamento, já a empresa 01 citou a contribuição com o meio ambiente, o que segundo RevLog (2012), se justifica pelo aumento da conscientização dos consumidores, e o conhecimento do que certas atitudes acarretam ao meio ambiente.

Sobre responsabilidade compartilhada, obteve-se respostas distintas, a empresa 01 afirmou desconhecer o termo, mas citou uma parceria que exerce com a delegacia de polícia local, onde são doadas garrafas pet's para que os presos produzam vassouras. Já a empresa 02 considerou que responsabilidade compartilhada seria, também, o compartilhamento de responsabilidades entre os funcionários no funcionamento da empresa.

\subsubsection{RISCOS DO DESCARTE PERCEBIDO PELAS EMPRESAS}

Para saber sobre os conhecimentos dos riscos que o descarte do óleo de cozinha poderia trazer a empresa 01 afirmou que o descarte irregular poderia acarretar na poluição ao meio ambiente, já a empresa02 afirmou ter pouco conhecimento sobre, mas complementou dizendo que o reuso para fins alimentícios não causa danos à saúde.

Segundo Gonçalves e Chaves (2014), há a necessidade de reduzir o impacto ambiental pela expansão do consumo e consequente geração de resíduos sólidos, para isso os processos logísticos surgem como solução, pois além de benefícios ambientais, gera benefícios econômicos e sociais.

Ao o contrário do que diz a literatura as empresas investigadas não se encaixam no quesito de desinformação em relação aos resíduos do óleo de cozinha. Apesar disso, abre-se possibilidades para uma investigação mais ampla e comparativa, para saber das empresas pesquisadas, se estas também se sensibilizam assim como as empresas investigadas. A fim de saber sobre possíveis soluções para óleos e gorduras que não seja o descarte e além da percepção das empresas em relação a isso, obteve-se que a empresa 01 desconhece qualquer fim que não seja o descarte, já a empresa 02 afirma que a produção de sabão é uma solução.

Notou-se que a empresa 01 afirmou não saber o que fazer com os resíduos, sendo assim ela adota parcerias com terceiros que encontram um destino adequado aos resíduos. Quanto a empresa 02, mesmo não tendo a necessidade do uso da logística reversa para o óleo de cozinha, tanto por vias legais ou de forma voluntária, demonstrou uma possível solução.

\subsubsection{INTENÇÃO DE COMPRA E IMPLEMENTAÇÃO}

Ambas as empresas afirmam que com certeza comprariam algum produto que fosse resultado de um processo logístico reverso. A empresa 01 ainda citou a parceria com terceiros de uma casa de reabilitação de alcoólatras, para quem são doados os resíduos de óleo e assim produzirem sabão líquido.

0 que motiva a empresa 01 a implementar a logística reversa são dois dos itens propostos por RevLog (2012), os benefícios econômicos de usar produtos devolvidos no processo de produção em vez de pagar pelos altos custos de eliminação e a crescente consciência ambiental. A referida empresa acaba empregando um papel importante no sentido de conscientização, ou seja, uma influência mútua entre seus colaboradores com iniciativa partida dela mesmo.

Quanto a implementação da logística reversa por meios legais, a empresa 01 afirma que sim, com certeza consideraria. Em contrapartida a empresa 02, devido ao que oferece não apresentar um uso considerável do resíduo de óleo, a mesma desconsidera. Segundo RevLog (2012), um dos principais motivos da implementação da logística reversa é a conscientização ao meio ambiente que cada vez mais vem ganhando força e influenciando em processos decisórios nas empresas. Apesar de a empresa 02 não considerar a implementação do ciclo, percebe-se mesmo assim que há uma sensibilização caso fosse necessário. Em relação ao grau de interesse sobre a reciclagem do óleo de cozinha a empresa 01 afirma que já recicla, a empresa 02 afirma não ter interesse algum já que não há resíduos produzidos do óleo de cozinha. 


\section{CONSIDERAÇÕES FINAIS}

Ambas as empresas estudadas foram MPEs que atuam no ramo de lanche (com exceção da 01 que também oferece refeição). Notou-se dificuldades em ambas as empresas quanto ao que poderia ser LR na prática, foi notório observar que a empresa 01 apenas não conhecia nem mesmo o termo LR, mesmo implementando práticas de reuso e destinação adequada de resíduos. As possíveis punições e preocupação com o meio ambiente eram os motivos para a o uso espontâneo da LR na a empresa 02, bem como a necessidade de implementação é desnecessária, porém a preocupação com o meio ambiente foi evidente.

Para ambas as empresas, notou-se que dependendo do que é feito com os resíduos do óleo de cozinha há algumas consequências, para a empresa 01 o meio ambiente é afetado pela poluição, já para a 02, o reuso alimentício não é aconselhável. Tratando-se de possíveis soluções que não seja o descarte, ambas adotam e/ou possuem conhecimento sobre tal. Para a implementação da logística reversa a empresa 01 já atua de forma espontânea, para empresa 02 o interesse só é válido na presença de necessidade.

No que compete as limitações presentes neste estudo, identificou-se o tempo reduzido no desenvolvimento pesquisa e o espaço amostral pequeno (apenas 2 empresas de uma cidade). Para futuros trabalhos surge a necessidade de aumento da quantidade de amostras (número de empresas), para se ampliar a visão ao se conhecer por exemplo o perfil e benefícios da implantação da LR por setor.

\section{REFERÊNCIAS}

[1] Brasil. Lei no 12.305, de 02 de agosto de 2010. Institui a Política Nacional de Resíduos Sólidos; altera a Lei 9.605, de 12 de fevereiro de 1998; e dá outras providências. Diário Oficial da União, Brasília, 02 ago. 2010. Disponível em: <http://www.planalto.gov.br/ccivil_03/_ato2007- 2010/2010/lei/l12305.htm> Acesso em: 12 Mai. 2019.

[2] Brasil. Projeto de Lei (PLS 75/2017). Senado Notícias, 2017. Disponível em <https://www25.senado.leg.br/web/atividade/materias/-/materia/128531>. Acesso em 10 de jan. de 2019.

[3] Brasil. Política Nacional de Resíduos Sólidos (Lei 12.305). Senado Notícias, 2018. Disponível em <https://www12.senado.leg.br/noticias>. Acesso em 25 de jan. de 2019.

[4] Castellanelli, C. A. et al. Óleos Comestíveis: O Rótulo das Embalagens Como Ferramenta Informativa da Correta Destinação Pós Uso. I Encontro de Sustentabilidade em Projeto do Vale Do Itajaí. 2007. Disponível em <https://ensus2007.paginas.ufsc.br/files/2015/08/\%C3\%93leos-Comest\%C3\%ADveis-O-R\%C3\%B3tulo-dasEmbalagens-como-Ferramenta-I1.pdf>. Acesso em 25 de jan. de 2019.

[5] Gonçalves, M. F. S; Chaves, G. de L. D. Perspectiva do Óleo Residual de Cozinha (ORC) no Brasil e suas dimensões na Logística Reversa. Espacios. Espírito Santo, v. 35,n.8,p. 16,mai/jun.2014.Disponívelem <http://www.revistaespacios.com/a14v35n08/14350816.html >. Acesso em $11 \mathrm{de}$ fev. de 2019.

[6] Gonçalves, M. E.; Marins, F. A. S. Logística Reversa numa empresa de laminação de vidros. Gestão \& Produção, São Paulo, v. 13, n.3, p. 397-410, set./dez. 2006. Disponível em <http://www.scielo.br/pdf/gp/v13n3/03.pdf>. Acesso em: 12 de mai. de 2019.

[7] Godoy, P. 0; Oliskovicz, K; Bernardino, V. M; Chaves, W. R; Consciência Limpa: Reciclando o Óleo de Cozinha. Anuário Da Produção de Iniciação Científica Discente. v. 13, n. 17, p. 205-2017, jun.,2010. Disponível em <https://repositorio.pgsskroton.com.br/bitstream/123456789/1156/1/artigo\%2015.pdf>. Acesso em 12 de mai. de 2019.

[8] Marchi, C. M. D. F. Cenário Mundial dos Resíduos Sólidos e o Comportamento Corporativo Brasileiro Frente à Logística Reversa. Perspectivas em Gestão \& Conhecimento, João Pessoa, v. 1, n. 2, p. 118-135, jul./dez. 2011. Disponível em <http://periodicos.ufpb.br/ojs2/index.php/pgc>. Acesso em 12 de mai. de 2019.

[9] Oliveira, R. B. de et al. Sustentabilidade Ambiental e Logística Reversa: Análise das Redes de Reciclagem de Óleo de Cozinha na Região Metropolitana de São Paulo. Revista do Mestrado em Administração e Desenvolvimento Empresarial da Universidade Estácio de Sá, ano 14, v.18, n.2, p.115-132, mai./ago. 2014. Disponível em <http://revistapuca.estacio.br/index.php/admmade/article/viewFile/683/523>. Acesso em 12 de mai. de 2019.

[10] Paraíso. Programa de coleta seletiva de óleo de cozinha usado. Disponível em <http://www.ssparaiso.mg.gov.br/>. Acesso em: 12 de mai. de 2019.

[11] Pitta Junior, O. S. R.; Neto, M. S. Nogueira; Sacomano, J. B.; Lima, J. L.A. Reciclagem do Óleo de Cozinha Usado uma Contribuição para Aumentar a Produtividade do Processo. 2nd International Workshop - Advances in Cleaner Production. Key Elements For A Sustainable World: Energy, Water And Climate Change. Brazil: São Paulo, May 20th22nd, 2009. Disponível em <https://limpezapublica.com.br/textos/m._s._nogueira_-_resumo_exp.pdf>. Acesso em 15 de jan. de 2019. 
[12] Prodanov, Cleber Cristiano; Freitas, Ernani Cesar de. Metodologia do trabalho científico. $2^{\text {a }}$ ed. - Novo Hamburgo: Freevale, 2013.

[13] Revlog. The European Working Group on Reverse Logistics. Why reverse logistics?. 2009. Disponível em: <http://www.fbk.eur.nl/OZ/Revlog/Introduction.htm>. Acesso em 25 de jan de 2019.

[14] Rodrigues, F. McDonald's rodou 5 milhões de km com biodiesel puro. BiodieselBr, 2015. Disponível em . Visto em 12 de mai. de 2019.

[15] Sabesp. Reciclagem de óleo. Companhia de Saneamento Básico do Estado de São Paulo - Sabesp, 2014. Disponível em <http://site.sabesp.com.br/site/interna/Default.aspx?secaoid=82>. Acesso em 12 de mai. de 2019.

[16] Santos, R. S. Gerenciamento de resíduos: coleta de óleo de cozinha. Trabalho de Conclusão de Curso em Tecnologia em Logística, Faculdade de Tecnologia da Zona Leste, São Paulo, 2009.

[17] Sebrae. Sondagem conjuntural dos pequenos negócios. Serviço Brasileiro de Apoio a Micro e Pequenas Empresas,2017.Disponível em <https://www.sebrae.com.br/Sebrae/Portal\%20Sebrae/Anexos/7609.pdf>. Acesso realizado em 11 ago. de 2017.

[18] Yin, R. K. (2005). Estudo de caso: planejamento e métodos. Porto Alegre, RS: Bookman. Disponível em <http://www.scielo.br/pdf/pusp/v29n2/1678-5177-pusp-29-02-314.pdf>. Acessoem 14 de jun. de 2019 


\section{Capítulo 11}

\section{Soluções tecnológicas para a segurança da navegação fluvial no Rio Negro}

\section{Celia Edi Lobo Silva \\ Jorge Gonçalves de Souza \\ Adão Marques dos Santos Cardoso \\ Paulo Ricardo de Oliveira Ramos}

Resumo: Este artigo tem como objetivo descrever como o uso de tecnologias pode desenvolver a navegação no Rio Negro. Visa também contribuir para o desenvolvimento acadêmico, impulsionar e dinamizar para que os resultados positivos sejam para a sociedade, a economia e para organizações de interesse. As problemáticas encontradas na navegação fluvial vêm como forma de justificativa para o estudo, a sazonalidade, falta de sinalização e cartas náuticas que são um dos principais fundamentos para a pesquisa. A tecnologia é uma aliada para soluções dos problemas encontrados atualmente, e que se utilizado para fins de pesquisas e estudos podem beneficiar e juntamente apresentar resultados positivos em uma junção onde haja ganha-ganha. Com auxílio de metodologias axiomáticas como o estudo de caso, entrevistas, questionário entre outras foi possível dar natureza a pesquisa e assim encontrar possíveis soluções para a problemática abordada. A tríplice hélice é necessária para a realização deste projeto e sendo imprescindível a colaboração entre as instituições para a construção de cartas náuticas e o desenvolvimento técnico-cientifico em benefício da região.

Palavras chave: Navegação, Tecnologia, Segurança. 


\section{INTRODUÇÃO}

A logística inicialmente esteve sempre ligada essencialmente a operações militares no contexto histórico desde a Grécia Antiga, o período "Clássico" da China até os dias atuais. O termo atualmente conhecido surgiu na primeira fase da logística durante a segunda guerra mundial, que conforme Novaes $(2007, \mathrm{p}, 40)$, a logística "[...] após a guerra, procurou preencher importantes lacunas de demanda no mercado consumidor".

A Amazônia Ocidental que compreende aos estados do Amazonas, Acre, Rondônia e Roraima, apresenta como principal modal logístico o Fluvial que é hoje de fato mais acessível e viável devido a suas características geográficas, que corresponde a maior bacia hidrográfica e maior floresta continua do mundo. Moita (2011) afirma que "a maioria das cidades na região amazônica não possui acesso rodoviário, tendo o modal fluvial como o principal, o mais utilizado e o mais importante meio de transporte na Amazônia".

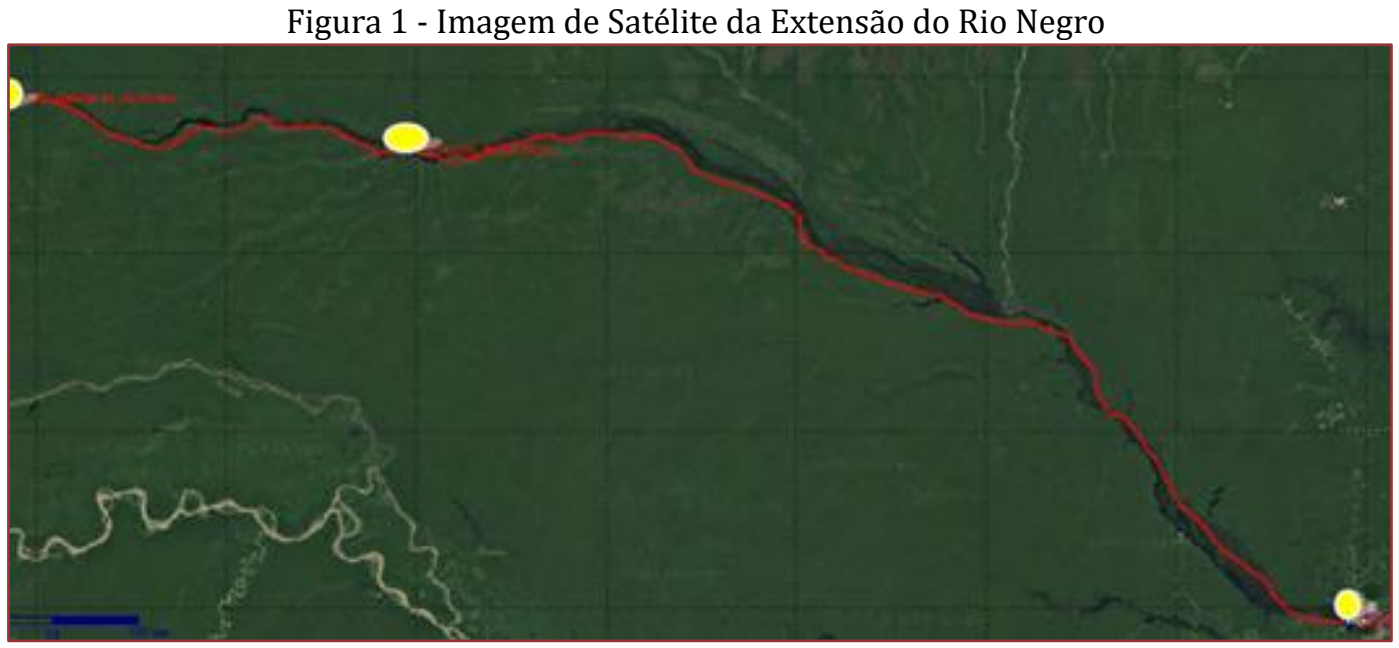

Fonte: Google Earth, 2017.

Na região que compreende o Rio Negro um dos maiores problemas encontrados é a falta de Mapeamento e Sinalização dos rios da Amazônia, que necessita de estudos em conjunto com vários segmentos que estudam a logística, seja para escoar suprimentos, e produtos que chegam a Manaus que devem suprir as necessidades do interior do Amazonas.

Sempre que se fala em diferenciação da região Norte acaba-se falando da logística, pois uma das principais formas de abastecer é pelos rios, e também um dos principais problemas a ser observado. 0 uso de tecnologias de mensuração do Rio Negro torna-se um ponto de estudo essencial para a navegabilidade e transporte de suprimentos no percurso que compreende a Manaus - São Gabriel da Cachoeira. Um dos objetivos deste artigo é descrever quais os problemas encontrados pela falta de mapeamento e sinalização do Rio Negro, e como as tecnologias podem contribuir para a segurança na navegação e para a constituição destes.

O processo de Mapeamento e Sinalização é um dos principais desafios para a navegação fluvial, pois ainda há dificuldades em se realizar estudos para a resolução do problema que visa especificamente melhorar a navegação e a segurança do mesmo. Sendo que estes estudos se justificam devido às alterações de alguns canais de navegação, provocadas pelas constantes mudanças dos bancos de areia, quebra de margens dos rios (fenômeno conhecido como "terras caídas"), aparecimento e desaparecimento de ilhas que comprometem a navegação.

\section{FUNDAMENTAÇÃO TEÓRICA}

No âmbito econômico a logística está principalmente caracterizada como um processo de distribuição física, em que segundo Ballou (2006, p.40) “a logística de distribuição física preocupa-se principalmente com bens acabados ou semiacabados, ou seja, com mercadorias que a companhia oferece para vender e que não planeja executar processamentos posteriores".

0 rio em estudo é o principal canal de distribuição no processo de escoamento de suprimentos para os 
municípios que estão ligados pelo mesmo. Para Las Casas (2007, p. 137) o canal de distribuição "é uma sequência pelo qual os serviços se movimentam, ou seja, é o caminho percorrido entre o produtor ou fornecedor até o consumidor, entre suas diversas atividades na distribuição estão envolvidos agentes e intermediários".

Para fins de proposta observa-se a tecnologia como um ponto de ignição para o desenvolvimento local no que diz respeito ao processo de atualização de cartas náuticas do Rio Negro, onde há uma diversificação geográfica que dificulta a navegação principalmente no período de vazante. Segundo Tavares (2000, p. 213), a tecnologia "é a contínua simplificação de sua operação, tornando-a mais amigável, e a redução de seus custos de produção, tornando-a mais acessível”.

A tecnologia se aplicada no sentido de agilizar a navegação até o seu destino final possibilita inúmeros benefícios relacionadas à segurança e confiabilidade da navegação. 0 modal fluvial é o mais utilizado na região, considerada uma indústria que necessita do uso dos equipamentos existentes para fluir. A mudança tecnológica na indústria naval não requer grandes descobertas, ao utilizar de recursos já disponíveis o resultado pode ser suficiente, sendo que o uso de incrementos em técnicas conhecidas e metodologias axiomáticas agregariam e muito na navegação. Lima (2006, pg. 135) atribui que a “Tecnologia em linhas gerais, é um conjunto de princípios, métodos, instrumentos e processos que ampliam a inúmeras atividades com o fim de torna-las mais eficientes e eficazes".

Ao analisarmos este conceito é possível identificar que a tecnologia hoje está mais acessível e de fácil manuseio, além de ter um custo benefício mais agradável em muitos casos possui uma eficácia que resulta em benefícios para quem a utiliza. Partindo deste princípio, tendo em vista a melhoria da navegação regional a utilização das tecnologias justifica-se, pois, o mesmo consiste em auxiliar no processo de estudo do mapeamento e sinalização do Rio Negro que compreende ao trajeto Manaus - São Gabriel da Cachoeira. Em que segundo informações do (CECMA, 2016) "Esse trecho oferece alto perigo a navegação devido à grande quantidade de pedras existentes e muito próximas ao canal do rio".

Pode-se observar na FIG 2 que no trajeto entre Camanaus até são Gabriel da Cachoeira há diversos barrancos de areia, além destes há também rochas que ficam no fundo do rio, estes no período de seca onde o rio diminui pode ocasionar diversos acidentes com embarcações na região.

Figura 2 - Trecho Camanaus - São Gabriel da Cachoeira

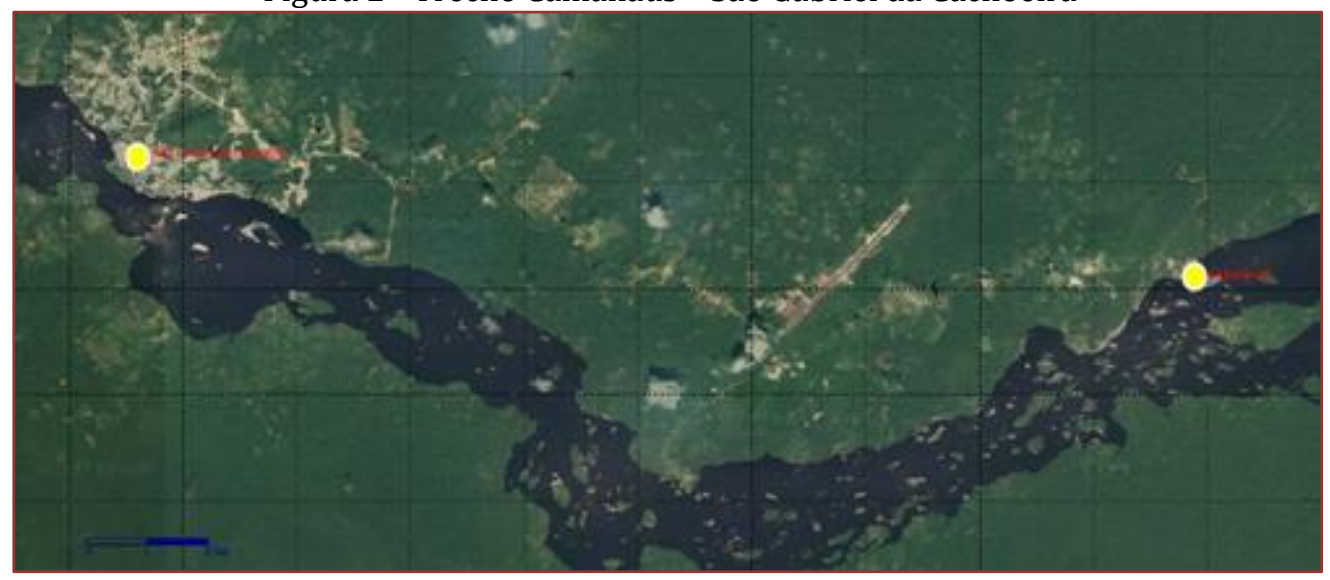

Fonte: Google Earth, 2017.

Como justificativa também se leva em consideração a economia como um fator principal para trazer melhorias na navegação no Rio Negro, pois de acordo com Medeiros (2012, p. 16).

A navegação fluvial é ainda a principal responsável pelo escoamento da produção e da sobrevivência de muitos municípios, [...] e outros centros de produção da Floresta Amazônica e, da própria capital amazonense em escala um pouco menor.

Além de estar fortemente ligada ao desenvolvimento econômico local e da própria região, sendo de fato o principal meio de transporte desta região, há algumas localidades em que o único meio de transporte é o fluvial, que fica responsável pelo processo de troca comercial, quanto de locomoção de pessoas destas localidades. Há uma questão regional conhecida como sazonalidade em que ocorrem seis meses de cheia, seis meses de vazante, a priori estudos feitos em conjunto com todas as partes interessadas sobre o 
assunto podem trazer benefícios a região. A forma como deve se proceder nestes momentos de mudanças de clima fará a diferença na eficiência dos resultados. Ching (2016, p 195) descreve, "A tendência atual no Brasil é a integração de diferentes modalidades de transporte com objetivo principal de obter ganho de eficiência e redução de custos".

0 processo de batimetria é um instrumento fundamental para a construção da carta náutica do Rio Negro, este consiste na medição da profundidade de lagos, rios e oceanos, em que é expressa cartograficamente por curvas batimétricas, seus pontos e topografia. Entretanto devido as mudanças constantes do rio é necessário a análise contínua do mesmo.

No que diz respeito ao Rio Negro o processo batimétrico é igualmente desafiador devido ao processo de sedimentação que ocorre durante o período de vazão, e com isso tendo como consequência deste fenômeno surgem locais críticos que variam durante o mesmo e prejudicam a navegação, assim podendo causar acidentes durante a navegação de embarcações que transportam suprimentos para o interior do estado além das que que fazem o transporte de pessoas. Adotando este equipamento pode-se ter uma seguridade maior evitando assim expor ao perigo tanto pessoas quanto a embarcação.

Figura 3 - Empurrador sendo Resgatado Após Acidente

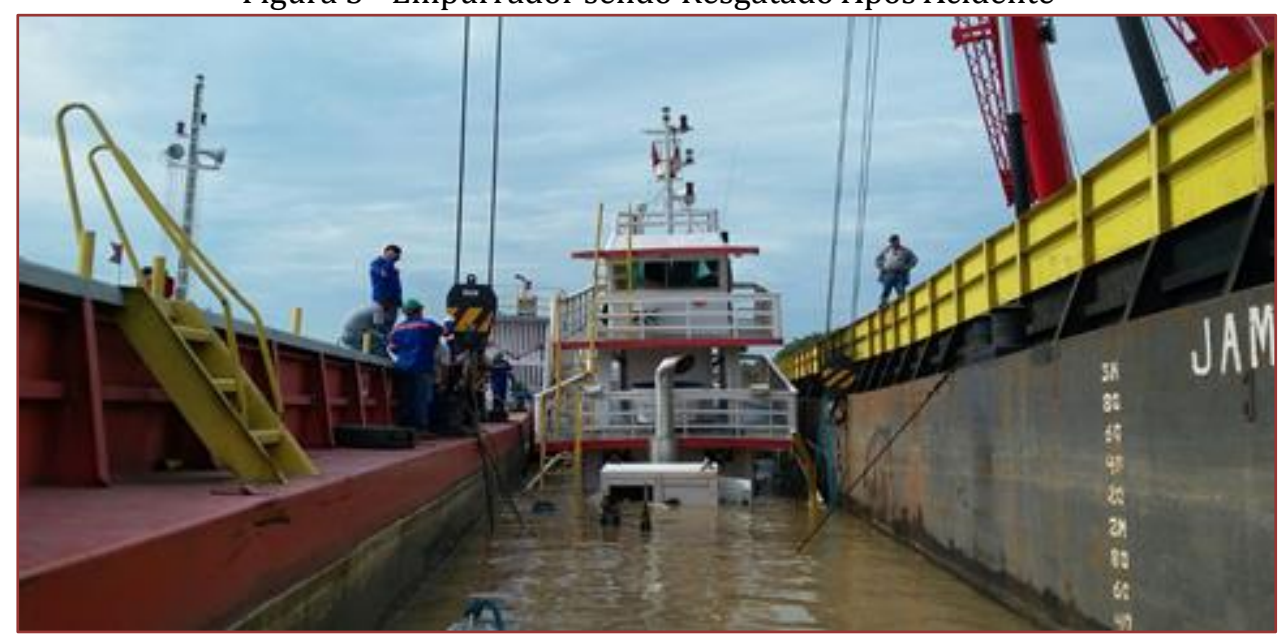

Fonte: Os Autores, 2017.

Dito isto a utilização de Ecobatímetro torna-se fundamental para a navegação fluvial, pois são equipamentos que permitem a determinação de valores de profundidade. Detalhar medidas do fundo dos rios, lagos, oceanos, faz parte da topografia, processo indispensável em várias atividades como na logística, dragagem, agricultura, em prevenção de acidentes é muito usada também. Entretanto 0 ciclo hidrológico exerce influência sobre o transporte de sedimentos em rios com fundos móveis e pode alterar ao longo do tempo a batimetria dos trechos navegáveis.

O estado do Amazonas possui a particularidade de rios com grande extensão, daí a complexidade da navegação e instalação de portos na região. Manaus é uma das vias fluviais que faz a logística para o interior, o Rio Negro é um dos quem direciona para os municípios em suas margens, majestoso e imponente nos períodos de cheia, com sua sazonalidade órgãos necessitam continuar cumprindo sua missão de entregar material para suprir as necessidades dos municípios que compreendem ao trajeto Manaus - São Gabriel da Cachoeira no período da vazante, e assim cumprir a missão para o bom funcionamento da localidade. 0 Rio Negro é navegável por $1.070 \mathrm{~km}$, sendo $310 \mathrm{~km}$ entre a foz e a confluência com o rio Branco. Sua profundidade mínima é de 2,50 m. É navegável além da fronteira com a República da Venezuela, sendo que no período de águas baixas, existem restrições de profundidade acima da cidade de São Gabriel da Cachoeira (AM), podendo chegar a um calado de menos de 1,20 m. "A região do Rio Negro compreende a maior bacia de águas pretas do mundo - uma das mais importantes da Amazônia" (Pinto, 2013 p.196).

As condições de navegação de forma tranquila dependem do leito do rio, esse item é que fará com que a segurança da distribuição de suprimentos, todos divididos em classes para um melhor entendimento e não ocorram impedimentos na logística. No Rio Negro, a territorialidade é exercida por meio do controle dos trechos mais produtivos do rio. (Becker, 2010, p. 19-20). Segundo a autora, "a territorialidade humana é uma relação com o espaço que tenta afetar, influenciar ou controlar por meio do reforço do domínio 
sobre uma área geográfica específica, isto é, o território".

A característica principal do processo de incorporação tecnológico é que as mudanças observadas ao longo da história, tanto em relação ao projeto como em relação a produção mudam diariamente. Os sistemas de controle e navegação também são constantemente aperfeiçoados, visando melhor navegabilidade.

\section{METODOLOGIA}

As metodologias axiomáticas contribuem para a fomentação e desenvolvimento de qualquer pesquisa cientifica, ao adotar tais métodos estas contribuem para a melhoria contínua do estudo. Gonçalves (2006, p. 120) discorre que "o pesquisador ensaiará os primeiros passos, na definição de uma metodologia de trabalho, orientada para o planejamento e a coleta dos dados, bem como para a análise do mesmo". Utiliza-se de métodos de pesquisa para a seguridade das informações, dando a elas veracidade e aproximando da realidade dos fatos.

Buscando compreender um pouco mais sobre as metodologias, a pesquisa em questão utiliza tais para estruturar e desenvolver o estudo de caso em questão. Segundo Andrade (2010, p. 117) Metodologia, "é o conjunto de métodos ou caminhos que são percorridos na busca do conhecimento".

Foram estabelecidos objetivos a fim de encaminhar e dar sentido a pesquisa sobre o processo de mapeamento, sinalização e seguridade no Rio Negro, informações colhidas através de questionários e entrevistas com profissionais visa contribuir para a melhoraria da navegabilidade e segurança no rio, quanto aos objetivos Marconi e Lakatos (2010, p. 201) os definem como: " A especificação do objetivo de uma pesquisa responde as questões para quê? E para quem?"

Esta pesquisa enquadra-se no processo metodológico de estudo de caso onde serão avaliadas as problemáticas a serem solucionadas dando veracidade ao que se estuda. De acordo com Gil (2010, p. 37) o estudo de caso "consiste no estudo profundo e exaustivo de um ou mais objetos, de maneira que permita seu amplo e detalhado conhecimento".

Para dar riqueza ao estudo utilizou-se do método observacional que é um tipo de metodologia das ciências sociais que pode ser considerada primitiva e imprecisa, porém moderna e rica em informações, Segundo Gil (2008, p. 16) a metodologia em questão "[...] possibilita o mais elevado grau de precisão nas ciências sociais". Além deste método utiliza-se do Método Indutivo que generaliza a pesquisa saindo do particular para uma questão mais ampla diferentemente do método dedutivo. E segundo Lakatos e Marconi (2007, p. 86),

Indução é um processo mental por intermédio do qual, partindo de dados particulares, suficientemente constatados, infere-se uma verdade geral ou universal, não contida nas partes examinadas. Portanto, o objetivo dos argumentos indutivos é levar a conclusões cujo conteúdo é muito mais amplo do que o das premissas nas quais se basearam.

A pesquisa bibliográfica é elaborada a partir de materiais já publicados, em Prodanov (2013, p. 54) descreve que este é "constituído principalmente de: livros, revistas, publicações em periódicos e artigos científicos, jornais, boletins, monografias, dissertações, teses, material cartográfico, internet". Isto com o intuito de aproximar o pesquisador com o material já publicado sobre o assunto em estudo. Sendo necessário ainda verificar a veracidade das informações neles contidos.

Para coleta de dados utilizou-se de pesquisa descritiva que utiliza de técnicas padronizadas de coleta de dados e para Alyrio (2009 p. 58) através deste "se busca essencialmente a enumeração e a ordenação de dados, sem o objetivo de comprovar ou refutar hipóteses exploratórias, abrindo espaço para uma nova pesquisa explicativa, fundamentada na experimentação".

Ainda segundo Prodanov (2013, p. 52) este tipo de metodologia,

Procura descobrir a frequência com que um fato ocorre, sua natureza, suas características, causas, relações com outros fatos. Assim, para coletar tais dados, utiliza-se de técnicas específicas, dentre as quais se destacam a entrevista, o formulário, o questionário, o teste e a observação. 


\section{RESULTADOS}

O setor fluvial como descrito é a principal via acesso do processo de transporte na região, e que necessita de investimentos em mapeamento e sinalização para benefício e seguridade daqueles que utilizam deste modal de transporte. De acordo com o (CECMA 2016),

Registros apontam que a navegação fluvial militar na Amazônia é realizada em $80 \%$ das vezes somente com o auxílio de equipamentos eletrônicos como a ecosonda, GPS, radar e carta eletrônica/impressa, sendo $20 \%$ das vezes apoiada pela utilização de um prático.

Quanto a tecnologia objeto de solução deste estudo apontam-se diversos equipamentos e ferramentas tecnológicas para a navegação, algumas tornam-se indispensáveis as quais destacam-se o Radar, Ecobatímetro, GPS, AIS (Automatic Identification System), estes equipamentos em conjunto podem contribuir para a construção de cartas náuticas do Rio Negro.

\subsection{RADAR}

Para obter-se uma navegação segura é necessário o uso de equipamento de navegação dos quais temos o Radar (Radio Detection And Ranging - Detecção e Medição de Distância por Rádio), equipamento este que auxilia na navegação tanto marítima quanto fluvial. 0 Radar é um instrumento que auxilia a navegação dando-lhe mais segurança e precisão, lhe mostrando em pontos o espaço e a distância do ambiente navegável. Este equipamento auxilia a navegação demonstrando em imagens informações sobre a região em que se navega, sendo que tal aparelho é útil durante uma chuva ou durante uma forte serração onde não temos uma boa visibilidade.

Figura 4 - Equipamento Radar

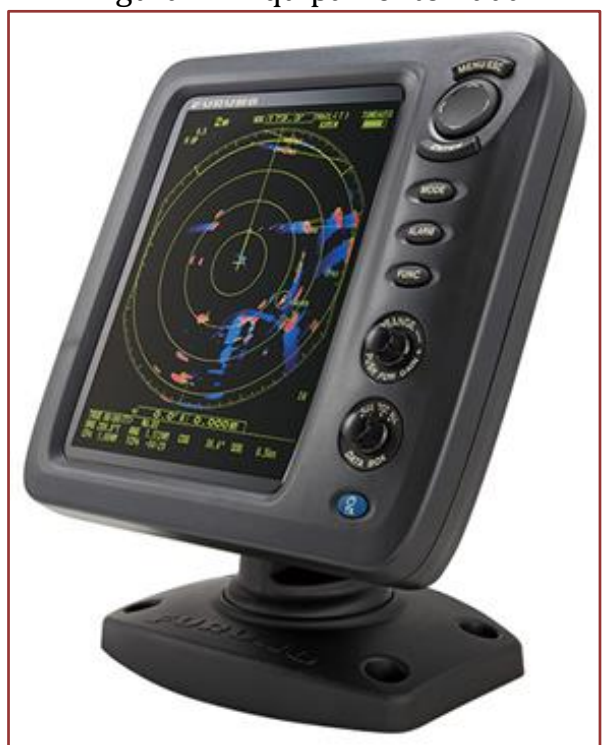

Fonte: Furuno, 2017.

A navegação RADAR em sua forma mais precisa é feita com a medida de três distâncias a pontos de terra notáveis, presentes na tela do equipamento e na carta náutica. Segundo Vannucci (1999, p.01), "as imagens de radar expressam as propriedades geométricas e dielétricas das superfícies observadas.

Estas características permitem que o Radar encontre uma vasta gama de aplicações em diferentes campos do monitoramento e estudo da superfície da Terra".

\subsection{ECOBATÍMETRO}

Instrumento que, por meio de ondas eletromagnéticas (Ressonância), identifica a distância (a altura) entre a quilha da embarcação até o fundo do rio. É um equipamento indispensável na hora da navegação fluvial 
pois este garante uma seguridade a mais no processo. 0 dado batimétrico, pontual e preciso mostra que a execução e levantamento gera resultados, o equipamento emite onda sonora. 0 método utilizado durante o período da vazante é a análise da lâmina do rio através de desse sensor, após esta etapa as coordenadas e delimitação da área serão feitas para as embarcações.

Figura 5 - Equipamento Ecobatímetro

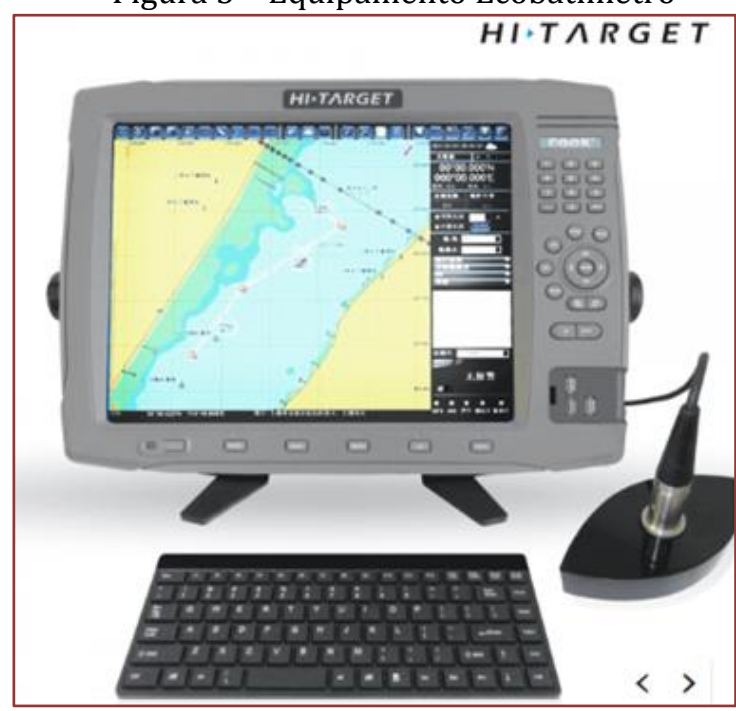

Fonte: TECNOSAT, 2017.

O Ecobatímetro, pois se bem projetado (posicionado) tendo um raio de alcance avante da embarcação é de extrema importância. 0 planejamento para uso do Ecobatímetro oferece resultados, benefícios através de outros instrumentos usados em conjunto.

\subsection{GPS - GLOBAL POSITIONING SYSTEM}

No decorrer dos tempos a humanidade vem concentrando esforços em desenvolver tecnologias e muitos se questionam o porquê destes avanços e como estes vem alavancando a engenharia sem precedentes. Uma das tecnologias que foram desenvolvidas e hoje praticamente está em destaque e acessível a qualquer pessoa no globo é o Sistema de Posicionamento Global, conhecido como GPS acrônimo em inglês para Global Positioning System, e este destaque deve-se a rapidez e pela precisão que este sistema dá sobre a posição de um determinado ponto no globo, e de acordo com Zanotta et al (2011, p. 2) o GPS “tem sido de grande utilidade para a navegação (terrestre, marítima e aérea), cartografia, geodinâmica, entre tantos outros procedimentos que necessitam de posicionamento".

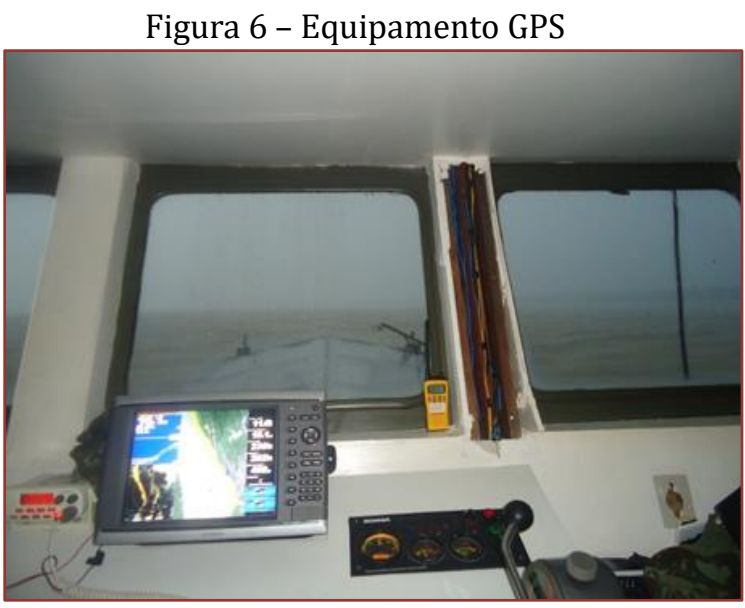

Fonte: Os Autores, 2017 
Existem dois tipos padrões de posicionamento global em funcionamento atualmente o SPS (Standard Positioning Service) e o preciso PPS (Precise Positioning Service). Sendo que o primeiro está disponível para todos os usuários deste padrão dita-se pessoas que possuam como por exemplo smartphones com uso de mapas para localização pessoal, onde este apresenta uma posição em valores de 100 a $140 \mathrm{~m}$ ou 10 a 20 m. O PPS por sua vez é um sistema para uso militar e tem por característica apresentar uma precisão mais elevada em relação ao SPS que parte do valor de 10 a $20 \mathrm{~m}$, valores estes que são transmitidas através de satélites posicionados na orbita terrestre e segundo Orth et al $(2004$, p. 4) "O sistema GPS consiste, atualmente, de 24 satélites [...] os quais estão distribuídos em 6 órbitas planas. Cada plano possui uma inclinação de 55 em relação ao plano do equador". Nota-se que ambos conseguem alcançar valores de posicionamento iguais, porém o SPS é mais limitado em relação ao outro padrão, pois este possui um sistema de criptografia que o torna menos preciso, isso deve a imposições feitas pelo Departamento de Defesa Americano visando a segurança nacional, sendo que o GPS foi desenvolvido por este órgão de defesa americano.

\subsection{AIS (AUTOMATIC IDENTIFICATION SYSTEM)}

De acordo com a Marinha do Brasil inicialmente este sistema surgiu para auxiliar as estações de terra que controlam o trafego marítimo. Posteriormente, a IMO acrônimo de (Organização Marítima Internacional) aperfeiçoou o sistema com a finalidade de proporcionar maior segurança à navegação.

Este sistema tem por finalidade compartilhar informações entre embarcações que estejam dentro do alcance de comunicações VHF (Very High Frequency), auxiliando a tomada de decisões na navegação, com isso possibilita a melhoria na segurança durante a navegação, auxiliando na troca de informações e reduzindo os ricos com acidentes. $O$ equipamento depende de um transceptor alocado na embarcação que em conjunto com outros equipamento e softwares demonstram a posição da embarcação e também para fazer o sincronismo com outros AIS. Este equipamento é dividido em Classe A e Classe B, em que navios são obrigados a utilizar esta classe, e outras embarcações que não estejam enquadradas nesta devem fazer uso da classe B que possui características muito semelhantes ao primeiro.

Figura 7 - Equipamento de AIS (Automatic Identification System):

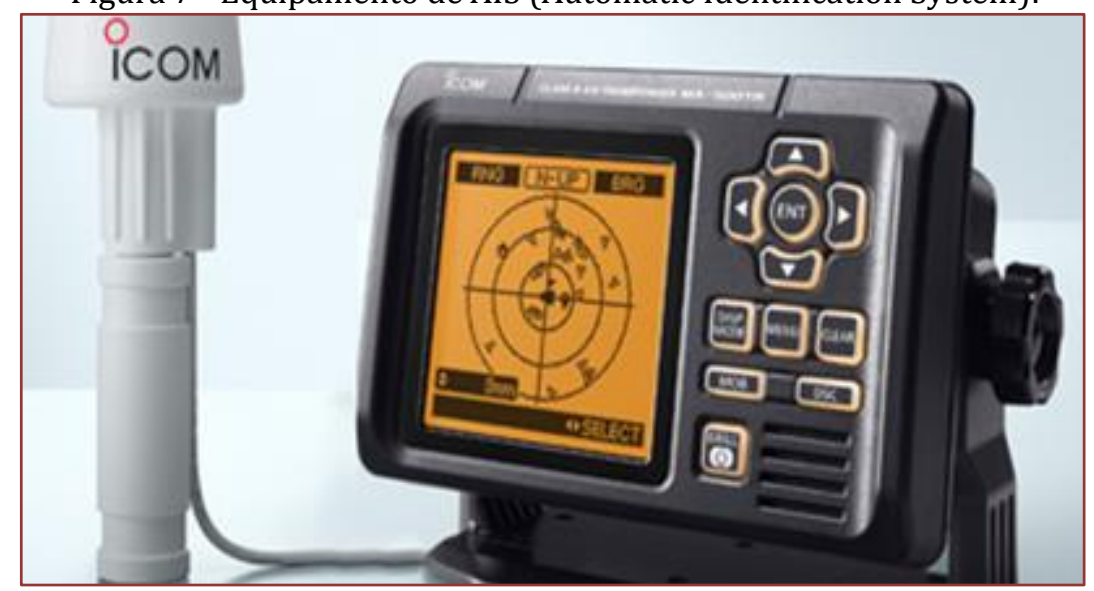

Fonte: ICOM, 2017.

O que diferencia ambos é que a classe B não transmite dados de viagem que são consideradas de baixa relevância quando não se trata de navios. De acordo com a CASH (2017) empresa especializada na venda deste equipamento as informações transmitidas/recebidas incluem dados como:

Estáticos: (identificações e características da embarcação)

(a cada 6min, após alterações ou quando solicitado);

Dinâmicos: (relativos à localização e deslocamento da embarcação)

(Conforme tabela: depende da velocidade e alteração de curso);

Relacionados à viagem: (calado, carga, destino e ETA)

(A cada $6 \mathrm{~min}$, após alterações ou quando solicitado). 
Para que o AIS esteja apto a transmitir informações é necessário o MMSI (Maritime Mobile Service Identity) da embarcação que deverá ser infamado no ato da configuração do mesmo. No Brasil a ANATEL (Agencia Nacional de Telecomunicações) é a entidade responsável por fornecer o MMSI, sendo necessário solicitar a esta agencia a identificação para a embarcação.

Com isto observa-se que este transceptor em conjunto de outros equipamentos pode substancialmente melhorar a navegação fluvial principalmente em mal tempo e em viagens noturnas.

Conforme FIG 8 a Marinha do Brasil é responsável pela instalação e manutenção das torres de transmissão destes dados do AIS, sendo este transmitido em ondas de alta frequência VHF (Very High Frequency), ainda conforme a imagem é possível observar que há planos de instalação na região sendo especificamente nos municípios de Tabatinga e Tefé, onde Manaus a capital possui a única torre de transmissão da região que compreende a Amazônia Ocidental.

Figura 8 - Pontos fixos e móveis dos AIS instalados no Brasil

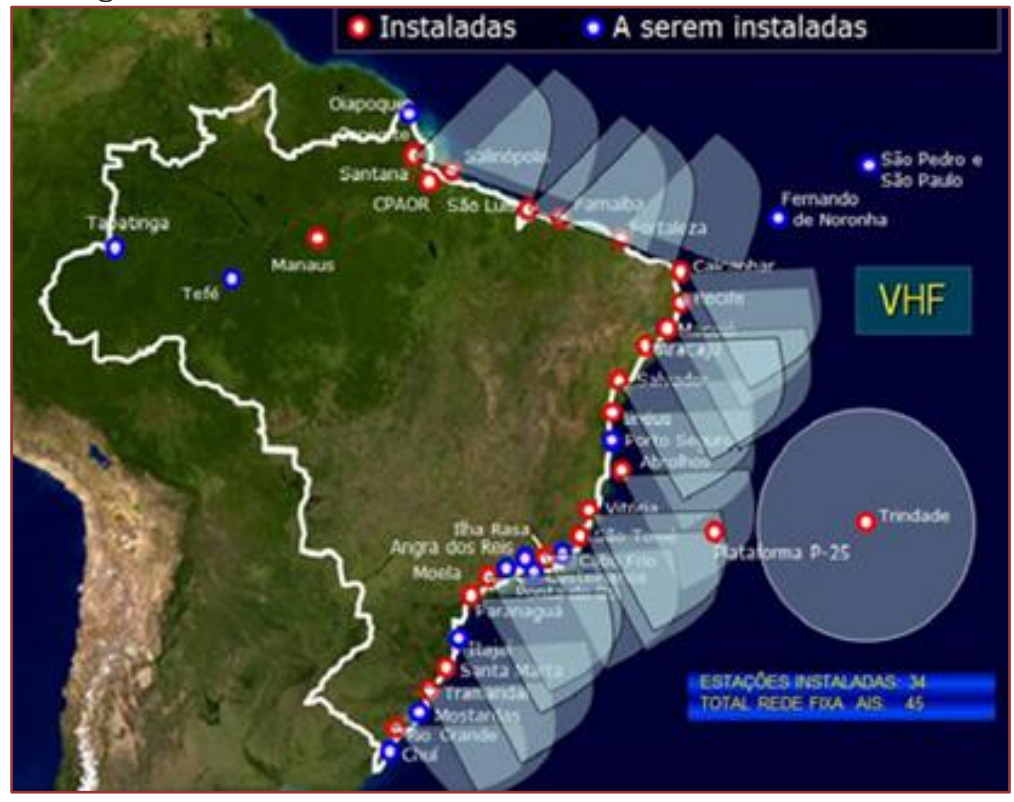

Fonte: Marinha do Brasil, 2017.

\section{PROSPOSTA DE SOLUÇÃO}

Conforme supracitado conclui-se que, com o uso destas tecnologias pode-se melhorar a navegação no Rio Negro trazendo mais segurança e viabilizando economicamente melhorias para os municípios que compreendem ao trajeto Manaus - São Gabriel da Cachoeira. Através da Tríplice Hélice busca-se desenvolver este projeto de construção das cartas náuticas, que necessitam da colaboração entre instituições governamentais, privadas e sociedade, que além da região beneficiam o desenvolvimento técnico-cientifico. 
Figura 9 - Modelo de Carta Náutica que se Propõe a Construção

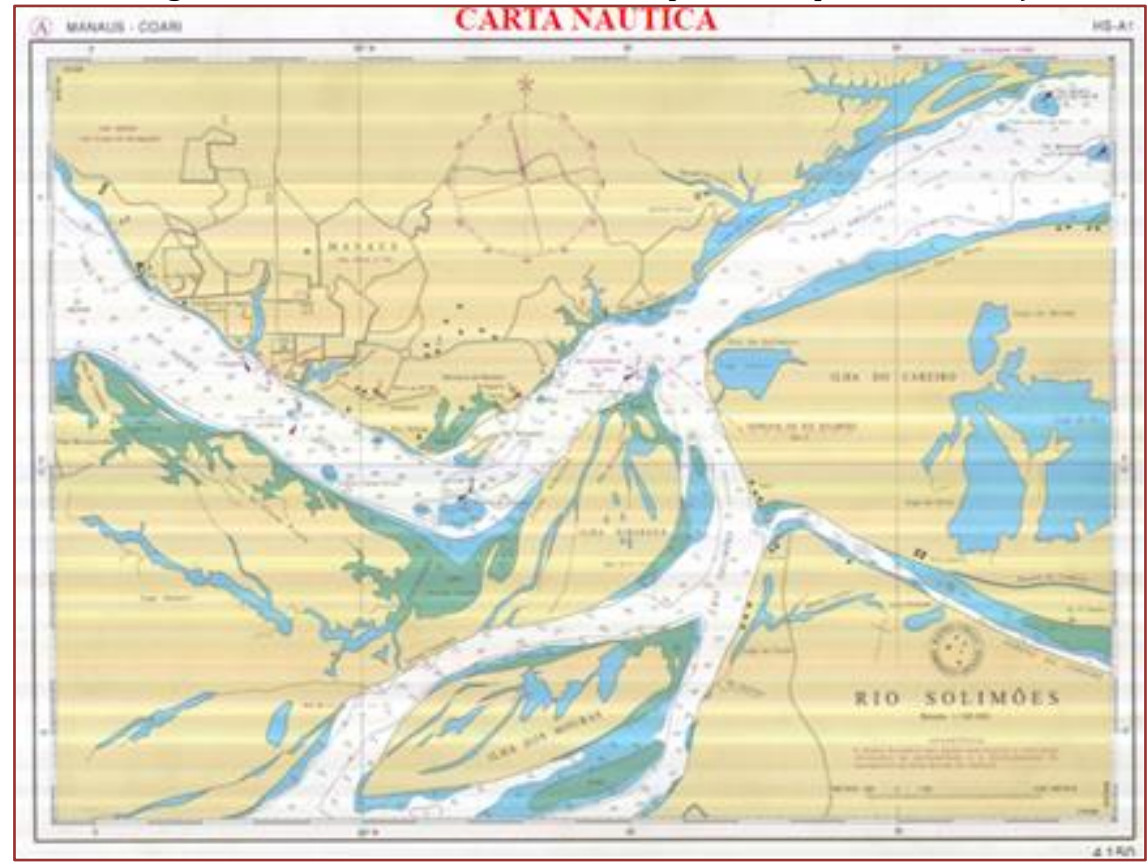

Fonte: CECMA, 2016.

Este estudo visa demonstrar que além de trazer seguridade a navegação o uso de tais equipamentos podem ser utilizado também para a construção das cartas náuticas do Rio Negro, este que não disponibiliza de tal para a navegação fluvial. Estas cartas náuticas compreendem em mapas que são uma representação da superfície terrestre sobre um plano, com finalidade de ser usada em navegação ou outra atividade técnica ou científica. As cartas permitem medições precisas de distâncias e direções (rumos ou azimutes). Desta forma, os documentos cartográficos utilizados em navegação são sempre chamados de Cartas Náuticas. Este nada mais é do que a representação de um trecho da superfície terrestre, reduzida a um plano e que contém os meridianos e paralelos, área de mares, rios, linha da costa, sondagens, pontos notáveis em terra e demais dados úteis à navegação.

Acidentes em hidrovias que são consideradas estradas na região podem ser evitados, com a atuações dos órgãos responsáveis pela fiscalização e os proprietários de embarcações para o desenvolvimento da segurança fluvial da região, olhar profundo as necessidades pertinentes nesse trajeto, força de vontade conjunta para oferecer melhorias através de segurança na navegação. Amazônia dona de uma das maiores hidrovias de grandes dimensões, onde percursos do Rio Negro de Manaus á São Gabriel da Cachoeira necessitam de estudos, pesquisas de grande relevância para assegurar que haja segurança e o futuro mapeamento desta hidrovia muito usada para distribuições de todas as classes (produtos).

\section{REFERÊNCIAS}

[1] Alyrio, Rovigati Danilo. Métodos e técnicas de pesquisa em administração. Volume único. Rio de Janeiro: Fundação CECIERJ, 2009.

[2] Andrade, Maria Margarida de. Introdução à Metodologia do Trabalho Científico. 10ª ed. São Paulo: Atlas, 2010.

[3] Ballou, Ronald H. Gerenciamento da cadeia de suprimentos/logística empresarial. São Paulo: Bookman, 2006

[4] Becker, B. K. Novas territorialidades na Amazônia: desafio às políticas públicas. Boletim do Museu Paraense Emílio Goeldi. Ciências Humanas, v. 5, n. 1, p. 17-23, 2010.

[5] CASH Computadores e Sistemas: Transceptores AIS Classe A e Classe B. Disponível em: <http://www.nasareh.com.br/index.php?page=integras\&subcategory=52>. Acesso: 2017.

[6] Centro de Embarcações do CMA. Curso de navegação fluvial. Manaus: Div. Instr., 2016, Manual.

[7] Ching, Hong Yuh. Gestão de Cadeia de Logistica Integrada -Supply Chain. 4 ed- São Paulo Atlas 2016. 
[8] Logistica Empresarial Transpostes Administração de Materias, Distribuição Fisica. 1 ed. 30ํำ Reimpressão, São Paulo: Atlas, 2015.

[9] Gil, A. C. Métodos e técnicas de pesquisa social. 6. ed. São Paulo: Atlas, 2008.

[10] Como elaborar projetos de pesquisa. 5. ed. São Paulo: Atlas, 2010.

[11] Furuno. Marine Radar. Disponível em: < http://www.furuno.com/en/products/radar/MODEL1815>. Acesso em: 2017.

[12] Gonçalves, Elias Rocha. Faça Fácil Monografia, Campos dos Goytacazes, RJ: Instituto Brasileiro de Educação e Cultura, 2006.

[13] ICOM. MA-500TR. Disponível em: <

http://www.icomamerica.com/en/products/marine/navigation/ma500tr/default.aspx >. Acesso em: 2017.

[14] Lakatos, Eva Maria; MARCONI, Marina de Andrade. Fundamento de metodologia cientifica. 7. Ed. São Paulo: Atlas, 2010.

[15] Lima, A. Gestão de marketing direto da conquista ao relacionamento com cliente. Colaboração Fernando Alves - São Paulo: Atlas 2006

[16] Marinha do Brasil. AIS - Automatic Identification System. Disponível em: <https://www.marinha.mil.br/comcontram/?q=ais>. Acesso: 2017.

[17] Medeiros, Juliana Terezinha da Silva. 0 transporte fluvial e o direito à dignidade da pessoa humana na Amazônia. Dissertação (Mestrado) -Universidade do Estado do Amazonas, Programa de Pós-graduação em Direito Ambiental, 2012.

[18] Moita, M. H. V. et al. Transporte Fluvial de Passageiros: um estudo na Região Amazônica. 2011.

[19] Novaes, Antônio Galvão. Logística e gerenciamento da cadeia de distribuição: estratégia, operação e avaliação. Rio de Janeiro: Elsevier, 2007.

[20] Orth, Maria Dora Dra. Profa., Vieira, José Sálvio M.Eng., DEBERT, Emiliana M.Eng. SILVA JR., Rony Sérgio. GPS - Global Positioning System - Ferramenta Utilizada para Mapear Unidades de Conservação. Congresso Brasileiro de Cadastro Técnico Multifinalitário · UFSC Florianópolis. 2004.

[21] Prodanov, C. Cleber. Freitas, C. Ernani. Metodologia do trabalho científico [recurso eletrônico]: métodos e técnicas da pesquisa e do trabalho acadêmico / - 2. ed. - Novo Hamburgo: Feevale, 2013.

[22] Pinto, I. C. Agrobiodiversidade de quintais agroflorestais e perfil social de etnias indígenas em São Gabriel da Cachoeira, AM. Tese de Doutorado. Lavras: UFLA, 2013.

[23] Tecnosat, Ecobatimetro: Hi-Target HD. Disponível em: < https://www.tecnosat.com.br/tecnosat/ecobatimetro-hi-target-hd-max/>. Acesso em: 2017.

[24] Vannucci, T. A. M. Redução de Specklel em Imagem Radar. (Dissertação de Mestrado) - Universidade Federal do Paraná, Curitiba, 1999.

[25] Zanotta, Capella Daniel, Cappelletto, Eliane, Matsuoka Marcelo. O GPS: unindo ciência e tecnologia em aulas de física. Revista Brasileira de Ensino de Física, v. 33, n. 2, 2313, 2011. 


\section{Capítulo 12}

Fatores limitantes para a inovação em micro e pequenas empresas no município de Zé Doca, Maranhão

Hugo da Costa Reis

Alexandre da Costa Reis

Stênio Lima Rodrigues

Marali Silva Santos

Ana Carla Cavalcante das Chagas

João Vitor de Oliveira Sousa

Resumo: A inovação é um assunto bastante discutido ultimamente, possuindo grande relevância para as Micro e Pequenas Empresas. Dentro dessa perspectiva foi a adotada a seguinte questão de pesquisa: quais fatores críticos de sucesso propiciam a inovação em empresas de pequeno porte do município de Zé Doca? Em âmbito científico esta pesquisa justifica-se no fato de que o tema inovação em empresas de pequeno porte é pouco explorado na literatura. É necessário se demonstrar que a inovação ao contrário do que muitos pensam, não se restringe apenas ao ambiente das grandes empresas, podendo ser aplicada no contexto das pequenas empresas. A pesquisa teve como objetivo identificar quais são as dificuldades enfrentadas na implementação de inovações pelas Micro e Pequenas Empresas do município de Zé Doca. Especificamente buscou-se entender quais os fatores limitantes para a implementação de inovações no ambiente dessas empresas, entender como funciona o processo de inovação e propor sugestões para driblar as limitações, além de identificar os benefícios da implementação de inovações. Desta forma, o artigo permitiu compreender os fatores críticos de sucesso para a implementação da inovação nas Micro e Pequenas Empresas, juntamente com os fatores limitantes que dificultam o processo inovativo.

Palavras-Chave: Inovação; Micro e Pequenas Empresas; Fatores limitantes. 


\section{INTRODUÇÃO}

Uma inovação é a implementação de um produto (bem ou serviço) novo ou significativamente melhorado, ou um processo, ou um novo método de marketing, ou um novo método organizacional nas práticas de negócios, na organização do local de trabalho ou nas relações externas (OECD, 2005).

Com as mudanças significativas no mundo das Micro e Pequenas Empresas (MPEs), surge a necessidade de manter os negócios da empresa firmes diante da competividade, e qual seria essa necessidade? A inovação que está cada vez mais recorrente entre os empresários, fazendo o uso da inovação com produtos novos e diferentes entre os concorrentes, atraindo mais clientes, e consequentemente mais lucro.

É relevante destacar que a inovação pode ser entendida também como toda e qualquer ideia que auxilia um gestor a resolver um problema, evidenciar uma melhoria e reverter às instabilidades em meio à crise.

Considerando a inovação como fator importante para o crescimento de MPEs e mais especificamente para a implementação de mudanças sociais no desenvolvimento local, este estudo será norteado pela seguinte problemática: quais fatores críticos de sucesso propiciam a inovação em empresas de pequeno porte no município de Zé Doca?

Em âmbito científico esta pesquisa justifica-se no fato de que o tema inovação em empresas de pequeno porte é pouco explorado na literatura. É necessário se demonstrar que a inovação ao contrário do que muitos pensam, não se restringe apenas ao ambiente das grandes empresas, podendo ser aplicada no contexto de micro ou pequenas empresas.

Entretanto, o artigo se torna relevante para as empresas da região pelo fato de buscar propor sugestões de melhorias paras as empresas do setor de comércio do município de Zé Doca.

A pesquisa teve como objetivo geral identificar quais são as dificuldades enfrentadas na implementação de inovações pelas Micro e Pequenas Empresas do município de Zé Doca. Especificamente buscou-se entender quais os fatores limitantes para a implementação de inovações no ambiente das empresas, entender como funciona o processo de inovação e propor sugestões para driblar as limitações, além de identificar os benefícios da inovação nas pequenas empresas.

Além desta introdução, o artigo está estruturado em mais quatro seções. Na segunda serão apresentadas as discussões e abordagens dos autores sobre a temática contemplando os temas: Inovação e Inovação em Micro e Pequenas Empresas (MPEs). Na terceira, serão apresentados os procedimentos metodológicos utilizados para a realização da pesquisa. Na quarta, os resultados da pesquisa e finalmente na quinta seção, as considerações finais.

\section{REFERENCIAL TEÓRICO}

\subsection{INOVAÇÃO}

A necessidade frequente em mostrar algo novo, melhorado ou inédito ao consumo, mostra o nível de competitividade em que as firmas estão atuando. Aquilo que era ótimo ontem, já sofre contestações hoje e possivelmente não se sustentará amanhã (CONTO; JUNIOR; VACCARO, 2016).

Segundo Bachmann e Destefani (2008), a atividade de inovação apresenta diversas faces, como: adaptação, imitação, experimentação, design, desenvolvimento e pesquisa. Inclusive a forma de buscar inovações pode ser inovadora.

De acordo com Ceretta, Reis e Rocha (2016), em detrimento da amplitude conceitual que envolve a inovação, nota-se que diversas correntes tratam do tema de acordo com sua gênese epistemológica, não tendo uma única vertente teórica para o tema.

0 quadro à seguir mostra os diferentes tipos de inovação segundo o Manual de Oslo, bem como os seus conceitos. 
Quadro 1 - Definição de inovação segundo o manual de Oslo:

\begin{tabular}{|c|c|}
\hline Nome & Definição \\
\hline Inovação de produtos & $\begin{array}{l}\text { Inovação de produto envolve mudanças significativas nas potencialidades de } \\
\text { produtos e serviços. Incluem-se bens e serviços totalmente novos e } \\
\text { aperfeiçoamentos importantes para produtos existentes. }\end{array}$ \\
\hline Inovação de processo & $\begin{array}{l}\text { Inovação de processos representa mudanças significativas nos métodos de } \\
\text { produção e distribuição. }\end{array}$ \\
\hline Inovação em marketing & $\begin{array}{l}\text { Inovação em marketing envolve a implementação de novos métodos de } \\
\text { marketing, incluindo mudanças no design do produto e na embalagem, na } \\
\text { promoção do produto e sua colocação, em métodos de estabelecimento de preços } \\
\text { e de bens de serviços. }\end{array}$ \\
\hline Inovações organizacionais & $\begin{array}{l}\text { Inovações organizacionais referem-se à implementação de novos métodos } \\
\text { organizacionais, tais como mudanças em práticas de negócios, na organização do } \\
\text { local de trabalho ou nas relações externas das empresas. }\end{array}$ \\
\hline
\end{tabular}

Cabe salientar que a transferência desses conhecimentos necessários a inovação não é um processo simples nem unidirecional, que ocorre em determinado tempo. De acordo com Balestrine e Bueno (2012) as empresas organizam processos para a geração de inovação com o intuito de lançar novos produtos e serviços, desenvolver novos processos ou novas configurações organizacionais e atuar em novos mercados.

A inovação pode ser entendida também como toda e qualquer ideia que auxilia um gestor a resolver um problema, evidenciar uma melhoria e reverter às instabilidades em meio à crise.

\subsection{INOVAÇ̃̃O EM MPEs}

As Micro e Pequenas Empresas desempenham um papel fundamental na geração de emprego e renda, o que as credencia como instrumentos indutores do desenvolvimento econômico. Inseridas em mercados cada vez mais competitivos e globalizados, as empresas de micro e pequeno porte dependem cada vez mais da capacitação tecnológica e da geração de inovações para garantir sua sobrevivência e o seu sucesso (MAIA, 2012).

A partir dos diferentes contextos econômicos que surgiram nos últimos anos, a inovação passou a ser considerada como uma nova "moeda" para competição global e desenvolvimento de mercados (OLIVEIRA ET AL, 2014). No caso do Brasil, verifica-se turbulências na economia e esse cenário instável tem estimulado as MPEs a procurarem melhores alternativas para suprir as suas necessidades mercadológicas que impactam diretamente nos seus resultados financeiros. Desta maneira, a inovação é também associada como uma forma criativa de driblar as dificuldades impostas em uma concorrência global para sobrevivência em um mercado dinâmico e complexo (COSTA; OLAVE, 2014).

Tais aspectos, por conseguinte, constituem desafios a serem gerenciados tanto pelas grandes empresas quanto pelas micro e pequenas empresas, MPEs. Entretanto, a maior disponibilidade de recursos e estrutura, além de maior poder político, tornam as grandes empresas menos suscetíveis aos ciclos econômicos e lhes conferem uma vantagem natural em relação aos pequenos empreendimentos, que, dada a própria estrutura de porte, com recursos escassos e possibilidade de investimento limitado, apresentam menos chances de crescimento e de adquirir tecnologia e conhecimento que as façam prosperar (SILVA; DARCOSO, 2013).

Mesmo tendo papel importantíssimo na economia atual, as MPEs ainda sofrem com uma menor disponibilidade de recursos financeiros para a aplicação de mudanças e melhorias nos seus setores de atuação, o que as deixa vulneráveis a possíveis estagnações.

Em contrapartida, segundo o SEBRAE (2011), as MPEs representam cerca de 20\% do PIB nacional, 99\% do total de empresas brasileiras, 51,6\% dos empregos formais não agrícolas gerados no Brasil e quase $40 \%$ da massa salarial do país, o que revela a elevada importância destas firmas para a economia brasileira e traz a necessidade de pensar em formas alternativas que subsidiem a maximização de seu potencial competitivo, a fim de agregar valor a esses negócios.

Muitas MPEs fracassam porque não vêem ou não reconhecem a necessidade de mudanças em seus produtos e processos. Surge então um dos problemas clássicos da gestão empresarial: o excesso de enfoque operacional dos dirigentes, que estão mais preocupados em resolver seus problemas diários e 
lidar com crises do que se preocupar estrategicamente com possíveis mudanças futuras. Contudo, a busca por novas formas de se manter no mercado competitivo é um dos grandes desafios das MPEs (BESSANT; JOHN, 2009).

Apesar de sua importância, as MPEs enfrentam dificuldades que não possibilitam a sobrevivência de parte significativa delas. Embora essas empresas se mostrem criadoras de campos de trabalho, as mesmas são vulneráveis e apresentam diversidade extrema.

Suas dificuldades são atribuídas, principalmente, ao fracasso administrativo, à incapacidade de atrair e manter pessoal qualificado, ao uso de tecnologia obsoleta e aos recursos financeiros limitados (MAÇANEIRO; CHEROBIM, 2011).

Um dos fatores que leva as MPEs ao declínio é a incapacidade administrativa, a falta de experiência dos seus gestores muitas vezes tem forte influência no seu rendimento, muitas vezes por não ter recursos financeiros suficientes as mesmas não têm a sua disposição uma mão de obra capacitada e qualificada.

\section{METODOLOGIA}

Inicialmente foi desenvolvido uma revisão de literatura sobre inovação em Micro e Pequenas Empresas (MPEs) e fatores críticos de sucesso. Posteriormente foi aplicada uma pesquisa de campo em MPEs de Zé Doca, Maranhão. Segundo Freitas e Prodanov (2013), a pesquisa de campo é aquela utilizada com o objetivo de conseguir informações e/ou conhecimentos acerca de um problema para o qual procuramos uma resposta, ou de uma hipótese, que queiramos comprovar, ou ainda, descobrir novos fenômenos ou as relações entre eles. Consiste na observação de fatos e fenômenos tal como ocorrem espontaneamente, na coleta de dados a eles referentes e no registro de variáveis, que presumimos relevantes, para analisa-los.

A princípio foi lido e entregue para os entrevistados (proprietários das empresas) assinarem o termo de consentimento livre e esclarecido (TCLE), onde foram expostos todos os direitos dos mesmos, bem como o objetivo da pesquisa. Feito isso, deu-se início à aplicação dos questionários semiestruturados. Com o consentimento dos entrevistados, as entrevista foram gravada para posterior tabulação.

Após a coleta dos dados, que se deu por meio de entrevistas onde foi aplicado o questionário semiestruturado, os mesmos passaram por uma tabulação onde foram reunidos os dados, os mesmos foram transcritos e analisados.

Quanto a natureza, a pesquisa desenvolvida pode ser classificada como exploratória. Segundo Gil (2010) esta modalidade tem como propósito proporcionar maior familiaridade com o problema, com vistas a torná-lo mais explícito. Também é realizada quando se busca conhecer detalhadamente os aspectos ou situações que não foram ainda exploradas, ou pouco exploradas na literatura.

Em relação a abordagem de tratamento dos dados, este estudo é classificado como de cunho qualitativo. A pesquisa qualitativa se preocupa com o aprofundamento da compreensão de um grupo social, de uma organização (GOLDENBERG, 1997).

Os dados foram coletados em duas empresas do município, uma do setor de artigos para presentes e a outra no setor de vendas de calçados femininos. Foi aplicado uma entrevista semiestruturada contendo exemplos de fatores críticos que foram identificados na literatura.

Quanto ao delineamento, esta pesquisa se configura como um estudo de caso múltiplo. 0 estudo de caso é citado na literatura como adequado para a investigação de um fenômeno contemporâneo dentro de seu contexto real, onde os limites entre o fenômeno e o contexto não são claramente percebidos, o que se aplica a claramente de acordo com os objetivos e problema delimitados nesta pesquisa (YIN, 2005).

\section{APRESENTAÇÃO E DISCUSSÃO DOS RESULTADOS}

Atualmente, a inovação vem sendo muito discutida, como essencial para a sobrevivência dos negócios visto que o ambiente do empreendedor está cada vez mais competitivo. A competição está cada vez mais presente no ambiente dos negócios, no ambiente da firma e na tomada de decisão dos gestores segundo Conto et al (2016). Para o autor, a necessidade frequente de mostrar algo novo, melhorado ou inédito ao consumo, mostra o nível de competitividade em que as firmas estão atuando, reforçando assim a ideia de que a inovação é fundamental para micro e pequenas empresas e nesse sentido a inovação é o principal fator de competitividade das firmas para ampliar e manter a sua atuação. 
Dentro da perspectiva, os dados foram coletados em uma amostra limitada de duas empresas no Município de Zé Doca, Estado do Maranhão, sendo uma do setor de artigos para presentes e a outra de calçados, cosméticos e variedades.

A Empresa 1 está atuando no mercado há 3 anos e seu público alvo são mulheres de classe média, a proprietária da empresa relatou que um dos motivos de seus produtos serem mais atraentes para mulheres é o fato destas possuírem um habito maior de presentear as pessoas.

A Empresa 2 está atuando no mercado há 5 anos, os produtos oferecidos pela empresa são calçados femininos e o seu público alvo são mulheres de todas as classes sociais, os produtos da loja são voltados apenas para mulheres, são produtos acessíveis e diversificados. Embora sejam apenas produtos voltados para o público feminino a proprietária pensa em futuramente trabalhar com produtos do universo masculino.

\subsection{MUNICÍPIO DE ZÉ DOCA}

Com população estimada em cerca de 50,190 habitantes Zé Doca é uma cidade que fica localizada microrregião de Pindaré, mesorregião do Oeste maranhense. A cidade foi criada no ano de 1988 (IBGE, 2014).

O município é o maior da sua região, o Alto Turi, conforme a gerência de desenvolvimento e articulação regional, a região é caraterizada por ações em mais de 17 municípios circunvizinhos. Sendo, portanto, carinhosamente chamada pelos habitantes da região como "Metrópole" do Alto Turi. A economia zedoquense se baseia no comércio regional de artigos de agropecuária, além de ser o mais importante centro comercial da região maranhense do Alto Turi.

Todavia a pesquisa foi aplicada em duas empresas do setor de comércio varejista, que é um grande gerador de renda para o município.

\subsection{CASO DA EMPRESA 1}

Como já foi citado acima Empresa 1 atua no setor de artigos para presentes, a mesma dispõe de uma vasta variedade de artigos de perfumaria, flores e chocolates.

Após questionamento sobre como surgiu a ideia em montar um negócio, a proprietária respondeu que foi a partir da necessidade da busca pela autonomia e principalmente pela sua subsistência surgiu à ideia de montar um negócio que até então era novo e diferente de tudo o que já havia sido implementado na cidade, a ideia surgiu após a proprietária encontrar-se desempregado e sem ter outra saída decidiu empreender por necessidade.

Segundo Moreira (2010), os empreendedores por necessidade iniciaram seu empreendimento de maneira autônoma, por não possuírem melhores opções para trabalho, e se veem diante da abertura de um negócio a fim de gerar renda para manter suas famílias. Para Hisrich\&Peters, (2004) o empreendedorismo por necessidade está mais ligado à situação econômica dos países, tendendo a diminuir quando a oferta de emprego é maior, sendo mais praticado por pessoas em vulnerabilidade financeira.

Foi relatado durante a entrevista pela proprietária, que a mesma já tivera um negócio no passado, mas o mesmo não atuava diretamente no dia-a-dia e no ambiente da empresa a mesma acabou entrando em um colapso e fechou as portas.

A proprietária está a atuando no mercado há 3 anos com o negócio atual, durante a entrevista foi relatado pelo proprietário que a principal dificuldade enfrentada para a implementação do negócio foi a falta de dinheiro para abrir a empresa, a proprietária relatou que até hoje a dificuldade com recursos financeiros é um fator limitante para a manutenção do negócio a implementação de inovações.

A empresária relatou durante a entrevista que seu entendimento a respeito de inovação é a implementação de um bem, serviço ou processo novo ou significativamente melhorado, visão essa que vai de encontro com o Manual de Oslo (OECD, 2005). A proprietária da empresa disse também nunca ter buscado nenhum tipo de ajuda ou assessoria, mas que sempre buscou obter conhecimento a respeito da área de atuação da sua empresa em cursos promovidos pelo Serviço Brasileiro de Apoio a Micro e Pequenas Empresas (SEBRAE) da sua região. 
Foi relatado também que já foram analisadas as oportunidades para inovar, e a primeira ideia foi a da venda de cestas de presentes com uma vasta variedade de produtos, levando isso em consideração, a empresaria relatou que essa é uma forma de vender os produtos mais rapidamente, o que facilita na organização dos estoques e também na liquidação dos produtos que estão há muito tempo nas prateleiras, com preços bem acessíveis, o que é bom para a loja e para o consumidor.

A proprietária relatou que a inovação na sua empresa não é acompanhada, e que os próprios produtos nas suas prateleiras são o diferencial do seu negócio, segundo a mesma, no momento de procurar fornecedores a empresa buscou algo que fosse novidade na cidade.

Frequentemente são buscadas maneiras de inovar pela empresa, e a áreas com um maior índice de inovação são em marketing e processos, para a empresa, os benefícios gerados através da implementação de inovações giram em torno dos seus produtos e serviços dos concorrentes, criando um valor adicional ou novo para os clientes. Na Empresa raramente são avaliados os benéficos da implementação de inovações, isso se deve ao fato de não saber como suceder aos resultados da inovação.

Por ser uma empresa pequena, a mesma só contrata funcionários em épocas de maior demanda, a proprietária da empresa é quem fica encarregada do atendimento aos clientes e grande parte do tempo, a mesma disse já conhecer bem os seus clientes e possuir uma relação mais próxima com os mesmos, foi relatado pela empresa que é sempre buscado por ela maneiras de obter conhecimento a respeito da inovação dentro do seu ambiente de trabalho, tendo sucesso em todas as suas tentativas de implementar algo novo.

\subsection{CASO DA EMPRESA 2}

A Empresa atua no mercado há 5 anos com vendas de produtos e variedades em geral para o público feminino, são comercializados calçados, cosméticos, bolsas e peças intimas. Segundo a proprietária seus produtos são acessíveis para todas as classes sociais. A iniciativa de abrir a empresa foi todo um conjunto de ideias e começou através de uma oportunidade, a principal dificuldade encontrada na implementação do negócio foi a aquisição de capital financeiro, e conquistar clientes.

Após anos realizando pesquisas no Brasil, a Global Entrepreneurship Monitor (GEM, 2008) percebeu que o perfil do empreendedor brasileiro tem mudado, onde os empreendedores estão em busca do conhecimento para melhor gerenciar seu empreendimento, o que gera competitividade para a sua empresa, nessas mesmas pesquisas realizadas pela GEM (2008), foi notável que os empreendedores motivados por oportunidade têm aumentado, sendo um dado otimista e promissor para o desenvolvimento da economia do país. Este empreendedor por oportunidade de tem sido o principal alvo do Serviço Brasileiro de Apoio a Micro e Pequenas Empresas (MORREIRA et al., 2018).

No campo dos negócios, a motivação de empreendedorismo por oportunidade, surge quando os futuros empreendedores possuem outras opções de emprego, ou escolhem um novo negócio, onde já tem em mente o que querem buscar para a sua empresa e visa à geração de lucros, empregos e riquezas, este por sua vez, refere-se a uma melhor visão do que é ser um empreendedor (DORNELAS, 2008).

A proprietária já buscou ajuda e conhecimento, segundo a mesma, a empresa está sempre em busca de conhecimento. Para a empresária, a inovação é um conjunto de ideias inovadoras que não foram aplicadas antes. É um produto que seja ele bem/serviço novo ou significativamente melhorado, de um novo processo, de um novo método de marketing, visão essa que também está de acordo com o Manual de Oslo (OECD, 2005).

A ideia de inovação da proprietária é abrir um ponto próprio, que já está em andamento, a mesma trabalha em um local alugado e tem um espaço limitado. Foi destacado pela empresária sempre prezar pela qualidade do atendimento aos clientes, oferecendo produtos acessíveis aos consumidores. A proprietária relatou que a sua empresa realiza esforços para inovar com frequência, uma inovação implementada pela empresa recentemente foi nos meios de pagamento, com a implementação da venda no boleto bancário.

Os benefícios gerados através da implementação de inovação pela empresa é o aumento do número de clientes, a empresa avalia os benefícios da implementação das inovações com estudo dos níveis de "inadimplência". O processo de inovação adotado pela empresa é sempre buscar conhecimento sobre a área, e tratar com os funcionários sobre assuntos relacionados a empresa. 
A Empresa destacou nunca ter tido resultados negativos ao tentar inovar, as dificuldades encontradas no processo de implementação das melhorias e/ ou inovação se deve ao fato de o local da empresa não ser da empresária, ou seja, é alugado.

A empresária diz que ao pensar em inovação, não usou como referências algo que deu certo em outros seguimentos, a empresa tem colaboradores que adotam medidas inovadoras no seu atendimento aos clientes, os colaboradores da empresa usam da inovação como por exemplo no ambiente da empresa, marketing e divulgação da marca da empresa.

\subsection{DISCUSSÃO DOS RESULTADOS}

A partir dos dados coletados por meio das entrevistas podemos ter a mais completa convicção de que a inovação não se restringe apenas as firmas ou empresas de grande porte, podendo assim expandir-se no ambiente de pequenas empresas do setor comercial.

No caso da Empresa 1, que é uma empresa onde a inovação não é acompanhada, e que tem como principal diferencial os próprios produtos oferecidos pode-se destacar as cestas para presentes como um grande diferencial das empresas do mesmo seguimento, como já foi dito anteriormente essas cestas dispõe de uma gama de produtos diferenciados, e com um preço acessível a mesma é uma forma inusitada de queimar o estoque e esvaziar as prateleiras o que é bom tanto para o cliente como para a empresa que lucra bastante com a venda das mesmas.

A Empresa 2 dispõe de um ambiente despojado com uma ampla variedade de artigos de calçados para o público feminino, uma grande vantagem competitiva que aqui se pode destacar é o fato de a empresa atender a demanda de todas as classes sociais, com seus preços acessíveis e um ótimo atendimento. Outro diferencial dessa empresa é a emissão de boletos bancários para os clientes, o que até então é algo novo na região em que se localiza a loja.

O quadro a seguir mostra algumas dificuldades que podem ser diagnosticadas como fatores limitantes, bem como propostas de melhorias para essas limitações.

Quadro 2- Fatores limitantes versus proposições de melhorias

\begin{tabular}{|c|c|c|}
\hline Empresas & Fatores limitantes & Proposições de melhorias \\
\hline Empresa 1 & $\begin{array}{l}\text { Dificuldades de vendas para } \\
\text { alguns clientes que } \\
\text { desconhecem os produtos da } \\
\text { loja }\end{array}$ & $\begin{array}{l}\text { Apresentar aos clientes o que o produto oferece, bem como } \\
\text { os seus benefícios ao adquirir o mesmo. }\end{array}$ \\
\hline Empresa 2 & Espaço e ambiente de trabalho & $\begin{array}{l}\text { Tentar manter sempre a boa qualidade do produto, e } \\
\text { atendimento mesmo com algumas limitações no ambiente } \\
\text { de trabalho. }\end{array}$ \\
\hline Empresa 1 & $\begin{array}{l}\text { Falta de capital para } \\
\text { implementar mudanças } \\
\text { significativas }\end{array}$ & $\begin{array}{l}\text { Um método para a aquisição de mais capital financeiro seria } \\
\text { o de adotar medidas de vendas de produtos externamente, } \\
\text { dentro dessa perspectiva é uma maneira de ter um maior } \\
\text { alcance e reconhecimento de mercado. }\end{array}$ \\
\hline Empresa 2 & $\begin{array}{l}\text { Falta de capital financeiro para } \\
\text { alavancar mudanças e } \\
\text { melhorias no ambiente da loja }\end{array}$ & $\begin{array}{l}\text { Uma maneira simples de conseguir mais recursos } \\
\text { financeiros seria a adoção de um novo mercado, mais } \\
\text { especificamente o mercado masculino, dentro dessa } \\
\text { perspectiva a loja conseguiria mais clientes e venderia bem } \\
\text { mais do que atualmente. }\end{array}$ \\
\hline
\end{tabular}

Fonte: Elaborado pelo autor (2019)

Apesar de ter preços acessíveis para mulheres de todas as classes sociais e ainda assim vender bastante, ainda assim a Empresa 2 sofre com a crise econômica atual. Seguindo à risca algumas mudanças que a empresária vê como necessárias para fugir da crise e se manter sempre firme no mercado, pode ser que uma boa opção seja optar pela inovação como sua principal base para se destacar entre as outras empresas do mesmo seguimento do município.

A Empresa 1 por sua vez tem como seu principal diferencial os próprios produtos oferecidos pela loja, porém a empresa não é acompanhada no processo de inovação, o que pode dificultar no seu processo de crescimento, a empresa quando acompanhada nos processos de inovação abre precedentes para que seu proprietário saiba como lidar com as mudanças que uma possível inovação pode oferecer. 
Para ambas as empresas o ideal seria repensar a possibilidade de buscar consultorias com profissionais especializados na área do seu ramo de atuação comercial, essa é uma alternativa válida de adquirir conhecimento acerca de como crescer empresarialmente e alavancar o seu negócio. Ou seja, existem fatores considerados essências para a inovação, Nelson \&Winter (1982) e Dosi (1982) destacam como: rotinas, habilidades e aprendizado. As empresas colocando em prática seus projetos e com uma ajuda de pessoas especializadas no ramo da consultoria, seria um investimento de grande valor para os negócios e serviços das empresas. Porém, tudo dentro da realidade de cada empresário, analisando possibilidades que realmente tragam algum benefício.

O principal passo para sair de uma situação não desejada para cada empresa, é que as empresárias precisam reconhecer dentro dos seus negócios seja ele futuro ou não, que a inovação é o caminho mais viável a percorrer.

\section{CONSIDERAÇÕES FINAIS}

Essa pesquisa teve como objetivo geral identificar quais são as dificuldades enfrentadas na implementação de inovações pelas Micro e Pequenas Empresas do município de Zé Doca. Especificamente buscou-se entender quais os fatores limitantes para a implementação de inovações no ambiente das empresas, entender como funciona o processo de inovações e propor sugestões para driblar as limitações, identificando-se assim os benefícios da inovação na pequena empresa.

A princípio foi feita uma revisão de literatura para buscar compreender quais fatores críticos de sucesso propiciam a inovação em Micro e Pequenas Empresas, por meio da literatura pôde-se observar que a inovação é um tema bastante discutido na atualidade, assim como a sua importância para empresas de grande, médio e pequeno porte.

A pesquisa que foi realizada em duas empresas com realidades bastante distintas, uma das empresas surgiu a partir de uma necessidade e a outra por meio de uma oportunidade. A empreendedora por oportunidade é, antes de tudo, uma observadora da realidade onde vive. Ela está sempre atento às necessidades e demandas do consumidor contemporâneo e, ao enxergar a carência de determinado produto ou serviço, resolve implementá-lo. Já a empreendedora por necessidade age de forma mais cautelosa quanto a possibilidade de inovação.

De modo geral esse trabalho é relevante para as MPEs não só do município de Zé Doca e região, podendo também ser um importante estudo para a compreensão de fatores críticos de sucesso para a inovação em Micro e Pequenas Empresas.

Todavia, o fato do tema Inovação em MPEs ser pouco explorado na literatura, dificulta e ao mesmo tempo abre espaço para o avanço no conhecimento dos caminhos a serem percorridos para a implementação de melhorias no ambiente empresarial. A pesquisa teve como principal limitação o fato da investigação ter sido realizada em empresas de setores e seguimentos diferentes e a amostra limitada de 2 empresas.

Sugere-se que futuramente sejam feitos mais estudos com uma amostra maior de empresas do mesmo seguimento, para que haja uma representatividade melhor dos setores estudados. Também se sugere que sejam feitos estudos estatísticos na amostra a ser pesquisada.

\section{REFERÊNCIAS}

[1] Aparecida, G; Souza, J. A; Teza, P; Fernandes, R. F; Miguez, V. B. Ideias para a inovação: Um mapeamento sistemático da literatura. Gest. Prod., São Carlos, v. 23, n. 1, p. 60-83, 2016. Disponível em:<http://www.scielo.br/pdf/gp/v23n1/0104-530X-gp-0104-530X1454-14.pdf>. Acesso em 14 jan. 2019.

[2] Araujo, A. K; Araujo, R. M. Inovação de processos: Um estudo no segmento de restaurantes. Revista Cultur Revista de cultura e turismo Ano 7 - № 03 - OUT, 2013. Disponível em: <http://periodicos.uesc.br/index.php/cultur/article/view/333/339>.. Acesso em: 14 jan. 2019.

[3] Bachmann, D. L; Destefani, J. H. Metodologia para estimar o grau de inovação nas MPE. 2008. Disponível em:<http://www.bachmann.com.br/website/documents/ArtigoGraudeInovacaonasMPE.pdf>. Acesso em: 20 fev. 2019.

[4] Balestrin, A; Bueno, B. Inovação Colaborativa: Uma Abordagem Aberta no Desenvolvimento de novos Produtos. 2012. Disponível em:<http://www.scielo.br/pdf/rae/v52n5/a04v52n5.pdf>. Acesso em: 20 jan. 2019. 
[5] Balestrin, A; Verschoore. J. Aprendizagem e Inovação no contexto das redes de Cooperação entre pequenas e médias Empresas. Revista 0 \& S. Salvador, v.17 - n.53, p. 311-330 - Abril/Junho - 2010. Disponível em:<http://www.scielo.br/pdf/osoc/v17n53/05.pdf>. Acesso em: 20 jan. 2019.

[6] Bessant, J; Tidd, J. Inovação e Empreendedorismo. São Paulo: Bookman. 2009

[7] Bueno, Bruna; Balestrin, A. Inovação colaborativa: uma abordagem aberta no desenvolvimento de novos produtos. Revista de Administração de empresas, São Paulo, v. 52, n. 5, p. 517-530, Oct. 2012 . Disponível em <http://www.scielo.br/scielo.php?script=sci_arttext\&pid=S0034-75902012000500004\&lng=en\&nrm=iso>. Acesso em 14 de jan. 2020.

[8] Ceretta, G. F.; REIS, D. R. dos; ROCHA, A. C. da. Inovação e modelos de negócio: um estudo bibliométrico da produção científica na base Web of Science. Gestão \& Produção, São Carlos, v. 23, n. 2, p. 433-444, Jun. 2016 Disponível em <http://www.scielo.br/scielo.php?script=sci_arttext\&pid=S0104530X2016000200433\&lng=en\&nrm=iso>. Acesso em 14 Mar. 2019. Epub May 31, 2016.

[9] Cherobim, A. P. M. S; Maçaneiro. M. B. Fontes de financiamento a inovação: Incentivos e óbices às Micro e Pequenas Empresas - Estudo de Casos Múltiplos no Estado do Paraná. Revista O \& S. Salvador, v.18 - n.56, p. 57-75 Janeiro/Março 20112011.2 Disponível em: https://www.researchgate.net/publication/315945086_Fontes_de_Financiamento_a_Inovacao_incentivos_e_obices_a s_micro_e_pequenas_empresas_-_estudo_de_casos_multiplos_no_estado_do_Parana. Acesso em 07 mar. 2019.

[10] Conto, S. M. de; Antunes Junior, J. A. V; Vaccaro, G. L. R. A inovação como fator de vantagem competitiva: estudo de uma cooperativa produtora de suco e vinho orgânicos. Gestão \& Produção, São Carlos, v. 23, n. 2, p. 397-407, jun. 2016. Disponível em <http://www.scielo.br/scielo.php?script=sci_arttext\&pid=S0104530X2016000200397\&lng=pt\&nrm=iso>. Acesso em 03 fev. 2019.

[11] Costa, M. de S.; Olave, M. E. L. Inovação em Micro e Pequenas Empresas: Uma Visão dos Agentes Locais de Inovação do Sebrae em Aracaju-se. VIII Encontro de Estudos em Empreendedorismo e Gestão de Pequenas Empresas (EGEPE), Goiânia, 24 a 26 de março, 2014. Disponível em <http://www.egepe.org.br/anais/tema01/167.pdf>. Acesso em 05 fev. 2019.

[12] Darcoso. A L. R; Silva. G. Inovação aberta como uma vantagem competitiva para a Micro e Pequena Empresa. Revista de Administração e Inovação v. 10, n.3, p.251-268, jul./set. 2013. Disponível em: <http://www.revistas.usp.br/rai/article/view/79337/pdf_1>. Acesso em: 15 fev. 2019.

[13] Dornelas, J. C. A. Empreendedorismo corporativo: como ser empreendedor, inovar e se diferenciar na sua empresa. 2. ed. Rio de Janeiro: Elsevier, 2008.

[14] Freitas, E. C; Prodanov, C. C. Metodologia do trabalho cientifico: Métodos e técnicas da pesquisa e do trabalho acadêmico. 2 ed.: Novo Hamburgo, 2013.

[15] Gem. Empreendedorismo no Brasil: 2008. Curitiba: IBQP, 2009. Disponível em <https://m.sebrae.com.br/Sebrae/Portal\%20Sebrae/Anexos/GEM-Brasil-2008.pdf>. Acesso em 17 fev. 2019.

[16] Gil, A. C. Como elaborar projetos de pesquisa. 5. ed. São Paulo: Atlas, 2010

[17] Goldenberg, M. A arte de pesquisar: como fazer pesquisa qualitativa em Ciências Sociais. 8 ${ }^{\underline{a}}$ ed. - Rio de Janeiro: Record, 2004.

[18] Hisrich, R.D; Peters, M.P. Empreendedorismo. 5a ed. Porto Alegre. McGraw-Hill. 2004.

[19] Maia, A. F. S. Inovação em Micro e Pequenas Empresas: Uma análise do caso Brasileiro. 2012. Disponível em: https://repositorio.ufu.br/bitstream/123456789/13546/1/d.pdf. Acesso em: 07 mar. 2019.

[20] Morreira, A. P; Farias, C. S. S; Rodrigues, F. L; Jesus, L. S. Empreendedorismo Por Oportunidade x Empreendedorismo Por Necessidade: Uma Análise do Micoempreendedor individual do comércio varejista de vestuário da cidade de Guanambi. Congresso Internacional de Admnistração. 2018. Disponível em: https://admpg2018.com.br/anais/2018/arquivos/04302018_160441_5ae76c4d402ae.pdf. Acesso em: 12 de mar. 2019.

[21] Moreira, P. A. Contexto de Empreendedorismo. 1aㅡ ed. Brasília: Elsevier, 2010.

[22] Oecd. Manual de Oslo. Ed. 3. Traduzido sob a responsabilidade da FINEP — Financiadora de Estudos e Projetos. São Paulo. 1997.

[23] Staub, E. Desafios estratégicos em ciência e tecnologia da inovação. 2001. Disponível em: <http://seer.cgee.org.br/index.php/parcerias_estrategicas/article/viewFile/205/199>. Acesso em: 18 fev. 2019.

[24] Yin, R. K. Estudo de caso: planejamento e métodos. 4. ed. Porto Alegre: Bookman, 2005. 


\section{Capítulo 13}

\section{A aplicação do Octógono da Inovação em uma organização pública}

\section{Ana Clara Cavalcanti de Miranda \\ Sérgio de Oliveira Lima \\ Millena de Carvalho da Cunha \\ Gesualdo Menezes Cavalcante \\ Alessandra Carla Ceolin}

Resumo: A inovação possui uma perspectiva de quebrar paradigmas por meio da criação de produtos inovadores ou campos do conhecimento, que pode ser preparada, estuda e propiciada. Este artigo aborda o uso do Octógono da Inovação em um setor público ao se propor inovação em suas práticas. Esta ferramenta possibilita identificar e diagnosticar o grau e gaps de inovação nas organizações ao mesmo tempo em que indica pontos a serem melhorados, otimizando assim o controle e a gestão pública. 0 presente artigo é uma pesquisa exploratória e descritiva, o método de coleta de dados se deu através de questionário, numa instituição militar, através da metodologia do octogno da inovação. Buscou-se observar o caminhar das práticas inovadoras nesta instituição em seus diversos aspectos. Logo, é possível observar com a análise dos resultados que o Octógono da Inovação é uma ferramenta que pode ser aplicada na administração pública, possibilitando aos gestores viabilizar estratégias de adequação às suas práticas proporcionando inovação no uso dessa ferramenta, onde não se acredita ser possível inovar.

Palavras-chave: Inovação; Gestão; Controle. 


\section{INTRODUÇÃO}

As práticas inovadoras fazem com que as empresas que delas sejam utilizam se diferenciam no mercado e em sua gestão organizacional. Nessa perspectiva o conceito de inovação aparece na busca de aumentar a qualidade, de fazer o melhor onde se está, de inovar e de criar.

É inegável que não há de se falar em instituições inovadoras sem que a gestão da empresa também seja inovadora, dessa forma, toma-se por Gestão da Inovação (GI) uma capacidade que é desenvolvid e que se aprende. Além disso a GI parte de um contexto de onde cada instituição deve buscar seus caminhos para as soluções de seus problemas/necessidades, desenvolvido e realizado localmente (TIDD; BESSANT E PAVITT, 2008).

A capacitação para se ter a inovação é fundamental, devendo-se criar um ambiente propício para isso. 0 gerenciamento do conhecimento é uma competência que vem desde o século passado, quando se perceber que a inteligência produzida quando se o adquire formenta a inovação. Faz-se necessário estimular o indivíduo, como afirma Bezerra (2011, p.71) "Em inovação não existem fórmulas. Antes de criar as inovações, precisamos criar os inovadores".

Partindo dessa compreensão, a dinâmica das tecnologias e as exigências de um público alvo interativo com os novos cenários têm levado as empresas que possuem como cliente o mercado em expansão a investir em inovação.

Esse cenário proporciona aos gestores ter uma visão integrada de todo o sistema utilizado em sua instituição, assim corroborando com essa compreensão Scherer e Ribeiro (2012) irão dizer que é importante que as empresas busquem incorporar em seu sistema de gestão características que fomentem a inovação, a instituição deixa de ser ortodoxa, para torna-se uma instituição social inovadora.

Segundo o Manual de Oslo (1997) inovação é a implementação de um produto (bem ou serviço) novo ou significativamente melhorado, ou um processo, ou um novo método de marketing, ou um novo método organizacional nas práticas de negócios, na organização do local de trabalho ou nas relações externas, dessa forma a inovação de métodos foi potencializada pelo uso de tecnologias interativas, uma vez que a construção de aplicativos e materiais virtuais inovou o mercado através de empresas que trabalham com tecnologia.

Assim, este artigo se propõe a analisar uma instituição pública que propõe inovação em suas práticas, para a análise utilizou-se a ferramenta do Octógono da Inovação desenvolvida para identificar o nível de inovação que apresenta e diagnosticar pontos a serem melhorados.

Este artigo se estrutura em três partes: inicialmente há uma breve revisão da literatura sobre o Octógono da Inovação, em seguida é apresentada a metodologia proposta e por fim a análise dos resultados da aplicação do questionário na instituição de pública que trabalha com técnicas inovadoras.

\section{DIMENSÕES DOS ARTIGOS E DAS PÁGINAS}

A inovação surgiu desde os primórdios da humanidade, onde o homem primitivo procurava inventar novas formas de ferramentas para poder sobreviver diante das adversidades da natureza e concorrência em busca de alimentos com outros animais selvagens, observa-se que a inovação sempre esteve presente no progresso da humanidade; porém foi na Inglaterra, com a revolução industrial que o tema começou a ter destaque no mundo corporativo (RAUEN, 2015; ROCHA, 2019).

Na atualidade, com a velocidade e desenvolvimento tecnológico ditado pela "era da informação", inovar tornou-se uma questão de sobrevivência para as organizações, pois em um cenário onde o cliente possui um perfil bastante exigente e o mercado está em constante transformação, ela poderá aumentar a vantagem competitiva e ser responsável direta pelo sucesso ou insucesso de uma organização (BRANDÃO; FARIA, 2013).

Nas últimas décadas, as organizações públicas brasileiras têm evoluído em termos de inovação tanto nos processos internos (com melhoria de gestão e controle dos bens públicos) como nos serviços prestados à sociedade como um todo (KLUMB; HOFFMANN, 2016). 
Como exemplo, pode-se citar as ações desenvolvidas pela Justiça Eleitoral que desenvolveu novas tecnologias para aprimorar o processo eleitoral; as ações desenvolvidas pelas Secretarias da Fazenda Estaduais e Receita Federal do Brasil, onde o desenvolvimento se deu em software inovadores que otimizou a fiscalização e arrecadação de tributos; a modernização das Universidades e Institutos Federias com a introdução de ferramentas modernas de ensino com uso de tecnologia em sala e ensino a distância (EAD), ou seja em todos as áreas da administração pública a inovação parece seu um atributo presente que promove uma maior transparência e melhora a qualidade dos serviços públicos.

Segundo Carvalho e Ruiz (2018), o processo de acelerada evolução tecnológica nos serviços públicos vêm ocasionando também transformações estruturais nas forças armadas e nos setores de defesa de vários países. Isto porque, na visão de Galvão Netto (2011), a capacidade de conduzir e definir as guerras contemporâneas passou a depender de posturas militares baseadas em vantagens estratégicas e táticas obtidas pelo uso intensivo da tecnologia e do conhecimento adquirido através do processo de inovação. Não é a toa que a maior potência militar do mundo, os Estado Unidos, possui uma arsenal bélico de alta tecnologia e vem investindo cada vez mais em inovação para criar novos mísseis e artefatos militares mais eficazes.

Em síntese, Galvão Netto (2011) pontua que as características das guerras e dos conflitos atuais vêm se alterando desde o final do século XX até o século presente, onde as mudanças são notórias e baseadas na conjugação de vários fatores, incluindo a inovação. Essas mudanças foram apontadas por Toffler (1995) como sendo: (a) frentes de batalha indefinidas; (b) vitória militar dependente da velocidade em relação ao oponente; (c) informações como um dos principais fatores para a obtenção de vantagens táticas e estratégicas; (d) papel central desempenhado pelas inovações tecnológicas nas estratégias militares. 0 que pode ser acrescentado, conforme esclarece Galvão Netto (2011) é a aglutinação de todos estes fatores, ocasionando uma profunda transformação no âmbito das defesas nacionais.

Inovar é uma constante no mundo empresarial, e não geradas de modo livre, descomprometido. Pelo contrário, são formadas de maneira deliberada, incubadas em meio favorável, onde as imaginações são propícias. A inovação tem corroborado com o crescimento e fortalecimento das entidades empresariais, e o público consumidor se mostra adepto aos valores advindo da inovação. Os funcionários desejam se enquadrar em empresas que utilizam a inovação. Assim, resta a empresa ter a forma de como adentrar nesse curso de modo perene, organizado e deliberadamente.

Considerado o "pai da inovação" Schumpeter (1957) que diz que é possível inovar introduzindo um novo método de produção, ainda não experimentado do ramo produtivo, e com essa compreensão, fazer a introdução de um novo método no ramo produtivo ou em qualquer área, é fazer inovação.

Para facilitar a compreensão do conceito de inovação Mello e Martins (2013) confeccionaram um quadro conceitual, apresentado no quadro 1, no qual apresenta-se vários conceitos de inovação que podem se configurar como partes importantes para obtê-la.

O quadro 1 apresenta então as várias visões sobre o que ultimamente pesquisa-se em relação a inovação e quais os caminhos que estão sendo percorridos. Byrd e Brown (2003), asseveram que uma empresa inovadora incentiva aos colaboradores ao uso da autonomia, concede gratificação como reconhecimento e valorização do seu envolvimento, reconhece a superação face a obstáculos, que se apropria do vigor ante a momentos de turbulência. Com esse porte a empresa se treina para responder às questões externas, concebem novas ideais, prosperam no campo da eficiência, atendem com melhor qualidade o cliente e garante maior rentabilidade.

Assim corroborando com essa compreensão Pierre Bourdieu diz que "para mudar o mundo, é preciso mudar as maneiras de fazer o mundo, isto é, a visão de mundo e as operações práticas pelas quais os grupos são produzidos e reproduzidos" (Bourdieu, p. 166, 2004). Dessa forma, ao desejar novos cenários é necessário repensá-los e trabalhar novas possibilidades, o que pode ser viabilizado por meio da inovação. 
Quadro 1 - Conceitos de Inovação

\begin{tabular}{|l|l|}
\hline \multicolumn{2}{|c|}{ AUTOR(S) } \\
\hline Van de Ven et al. (1989) & $\begin{array}{l}\text { É um processo que envolve geração, adoção, implementação e incorporação de } \\
\text { novas ideias, práticas ou artefatos dentro da organização. }\end{array}$ \\
\hline Gonçalves e Gomes (1993) & $\begin{array}{l}\text { Inovações são mudanças nos processos de produção e nos modelos dos } \\
\text { produtos que sejam à base do progresso tecnológico. }\end{array}$ \\
\hline Tijssen (2002) & $\begin{array}{l}\text { É uma consequência das pesquisas básicas } \\
\text { e invenções que são inseridas no mercado. }\end{array}$ \\
\hline Byrd e Brow (2003) & Inovação é uma combinação entre a criatividade e a tomada de risco. \\
\hline Tidd; Bessant e Pavitt (2005) & $\begin{array}{l}\text { Nova tecnologia incorporada a produtos, que são diferentes daqueles já } \\
\text { produzida pela empresa. }\end{array}$ \\
\hline $\begin{array}{l}\text { Mcfadzean; O`loughlin; Shaw } \\
\text { (2005, p. 3) }\end{array}$ & $\begin{array}{l}\text { Um processo que fornece valor adicionado e um nível de novidade para a } \\
\text { organização e para seus fornecedores e clientes através do desenvolvimento de } \\
\text { novos procedimentos, soluções, produtos, e serviços e também de novos } \\
\text { métodos de comercialização. }\end{array}$ \\
\hline $\begin{array}{l}\text { Manual de Oslo (OECD, 2005, } \\
\text { p.46; FINEP, 2006, p.55) }\end{array}$ & $\begin{array}{l}\text { Implementação de um produto (bem ou serviço) novo ou significativamente } \\
\text { melhorado, ou um processo, ou um novo método de marketing, ou um novo } \\
\text { método organizacional nas práticas de negócios, na organização do local de } \\
\text { trabalho ou nas relações externas. }\end{array}$ \\
\hline $\begin{array}{l}\text { Haines e Sharif (2006); MCT } \\
\text { (2002). }\end{array}$ & $\begin{array}{l}\text { Melhoria da gestão organizacional e de suas relações com o ambiente externo e } \\
\text { interno. }\end{array}$ \\
\hline $\begin{array}{l}\text { Roberts (2007); Lakemond et al } \\
\text { (2007). }\end{array}$ & $\begin{array}{l}\text { Processo que inicia com a criação de uma ideia e finaliza com o lançamento do } \\
\text { produto no mercado. }\end{array}$ \\
\hline
\end{tabular}

Dentre as instrumentalidades que guiam para o horizonte da Inovação, o Octógono da Inovação, ferramenta de trabalho elaborada por Carlomagno e Scherer (2009), é um meio usado para a diagnose e gerenciamento de empresas imbuídas no objetivo de renovar, inovar, e fazem a utilização do polígono do octógono, que se delimitam pelas faces da: Estratégia - primeira instância analítica, onde se verifica qual a forma que a empresa se apresenta para investidas inovadoras; Cultura - ambiente que positiva a inovação pretendida; Estrutura - onde se localiza a parte que será alvo da inovação e qual a forma que se organiza; Pessoas - modo como será apoiado e ofertado o reconhecimento as pessoas englobadas nesse mister; Processos - identificação de como as oportunidades são criadas, avaliadas e aperfeiçoadas; Funding - onde serão encontrados os implementos financeiros; Liderança - suporte para o desenvolvimento da inovação; e Relacionamentos - prospecção para uso de parceiros, fornecedores, clientes, e concorrentes, na criar da inovação.

Visualiza-se o modelo proposto por Carlomagno e Scherer (2009) na figura 1.

Figura 1 - Octogono da inovação

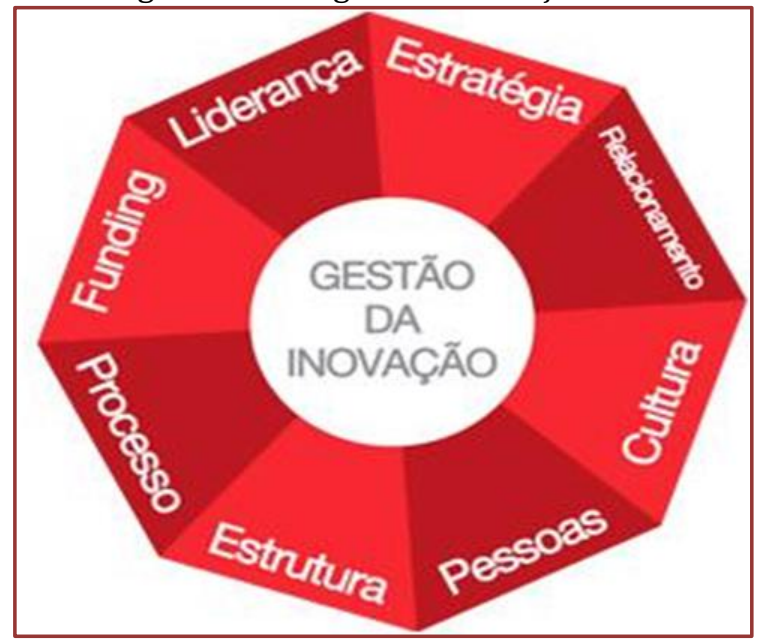


0 octógono da inovação apresentado na figura 1 permite visualizar qual a situação em relação à inovação que a instituição estudada se encontra, com a possibilidade de identificar quais são as lacunas que existem, onde a instituição está dando mais ou menos atenção. Isso é possível através da aplicação de um questionário o qual deve ser produzido de acordo com o perfil da instituição a ser pesquisada e para obtenção de dados objetivos esse questionário deve ser relacionado a outros instrumentos de mensuração como uma escala alguma escala.

Quando se pensa em empresas, principalmente as tradicionais, geralmente relaciona-se a transmissão do conhecimento formal com algo ortodoxo e pouco flexível, contudo é possível e desejável que a área empresarial seja inovadora. E para que esta dimensão seja alcançada faz-se necessário analisar e identificar as práticas e o perfil da instituição estudada, e neste momento é importante ter uma ferramenta como o octógono da inovação para ir além do mapeamento, esse instrumento permite visualizar os gaps a serem trabalhados, repensados e inovados.

\section{METODOLOGIA}

A metodologia deste artigo se enquadra numa pesquisa qualitativa pois o objetivo da amostra na pesquisa qualitativa "é de produzir informações aprofundadas e ilustrativas: seja ela pequena ou grande, o que importa é que ela seja capaz de produzir novas informações" (DESLAURIERS, 1991, p. 58). Como também "a pesquisa qualitativa não se preocupa com representatividade numérica, mas, sim, com o aprofundamento da compreensão de um grupo social, de uma organização" (GERHARDT; SILVEIRA, 2009, p. 31)

Esse artigo tem características de pesquisa exploratória pois "buscam uma abordagem do fenômeno pelo levantamento de informações que poderão levar o pesquisador a conhecer mais a seu respeito descritiva" (GERHARDT; SILVEIRA, 2009, p. 67) e descritivas uma vez que "são realizadas com o intuito de descrever as características do fenômeno" (GERHARDT; SILVEIRA, 2009, p. 67) ao na tentativa de compreensão de como se encontra a inovação dentro de uma instituição do setor público e diante disso explorar seus dados descrevendo as características encontradas.

Procurou-se realizar um estudo de caso, pois segundo Fonseca (2002, p. 33) o mesmo "procura compreender como é o mundo do ponto de vista dos participantes", com isso foi realizado um quesrionário com um representante das forças do exército brasileiro lotado em Pernambuco, "um bom estudo de caso pode envolver uma família, uma pequena escola ou instituição" (GERHARDT; SILVEIRA, 2009, p. 68)

0 método de coleta de dados foi através de quesionário, buscando-se aproveitar algumas vantagens segundo (GERHARDT; SILVEIRA, 2009, p. 7) como: “Obtém respostas mais rápidas e mais precisas, dá mais segurança, pelo fato de suas respostas não serem identificadas, dá mais tempo para responder, e em hora mais favorável e obtém respostas que materialmente seriam inacessíveis."

Para poder observar os dados da instituição foi aplicado um questionário, desenvolvido por Innoscience (2010) citado por Carvalho et al (2011, p. 109) estes questionários contêm cem afirmativas relacionadas a oito dimensões da inovação definidas pelo autor, estas são: liderança, estratégia, relacionamento, cultura, pessoas, estrutura, processo e financeiro. Cada afirmativa foi pontuada com uma nota entre 1 e 7 , através desta pontuação foi gerado o octógono da Inovação, contemplando as dimensões que influenciam a Inovação nas organizações. 0 questionário foi respondido por uma pessoa do exército que ocupa cargo de gestão.

0 questionário aplicado possui 100 perguntas fechadas com scores de 1 a 7 colocados em escala likert, pois segundo (SILVA JÚNIOR; COSTA, 2014, p. 5) "a grande vantagem da escala de Likert é sua facilidade de manuseio, pois é fácil a um pesquisado emitir um grau de concordância sobre uma afirmação qualquer". As perguntas foram destruídas em 8 dimensões sendo: estratégia, cultura relacionamento, financeiro, estrutura, processo, pessoas e liderança.

A análise será através de descrição dos resultados, sendo realizada no sentido horário, observadno a pontuações de no mínimo 0 e no máximo 7 , ao qual foi possível através do questionário aplicado chegar a um quantitativo para cada área abordada e assim poder analisá-las, essa média também é proposta por Carlomagno e Scherer (2009), o qual permite que os dados sejam de fato determinados por cada resposta do respondente, possuindo a sua área cada peso diferentes de acordo com o nível de inovação que possuem. 


\section{RESULTADOS}

0 resultado será estruturado através da análise dos dados dispostos na figura 2, a qual se encontra os números desenhados no gráfico do octógono da inovação. Com a finalidade de determinar o propósito da inovação, foram mensuradas as dimensões habilitadas da inovação, de acordo com Sawhney et al. (2006) explicitada pelo radar da inovação. Cada dimensão será analisada em separado podendo haver ligações entre elas a depender dos dados apresentados.

Figura 2 - Octogono da inovação da área militar

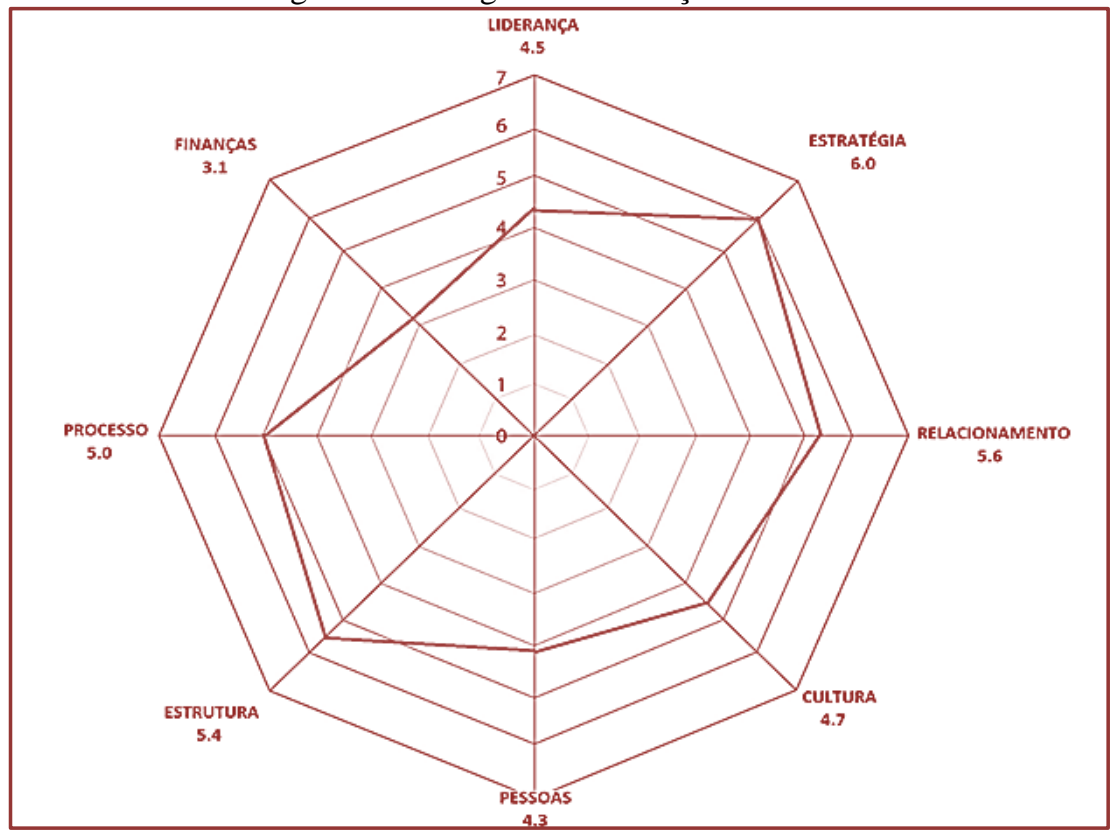

Observa-se na figura 1 as 8 (oito) dimensões que foram levantadas para assim formar o octógono da inovação para o serviço militar do exército.

A estratégia é um dos instrumentos mais trabalhadas dentro do Exército Brasileiro, pois desde o seu início sempre se pensava em como melhorar a parte estratégica como um todo. Merece ser citado que a Estratégia Nacional de Defesa (END), é assunto levado a debates, desde o seu surgimento, em dezembro de 2008, e que mesmo tentando a aproximação dos componentes da academia brasileira, que são próximos ao tema pertinente à Defesa, não angariam deles um esquadrinhar a contento no país (Oliveira, 2009; Domingos Neto, 2013). Winand e Saint-Pierre (2010) asseveram o desconhecimento e ínfimo interesse da comunidade sobre os assuntos de Defesa; e que, nas escolas, em particular, imperam o desprezo e a segregação contra as considerações tocantes ao assunto. Como é de notório conhecimento, os administradores aprenderam com o Exército, e assim levaram esses conhecimentos de estratégias para o âmago da empresa. Talvez o que tenha ocasionado não alcançar a nota máxima, para chegar ao mais alto escore do octógono, seja a ideia de que ao inovar seja necessário a participação e contribuição de vários colaboradores, o que não ocorre quando se trata de Exército Brasileiro. Outro ponto que também pode deixar a desejar nessa área é o campo de Marketing, que não diretamente valoriza a inovação como uma prática positiva e que agregue valores à instituição.

O relacionamento no Exército apesar de toda a hierarquia, que é algo de merecida consideração, e atrelada com a disciplina, conforme Rêgo (2015), são de importância elevada, e que são pertinentes a base, aos fundamentos da instituição, vem ganhando cada vez mais espaço, talvez por este motivo tenha ficado com a média $(5,6)$, como observa-se na figura 2, principalmente quando se trata do relacionamento interpessoal, contudo com clientes indiretos no caso da sociedade esse relacionamento normalmente é mediado, mostrando quanto mais a sua impessoalidade. Algo por exemplo, como contato direto como brindes ou serviços são ações pontuais de características humanitárias o que se torna fatos tão isolados que por muitas vezes parece não ser significativo no contexto social de maior proporção. Quanto então trata-se desse relacionamento, ao buscar a inovação, percebe-se que a mesma encontra cada vez mais 
fechada em suas pesquisas e suas verdades, deixando por vezes de conseguir informações valiosas que poderiam ajudar e inovar em suas ações.

Tende-se a pensar que a cultura de uma estrutura tão antiga, torna-se obsoleta e ultrapassada, a média do octógono do Exército foi (4.7), de acordo com a figura 2, o tratar da cultura, mostra que apesar de parecer bem definida e estruturada a cultura do Exército não está aberta ainda as práticas de inovação, afinal, da forma como está disposta a organização, por cargos e funções, cada componente militar trabalha num cargo definido previamente (Rêgo, 2015), onde labuta suas atribuições.

O cargo é como uma mística, que de tão importante para a Força Armada Terrestre, que se põe na condição de ser o seu terceiro sustentáculo, se aliando a hierarquia e a disciplina, propiciando uma posição de imobilidade, não ofertando condições para que todos que estão na instituição sintam-se livres para assim dar ideias e sugestões. Observa-se entraves nesse aspecto principalmente quando a comunicação interna é fechada e não se permite que seja realizado o compartilhamento de conhecimento com facilidade.

Essa falta de comunicação também interfere diretamente na inovação no setor de pessoas, uma vez que os colaboradores não compreendem a necessidade real de inovar e como essa inovação poderia ajudar a instituição como um todo, inclusive a melhoria de suas práticas. A média da gestão de pessoas quanto a inovação no Exército Brasileiro foi de (4.3), de acordo com a figura 2, essa média pode ter dito uma queda também quando se trata de se adestrar para a inovação, pois a maioria dos treinamentos que acontecem dentro do Exército Brasileiro, são para treinar para serviços que já estão pré-determinados ou prontos, não se pratica com o intuito de inovar, e sim de repetir. Logo, cultura, pessoas e relacionamento conversam entre si uma vez que não estão procurando caminhos e pessoas para estruturar uma rede de inovação.

A estrutura é o terceiro melhor resultado em média $(5,4)$, apresentado na figura 2, do octógono da inovação do Exército. Esse bom resultado é perceptível quando essa área militar propõe cursos superiores que estejam ligados diretamente ao seu desempenho tático, com isso, são desenvolvidas escolas e até cursos superiores dentro de sua estrutura bem organizada e harmonizada, possibilitando que alguns tenham acesso ao conhecimento, apesar das críticas apresentadas por alguns pesquisadores (HAJJAR, 2005; PRICE, 2008) que elevam a metodologia pedagógica adotada, por se empregar qualidades nãocognitivas dos alunos, onde se englobam a disciplina, obediência hierárquica, exercícios em equipe e a limpeza e higiene corporal. Em lado contrário, se postam educadores, instrutores e estudiosos (GALAVIZ et al., 2011; LIPMAN, 2003; LUNENBURG et al. 1999), ao dizer que esse modo produz um grupo de discentes que não possuem uma formação crítica formada, que se norteiam mais pelo amedrontamento do que pelo respeito. 0 rigoroso regime disciplinar e devidas reprimendas pelas transgressões para o aluno que quebre os regulamentos pode acarretar dano social e psicológico, asseveram estes estudiosos. Todavia com toda composição existente, esse quadro de escolaridade diferenciada potencializa pessoas específicas e a buscarem a inovação para o melhor desenvolvimento do próprio Exército, possuindo espaços concordantes com a visão de inovação dentro dessa estrutura.

0 processo dentro dos aspectos da inovação na instituição obteve uma nota mediana $(5,0)$, apresentado na figura 2, essa dimensão pode ter diminuído principalmente pela falta de renovação de projetos dentro da instituição pois em sua maioria não são projetos que possuem uma atualização constante de acordo com as necessidades populacionais e tecnológicas existentes, além do que por ser uma instituição pública, que não tem concorrência e não pensa em conquistar clientes para se manter, ou para procurar novos mercados. Por oportuno vale destacar que por meio da Portaria no 109 - EME, de 1o junho de 2015, se aprovou a Diretriz de Implantação da AGITEC (EB20D-07.038), que determina que a Agência deve ter por objetivo proporcionar um ambiente propício à gestão da inovação tecnológica no Exército, com foco na capacidade de antecipação e no atendimento das demandas da Força Terrestre - 2022. A Portaria ordena à AGITEC-Agência de Gestão e Inovação Tecnológica, a responsabilidade de compelir à amplificação do desenvolvimento científico e tecnológico e a inovação tecnológica em áreas benéficas para a defesa nacional, incentivando uma maior harmonia envolvendo aspectos de gestão da inovação tecnológica, entre as Organizações Militares do SCTIEx-Sistema de Ciência, Tecnologia e Inovação do Exército, e demais instituições, particularmente as de ensino, pesquisa, desenvolvimento e inovação. Contudo a compreensão da inovação para a necessidade do bem-estar das unidades militares deveria ser bem discutida nessa área conjuntamente com as Organizações Militares, compreendidas pelos vários quartéis que existem e que por muitas vezes não possuem muita autonomia, principalmente quando se trata de inovação.

Como uma área que financeiramente depende do Estado, o que se observa é que não existe nenhuma participação de outras empresas em capitais e nem a presença de capitais de risco e não há participação, 
nem colaboração financeira, para o desenvolvimento das inovações entre os colaboradores. Ainda assim acontece, como em qualquer instituição, a gestão de seu financeiro por muitas vezes para manter as ideais já existentes, ficando entre poucos membros a possibilidade de adequar as ideias apresentadas para as possíveis aplicabilidade. Não sendo apresentado também nenhum indicador financeiro.

Encontra-se na segunda média mais baixa a liderança, que por sua vez possui um entrave cultural conquanto sua manutenção dentro da instituição militar, pois mesmo possuindo uma visão maior relacionada a inovação, a hierarquia militar, um dos esteios da caserna (Corrêa, 2002), por muitas vezes não permite que seja colocada em prática, o que é um diferencial de um membro da sociedade civil, porque que faz recair sobre os componentes das Forças Armadas deveres e obrigações diferenciadas. Logo, se não existe um poder de gestão com maior flexibilidade fica difícil ser inovador, pois os caminhos ficam limitados.

\section{CONCLUSÃO}

A inovação deve ser estimulada em todos os setores, seja ele privado ou público, uma vez que é através da disrupção que se obtém os melhores resultados nas instituições. Dessa forma, o Octógono da Inovação permite através do seu uso ter uma percepção paradoxal em relação a inovação, de um lado a possibilidade de sua aplicação no setor público, que carrega o estigma da hierarquia organizacional e do outro, sua aplicação na própria esfera pública, que se identifica como inovadora. Com os resultados, entretanto, observa-se que identificar-se como instituição inovadora na realidade não a caracteriza como inovadora de fato. Contudo, vale ressaltar a importância do uso do octógono da inovação para a percepção e diagnóstico do quanto é possível trabalhar na administração pública para melhorar os indicadores no que concerne a finanças, liderança, pessoas e cultura organizacional.

Em análise aos dados compreende-se que a estratégia e a estrutura foram os itens com maior média, o que pode se ver como algo positivo dentro da instituição do Exército Brasileiro a medida em que, mesmo sendo uma instituição pública, sem o envolvimento de clientes indiretos ou concorrência se pensa na necessidade e na importância da inovação o que apresenta um degrau inicial já alcançado no desenvolvimento da inovação dentro da instituição.

0 fato de a cultura, relacionamento e liderança terem obtido médias abaixo de 5 e serem interligadas, nos apresenta um questionamento, será que as pessoas que estão ou deveriam estar envolvidas no processo de inovação, são engajadas e reconhecem a importância do bom relacionamento e comunicação para o desenvolvimento positivo inovador? Tratando-se de uma instituição pública, com hierarquia rígida e bem definida, talvez isso seja a resposta para as lacunas que ocasionam esse resultado não tão positivo no que tange a interação das pessoas. Percebe-se também que a inovação é algo trabalhado por um grupo de pessoas mais restrito e na maior parte de hierarquias mais elevados, porém talvez seja necessário a interação de um número maior de forma coordenada para que as ideias e o processo de inovação tenham mais integração dentro da instituição.

Os fatores apresentados com desenvolvimento menor apresentam oportunidades de atuação para empresas de consultoria em inovação que podem usar esses fatores como algo a serem transformado e melhorado, tanto para o Exército Brasileiro quanto para outras instituições públicas e privadas que apresentam situações parecidas.

\section{REFERÊNCIAS}

[1] Brasil, "Portaria no 109-EME, de 1ํo de junho de 2015. - Aprova a Diretriz para a Implantação da Agência de Gestão e Inovação Tecnológica, Exército Brasileiro, Estado Maior do Exército, 2015.

[2] Araújo, C. A. Bibliometria: evolução histórica e questões atuais. Em Questão, vol. 12, núm. 1, enero-junio, 2006, pp. 11-32 Universidade Federal do Rio Grande do Sul Porto Alegre, Brasil

[3] Bezerra, C. A máquina de inovação: mentes e organizações na luta por diferenciação. Porto Alegre: Bookman, 2011.

[4] Bourdieu. P. Coisas Ditas; tradução Cássia R. da Silveira e Denise Moreno Pegorim; revisão técnica Paula Montero. - São Paulo: Brasiliense, 2004.

[5] Brandão, S. M.; Faria, B. M. F. Inovação no setor público: análise da produção científica em periódicos nacionais e internacionais da área de administração. Revista de Administração Pública, v. 47, n. 01, p. 227-248, jan. 2013. 
[6] Carvalho, C. M. B. de.; Ruiz, A. U. Revista Brasileira de Inovação, Campinas-SP, v. 17, n. 2, p. 229-258, jal-dez. 2018. Disponível em: <https://periodicos.sbu.unicamp.br/ojs/index.php/rbi/article/view/8653575/20771>. Acesso em 26 jun. 2019.

[7] CoRrêA, S. F. A Integridade das Forças Armadas: Hierarquia E Disciplina E A Utilização da via Judicial. 2002. Disponível EM: <HTTPS://www.editorajc.com.br/a-integridade-das-forcas-armadas-hierarquia-e-Disciplina-E-AUtilizacao-DA-VIA-Judicial/>. acesso EM 23 JUN 2019.

[8] Deslauriers J. P. Recherche qualitative: guide pratique. Québec (Ca): McGrawHill, Éditeurs, 1991.

[9] Domingos Neto, M. A necessidade dos estudos da Defesa. In: Monteiro, Álvaro Dias.; Winand, Érica Cristina Alexandre; Goldoni, Luiz Rogério Franco. Pensamento brasileiro em Defesa: VI - ENABED. Aracaju: Editora UFS, 2013.

[10] Galaviz, Brian et. al. The militarization and the privatization of public schools. Berkeley Review of Education, v. 2, n. 1, p. 27-45, 2011.

[11] Galvão-Netto, A. Gestão de ciência, tecnologia e inovação no exército brasileiro no contexto da lei da inovação. Dissertação (Mestrado em Política Científica e Tecnológica) - Programa de Pós Graduação em Política Científica e Tecnológica - Universidade Estadual de Campinas (UNICAMP). Campinas-SP, 2011.

[12] Hajjar, Remi M. The public military high school: a powerful educational possibility. Armed Forces \& Society, v. 32, n. 1, p. 44-62, 2005.

[13] Innoscience. Como aumentar a eficiências das atividades inovadoras. Acesso em: 05 de Agosto de 2018. Disponível em: http://www.innoscience.com.br/como-aumentar-a-eficiencia-das-atividades-inovadoras/

[14] Klumb, R.; Holffmann, M. G. Inovação no setor público e evolução dos modelos de administração pública: o caso do TER-SC. Caderno Gestão Pública e Cidadania, São Paulo, v. 21, n. 69, p. 84-100, maio-ago. 2016. Disponível em: <http://bibliotecadigital.fgv.br/ojs/index.php/cgpc/article/view/53902/61863>. Acesso em 25 jun. 2019.

[15] Lipman, Pauline. Chicago school policy: regulating black and latino youth in the global city. Race Ethnicity and Education, v. 6, n. 4, p. 331-355, 2003.

[16] Lunenburg, Fred; Sartori, Mary Ann; Bauske, Terri. Classroom climate, teacher control behavior, and student self-control: urban public and military high schools. In: Annual Meeting of the National Council of Professors of Educational Administration. Wyoming: agosto, 1999.

[17] Manual de OSLO - Diretrizes Para Coleta e Interpretação Sobre Inovação. 3ª ed. Tradução: FINEP,1997.

[18] Martins, P. S. Estudo da relevância de práticas de inovação: um comparativo universidade-empresa. Trabalho de conclusão de curso (Graduação em Engenharia de Produção)-Universidade Federal de Juiz de Fora, Juiz de Fora, 2011.

[19] Mello, J.; Martins, W. L. S.; Vaz, C. R.; Francisco, A. C.; Selig, P. M. gestão da inovação em organizações: um estudo de caso em uma empresa de pequeno porte no segmento metalúrgico na cidade de Curitiba -PR. HOLOS, vol. 3, 2013, pp. 38-50. Instituto Federal de Educação, Ciência e Tecnologia do Rio Grande do Norte Natal, Brasil

[20] Mensuração e Escalas de Verificação: uma Análise Comparativa das Escalas de Likert e Phrase Completion Severino Domingos da Silva Júnior/ Francisco José Costa. PMKT - Revista Brasileira de Pesquisas de Marketing, Opinião e Mídia (ISSN 2317-0123 On-line), São Paulo, Brasil, V. 15, p. 1-16, outubro, 2014 - www.revistapmkt.com.br

[21] Métodos de pesquisa / [organizado por] Tatiana Engel Gerhardt e Denise Tolfo Silveira ; coordenado pela Universidade Aberta do Brasil - UAB/UFRGS e pelo Curso de Graduação Tecnológica - Planejamento e Gestão para o Desenvolvimento Rural da SEAD/UFRGS. - Porto Alegre: Editora da UFRGS, 2009.

[22] Oliveira, E. R.. A Estratégia Nacional de Defesa e a Reorganização e Transformação das Forças Armadas. Interesse Nacional, Brasília, a. 2, n. 5, p. 71-83, abr.-jun. 2009.

[23] Oliveira, M. M. Gestão da inovação nas organizações: estudo sobre o nível de inovação nas empresas que prestam serviços logísticos. Monografia (Especialização em Gestão Industrial: Conhecimento e Inovação) - Programa de Pós Graduação em Engenharia de Produção - Universidade Tecnológica Federal do Paraná. Ponta Grossa, 2012.

[24] Price, H. B. About Face: a case for quasi-military public high schools. Educational Leadership, v. 65,p. 28-34, maio, 2008.

[25] Rauen, A. Campras públicas de P\&D no Brasil: o uso do artigo 20 da lei da inovação. Revista Radar, n. 40, p. 7$17,2015$. 
[26] Rêgo, L. E. M. Valores Observados no Exército Brasileiro. Publicado Originalmente na Revista Da CULTURAEdição 19 • Janeiro de 2012. Disponível em: <http://www.defesanet.com.br /doutrina/noticia/19229/Valores-Observados-no-Exercito-Brasileiro-/>. Acesso em 23 jun. 2019.

[27] Rocha, F. Does public procurement for innovation increase innovative efforts? The case of Brazil. Revista Brasileira de Inovação, Campinas-SP, v. 18, n. 2, p. 37-62, jan-jun. 2019. Disponível em: <https://periodicos.sbu.unicamp.br/ojs/index.php/rbi/article/view/8653575/20771>. Acesso em 26 jun. 2019.

[28] Sawhney, M. The 12 Different Ways for Companies to Innovate. MITSloan Management Review, v. 47 p. $74-$ 81,2006

[29] Scherer, F. O. Carlomagni, M. S. Gestão da inovação na prática. São Paulo. Atlas, 2009.

[30] Schumpeter, Joseph A. The theory of economic development. Cambridge Harvard University. 1957

[31] Tidd, J.; Bessant, J.; Pavitt, K. Gestão da Inovação. 3aㅡ edição. Porto Alegre: Bookman, 2008.

[32] Toffler, A. Criando uma nova civilização: a política da terceira onda. Rio de Janeiro: Record, 1995.

[33] Winand, E; Saint-Pierre, H. L., A fragilidade da condução política da defesa no Brasil, História (São Paulo), v. 29, n. 2, p. 3-29, 2010. 


\title{
Capítulo 14
}

Contabilidade de custos e formação do preço de venda: Um estudo de caso em uma padaria

\author{
Citania Aparecida Pilatti Bortoluzzi \\ Solange Chiossi \\ Tiago Francisco Camargo \\ Juliano Correa Daleaste \\ Ariberto Dalchiavon \\ Leossania Manfroi
}

Resumo: Este estudo objetivou identificar os custos e a formação do preço de venda dos produtos de uma indústria de panificação localizada no município de Arvoredo- SC. 0 estudo foi realizado durante os meses de julho a outubro de 2017. Para atingir esse objetivo realizou-se um estudo de caso. A pesquisa caracteriza-se quanto aos objetivos, como um estudo exploratório, e a coleta de dados desenvolveu-se com a aplicação de uma entrevista semiestruturada, observação e análise documental. Os resultados da pesquisa foram submetidos a tratamento quantitativo, por meio do método de custeio por absorção. Por meio dos dados levantados foi possível identificar os custos e despesas da atividade bem como sua alocação para cada produto possibilitando formular o preço de venda e sua correta margem de contribuição. Dentre os principiais resultados evidenciados constatou que haviam diferenças entre o preço de venda orientativo e o praticado, sendo que para os três produtos analisados as margens de contribuição unitárias ficaram menores através do preço praticado do que pelo orientativo. Diante destes parâmetros conclui-se que o empresário não possui o retorno da margem de lucro que ele projeta receber, evidenciado na DR (Demonstração de Resultado gerencial) que permitiu apurar uma diferença de 14,6\% a menor no lucro liquido, por não ser utilizado a precificação com as margens corretas indicadas pelo Markup, o que representa algumas ineficiências da gestão por não utilizar-se das ferramentas da contabilidade de custos para tais controles. Apesar disso, o empresário ainda não está tendo prejuízo, porém está perdendo a oportunidade de melhorar seus resultados. Ressalta-se a relevância que as informações oriundas da correta apuração dos custos de produção e consequentemente formação do preço de venda, produz para auxiliar a empresa, gestores ou investidores a traçar suas estratégias, controlar seus custos e aproveitar de maneira mais eficaz os recursos financeiros disponíveis.

Palavras-chaves: Contabilidade de custos; Classificação dos custos; Formação de preço. 


\section{INTRODUÇÃO}

De acordo com o Instituto Tecnológico de Panificação e Confeitaria (ITPC) em 2017 as empresas deste segmento apresentaram crescimento de 3,2\% em nível nacional, apresentando um faturamento projetado de R\$ 90,3 bilhões. Segundo o Sebrae (2018) em Santa Catarina haviam 29.491 estabelecimentos deste segmento registrados, que foram responsáveis por 10.798 empregos diretos.

No entanto este segmento vem sofrendo muitos impactos como: as alterações no comportamento do cliente, crescimento da concorrência, entrada de atacarejos, lojas de vizinhanças, conveniências e foodtrucks (ambulantes). Por estes e demais motivos, evidencia-se a necessidade de conhecimento profundo e detalhado da estrutura de custos e despesas destas relevantes e importantes organizações empresariais.

Para que seja possível administrar uma organização, as informações de custos têm papel relevante, pois atendem a diversos usuários e cada qual com propósitos diferentes de uso no âmbito do sistema empresa, dentre os quais, os mais comuns são: custear estoques para fins de apuração de resultado de acordo com a legislação societária, cálculo de formação de preço de venda e planejamento, controle e tomada de decisão (ALMEIDA; SANTOS, 2007).

Diante de mercados cada vez mais competitivos, as organizações precisam estar sempre à frente da concorrência para se manterem atuantes e sobre tudo com resultados positivos, onde o lucro possa ser alcançado maximizando a produção e minimizando os custos e a perda. Deste modo, o gestor necessita de informações que lhe auxilie na tomada de decisão, sendo que uma das informações indispensáveis é o conhecimento dos custos e formação do preço (NIEDERLE, 2012).

Com o advento da globalização, a facilidade de encontrar o produto desejado é cada vez maior. Sendo assim, para se tornarem mais atraentes, as empresas precisam de fatores que as diferenciem das demais, $o$ conhecimento dos elementos de formação do preço de venda dos produtos e serviços constitui-se numa vantagem competitiva relevante para as organizações. Partindo da premissa de que os clientes, o governo, os avanços tecnológicos são fatores que influenciam no crescimento e na existência da organização (CUNHA; FERNANDES, 2007).

De acordo com Sepp, Manfroi, Theisen, Deil e Diel J. (2015), empresas enfrentam diversas dificuldades para manterem atuantes no mercado. Um dos fatores recorrentes entre os empresários são os altos custos de produção e despesas de comercialização do produto final. Neste sentido, é de extrema importância que a gestão de custos, esteja alinhada ao planejamento estratégico das indústrias e que seja uma ferramenta que auxilie na tomada de decisões mais corretas possíveis.

Conforme Silva Filho, Lagioia, Araújo Araujo e Carlos Filho (2015) compete à gestão da contabilidade de custos, produzir informações capazes de otimizar a qualidade das decisões, auxiliando no controle dos processos da empresa e tornando a empresa mais competitiva. Ainda conforme os autores, os gestores devem ter o entendimento pleno do processo produtivo para o qual a entidade está inserida como atividade principal, alinhando tal entendimento aos conhecimentos das ferramentas de gestão de custos, conseguindo através delas definir estratégias para formação do preço de venda, mantendo-se competitiva e lucrativa no mercado.

Estudos como de Hall, Costa, Kreuzberg, Moura e Hein (2012), Pelissari, Gonzalez e Vanalle (2011) procuraram identificar uso e o conhecimento das informações contábeis como subsídios para tomada de decisão para a redução da mortalidade das empresas, no entanto constataram que é muito limitado e inexpressivo a quantidade de empreendedores que se utilizam deste critério para tomada de decisões; por outro lado muitas decisões são subsidiadas apenas com base na experiência operacional pessoal ou de terceiros, reduzindo drasticamente desta maneira as possibilidades tomar decisões com base em fatos e dados de seu próprio negócio.

Nesse contexto, surge a seguinte questão de pesquisa que se propõe a investigar: Quais os custos que incidem na formação do preço de venda dos produtos de uma indústria de panificação localizada no município de Arvoredo- SC? Portanto, o objetivo geral desta pesquisa consiste em identificar os custos e a formação do preço de venda dos produtos de uma indústria de panificação localizada no município de Arvoredo- SC. 
A escolha do tema justifica-se pela necessidade de aprimorar os conhecimentos dos empreendedores (principalmente aqueles pequenos e micro que utilizam-se apenas de conhecimentos empíricos para gestão de seus negócios) permitindo apresenta-los algumas das ferramentas de custos, que permitem o controle e a evidenciação de informações úteis para a tomada de decisão dos investidores, gestores, contadores e sociedade em geral. Além de que o setor da indústria de panificação apresenta-se em constante crescimento, sendo o setor alimentício de importância para a economia. Dessa forma torna-se relevante estudar e calcular os custos e a formação do preço dos produtos deste segmento, que envolve a transformação de fatores de produção em produto acabado.

Neste sentido este estudo, se propõem a apresentar o modelo de cálculo dos custos e formação do preço de venda para pequenos empreendedores, servindo como fonte de dados primária a suas tomadas de decisões. Pesquisas com este viés, com abordagem clara e objetiva de cases reais, que procura abordar a desinformação dos pequenos empresários do setor de panificação ainda são escassos. Corrobora com este entendimento as pesquisas de Niemi e Jansik (2010) realizadas na Finlândia, onde os autores inferem que a técnica de mensuração e análises de preços através de registros contábeis oferece muito mais detalhes e consistência da realidade de um segmento, embora exista uma forte relutância das empresas em divulgar seus dados, o que limita ou geralmente inviabiliza a pesquisa.

Desta maneira, pretende-se através desta pesquisa diminuir esta assimetria informacional entre pequenos e grandes empreendedores, além de contribuir para o desenvolvimento de pesquisas relacionadas com esta temática.

Assim a pesquisa se propõem a trazer subsídios para futuras pesquisas com foco em formação do preço de venda e, podendo servir de amparo e parâmetro na aplicação dos resultados aqui encontrados em outros setores da economia nacional. Portanto, abordagem de uma metodologia de formação de preço de venda de produtos no qual o modelo poderá ser replicado em outras empresas, auxiliando a projetar resultados que permitem aos tomadores de decisões, menores achismos empíricos, diante de decisões que resultam em consequências financeiras relevantes na curto e longo prazo para organização. Neste viés a presente pesquisa é de fundamental importância ao gestor do negócio e comunidade cientifica.

Este estudo além desta introdução está organizado em cinco seções, sendo que na segunda seção serão abordados os embasamentos conceituais necessário para o desenvolvimento da pesquisa. Após na terceira seção são abordados os aspectos metodológicos. Já na quarta seção são apresentados a análise dos dados e por fim as considerações finais.

\section{REFERENCIAL TEÓRICO}

Neste tópico apresenta-se a revisão da literatura que embasa o estudo. Aborda-se aspectos sobre a contabilidade de custos, a classificação dos custos, formação do preço de venda e aplicação do Mark up.

\subsection{CONTABILIDADE DE CUSTOS}

A contabilidade de custos é um ramo da contabilidade que produz informações para os diversos níveis gerenciais de uma entidade, auxilia as funções de determinação de desempenho, de planejamento e controle das operações e de tomada de decisão. Este ramo da contabilidade classifica, coleta e registra dados operacionais, denominados dados internos, e em alguns casos, coleta e organiza dados externos da organização (LEONE, 2000).

Entre as finalidades mais relevantes da contabilidade de custos, tem-se a avaliação dos estoques, o auxílio na determinação dos preços e, principalmente, o controle e a avaliação de desempenho de produtos/serviços ou unidades de negócios. Neste sentido estas informações produzidas, ensejam para os instrumentos gerenciais de planejamento e controle de uma organização (LIMA, 2014). Tais finalidades são utilizadas pela empresa na otimização das decisões relativas ao gerenciamento amplo e profundo dos custos.

Com o forte aumento da concorrência entre empresas em virtude da globalização e as recentes crises, as empresas foram obrigadas a dar mais atenção para a gestão dos custos como ferramenta de gestão estratégica de custos (SILVA; LINS, 2014). 
Os custos podem ser classificados como diretos e indiretos, fixos e variáveis, dependendo como são alocados aos produtos/serviços. Megliorini (2001) destaca que os custos indiretos são aqueles que não podem ser facilmente identificados, e que necessitam de algum tipo de distribuição ou de rateio para serem alocados aos produtos. Ribeiro (2014) define que os custos diretos são aqueles que estão diretamente ligados na fabricação dos produtos, e sua determinação se dá em função de que, além de integrarem os produtos, suas quantidades e valores podem ser facilmente identificados em relação a cada produto.

Zanluca (2017) define como custos variáveis aqueles que variam proporcionalmente com o nível de produção ou atividades, seus valores dependem do volume produzido ou de vendas efetivados num período. Viceconti e Neves (2013) destacam que os custos fixos são aqueles que cujos valores são os mesmos, independentemente do volume de produção da empresa, ou, em caso de a empresa nada produzir, os custos fixos existirão da mesma forma.

Existem vários métodos de custeio utilizados para distribuição e apropriação dos custos, no entanto nesta pesquisa delimitaremos maior ênfase para o custeio por absorção e variável. 0 método de custeio por absorção consiste na apropriação de todos os custos de produção aos produtos elaborados de forma direta e indireta (SANTOS, 2009). Já para Leone (2000) o método de custeio variável é aquele que inclui no custo das operações, dos produtos, serviços e atividades os custos diretos e variáveis. De modo geral, custeio significa apropriação de custos.

Percebe-se que a contabilidade de custos não se limita a atender somente a função de custear produtos para avaliação de estoques e determinação de lucros, mas também de gerar informações que permita aos gestores se posicionarem quanto à eficiência e eficácia do processo produtivo e de sua capacidade de manutenção da continuidade rentável do empreendimento com as informações para controle e tomada de decisão (ALMEIDA; SANTOS, 2007).

\subsection{FORMAÇÃO DO PREÇO}

A correta formação do preço de venda é uma questão fundamental para a sobrevivência e crescimento das empresas, independente do porte e da área de atuação. Com uma política eficiente de preços, as empresas podem atingir seus objetivos de lucro, crescimento em longo prazo, qualificação no atendimento dos clientes, dentre outras melhorias (CUNHA; FERNANDES, 2007).

A preocupação em formar preços está ligada as condições de mercado, ás características da concorrência, aos custos, ao nível de atividade e a remuneração do capital investido. A formulação do preço precisa apresentar para a empresa as possibilidades de maximização dos lucros, manter a qualidade dos produtos e atender os anseios do mercado (SANTOS, 2009). Mas deve-se ter cuidado ao formar os preços de acordo com o mercado, uma vez que o empresário poderá ter prejuízos, pois o preço praticado poderá gerar uma receita final que não cobre os custos da produção ou comercialização (ZAHAIKEVITCH; MATOS, 2013).

Wernke (2005) argumenta que definir o preço é uma tarefa importante para os gestores, pois é por meio da formação do preço de venda que a empresa, efetivamente passa a competir no mercado. Para fazer o cálculo do preço de venda correto, os gestores precisam ter em mente suas margens de lucratividade de forma que os valores repassados ao consumidor final permitam cobrir seus custos básicos trazendo resultados financeiros satisfatórios. 0 preço de venda deverá cobrir o custo do produto, as despesas variáveis, as despesas fixas, e ainda sobrar um lucro líquido adequado (LORENTZ, 2015).

0 método para formar e analisar o preço deve ser aquele que melhor se adequar as necessidades da empresa. Dentre os métodos existentes, destaca-se o mark-up multiplicador, que contribui favoravelmente com a formação de preços compatíveis com as necessidades da empresa (LORENTZ, 2015). Mas ainda de acordo com Bruni e Famá (2011) existem duas outras formas de calcular o preço de venda de um produto ou serviço: Mark-up sobre o gasto variável que consiste na utilização sobre a somatória dos gastos variáveis da empresa, ou seja, os custos e despesas que variam. Porém, somente poderá ser utilizado quando se conhece o preço de venda e a somatória dos seus gastos. Mark-up sobre o gasto total: 0 Markup é sobre os custos e despesas totais. Não é muito utilizado, pois muitas empresas não conseguem alocar os custos indiretos no custo do produto, e isso requer um grande esforço por parte da empresa. 
o Mark-up é um multiplicador que se aplica sobre o custo da mercadoria ou serviço. É praticado com frequência para o cálculo dos preços de venda de forma rápida e sua aplicação está ligado sobre o custo de aquisição ou produção. Integram o mark-up os impostos sobre as vendas (ICMS, ISS, PIS e COFINS) e lucros (IRPJ e CSLL), e também, as despesas gerais, administrativas, comerciais e financeira e o lucro desejado (THEISS; KRIECK, 2012).

Para Bruni e Famá (2011) quando se quer chegar ao preço de venda a ser praticado, aplica-se o mark-up sobre os gastos de determinado bem ou serviço, permitindo assim, a formação do preço de venda. 0 markup pode ser empregado de diferentes formas: sobre os custos variáveis, sobre os gastos variáveis e sobre os gastos integrais. A principal razão para sua aplicação se dá pelo fato de possibilitar uma grande simplificação do processo de formação do preço de venda. Para Morais e Vieira (2013), em empresas industriais, comerciais ou de serviços a formação de preços é uma tarefa complexa em virtude de que formar preços envolve diversas áreas, entre elas, marketing, economia, contabilidade de custos e finanças, que subsidiam as decisões dos gestores. Além de que há diversas técnicas de formação de preços que visam maximizar a rentabilidade do negócio, seus impactos econômicos, bem como sua relação com os clientes. Podem-se destacar três delas: a precificação baseada em custos (mark-up); a precificação baseada na concorrência; e por fim, a precificação com base no valor percebido pelos clientes.

Para Pinto (2011) o método baseado na concorrência preocupa-se com os concorrentes, seus preços são constituídos em consequência do praticado no mercado. Já com o método baseado no valor percebido pelo consumidor é realizada uma investigação do quanto o cliente está disposto a pagar pelo produto. Em resumo, o consumidor é responsável pelo reajuste do preço, podendo variar o montante a ser pago de acordo com o público alvo. Por fim o método baseado no custo, os preços são formados com base nos custos da entidade e são classificados por serem formados de dentro para fora.

Na literatura internacional conforme Niemi e Jansik (2010) sobre as técnicas de identificação dos preços e de suas margens, existem três técnicas amplamente utilizadas, sendo que a primeira consiste em analisar as tendências dos preços dos alimentos, correlacionando com a distribuição do preço de varejo pago pelo consumidor na cadeia alimentar; a segunda abordagem é o uso de preços comparativos, é muito utilizada em vários exames de preços e margens no setor de alimentos. Neste viés Elitzak 1997, Reed e Clark. 1998, Reed et al. 2002, abordam que o Departamento de Agricultura dos Estados Unidos, também emprega esta segunda técnica há muitos anos no cálculo de spreads de preços para uma variedade de produtos agrícolas. Ainda segundo Niemi e Jansik (2010), a terceira técnica muito utilizada é o uso dos registros contábeis internos das empresas. Essa abordagem oferece muito mais detalhes, embora exista resistência das empresas em divulgar seus dados.

\section{METODOLOGIA}

Quanto aos objetivos, o presente estudo constitui-se de uma pesquisa exploratória. Segundo Raupp e Beuren (2004) busca-se por meio do estudo exploratório conhecer com profundidade o assunto e tornalo, mas claro ou construir questões importantes para a condução da pesquisa. Já a coleta de dados foi utilizada a entrevista estruturada, observação e análise documental. Quanto a estratégia documental consolida-se ao utilizar como fonte de dados, informações e evidências empregando fontes primárias de informações (MARTINS; THEÓPHILO, 2016).

A pesquisa é caracterizada como estudo de caso pelo fato de considerar uma determinada unidade de análise específica, a qual permite levantar e examinar dados e fatos, sem comprometer a realidade da qual está sendo verificada (COSTA, 2004). Neste sentido Yin (2001) reforça que o estudo de caso é a estratégia escolhida ao se examinar acontecimentos, e conta com duas fontes de evidências: a observação direta e série sistemática de entrevistas.

Para este estudo, foi escolhida como amostra intencional no setor panificação, sendo utilizada como instrumento de coleta de dados a entrevista semiestruturada, observação e análise documental. Barros e Lehfeld (2007) destacam que a entrevista é uma técnica que permite o relacionamento estreito entre o entrevistador e o entrevistado, sendo que, na entrevista não estruturada o pesquisador busca conseguir por meio da conversação, os dados que possam ser utilizados na análise, buscando os aspectos que são mais relevantes para a pesquisa. 
A entrevista foi realizada in loco em dois momentos: No primeiro momento diretamente com o proprietário para entender quais eram as metodologias e ferramentas de controle que o mesmo utilizava, e como eram controlados os gastos indiretos de fabricação; Já para o segundo momento, direcionou-se a entrevista com o funcionário responsável pela produção, para se extrair os dados necessários ao desenvolvimento do estudo, como as fichas técnicas, tempo de produção, ciclo produtivo, quantidades produzidas. Após a coleta dos dados, os mesmos foram dispostos em planilhas do Excel®. Na sequência foi desenvolvida uma tabela para cada produto, o qual facilitou a leitura e análise dos dados.

Para apuração do custo total de produção aplicou-se o método de custeio por absorção para que fossem analisados os dados, utilizando-se através de um mapa de custos alocando-os, em custos diretos e indiretos para cada produto, a fim de encontrar o valor unitário por quilo em cada um dos produtos analisados, e posteriormente formular o preço de venda ideal de acordo com as metas e objetivos planejados pelo empreendedor. Santos (2009) define que custeio por absorção consiste na apropriação de todos os custos de produção aos produtos elaborados de forma direta e indireta os quais são causados pelo uso de recursos necessário para elaboração dos produtos. 0 uso do custeio de absorção se dá tendo em vista ser o sistema utilizado pela contabilidade. Com base no estudo de Eckert, Mecca, Biasioe Novello ( 2014) o custeio por absorção, é o sistema que é mais utilizado quando se trata de sistema de custos integrado à contabilidade, além de ser o mais prático e adequado para os objetivos do estudo em questão. Ainda para Backes; Perleberg e Dalben (2007) o custo por absorção é o sistema adotado para determinar o custo integrado com a contabilidade e para determinar o custo do produto e dos estoques, tanto para fins societários como para fins fiscais.

Como técnica de análise e interpretação dos dados, utilizou-se a pesquisa quantitativa, na qual tem como objetivo principal quantificar ou mensurar uma ou mais variáveis estudadas, avaliar o comportamento de uma variável analisando a frequência com que ela ocorre, e a partir da análise dos resultados, busca explicar ou solucionar o fenômeno estudado (CASARIN; CASARIN, 2012).

\section{ANÁLISE DOS DADOS}

Neste tópico é aplicado o modelo de mapa de custo por absorção, além de apresentar a caracterização da empresa e seu layout organizacional.

\subsection{CARACTERIZAÇÃO DA ORGANIZAÇÃO E APLICAÇÃO DO CASO}

O estudo de caso trata de uma empresa de uma micro empresa, que possui 2 funcionários em tempo integral, sendo eles: o proprietário e um funcionário, o qual trabalha no processo produtivo. 0 layout do estabelecimento é composto por um espaço onde fica a produção, e outro espaço para vendas.

A padaria em estudo está localizada na cidade de Arvoredo - SC, a qual iniciou suas atividades em 2013, trabalha com um mix variados de produtos que ela mesmo produz, comercializa e as vezes distribui. 0 estudo foi realizado durante os meses de julho a outubro de 2017, no qual será observado o processo produtivo nesse período, e análise dos documentos e dos processos internos, os quais foram necessários para a realização da pesquisa.

Para atender aos objetivos desta pesquisa foram investigados apenas os três produtos mais representativos no faturamento global do empreendimento. Desta maneira, para fins de análise dos custos e formação do preço de venda, considerou-se os produtos: o pão francês, cuca simples e a bolacha de milho.

Quanto ao levantamento e mensuração dos custos, é necessário a utilização de operações matemáticas simples: soma, subtração, multiplicação, divisão e porcentagem (proporção) dos custos aos produtos. Os dados de custos foram organizados em planilhas eletrônicas, utilizando-se o programa Excel.

Desta maneira, apresenta-se na Tabela 01, parte do layout da planta do empreendimento, sendo caracterizado pelo imobilizado e suas despesas com depreciações, utilizadas somente pela área de vendas e administrativa da padaria. 
Tabela 01- Imobilizado setor vendas/administrativo

\begin{tabular}{|c|c|c|c|}
\hline Imobilizado vendas/administrativo & Valor & Depreciação anual & Depreciação mensal \\
\hline Expositor & $\mathrm{R} \$ 8.000,00$ & $\mathrm{R} \$ 800,00$ & $\mathrm{R} \$ 66,67$ \\
\hline Bancada & $\mathrm{R} \$ 1.500,00$ & $\mathrm{R} \$ 150,00$ & $\mathrm{R} \$ 12,50$ \\
\hline Computador & $\mathrm{R} \$ 3.000,00$ & $\mathrm{R} \$ 600,00$ & $\mathrm{R} \$ 50,00$ \\
\hline Climatizador & $\mathrm{R} \$ 6.000,00$ & $\mathrm{R} \$ 600,00$ & $\mathrm{R} \$ 50,00$ \\
\hline Móveis & $\mathrm{R} \$ 2.500,00$ & $\mathrm{R} \$ 250,00$ & $\mathrm{R} \$ 20,83$ \\
\hline Utensílios & $\mathrm{R} \$ 900,00$ & $\mathrm{R} \$ 90,00$ & $\mathrm{R} \$ 7,50$ \\
\hline Prédio & $\mathrm{R} \$ 30.000,00$ & $\mathrm{R} \$ 1.200,00$ & $\mathrm{R} \$ 100,00$ \\
\hline Telefone (aparelho) & $\mathrm{R} \$ 115,00$ & $\mathrm{R} \$ 23,00$ & $\mathrm{R} \$ 1,92$ \\
\hline Veículo & $\mathrm{R} \$ 30.000,00$ & $\mathrm{R} \$ 6.000,00$ & $\mathrm{R} \$ 500,00$ \\
\hline TOTAL & $\mathrm{R} \$ 82.015,00$ & $\mathrm{R} \$ 9.713,00$ & $\mathrm{R} \$ 809,42$ \\
\hline
\end{tabular}

Fonte: Conforme dados da pesquisa, (2017).

A Tabela 01 apresentada refere-se ao investimento e despesas total com depreciação dos móveis, equipamentos e veículo utilizado pela área de vendas e administrativa da padaria, totalizando despesas fixas mensal de depreciação de $\mathrm{R} \$ 809,42$. Sendo calculada através do método linear, de acordo com as taxas de depreciação previstas pela Receita Federal do Brasil, de $20 \%$ ao ano para os equipamentos e veículo, e taxa de $10 \%$ ao ano para os móveis e utensílios, e $4 \%$ ao ano para o prédio. 0 valor da depreciação mensal será lançado como despesa mensal diretamente na demonstração do resultado por tratar-se de gastos não relacionados com o custo de produção. Tarifa e Silva (2009) definem despesa como sendo os gastos que ocorrem na obtenção da receita, os quais são necessários para vender e distribuir produtos. Na Tabela 02 é apresentado o imobilizado do setor de produção.

Tabela 02- Imobilizado setor de produção

\begin{tabular}{|l|c|c|c|}
\multicolumn{2}{c}{ Imobilizado produção } & \multicolumn{2}{c|}{ Valor } \\
\hline Utensílios & $\mathrm{R} \$ 2.100,00$ & $\mathrm{R} \$ 210,00$ & Depreciação mensal \\
\hline Equipamentos & $\mathrm{R} \$ 39.000,00$ & $\mathrm{R} \$ 3.900,00$ & $\mathrm{R} \$ 17,50$ \\
\hline Prédio & $\mathrm{R} \$ 70.000,00$ & $\mathrm{R} \$ 2.800,00$ & $\mathrm{R} \$ 325,00$ \\
\hline TOTAL & $\mathrm{R} \$ 111.100,00$ & $\mathrm{R} \$ 6.910,00$ & $\mathrm{R} \$ 233,33$ \\
\hline
\end{tabular}

Fonte: Conforme dados da pesquisa, (2017).

Observa-se na Tabela 02 o valor do imobilizado, sendo que, foi utilizada a depreciação linear, definida por Ribeiro (2013, p. 208) como sendo a "aplicação de taxas constantes durante o tempo de vida útil estimado para o bem". O valor da depreciação mensal do imobilizado do setor de produção é de R \$ 575,83. Utilizouse a taxa de depreciação de $10 \%$ ao ano para os utensílios e equipamentos e de $4 \%$ ao ano para o prédio.

Na Tabela 03 são evidenciados os valores dos custos indiretos relacionados à produção. Pode-se observar que a conta prédio possui valores distintos, isso ocorre porque foi necessário fazer um rateio para distribuir a depreciação do prédio para a área de vendas/administrativo e para a produção. 0 valor total do prédio é de $\mathrm{R} \$ 100.000,00$, sendo que foi distribuído 30\% para vendas/administrativo e $70 \%$ para produção. A Tabela 03 apresenta o rol de custos indiretos do setor de produção.

Tabela 03- Custos indiretos setor de produção

\begin{tabular}{|c|c|c|c|c|c|c|}
\hline Descrição & Valor anual & Valor mensal & Vendas & Rateio & Produção & Rateio \\
\hline Seguro prédio & $\mathrm{R} \$ 648,00$ & $\mathrm{R} \$ 54,00$ & $\mathrm{R} \$ 13,50$ & $25 \%$ & $\mathrm{R} \$ 40,50$ & $75 \%$ \\
\hline IPTU & $\mathrm{R} \$ 401,76$ & $\mathrm{R} \$ 33,48$ & $\mathrm{R} \$ 8,37$ & $25 \%$ & $\mathrm{R} \$ 25,11$ & $75 \%$ \\
\hline Material limpeza & $\mathrm{R} \$ 388,80$ & $\mathrm{R} \$ 32,40$ & $\mathrm{R} \$ 8,10$ & $25 \%$ & $\mathrm{R} \$ 24,30$ & $75 \%$ \\
\hline Contador & $\mathrm{R} \$ 1.053,00$ & $\mathrm{R} \$ 87,75$ & $\mathrm{R} \$ 14,04$ & $16 \%$ & $\mathrm{R} \$ 73,71$ & $84 \%$ \\
\hline Energia elétrica & $\mathrm{R} \$ 1.749,60$ & $\mathrm{R} \$ 145,80$ & $\mathrm{R} \$ 23,33$ & $16 \%$ & $\mathrm{R} \$ 122,47$ & $84 \%$ \\
\hline Dedetização & $\mathrm{R} \$ 252,72$ & $\mathrm{R} \$ 21,06$ & $\mathrm{R} \$ 5,27$ & $25 \%$ & $\mathrm{R} \$ 15,80$ & $75 \%$ \\
\hline Manutenção & $\mathrm{R} \$ 972,00$ & $\mathrm{R} \$ 81,00$ & $\mathrm{R} \$ 12,96$ & $16 \%$ & $\mathrm{R} \$ 68,04$ & $84 \%$ \\
\hline TOTAL & $\mathrm{R} \$ 5.465,88$ & $\mathrm{R} \$ 455,49$ & $\mathrm{R} \$ 85,56$ & & $\mathrm{R} \$ 369,93$ & \\
\hline
\end{tabular}

Fonte: Conforme dados da pesquisa, (2017). 
Em relação aos custos fixos indiretos, é permitido que o gestor ou contador atribua bases de rateios e suas proporções para rateio das proporções, sendo que: para o seguro do prédio, IPTU, material de limpeza e dedetização, a base de rateio foi sobre a área total do prédio, ficando em 75\% para a produção e 25\% para vendas. Já para o custo com contador, energia elétrica e manutenção a base de rateio utilizada foi o valor do imobilizado total, sendo distribuídos $84 \%$ para a produção e 16\% para a área de vendas representando um valor mensal total de $\mathrm{R} \$ 455,49$.

Na Tabela 04 é apresentada a ficha técnica unitária para a produção de cada um dos três produtos, tendo como base apenas a relação da matéria prima constante na receita do pão francês, da cuca simples e da bolacha de milho, assim como suas respectivas quantidades e o custo total das mesmas.

Tabela 04- Custos com matéria prima

\begin{tabular}{|c|c|c|c|c|}
\hline \multicolumn{5}{|c|}{ Custos com matéria-prima do pão francês } \\
\hline Descrição & Unidade & Quantidade & Custo unitário & Custo total \\
\hline Farinha & KG & 10 & $\mathrm{R} \$ 1,50$ & $\mathrm{R} \$ 15,00$ \\
\hline Fermento & KG & 0,2 & $\mathrm{R} \$ 12,50$ & $\mathrm{R} \$ 2,50$ \\
\hline Água & LT & 10 & $\mathrm{R} \$ 0,05$ & $\mathrm{R} \$ 0,50$ \\
\hline \multicolumn{5}{|c|}{ Material Secundário } \\
\hline Lenha & MT & 0,16 & $\mathrm{R} \$ 50,00$ & $\mathrm{R} \$ 8,00$ \\
\hline TOTAL & & & & $\mathrm{R} \$ 26,00$ \\
\hline \multicolumn{5}{|c|}{$\begin{array}{l}\text { Custos com matéria-prima da cuca simples } \\
\text { MASSA }\end{array}$} \\
\hline Descrição & Unidade & Quantidade & Custo unitário & Custo total \\
\hline Farinha & $\mathrm{KG}$ & 5 & $\mathrm{R} \$ 1,50$ & $\mathrm{R} \$ 7,50$ \\
\hline Açúcar refinado & KG & 0,6 & $\mathrm{R} \$ 3,00$ & $\mathrm{R} \$ 1,80$ \\
\hline Sal & KG & 0,05 & $\mathrm{R} \$ 2,00$ & $\mathrm{R} \$ 0,10$ \\
\hline Ovos & UND & 5 & $\mathrm{R} \$ 0,25$ & $\mathrm{R} \$ 1,25$ \\
\hline Margarina & KG & 0,3 & $\mathrm{R} \$ 5,60$ & $\mathrm{R} \$ 1,68$ \\
\hline Adoçante & ML & 0,05 & $\mathrm{R} \$ 19,00$ & $\mathrm{R} \$ 0,95$ \\
\hline Erva doce & KG & 0,05 & $\mathrm{R} \$ 11,00$ & $\mathrm{R} \$ 0,55$ \\
\hline Corante & KG & 0,01 & $\mathrm{R} \$ 13,00$ & $\mathrm{R} \$ 0,13$ \\
\hline Aroma & ML & 0,05 & $\mathrm{R} \$ 11,20$ & $\mathrm{R} \$ 0,56$ \\
\hline Fermento & KG & 0,15 & $\mathrm{R} \$ 15,00$ & $\mathrm{R} \$ 2,25$ \\
\hline Água & & 3 & $\mathrm{R} \$ 0,05$ & $\mathrm{R} \$ 0,15$ \\
\hline \multicolumn{5}{|c|}{ Material Secundário } \\
\hline Gás & KG & 1,7 & $\mathrm{R} \$ 4,62$ & $\mathrm{R} \$ 7,85$ \\
\hline TOTAL & & & & $\mathrm{R} \$ 24,77$ \\
\hline \multicolumn{5}{|c|}{ Cobertura cuca simples } \\
\hline Açúcar & KG & 0,5 & $\mathrm{R} \$ 3,00$ & $\mathrm{R} \$ 1,50$ \\
\hline Margarina & KG & 0,3 & $\mathrm{R} \$ 5,60$ & $\mathrm{R} \$ 1,68$ \\
\hline Farinha & KG & 0,25 & $\mathrm{R} \$ 1,50$ & $\mathrm{R} \$ 0,38$ \\
\hline Cachaça & ML & 0,05 & $\mathrm{R} \$ 5,00$ & $\mathrm{R} \$ 0,25$ \\
\hline Total & & & & $\mathrm{R} \$ 3,81$ \\
\hline $\begin{array}{l}\text { TOTAL DA } \\
\text { RECEITA }\end{array}$ & & & & $\mathrm{R} \$ 28,58$ \\
\hline Ovos & UND & 12 & $\mathrm{R} \$ 0,33$ & $\mathrm{R} \$ 4,00$ \\
\hline Açúcar & KG & 1 & $\mathrm{R} \$ 2,00$ & $\mathrm{R} \$ 2,00$ \\
\hline Manteiga & $\mathrm{KG}$ & 0,5 & $\mathrm{R} \$ 10,00$ & $\mathrm{R} \$ 5,00$ \\
\hline Polvilho doce & KG & 1 & $\mathrm{R} \$ 8,50$ & $\mathrm{R} \$ 8,50$ \\
\hline Fermento químico & KG & 0,06 & $\mathrm{R} \$ 7,50$ & $\mathrm{R} \$ 0,45$ \\
\hline Farinha & KG & 2,5 & $\mathrm{R} \$ 1,50$ & $\mathrm{R} \$ 3,75$ \\
\hline Farinha milho & KG & 0,25 & $\mathrm{R} \$ 3,60$ & $\mathrm{R} \$ 0,90$ \\
\hline \multicolumn{5}{|c|}{ Material Secundário } \\
\hline Lenha & MT & 0,14 & $\mathrm{R} \$ 50,00$ & $\mathrm{R} \$ 7,00$ \\
\hline TOTAL & & & & $\mathrm{R} \$ 31,60$ \\
\hline
\end{tabular}

Fonte: Conforme dados da pesquisa, (2017). 
Na Tabela 04 foram descritos os ingredientes utilizados no processo de produção de cada produto bem como sua unidade de medida e o custo de aquisição, além do material secundário utilizado no momento do cozimento de cada produto, apresentando a quantidade mensal e por porção de cada ingrediente.

Percebe-se que apenas três ingredientes são necessários para se produzir o pão francês, isso se deve em função de que é utilizada a farinha com mistura pré-pronta, onde basta apenas adicionar a água e o fermento, o custo da matéria prima e do material secundário para uma receita do pão francês é de $\mathrm{R} \$ 26,00$.

A cuca simples é dentre os três produtos a que mais tem ingredientes, pois são necessários ingredientes para a massa e para a cobertura, uma espécie de farofa, tendo um valor de $\mathrm{R} \$ 28,58$.

A bolacha de milho é produto, dentre os três que tem maior custo por receita, considerando os ingredientes e o material secundário, no valor de $\mathrm{R} \$ 31,60$. É importante salientar que todas as matériasprimas referenciadas para o processo produtivo foram avaliadas através do preço de mercado, sendo que qualquer alteração de valor afeta diretamente no custo unitário de cada produto, que por sua vez impacta a política de preços e a lucratividade.

Na Tabela 05 são apresentados os custos com salários e encargos do funcionário responsável pela produção, e o custo com salário do proprietário (pró-labore) o qual é responsável pelo setor de vendas/administrativo. 0 cálculo da mão de obra foi de acordo com a tributação da empresa que está enquadrada no regime do Simples Nacional.

Tabela 05- Custos com salários e encargos

\begin{tabular}{|c|c|}
\hline \multicolumn{2}{|l|}{ SALÁRIO SETOR DE PRODUÇÃO } \\
\hline Descrição & $\mathrm{R} \$$ \\
\hline Salário produção & $\mathrm{R} \$ 1.900,00$ \\
\hline FGTS parte empresa sobre folha do setor de produção & $\mathrm{R} \$ 152,00$ \\
\hline Provisão para férias com $1 / 3$ sobre folha do setor de produção & $\mathrm{R} \$ 209,00$ \\
\hline Provisão para $13^{\circ}$ salário sobre folha do setor de produção & $\mathrm{R} \$ 158,27$ \\
\hline Provisão para multa rescisão FGTS $(4 \%+2,33 \%)$ sobre salário bruto & $\mathrm{R} \$ 120,27$ \\
\hline TOTAL & $\mathrm{R} \$ 2.539,54$ \\
\hline \multicolumn{2}{|l|}{ SALÁRIO SETOR VENDAS/ADMINISTRATIVO } \\
\hline Descrição & $\mathrm{R} \$$ \\
\hline Pró-labore & $\mathrm{R} \$ 937,00$ \\
\hline INSS (11\%) & $\mathrm{R} \$ 103,07$ \\
\hline TOTAL & $\mathrm{R} \$ 1.040,07$ \\
\hline
\end{tabular}

Fonte: Conforme dados da pesquisa, (2017).

Conforme apresentado na Tabela 05, verifica-se que o custo total do salário do funcionário que trabalha no setor de produção é de $\mathrm{R} \$ 2.539,54$, considerando o salário bruto e os encargos incidentes sobre o mesmo, os quais foram calculados conforme previsto na Consolidação das Leis do Trabalho. Já para a parte de vendas/administrativo é o próprio proprietário responsável por esse setor, assim tem-se apenas o pró-labore, o qual na legislação trabalhista não é equiparado ao salário, sendo que, o empregador/proprietário pode conceder a si próprio um período de descanso remunerado, bem como efetuar pagamento adicional e denominá-lo como $13^{\circ}$ salário. Totalizando um custo de $\mathrm{R} \$ 1.040,07$. A Tabela 06 define o cálculo da formação do preço de venda dos três produtos.

A Tabela 06 apresentou a formação do preço de venda do pão francês, cuca simples e da bolacha de milho. Para se chegar ao preço utilizou-se o mark-up multiplicador, considerando que a empresa deseja atingir uma margem de lucro de $55 \%$ para o pão francês, $45 \%$ para a cuca simples e $35 \%$ para a bolacha de milho, e por se tratar de uma empresa optante pelo Simples Nacional, os impostos são de 5,47\% de acordo como o anexo 1(comércio) da tabela do Simples Nacional. Para que a padaria se enquadre como atividade de comércio existe uma previsão legal, que, de acordo com a Receita Federal do Brasil (2007) o preparo, em padaria, confeitaria e pastelaria, de produtos alimentares não acondicionados em embalagens de apresentação, desde que vendidos diretamente ao consumidor final, não são considerados como produtos de industrialização. 
Tabela 06- Formação do preço de venda

\begin{tabular}{|c|c|c|c|c|}
\hline \multicolumn{2}{|c|}{ Impostos } & Pão francês & Cuca simples & Bolacha milho \\
\hline IRPJ & $0,00 \%$ & & \\
\hline CSLL & $0,00 \%$ & & & \\
\hline Cofins & $0,86 \%$ & & & \\
\hline PIS/PASEP & $0,00 \%$ & & & \\
\hline CPP & $2,75 \%$ & & & $5,47 \%$ \\
\hline ICMS & $1,86 \%$ & & $5,47 \%$ & $35 \%$ \\
\hline TOTAL & $5,47 \%$ & $55 \%$ & $45 \%$ & $40,47 \%$ \\
\hline Margem Lucro Desejada & $60,47 \%$ & $50,47 \%$ & $59,53 \%$ \\
\hline \multicolumn{2}{|c|}{ Total (\%) } & $39,53 \%$ & $49,53 \%$ & $\mathrm{R} \$ 10,35$ \\
\hline \multicolumn{2}{|c|}{ Cuk-up (1- (\%)) } & $\mathrm{R} \$ 3,70$ & $\mathrm{R} \$ 4,99$ & $\mathrm{R} \$ 17,39$ \\
\hline
\end{tabular}

Fonte: Conforme dados da pesquisa, (2017).

Após encontrados os valores é aplicado o Mark-up, o qual é feito da seguinte maneira: consideramos o pão francês para exemplo de cálculo $100 \%-55 \%-5,47 \%=39,53 \%$, após é feita o seguinte cálculo: $3,70 / 39,53 \%=0,0936 * 100=R \$ 9,36$ assim é encontrado o preço de venda para o pão (orientativo), e o mesmo cálculo deve ser aplicado para os demais produtos.

Para Wernke (2017) o Markup tem por finalidade cobrir tributos, despesas sobre vendas e despesas administrativas. Esses dados são essenciais para um bom gerenciamento de custos, pois a partir deles a empresa pode gerenciar com efetividade desde a sua margem de lucro até o preço final, conseguindo conhecer a margem de lucro desejada e comparar com a realidade da praticada pelo mercado.

A partir do preço de venda formulado, é possível fazer uma comparação entre o preço orientativo e o preço praticado pela padaria estudada em relação a cada produto, conforme a Tabela 07.

Tabela 07- Comparação entre preço orientativo e preço praticado

\begin{tabular}{|l|c|c|c|c|}
\multicolumn{1}{|c}{ Produtos } & $\begin{array}{c}\text { Preço de venda } \\
\text { orientativo -Kg }\end{array}$ & \multicolumn{1}{c|}{$\begin{array}{c}\text { Preço de venda } \\
\text { praticado- Kg }\end{array}$} & $\begin{array}{c}\text { Diferença \% entre Pv } \\
\text { orientativo e o praticado }\end{array}$ & Diferença $(\mathrm{R} \$)$-Kg \\
\hline \hline Pão francês & $\mathrm{R} \$ 9,36$ & $\mathrm{R} \$ 8,89$ & $-5,02 \%$ & $\mathrm{R} \$(0,47)$ \\
\hline Cuca simples & $\mathrm{R} \$ 10,07$ & $\mathrm{R} \$ 8,75$ & $-13,11$ & $\mathrm{R} \$(1,32)$ \\
\hline Bolacha de milho & $\mathrm{R} \$ 17,39$ & $\mathrm{R} \$ 16,98$ & $-2,36 \%$ & $\mathrm{R} \$(0,41)$ \\
\hline
\end{tabular}

Fonte: Conforme dados da pesquisa, (2017).

Verifica-se na Tabela 07 que o preço de venda praticado por quilo $(\mathrm{kg})$ do pão francês, da cuca simples e da bolacha de milho é menor que o preço de venda orientativo, tendo uma diferença $-5,02 \%$ o que representa $\mathrm{R} \$ 0,47$ por quilo $(\mathrm{kg})$ para o pão francês, e de $-13,11 \%$ para a cuca simples oque reflete em valores $\mathrm{R} \$ 1,32$ por quilo $(\mathrm{kg})$ vendido e de $\mathrm{R} \$ 0,41$ por quilo $(\mathrm{kg})$ para a bolacha de milho. Sendo que, a cuca simples é o produto, dentre os três produtos analisados, o que mais tem diferença entre o preço praticado e o preço orientativo, no entanto o produto mais vendido e mais representativo no faturamento é o Pão Frances. Na sequência por meio da Tabela 08 é demonstrado a apuração do resultado do exercício. 
Tabela 08- Demonstração do Resultado do Exercício - Anual

\begin{tabular}{|c|c|c|c|c|}
\hline & PÃO FRANCÊS & CUCA SIMPLES & BOLACHA MILHO & VALOR TOTAL \\
\hline (=)RECEITA OPERACIONAL BRUTA & $\mathrm{R} \$ 10.134,60$ & $\mathrm{R} \$ 1.312,50$ & $\mathrm{R} \$ 509,40$ & $\mathrm{R} \$ 11.956,50$ \\
\hline (-) DEDUÇÕES DA RECEITA BRUTA & $\mathrm{R} \$ 554,36$ & $\mathrm{R} \$ 71,79$ & $\mathrm{R} \$ 27,86$ & $\mathrm{R} \$ 654,02$ \\
\hline (-) Impostos & $\mathrm{R} \$ 554,36$ & $\mathrm{R} \$ 71,79$ & $\mathrm{R} \$ 27,86$ & $\mathrm{R} \$ 654,02$ \\
\hline$(-) \mathrm{CPP}(2,75 \%)$ & $\mathrm{R} \$ 278,70$ & $\mathrm{R} \$ 36,09$ & $\mathrm{R} \$ 14,01$ & $\mathrm{R} \$ 328,80$ \\
\hline$(-)$ Cofins $(0,86 \%)$ & $\mathrm{R} \$ 87,16$ & $\mathrm{R} \$ 11,29$ & $\mathrm{R} \$ 4,38$ & $\mathrm{R} \$ 102,83$ \\
\hline (-)ICMS $(1,86 \%)$ & $\mathrm{R} \$ 188,50$ & $\mathrm{R} \$ 24,41$ & $\mathrm{R} \$ 9,47$ & $\mathrm{R} \$ 222,39$ \\
\hline (=) RECEITA OPERACIONAL LÍQUIDA & $\mathrm{R} \$ 9.580,24$ & $\mathrm{R} \$ 1.240,71$ & $\mathrm{R} \$ 481,54$ & $\mathrm{R} \$ 11.302,48$ \\
\hline$(-)$ CUSTOS DAS VENDAS & $\mathrm{R} \$ 4.218,00$ & $\mathrm{R} \$ 748,50$ & $\mathrm{R} \$ 310,50$ & $\mathrm{R} \$ 5.277,00$ \\
\hline (=) RESULTADO OPERACIONAL BRUTO & $\mathrm{R} \$ 5.362,24$ & $\mathrm{R} \$ 492,21$ & $\mathrm{R} \$ 171,04$ & $\mathrm{R} \$ 6.025,48$ \\
\hline$(-)$ DESPESAS OPERACIONAIS & $\mathrm{R} \$ 1.869,25$ & $\mathrm{R} \$ 245,89$ & $\mathrm{R} \$ 49,13$ & $\mathrm{R} \$ 2.164,39$ \\
\hline (-) Despesas administrativas & $\mathrm{R} \$ 984,56$ & $\mathrm{R} \$ 129,51$ & $\mathrm{R} \$ 25,88$ & $\mathrm{R} \$ 1.140,07$ \\
\hline (-) Despesas com telefone/internet & $\mathrm{R} \$ 56,13$ & $\mathrm{R} \$ 7,38$ & $\mathrm{R} \$ 1,48$ & $\mathrm{R} \$ 65,00$ \\
\hline (-) Despesas com material escritório & $\mathrm{R} \$ 30,23$ & $\mathrm{R} \$ 3,98$ & $\mathrm{R} \$ 0,79$ & $\mathrm{R} \$ 35,00$ \\
\hline (-) Pro labore & $\mathrm{R} \$ 898,20$ & $\mathrm{R} \$ 118,15$ & $\mathrm{R} \$ 23,61$ & $\mathrm{R} \$ 1.040,07$ \\
\hline (-) Despesas com vendas & $\mathrm{R} \$ 884,69$ & $\mathrm{R} \$ 116,37$ & $\mathrm{R} \$ 23,25$ & $\mathrm{R} \$ 1.024,32$ \\
\hline (-) Despesas com depreciação & $\mathrm{R} \$ 699,02$ & $\mathrm{R} \$ 91,95$ & $\mathrm{R} \$ 18,37$ & $\mathrm{R} \$ 809,42$ \\
\hline (-) Despesas com embalagens & $\mathrm{R} \$ 95,00$ & $\mathrm{R} \$ 12,50$ & $\mathrm{R} \$ 2,50$ & $\mathrm{R} \$ 110,00$ \\
\hline (-) Despesas com combustível & $\mathrm{R} \$ 90,68$ & $\mathrm{R} \$ 11,93$ & $\mathrm{R} \$ 2,38$ & $\mathrm{R} \$ 105,00$ \\
\hline (=) LUCRO LÍQUIDO ANTES PARTICIPAÇÕES & $\mathrm{R} \$ 3.492,98$ & $\mathrm{R} \$ 246,32$ & $\mathrm{R} \$ 121,90$ & $\mathrm{R} \$ 3.861,21$ \\
\hline (=) RESULTADO LÍQUIDO DO EXERCÍCIO & $\mathrm{R} \$ 3.492,98$ & $\mathrm{R} \$ 246,32$ & $\mathrm{R} \$ 121,90$ & $\mathrm{R} \$ 3.861,21$ \\
\hline
\end{tabular}

Fonte: Conforme dados da pesquisa, (2017).

Conforme a Tabela 08 apresenta-se a demonstração do resultado do exercício gerencial, pois está estruturada por produto, e que segundo Hong (2006) é desenvolvida para atender às necessidades de planejamento, controle e avaliação de desempenho, voltada para o público interno da organização.

A receita operacional bruta de cada produto foi calculada considerando o preço de venda praticado, o qual foi multiplicado pelo total de quilos vendidos durante o mês, sendo $1.140 \mathrm{Kg}$ vendidos de pão francês, 150 Kg de cuca simples e $30 \mathrm{Kg}$ de bolacha de milho. Na dedução de vendas, os impostos estão de acordo com o anexo 1 do Simples Nacional. Para a formação do custo do produto vendido utilizam-se as quantidades vendidas no mês de cada produto multiplicado pelo custo unitário.

Nas despesas operacionais constam as despesas administrativas e de vendas, que, por se tratarem de gastos feitos pela empresa e que não compõe o custo dos produtos são considerados despesas operacionais. Na despesa administrativa tem-se o gasto com telefone/internet, material de escritório e o pró-labore, totalizando um valor mensal de $\mathrm{R} \$ 1.140,07$. Para as despesas de vendas o gasto é com depreciação do imobilizado, combustível e embalagens, valor mensal de R\$1.024,32.

0 resultado líquido do mês em estudo para o pão francês foi de $\mathrm{R} \$ 3.492,98$, para a cuca simples $\mathrm{R} \$ 246,32$ e de $\mathrm{R} \$ 121,90$ para bolacha de milho. E um total mensal de $\mathrm{R} \$ 3.861,21$ considerando a soma do resultado líquido dos três produtos.

O empresário ao analisar a demonstração do resultado, saberá quais os produtos que estão tendo mais lucro ou prejuízo, podendo assim, focar em determinado produto para melhorar seu resultado, ou até mesmo alavancar as vendas daquele produto que tem um bom resultado a fim de aumentar a lucratividade. 
Por meio da Tabela 09 é demonstrado o resultado do exercício pelo preço de venda orientativo. Após, será comparado com o resultado do exercício pelo preço de venda praticado.

Tabela 09- Demonstração do Resultado do Exercício pelo preço de venda orientativo

\begin{tabular}{|c|c|c|c|c|c|c|}
\hline & PÃO FRANCÊS & $\begin{array}{c}\text { CUCA } \\
\text { SIMPLES }\end{array}$ & $\begin{array}{l}\text { BOLACHA } \\
\text { MILHO }\end{array}$ & TOTAL & $\begin{array}{c}\text { VARIA-ÇÃO } \\
\text { R\$ }\end{array}$ & $\begin{array}{l}\text { VARIA- } \\
\text { ÇÃO \% }\end{array}$ \\
\hline $\begin{array}{l}\text { Quantidade produzida } \\
\text { mês }\end{array}$ & $1140 \mathrm{~kg}$ & $150 \mathrm{~kg}$ & $30 \mathrm{~kg}$ & & & \\
\hline $\begin{array}{l}\text { Preço de venda } \\
\text { sugerido }\end{array}$ & $\mathrm{R} \$ 9,36$ & $\mathrm{R} \$ 10,07$ & $\mathrm{R} \$ 17,39$ & & & \\
\hline (=) Receita bruta & $\mathrm{R} \$ 10.670,40$ & $\mathrm{R} \$ 1.510,00$ & $\mathrm{R} \$ 521,70$ & $\mathrm{R} \$ 12.702,60$ & $\mathrm{R} \$ 746,10$ & $5,9 \%$ \\
\hline $\begin{array}{c}\text { (-) Impostos sobre } \\
\text { vendas }\end{array}$ & $\mathrm{R} \$ 583,67$ & $\mathrm{R} \$ 82,62$ & $\mathrm{R} \$ 28,54$ & $\mathrm{R} \$ 694,83$ & $\mathrm{R} \$ 40,81$ & $5,9 \%$ \\
\hline (=) Receita líquida & $\mathrm{R} \$ 10.086,73$ & $\mathrm{R} \$ 1.427,88$ & $\mathrm{R} \$ 493,16$ & $\mathrm{R} \$ 12.007,77$ & $\mathrm{R} \$ 705,29$ & $5,9 \%$ \\
\hline $\begin{array}{c}\text { (-) Custo produto } \\
\text { vendido }\end{array}$ & $\mathrm{R} \$ 4.218,00$ & $\mathrm{R} \$ 748,50$ & $\mathrm{R} \$ 310,50$ & $\mathrm{R} \$ 5.277,00$ & $\mathrm{R} \$-$ & $0 \%$ \\
\hline (=) Resultado bruto & $\mathrm{R} \$ 5.868,73$ & $\mathrm{R} \$ 679,38$ & $\mathrm{R} \$ 182,66$ & $\mathrm{R} \$ 6.730,77$ & $\mathrm{R} \$ 705,29$ & $10,5 \%$ \\
\hline $\begin{array}{c}(-) \text { Despesas } \\
\text { administrativas }\end{array}$ & $\mathrm{R} \$ 984,56$ & $\mathrm{R} \$ 129,51$ & $\mathrm{R} \$ 25,88$ & $\mathrm{R} \$ 1.140,07$ & $\mathrm{R} \$-$ & $0 \%$ \\
\hline (-) Despesas vendas & $\mathrm{R} \$ 884,69$ & $\mathrm{R} \$ 116,37$ & $\mathrm{R} \$ 23,25$ & $\mathrm{R} \$ 1.024,32$ & $\mathrm{R} \$-$ & $0 \%$ \\
\hline (=) Lucro líquido & $\mathrm{R} \$ 3.999,48$ & $\mathrm{R} \$ 433,49$ & $\mathrm{R} \$ 133,53$ & $\mathrm{R} \$ 4.566,50$ & $\mathrm{R} \$ 705,29$ & $14,6 \%$ \\
\hline
\end{tabular}

Fonte: Conforme dados da pesquisa, (2017).

Com base na Tabela 09 são apresentados os possíveis resultados auferidos pela utilização do sistema de custeio por absorção, e o que este influenciou diretamente no resultado global da empresa conforme disposto na DRE gerencial.

0 primeiro ponto a ser considerado é o preço de venda praticado versus o preço de venda orientativo, onde, conforme os resultados da análise, o empresário está praticando preços menores (subavaliados) com relação aos preços sugeridos pelo Mark-up e no seu planejamento estratégico (identificado na entrevista) para os três produtos.

Na prática a cada quilo vendido do produto pão francês, o empresário deixa de ganhar $R \$ 0,47$, e $R \$ 1,32$ na cuca simples assim como $\mathrm{R} \$ 0,41$ na bolacha de milho. É relevante considerar que através do total de quilos vendidos no mês (meta) somente no pão francês a empresa deixa de gerar lucro líquido de $\mathrm{R} \$ 535,80$ mensal ou $14,51 \%$ menor lucro neste produto.

Estes resultados vem de encontro com os evidenciados na pesquisa de Rocha et al. (2019), onde os autores procuraram comparar os resultados dos preços praticados em uma grande empresa de panificação, com aqueles apurados devidamente através do Markup. Em sua pesquisa os autores identificaram que de todo o mix de produto analisado apenas no pão francês, a empresa estava comercializando com preço superior ao orientativo, de maneira geral em todos os demais itens a empresa estava comercializando a valores, que produziam margens de contribuição abaixo do esperado pelos gestores (investidores).

0 segundo ponto analisado, trata dos impostos sobre as vendas, tomando como base os impostos sobre a receita bruta pelo preço de venda praticado, o empresário economiza $R \$ 40,81$ por mês, ou seja, 5,9\% a menos do que pagaria se vendesse os produtos pelo preço orientativo. No entanto, mesmo tendo uma certa "economia" nos impostos, nada se equivale ao valor que se está deixando de ganhar, ou seja, $\mathrm{R} \$ 746,10$ ao mês considerados os três produtos.

Com relação ao valor dos custos mensais referentes aos CPV este representou $R \$ 5.277,00$, sendo que o produto com maior demanda, necessita de investimentos em matéria prima (capital de giro) de $\mathrm{R} \$ 4.218,00$ foi o pão francês, e o que necessita de menores investimentos em matéria prima foi a bolacha de milho com apenas R $\$ 310,50$ de CPV. Já com relação ao total das despesas operacionais (venda e entrega) mensais o valor gasto foi de $\mathrm{R} \$ 2.164,39$. 
Em relação ao lucro líquido do período, a padaria seria mais lucrativa e mais eficiente se adotasse o preço de venda orientativo, pois, comprovou-se que o uso e o conhecimento das informações de custos e a correta precificação podem auxiliar os empreendedores a melhorar a lucratividade de seus negócios, assim como a tomada de decisão entre produzir ou não determinado produto em seu mix. 0 que ficou comprovado através resultado líquido do DRE utilizando o preço de venda praticado com o preço de venda orientativo, que existe uma perda de lucro de $14,6 \%$ ao mês.

Quanto à margem de lucro líquida, que é implementada na formação do preço de venda a padaria também tem perda por não praticar o preço de venda ideal, pois, quanto maior for à margem de contribuição em cada produto, maior será a sobra da padaria após o recebimento das vendas e a retirada dos impostos e das deduções. Verificou-se que há uma redução de margem líquida de $3 \%$ para o pão francês, $10 \%$ na cuca simples e $2 \%$ na bolacha de milho. Dentre os três produtos analisados, a cuca simples foi o que apresentou a maior diferença na margem líquida, deixando de lucrar $\mathrm{R} \$ 187,17$ com esse produto.

Em relação aos níveis de despesas operacionais, considerando as despesas de vendas e administrativas, as mesmas permanecem iguais em valores (R\$), mas, se alteram na proporção (\%). Sendo, a menor proporção de despesa na DRE pelo preço orientativo, representando 15,9\% do total da receita, enquanto que DRE utilizando o preço praticado, o nível de despesa alcança 16,9\% do total.

Em relação à variação total do lucro líquido, observa-se que, por não estar sendo praticado o preço de venda orientativo, existe uma diminuição no lucro líquido de $14,6 \%$, isso quer dizer que, todo mês o empresário deixa de lucrar $\mathrm{R} \$ 705,29$.

A partir destas analises pode-se afirmar que a correta precificação do custo e de preço de venda permite melhorar todos os indicadores da DRE de um empreendimento. Desta forma constata-se que durante o ano, a variação total acumulada do lucro líquido que deixou de ser auferida é de $\mathrm{R} \$ 8.463,48$, podendo ser um valor bem significativo para uma empresa pequena.

De maneira geral, o único ponto que se torna satisfatório em vender com preço subavaliado do ponto de vista do empreendedor é o valor dos impostos pago. Porém, como já salientado, o valor financeiro não é relevante diante do que o empresário está deixando de lucrar. É importante ressaltar que o empresário não está tendo prejuízo com o preço de venda que ele está praticando, no entanto, não está obtendo o retorno do lucro que deseja.

\section{CONSIDERAÇÕES FINAIS}

0 presente estudo teve como objetivo geral identificar os custos e a formação do preço de venda dos produtos de uma indústria de panificação localizada no município de Arvoredo- SC. Para tanto foi utilizado a técnica do estudo de caso, o qual evidenciou para a relevância de se ter uma assessoria e acompanhamento no conhecimento de todos os custos de um empreendimento seja ele grande ou pequeno (micro). Entende-se que pesquisa atendeu ao seu objetivo geral, pois permitiu identificar os custos e a influência do preço de venda que um produto ou serviço têm no resultado final de uma atividade e consequentemente na tomada de decisão.

A empresa em estudo não possuía nenhuma ficha de controle para gerenciar os custos em relação aos produtos. Contudo o empresário está praticando preços abaixo do ideal nos três produtos analisados. Entretanto, não está tendo prejuízo, apenas não tem o retorno de lucro que deseja.

Com isso, conclui-se que, o conhecimento dos custos é um fator essencial na vida do empreendedor (investidor) e para a sobrevivência de qualquer empresa. A elaboração correta do preço de venda garante o lucro que os proprietários almejam auferir, permitindo que caso apresentado uma otimização dos resultados líquidos de $14,6 \%$ o que pode ser significativo no resultado global.

Como limitações do estudo, destacam-se as dificuldades em encontrar a base ou critérios de rateio dos custos indiretos relacionados a cada produto, pelo fato da padaria não dispor de dados internos organizados para isso, e por haver um mix de produtos superior ao estudado, além do fato do próprio empresário não ter conhecimento sobre custos indiretos.

Como sugestões para pesquisas futuras orienta-se a verificar se seria mais vantajoso para uma padaria comprar o pão francês pré-pronto, e apenas assá-lo para comercialização, ou manter a linha de produção. 


\section{REFERÊNCIAS}

[1] Almeida, L. B. De; Santos, A. R. Dos. Práticas De Contabilidade De Custos: Uma Investigação Nas Indústrias Paranaenses. Sociedade, Contabilidade E Gestão, V. 2, N. 1, P. 19-34, 2007.

[2] Backes, R. G.; Perleberg, C. R.; Dalben, L. C. Aplicação Do Método De Custeio Rkw Em Uma Cooperativa Agrícola. Custos E @Gronegócio On Line, V. 3, P. 18-39, 2007.

[3] Barros, A. J. S., Lehfeld, N. A. S. (2007). Fundamentos De Metodologia Científica. 3. Ed. São Paulo: Pearson Prentice Hall

[4] Bruni, A. L., Famá, R. (2011). Gestão De Custos E Formação De Preços: Com Aplicações Na Calculadora Hp 12c E Excel. 5. Ed. São Paulo: Atlas.

[5] Casarin, H. C. S., Casarin, S. J. (2012). Pesquisa Científica: Da Teoria À Prática. Curitiba: Intersaberes.

[6] Costa, O. S. Da. (2004). Estudo De Caso Na Produção Da Panificadora Orlessan Orlando. In Universidade Federal De Santa Catarina Centro Sócio-Econômico Departamento De Ciências Econômicas Curso De Graduação Em Ciências Econômicas Estudo.

[7] Cunha, M. C. F., \& Fernandes, M. S. A. (2007). A Utilização Da Contabilidade De Custos Na Formação Do Preço De Venda. In: $X \quad$ Encontro De Iniciação À Docência. Ufpb - Prg. Disponível Em: $<$ Http://Www.Classecontabil.Com.Br/Artigos/A-Utilizacao-Da-Contabilidade-De-Custos-Na-Formacao-Do-Preco-DeVenda>. Acesso Em: 04 Mar. 2017.

[8] Eckert, A. Et Al. Alocação Dos Custos Indiretos De Fabricação: Impactos No Custo Final E Na Fixação De Preços De Venda Em Uma Empresa De Serviços De Pintura Automotiva. Ric - Revista De Informação Contábil, V. 8, N. 2, P. 1-28, 2014.

[9] Morais, J. F.; Vieira, E. P. Estratégias De Precificação Para Empresas Comerciaisijuí, 2013.

[10] Elitzak, H. 1997. Food Cost Review, 1996. U.S. Department Of Agriculture, Economic Research Service, Aer761.

[11] Filho, L. L. S., Lagioia, U. C. T., Araújo, J. G. N., Araujo, J. G., Filho, F. A. C., 2015. “Gestão De Custos E Formação De Preço De Venda, Gestão De Caixa E Gestão De Riscos: Um Estudo Exploratório No Arranjo Produtivo Local Gesseiro Do Estado De Pernambuco". Abcustos 10(3): 107-42.

[12] Hall, R. J., Costa, V. C., Kreuzberg, F., Moura, G. D., Hein, N., (2012). Contabilidade Como Uma Ferramenta Da Gestão: Um Estudo Em Micro E Pequenas Empresas Do Ramo De Comércio De Dourados-Ms. Revista Da Micro E Pequena Empresa, Campo Limpo Paulista, 6: (3), P. 4-17.

[13] Hong, Y. C. (2006). Contabilidade Gerencial. São Paulo: Pearson Prentice Hall.

[14] Leone, J. S. G. (2000). Curso De Contabilidade De Custos. 2. Ed. São Paulo: Atlas.

[15] Lima, E. B.. Contabilidade De Custos. 2014 Pg. 3. Conselho Regional De Contabilidade Do Estado Do Rio De Janeiro.

[16] Lorentz, F. (2015). Contabilidade E Análise De Custos: Uma Abordagem Pratica E Objetiva: 250 Exercícios Resolvidos. Rio De Janeiro: Freitas Bastos.

[17] Martins, G. A., Theóphilo, C. R. (2016). Metodologia Da Investigação Cientifica Para Ciências Sociais E Aplicadas. 3 Ed. Atlas: São Paulo.

[18] Megliorini, E. (2001). Custos. São Paulo: Makron Books.

[19] Megliorini, E. (2012). Custos: Análises E Gestão. 2. Ed. São Paulo: Pearson Prentice Hall.

[20] Morais, J. F., \& Vieira, E. P. (2013). Estratégias De Precificação Para Empresas Comerciais. Ijuí.

[21] Niederle, F. Sistema De Custos E Analise De Preços Na Padaria Bom Gostouniversidade Regional Do Noroeste Do Estado Do Rio Grande Do Sul Dacec - Departamento De Ciências Administrativas, Contábeis, Econômicas E Da Comunicaçãotrês Passostrabalho De Conclusão De Curso (Curso De Ciências Contábeis Da Unijuí), , 2012.

[22] Niemi, Jyrki Et Al. Price Formation And Margin Behaviour In The Finnish Food Markets. In: 21st Annual Ifama World Symposium In Frankfurt On June. 2010. P. 20-31.

[23] Pelissari, A. S.; Gonzalez, I. V. D. P.; Vanalle, R. M. (2011). Competências Gerenciais: Um Estudo Em Pequenas Empresas De Confecções. Revista Eletrônica De Administração, 17:(1) P.149-180. 
[24] Pinto, L. J. S. Formação Do Preço De Venda Com Base No Lucro Desejado: Um Estudo De Caso Através Do Mapeamento Dos Custos E Despesas. Viii Seget - Simpósio De Excelência Em Gestão E Tecnologia, V. V, 2011.

[25] Raupp, M. F.; Beuren, I. M. Metodologia De Pesquisa Aplicável As Ciências Sociais. In: Beuren, Ilse Maria. Como Elaborar Trabalhos Monográficos Em Contabilidade: Teoria E Prática. 2.Ed. São Paulo: Altas, 2004.

[26] Reed, A.J., And J.S. Clark. 1998. Nonfarm Input Prices, Price Margins, And Consumer Food Prices. S. Department Of Agriculture, Economic Research Service, Technical Bulletin No. 1867

[27] Reed, A., Elitzak, H. And Wohlgenant, M. 2002. Retail-Farm Price Margins And Consumer Product Diversity. U.S. Department Of Agriculture, Economic Research Service, Technical Bulletin No. 1899. 29 P.

[28] Receita Federal Do Brasil (Rfb), 2007. Solução De Consulta No 341 De 26 De Setembro De 2007, Dou De 02.10.2007. Disponível Em: Http://Blog.Esimplesauditoria.Com.Br/Panificadoras-Optantes-Pelo-Simples-Industria-OuComercio/. Acesso Em: 14 De Outubro De 2017.

[29] Ribeiro, O. M. (2013). Contabilidade Comercial Fácil. 18. Ed. São Paulo: Saraiva.

[30] Ribeiro, O. M.. (2014). Contabilidade De Custos Fácil. 9. Ed. São Paulo: Saraiva. 272 P.

[31] Rocha, I. C.; Oliveira, A.M.;Soares, F.I.L; Silva,G.V.;Oliveira.A.M.; Valdevino.R.Q.S.; Oliveria, M.C.S. Cost Acoounting As A Tool In Sales Price Formation In A Bakery Industry. Braz. J. Of Develop., Curitiba, V. 5, N. 9, P. 15957 15980 Sep. 2019

[32] Santos, J. J. (2009). Contabilidade E Análise Dos Custos: Modelo Contábil, Métodos De Depreciação, AbcCusteio Baseado Em Atividades, Análise Atualizada De Encargos Sociais Sobre Salários. 5. Ed. São Paulo: Atlas.

[33] Serviço Brasileiro De Apoio As Micro E Pequenas Empresas - Sebrae (2018). Panificadoras Oferecem Oportunidades Para Quem Investir Em Inovação. Acesso Em 15/03/2020. Disponível Em: Https://Blog.SebraeSc.Com.Br/Panificadoras-Oferecem-Oportunidades-Para-Quem-Investir-Em-Inovacao/

[34] Sepp, C., Manfroi, L., Theisen, C.P., Diel, H. E., Diel, J. F. 2015. "Formação Do Preço De Venda: Um Estudo Aplicado Em Um Restaurante Do Município De Chapecó- Sc." Revista Cientifica Tecnologica 3(2): 105-21.

[35] Silva, R. N. S., \& Lins, L. S. (2014). Gestão De Custos: Contabilidade, Controle E Análise. 3. Ed. São Paulo: Atlas.

[36] Tarifa, M. R., Silva, L. F. S. (2009). Contabilidade Gerencial: Ciências Contábeis. São Paulo: Pearson Education Do Brasil.

[37] Theiss, J. R., Krieck, M. (2012). Custos E Preços Sugeridos De Vendas: Cálculos E Enfoques Práticos, Serviços, Comércio E Indústria. 4. Ed. Blumenau: Odorizzi.

[38] Viceconti, P., Neves, S. (2013). Contabilidade De Custos: Um Enfoque Direto E Objetivo. 11. Ed., Rev. E Atual. São Paulo: Saraiva.

[39] Zahaikevitch, E. V.; Matos, S. N. Formação De Preço De Venda Em Micro E Pequenas Empresas : Um Estudo De Caso Nas Empresas Do Ramo De Informática Em Uma Cidade Do Interior Do Parará. Facesi Em Revista, V. 5, N. 1, 2013.

[40] Zanluca, J. S. (2017). Custos Fixos E Variáveis. Disponível Em: <Http://Www.Portaldecontabilidade.Com.Br/Tematicas/Custo-Fixo-Variavel.Htm>. Acesso Em: 26 Mar. 2017.

[41] Wernke, R.. Análise De Custos E Preços De Venda. 11. Ed. São Paulo: Saraiva, 2017

[42] Wernke, R. (2005). Análise De Custos E Preços De Venda: Ênfase Em Aplicações E Casos Nacionais. São Paulo: Saraiva.

[43] Yin, R. K. (2001). Estudo De Caso: Planejamento E Métodos. Trad. Daniel Grassi - 2.Ed. Porto Alegre: Bookman. 


\section{Capítulo 15}

Índice de distorções financeiras do orçamento - IDFO: Uma proposta de ferramenta de avaliação da execução orçamentária municipal

\section{Gustavo Silva de França}

Marcos Paulo Andrade Silva

Silvana Maria de Jesus Vetter

Resumo: A legislação brasileira impõe aos gestores públicos que seja realizado o orçamento público anual com a finalidade de envolver e debater com a comunidade aspectos importantes no tocante às receitas e despesas orçamentárias. Porém durante a execução orçamentária ocorrem diversas alterações, que quando excessivas prejudicam os processos de planejamento, controle, avaliação, prestação de contas e responsabilização. Assim levanta-se a problemática se é possível estabelecer um mecanismo de medição das distorções financeiras entre o planejado e o executado no âmbito da gestão municipal. Para responder a essa questão utilizou-se uma pesquisa bibliográfica e documental, ex post facto, de caráter exploratória e com abordagem quantitativa. Objetivou-se apresentar um índice para mensurar as distorções financeiras do orçamento, demonstrar a importância da avaliação da execução orçamentária e testar o índice no orçamento de 2018 do município de Imperatriz - MA, identificando e descrevendo as principais distorções financeiras encontradas neste documento. 0 estudo resultou na elaboração do Índice de Distorção Financeira do Orçamento - IDFO.

Palavras-Chave: Orçamento público; Avaliação da execução orçamentária; IDFO. 


\section{INTRODUÇÃO}

No Brasil, a Constituição Federal (1988) deixou a cargo do poder Executivo a responsabilidade de elaborar o orçamento público anual. Assim, o chefe do poder Executivo de cada ente federativo deve anualmente elaborar e enviar ao poder Legislativo o Projeto de Lei Orçamentária Anual (PLOA), que será executada no ano seguinte. Após aprovação da Casa Legislativa, o orçamento é devolvido, agora como Lei Orçamentária Anual (LOA), ao Executivo para sanção.

A LOA terá vigência do dia $1^{\text {o }}$ de janeiro até o dia 31 de dezembro do ano subsequente a sua elaboração. No entanto, durante sua execução, o orçamento geralmente sofre alterações para suprir demandas não previstas, corrigir erros e omissões e compatibilizar os dispêndios com as efetivas entradas de recursos. Autores como Pedrosa (2015), Aquino e Azevedo (2015) vêm percebendo uma significativa volatilidade durante a execução orçamentária, sobretudo, no que se refere às distorções financeiras entre o que foi inicialmente aprovado pelo Legislativo e o que é de fato executado no decorrer do exercício financeiro.

Tal situação vem sendo destacada em algumas pesquisas como prejudiciais ao processo de planejamento, controle, avaliação, prestação de contas e responsabilização. Com isso, buscou-se nesta pesquisa responder a seguinte problemática: é possível estabelecer um mecanismo de medição da variação financeira das receitas e despesas entre o planejado e o executado no âmbito da gestão municipal?

A partir de uma pesquisa bibliográfica, documental, ex post facto e exploratória, buscou-se apresentar um índice que possibilitasse mensurar as distorções financeiras ocorridas entre a elaboração e execução do orçamento municipal. Concomitante a isso, procurou-se demonstrar a importância da avaliação da execução orçamentária e testar o índice apresentado no orçamento do ano de 2018, do município Imperatriz - MA, bem como identificar e descrever as principais distorções financeiras encontradas.

Durante o levantamento bibliográfico para a fundamentação teórica do estudo, os mecanismos de avaliação da execução orçamentária identificados não atenderam à problemática desta pesquisa, assim formulou-se, no decorrer do estudo, o Índice de Distorção Financeira do Orçamento - IDFO.

0 artigo segue dividido em mais 6 seções, sendo as próximas 3 seções conceituais, que tratam do orçamento público, da execução orçamentária e dos créditos adicionais, seguidas da metodologia, análise dos dados e considerações finais.

\section{ORÇAMENTO PÚBLICO}

Coronado e Oliveira (2004, p. 132) definem orçamento público como “[...] um plano de trabalho governamental expresso em termos monetários, onde evidencia a política econômica, financeira e social do Governo, que apresenta os propósitos e objetivos [...]". Assim, compreende-se que o orçamento público é uma ferramenta de planejamento, na qual o gestor público estabelece as políticas públicas que irá priorizar em um determinado período, com base nos recursos que prevê ter a sua disposição durante esse período.

O orçamento público deve ser anualmente formalizado em lei por cada ente federado, a qual denomina-se de Lei Orçamentária Anual (LOA), que apresenta, em termos monetários, as receitas previstas a serem arrecadadas e as despesas a serem executadas durante o exercício financeiro seguinte (COUTO et al, 2018). Deve ser elaborada pelo Executivo e aprovada pelo Legislativo.

O orçamento público faz-se necessário, entre outros motivos, pelo fato de os recursos serem limitados frente as demandas quase ilimitadas. Corroborando com o assunto, Rocha et al (2013, p. 814) diz que: "[...] o Estado não possui recursos suficientes para suprir todas as necessidades da sociedade e, por consequência, tem de escolher em quais demandas alocará os recursos escassos provenientes dos seus tributos financiadores."

\subsection{RECEITAS X DESPESAS}

As definições dos conceitos "receita" e "despesa" podem variar, dependo do ambiente no qual os termos estão sendo estudados. Neste sentido, esta pesquisa se restringe às suas definições no ambiente orçamentário. 
Carvalho Junior e Feijó (2015, p. 36) definem receita orçamentária como "[...] toda fonte de recurso obtida ou angariada com o objetivo de autorizar despesas de natureza orçamentária" e despesa orçamentária como "[...] toda aplicação de recursos que precisa ser autorizada em lei orçamentária ou em créditos adicionais".

Pedrosa (2015) ressalta que a Lei 4.320/1964 estabelece que as receitas serão identificadas por códigos decimais, o qual convencionou-se chamar de natureza da receita. Essa classificação, regulamentada pela Portaria Interministerial 163/2001, deve ser utilizada por todos os estados da federação e visa identificar a origem do recurso segundo o fato gerador.

As despesas orçamentárias são apresentadas de forma individualizada, na LOA, por meio das dotações orçamentárias, que são representadas por códigos numéricos de classificação. As classificações apresentadas na dotação orçamentária podem variar em amplitude, dependendo do ente federativo, mas segundo Pacelli (2019), será obrigatório para todos os entes a classificação institucional, classificação funcional, classificação programática e classificação quanto a natureza.

As receitas e as despesas orçamentárias "[...] representam o montante que o Estado se apropria da sociedade por intermédio da tributação e a sua contrapartida aos cidadãos por meio da geração de bens e serviços" (BRASIL, 2018, p. 30). Assim, é fundamental o efetivo planejamento, controle e avaliação desses elementos do orçamento público, tanto quando na fase de elaboração como na fase execução, como será discutido na próxima seção.

\section{EXECUÇÃO ORÇAMENTÁRIA}

Tão importante como a elaboração do orçamento é sua execução, pois é nesse momento que o que foi planejado toma forma. Faz-se necessário que toda essa atividade seja monitorada e avaliada, para que não se distorça aquilo que foi autorizado por lei.

Couto et al (2018, p. 46) diz que "[...] a execução é quando o que foi elencado na LOA assume a natureza financeira na forma de fluxos de recursos que entram e saem dos cofres públicos". A execução orçamentária ocorre a partir do dia $1^{\circ}$ de janeiro até o dia 31 de dezembro de cada exercício financeiro, através da arrecadação das receitas e realização das despesas.

Entretanto, geralmente a execução do orçamento não ocorre exatamente como foi programado na LOA. Isso porque a LOA apenas prevê as receitas, que podem ocorrerem em valores maiores ou menores, e autoriza as despesas, as quais o Governo pode definir se irá executar integralmente ou parcialmente, ou até mesmo abrir mão de executar algumas. Mas caso deseje executá-las em valores maiores ou executar despesas não previstas inicialmente, deve utilizar créditos adicionais, que serão detalhados na próxima seção. Assim, pode haver diferenças na arrecadação e na realização das despesas, são essas diferenças objeto desta pesquisa.

Essa realidade independe do nível ou porte do ente federado. Pedrosa (2015), por exemplo, alertou sobre extrema volatilidade na execução do orçamento federal entre os anos de 2000 e 2011. Já no âmbito municipal, Aquino e Azevedo (2015) analisaram quase 3 mil municípios e concluíram que, no ano de 2013, $25 \%$ do orçamento foi aplicado em destinações diferentes do que foi inicialmente aprovado pelo Legislativo.

Rocha et al (2013) justifica a necessidade de ajustar o orçamento durante a execução, devido ao intervalo de tempo entre a sua elaboração e efetiva execução, podendo ocorrer situações imprevistas, mudanças no cenário político e econômico, bem como erros e omissões. No entanto, Aquino e Azevedo (2015) chamam a atenção de que as receitas podem ser subavaliadas ou superestimadas de forma intencional e estratégica, para o gestor ter mais flexibilidade na execução do orçamento e de forma menos dependente de autorização do Legislativo.

Fiirst et al (2015) alertam que as falhas nas previsões durante a elaboração do orçamento, promovem distorções durante a execução, frustrando as expectativas da população, além de comprometer as atividades de planejamento, avaliação, controle, prestação de contas e responsabilização. Assim, percebese a importância de um planejamento coerente e eficaz para uma execução estável, para isso faz-se necessário que haja mecanismos de medição e avaliação da execução orçamentária. 


\section{CRÉDITOS ADICIONAIS}

Como foi mencionado, durante a execução do orçamento podem ocorrer situações que impetrem alterações no planejamento inicial. Rocha et al. (2013) frisa que tais situações devem ser absorvidas pelo orçamento durante a sua execução, e para isso, deve-se utilizar os mecanismos retificadores do orçamento, denominados de créditos adicionais. Definidos pela Lei 4.320/1964, em seu art. 40 como "[...] as autorizações de despesa não computadas ou insuficientemente dotadas na Lei de Orçamento", ou seja, as autorizações para realização de despesas que não foram previstas ou para despesas que foram autorizadas com valores insuficientes. 0 art. 41 da mesma lei classifica os créditos adicionais em três tipos: suplementares, especiais e extraordinário.

Segundo essa lei, os créditos suplementares são aqueles destinados a reforçar as dotações orçamentárias já existentes na LOA, mas com valores insuficientes; os créditos especiais, por sua vez, são destinados à introdução de dotações orçamentárias não existente no orçamento inicial; e por fim, os créditos extraordinários são destinados a despesas urgentes e imprevistas, em caso de guerras, comoção intestina ou calamidade pública

A Lei 4.320/1964 ainda estabelece que para abertura de créditos suplementares ou especiais o gestor deve indicar quais os recursos serão utilizados, podendo ser:
I - o superávit financeiro apurado em balanço patrimonial do exercício anterior;
II - os provenientes de excesso de arrecadação;
III - os resultantes de anulação parcial ou total de dotações orçamentárias ou de créditos adicionais, autorizados em Lei;

IV - o produto de operações de credito autorizadas, em forma que juridicamente possibilite ao poder executivo realiza-las (BRASIL, 1964).

Os créditos adicionais são importantes mecanismos legais, cujo objetivo é corrigir erros do orçamento e acomodar situações imprevistas, dando mais flexibilidade à execução orçamentária. No entanto, não devem ser utilizados indiscriminadamente, de modo que desvirtue o orçamento apresentado à sociedade e aprovado pelos seus representantes. Diante disso, eles foram incluídos entre os documentos a serem analisados neste do estudo, como segue detalhado na próxima seção.

\section{METODOLOGIA}

0 estudo se deu por meio de pesquisa exploratória, documental, ex post facto e bibliográfica, com abordagem quantitativa.

Quantos aos fins, a pesquisa se caracterizou como exploratória, pois “[...] é realizada em área na qual há pouco conhecimento acumulado e sistematizado" (VERGARA, 2010, p. 42). Quanto aos meios caracterizouse como documental, bibliográfica e ex post facto. Documental porque a investigação se deu por meio de documentos; bibliográfica por se basear também em materiais publicados de acesso ao público em geral, como livros, revistas, jornais e redes eletrônicas; e ex post facto por referir-se a fatos já ocorridos, sem que houvesse controle ou manipulação das variáveis pelo pesquisador (VERGARA, 2010). Por fim, a abordagem quantitativa permitiu "[...]traduzir em números opiniões e informações para classificá-las e analisá-las." (PRODANOV; FREITAS, 2013, p. 69).

Buscou-se na literatura acadêmica e em artigos científicos, algum mecanismo de medição das diferenças entre o orçamento público aprovado e sua efetiva execução. No entanto, não se obteve êxito. Para sanar a problemática levantada na pesquisa, optou-se então por elaborar um índice que atendesse ao objetivo do estudo, o qual denominou-se de Índice de Distorção Financeira do Orçamento (IDFO).

Para elaborar e testar a viabilidade do índice apresentado, na próxima seção, utilizaram-se documentos extraídos do portal da transparência do município de Imperatriz - MA (2018) e do site do Tribunal de Contas do Estado do Maranhão (2013). Os documentos utilizados foram: Lei Ordinária no 1.710/2017 (IMPERATRIZ, 2017), relatório "Quadro Detalhado da Receita", relatório "Quadro Detalhado da Despesa" e o relatório de "Créditos Adicionais do Exercício". 


\section{ANÁLISE DOS DADOS}

O IDFO objetiva medir as distorções financeiras do que foi planejado e de fato executado dos orçamentos municipais. As variações são medidas comparando o orçado e o realizado de cada natureza da receita e de cada dotação orçamentária. 0 resultado da fórmula do IDFO, aqui apresentado, sempre será positivo e o valor obtido demonstra a distorção total apurada, sendo que, quando mais próximo de zero for o resultado, menores foram as alterações no orçamento, e quanto mais distante de zero, maiores foram as alterações durante a execução orçamentária. 0 índice é calculado a partir de dois outros índices subordinados, denominados aqui de sub-índices, também elaborados durante a pesquisa, como demonstra a seguinte fórmula:

$$
\text { IDFO }=(\text { Idfr } .0,5)+(\operatorname{Idfd} .0,5)=\frac{\text { Idfr }+ \text { Idfd }}{2}
$$

Idfr - índice de distorção financeira das receitas

Idfd - índice de distorção financeira das despesas

Cada um dos sub-índices é multiplicado por 0,5 por entender-se que metade do processo de elaboração do orçamento consiste em prever receitas e a outra metade em fixar despesas, cada qual tem igual importância para a eficiência do planejamento.

A aplicação do IDFO, na execução do orçamento de Imperatriz - MA, do ano de 2018, buscou testar a viabilidade do índice como mecanismo de avaliação da execução orçamentária. Para isso, foi primeiramente analisado a LOA 2018 do município, posteriormente, aplicado os sub-índices, Idfr e Idfd, e por fim, aplicado à fórmula do IDFO.

Ao analisar o texto da Lei Ordinária no 1.710/2017, Imperatriz - MA, LOA 2018, percebe-se, no art. 6으, inciso I, que autoriza abertura de créditos suplementares até o limite de $50 \%$ do orçamento total, um indício de que durante a execução orçamentária o orçamento poderia sofrer significativas alterações

O Idfr foi aplicado com auxílio do relatório "Quadro Detalhado da Receita", disponibilizado no portal da transparência, que registra uma previsão total de $\mathrm{R} \$ 818.910 .183,00$.

O Idfr calcula a somatória de todas as distorções financeiras das receitas que ocorreram durante a execução, apurando cada distorção individualmente, por natureza da receita, conforme segue a fórmula abaixo:

$$
\operatorname{Idfr}=\sum \mathrm{df}
$$

A $d f$ é a pontuação individual de distorção financeira de um item do orçamento, natureza da receita ou dotação orçamentária. Para fins de cálculo das $d f$ das naturezas de receitas, utilizou-se o valor percentual absoluto da diferença entre o previsto e o arrecadado durante o exercício (v), multiplicado pelo valor percentual de sua representatividade na previsão total (p). Uma receita é considerada arrecadada quando o contribuinte ou devedor do Estado realiza a entrega dos valores devido por meio dos agentes arrecadadores ou instituições financeiras (PEDROSA, 2015).

$$
\mathrm{df}=|\mathrm{v}| \cdot \mathrm{p}
$$

v - variação, é a variação percentual entre o previsto e o realizado;

p - peso, é o percentual que representa sob o orçamento total.

Para melhor entendimento segue a Tabela 1 com a aplicação do Idfr: 
Tabela 1 - Idfr Imperatriz - MA, 2018.

\begin{tabular}{|c|c|c|c|c|c|}
\hline \multicolumn{5}{c}{ Nrevisto } & \multicolumn{2}{c}{$\begin{array}{c}\text { Arrecadado } \\
2018(\mathrm{R} \$)\end{array}$} & Peso (p) & Variação (v) & $\mathrm{df}$ \\
\hline $\begin{array}{c}\text { Natureza da receita } \\
\text { Trabalho - Principal- }\end{array}$ & $12.600 .000,00$ & $11.176 .505,58$ & $1,54 \%$ & $-11,30 \%$ & 0,0017 \\
\hline $\begin{array}{c}\text { 1.1.1.8.01.1.1- IPTU - } \\
\text { Principal- }\end{array}$ & $10.800 .000,00$ & $8.820 .841,82$ & $1,32 \%$ & $-18,33 \%$ & 0,0024 \\
\hline $\begin{array}{c}\text { 1.1.1.8.01.1.2- IPTU - } \\
\text { Multas e Juros }\end{array}$ & $100.000,00$ & - & $0,01 \%$ & $-100 \%$ & 0,0001 \\
\hline $\begin{array}{c}\text { 2.4.2.8.10.9.1 - Outras } \\
\text { Trans. de Conv. dos } \\
\text { Estados }\end{array}$ & $6.611 .061,00$ & $250.690,97$ & $0,81 \%$ & $96,21 \%$ & 0,0078 \\
\hline Total & $818.910 .183,00$ & $667.461 .883,47$ & - & $-18,49 \%$ & - \\
\hline \multicolumn{7}{|c|}{ Idfr } & & & 0,4236 \\
\hline
\end{tabular}

Fonte: Elaborado pelo autor com base nos dados do portal da transparência de Imperatriz - MA.

Apesar dos valores de peso e variação serem expressos em percentual (\%), o cálculo é realizado com seus valores expressos em números decimais, no qual $1 \%=0,01$. A representação no formato de porcentagem é apenas para facilitar a compreensão, porém o resultado deve ser apresentado em números decimais.

Para as receitas que foram arrecadadas sem que houvesse uma previsão inicial, a $d f$ será igual ao percentual que o valor arrecado representa em relação a previsão total do orçamento. Isso porque não havendo uma previsão inicial, não é possível calcular a variação. No entanto, o recurso arrecadado terá impacto na execução do orçamento e deve ser mensurado.

Outro ajuste que se faz necessário é a dedução de $20 \%$ do valor previsto e do arrecado para as naturezas de receita que sofrem dedução para formação do Fundo de Manutenção e Desenvolvimento da Educação Básica e de Valorização dos Profissionais da Educação (FUNDEB), conforme estabelece a Lei 11.494/2007. Isso porque, os valores deduzidos são posteriormente computados na natureza da receita 1.7.5.8.01.1.11.

Assim, apesar de ter sido arrecadado quase $82 \%$ do total previsto para o ano de 2018, o Idfr apurado foi de 0,4236, que significa dizer que o equivalente a $42 \%$ da previsão total ocorreu de forma diferente do previsto. Para demonstrar os resultados obtidos, a tabela 2 apresenta os valores de $d f$ agrupados por origem da receita, o segundo nível da classificação da natureza da receita.

Tabela 2 - Idfr agrupado por origem da receita.

\begin{tabular}{|c|c|c|c|c|c|}
\hline \multirow{2}{*}{ Natureza da Receita } & \multicolumn{2}{c|}{ Origem da Receita } & \multicolumn{2}{c|}{ Peso df total $\begin{array}{c}\text { df por variação } \\
(+)\end{array}$} & $\begin{array}{c}\text { df por variação } \\
(-)\end{array}$ \\
\hline 1.1.X.X.XX.X.X & $\begin{array}{c}\text { Impostos, Taxas e } \\
\text { Contribuições de } \\
\text { Melhoria }\end{array}$ & $11,07 \%$ & 0,0166 & 0,0058 & 0,0108 \\
\hline 1.2.X.X.XX.X.X & Contribuições & $2,44 \%$ & 0,0031 & 0,0031 & 0,0000 \\
\hline 1.3.X.X.XX.X.X & Receita Patrimonial & $0,47 \%$ & 0,0036 & 0,0000 & 0,0036 \\
\hline 1.7.X.X.XX.X.X & Transferências Correntes & $73,21 \%$ & 0,2777 & 0,1064 & 0,1713 \\
\hline 1.9.X.X.XX.X.X & $\begin{array}{c}\text { Outras Receitas } \\
\text { Correntes }\end{array}$ & $5,32 \%$ & 0,0458 & 0,0001 & 0,0456 \\
\hline 2.2.X.X.XX.X.X & Alienação de Bens & $0,01 \%$ & 0,0001 & 0,0000 & 0,0001 \\
\hline 2.4.X.X.XX.X.X & Transferências de Capital & $7,47 \%$ & 0,0766 & 0,0038 & 0,0729 \\
\hline & Idfr & 0,4236 & 0,1193 & 0,3043 \\
\hline
\end{tabular}

Fonte: Elaborado pelo autor com base nos dados do portal da transparência de Imperatriz - MA.

Percebe-se que as variações negativas provocaram uma distorção financeira de 0,3043, ou seja, mais de $30 \%$ do valor previsto não foi arrecadado dentro das naturezas de receitas que as previam. Enquanto as variações positivas atingiram 0,1193 , que demonstra que o equivalente a quase $12 \%$ da previsão total foi arrecado sem previsão ou acima da previsão inicial para algumas naturezas da receita.

\footnotetext{
1 Transferências de Recursos do Fundo de Manutenção e Desenvolvimento da Educação Básica e de Valorização dos Profissionais da Educação - FUNDEB (IMPERATRIZ, 2017).
} 
Ainda se observa que mais da metade das distorções financeiras foram provocadas por falhas de previsibilidade das receitas de transferências correntes, que representavam um pouco mais de $73 \%$ do previsto para 2018.

De modo a entender melhor como se deu as distorções financeiras das receitas, foi elaborada a Tabela 3, que demonstra as distorções das naturezas de receitas por ordem decrescente de $d f$, como segue abaixo:

Tabela 3 - Classificação por df.

\begin{tabular}{|c|c|c|c|c|c|c|c|}
\hline $\begin{array}{l}\text { Classif. } \\
\text { por } d f\end{array}$ & $\begin{array}{l}\text { Natureza da } \\
\text { Receita }\end{array}$ & $\begin{array}{l}\text { Previsto p/ } \\
2018(\mathrm{R} \$)\end{array}$ & $\begin{array}{l}\text { Arrecadado em } \\
2018(\mathrm{R} \$)\end{array}$ & $\begin{array}{c}\text { Peso } \\
(p)\end{array}$ & $\begin{array}{l}\text { Variação } \\
\text { (v) }\end{array}$ & $d f$ & $\begin{array}{c}\text { Classif. } \\
\text { por } \\
\text { variação }\end{array}$ \\
\hline $1^{\mathrm{o}}$ & $\begin{array}{l}\text { 1.7.1.8.10.3.1- } \\
\text { Convên. da União } \\
\text { - Prog. de Assist. } \\
\text { Social }\end{array}$ & $103.329 .760,00$ & & $12,62 \%$ & $-100 \%$ & 0,1262 & $5^{\circ}$ \\
\hline $2^{o}$ & $\begin{array}{l}\text { 1.7.2.8.01.1.1- } \\
\text { Cota-Parte do } \\
\text { ICMS }\end{array}$ & $92.384 .000,00$ & $130.558 .396,58$ & $11,28 \%$ & $41 \%$ & 0,0466 & $41^{\circ}$ \\
\hline \multicolumn{8}{|c|}{$[\ldots]$} \\
\hline $6^{0}$ & $\begin{array}{l}\text { 1.7.5.8.01.1.1- } \\
\text { Transf. de Recur. } \\
\text { do FUNDEB }\end{array}$ & $65.040 .849,30$ & 83.313.780,99 & $7,94 \%$ & $28 \%$ & 0,0223 & $43^{\circ}$ \\
\hline $7^{\circ}$ & $\begin{array}{l}\text { 1.7.1.8.01.2.1 - } \\
\text { Cota-parte FPM }\end{array}$ & $94.705 .670,00$ & $80.330 .346,67$ & $11,56 \%$ & $-15 \%$ & 0,0176 & 490 \\
\hline \multicolumn{8}{|c|}{$[\ldots]$} \\
\hline $33^{\circ}$ & $\begin{array}{l}\text { 1.7.1.8.05.9.1- } \\
\text { Outras Transf. do } \\
\text { FNDE }\end{array}$ & $50.000,00$ & $580.627,84$ & $0,01 \%$ & $1061 \%$ & 0,0006 & $1^{\mathrm{o}}$ \\
\hline $34^{\circ}$ & $\begin{array}{l}\text { 1.1.1.8.02.3.4- } \\
\text { ISSQN - Dívida } \\
\text { Ativa - Multas e } \\
\text { Juros }\end{array}$ & $50.000,00$ & $579.629,39$ & $0,01 \%$ & $1059 \%$ & 0,0006 & $2^{o}$ \\
\hline \multicolumn{8}{|c|}{$[\ldots]$} \\
\hline
\end{tabular}

Fonte: Elaborado pelo autor com base nos dados do portal da transparência de Imperatriz - MA.

A primeira informação que chama atenção é a existência de uma natureza da receita, que representa mais de $12 \%$ da previsão total, não se tenha arrecadado nenhum real, provocando a maior distorção apurada. Essa natureza da receita tem uma aplicabilidade específica, no caso, é destinada aos programas de assistência social, assim sua não realização provocará a necessidade de reajuste desse grupo de despesa.

Outro ponto que se destaca é que algumas receitas, como as transferências para o FUNDEB e o FPM, mesmo não tendo variações tão elevadas, provocaram significativas distorções financeiras, enquanto outros que lideraram a classificação por variação provocaram $d f$ próxima de zero. Isso é explicado pelas suas representações sobre a previsão total, no qual, quanto mais relevante é uma natureza da receita sobre a previsão total maior será seu impacto durante a execução. Assim quanto maior for a relevância da natureza da receita, maior será a necessidade de acurácia durante a previsão.

O Idfr é necessário ser mensurado por duas razões principais: primeiro porque são as receitas que demonstram como o Estado financia suas despesas. A partir delas é possível perceber o quanto o ente depende da arrecadação própria, da exploração de seu patrimônio, das transferências de outros entes e da constituição de dívida. Assim, uma previsão incorreta levará a um entendimento incorreto pela sociedade, de como o governo financia suas atividades. 0 outro motivo se dá pelo fato de que muitos recursos têm destinações preestabelecidas, dessa forma, mesmo que o governo arrecade o total previsto, mas de modo individual, as receitas tenham sofridas grandes variações, a qual uma natureza da receita compense outra, a capacidade de financiar determinadas despesas pode ser comprometida. 
O Idfd, por sua vez, calcula a somatória de todas as distorções financeiras das despesas que ocorreram durante a execução, apurando cada distorção, individualmente, por dotação orçamentária, conforme segue a fórmula:

$$
\operatorname{Idfd}=\sum \mathrm{df}
$$

O Idfd é calculado da mesma maneira que o Idfr, mas, em vez de utilizar os valores das naturezas das receitas, utiliza-se os das dotações orçamentárias. Para fins do cálculo das $d f$ a serem somadas na $I d f d$, o valor utilizado será a diferença percentual absoluta entre o crédito orçamentário inicial e o empenhado no exercício (v), descontando as anulações, multiplicando pelo peso da dotação orçamentária sob o orçamento total (p) (Ver tabela 4). 0 empenho refere-se ao "[...] ato emanado de autoridade competente que cria para o Estado obrigação de pagamento pendente ou não de implemento de condição" (BRASIL, 1964).

Tabela 4 - Idfd Imperatriz - MA, 2018.

\begin{tabular}{|c|c|c|c|c|c|}
\hline Dotação Orçamentária & $\begin{array}{c}\text { Crédito } \\
\text { Orçamentário } \\
2018(\mathrm{R} \$)\end{array}$ & $\begin{array}{c}\text { Empenhado } \\
2018(\mathrm{R} \$)\end{array}$ & Peso (p) & Variação (v) & df \\
\hline $\begin{array}{c}\text { 01001.01.122.0001.2001.319011- } \\
\text { Vencimentos e Vantagens Fixas - } \\
\text { Pessoal Civil }\end{array}$ & $10.220 .000,00$ & $13.414 .228,19$ & $1,25 \%$ & $31,25 \%$ & 0,0039 \\
\hline $\begin{array}{c}\text { 01001.01.122.0001.2001.319013- } \\
\text { Obrigações Patronais }\end{array}$ & $1.500 .000,00$ & $1.169 .267,14$ & $0,18 \%$ & $-22,05 \%$ & 0,0004 \\
\hline $\begin{array}{c}\text { 01001.01.122.0001.2001.319092- } \\
\text { Desp. de Exercícios Anteriores }\end{array}$ & $100.000,00$ & $3.423,65$ & $0,01 \%$ & $-96,58 \%$ & 0,0001 \\
\hline \multicolumn{6}{|c|}{$[\ldots]$} \\
\hline $\begin{array}{c}\text { 16001.08.122.0032.2647.339093- } \\
\text { Indenizações e Restituições }\end{array}$ & - & $205.006,59$ & - & - & 0,0003 \\
\hline Total & $818.910 .183,00$ & $708.485 .632,87$ & - & $-13,48 \%$ & - \\
\hline \multicolumn{5}{|c|}{ Idfd } & 0,8831 \\
\hline
\end{tabular}

Fonte: Elaborado pelo autor com base nos dados do portal da transparência de Imperatriz - MA.

As dotações orçamentárias inseridas por meio de créditos especiais ou extraordinários, excetuadas as que sejam oriundas de superávit financeiro de exercícios anteriores ou reserva de contingência, resultarão em $d f$ igual ao percentual que valor empenhado representa em relação ao crédito orçamentário total. Isso porque não havendo uma previsão inicial, não é possível calcular a variação. No entanto, tais dotações orçamentárias alteram a programação orçamentária, sendo importante mensurar seus impactos.

Os créditos adicionais que tenham como fonte de recursos o superávit financeiro de exercícios anteriores, não serão computados no Idfd. Isso devido ao fato de que apesar de eles alterarem o orçamento, eles não necessitam de um esforço maior de arrecadação e nem do sacrifício de outras despesas. Além disso, a única forma de tais recursos serem utilizados no orçamento, é por meio da abertura de créditos adicionais. Assim, a sua inclusão não se configura um erro ou alteração do planejamento inicial.

Também não serão computados na Idfd os créditos adicionais que indiquem como recurso a reserva de contingência, que é uma dotação do orçamento. Isso porque segundo o Manual de Contabilidade Aplicado ao Setor Público (BRASIL, 2018), uma das finalidades da reserva de contingência é justamente servir de fonte de recurso para abertura de créditos adicionais, haja vista que não possui execução direta. Assim, a utilização deste recurso não afeta o restante do orçamento. Também não será computada na Idfd quando não utilizadas, já que não possui execução direta e sua finalidade ser justamente servir como recurso orçamentário para situações imprevistas e emergências. Significa dizer que caso tudo saia como previsto, não se espera que esse recurso seja utilizado, desta forma não faria sentido considerar no cálculo sua não utilização. 
Durante a execução orçamentária de Imperatriz - MA, em 2018, as despesas obtiveram alto percentual de execução, computando mais de $87 \%$ do valor autorizado empenhado durante a execução orçamentária. No entanto, as distorções financeiras foram ainda maiores que as das receitas. 0 Idfd, apurado (Tabela 4) com auxílio do relatório "Quadro Detalhado da Despesa", foi de 0,8831, demonstrando que o equivalente a quase $90 \%$ do valor total das despesas autorizadas foi ajustado durante o exercício financeiro. Para melhor compreensão dos dados, as dotações orçamentárias foram agrupadas por grupo de natureza de despesa (GND), que é o segundo nível da classificação quanto a natureza, como segue na Tabela 5.

Tabela 5 - Idfd agrupado por GND

\begin{tabular}{|c|c|c|c|c|c|} 
Natureza da Despesa & \multicolumn{2}{c}{ GND } & Peso & df total & df por \\
variação (+) & df por \\
variação (-)
\end{tabular}

Fonte: Elaborado pelo autor com base nos dados do portal da transparência de Imperatriz - MA.

Observa-se que a somatória das $d f$ por variações positivas foi de 0,3833, mas foi subtraído 0,0095 por conta de créditos adicionais abertos com utilização de reserva de contingência e superávit financeiro do exercício anterior, resultando no valor de 0,3738 .

A tabela 5 demonstra que mais de $50 \%$ do valor do orçamento autorizado não foi executado dentro das dotações orçamentárias apresentadas na LOA 2018 e um pouco mais do equivalente a 37\% do valor do orçamento foi utilizado por meio da abertura de créditos adicionais. Os créditos adicionais foram autorizados por meio de 15 decretos elaborados durante o exercício financeiro, sendo ao menos 1 por mês.

Além disso, percebe-se que os grupos de outras despesas correntes e despesas com pessoal e encargos sociais foram as que mais promoveram distorções durante a execução do orçamento, vale ressaltar que as despesas com pessoal e encargos sociais deveriam ser fáceis de se prever, já que o quadro de pessoal não se altera tão drasticamente durante um curto período de tempo. Outro ponto importante a destacar é que as distorções do grupo de investimento foram causadas quase que na totalidade por variações negativas, esse grupo de despesa representava quase $18 \%$ do orçamento e empenhou aproximadamente $6 \%$ do crédito autorizado para essa finalidade.

A análise das distorções por dotação orçamentária julga-se necessária porque sua apresentação na elaboração do orçamento municipal pode produzir uma certa expectativa na sociedade, principalmente no que diz respeito às despesas de investimento. Além disso, ressalta-se que as despesas demonstram o quanto custa a manutenção da máquina pública justificando a necessidade de tributação e constituição de dívidas. Assim, percebe-se que, mesmo a gestão utilizando $87 \%$ do valor autorizado, não se pode dizer que o orçamento foi executado conforme foi apresentado a sociedade.

Obtido os resultados dos dois sub-índices, aplicou-se a fórmula do IDFO:

$$
\mathrm{IDFO}=\frac{\mathrm{Idfr}+\mathrm{Idfd}}{2}=\frac{0,4236+0,8831}{2}=0,6533
$$

O valor obtido no IDFO demonstra, mesmo que neste estudo não se tenha apresentado valores de referência, com base nos dados evidenciados acima, uma significativa volatilidade da execução do orçamento do município de Imperatriz - MA. Essa volatilidade se deu tanto no que diz respeito ao processo de previsão e arrecadação de receitas, como no processo de fixação e execução das despesas. 
No geral, a execução do orçamento de Imperatriz - MA, no ano de 2018 demonstrou que a gestão municipal tinha uma razoável previsibilidade da sua capacidade total de arrecadação, no entanto não foi tão efetiva em identificar a origem desses recursos na fase de previsão. Já quanto a fixação das despesas, destaca-se a necessidade de reavaliar seu processo orçamentário, pois mais de $50 \%$ do valor que foi autorizado pelo Legislativo não foi executado, e ainda teve que, constantemente, recorrer à utilização de créditos adicionais.

\section{CONSIDERAÇÕES FINAIS}

O orçamento público é um importante instrumento de planejamento da gestão pública. No entanto, em sua fase de execução, é necessário que haja acompanhamento, controle e avaliação, de modo a identificar e corrigir as possíveis falhas do processo orçamentário.

Deste modo, foi a apresentado o IDFO como uma proposta de mecanismo de avaliação da execução orçamentária municipal, o qual permite mensurar as distorções financeiras ocorridas durante a execução do orçamento municipal. A aplicação do IDFO no orçamento de Imperatriz - MA, do ano de 2018, permitiu testar a viabilidade do mecanismo. Os dados analisados evidenciaram relevantes falhas no processo orçamentário do município, demonstrando que a arrecadação das receitas e a execução das despesas, em grandes partes, ocorreram de forma distinta do que se previa na LOA.

No entanto, a ausência de um valor de referência, deixa a critério do usuário da informação o entendimento se a gestão foi ou não eficiente em seu planejamento. Assim, recomenda-se que a utilização do IDFO seja acompanhada dos relatórios das aplicações do $I d f r$ e $I d f d$, e se o índice for utilizado pela própria gestão, recomenda-se, também, a apresentação das justificativas para as distorções financeiras mais significativas.

O estudo limitou-se a apresentação da ferramenta de avaliação e ao seu teste, de modo a demonstrar sua aplicabilidade, desta maneira, não buscou-se identificar as causas das distorções financeiras encontradas. Para pesquisas futuras, sugere-se estabelecer valores de referências para IDFO e testes em amplitudes maiores de entes e de períodos. Por fim, espera-se que este artigo seja fonte indicativa para o meio científico e profissional no que tange o estudo da execução orçamentária.

\section{REFERÊNCIAS}

[1] Aquino, André Carlos Busanelli de; Azevedo, Ricardo Rocha de. O “ir"realismo orçamentário nos municípios brasileiros. In: Congresso USP Controladoria e Contabilidade, 15, 2015. São Paulo. Anais [...]. São Paulo, 2015. Disponível em: https://bdpi.usp.br/item/002768038. Acesso em: 12 abr. 2019.

[2] Brasil. [Constituição (1998)]. Constituição da República Federativa do Brasil. Disponível em: http://www.planalto.gov.br/ccivil_03/constituicao/constituicao.htm. Acesso em: 1 abr. 2019.

[3] __ Lei no 4.320, de 17 de março de 1964. Estatui normas gerais de direito financeiro para elaboração e controle dos orçamentos e balanços da União, dos Estados e do Distrito Federal. Disponível em: http://www.planalto.gov.br/ccivil_03/Leis/L4320.htm. Acesso em: 13 dez. 2017.

[4] __ Lei no 11.494, de 20 de junho de 2007. Regulamenta o Fundo de Manutenção e Desenvolvimento da Educação Básica e de Valorização dos Profissionais da Educação - FUNDEB. Disponível em: http://www.planalto.gov.br/ccivil_03/_ato2007-2010/2007/lei/l11494.htm. Acesso em: 30 abr. 2019.

[5] __ Ministério da Fazenda. Manual de Contabilidade Aplicado ao Setor Público. 8. ed. Brasília: 2018. Disponível em: http://www.tesouro.fazenda.gov.br/mcasp. Acesso em: 25 fev. 2019.

[6] __ Ministério da Fazenda. Portaria Interministerial no 163, de 04 de maio de 2001. Dispõe sobre normas gerais de consolidação das contas públicas no âmbito da União, Estados, Distrito Federal e Municípios, e dá outras providências. Brasília: 2001. Disponível em: http://www.planejamento.gov.br/assuntos/orcamento-1/legislacao. Acesso em: 30 abr. 2019.

[7] Carvalho Junior, Antonio Carlos Costa d'Ávila; Feijó, Paulo Henrique. Entendendo Resultados Fiscais: teoria e prática de resultados primário e nominal. Brasília: Gestão Pública, 2015. 
[8] Coronado, Osmar; Oliveira, Antonio de. A contabilidade Pública como instrumentos de controle do ciclo orçamentário da gestão pública municipal. Congresso Brasileiro de Contabilidade, 17, 2004. Santos - SP: 2004. Disponível em: http://biblioteca.sophia.com.br/4735/. Acesso em: 10 abr. 2019.

[9] Couto, Lucas Carrilho do; Barbosa Neto, João Estevão; Resende, Leandro Lima. Flexibilidade do orçamento público perante a execução orçamentária. Revista Mineira de Contabilidade. Belo Horizonte, 2018. Disponível em: http://revista.crcmg.org.br/index.php?journal=rmc. Acesso em: 10 abr. 2019.

[10] Fiirst, Clóvis; et al. Eficiência de Previsibilidade Orçamentária da Receita Pública: um estudo em municípios do Estado do Paraná entre os exercícios de 2002 a 2013. XXII Congresso Brasileiro de Custos. Foz do Iguaçu - PR: 2015.

[11] Imperatriz (MA). Lei Ordinária no 1.710, de 29 de dezembro de 2017. Estima a receita e fixa a despesa do município para o exercício financeiro de 2018. Disponível em: http://servicos.imperatriz.ma.gov.br/governotransparente/. Acesso em: 30 abr. 2019.

[12] Imperatriz.ma.gov.br. Prefeitura de Imperatriz. Imperatriz - MA: 2018. Disponível em: http://www.imperatriz.ma.gov.br/. Acesso em 06 abr. 2019.

[13] Pacelli, Giovanni. Contabilidade Pública 3d. ed. 2. Salvador: Juspodivm, 2019. Cap. 3 a 9, p. 67 a 288.

[14] Pedrosa, Cézar. Teoria Geral do Orçamento Público. 1 ed. São Paulo: Baraúna, 2015.

[15] Prodanov, Cleber Cristiano; Freitas, Ernani Cesar de. Metodologia do Trabalho Científico: métodos e técnicas da pesquisa e do trabalho acadêmico. ed. 2. Novo Hamburgo: Feevale, 2013. Disponível em: https://biblioteca.feevale.br/pergamum/biblioteca/index.php. Acesso em: 20 ago. 2019.

[16] Rocha, Diones Gomes; Marcelino, Gileno Fernandes; Santana, Cláudio Moreira. Orçamento Público no Brasil: a utilização do crédito extraordinário como mecanismo de adequação da execução orçamentária brasileira. São Paulo: Revista de Administração/USP, 2013, p. 813 - 827. Disponível em: https://www.scielo.org. Acesso em: 03 mar. 2019.

[17] Site.Tce.ma.gov.br. Tribunal de Contas do Maranhão. São Luís: 2013. Disponível em: http://site.tce.ma.gov.br/. Acesso em: 14 jun. 2019.

[18] Vergara, Sylvia Constant. Projetos e Relatórios de Pesquisa em Administração. ed. 12. São Paulo: Atlas, 2010. 


\section{Capitulo 16}

\section{Educação financeira em ambientes colaborativos: 0 comportamento financeiro dos usuários de Coworking}

\section{Pedro Henrique da Silva Teles \\ Rebeca Sá do Nascimento Carrazzoni \\ Patrícia Lacerda de Carvalho}

Resumo: 0 trabalho em ambientes compartilhados de forma colaborativa surge como característica do século XXI. Nesse contexto encontram-se os coworking, espaços em que recursos, ideias e serviços são divididos e que o gerenciamento das finanças empresais e pessoais são simultâneos. A pesquisa objetivou analisar o comportamento financeiro dos usuários de Coworking de João Pessoa na Paraíba, com base na educação financeira e propensão ao endividamento. A pesquisa descritiva de abordagem quantitativa utilizou como meio de coleta de dados um questionário estruturado. Os resultados apontam que o perfil dos usuários é de jovens com alto grau de instrução, sendo 99\% empreendedores, influenciados pelas vantagens ofertadas: colaboração, networking e redução de custos. Os respondentes concordam com o planejamento no presente para resultados financeiros futuros, ressaltando a importância de compreender o comportamento financeiro das novas formas de trabalhos quanto a educação financeira e propensão ao endividamento.

Palavras-Chave: Comportamento financeiro; Educação financeira; Endividamento; Coworking. 


\section{INTRODUÇÃO}

As mudanças ocorridas nos processos produtivos nas duas últimas décadas do século XX se deram em decorrência do desenvolvimento acelerado da tecnologia, do capitalismo e da globalização e, como resultado, reformularam o posicionamento do homem no trabalho, assim como sua forma de atuar e os espaços utilizados para realização das atividades (Antunes; Alves, 2004). Segundo Eaton (2001), a partir desse contexto o crescimento do denominado trabalho flexível surge como característica do século XXI, visto que a internet e o desenvolvimento tecnológico possibilitam a realização das atividades laborais, independentemente do lugar em que o sujeito se encontra. Nesse sentido, surgem no mercado as empresas denominadas como Coworking.

Os Coworking são espaços em que recursos, ideias e serviços são divididos por seus membros. Nesse modelo, a empresa além de diminuir seus gastos, desfruta de um ambiente de colaboração e um networking de empreendedores em situação semelhante, favorecendo e incentivando parcerias (Leforestier, 2009). 0 espaço de coworking é um ambiente compartilhado entre pessoas com funções diferentes entre si, que além da estrutura física, também compartilham custos de locação, com o objetivo de criar um ambiente adequado ao relacionamento, troca de experiências, valores, sinergia e networking (MUNHOZ et al, 2013).

Tais mudanças demandam que as empresas se adaptem constantemente às inovações para manter-se no mercado que está cada vez mais competitivo, exigindo igualmente que as empresas detenham pessoas capacitadas. Sendo assim, o cenário exposto exige que o gestor da empresa esteja preparado para administrar suas necessidades. Nesse contexto, a educação financeira pode ser definida como a ciência da gestão de dinheiro, onde incorpora o estudo do dinheiro, assim como o gerenciamento e controle de recursos e a análise e gerenciamento de riscos e projetos. É uma área ampla já que afeta a vida das pessoas e das organizações (GITMAN, 2006).

Notadamente, os usuários são empreendedores, profissionais de startups, microempreendedores e até profissionais autônomos, que na grande maioria das vezes, optam por exercer suas atividades em um ambiente de coworking pela praticidade que o mesmo oferece. Partindo desse pressuposto, torna-se importante conhecer o comportamento financeiro dos usuários de Coworking, tendo em vista seu crescimento na cidade de João Pessoa/PB.

Desse modo, o objetivo desta pesquisa é analisar o comportamento financeiro dos usuários de Coworking de João Pessoa na Paraíba, com base na educação financeira e propensão ao endividamento. Além disso, pretendeu-se caracterizar, no contexto da cidade de João pessoa na Paraíba, o perfil dos usuários de Coworking; descrever a importância do ambiente colaborativo de Coworking na percepção de seus usuários; identificar a propensão ao endividamento por parte dos usuários de Coworking; e, identificar o nível de educação financeira nos usuários de Coworking.

\section{REVISÃO TEÓRICA}

\subsection{COMPORTAMENTO FINANCEIRO}

Em um mercado amplo e de inúmeras mudanças, o desenvolvimento de competências empreendedoras torna-se imprescindível para a manutenção e expansão dos negócios. As competências empreendedoras estão relacionadas com as capacidades do indivíduo em criar práticas administrativas no ambiente de negócios (MAMEDE; MOREIRA, 2005).

Competências estas que se referem ao conjunto de conhecimentos, habilidades e atitudes geradas pelo indivíduo, que lhe possibilitam analisar adequadamente estratégias empresariais e criar ações com o intuito de agregar valor à organização (Antonello, 2006). Indivíduos que desenvolvem competências empreendedoras têm melhores condições para administrarem seus negócios.

De acordo com Ross et al. (2009) afirmam que identificar os objetivos da administração financeira são primordiais para gerar embasamento concreto e assim tomar e avaliar decisões financeiras. Corroborando, Assaf Neto (2009) explica que no processo de escolha das decisões financeiras, a empresa deve traçar seu objetivo a ser alcançado, de modo que essas decisões sejam tomadas seguindo o critério mais racional. 
Cabe ao gestor financeiro delimitar os tipos de ativos que compõem o balanço da empresa, composição essa que é referente ao valor dos ativos circulantes e não circulantes. Ainda é papel do gestor financeiro traçar metas para a captação de recursos e mantê-los sempre equilibrados, além de determinar quando é viável a obtenção de novos ativos e o descarte daqueles que foram considerados (GITMAN, 2006). O Brasil vivenciou variações econômicas por vários anos, fato que pode expressar o motivo o qual o tema educação financeira foi classificado como desnecessário, "numa economia sufocada pela inflação, qualquer tentativa de planejamento financeiro tinha resultados frágeis e desanimadores" (D'AQUINO; CERBASI, 2008, p.9).

0 mesmo autor ainda diz que em razão da constante mudança diária de preços graças à alta inflação, os brasileiros criaram a preconcepção de "adquirir agora", com medo de horas depois os preços subissem, assim, ao passo que os anos passavam esse conceito crescia mais e mais, e mesmo depois de mais de uma década de estabilidade econômica a população ainda está presa a esse hábito.

Segundo Silva et al. (2016), a falta de uma educação financeira propicia a empresa gera uma consequência de problemas de análise, planejamento e controle financeiro das suas atividades operacionais, gerando uma série de resultados negativos referentes ao mercado, perdendo competitividade, fornecedores e clientes, sem apontar a queda da qualidade no produto ou serviço, buscando reduzir custos.

Deste modo, a relevância da educação financeira consiste em dar o conhecimento e as informações necessárias ao gestor para que o mesmo possa compreender o estado econômico, tanto em uma visão micro e pessoal, focando em suas finanças pessoais, como em uma visão macro, compreendendo a situação do país e do mundo, e identificando que as variações globais e nacionais da economia vão interferir na sua empresa, sua família e sua vida (ROSS et al., 2009).

\subsection{COWORKING}

0 termo coworking não é recente, existem livros que datam os primeiros registros do uso deste termo em meados dos anos de 1600. Nesta época, já se falava sobre "o poder do coworking", porém, o espaço como é conhecido atualmente veio à tona na descrição de DeKoven (1999), que o definiu como uma forma de identificar um método que facilitaria o trabalho colaborativo e encontros de negócios coordenados através de computadores.

Os espaços de coworking se proliferaram no mundo devido ao caráter de novidade do conceito e à crise econômica mundial (GANDINI, 2015). Para SPINUZZI (2012), os espaços de coworking são ambientes complexos, compostos por uma grande variedade de atores, com intenções e expectativas diversas.

Os ambientes de trabalho colaborativos ofertam aos usuários a possibilidade de desenvolver networking com profissionais de várias áreas distintas, realizar parcerias e participar de cursos de qualificação no mesmo ambiente (DEIJL, 2011). Com a compra de um determinado tempo para utilização desses espaços, empreendedores começaram a interagir entre si, de modo a inspirarem-se e tornarem-se mais produtivos em suas atividades (STRAUSS, 2013).

De acordo com Medina e Krawulski (2015), sabe-se pouco sobre o coworker no contexto nacional brasileiro como um todo, principalmente em regiões e contextos com características socioeconômicas e culturais diferentes dos grandes centros urbanos. Sobre o tema, Spinuzzi (2012), ao realizar um estudo com gestores e usuários de coworking nos Estados Unidos, mapeia o perfil dos coworkers e o modo como eles definem os ambientes de coworking, externando o o ponto de vista dos coworkers quanto às dificuldades para realização de trabalhos em casa, como distrações de ambientes barulhentos e o isolamento, destacando-os como fatores que influenciam diretamente na busca por um ambiente de coworking, atrelado ao seu baixo custo de utilização

Tendo em vista o contexto comentado, Merkel (2015) apresenta como motivadores à participação de ambiente de coworking pelos empreendedores: a ampliação do networking, sair do isolamento de um escritório comum, ter amplo acesso a conhecimentos novos e estar interagindo com pessoas que estão enfrentando os mesmos desafios e problemas em seus negócios, são alguns exemplos dos motivos para as pessoas optarem por um espaço de coworking (MERKEL, 2015).

Por outro lado, Brinks (2012) evidencia uma visão sobre o coworking considerando-o como um novo método de trabalho, com foco nos profissionais autônomos que se utilizam desse ambiente como método de ampliação de sua rede de contatos. Sendo assim, espaços de coworking são descritos como "ambientes de mercado" onde o networking é viável em função do próprio ambiente físico que proporciona o compartilhamento, entendendo-se que esse ambiente seja um novo método de contextualização das situações trabalhistas. 
Mesmo com todas as vantagens oferecidas aos empreendedores, Leforestier (2009) afirma que o modelo de coworking apresenta alguns pontos inconvenientes. Sua estrutura libera espaço para a falta de privacidade, tornando os projetos vulneráveis e facilitando o roubo de ideias. Os usuários podem não se adaptar ao espaço de trabalho e, portanto, não corresponderem à proposta do modelo, não sendo colaborativos e abertos. Além desses problemas, podem ser listadas outras ameaças, como facilidades oferecidas por cafeterias com Internet wireless e o impacto da crise no desenvolvimento de novos negócios e novas empresas.

\begin{tabular}{|l|l|}
\multicolumn{2}{|c|}{ Quadro 1: Swot do Coworking } \\
\hline $\begin{array}{l}|c| \\
\text { Redução de custos }\end{array}$ & \multicolumn{1}{|c|}{ Pontos Fracos } \\
$\begin{array}{l}\text { Flexibilidade } \\
\text { Grande variedade de serviços } \\
\text { Grande índice de interação e colaboração } \\
\text { Ampliação de participações em eventos e reuniões } \\
\text { Ambiente receptível e inovador } \\
\text { Interação com outros profissionais talentosos }\end{array}$ & $\begin{array}{l}\text { Pouca privacidade } \\
\text { Propriedade intelectual desprotegida } \\
\text { Vulnerabilidade dos projetos } \\
\text { Colaboração variável } \\
\text { Problemas na adaptação ao espaço } \\
\text { Falta de assiduidade }\end{array}$ \\
\hline \multicolumn{1}{|c|}{ Oportunidades } & \multicolumn{1}{|c|}{ Ameaças } \\
\hline $\begin{array}{l}\text { Divulgação dos serviços oferecidos } \\
\text { Coworking específico para alguns setores } \\
\text { Conceito globalizado } \\
\text { Criação de rede mundial de interações } \\
\text { Possibilidade de implementação nas organizações }\end{array}$ & $\begin{array}{l}\text { Impacto da crise nas grandes empresas } \\
\text { Inovações do mercado competitivo }\end{array}$ \\
\hline
\end{tabular}

O Quadro 1 demonstra uma análise de SWOT elaborada por Leforestier (2009) e adaptada por Munhoz et al (2013), explicando quais os pontos fortes e fracos, assim como as oportunidades e ameaças geradas em um ambiente de coworking. Tais fatores tem o papel importante no auxílio do gestor para análise de situações de risco e aberturas para o crescimento.

De acordo com Leforestier (2009), os espaços de coworking tem grande potencial de crescimento devido a sua demanda imediata, considerando que por ser um ambiente de trabalho tão volátil, a influência das inovações contribui para um crescimento também acelerado, gerando assim oportunidades para seus usuários frente o mercado tradicional. Entretanto, fatores em sua grande maioria internos, tais como a falta de privacidade, as vulnerabilidades na preservação de ideias são consideradas como ameaças para o desenvolvimento dos espaços de coworking, já que pode gerar receio por parte dos potenciais usuários.

\section{PROCEDIMENTOS METODOLÓGICOS}

A natureza da presente pesquisa caracteriza-se como aplicada. Em relação à natureza, enquadra-se como de campo do tipo survey. Para Prodanov e Freitas (2013, p. 57) "esse tipo de pesquisa ocorre quando envolve a interrogação direta das pessoas cujo comportamento desejamos conhecer através de algum tipo de questionário". Quanto aos objetivos, a pesquisa é classificada como descritiva. Segundo Vergara (2000, p. 47) as pesquisas descritivas "não têm o compromisso de explicar os fenômenos que descreve, embora sirva de base para explicação".

A forma de abordagem é quantitativa. De acordo com Lakatos e Marconi (2007), a pesquisa quantitativa apoia o modelo de conhecimento chamado positivista, em que prevalece a preocupação estéticomatemática e tem a pretensão de ter acesso racional à essência dos objetos e fenômenos examinados. Tem como sua característica a configuração experimental.0 universo da pesquisa é composto pelos os usuários de coworking da cidade de João Pessoa/PB. A amostra não-probabilística por conveniência se estrutura em usuários de 04 espaços de coworking da cidade, selecionados de acordo com sua aceitabilidade para participação da pesquisa, desse modo foram entrevistados 100 usuários.

Para a coleta dos dados, o instrumento elaborado foi um questionário estruturado. Segundo Barros e Lehfeld (2007, p.106), o questionário "é o instrumento mais usado para o levantamento de informações". 0 questionário foi disponibilizado em formato de formulário online da plataforma Google Docs, contendo perguntas abertas e fechadas. Além disso, o questionário também foi aplicado presencialmente pelos pesquisadores. 
Para atender aos objetivos específicos da pesquisa, o questionário foi dividido em quatro etapas, a primeira seção buscou identificar o perfil sociodemográfico dos respondentes, considerando quatro alternativas as quais questionavam o sexo, a faixa etária, ou nível de escolaridade e a faixa de renda individual mensal. Após o levantamento básico de perfil, buscou-se conhecer até onde vão suas instruções sobre educação financeira, contemplando dívidas, os gastos e investimentos. Essa seção do questionário foi estruturada segundo o modelo testado e aprovado de Flores et al. (2012).

A terceira seção teve como objetivo conhecer a relação dos usuários com os ambientes de coworking, tomando como base as afirmações acima citadas de autores como Spinuzzi (2012), Leforestier (2009), Brinks (2012), dentre outros. A quarta e última seção objetivava conhecer a autoeficácia percebida e as considerações de consequências futuras relacionadas a educação financeira, tendo como base questionamentos testados e aprovados por Donadio (2014), utilizando como intervalo de resposta uma escala do tipo Likert, adaptada para sete pontos.

As pesquisas foram aplicadas em quatro escritórios de coworkings, que são o Tot Coworking, Clubjob Coworking, Two One One Coworking e TMG Coworking, todos localizados na cidade de João Pessoa na Paraíba. Os questionários tiveram o período para respostas de um mês e meio, com o intervalo entre o mês de dezembro de 2018 e janeiro de 2019. Os dados foram analisados com estatística descritiva simples, por meio do Excel, com o objetivo de interpretar os dados e relacioná-los ao referencial escolhido.

\section{RESULTADOS E DISCUSSÕES}

\subsection{PERFIL SOCIODEMOGRÁFICO}

Com o intuito de responder ao primeiro objetivo específico, que busca caracterizar quem são os usuários de Coworking na cidade de João Pessoa na Paraíba. A pesquisa demonstrou que 56\% dos usuários de coworking são do sexo masculino, enquanto $44 \%$ são do sexo feminino, mostrando um equilíbrio de gênero. Relacionado a faixa etária, ocorre a constatação de que $73 \%$ dos usuários de coworking possui de 19 a 30 anos, $25 \%$ possui de 31 a 40 anos e apenas $2 \%$ têm de 41 a 50 anos, o que demonstra que em sua grande maioria, se trata de um público jovem e consequentemente mais voltado para as inovações de mercado e tendências relacionadas aos novos ambientes de trabalho colaborativo, como retrata Leforestier (2009).

Quando questionados sobre o nível de escolaridade, 11,9\% dos usuários afirmaram ter o ensino médio, $61,4 \%$ afirmaram ter o ensino superior, 24,8\% afirmaram possuir pós-graduação profissional e 2\% afirmaram possuir mestrado ou doutorado, o que mostra a busca do aprimoramento de conhecimento na educação como um fator importante para atuação profissional. Tratando-se da faixa de renda individual mensal, 10,9\% afirmaram não possuir renda individual fixa, 29,7\% afirmaram ganhar até 2.000,00 reais, $47,5 \%$ disseram que ganham de $2.001,00$ a 5.000,00 reais, 8,9\% disseram que ganham de 5.001,00 a $7.000,00$ reais e $3 \%$ afirmaram ganhar de $7.001,00$ a $10.000,00$ reais mensais.

\subsection{EDUCAÇ̃̃O FINANCEIRA}

Em decorrência do segundo objetivo específico, que busca identificar o nível de educação financeira nos usuários de Coworking na cidade de João pessoa na Paraíba, foram levantados sete questionamentos com base no modelo desenvolvido e aplicado por Flores et al. (2012), com o intuito de analisar conhecimento sobre educação financeira.

Quando questionados sobre o conhecimento que possuíam sobre educação financeira, 50\% dos respondentes afirmaram que conheciam pouco, 2\% disseram ser indiferentes, $43 \%$ afirmaram conhecer parcialmente e 5\% disseram que possuíam total conhecimento sobre educação financeira. No questionamento que abordava como os respondentes avaliaram a importância da educação financeira para um gestor/empreendedor, $10 \%$ afirmaram que consideravam razoavelmente importante, $29 \%$ consideraram importante e $61 \%$ classificaram como muito importante.

Quando indagados sobre a existência de dívidas, 80\% afirmaram que possuíam dívidas e 20\% afirmaram que não possuíam, dívidas essas dos quais 14\% disseram estar em atraso e $86 \%$ afirmaram que não estavam em atraso. No tocante ao modo como gastavam seu dinheiro, 10\% dos respondentes afirmaram que gastam mais do que ganham, 30\% afirmaram que gastam proporcionalmente ao que ganham e $60 \%$ dos respondentes afirmaram que gastam menos do que ganham. 
Considerando que $80 \%$ dos respondentes afirmaram que possuíam dívidas, levantou-se o questionamento para identificar quais os tipos de dívidas, podendo ser assinalada mais de uma alternativa. Os resultados demonstraram que $76,20 \%$ dos que possuem dívidas, confere-as ao uso do cartão de crédito, $56,40 \%$ possuíam dívidas com recursos de terceiros (familiares ou amigos), 44,60\% possuíam dívidas com financiamento de bem móvel, 24,80\% afirmaram possuir dívidas com financiamento de bem imóvel, $13,90 \%$ estavam endividados com o cheque especial e 10,90\% deviam a cooperativas de crédito e/ou financeiras.

Considerando que $14 \%$ dos usuários de coworking respondentes da pesquisa afirmaram possuir dívidas em atraso, levantou-se o questionamento que identificar quais as principais razões para o atraso, onde a pessoa poderia assinalar mais de uma alternativa, e ficou constatado que para os respondentes, o principal motivo para o atraso das dívidas é a falta de planejamento financeiro, com 12,90\% das respostas, seguido pelos imprevistos pessoais com 10,90\%, pela má gestão orçamentária pessoal juntamente com a alta taxa de juros com $7,90 \%$ cada e por último pela diminuição na renda mensal, com 5,90\%. Por meio da análise, é perceptível que a maioria dos respondentes demonstra pouco de conhecimento ou conhecimento parcial sobre educação financeira, os quais somados, representam 93\%.

\subsection{PERCEPÇ̃̃O SOBRE O AMBIENTE DE COWORKING}

Considerando a obtenção de resultados que respondessem o objetivo específico de descrever a influência do ambiente colaborativo de Coworking na percepção de seus usuários, ao indagar sobre a classificação da empresa, $1 \%$ dos respondentes afirmaram não possuir empresa, $4 \%$ afirmaram estar no processo de abertura de um negócio, 34\% disseram que são profissionais liberais, $8 \%$ afirmaram ser estudante, 34\% disseram que eram Micro Empreendedores Individuais (MEI), 12\% afirmaram possuir uma microempresa e 7\% dos respondentes disseram que tinham uma Empresa de Pequeno Porte (EPP).

Quando questionados sobre o tempo em que atuavam no ramo de empreendedorismo, 10,8\% disseram que atuavam a menos de 01 ano, 28,8\% afirmaram atuar de 01 a 03 anos, $41,7 \%$ disseram atuar de 03 a 05 anos, $11,7 \%$ disseram que atuavam de 05 a 07 anos e $7 \%$ dos respondentes afirmaram atuar acima de 07 anos.

No tocante a área em que empreendiam, 1\% dos usuários de coworking disseram que não eram empreendedores, $2 \%$ disseram que atuavam na área de gestão de condomínios, $23 \%$ afirmaram atuar com assessoria (jurídica, contábil, financeira e afins), 32\% dos usuários de coworking disseram que atuavam na área de comunicação, publicidade, propaganda e afins, $18 \%$ dos respondentes afirmaram atuar na área de programação, desenvolvimento de software e afins e 12\% afirmaram atuar na área de construção civil e consultoria cada.

No que se refere ao tempo em que utilizavam as dependências de um espaço de coworking, $14 \%$ dos empreendedores disseram ter até 06 meses de atuação, 15\% disseram possuir entre 06 meses e 01 ano, $41 \%$ disseram que atuavam entre 01 e 02 anos, $27 \%$ disseram atuar entre 03 e 05 anos, $2 \%$ disseram atuar entre 05 e 07 anos e apenas $1 \%$ disseram que não possuíam empresa ou eram empreendedores.

Quando questionados sobre o que mais os atraía no ambiente de coworking, os respondentes tiveram a possibilidade de assinalar mais de uma alternativa. Nesse resultado, observou-se que $95 \%$ dos respondentes consideram que o fator mais atrativo é o networking, seguido pela redução de custos de operação com $90,1 \%$ e a interação social com outros membros ficando com $80,2 \%$. Os outros pontos destacados foram espaço colaborativo, incentivo à produção de produtos e serviços, ambiente propício à inovação, busca por inspiração, procura por sócios e investidores, busca por ferramentas de gestão, participação em eventos e vantagens em informações de mercado.

\subsection{PROPENSÃO AO ENDIVIDAMENTO}

De acordo Donadio (2014) as afirmações que correspondem ao primeiro buscam analisar a autoeficácia percebida pelos usuários, conforme Quadro 2. 
Quadro 2: Autoeficácia percebida.

Autoeficácia percebida

15 - Sempre consigo dar um jeito de resolver problemas financeiros difíceis, se eu conseguir fazer o esforço

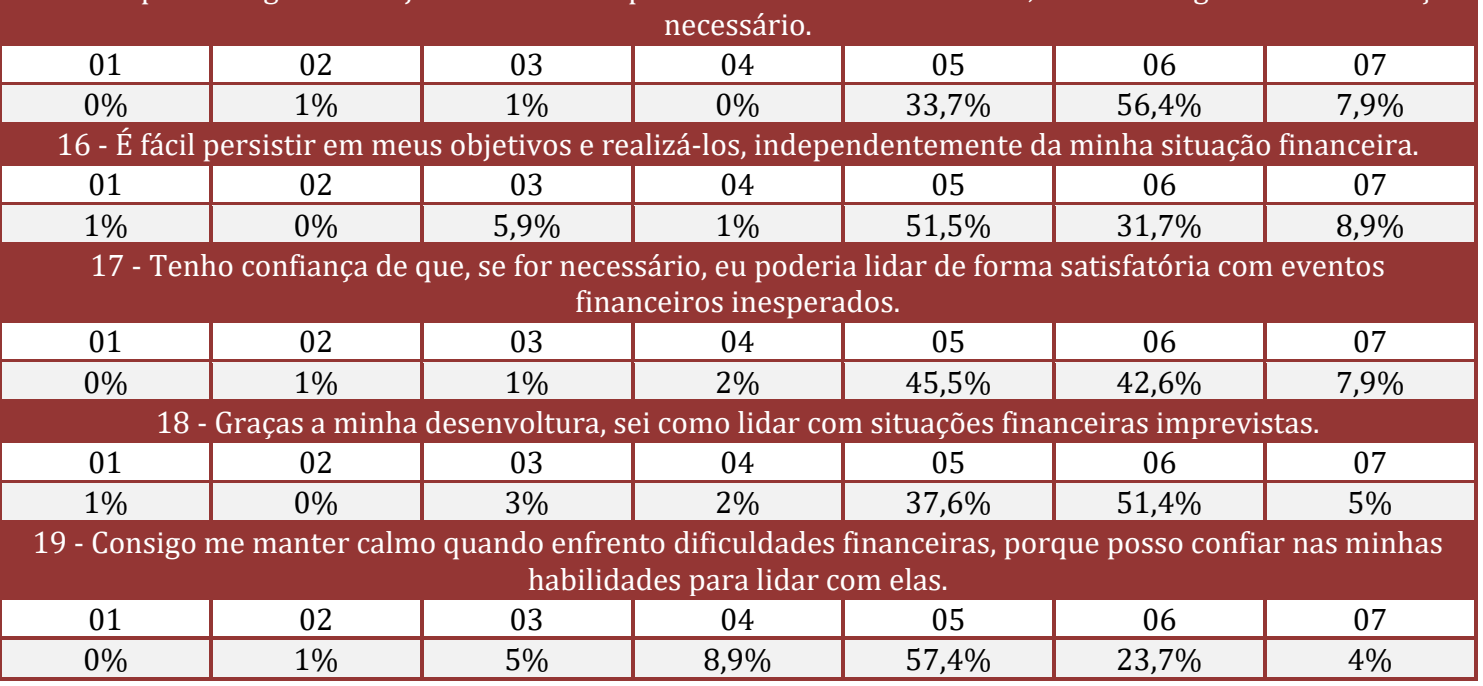

Fonte: Dados da Pesquisa (2019).

Com base na afirmação de que "Sempre consigo dar um jeito de resolver problemas financeiros difíceis, se eu conseguir fazer o esforço necessário", a grande maioria dos respondentes mostraram concordância, sendo $33,7 \%$ concordando parcialmente, 56,4\% concordando e 7,9\% concordando totalmente. Na afirmativa de que "É fácil persistir em meus objetivos e realizá-los, independentemente da minha situação financeira", mais uma vez os respondentes demonstraram concordância em sua maioria, com 51,5\% concordando parcialmente, $31,7 \%$ concordando e 8,9\% concordando totalmente.

Quando indagados de que "Tenho confiança de que, se for necessário, eu poderia lidar de forma satisfatória com eventos financeiros inesperados", novamente a grande maioria dos respondentes demonstraram concordância, sendo 45,5\% concordando parcialmente, 42,6\% concordando e 7,9\% concordando totalmente. Na afirmação que diz "Graças a minha desenvoltura, sei como lidar com situações financeiras imprevistas", mais uma vez a maioria dos usuários tendem para concordância, sendo $37,6 \%$ concordando parcialmente, $51,4 \%$ concordando e $5 \%$ concordando totalmente.

Ao afirmar que "Consigo me manter calmo quando enfrento dificuldades financeiras, porque posso confiar nas minhas habilidades para lidar com elas", novamente a grande maioria dos respondentes tenderam para a concordância, sendo 57,4\% concordando parcialmente, $23,7 \%$ concordando e $4 \%$ concordando totalmente. Seguindo o modelo de Donadio (2014), o segundo ponto busca identificar as considerações de consequências futuras e seus resultados, a ser observado no Quadro 3.

Com base na afirmativa "Eu planejo como as coisas deveriam ser no futuro e tento influenciá-las com meu comportamento no dia-a-dia”, a maioria dos respondentes demonstraram concordância, sendo 15,8\% concordando parcialmente, $41,6 \%$ concordando e 39,6\% concordando totalmente. Na afirmação de que "Frequentemente, me dedico a um comportamento em particular, com a intenção de conseguir resultados que podem acontecer apenas daqui a vários anos" novamente os respondentes tenderam para a concordância, sendo 24,8\% concordando parcialmente, 59,4\% concordando e 12,9\% concordando totalmente.

Já na afirmação que diz que "Eu apenas me dedico a resolver minhas preocupações imediatas, imaginando que o futuro tomará conta de si mesmo" o que prevaleceu foi a discordância, sendo 16,8\% discordando totalmente, $51,5 \%$ discordando e $29,7 \%$ discordando parcialmente, assim como na afirmativa que diz que "Acredito que é desnecessário sacrificar-se agora, uma vez que se pode lidar com resultados futuros num momento posterior" onde 56,4\% dos respondentes disseram discordar totalmente, 39,6\% afirmaram discordar e $2 \%$ discordaram parcialmente. Na assertiva que diz que "Estou disposto a sacrificar minha felicidade ou bem-estar imediatos para alcançar determinados resultados futuros", há o retorno maior da concordância, sendo 48,5\% afirmando concordar parcialmente, 46,5\% concordando e 1\% concordando totalmente. 
Quadro 3: Considerações de consequências futuras. Considerações de consequências futuras

20 - Eu planejo como as coisas deveriam ser no futuro e tento influenciá-las com meu comportamento no dia-a-dia.

\begin{tabular}{|c|c|c|c|c|c|c|}
\hline 01 & 02 & 03 & 04 & 05 & 06 & 07 \\
\hline $0 \%$ & $0 \%$ & $2 \%$ & $1 \%$ & $15,8 \%$ & $41,6 \%$ & $39,6 \%$ \\
\hline \multicolumn{7}{|c|}{$\begin{array}{l}21 \text { - Frequentemente, me dedico a um comportamento em particular, com a intenção de conseguir } \\
\text { resultados que podem acontecer apenas daqui a vários anos. }\end{array}$} \\
\hline 01 & 02 & 03 & 04 & 05 & 06 & 07 \\
\hline $0 \%$ & $0 \%$ & $0 \%$ & $3 \%$ & $24,8 \%$ & $59,4 \%$ & $12,9 \%$ \\
\hline \multicolumn{7}{|c|}{$\begin{array}{c}22 \text { - Eu apenas me dedico a resolver minhas preocupações imediatas, imaginando que o futuro tomará } \\
\text { conta de si mesmo. }\end{array}$} \\
\hline 01 & 02 & 03 & 04 & 05 & 06 & 07 \\
\hline $16,8 \%$ & $51,5 \%$ & $29,7 \%$ & $0 \%$ & $1 \%$ & $0 \%$ & $1 \%$ \\
\hline \multicolumn{7}{|c|}{$\begin{array}{l}23 \text { - Acredito que é desnecessário sacrificar-se agora, uma vez que se pode lidar com resultados futuros } \\
\text { num momento posterior. }\end{array}$} \\
\hline 01 & 02 & 03 & 04 & 05 & 06 & 07 \\
\hline $56,4 \%$ & $39,6 \%$ & $2 \%$ & $0 \%$ & $2 \%$ & $0 \%$ & $0 \%$ \\
\hline \multicolumn{7}{|c|}{$\begin{array}{l}24 \text { - Estou disposto a sacrificar minha felicidade ou bem-estar imediatos para alcançar determinados } \\
\text { resultados futuros. }\end{array}$} \\
\hline 01 & 02 & 03 & 04 & 05 & 06 & 07 \\
\hline $1 \%$ & $0 \%$ & $3 \%$ & $0 \%$ & $48,5 \%$ & $46,5 \%$ & $1 \%$ \\
\hline
\end{tabular}

Fonte: Dados da Pesquisa (2019).

Analisando os resultados obtidos, pode-se dizer que relacionado a autoeficácia percebida, os usuários de coworking mostram-se determinados a solucionar problemas financeiros, além de possuírem o controle emocional para lidar com situações adversas. Esses fatores são considerados competências empreendedoras, consoante Mamede e Moreira (2005) ao explanar que em um mercado amplo e de inúmeras mudanças, o desenvolvimento de competências empreendedoras torna-se imprescindível para a manutenção e expansão dos negócios.

Tratando-se das considerações de consequências futuras, os usuários de coworking mostraram-se preparados para enfrentar adversidades futuras que são comuns em um ramo de atuação tão volátil, considerando que a demonstração de consciência presente relacionada a consequências futuras foram significativas, com suas concordâncias em preparação para alcance de benefícios maiores, sacrificando até a felicidade e o bem-estar imediatos. Tais fatores seguem a linha de raciocínio de Ross et al (2009), quando afirmam que as tomadas de avaliações e boas decisões financeiras são primordiais para identificar os benefícios da administração financeira.

\section{CONSIDERAÇÕES FINAIS}

O objetivo geral desta pesquisa foi analisar o comportamento financeiro dos usuários de coworking de João Pessoa na Paraíba, com base na educação financeira e propensão ao endividamento. Diante disso, é possível inferir que os respondentes demonstram consciência dos seus gastos. Ainda que $80 \%$ dos respondentes afirmem ter dívidas, apenas $14 \%$ se encontram com dívidas em atraso, o que pode ser considerado positivo, já que a grande maioria das dívidas são relacionadas a meios de consumos bastante comuns, tais como o uso do cartão de crédito, empréstimo com terceiros (familiares e amigos) e financiamento de bens móveis e imóveis.

Outro fator que reafirma essa consciência é o fato do ramo de atuação, já que 99\% dos usuários de coworking respondentes da pesquisa, atuam no ramo de empreendedorismo, em grande maioria como profissionais liberais e microempreendedores individuais (MEI) e é sabido que a renda mensal neste ramo oscila de acordo com as variações de mercado.

Pode-se inferir, por meio da pesquisa, que o perfil dos usuários de coworking na cidade de João Pessoa é composto, majoritariamente, por jovens com maior grau de instrução, sendo estes fortemente influenciados pelas vantagens que o ambiente de coworking propicia. Nesse contexto, aspectos como constante colaboração entre membros, amplo networking e redução de custos em um espaço 
compartilhado colaboram, diretamente, para o conhecimento em educação financeira, já que tais fatores geram troca de conhecimentos, formação de parcerias e economia de custos.

Ademais, a pesquisa constatou que os usuários de coworking são propensos ao endividamento, porém destaca-se a presença de educação financeira, já que por mais que a grande maioria apresente dívidas, estas não estão em atraso. Faz-se interessante destacar que no comportamento financeiro foi observado que os usuários que gastam menos do que ganham ou igual ao que ganham é significativamente alta, correspondendo a $90 \%$ da amostra. Outro aspecto importante para atestar a presença de educação financeira foi o fato de que grande maioria dos usuários de coworking da pesquisa concordam com afirmações de que é necessário se planejar no presente, para se obter resultados financeiros futuros.

Todos os objetivos propostos na presente pesquisa foram alcançados de forma satisfatória, demonstrando a importância da educação financeira na vida das pessoas, e no caso estudado, principalmente na vida daquelas que atuam no ramo de empreendedorismo, já que para gerir um negócio, o conhecimento de como tomar decisões financeiras é primordial para geração de saldos positivos. $\mathrm{O}$ ambiente de coworking demonstrou ser positivo para os novos métodos de trabalho, influenciando nos modelos que visam a inovação, a ampliação das redes de relacionamento e o custo baixo de funcionamento para cada usuário. Além disso, este ambiente colaborativo demonstrou forte atração ao longo dos resultados, reforçado por dados do mercado que expressam o aumento do número de adeptos.

Por fim, faz-se mister ressaltar a importância de compreender o comportamento financeiro de públicos como os usuários de Coworking, os quais fazem parte das novas formas de negócios, cujo enquadram-se nas discussões sobre profissionais do futuro e, ainda, impulsionam a inovação e o empreendedorismo por meio de suas conexões e ideias. Somente analisando seus comportamentos financeiro é possível entender e auxiliar da forma correta e, consequentemente, evitar problemas estruturais e de sustentabilidade desse novo modelo de negócio.

\section{REFERÊNCIA}

[1] Antonello, Claudia Simone. Aprendizagem na ação revisitada e sua relação com a noção de competência. Comportamento organizacional e gestão, v. 12, n. 2, p. 199-220, 2006.

[2] Antunes, Ricardo; Alves, Giovanni Antonio Pinto. As mutações no mundo do trabalho na era da mundialização do capital. Educação \& Sociedade, p. 335-351, 2004.

[3] Assaf Neto, A. Finanças Corporativas e Valor. 4. ed. São Paulo: Atlas, 2009.

[4] Barros, Aidil J. da S.; Lehfeld, Neide Aparecida de S. Fundamentos de metodologia científica. 3. ed. São Paulo: Pearson Prentice Hall, 2007.

[5] Brinks, Verena. Networking practices and social gathering in Coworking Spaces-Working between Digitalization and Re-Localization. Geographische Zeitschrift, v. 100, n. 3, p. 129-145, 2012.

[6] D'aquino, Cássia; Cerbasi, Gustavo. Educação Financeira: como educar seus filhos. Elsevier, 2008.

[7] Deijl, C. M. Two heads are better than one, a case study of the co-working community in the Netherlands (MasterVs thesis). Erasmus University Rotterdam, Rotterdam, 2011.

[8] Donadio, Rosimara. Educação financeira de estudantes universitários: uma análise dos fatores de influência. Tese de doutorado. Universidade Nove de Julho. 2014.

[9] Eaton, Susan C. If you can use them: Flexibility policies, organizational commitment, and perceived productivity. 2001.

[10] Flores, Silvia Amélia Mendonça; VIEIRA, Kelmara Mendes; Coronel, Daniel Arruda. Influência de fatores comportamentais na propensão ao endividamento. Revista de Administração Faces Journal, v. 12, n. 2, 2013.

[11] Gandini, Alessandro. The rise of coworking spaces: A literature review. ephemera, v. 15, n. 1, p. $193,2015$.

[12] Gitman, Lawrence J. Princípios de Administração Financeira. [s.l.]: Bookman, 2006.

[13] Lakatos, Eva Maria; Marconi, Marina de Andrade. Fundamentos de metodologia científica. 5. reimp. São Paulo: Atlas, p. 310, 2007.

[14] Leforestier, Anne. The co-working space concept. CINE Term project, 2009.

[15] Mamede, MI de B.; Moreira, M. Z. Perfil de competências empreendedoras dos investidores Portugueses e Brasileiros: Um estudo comparativo na rede hoteleira do Ceará. Anais do XXIX Encontro Anual da Associação de PósGraduação e Pesquisa em Administração, Brasília, 2005. 
[16] Medina, Paloma Fraga; Krawulski, Edite. Coworking como modalidade e espaço de trabalho: uma análise bibliométrica. Cadernos de Psicologia Social do Trabalho, v. 18, n. 2, p. 181-190, 2015.

[17] Merkel, Janet. Coworking in the city. ephemera, v. 15, n. 2, p. 121-139, 2015.

[18] Munhoz, Anny Carolina Cantarero et al. Coworking e crowdsourcing: como modelos de negócios inovadores influenciam no desenvolvimento de start-ups. Anais do XVI Semead-Seminários em Administração. São Paulo, SP, Brasil, 2013.

[19] Prodanov, Cleber Cristiano; de Freitas, Ernani Cesar. Metodologia do trabalho científico: métodos e técnicas da pesquisa e do trabalho acadêmico-2 ${ }^{\text {a }}$ Edição. Editora Feevale, 2013.

[20] Ross, Stephen A. et al. Fundamentos de Administração Financeira. São Paulo: McGraw-Hill, 2009.

[21] Silva, Breno H.P., Júnior, Pedro dos S.P., Souza, Reginaldo da S., Piurcosky, Fabrício P., Lemes, Poliana T. A essencialidade da educação financeira na vida do gestor financeiro: uma análise com profissionais da macrorregião de Varginha-Mg. XIII SEGeT - Simpósio de Excelência em Gestão e Tecnologia - 2016.

[22] Spinuzzi, Clay. Working alone together: Coworking as emergent collaborative activity. Journal of Business and Technical Communication, v. 26, n. 4, p. 399-441, 2012.

[23] Strauss, K. Why Coworking Spaces are Here to Stay. Forbes Magazine. 2013. Disponível em <http://www.forbes.com/sites/karstenstrauss/2013/05/28/why-coworking-spaces-are-here-to-stay/>. Acesso em: $02 / 12 / 2018$.

[24] Vergara, Sylvia C. Projetos e relatórios de pesquisa em administração. Editora Atlas, 3ạ edição. Rio de Janeiro, 2009. 


\section{Capítulo 17}

\section{Compliance na iniciativa privada em Boa Vista Roraima}

\section{Eduardo Codevilla Soares \\ Aléxa Lauren Sousa Vasconcelos \\ Célia Dark Luzeiro Ribeiro}

Resumo: O Compliance passou a ganhar espaço na atualidade, uma vez que se trata de uma ferramenta relevante para organizações que prezam por sua integridade, tal programa funciona como um conjunto de ações que se destinam a observância do ato de cumprir, estar em conformidade e ainda de fazer com que se cumpram as leis e demais regulamentos. 0 presente artigo teve como objetivo analisar os elementos relacionados a interação do Compliance no Poder Público de Boa Vista-Roraima. Neste sentido, o estudo caracterizou-se como uma pesquisa de abrangência exploratória de natureza qualitativa, na qual os dados foram coletados por meio de entrevistas semiestruturadas e analisados utilizando o método de análise de conteúdo. Entrevistaram-se seis profissionais atuantes na Iniciativa Privada. 0 objetivo pretendido com este estudo foi atingido ao se analisar a interação dos elementos relacionados ao Compliance dentro da Iniciativa Privada mediante a realidade local.

Palavras-chave: Compliance, Programas de Integridade, Iniciativa Privada. 


\section{INTRODUÇÃO}

A corrupção é um elemento inerente a muitas civilizações, contemporaneamente este problema vem se fortalecendo e perpassando as divisas entre países, estados, cidades e regiões, independentemente de seu grau de desenvolvimento. De acordo com Trevisan et al. (2003) a corrupção é considerada uma conduta arbitrária que arruína e corrói a dignidade dos cidadãos e gera extensos prejuízos a sociedade.

Ainda a este respeito Ramos (2009) ressalta que tal mazela não é exclusividade de determinado povo ou cultura, mas que se trata de um fenômeno transnacional, possível de ser encontrado em qualquer segmento sendo este social ou econômico, em diversas escalas e seguramente constatado dentro de corporações públicas e privadas no mundo todo.

Frente a situação atual, tornou-se notório o fato de que esta é uma prática já enraizada no Brasil, principalmente quando são analisados alguns aspectos vinculados ao serviço público, contudo percebe-se também a disseminação desta prática junto a atividades privadas, em ambos os casos com o envolvimento direto de atores públicos e privados. Medeiros e Rocha (2016) afirmam que o grande avanço da corrupção em suas diversas faces, impõe aos Estados, a necessidade de encontrar ferramentas que atuem no combate a esse complexo e enraizado problema, capaz de ameaçar à democracia, aumentar a pobreza e prejudicar o desenvolvimento. No Brasil, uma dessas ferramentas é a Lei Anticorrupção (Lei $\mathrm{n}^{\circ}$ 12.846/13), este dispositivo legal traz consigo a previsão expressa do Programa de Integridade para as organizações, reconhecido internacionalmente como "Compliance", tal mecanismo funciona como um conjunto estruturado de práticas, procedimentos internos de integridade, auditoria, incentivo à denúncia de irregularidades e aplicação efetiva de códigos de ética e de conduta, políticas e diretrizes voltadas para a prevenção, detecção e remediação bem como punição de desvios, fraudes e irregularidades.

O debate sobre Compliance passou a ganhar espaço na atualidade, uma vez que se trata de uma ferramenta relevante para organizações que prezam por sua integridade, desta maneira em Boa Vista - RR passouse a considerar o Compliance desde que o poder legislativo municipal empreendeu o debate aberto à sociedade sobre o assunto, com isso, dado a existência de um crescente referencial teórico sobre o tema, associado a um debate vigente no âmago da sociedade local, verifica-se a viabilidade e a relevância da proposição levantada neste estudo.

Levando em conta a promulgação da chamada Lei Anticorrupção, o Compliance tornou- se ainda mais relevante no contexto brasileiro, com muitos estudos que passaram a abordar o tema, dado ao contexto exposto este estudo é norteado pela seguinte questão: Quais os elementos relacionados à interação do Compliance na Iniciativa Privada de Boa Vista-Roraima? Para tanto o objetivo desta pesquisa será analisar os elementos relacionados à interação do Compliance dentro da Iniciativa Privada de Boa Vista - Roraima.

Ademais, o Compliance está relacionado ao cumprimento de regulamentos internos das empresas, tal como as suas políticas de controle contábil, ética empresarial e regras de conduta, consequentemente, a pesquisa sobre o Compliance torna-se relevante para estudantes e profissionais da área contábil por trazer à tona aspectos relacionados as atividades desempenhadas por estes profissionais.

Além desta (I) Introdução o artigo em tela possui as seguintes seções: (II) Referencial Teórico, que aborda conceitos relacionados ao Compliance, tanto como prática organizacional quanto como ferramenta de interação entre organizações privadas e os entes públicos; (iii) Procedimentos Metodológicos com o conjunto de decisões e procedimentos que foram empregados em vias de concretizar o estudo. Em sequência, no item (iv) Análise de Dados que apresenta os dados coletados bem como tecidas análises com foco nas teorias abarcadas e; (v) Considerações Finais, demonstrando os resultados da pesquisa.

\section{REVISÃO DA LITERATURA}

Neste tópico serão abordados: (I) O Compliance e a Iniciativa Privada, vinculado a utilização do Compliance pela Iniciativa Privada como forma de promover a integridade de suas relações e atividades e; (II) que aborda o Compliance sob o enfoque da interação entre Iniciativa Privada e Poder Público e a iniciativa privada, agindo como um mecanismo mediador de interesses em prol do estabelecimento de balizadores morais e legais. 


\subsection{COMPLIANCE E A INICIATIVA PRIVADA}

De acordo com Azevedo (2018) com a publicação da Lei 12.846/2013 e a exigência de que as empresas adotem mecanismos e procedimentos internos de integridade, auditoria, códigos de ética e de conduta, muito passou a se falar sobre Compliance no âmbito privado.

Neste sentido, o Compliance nasce da necessidade de que as instituições privadas iniciem um ciclo de mudanças, com reestruturações estratégicas, organizacionais e tecnológicas, para construir uma imagem forte perante clientes e fornecedores (RODRIGUES; OLIVEIRA; ARAÚJO; 2016). Ainda, de acordo com Góis (2014) o programa de integridade, designa uma política regulatória de anticorrupção para o setor privado em suas relações com o Estado, concebendo um conjunto de procedimentos de fiscalização, ética corporativa e auditoria para as empresas enquanto setor econômico privado.

Conforme Doná et al. (2015) a falta de controles e gerenciamentos eficazes do risco tem feito com que muitas empresas passem a primar pelo aperfeiçoamento das técnicas utilizadas para avaliar riscos, adotando técnicas de Compliance que têm se mostrado eficazes. Xavier et al. (2017), Wanderer (2017) salientam que são vários os riscos aos quais uma empresa está exposta pelo fato de não estar em Compliance, como o sofrimento de sanções legais, riscos operacionais, de imagens, bem como riscos que variam de acordo com as atividades e peculiaridades de cada organização.

Para Debbio et al.(2013); Zapatero e Martín (2013), o fato de uma empresa possuir programas de Compliance eficazes e anteriores a ocorrência de algum tipo de violação é considerado importante fator mitigador (ou potencial excludente, quando combinado a outros fatores) de sanções, sendo até capazes de incentivar condutas socialmente desejáveis.

Neste sentido, Andreisová (2016) assegura que a manutenção de um forte programa de prevenção de fraude que preza pela ética e Compliance não deve ser tido apenas como um mero facilitador para o não pagamento de multas, mas como uma questão de proteção a própria empresa, seus acionistas, executivos, líderes, gerentes e funcionários. Ademais, a implantação de programas de integridade de Compliance melhoram o gerenciamento de riscos corporativos e aumentam a capacidade de atingir os objetivos estratégicos, operacionais e de conformidade (MCNALLY, 2013; ZAPATERO E MARTÍN, 2013; ALBRES, 2018).

Ressalta-se que com as atividades de Compliance, os possíveis desvios em relação à política interna são mais facilmente identificados e evitados, além do mais, as atividades de Compliance propiciam as empresas transparência de suas ações mediante aos investidores e outros interessados, melhorando na sua imagem, trazendo ótimos benefícios. (BLOK, 2014; OECD, 2010). 0 Quadro 2 apresenta elementos que impactam de forma positiva nas atividades desenvolvidas dentro do Setor Privado, através da implantação do Programa de Compliance.

Quadro 1. Elementos que impactam na atividade organizacional privada a partir da implantação do Compliance

\begin{tabular}{|c|c|c|}
\hline Elementos & Descrição & Autor \\
\hline Conformidade & $\begin{array}{l}\text { Está relacionado ao cumprimento, conformidade com leis, regulações, } \\
\text { convenções do mercado, códigos e padrões estabelecidos por associações, } \\
\text { órgãos regulatórios e códigos de conduta. }\end{array}$ & $\begin{array}{l}\text { Lamboy }(2018) ; \\
\text { Schramm } \\
\text { (2018), } \\
\text { Góis (2014) }\end{array}$ \\
\hline Imagem & $\begin{array}{l}\text { Elemento que se baseia no modo positivo partindo-se da forma pela qual os } \\
\text { clientes, acionistas e demais stakeholders vislumbram a organização. }\end{array}$ & $\begin{array}{l}\text { CADE(2016); } \\
\text { Blok (2014). }\end{array}$ \\
\hline \multirow[t]{2}{*}{ Gestão de Riscos } & \multirow{2}{*}{$\begin{array}{l}\text { Lida com as incertezas de um negócio, de modo a planejar, organizar, } \\
\text { controlar e gerir os recursos financeiros, materiais, além do capital } \\
\text { intelectual existente em uma organização visando a minimização máxima dos } \\
\text { efeitos dos riscos. }\end{array}$} & $\begin{array}{c}\text { CGU(2015); } \\
\text { Mcnally (2013); } \\
\text { Debbioet }\end{array}$ \\
\hline & & \begin{tabular}{|c|} 
al.(2013); \\
UNODC (2013) \\
\end{tabular} \\
\hline Controle & $\begin{array}{l}\text { Auxilia a empresa, prevenindo práticas de irregularidades e identificação de } \\
\text { erros, protegendo-a, dando a esta a possibilidade de que os objetivos e metas } \\
\text { sejam atingidos. }\end{array}$ & $\begin{array}{l}\text { CADE(2016); } \\
\text { CGU (2015) }\end{array}$ \\
\hline Ética & $\begin{array}{l}\text { É composta pelo conjunto de valores, princípios e fins que orientam o } \\
\text { comportamento da organização e compõem a sua cultura corporativa. }\end{array}$ & $\begin{array}{c}\text { Lamboy (2018), } \\
\text { Rodrigues; } \\
\text { Oliveira; Araújo } \\
\text { (2016); Terra e } \\
\text { Bianchi (2018) }\end{array}$ \\
\hline
\end{tabular}


(continuação ..)

Quadro 1. Elementos que impactam na atividade organizacional privada a partir da implantação do

Compliance

Elementos

Descrição

\begin{tabular}{|c|c|c|}
\hline $\begin{array}{c}\text { Governança } \\
\text { Corporativa }\end{array}$ & $\begin{array}{c}\text { Ferramenta alinhada aos interesses da empresa com a finalidade de preservar e } \\
\text { aperfeiçoar o valor da organização, facilitando seu acesso ao capital e } \\
\text { contribuindo para a sua longevidade. }\end{array}$ & $\begin{array}{c}\text { IBGC(2017); } \\
\text { Schramm (2018) }\end{array}$ \\
\hline Integridade & Significa a atuação concreta da organização segundo a sua visão e missão. & $\begin{array}{c}\text { Lamboy (2018); } \\
\text { CGU(2015); } \\
\text { Blok (2014) }\end{array}$ \\
\hline
\end{tabular}

Fonte: As autoras (2019).

\subsection{COMPLIANCE COMO FERRAMENTA DE INTERFACE DA INICIATIVA PRIVADA COM O PODER PÚBLICO}

De acordo com Blok (2014) em meados da década de 90, todas as organizações públicas e privadas passaram a adotar o Compliance como uma de suas regras primárias e essenciais para a transparência de suas atividades, ainda para este autor, as empresas ou órgãos públicos que não possuem uma área forte de Compliance acabam perdendo em credibilidade perante as partes interessadas (stakeholders) e cada vez mais perdem oportunidades no mercado, principalmente no financeiro.

CGU (2015) acredita que qualquer instituição, sendo esta pública ou privada, deve realizar diligencias de autoconhecimento para identificar suas vulnerabilidades e para definir o que precisa ser feito no intuito de fortalecimento de sua integridade, pois considera que atuação de uma instituição que é pautada pela improvisação e desorganização, acaba por comprometer de forma negativa na sua integridade, já que a suas vulnerabilidades e riscos não serão conhecidos e tampouco mitigados.

A necessidade pela aplicação de processos que mantenham as suas estruturas de acordo com o Compliance dentro das organizações está se desenvolvendo no mundo todo. Já se percebe a elevação do nível de consciência dos executivos, de que Compliance é fundamental para manter elevada a imagem e a reputação da organização, bem como, gerará a garantia da redução de perdas invisíveis por desvios operacionais, erros involuntários, corrupção e fraudes ocupacionais, entre outros fatores que contribuem com a redução do desempenho dos negócios. (BRIZOTI E PERES, 2016).

Como corrobora IBGC (2017), a respeito do aperfeiçoamento das práticas de Compliance - e de governança corporativa como um todo - visto que se observa que tal aspecto tem ganhado muito mais relevância à medida que o mercado e a sociedade valorizam organizações comprometidas com a integridade, levando a uma vantagem competitiva diante dos concorrentes e a critérios diferenciados na obtenção de investimentos, créditos ou financiamentos.

Para Blok (2014), é imprescindível que as empresas privadas adaptem-se às inovações trazidas pela Lei Anticorrupção, implantando suas ferramentas e mecanismos de prevenção e planejamento estratégico, para, assim, monitorarem seu relacionamento com a Esfera Pública, com a finalidade de evitar, no futuro, alguma surpresa indesejada. Além de que, o mecanismo ligado à integridade permitirá alçar um novo patamar de cultura cidadã e empresarial de honestidade, que reverberará em toda a sociedade.

Lamboy (2018) salienta que talvez a implementação de um programa de Compliance não seja o suficiente para tornar uma organização, sendo esta pública ou privada, à prova de desvios de conduta e dos transtornos causados por estes. Mas afirma que, certamente a utilização desta ferramenta servirá como uma proteção da integridade, com a redução de riscos, aprimoramento do sistema de controles internos e combate a corrupção e a fraudes.

É importante ressaltar que não existe fórmula única para os programas de Compliance, mas para que estes sejam efetivos é fundamental que estes programas sejam adaptados de forma proporcional a realidade de cada organização, onde este seja específico para a organização como um todo. (DEBBIO et al., 2013; ANDREISOVÁ, 2016; UNODC,2013; OECD, 2010)

Através dos programas de Compliance, as empresas robustecem seu compromisso com os valores, prevenção e diminuição de riscos, primordialmente com o cumprimento da legislação, mas o mesmo somente terá melhores resultados quando conseguir penetrar de fato nos colaboradores dentro das organizações a importância em fazer a coisa certa. (CADE, 2017; KELMAN, 1958) 
O Compliance possui a missão de garantir que os controles internos da empresa funcionem de maneira ordenada, buscando assim a redução dos riscos com base no modelo de negócios e a complexidade dos mesmos, além do mais visa disseminar uma cultura de controles internos em toda organização de forma a assegurar que as leis, normas, regulamentos internos e externos existentes sejam cumpridos (LAMBOY, 2018; CASTRO et al., 2019)

\section{PROCEDIMENTOS METODOLÓGICOS}

Levando em conta a questão de pesquisa em proposição e os objetivos traçados para este estudo, o mesmo possui enfoque qualitativo, que de acordo com Santos et al. (2007), são estudos onde o pesquisador observa os fatos de forma direta, privilegiando o contato com o contexto estudado, procurando pesquisar e representar a qualidade dos discursos apresentados.

Este estudo possui cunho exploratório (LEITE, 2008), por ser uma pesquisa que aborda um assunto emergente no campo científico e acadêmico, e como afirma Ruiz (2011) é um estudo que enfatiza a descoberta de ideias e discernimentos sobre o tema em análise. Assim sendo, o caráter exploratório da pesquisa em questão se caracteriza pela análise da influência dos elementos relacionados a interação do Compliance na Iniciativa Privada de Boa Vista- Roraima.

A seleção de entrevistados ocorreu por conveniência (FLICK, 2009; MARCONI e LAKATOS, 2010). Gil (2010) aponta que neste tipo de seleção de entrevistados o pesquisador seleciona os elementos a que tem acesso e que são representativos para o contexto de análise.

Para tanto, o presente estudo contou com seis entrevistados, colaboradores da Iniciativa Privada local. Tal vertente definida, tem por objetivo analisar como ocorre a interferência de cada um dos elementos abordados pelos autores utilizados neste estudo, de modo a entender como se dá a interação destes dentro do âmbito privado junto ao local abordado. No Quadro 2 são apresentadas as características dos entrevistados, bem como, as das respectivas entrevistas.

Quadro 2 - Caracterização dos entrevistados

\begin{tabular}{|c|c|c|c|c|c|c|}
\hline Entrevistado & Categorias & Função & $\begin{array}{l}\text { Formação } \\
\text { acadêmica }\end{array}$ & $\begin{array}{l}\text { Tempo na } \\
\text { função }\end{array}$ & $\begin{array}{c}\text { Data da } \\
\text { entrevista }\end{array}$ & $\begin{array}{l}\text { Duração da } \\
\text { entrevista }\end{array}$ \\
\hline 1 & \multirow{6}{*}{ Setor Privado } & $\begin{array}{l}\text { Gest. do Núcleo de } \\
\text { Compliance }\end{array}$ & Direito & 2 anos & 30.01 .19 & $30 \min 44 s$ \\
\hline 2 & & Ouvidora & Administração & 8 anos & 30.01 .19 & $31 \min 40 s$ \\
\hline 3 & & Téc. de Form. & Arquitetura & 6 anos & 30.01 .19 & $30 \min 40 s$ \\
\hline 4 & & Diretor Jurídico & Direito & 3 anos & 05.02 .19 & $01 \mathrm{~h} 30 \mathrm{~min}$ \\
\hline 5 & & Superintendente & Serviço Social & 24 anos & 05.02 .19 & $35 \min 5 \mathrm{~s}$ \\
\hline 6 & & Resp. de Controle Interno & Direito & 4 meses & 08.02 .19 & $39 \min 1 \mathrm{~s}$ \\
\hline
\end{tabular}

Fonte: Os autores (2019)

A coleta de dados foi realizada por meio de entrevista semiestruturada (FLICK, 2009; SAMPIERE, COLLADO E LÚCIO, 2013), e foram analisadas mediante a análise de conteúdo (BARDIN, 2011).

\section{ANÁLISE DOS DADOS}

Em vias de atender os objetivos desta pesquisa, bem como de verificar o alinhamento dos questionamentos apresentados à compreensão dos entrevistados sobre o assunto abordado neste estudo, de maneira inicial indagou-se aos entrevistados a respeito de sua compreensão sobre o Compliance, bem como quais seriam os elementos que o compõem.

Neste sentido, é possível ressaltar que todos os seis entrevistados conceituam o "Compliance” como um programa de integridade que por meio de um conjunto de procedimentos favorece o combate de práticas ilícitas dentro das instituições de modo com que estas ajam em conformidade com legislações, regulamentos internos e externos, instruções normativas, dentre outros, prezando pela ética e transparência.

Neste sentido, é possível observar que os entrevistados tratam o tema em conformidade com os autores Schramm (2018) e Bragato (2017) que entendem o "Compliance" como um programa constituído por ações que são destinadas ao ato de se fazer cumprir leis, diretrizes, regulamentos internos e externos e demais procedimentos que visam atenuar os possíveis riscos aos quais as organizações estão sujeitas. 
Vale ainda ressaltar que um dos entrevistados destacou que o Compliance vai além desta conceituação, tendo em vista que na atualidade tal ferramenta tem ganhado grandes proporções. Este pensamento corresponde a fala de Ribeiro e Diniz (2015) quando afirmam da não limitação do Compliance ao simples cumprimento de regras, sendo estas formais ou informais, pois o alcance deste é muito maior, servindo como o alinhamento principal na orientação das organizações em seu mercado de atuação.

Ainda em relação a esta ferramenta, outro dos respondentes destacou que o Compliance é uma tendência mundial e que considera de grande importância que as empresas privadas de Boa Vista - Roraima o utilizem, bem como os órgãos públicos, assim como enfatiza Bento (2018) ao declarar que os programas de Compliance estão se tornando uma tendência no mercado na atualidade e se mostrando oportuno e necessário, e em outros casos até mesmo obrigatório.

Com relação aos elementos que compõem a ferramenta de Compliance, quando questionados dois dos entrevistados salientaram que estes variam de acordo com o que se deseja implantar e trabalhar, já que para eles não existe um número certo de pilares como são também são conhecidos os elementos.

Tal apontamento está em concordância com o que salienta Debbio et al. (2013) ao revelar que o Compliance deve ser adaptado para atender as particularidades de cada organização, e que ainda complementa que é por meio desta modificação que o programa ganha a possibilidade de se tornar mais efetivo.

Os quatro entrevistados restantes apontaram como elementos primordiais dentro do programa de Compliance, os que de acordo com eles são os mais comuns a serem utilizados o: Apoio da Alta Administração, a Análise de Riscos, a Criação de Políticas e Códigos de Conduta, Canais de denúncia, Comunicação e Treinamento e a Auditoria, em comum com os já abordados por Debbio et al. (2013), é relevante ainda salientar que todos os entrevistados entendem que um dos elementos mais importantes a ser considerado é o Apoio da Alta Administração, já que de acordo com eles sem este, dificilmente seria possível atingir os objetivos de integridade corporativa.

Em sequência foram apresentados aos entrevistados um conjunto de possíveis elementos que de acordo com os autores abordados neste estudo estão relacionados a interação do Compliance no Setor Privado, para que eles indicassem se os mesmos representam ou não relação com o Compliance no dia a dia da organização. Com relação ao elemento conformidade, todos os entrevistados afirmaram que o mesmo influencia, tendo em vista que este elemento é a essência do Compliance, e embora estar em conformidade com leis e demais regulamentos já fosse uma preocupação para os empresários antes mesmo da Lei 12.846/13, a implantação do programa de integridade melhorou a cultura das organizações e fortaleceu ainda mais os padrões de conformidade, isso entra em consenso com a fala de Lamboy (2018), quando afirma que uma das funções do Compliance é a de adequar as organizações as legislações vigentes.

Sobre a imagem, quatro dos entrevistados entraram em consenso ao afirmar que tal elemento está intimamente relacionado as atividades de Compliance, pois de acordo com estes quanto mais se demonstrar que a organização está agindo de acordo com as regras para com seus stakeholders e sociedade em geral, mais se estará construindo e preservando a boa imagem da organização dentro do negócio, desta forma observa-se que tal colocação está em concordância com Blok (2014) que afirma que a implantação de um programa de Compliance em uma empresa privada amplia a credibilidade da organização, sob o olhar de seus colaboradores e stakeholders, resultando em um retorno maior de seus investimentos, preservação da sua reputação, dentre outros.

Somente dois dos entrevistados não associam o Compliance como influenciador na imagem da organização, sendo que um deles alegou que tal elemento estaria mais associado a questões relacionadas a transparência da organização do que meramente uma "imagem", ambos enxergam esse elemento como uma consequência do trabalho executado pela empresa que objetiva a consolidação no mercado altamente competitivo, independente de esta atuar com Compliance ou não.

Em relação a gestão de riscos, cinco dos entrevistados afirmam que há influência, pelo fato de considerarem que a aplicação do programa de integridade acarreta na prevenção de fraudes dentro da organização, sendo assim, com base nos elementos do Compliance existe a possibilidade do mapeamento e detecção de possíveis eventos que impactam de maneira negativa nas atividades da empresa, evitando ou excluindo possíveis problemas.

Entretanto, um dos entrevistados acredita que esse elemento não está relacionado a aplicação do Compliance, por acreditar que as questões relacionadas a gerência de riscos, exigem um conhecimento em especial por parte dos empresários e seus colaboradores, não bastando apenas a 
aplicação do Compliance para que esta mitigação de riscos ocorra.

A respeito do elemento controle houve totalidade na concordância de que este está relacionado a interação do Compliance nas empresas, tendo em vista que quando se busca manter a conformidade através do cumprimento de regras, faz-se necessária a manutenção de um controle maior dentro dos processos aos quais as empresas estão inseridas, de acordo com os entrevistados o elemento de controle está ligado a prevenção de práticas de irregularidades e até mesmo desvio de condutas por parte da empresa desde o seu mais alto nível ao menor, ressaltou-se ainda que a promoção do controle da entidade nesse aspecto se dá por meio do respeito aos códigos de conduta internos e externos aos quais a organização deve cumprimento. Quanto a ética todos os entrevistados concordaram por também enxergarem este elemento como essência do Compliance, pois, de acordo com estes quando uma organização está disseminando uma cultura onde se preserva estar em conformidade, buscando agir de maneira correta, a consequência será um ambiente onde a ética está presente, vale ressaltar que de acordo com os entrevistados o exemplo deve vir de cima, dos cargos de maior responsabilidade, de acordo com o afirmado por Lamboy (2018) que o efeito do Compliance vai além de barreiras legais e regulamentares, incorporando também princípios de integridade e conduta ética.

Sobre o elemento governança corporativa cinco dos entrevistados entendem que a mesma está relacionada as atividades de Compliance, tendo em vista que a governança está intimamente alinhada aos interesses da organização como um todo, com modelos claros que precisam ser seguidos e esta é um dos objetivos do Compliance.

No entanto, um dos entrevistados afirmou que para ele o elemento não possui influência, pois para ele, a governança corporativa exige dos empresários um conhecimento específico, onde não basta apenas a utilização de programas de integridade para se praticar a governança.

Quanto ao elemento integridade houve consenso por parte dos entrevistados ao afirmarem a relação deste com o Compliance, pois assim como os elementos de conformidade e ética, eles entendem a integridade também como importante característica do Compliance.

Após a apresentação dos elementos abordados anteriormente, os entrevistados foram questionados sobre a possibilidade de existência de outros elementos que não tivessem sido apontados pelos autores e que são importantes para as atividades do Compliance dentro do setor privado e quatro dos entrevistados citaram a melhoria contínua e os demais não fizeram novos apontamentos, apenas salientaram novamente a importância dos elementos já citados.

Buscando compreender uma possível relação de importância entre os elementos abordados nesta pesquisa, solicitou-se aos entrevistados que demonstrassem em ordem decrescente a importância de cada um dos sete elementos apresentados, onde o maior número representaria maior importância sobre os outros, sendo assim foi possível constatar através da análise das entrevistas cada elemento, na seguinte colocação: (7) Ética, (6) Conformidade, (5) Gestão de Riscos, (4) Controle, (3) Governança Corporativa, (2) Integridade e (1) Imagem.

É importante ressaltar, que ao enumerar esses graus de importância os entrevistados justificaram que todos os elementos possuem uma importância significativa nas atividades de Compliance, apenas um dos entrevistados não conseguiu enumerar e justificou dizendo o mesmo que os demais "todos os elementos dependem um do outro, todos possuem uma importância específica e para que o Compliance é preciso ter todos os elementos trabalhando juntos caso não possua um destes, não se tem o Compliance."

\section{CONSIDERAÇÕES FINAIS}

O controle da corrupção tornou-se um dos objetivos comuns dentro da sociedade, tendo em vista que tal mazela transformou-se em uma preocupação dentro dos contextos nacional e internacional, neste sentido é possível ressaltar mediante aos fatos apresentados nesta pesquisa, que a implantação de programas de Compliance faz-se essencial, principalmente no que tange o combate a corrupção dentro de toda e qualquer organização.

Atualmente os programas de integridade de Compliance quando bem estruturados são vistos como mecanismos que possibilitam as organizações na prevenção, detecção e em alguns casos até mesmo a mitigação de possíveis riscos que possam ferir a integridade dentro das ações desempenhadas por estas,

Neste sentido com base na realidade local de Boa Vista - Roraima no que diz respeito a Iniciativa 
Privada se torna nítido que as questões relacionadas ao Compliance já é uma realidade dentro das empresas, tendo em vista que com base nas respostas do entrevistados observou-se que os programas de integridade são tratados como parceiros válidos dentro dos negócios, onde estar em Compliance é parte da cultura organizacional destas empresas, além do mais este instrumento é considerado por estes uma tendência dentro do mercado, pois auxilia na transparência e dá confiabilidade aos negócios, tudo isso é muito relevante para as empresas tendo em vista que estar em conformidade com regulamentos, leis, normas e demais regras é essencial para qualquer entidade independente de seu ramo e tamanho.

Sendo assim, ressalta-se que o questionamento proveniente por este estudo: quais os elementos relacionados à interação do Compliance na Iniciativa Privada de Boa Vista-Roraima? Fora atendido, quando se levantou como conteúdo importante para o contexto proposto os elementos analisados individualmente por cada uma das categorias que emergem do enfoque teórico proposto, e que são verificados por profissionais da região, como elementos que estão relacionados às atividades de Compliance na realidade local. Ao analisar a interação dos elementos relacionados ao Compliance dentro da Iniciativa Privada mediante a realidade de Boa Vista-Roraima, atinge-se o objetivo do estudo.

Assim, frente ao exposto, ainda que não se possua a intenção de esgotar os debates sobre o tema, mas na intenção de lançar um novo olhar sobre as possibilidades relacionadas ao compliance, principalmente por entender que o assunto vem ganhando força e tomando espaço dentro dos contextos organizacionais e jurídicos, deve-se ressaltar que este estudo, dado seu enfoque qualitativo, não tem a intenção de extrapolar os achados para toda a localidade, ou região, mas sim descortinar debates possíveis quando se trata de questões tão sensíveis relacionadas a realidade dos serviços públicos em âmbito nacional.

Neste sentido, sugere-se que a presente abordagem possa ser ampliada, levando em consideração outras realidades locais brasileiras as quais o compliance também venha sendo utilizado como forma de promover maior desenvolvimento do setor privado em busca do oferecimento de maior transparência e combate à corrupção.

\section{REFERÊNCIAS}

[1] Albres, Hevellyn Menezes. Política pública para promoção da integridade corporativa: estudo de caso do Programa Pró-Ética. - Brasília: Ipea, 2018. 139 f. : il.

[2] Andreisová, Lucie. Building and Maintaining an Effective Compliance Program. International Journal of Organizational Leadership 5, p. 24-39. 2016.

[3] Bardin, Laurence. Análise de Conteúdo. São Paulo: Ed. 70, 2011.

[4] Bento, Alessandro Maier. Fatores relevantes para estruturação de um programa de Compliance. Revista da Fae. Curitiba, v. 21, n. 1, p. 98 - 109, jan./jun. 2018.

[5] Blok, Marcella. A nova lei anticorrupção (Lei 12.846/2013) e o compliance. Revista de Direito Bancário e do Mercado de Capitais, vol. 65, 2014.

[6] Bragato, Adelita Aparecida Podadera Bechelani. O Compliance no Brasil: a empresa entre a ética e o lucro. 134 f. Dissertação (Mestrado em Direito) - Universidade Nove de Julho, São Paulo, 2017.

[7] Brasil. Lei 12.846, de 10 de Agosto de 2013. Dispõe sobre a responsabilização administrativa e civil de pessoas jurídicas pela prática de atos contra a administração pública, nacional ou estrangeira, e dá outras providências. Disponível em:< http://www.planalto.gov.br/ccivil_03/_Ato2011-2014/2013/Lei/L12846.htm>. Acesso em: 25 Out. 2018.

[8] Castro, Patrícia Reis; Amaral, Ventura Juliana; Guerreiro, Renato. Aderência ao programa de integridade da lei anticorrupção brasileira e implantação de controles internos Revista Contabilidade \& Finanças. - USP, São Paulo, v. 30, n. 80, p. 186-201, mai./ago. 2019

[9] Conselho Administrativo de Defesa Econômica, Cade. Guia: Programas de Compliance. 2016. Disponível em: < http://www.cade.gov.br/acesso-a- informacao/publicacoes-institucionais/guias_do_Cade/guia-compliance-versaooficial.pdf/view>Acesso em: 20 Nov. 2018.

[10] Controladoria Geral da União - Cgu. Programa de Integridade: Diretrizes Para Empresas Privadas. Acesso em: < http://www.cgu.gov.br/Publicacoes/etica-e- integridade/arquivos/programa-de-integridade-diretrizes-paraempresas-privadas.pdf $>$.Acesso em: 20 Nov. 2018

[11] Debbio, Del Alessandra; Maeda, Carneiro Bruno; Ayres, Carlos Henrique da Silva.Temas de anticorrupção e Compliance. - Rio de Janeiro: Elsevier, 2013.

[12] Doná, Andréa Lúcia; et al. Fatores Determinantes do Conteúdo Divulgado no Relatório de Administração de 
Empresas Brasileiras. Revista Universo Contábil, ISSN 1809-3337, Furb, Blumenau, v. 11, n. 4, p. 82-106, out./dez., 2015.

[13] Flick, U. (2009). Introdução a pesquisa qualitativa. Tradução Joice Elias Costa. - 3.ed. - Porto Alegre: Artmed.

[14] Gil, Antonio Carlos. Métodos e técnicas da pesquisa social. São Paulo: Atlas 2010. Góis, Veruska Sayonara de; A Lei de Compliance e sua Configuração Enquanto Política

[15] Pública Regulatória para o Setor Privado Brasileiro. Dialnet - Revista Controle/ Doutrina e Artigos. Vol. 12, no 2, págs. 97-117, 2014.

[16] Instituto Brasileiro De Governança Corporativa - IBGC. Compliance à luz da governança corporativa. <https://conhecimento.ibgc.org.br/Lists/Publicacoes/Attachments/23486/Publicacao- IbgcorientaCompliancesobaluzdagc-2017.Pdf >. Acesso em: 03 Dez. 2018.

[17] Kelman, H. C. Compliance, Identification, and Internalization: Three processes of attitude change. Journal of Conflict Resolution, v. 2(1), pp. 51-60, 1958.

[18] Lamboy, Christian K. de; Manual de Compliance. São Paulo (SP): Via Ética, 2018.

[19] Leite, F. T. Metodologia científica: métodos e técnicas de pesquisa: monografias, dissertações, teses e livros. São Paulo: Ideias \& Letras, 2008.

[20] Marconi, Marina de Andrade; Lakatos, Eva Maria. Fundamentos de metodologia científica. 7.ed. São Paulo: Atlas, 2010.

[21] Mcnally, J. S. (2013). The 2013 Coso Framework \& Sox Compliance 2013. Disponível em: < https://www.coso.org/documents/COSO\%20McNallyTransition\%20Article- Final\%20COSO\%20Version\%20Proof_531-13.pdf>. Acesso em: 15 abr. 2019.

[22] Medeiros, R. V; Rocha, L.G. A corrupção no Brasil e no mundo. Ceará: Fundação Demócrito Rocha, 2016.. 0 Papel das Instituições brasileiras no combate à corrupção. Ceará: Fundação Demócrito Rocha, 2016.

[23] Organisation For Economic Co-Operation And Development- Oecd. (2010). Good practice guidance on internal controls, ethics, and compliance. Disponível em:< https://www.oecd.org/daf/ anti-bribery/44884389.pdf.>. Acesso em: 15 abr. 2019.

[24] Peres, João Roberto; Brizoti, Nilson. Compliance corrupção e fraudes no mundo empresarial. - 1. ed. - São Paulo, 2016.

[25] Ramos, Paulo Roberto de Araújo. Revista Mineira de Contabilidade. Corrupção na Administração Pública e crimes de 'lavagem' ou ocultação de bens, direitos e valores. Minas Gerais, v. 4, n.40, 2010.

[26] Ribeiro, Márcia Carla Pereira; Diniz, Patrícia Dittrich Ferreira. Compliance e Lei Anticorrupção nas Empresas. Revista de Informação Legislativa, Brasília, a. 52, n. 205, 20 Nov. 2015.

[27] Rodrigues, Maria Lúcia de Barros; OLIVEIRA, Pamela Danelon Justen de; Araújo, Alexandra Barbosa Campos de. Compliance no Setor Estatal. Revista Percurso, Curitiba, v. 2, n. 19, 2016.

[28] Ruiz, João Álvaro. Metodologia científica: guia para eficiência nos estudos. 6. ed. reimpr. São Paulo: Atlas, 2011.

[29] Sampieri, R. H.; Collado, C. F.; Lucio, M. P. B. Metodologia de pesquisa. 5 ed. Porto Alegre: Penso, 2013.

[30] Santos, G. R. C. M.; Molina, N. L.; Dias, V. F.; Orientações e dicas práticas para trabalhos acadêmicos. Curitiba: Ibpex, 2007.

[31] Schramm, Fernanda Santos. O Compliance como instrumento de combate à corrupção no âmbito das contratações públicas. Repositório Institucional da UFSC, Dissertação (mestrado) - Universidade Federal de Santa Catarina, Centro de Ciências Jurídicas, Programa de Pós-Graduação em Direito, Florianópolis, 2018.

[32] Terra, Donizete Mariano; Bianchi, Eliane Maria Pires Giavina. Compliance nas Micro e Pequenas Empresas: Percepções de seus Administradores. Revista de Empreendedorismo e Gestão de Pequenas Empresas v.7, n.3, p. 5866, Set/Dez. 2018.

[33] Trevisan, A. M. et al. O combate à corrupção nas prefeituras do Brasil. São Paulo: Ateliê, 2003.Unodc - United Nations Office On Drugs And Crimes. An Anti-Corruption

[34] Ethics and Compliance Programme for Business: A Practical Guide. Vienna: United Nations Office, 2013b. Disponível em:< https://www.unodc.org/documents/corruption/Publications/2013/13-84498_Ebook.pdf >. Acesso em: 15 abr. 2019.

[35] Wanderer, Luiz Carlos. A Validação e a Aderência à Implementação do Programa de Compliance no Sistema de Crédito Cooperativo (Sicredi). 144 f. Dissertação (Mestrado)

[36] - Programa de Pós-Graduação em Administração da Universidade Federal do Rio Grande do Sul, Porto 


\section{Alegre, 2017.}

[37] Xavier, Deiverson Felipe Souza; Costa, Pereira Dáphine; Almeida, Luiz Osvaldo Vilar de. Compliance uma ferramenta estratégica para a segurança das informações nas organizações. In: Simpósio Internacional de Gestão de Projetos, Inovação e Sustentabilidade. Anais do Vi Singep - São Paulo 13 - 14 Nov. 2017.

[38] Zapatero, Luiz Arroyo; Martín, Adán Nieto. El Derecho Penal Económico La Era Compliance. Valência: Tirant Lo Blanch, 2013. 


\section{Capítulo 18}

O desempenho da exportação do açúcar no Porto de Santos e Paranaguá: E o advento do Apocalipse tecnológico, para os portuários em uma sociedade 5.0

\section{Miriam Barbosa Soares}

Resumo: Com o avanço da tecnologia em especial, da combinação entre automação e inteligência artificial, modificará radicalmente a economia global e fará com que empregos desapareçam em escala massiva. Com a demanda crescente da logística 4.0, nascerá a sociedade 5.0 para alocar as pessoas na era da inteligência artificial, e com isso os portuários precisarão buscar tais recursos tecnológico para se adequar nos portos atuantes. 0 Açúcar é um commodities que tem sido exportado pelo porto de Santos e pelo porto de Paranaguá de modo operante diferentes, porém, tendo um ótimo recorde em suas movimentações. 0 artigo teve como objetivo analisar a logística 4.0, a nova ordem mundial para ter competitividade no comércio global, e verificar o desempenho na atividade da movimentação do porto de Santos e do porto de Paranaguá entre os anos de 2012 à 2019. E o objetivo específico identificar quais os efeitos causados dessa era apocalíptica tecnológica na área portuária e socioeconômica, exatamente dentro de uma sociedade 5.0 que está sendo organizada. A Metodologia aplicada foi pesquisa explicativa, "aprofunda o conhecimento da realidade porque explica a razão, o porquê das coisas." (GIL, 2010, p. 28), além de ser exploratória, descritiva e bibliográfica documental, baseados nos dados estatísticos de órgão oficiais do Estado.

Palavras-chave: Apocalíptica. Logística 4.0. Porto de Santos. Sociedade 5.0. 


\section{INTRODUÇÃO}

O Brasil é o maior produtor de açúcar da produção mundial. Gerando para a balança comercial um valor de superávit de US\$1,078 bilhão, resultado de exportações no valor de US\$ 4,590 bilhões. Com a nova ordem mundial, a tecnologia 4.0 fica mais atraente para o mundo dos negócios.

A vantagem de usar a logística 4.0, será determinada pela capacidade da flexibilidade, o planejamento sucessivo e a produção e o consumo da competitividade. Outra vantagem é que grandes estoques e centros de distribuição podem funcionar com agilidade e precisão, tendo o transporte integrado e gerenciado em tempo real a Logística 4.0 veio para automatizar processos com tecnologias e sistemas inteligentes, que têm a capacidade de reunir dados e conectar pessoas, redes e máquinas. Dessa forma, é possível eliminar erros e desperdício, além de poupar tempo e reduzir custos.

Com o avanço da tecnologia - em especial, da combinação entre automação e inteligência artificial mudará radicalmente a economia global e fará com que empregos desapareçam em escala massiva, chamado apocalipse da tecnologia.

0 artigo teve como objetivo analisar a logística 4.0, a nova ordem mundial para ter competitividade no comércio global, e verificar o desempenho na atividade da movimentação do porto de Santos e do porto de Paranaguá entre os anos de 2012 à 2019. E o objetivo específico identificar quais os efeitos causados dessa era apocalíptica tecnológica na área portuária e socioeconômica, exatamente dentro de uma sociedade 5.0 que está sendo organizada. A Metodologia aplicada foi pesquisa explicativa, "aprofunda o conhecimento da realidade porque explica a razão, o porquê das coisas." (GIL, 2010, p. 28), além de ser exploratória, descritiva e bibliográfica documental, baseados nos dados estatísticos de órgão oficiais do Estado.

\section{EMBASAMENTO TEÓRICO OU REVISÃO DA LITERATURA}

O Açúcar é um commodities que tem sido exportado pelo porto de Santos e pelo porto de Paranaguá de modo operante diferentes, porém, tendo um ótimo recorde em suas movimentações. De acordo com ADVFN, (2019), o Brasil, é o maior produtor de Açúcar mundial.

O Brasil exportou cerca de 1,82 milhão de tonelada de açúcar em Julho do ano de 2019, o que representa um aumento de 19,7\% (CONAB, 2019).

Os principais países de destino do açúcar brasileiro nos quatro primeiros meses da Safra 2019/20 foram: China (837,6 mil ton.); Argélia (831,4 mil ton.); Arábia Saudita (479,3 mil ton.); Bangladesh (447,3 mil ton.) e Emirados Árabes Unidos (392,8 mil ton.) (CONAB, 2019).

O PIB (Produto Interno Bruto) avançou 0,4\% no período em relação aos três meses imediatamente anteriores. A economia brasileira melhorou no segundo trimestre de 2019, segundo o IBGE (2019), Instituto Brasileiro de Geografia e Estatística. A Balança Comercial foi superávit de US\$1,078 bilhões.

Gráfico 1- Destino do açúcar Brasileiro Safra 2019 e 2020

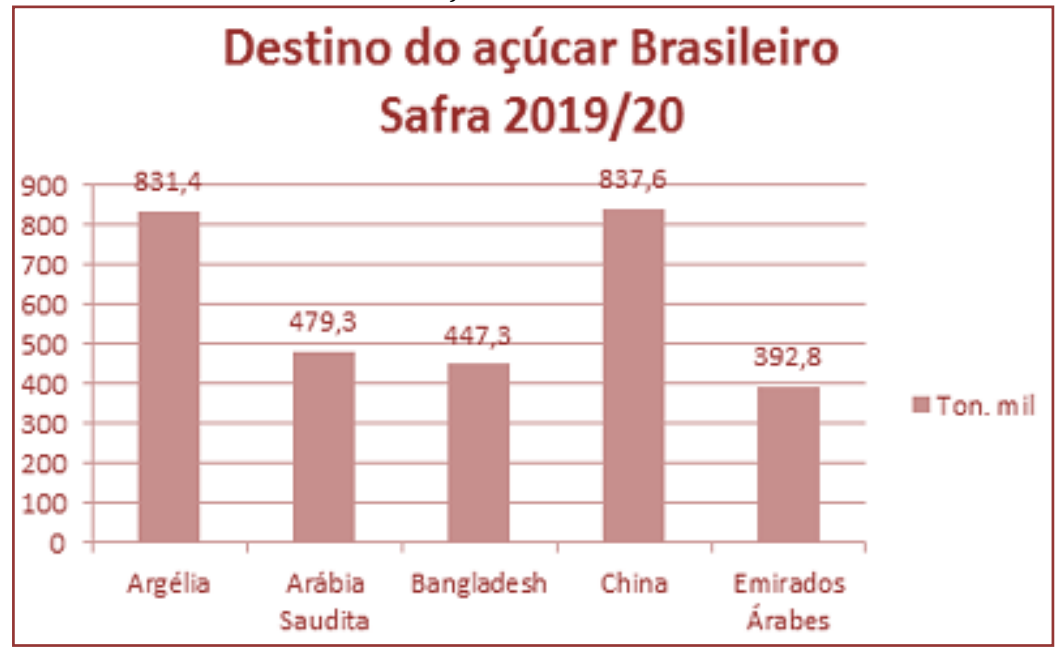

Fonte: CONAB, (2019) 
Com base nos dados avaliados da CONAB (2019), o gráfico 1, indica o destino em tonelada da safra do açúcar de 2019/20. 0 maior destino de açúcar segue para a China com 837,6 mil toneladas.

\subsection{O AÇÚCAR NO PORTO DE SANTOS}

O início da ocupação no estuário santista ocorreu em 1532, com o português donatário da capitania de São Vicente, Martin Afonso de Sousa, ao aportar na atual Barra Grande, na Ilha de São Vicente, local onde implantou o primeiro ancoradouro do estuário, (CODESP, 2017e).

Em Santos, a expansão da ocupação junto ao mar em decorrência da atividade portuária fortaleceu o vínculo entre o porto e o povoamento da região (ORNELAS, 2008). A relação mostrou-se fundamental para a consolidação de ambas as estruturas, levando a uma posterior elevação do povoado à categoria de Vila do Porto de Santos em 1546, e à instalação da Alfândega em 1550, (CODESP, 2017f).

O aumento da produção açucareira no interior paulista no fim do século 18, somado ao fato de o Porto de Santos ser o único da Capitania de São Paulo em funcionamento na época, resultou num incremento da operação de açúcar no Porto no início do século 19, alterando o cenário de estagnação. A construção da primeira via de ligação entre o litoral e a capital, a "Calçada do Lorena", em 1792, também contribuiu no processo de escoamento do produto, expandindo as atividades do Porto (ARAÚJO FILHO, 1969 apud ORNELAS, 2008, p. 54).

Algumas das vantagens do açúcar no embarque a carga granel está na velocidade da operação, pois embarca mais quantidade em menos tempo, elimina as despesas com embalagens, economiza nas despesas com mão de obra braçal, dentre outras.

A movimentação de açúcar por via marítima no mês de Julho de 2012, no porto de Santos, somatória de (longo curso e cabotagem) foi de 1.603.679 toneladas (CODESP, 2012)

Já em Julho de 2019, foram movimentados pela via marítima, (cabotagem e longo curso), 1.163.638 toneladas de açúcar no porto de Santos (CODESP, 2019).

Gráfico 2- Movimentação do Açúcar no Mês de Julho de 2012 e 2019, no Porto de Santos.

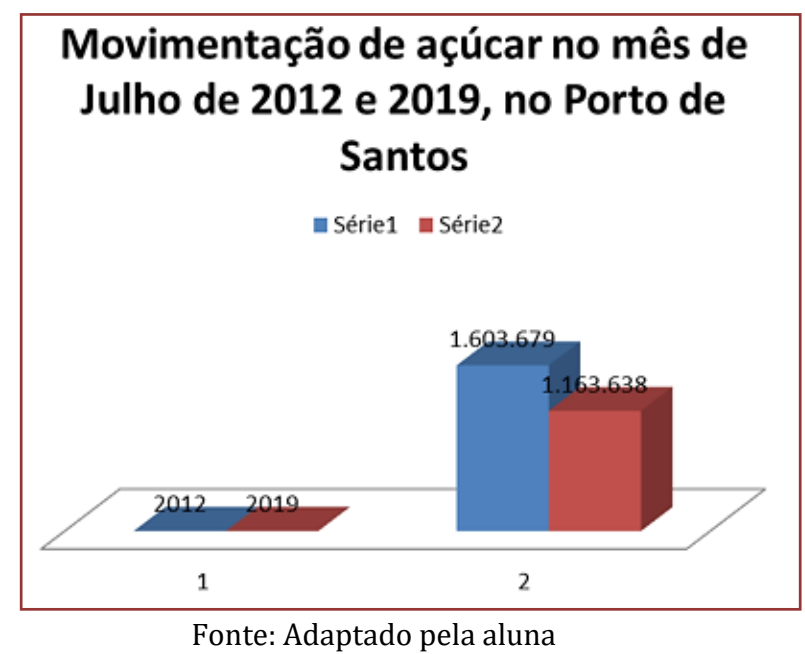

Com base nas estatísticas, adaptado pela aluna, Gráfico 2, indica a movimentação do açúcar no mês de Julho de 2012 e 2019, no porto de santos, resultando o valor do ano de 2012 foi maior, por conta da mão de obra, dos trabalhadores avulsos daquela época. Cada embarcação levava, em média, 80 mil sacos de 50 quilos, num total aproximadamente de 2.424 lingadas feitas no costado e desfeitas no porão para estivagem do mesmo.

As operações convencionais o qual é ensacado e carregado para o navio em uma lingada (os sacos são presos por uma faixa de lona, pendurada em um gato içadas por um guindaste).

Os guindastes do ano de 2012, não suportavam mais de 80 sacas por movimento e somente três estavam em funcionamento no ponto 12 para a operação, o equipamento utilizado para o içamento das sacarias era 
um mhc que tem capacidade para movimentar 600 sacas ou mais por içamento , o que não ocorria , pois para o equipamento ser usado em sua plenitude precisaria que as lingadas ja viessem prontas das usinas .0 veiculo da época poderia trazer sua carga estivada em quatro lingadas o que tornaria ágil a operação. (CAP, 2011)

\subsection{AÇÚCAR NO PORTO DE PARANAGUÁ}

o Complexo Portuário de Paranaguá e Antonina é composto pelo Porto Organizado de Paranaguá, pelo Porto Organizado de Antonina, pelo TUP Cattalini e pelo TPPP, doravante TUP. Os portos de Paranaguá e Antonina são administrados pela mesma entidade, a Administração dos Portos de Paranaguá e Antonina (APPA), uma empresa pública instituí da pela Lei Estadual no 17.895/2014, Decreto no 11.562/2014. Atualmente, a APPA é responsável por gerir os Portos Organizados paranaenses por meio do Convênio de Delegação no 037/2001, celebrado em 11 de dezembro de 2001 entre o Estado do Paraná e a União, com validade de 25 anos, e que vigorará até 1 o janeiro de 2027, com possibilidade de prorrogação,

Sobre a infraestrutura portuária destaque-se que o Porto de Paranaguá, por estar situado em uma baía, é abrigado naturalmente, conferindo segurança às embarcações que chegam ao porto. Sendo assim, não existem quaisquer obras de abrigo em Paranaguá. (MDIC, 2018).

o Porto dispõe de um Cais Público acostável, contínuo e com 3.131 metros de extensão, distribuídos em 14 berços de atracação. Dispõe, também, de um ponto de atracação para operações Roll-on/Roll-off (RoRo), sendo este composto por três dolfins de atracação e um de amarração. Ao todo são aproximadamente 3.400 metros acostáveis no Cais Público do Porto de Paranaguá. (MDIC, 2018)

Segundo o plano mestre de Paranaguá (2018), o Porto também conta com um terminal arrendado denominado Terminal Portuário Ponta do Félix (TPPF), que possui cais com 360 metros de extensão contemplando os berços 102 e 103, profundidade atual de 9,1 metros e área total de $263.824 \mathrm{~m}^{2}$

Os armazéns existentes na poligonal do Porto Organizado de Paranaguá de açúcar ensacado, está localizado na 6 A e B, operando pela TEAPAR e é um terminal arrendado.

De acordo com o APPA (2019), o qual administra o Porto de Paranaguá e Antonina resultou na sua estatística do mês de Julho do ano de 2019, 361.664 toneladas de açúcar. Já no ano de 2012, teve 590.797 toneladas movimentadas no porto.

0 açúcar ensacado, movimentado pelo TEAPAR, no Porto de Paranaguá, tem origem no oeste paulista e destina-se, principalmente, à África e países onde não existem ou são escassas as refinarias de açúcar e cujos portos não possuem instalações modernas para recebimento de grandes navios.

Segundo Antaq (2016), o Porto de Paranaguá foi responsável pela exportação de 403 mil toneladas, enquanto que o Porto de Antonina movimentou as 124 mil toneladas restantes.

Tabela 1 - Movimentação de açúcar em Julho de 2012

\begin{tabular}{|c|c|c|}
\hline \multicolumn{3}{|l|}{ EXPORTAÇÃo } \\
\hline & JUL12 & ACUM. ANO \\
\hline MERCADORIAS & TON. & TON. \\
\hline AÇUCAR & 590.797 & 2.040 .574 \\
\hline CONGELADOS & 102.490 & 842.533 \\
\hline DERIV. PETRÓLĒ & 111.895 & 596.993 \\
\hline FARELOS & -400.780 & 3.033 .610 \\
\hline MADEIRA & $34.5 \overline{7} 0$ & $310.53 \overline{3}$ \\
\hline MILHO & 492.385 & 1.360 .112 \\
\hline OLEŌ VE $\bar{E} \bar{E} \overline{T A L}$ & 98.189 & $\overline{6} 62.412$ \\
\hline PAPELIDERIV. & -19.645 & 194.605 \\
\hline SOJA & 626.343 & 5.635 .388 \\
\hline TRIGO & & 469.634 \\
\hline VEICULŌos & 5.240 & 59.483 \\
\hline OUTROS & 138.708 & 940.492 \\
\hline TOTAL & 2.621 .042 & 16.146 .370 \\
\hline APOIO (AGUA+COMB.) & 36.995 & 273.031 \\
\hline
\end{tabular}

Fonte: APPA (2012)

Com base nas estatísticas APPA (2012), na tabela1, indica a movimentação do açúcar referente ao mês de Julho de 2012, resultando em 590.797 ton. e o acumulado de 2.040.574 ton. 
Tabela 2 - Movimentação de açúcar em Julho de 2019

\begin{tabular}{|c|c|c|c|c|}
\hline \multicolumn{5}{|c|}{ RESUMO POR MERCADORIA } \\
\hline MERCADORIA & Julho.19(T) & Acum. 2019 (t) & Acum. $2018(\mathrm{t})$ & $\%$ \\
\hline MILHO & 945.398 & 3.123 .789 & 677.554 & $361 \%$ \\
\hline SOJA & 981.582 & 6.729 .995 & 9.143 .596 & $-26 \%$ \\
\hline FARELOS & 456.201 & 3.189 .245 & 3.669 .144 & $-13 \%$ \\
\hline AÇÚCAR (gr. + sc.) & 361.664 & 1.266 .527 & 1.630 .653 & $-22 \%$ \\
\hline ÓLEOS VEGETAIS & . & 433.848 & 768.630 & $-44 \%$ \\
\hline
\end{tabular}

Fonte: APPA (2019)

Com base nos dados avaliados da APPA (2019), na tabela 2, indica a movimentação de açúcar referente ao mês de Julho do ano de 2019, resultando em 361.664 toneladas, e o saldo acumulativo de 1.266.527. Sua redução foi de - 22\%, analisados do ano de 2018 .

Gráfico 3 - Distribuição Mensal da Movimentação de Açúcar no Porto de Paranaguá em 2012 (ton.)

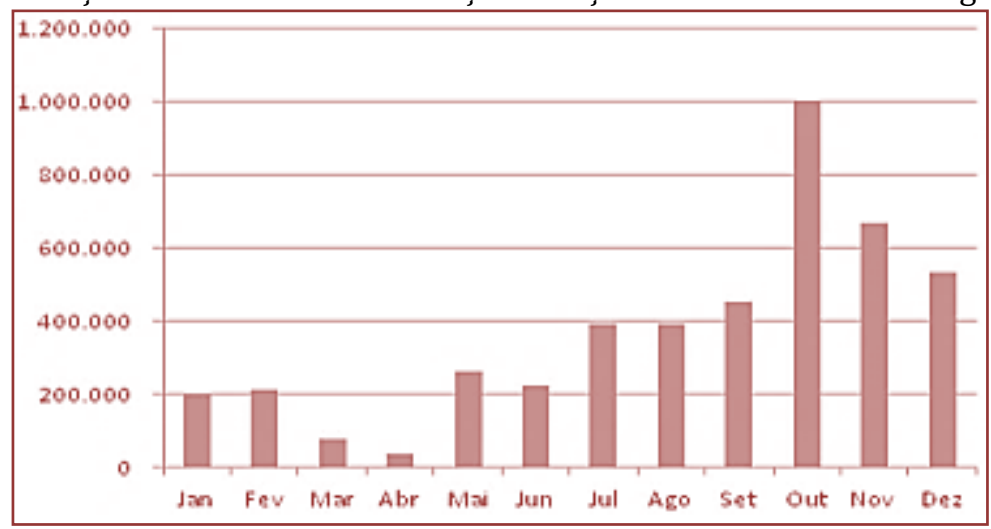

Fonte: SECEX/MDIC; Elaborado por LabTrans (2019)

Com base nos dados avaliados da SECEX/MDIC (2019), o gráfico 3, indica a Distribuição mensal da movimentação de açúcar no Porto de Paranaguá no ano de 2012, e a análise, indicou que foi no mês de Outubro, com sua maior distribuição com 1milhão de toneladas de açúcar, embarcado o produto do terminal da PASA, no berço 204 (MDIC, 2019).

\section{A LOGÍSTICA 4.0}

A Logística 4.0 é a nova ordem mundial para ter competitividade no comércio global. ( PORTOGENTE, 2016)

Através dela, os movimentos dos produtos e informações da indústria 4.0, serão utilizadas máquinas controladas por computadores, robotização de linhas de produção, impressões tridimensionais para a fabricação de produtos, bem como componentes para a produção inteligente. As necessidades de se acompanhar as tendências, se dá a nova ordem mundial que tem como um padrão a ser seguido, (ELLENCE, 2016).

Os principais objetivos da Logística 4.0 estão a integração e a automatização dos processos e a otimização do compartilhamento de dados, que, por meio do cloudcomputing, são armazenados na nuvem, atualizados constantemente e podem ser acessados a todo momento, por dispositivos diferentes e em qualquer lugar. Viabilizando a conexão simples e rápida entre máquinas, redes, pessoas e agentes da cadeia logística, constrói-se um fluxo operacional eficiente e autônomo, (PORTALIC,2019).

A vantagem de usar a logística 4.0, será determinada pela capacidade da flexibilidade, o planejamento sucessivo e a produção e o consumo da competitividade. 0 logística portuária por sua vez, aumentara as 
expectativa na redução da perda de ativos, economia nos custos de combustível, gerenciamento de estoque do armazém, e a eficiência de frotas de navios. A eficiência operacional, crescerá na medida que a internet das coisas (IOT), se conectar com aos embarques de navios. (ELLENCE, 2016)

Alguns benefícios da Logística 4.0, serão:

a) Redução da perda de ativos, conhecer os problemas dos produtos em tempo para encontrar uma solução.

b) Economia de custos de combustível - otimizar rotas de frota, monitorando as condições de tráfego.

c) Garantia da estabilidade de temperatura - monitorar resfriamento que, de acordo com o Ministério da Agricultura dos Estados Unidos, cerca de um terço dos alimentos perecem em trânsito a cada ano.

d) Gerenciamento do estoque do armazém - monitorar inventários em situações de peças fora do estoque.

e) Identificação da visão do usuário, sensores incorporados fornecem visibilidade sobre o comportamento do cliente e uso do produto e criação da eficiência de frotas - reduzir as redundâncias (ELLENCE, 2016).

Segundo Portolic (2019) a Logística 4.0 veio para automatizar processos com tecnologias e sistemas inteligentes, que têm a capacidade de reunir dados e conectar pessoas, redes e máquinas. Dessa forma, é possível eliminar erros e desperdício, além de poupar tempo e reduzir custos. Outra vantagem é que grandes estoques e centros de distribuição podem funcionar com agilidade e precisão, tendo o transporte integrado e gerenciado em tempo real.

Na revolução Industria 4.0, denota mudança abrupta e radical. Revolução a Nova tecnologia, desencadeando uma alteração profunda na estrutura social e sistema econômico, os pontos positivos, foi a benefício tecnológico, (Startups), blockchain, fusão no mundo físico, digitais, biológicos, e na comunicação. (KLAUS SCHWAB, 2015)

Os pontos negativos também trouxeram reflexos nos setores transporte marítimo e consequentemente na área portuária, e aumentará esse reflexo na desigualdade, produção e trabalho efeito plataforma, a economia global, envelhecimento, com a automação no porto, os equipamentos na área retro portuária será substituída por equipamento robótico (Porto de Rotterdã) o qual a, tecnologia é LGV, primeiro do mundo (KLAUS SCHWAB, 2015).

No porto de Santos, em num futuro próximo, não haverá mais mão de obra, isso acarretará demissão em massa, dos operadores. Pode ser compensado essa negatividade, qualificando os operadores em cursos tecnológico adequado, para não perder emprego.

\subsection{APOCALIPSE TECNOLÓGICO}

Antonio Garcia Martínez, de 40 anos (Ex executivo do facebook), vivia no epicentro da revolução digital, mais precisamente no Vale do Silício, região próxima de San Francisco, nos Estados Unidos, onde estão as sedes de algumas das principais empresas de tecnologia do mundo. Mas desde 2015 ele mudou radicalmente de vida ao chegar à conclusão que estaríamos prestes a enfrentar um "apocalipse tecnológico". Martínez afirma que o avanço da tecnologia - em especial, da combinação entre automação e inteligência artificial - mudará radicalmente a economia global e fará com que empregos desapareçam em escala massiva (BBC, 2017).

De acordo Garcia Martínez (2017), "Dentro de 30 anos, metade da humanidade não terá trabalho. E a coisa pode ficar feia, pode haver uma revolução. É por isso que estou aqui".

\subsection{IMPACTO SOCIOECONÔMICO}

A Sociedade 5.0 é uma revolução silenciosa, quase não discutida, nasce no Japão, mas já se espalha pelo mundo.

Em abril de 2016, o governo japonês decretou o 5o Plano Básico de Ciência e Tecnologia, um projeto que tem como intuito promover a inovação e a internacionalização. E um dos pontos desse plano, é justamente o desenvolvimento de uma sociedade comum, para uma sociedade super inteligente, a sociedade 5.0 (ACTIVA ID, 2019). 
Dos entrevistados que participaram do estudo, $56 \%$ consideram que as grandes empresas de tecnologia não se preocupam como deveriam na hora de preparar a sociedade para os avanços que promovem. No Brasil a quantidade é mais alta, subindo para $63 \%$, ficando atrás apenas das pessoas questionadas no Reino Unido, com $64 \%$. Entre as sociedades que menos concordam com isso está a japonesa e a sulcoreana, respectivamente com $41 \%$ e $43 \%$ (TECNOMUNDO, 2019).

A Sociedade 5.0 tornará o mundo mais sustentável, criativo e diversificado. Um dos pilares da Sociedade 5.0 envolve a forma como o ser humano lida com a força de trabalho. Referindo-se ao modo como estamos habituados, Yoko (2019) cita que devemos nos concentrar em formas de desenvolver nossas habilidades sem deixar de lado as coisas que mais nos tornam humano.

De acordo com Mercado Eletrônico (2018), em uma entrevista com Yoko Ishikura (2019) - consultora do Fórum Econômico Mundial, membro executivo do conselho de Ciência, Tecnologia e Inovação do Governo Japonês e grande defensora da ideia - a Sociedade 5.0 tem três valores-chave: sustentabilidade, abertura e inclusão. Ela não será limitada a grupos de cientistas, engenheiros e empresários. Nesta revolução, todos estarão a bordo e participando ativamente. 0 fato é que a Sociedade 5.0 irá moldar as pessoas para que elas consigam se adaptar para viver em uma sociedade inteligente, onde tudo será possível realizar com 0 auxílio de uma tecnologia de conectividade e rastreabilidade (ACTIVA ID,2019).

\section{RESULTADOS E DISCUSSÃO}

Na seção 1, Com base nos dados avaliados da CONAB (2019), o gráfico 1, podemos afirmar que o maior destino de açúcar foi para a China com o valor de 837,6 mil toneladas. O PIB (Produto Interno Bruto) avançou $0,4 \%$ no período em relação aos três meses imediatamente anteriores. A Balança Comercial foi superávit de US\$1,078 bilhões.

Já na seção 1.1 A comparativa da movimentação de açúcar por via marítima no mês de julho de 2012, podemos afirmar que foi muito maior que do ano de 2019, porque, a mão de obra avulsa era bem maior daquela época. Cada embarcação levava, em média, 80 mil sacos de 50 quilos, num total aproximadamente de 2.424 lingadas feitas no costado e desfeitas no porão para estivagem do mesmo. Maior que a do guindaste

Os guindastes do ano de 2012, não suportavam mais de 80 sacas por movimento e somente três estavam em funcionamento no ponto 12 para a operação, o equipamento utilizado para o içamento das sacarias era um mhc que tem capacidade para movimentar 600 sacas ou mais por içamento , o que não ocorria

Na seção1.2, Segundo Antaq (2016), o Porto de Paranaguá foi responsável pela exportação de 403 mil toneladas, enquanto que o Porto de Antonina movimentou as 124 mil toneladas restantes.

Em decorrência do que foi apresentado na seção 2 os resultados, a análise da logística 4.0, no âmbito portuário, aumentara as expectativa na redução da perda de ativos, economia nos custos de combustível, gerenciamento de estoque do armazém, e a eficiência de frotas de navios. A eficiência operacional, crescerá na medida que a internet das coisas (IOT), se conectar com aos embarques de navios. (ELLENCE, 2019)

No âmbito apocalipse tecnológico, seção 2.1, Martínez afirma que o avanço da tecnologia - em especial, da combinação entre automação e inteligência artificial - mudará radicalmente a economia global e fará com que empregos desapareçam em escala massiva.(BBC, 2017)

No tocante do impacto socioeconômico, seção 2.2, podemos firmar que: que os $56 \%$ consideram que as grandes empresas de tecnologia não se preocupam como deveriam na hora de preparar a sociedade para os avanços. E no Brasil a quantidade é mais alta, subindo para 63\% (TECNOMUNDO, 2019).

No tocante da sociedade 5.0,seção 2.2, podemos afirmar que segundo a YOKO, a Sociedade 5.0 tornará o mundo mais sustentável, criativo e diversificado. 0 fato é que a Sociedade 5.0 irá moldar as pessoas para que elas consigam se adaptar para viver em uma sociedade inteligente, onde tudo será possível realizar com o auxílio de uma tecnologia de conectividade e rastreabilidade. 


\section{CONSIDERAÇÕES FINAIS}

Nesta investigação, o Desempenho da exportação do açúcar no porto de Santos e Paranaguá e os efeitos do advento do apocalipse tecnológico, para os portuários, numa sociedade 5.0.

Agora é possível afirmar com a o avanço da tecnológica, e os efeitos causados da era apocalíptica será apavorante, trazendo demissão em massa, tanto na área portuária, pelo fim da mão de obra avulsa (Ogmo), já que tudo será automatizada com e com inteligência artificial, e os portuários precisarão de submeter as novas qualificações para se adaptar nessa nova tecnologia, dentro dessa nova sociedade, imposta pela nova ordem mundial para ter competitividade no comércio global o qual esta sendo desenvolvido em uma sociedade comum: a inovação e a internacionalização para uma sociedade super inteligente, a sociedade 5.0.

Esta pesquisa servirá como base para futuros estudos com uma estrutura para a exploração da inteligência artificial.

\section{REFERÊNCIAS}

[1] Gutierreza, Bruno. Debate A Tecnologia e o Futuro na mão de Obra no Porto de Santos - A Tribuna. Santos. 8 de Out.2018. Seção: Morto e mar. Disponível em: https://www.atribuna.com.br/trieventos/portomar/painel-debatea-tecnologia-e-o-futuro-da-m\%C3\%A3o-de-obra-no-porto-de-santos-1.57090 Acesso em: 24 ago. 2019

[2] A Tribuna Santos. Maior Terminal Automatizado de Contêineres do Mundo Inicia Testes. A Tribuna, Santos, 8 de Out. 2019. Seção: Porto e Mar. Disponível em: https://www.atribuna.com.br/2.713/maior-terminal-automatizadode-cont\%C3\%AAineres-do-mundo-inicia-testes-1.39628. Acesso em: 24 ago. 2019

[3] Advfn. Portal de Investimentos em Ações da Bolsa de Valores do Brasil, com Cotações da Bovespa e BM\&F. Investimento commodities açúcar. Disponível em:

https://br.advfn.com/investimentos/commodities/acucar/introducao Acesso em: 28 ago. 2019

[4] Codesp. Estatística documentos pdf.Disponível em:

http://intranet.portodesantos.com.br/docs_codesp/doc_codesp_pdf_site.asp?id=1231 Acesso em : 08 set. 2019

[5] Depec. Economia em dia. Disponível em:

https://www.economiaemdia.com.br/EconomiaEmDia/pdf/infset_acucar_etanol.pdf Acesso em: 28 ago. 2019

[6] Ellence Logisitca. Logística 4.0 o futuro é agora. Disponível em: https://www.ellecelogistica.com.br/logistica4-0-o-futuro-e-agora/. Acesso em: 24 de ago. 2019

[7] Ibge. Pib explicação. Instituto Brasileiro Geográfico e Estatístico. Disponível em: >> https://www.ibge.gov.br > explica > pib >> Acesso em>> 06 set. 2019.

[8] Joresimão. Blogspot. Disponível em: http://joresimao.blogspot.com/2010/04/ Acesso em: 28 ago. 2019

[9] Klaus Schwab. A Quarta Revolução Industrial. Edipro, 2015.

[10] Mdci. Planos mestre versão completa. Ministério do Desenvolvimento Infraestrutura. Disponível em: http://infraestrutura.gov.br/images/planos-mestres-versao-completa/pm22.pdf. Acesso em: 08 set. 2019

[11] Mtpa. Planejamento portuário, planos mestre. Ministérios dos Transportes, Portos e Aviação Civil - Ministro. Disponível em:

https://infraestrutura.gov.br/images/SNP/planejamento_portuario/planos_mestres/versao_preliminar/vp29v2.pdf Acesso em: 28 agosto de 2019

[12] Folha De São Paulo. Pib do Brasil Cresce 04\% no 2o Trimestre diz IBGE - Folha de São Paulo - Rio de janeiro e São Paulo 29 de Ago.2019. Seção: Mercado. Disponível em: https://www1.folha.uol.com.br/mercado/2019/08/pibdo-brasil-cresce-04-no-2o-trimestre-diz-ibge.shtml Acesso em: 14 Out. 2019

[13] Portogente. Notícias Logística 4.0. Disponível em: https://portogente.com.br/noticias/dia-a-dia/91467logistica-4-0 Acesso em: 24 agosto de 2019

[14] Porto de Paraná. Listagem de estatística operacional. Disponível em: http://www.portosdoparana.pr.gov.br/Operacional/listagem-de-estatisticas Acesso em: 08 set. 2019

[15] Portolic. Mercado de locação industrial logística 4.0 a inovação no setor. Disponível em: https://www.portalic.com.br/blog/mercado-de-locacao-industrial/logistica-4-0-a-inovacao-no-setor/ Acesso em: 07 Set.2019

[16] Revista Globo Rural. Globo rural, prevê açúcar produção de 282 mil de toneladas em 2019 e 2020. Disponível em: https://revistagloborural.globo.com/Noticias/Agricultura/Cana/noticia/2019/07/globo-rural-acucar-ismapreve-producao-de-282-mi-de-toneladas-em-20192020-na-india.html Acesso em : 28 ago. 2019 
[17] Tecnomundo. Mercado apocalipse tecnológico temido por 47 \% população mundial. Disponível em: https://www.tecmundo.com.br/mercado/142214-apocalipse-tecnologicotemido-47-populacao-mundial.htm Acesso em: 08 set. 2019

[18] Transbrasa. Porto de Santos precisa planejar automatização. Transitária Brasileira Ltda. Disponível em: https://www.transbrasa.com.br/o-porto-de-santos-precisa-planejar-automacao-visando-um-longo-prazo/ Acesso em: 24 ago. 2019

[19] Usp. Ronaldo Santos Ornelas PDF. Teses disponíveis dissertação. Disponível em: https://www.teses.usp.br/teses/disponiveis/8/8136/tde-10022009-

123934/publico/Dissertacao_Ronaldo_Santos_Ornelas.pdf Acesso em: 28 ago. 2019 


\section{Capítulo 19}

\section{Gestão e participação social na educação pública e}

conselhos gestores

\section{Alexandre de Freitas Carneiro}

Resumo: Com base na teoria da agência, o estudo busca delinear uma proposta mais efetiva de participação pelos Conselhos Gestores de Políticas Públicas de Educação, nos municípios e nos estados. Com base também na literatura atual sobre accountability social e engajamento cidadão, ao aliar ao já conhecidos orçamento participativo, sistema de custos no setor público, indicadores sociais, transparência, argumenta-se de forma complementar que deva-se criar um mecanismo de responsabilização ao governo que, ao deixar o mandato, obtiver os indicadores de eficiência e/ou do Ideb em queda, ou que apresentarem-se pior do que quando assumiu o seu mandato. Os Conselhos Gestores devem participar e acompanhar este processo, para o maior e devido empoderamento e representatividade. 0 estudo interessa aos gestores, contadores públicos, controle interno externo, aos conselheiros gestores, bem como aos cidadãos interessados na instrumentalização do controle social das contas públicas.

Palavras-chave: Controle social; Educação pública; Eficiência; Estados; Municípios. 


\section{INTRODUÇÃO}

Este estudo será útil para os conselheiros gestores estaduais de educação, que, segundo Gohn (2011), são inovações recentes e constituem espaço real de participação. Fiscalizados por eles, os gestores precisam aplicar o dinheiro público (recursos) atendendo aos princípios da economicidade, eficiência e eficácia de forma a cobrar mais resultados do setor público.

Esses conselhos são estratégicos para desenvolvimento social no século 21 (GOHN, 2011), são importantes instrumentos para a gestão compartilhada com a sociedade civil (OLIVEIRA; KEINERT, 2016) e, para ampliar e qualificar o processo de democratização da gestão pública, é fundamental o empoderamento nesses conselhos gestores de políticas públicas envolvendo pessoas e organizações, pois no nível estrutural desse empoderamento, pode-se desencadear sensibilização para recursos existentes (KLEBA; WENDHAUSEN, 2012), considerando-se que, atualmente esses recursos públicos estão ficando cada vez mais escassos na economia.

A Lei de Responsabilidade Fiscal, no seu artigo 49, explica que qualquer cidadão ou instituição, pode consultar e apreciar as contas do poder executivo, as quais ficam a disposição no órgão de sua elaboração, bem como no poder Legislativo (DIAS; VASCONCELOS, 2015). Sendo assim, qualquer cidadão, participante ou não de conselhos municipais ou gestores podem vir a solicitar informações quanto à utilização de recursos nas mais diversas áreas da administração pública.

Este ensaio, embasado em teorias consolidadas, busca delinear uma proposta mais efetiva de participação pelos Conselhos Gestores de Políticas Públicas de Educação (CGPPE), nos municípios e nos estados.

\section{OS CONSELHOS GESTORES}

Os conselhos gestores municipais foram instituídos para colaborar na fiscalização e acompanhamento dos gastos públicos. Através destes, os cidadãos podem atuar de forma efetiva junto á implementação de leis e ainda fiscalizarem se os recursos estão sendo aplicados de forma coerente. Na Constituição Federal de 1988 é mencionada a participação cidadã com a formação dos conselhos gestores, juntamente com o Estatuto da Cidade estimulando a gestão participativa nos conselhos.

A cartilha olho vivo (CGU, 2009) mostra alguns conselhos, suas atribuições e sua composição, que são indispensáveis para o bom desenvolvimento social e melhor distribuição dos recursos recebidos das esferas municipais e estaduais (Quadro 1).

Quadro 1 - Atribuições e Composições dos Conselhos de acordo com CGU.

\begin{tabular}{|c|c|c|}
\hline Conselho & Atribuições & Composição \\
\hline $\begin{array}{l}\text { Alimentação } \\
\text { Escolar }\end{array}$ & $\begin{array}{l}\text { - Controla o dinheiro para a merenda. Parte da } \\
\text { verba vem do Governo Federal. A outra parte vem } \\
\text { da prefeitura. } \\
\text { - Verifica se o que a prefeitura comprou está } \\
\text { chegando às escolas. } \\
\text { - Analisa a qualidade da merenda comprada. } \\
\text { - Examinar se os alimentos estão bem guardados e } \\
\text { conservados. } \\
\text { - Deve se reunir frequentemente. }\end{array}$ & $\begin{array}{l}\text { - representante da prefeitura. } \\
\text { - representante da câmara municipal. } \\
\text { - representantes dos professores. } \\
\text { - representantes de pais de alunos. } \\
\text { - representante de um sindicato ou } \\
\text { associação rural. (cada órgão ou entidade } \\
\text { indica seu representante). }\end{array}$ \\
\hline Saúde & $\begin{array}{l}\text { - Controla o dinheiro da saúde. • Acompanha as } \\
\text { verbas que chegam pelo Sistema Único de Saúde } \\
\text { (SUS) e os repasses de programas federais. } \\
\text { - Participa da elaboração das metas para a saúde. } \\
\text { - Controla a execução das ações na saúde. } \\
\text { - Deve se frequentemente. }\end{array}$ & $\begin{array}{l}\text { - Representantes das pessoas que usam o } \\
\text { Sistema Único de Saúde. } \\
\text { - Profissionais da área de saúde (médicos, } \\
\text { enfermeiras). } \\
\text { - Representantes de prestadores de } \\
\text { serviços de saúde (hospitais particulares). } \\
\text { - Representantes da prefeitura. }\end{array}$ \\
\hline
\end{tabular}




\section{(Continuação)}

Quadro 1 - Atribuições e Composições dos Conselhos de acordo com CGU.

\begin{tabular}{|c|c|c|}
\hline Conselho & Atribuições & Composição \\
\hline FUNDEB & $\begin{array}{l}\text { - Examina os gastos realizados com recursos do } \\
\text { Programa. } \\
\text { - Supervisiona o Censo Escolar Anual e a laboração } \\
\text { da proposta orçamentária anual, com objetivo de } \\
\text { concorrer para o regular e tempestivo tratamento e } \\
\text { encaminhamento dos dados estatísticos e } \\
\text { financeiros. } \\
\text { - Acompanhar a aplicação dos recursos do } \\
\text { Programa Nacional de Apoio ao Transporte Escolar } \\
\text { (PNATE) e ao Programa de Apoio aos Sistemas de } \\
\text { Ensino para Atendimento à Educação de Jovens e } \\
\text { Adultos e ainda receber e analisar as prestações de } \\
\text { contas, referente esses programas, formula } \\
\text { pareceres conclusivos sobre a aplicação desses } \\
\text { recursos e encaminha-os ao Fundo Nacional de } \\
\text { Desenvolvimento da Educação (FNDE). }\end{array}$ & $\begin{array}{l}\text { - Representantes do Poder Executivo } \\
\text { Municipal (Prefeitura), dos quais pelo } \\
\text { menos } 1 \text { deles da Secretaria Municipal de } \\
\text { Educação ou órgão equivalente. } \\
\text { - Representantes dos professores da } \\
\text { educação básica pública. } \\
\text { - Representante dos diretores das escolas } \\
\text { básicas públicas. } \\
\text { - Representante dos servidores técnico- } \\
\text { administrativos das escolas básicas } \\
\text { públicas. } \\
\text { - Representantes dos pais de alunos da } \\
\text { educação básica pública. } \\
\text { - Representantes dos estudantes da } \\
\text { educação básica pública, um é indicado por } \\
\text { entidade de estudantes secundaristas. } \\
\text { - Representantes do Conselho Municipal } \\
\text { de Educação } \\
\text { - Representante do conselho Tutelar da } \\
\text { Criança e do Adolescente, indicado por } \\
\text { seus pares, quando houver no Município. }\end{array}$ \\
\hline $\begin{array}{l}\text { Assistência } \\
\text { Social }\end{array}$ & $\begin{array}{l}\text { - Acompanha a chegada do dinheiro e a aplicação da } \\
\text { verba para os programas de assistência social. } \\
\text { - Aprova o plano de assistência social feito pela } \\
\text { prefeitura. }\end{array}$ & $\begin{array}{l}\text { - Representantes indicados pela prefeitura } \\
\text { e pelas entidades que fazem assistência } \\
\text { social no município, como creches, } \\
\text { associações de apoio ao adolescente, ao } \\
\text { idoso e associações comunitárias. }\end{array}$ \\
\hline
\end{tabular}

Fonte: Cartilha Olho vivo no dinheiro público da Controladoria Geral da União (2009).

A demonstração dos conselhos gestores por (CGU, 2009) representa a forma geral que deve ser utilizada pelos municípios para uma efetiva representatividade.

Já para Crepaldi e Crepaldi (2013), outros conselhos são aconselháveis para melhor transparência conforme o Quadro 2.

Quadro 2 - Conselhos Municipais de Controle Social

\begin{tabular}{|l|l|l|}
\hline \multicolumn{2}{|c|}{ Nome } & \multicolumn{1}{c|}{ Composição/caráter } \\
$\begin{array}{l}\text { Conselho Municipal dos } \\
\text { Direitos da Criança e do } \\
\text { Adolescente (CMDCA) }\end{array}$ & $\begin{array}{l}\text { Paritária, composta por membros do poder } \\
\text { público e sociedade civil (entidades e } \\
\text { movimentos populares). Deliberativo. }\end{array}$ & $\begin{array}{l}\text { Formular, controlar e fiscalizar as } \\
\text { políticas públicas sobre crianças e } \\
\text { adolescentes no município. }\end{array}$ \\
\hline $\begin{array}{l}\text { Conselho Municipal de } \\
\text { Assistência Social (CMAS) }\end{array}$ & $\begin{array}{l}\text { Paritária, composta por membros do poder } \\
\text { público e sociedade civil (entidades e } \\
\text { movimentos populares). Deliberativo. }\end{array}$ & $\begin{array}{l}\text { Definir e controlar a execução da } \\
\text { política de assistência social no } \\
\text { município. }\end{array}$ \\
\hline $\begin{array}{l}\text { Conselho Municipal dos } \\
\text { Diretos da Mulher (CMDM) }\end{array}$ & $\begin{array}{l}\text { Composto pelo poder público e sociedade } \\
\text { civil (a paridade é definida em lei municipal). } \\
\text { Deliberativo. }\end{array}$ & $\begin{array}{l}\text { Garantir os direitos da mulher do } \\
\text { município. }\end{array}$ \\
\hline $\begin{array}{l}\text { Conselho de Alimentação } \\
\text { Escolar }\end{array}$ & $\begin{array}{l}\text { Não paritária, composta pelo poder público e } \\
\text { profissionais da educação. }\end{array}$ & $\begin{array}{l}\text { Definir normas sobre alimentação } \\
\text { escolar e acompanhar o } \\
\text { desenvolvimento das ações. }\end{array}$ \\
\hline $\begin{array}{l}\text { Conselho Municipal de } \\
\text { Acompanhamento e } \\
\text { Controle do FUNDEB }\end{array}$ & Não paritária. Deliberativo. & $\begin{array}{l}\text { Analisar e proferir parecer sobre } \\
\text { gastos realizados com o Fundeb. }\end{array}$ \\
\hline $\begin{array}{l}\text { Conselho Municipal de } \\
\text { Saúde }\end{array}$ & $\begin{array}{l}\text { Composta por usuário se } 50 \% \text { por } \\
\text { profissionais de saúde, prestadores de } \\
\text { serviço e gestores. Deliberativo. } \\
\text { Regulamentado por lei federal e municipal. }\end{array}$ & $\begin{array}{l}\text { Definir a política publica de saúde } \\
\text { no município. }\end{array}$ \\
\hline
\end{tabular}




\section{(Continuação)}

\begin{tabular}{|l|l|l|}
\multicolumn{2}{|c|}{ Quadro 2 - Conselhos Municipais de Controle Social. } \\
\hline $\begin{array}{l}\text { Conselho Municipal de } \\
\text { Desenvolvimento Rural }\end{array}$ & $\begin{array}{l}\text { Composição paritária (poder público e } \\
\text { sociedade civil) função deliberativa. }\end{array}$ & $\begin{array}{l}\text { Definir políticas públicas para a } \\
\text { área rural do município. }\end{array}$ \\
\hline $\begin{array}{l}\text { Conselho Municipal do } \\
\text { Idoso }\end{array}$ & $\begin{array}{l}\text { Composição paritária (poder público e } \\
\text { sociedade civil) função deliberativa. }\end{array}$ & $\begin{array}{l}\text { Formular políticas públicas de } \\
\text { atendimento ao idoso. }\end{array}$ \\
\hline $\begin{array}{l}\text { Conselho Municipal de } \\
\text { Desenvolvimento do Meio } \\
\text { Ambiente (Condema) }\end{array}$ & $\begin{array}{l}\text { Composição dependente da lei municipal. } \\
\text { Deliberativo. }\end{array}$ & $\begin{array}{l}\text { Definir a política ambiental do } \\
\text { município. }\end{array}$ \\
\hline $\begin{array}{l}\text { Conselho Municipal do } \\
\text { Trabalho (Comut) }\end{array}$ & $\begin{array}{l}\text { Composição tripartite (trabalhadores, } \\
\text { empregadores e poder publico). } \\
\text { Deliberativo. }\end{array}$ & $\begin{array}{l}\text { Definir, acompanhar e fiscalizar as } \\
\text { ações de emprego e renda no } \\
\text { município. }\end{array}$ \\
\hline
\end{tabular}

Fonte: Crepaldi e Crepaldi (2013, p. 154-155).

Esses conselhos são de suma importância para uma boa gestão e controle social de todos os setores da administração pública.

\section{PARTICIPAÇÃO SOCIAL}

A participação social foi garantida e ampliada a partir da Constituição Federal de 1988. Segundo Matos e Dias (2013, p. 40), "Uma ampla participação contribui para a troca de informações necessárias para a efetiva tomadas de decisões e para a legitimidade dessas decisões". As informações sobre a eficiência técnica daquelas aplicações de recursos e sua relação com o IDH pode contribuir nesse processo, quando fornece mais ferramentas aos conselheiros. Mas para haver essa troca de informações e uma maior participação social deve haver uma maior transparência por parte do Estado e o devido processo de accountability. Este termo não tem o mesmo significado que transparência, embora esta seja uma das características da boa governança, segundo o Pnud.

Segundo a Controladoria Geral da União - CGU (2012), a transparência da gestão pública e das ações do governo depende portanto: da publicação de informações; de espaços para a participação popular na busca de soluções para problemas na gestão pública; da construção de canais de comunicação e de diálogo entre a sociedade civil e o governante; do funcionamento dos Conselhos, órgãos coletivos do poder público e da sociedade civil com o papel de participar da elaboração, execução e fiscalização das políticas públicas; da modernização dos processos administrativos, que muitas vezes, dificultam a fiscalização e o controle por parte da sociedade civil; da simplificação da estrutura de apresentação do orçamento público, aumentando assim a transparência do processo orçamentário.

Para Zuccolotto, Teixeira e Riccio (2015), o termo transparência tem sua origem no século XIX, mas é no século XX que seu uso tomou o significado que conhecemos hoje, relacionado à política e, mesmo que seu conceito seja cada vez mais encontrado na literatura acadêmica, seu significado ainda permanece fluido, pelo fato de esse conceito ser usado em vários aspectos relacionados ao fluxo de informações. Segundo esses autores, o conceito aplicado ao campo da administração pública entende-se como a gestão dos assuntos públicos para o publico, e concluem os autores que a definição de transparência está em construção.

Accountability é um termo da língua inglesa, sem tradução exata para o português, mas que pode ser entendido como o ato de prestação de contas de forma responsável. Pinho e Sacramento (2009) dizem que ao buscar em dicionários a tradução para o português do termo accountability, pode-se observar que o conceito envolve responsabilidade (objetiva e subjetiva), controle, transparência, obrigação de prestação de contas, justificativas para as ações que foram ou deixaram de ser empreendidas.

Pode-se entender a accountability como um processo de avaliação e responsabilização permanente dos agentes públicos, que abrange tanto os eleitos quanto os nomeados e os de carreira, em razão do múnus público que lhes é delegado pela sociedade (Rocha, 2011). É saber o que os agentes públicos estão fazendo, como estão fazendo, que consequências resultam das suas ações e como estão respondendo por isso (ROCHA, 2011). 
Nakagawa, Relvas e Dias Filho (2007) asseguram que a noção de accountability no setor público deve centrar-se nos seguintes objetivos: 1) dar explicações a todos os cidadãos, sejam eles eleitores ou não; 2) prover informações posteriores sobre fatos relevantes, quando se tornarem necessárias; 3) rever e, se necessário, revisando sistemas ou práticas para atingir as expectativas dos cidadãos sejam eles eleitores ou não; e 4) conceder compensações ou impondo sanções.

Portanto, accountability tem um conceito mais amplo do que quando se pensa em obedecer a legislação, prestar contas e ser transparente, deve haver o desejo de informar tempestiva e corretamente, com os erros e os acertos da gestão, com justificativas de ações não realizadas, numa linguagem em que o cidadão leigo possa entender.

Menezes e Ronconi (2019) discutem o conceito de Accountability Social e Engajamento Cidadão. Em seu trabalho tiveram por objetivo analisar como os Conselhos Locais de Saúde de Florianópolis, estado de Santa Catarina, obtêm e produzem informações, usam de tecnologias da comunicação e da informação e se relacionam com outros conselhos, organizações da sociedade civil e outras organizações públicas. Os autores concluíram que o trabalho dos Conselhos Locais de Saúde vai além das questões de saúde e é um mecanismo importante para aproximar a administração pública da cidade às comunidades, e, esses conselhos têm, ainda, contribuído para o envolvimento dos cidadãos nos processos de coprodução de bens e serviços públicos de saúde. Para Menezes e Ronconi (2019, p. 2827), Accountability Social é informação: produção e recolha de informação, utilização de tecnologias de informação e comunicação, comunicação com a comunidade; e, Engajamento Cidadão é relacionamento entre conselhos locais, relacionamento entre conselhos e sociedade civil, organização de relações entre conselhos e órgãos públicos.

Como esses Conselhos Locais de Saúde, os CGPPE, no âmbito de municípios e dos estados, fazem parte dos atores não estatais, integrantes da sociedade civil, importantes na governança pública, devendo obter, para isso, maior empoderamento e devem discutir, implantar e desenvolver accountability social e engajamento cidadão.

Na governança pública, a integração entre agentes estatais e agentes sociais é fundamental, pois se trata de uma atividade complexa, na gestão de sistema de rede entre atores públicos e privados (MATOS; DIAS, 2013). O Estado, além de criar espaços para a participação, deve também criar condições objetivas para que ela se efetive (CANÇADO, PEREIRA; TENÓRIO, 2015).

Matos e Dias (2013) afirmam que a participação social pode ser caracterizada por níveis de participação e apresentam seis níveis ou dimensões que, se combinados, podem definir a intensidade de participação social. Tais dimensões estão representadas na Figura 1.

Figura 1 - As dimensões da intensidade de participação.

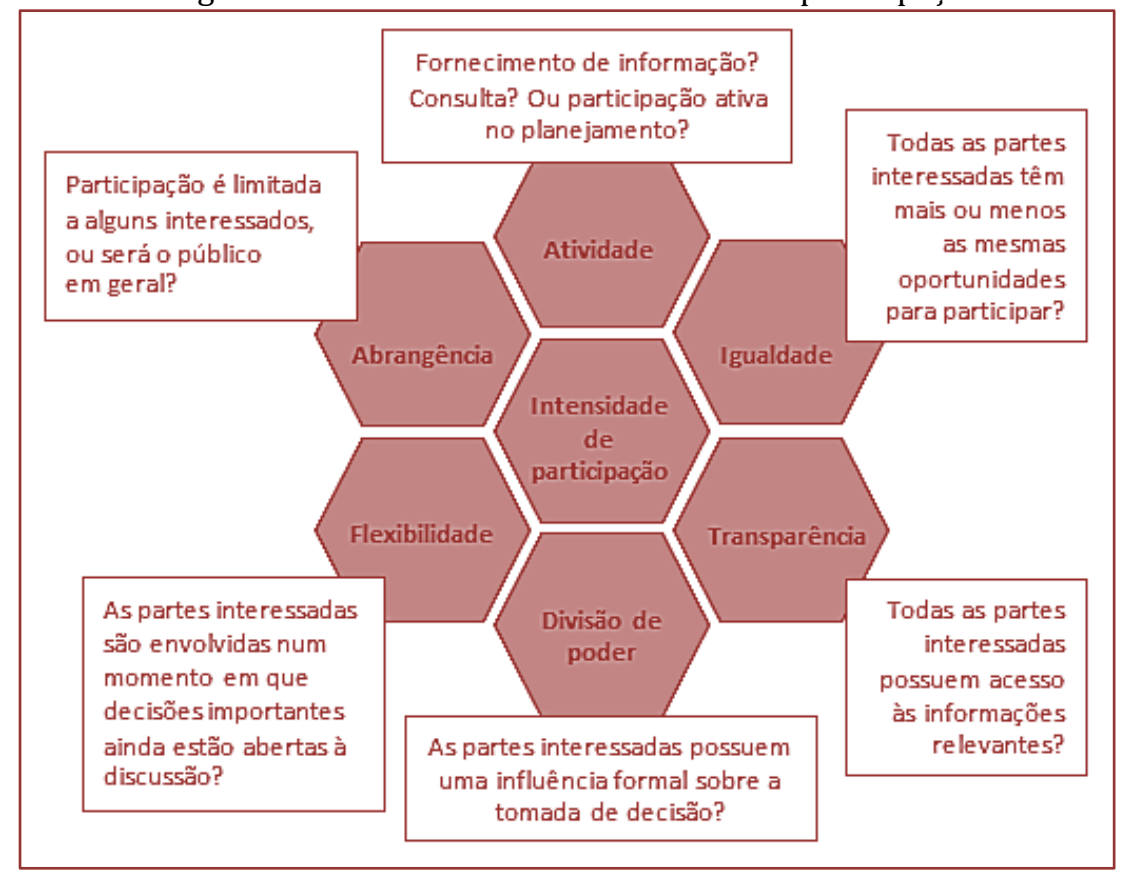

Fonte: Matos e Dias, 2013, p. 77. 
Uma reflexão por parte dos CGPPE sobre estas dimensões e questões da intensidade de participação social pode lhes fornecer maior empoderamento e inserção efetiva como ator na rede, e melhor análise de políticas pública educacionais.

\section{TEORIA DA AGÊNCIA PÚBLICA}

Ao se analisar políticas públicas sob a perspectiva da teoria da agência, entende-se que as organizações possuem duas figuras centrais: o principal e o agente. Essa teoria surge do fato do proprietário, ou do gestor público, de não ser capaz de administrar ou controlar todo o seu patrimônio e é explicada por Jensen e Meckling (1976) como uma relação de contrato, em que a parte contratante (principal) delega funções ao contratado (agente) para tomar decisões em seu nome.

Para Slomski (2007), esta relação de agência vai além do contrato entre proprietário e funcionário, e pode ser verificada nos diversos níveis da pirâmide organizacional, como por exemplo, entre a diretoria, chefe de departamento, encarregados e auxiliares. Segundo Slomski (2007), o proprietário ou principal, não dispõe de condições para monitorar todas as atividades dos seus funcionários que possuem melhores informações por estarem envolvidos nos processos organizacionais, o que geram a assimetria de informação.

No caso do setor público, o principal é a sociedade; e o gestor do Estado, o agente; e a contabilidade governamental pode contribuir com modelos de prestação de contas visando minimizar a assimetria informacional externa deste para àquela, e a interna, perante os servidores públicos, e reduzir conflitos de agência (SLOMSKI, 2007). Tais conflitos, também conhecidos como conflitos de interesse, foram a origem da teoria da agência, cuja contribuição para a administração, contabilidade e economia, tem sido fomentar investigações sobre os meios adequados para reduzir este conflitos (SCARPIN; SLOMSKI, 2007, p. 920).

Um dos maiores interesses dos munícipes é a maximização do desenvolvimento humano da coletividade, sendo que tal desenvolvimento é medido pelo IDH-M. Para que o interesse dos munícipes seja alcançado, é dever do administrador eleito pela população gerir as finanças públicas de modo que os gastos possam fazer com que haja uma maximização do desenvolvimento, visto que os gastos públicos possuem relação com o desenvolvimento (SCARPIN; SLOMSKI, 2007, p. 921).

A teoria da agência pública estuda as relações entre a sociedade e os seus representantes. Conforme afirmam Galvão, Gil e Oliveira Júnior (2016), a população desempenha o papel do acionista, investidor ou provedor financeiro (principal), e a administração pública e os profissionais do negócio privado (agentes, delegados de autoridade) desempenham tarefas em favor do interesse público. Ainda segundo esses autores, a sociedade é a responsável por prover recursos, por meio do pagamento de tributos (impostos, taxas e contribuições). Da equipe administrativa do governo, são esperadas práticas e resultados, estabelecendo-se uma espécie de contrato.

Divergências nesse contrato refletem conflitos de interessses e acontecem quando os gestores e profissionais tomam decisões em beneficio próprio com o intuito de obterem benefícios funcionais ou pessoais, negligenciando as politicas públicas de interesse do principal. Conforme afirma Cruz (2010, p. 41), "surge um conflito informacional, no qual o agente (Estado) não cria mecanismos de comunicação eficiente com o principal (sociedade), devido aos ruídos observados no processo (assimetria informacional)".

Segundo Avelino, Cunha, Lima e Colauto (2014, p. 578), "a transparência deve caracterizar todas as atividades realizadas pelos gestores públicos, de forma que os cidadãos tenham acesso e compreensão daquilo que os gestores governamentais têm realizado, após o poder de representação que lhes foi confiado". A assimetria informacional decorre da ineficiência de canais de comunicação, da insatisfação popular com a prestação de serviços públicos e da falta de políticas públicas que incentivem o exercício da cidadania (CRUZ, 2010). O processo contábil, por meio de inclusões de um fluxo de informações de relatórios financeiro-contábeis pode atuar no sentido de reduzir a assimetria informacional (FLORES, BRAUNBECK; CARVALHO, 2018).

Nesse contexto, aplica-se também o termo "accountability", que não possui tradução para o português. Ele designa a responsabilidade de prestar contas do desempenho e dos resultados de maneira efetiva, transparente, clara e tempestiva (CRUZ, 2010). 
Desse modo, a accountabilty promove a melhoria da qualidade dos serviços públicos, considerando que a transparência das informações é o principal instrumento do controle social. No fluxo da Teoria da Agência o conflito gerado decorrente da inexistência ou da assimetria da comunicação.

A accountability apresenta-se, portanto, como uma mediadora, aproximando o Estado e a sociedade por meio do incentivo à participação democrática. Segundo Galvão et al. (2016, p. 87), "a Governança/Transparência Governamental, como fundamento da Teoria da Agência Pública/Governamental, deve demonstrar o Interesse da População como objetivo dos Stakeholders Governamentais".

Nesse sentido, pode-se afirmar que a informação e as ferramentas tecnológicas de controle interno viabilizam o processo democrático, proporcionando uma gestão de alto desempenho ao alinhar a visão governamental às necessidades da sociedade. Para Galvão et al. (2016), o comportamento e a cultura governamental devem ser praticados com foco na Teoria da Agência Governamental, instrumento que permite desenhar a gestão pública a cada ciclo e adequá-la aos interesses da sociedade. Considerando o contexto do comportamento e da cultura organizacionais, a Figura 2 mostra como a observância dessa teoria promove o atendimento aos anseios da população.

Figura 2 - Comportamento e cultura governamental com foco na Teoria da Agência.

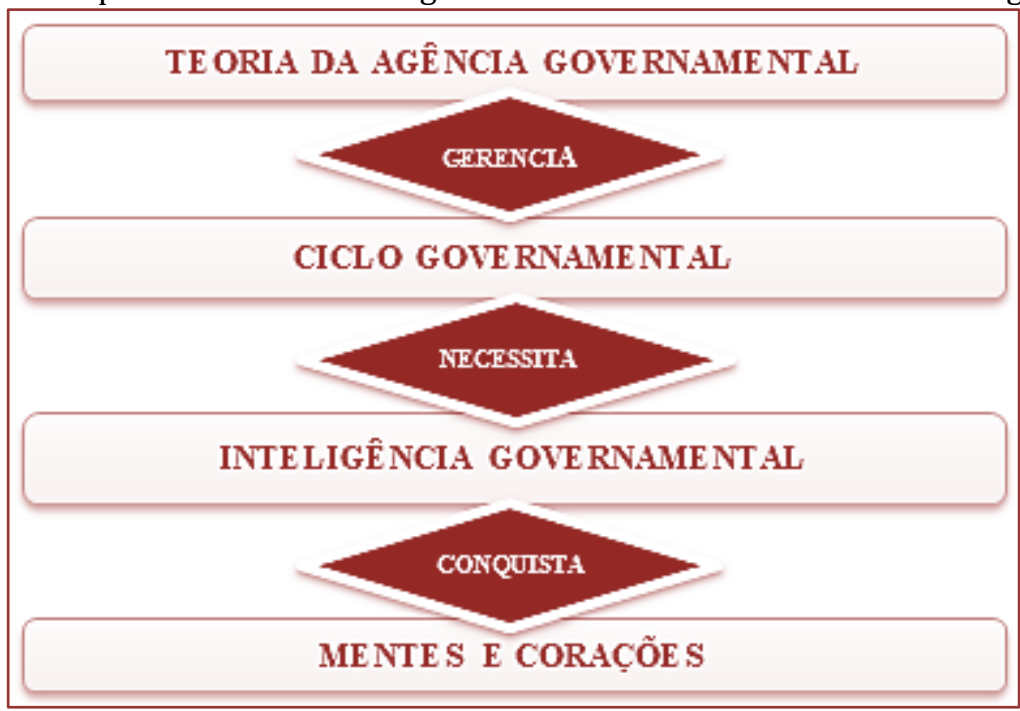

Fonte: Galvão et al., 2016, p. 117.

O gestor público é responsável por realizar as mudanças necessárias para atender à sociedade. Por lei, ele possui autonomia para tomar decisões e lidar com as questões de custo/benefício, tendo em vista a eficácia na aplicação dos recursos e dos resultados alcançados. A ênfase na Teoria da Agência Pública mostra que cada ciclo de vida governamental é influenciado pelo comportamento e pela cultura da organização; a inteligência governamental constitui caminho para sanar os conflitos entre os interesses da população, da equipe administrativa do Governo e da equipe administrativa de Estado. De acordo com Galvão et al. (2016, p. 114), “a inteligência governamental tem como foco a governança/transparência governamental baseada nas vertentes: 1 - qualidade e sustentabilidade; 2 - negociação e comunicação; 3 decisão/solução/resultado; 4 - contingência/incerteza e risco".

A Teoria da Agência Pública objetiva, também, potencializar o uso da tecnologia e minimizar perspectivas ideologicamente enviesadas, garantindo uma gestão isenta e produtiva, tendo em vista a busca da qualidade total e da sustentabilidade social. Nesse contexto, a negociação e a comunicação proporcionam o aperfeiçoamento funcional, evitando o desperdício dos recursos empregados (GALVÃo et al., 2016). Essas estratégias, negociação e comunicação, compreendem o uso de ferramentas tecnológicas como instrumentos metodológicos de gestão, no sentido de dar transparência às suas entidades integrantes sociedade, Estado e governo (Galvão et al., 2016). 


\section{PROPOSTA DE DESENHO DE PARTICIPAÇÃO EFETIVA NA GESTÃO DA EDUCAÇÃO PÚBLICA PELOS CONSELHOS GESTORES}

Argumenta-se que o papel dos CGPPE seja maior do que ficar restrito a analisar processo de pagamentos de despesas conforme a lei ou decidir sobre problemas cotidianos de escolas públicas. Deve-se além destas funções, verificar e acompanhar a evolução de índices como: o de eficiência, o IDEB - Índice de Desenvolviemnto da Educação Básica, e o IDH - Índice de Desenolvimento Humano. Sugere-se que um conselheiro, que possa ser um contador ou administrador ou economista, construa e alimente uma planilha de série histórica com esses dados e que fique responsável por atualiza-la, permanentemente. Ainda, verificar na série, se se têm scores de eficiência no seu estado, ou investigar o que pode estar ocorrendo quando houverem casos de scores de ineficiência ou baixa eficiência.

Com a elaboração de um banco de dados constante, periodicamente alimentando a planilha e/ou um sistema (com o uso da modelagem DEA - Análise Envoltória de Dados) com os scores de eficiência e sua relação com o respectivo IDH, ano a ano. Verifica-se a evolução ou involução, e, no caso de ineficiência ou baixa eficiência, comparar com os estados que obtêm eficiência (benchmark), para facilitar um trabalho de se investigar e reverter scores negativos.

Além de um trabalho de acompanhamento constante dos indicadores, os CGPPE devem elaborar suas próprias home pages para publicar tais resultados e análises para a sociedade. Com este trabalho fomentase maior transparência e controle social que, por consequência, diminuir os níveis de corrupção.

A proposta para os CGPPE pode contribuir para fomentar a "instrumentalização do controle social", um dos objetivos da Contabilidade Aplicada ao Setor Público, elencados pelo Conselho Federal de Contabilidade (CFC, 2008), de acordo com o que preconiza as NBCASP - Normas Brasileiras de Contabilidade Aplicada ao Setor Público (NBC T 16.1 e 2). 0 conselheiro responsável pode obter apoio das Contadorias Gerais dos Estados.

Esse trabalho efetivo e constante de divulgação de informações e a efetiva prestação de contas da eficiência na educação e desenvolvimento humano, por parte dos CGPPE, nas suas home pages, com respaldo na Lei Complementar no 131/2009 (Lei da Transparência), que aumenta a abrangência da Lei de Responsabilidade Fiscal - LRF (Lei Complementar no 101/2000); nas NBCASP; e na Lei de Acesso à Informação (Lei $\mathrm{n}^{\circ} 12.527 / 2011$ ), proporcionará que a qualquer pessoa física ou jurídica o acesso à informação referente à despesa, à receita à eficiência e ao desenvolvimento humano. Portanto, para todos os atos praticados pelos agentes públicos que gerem os entes da Federação, deverão ser divulgados uma quantidade mínima de dados referentes a tais atos. A LAI, de acordo com seu artigo 3oㅡㄹ os procedimentos previstos no corpo da lei, destinam-se a assegurar o direito fundamental de acesso à informação, devendo ser executados em conformidade com os princípios básicos da administração pública.

A LRF, alterada pela Lei Complementar $n^{\circ} 131 / 09$, sem dúvida, é considerada um grande avanço para o fortalecimento das relações entre os gestores públicos e os cidadãos, tornando-se instrumento fundamental no processo de fiscalização das contas e gestão públicas. Quanto à utilização dos portais eletrônicos, a LAI estabelece que os órgãos e entidades públicas deverão conter sítios na rede mundial de computadores (internet) que, entre outras disposições, contenham ferramenta de pesquisa de conteúdo, permitindo o acesso à informação de forma objetiva, transparente e em linguagem de fácil compreensão. No seu artigo 6으, incisos I e II, regra que todos os órgãos e entidades públicas devem garantir o gerenciamento transparente da informação, proporcionando acesso à mesma, bem como sua divulgação.

Os CGPPE devem incentivar o poder público, por meio da Secretaria de Estado de Educação, a elaborar um sistema de custos públicos da educação, como forma de melhorar a eficiência. A função do conselho seria acompanhar esse sistema e alimentar a sua home page com informações obtidas por tal sistema específico.

O Estado deve elaborar e aperfeiçoar um Sistema Integrado de Custo Estadual Educação - SICE-Educação, à exemplo de um software desenvolvido no âmbito municipal. Foi o que Avila-Santos, Kaster, Baccarin, Negreiros e Vieira (2015) tiveram por objetivo, demonstrar a eficácia de uma ferramenta de apoio ao controle social da gestão pública da qual batizaram de SICM-Educação (Sistema Integrado de Custos Municipais - Educação). De acordo com os autores, tal ferramenta foi desenvolvida pela Universidade Estadual de Londrina em um trabalho conjunto entre o Departamento de Computação e o Departamento de Administração. 
Avila-Santos et al. (2015) concluem demonstrando que o sistema/ferramenta pode ser utilizado em tomadas de decisão por parte do poder público, e é poderosa para impor a transparência, controle social e a fiscalização sobre a administração pública. 0 Estado deve inserir práticas gerenciais, devido ao movimento global da NGP, e tal ferramenta desenvolvida contribuirá para tais demandas (AVILA-SANTOS et al., 2015).

Este software (SICM-Educação) é voltado para a gestão de custos do Ensino Fundamental, disponibiliza relatório internos para a tomada de decisão e relatórios públicos, para que o cidadão tenha acesso a desempenho das escolas e efetuar comparações e alegam sobre a importância da gestão de custos para a melhoria do desempenho dos alunos do Ensino Fundamental (Avila-Santos et al., 2015). Os CGPPE devem incentivar seu Estado a desenvolver tal sistema adaptado ao âmbito estadual, e, posteriormente, acompanhar sua evolução, bem como sua produção de informações, incluindo a avaliação da eficiência técnica na educação do Ensino Médio (um SICM-Educação).

Com base na teoria da agência pública, o principal é a sociedade, e o gestor do Estado, o agente, e, os CGPPE podem contribuir com modelos de prestação de contas, complementadas pela proposta desta tese, a eficiência educacional e sua relação com o desenvolvimento humano, visando minimizar a assimetria informacional e reduzir conflitos de agência (SLOMSKI, 2007).

Slomski (2007) argumenta sobre a assimetria entre as informações produzidas pela administração pública e a sociedade. Segundo ele, o poder público informa, porém o cidadão não entende o que é informado. Para minimizar esta assimetria defende este autor não só a prestação de contas, mas a devida transparência, o balanço social e a demonstração do resultado econômico (DRE).

Esse modelo (DRE) evidencia o resultado econômico e, conceitua este resultado como "[...], sendo a diferença entre a receita econômica e a soma dos custos diretos/variáveis e indiretos identificáveis a entidade pública que produziu" (2007, p. 99). No Quadro 3 tem-se a estrutura da DRE e, conforme Slomski (2007), apresentam-se na sequência os conceitos dos elementos da Demonstração (DREEE).

Quadro 3 - Demonstração do Resultado Econômico na Educação Estadual (DREEE).

\begin{tabular}{|c|c|c|}
\hline \multicolumn{3}{|c|}{$\begin{array}{c}\text { NOME DO ESTADO } \\
\text { Secretaria Estadual de Educação } \\
\text { Nome do Programa Governamental "X" }\end{array}$} \\
\hline IDENTIFICAÇÃO & Exercício atual & Exercício anterior \\
\hline (+) Receita Econômica & & \\
\hline (-) Custos Diretos Identificáveis ao Programa & & \\
\hline (=) Margem Bruta & & \\
\hline (-) Depreciações & & \\
\hline (-) Custos Indiretos Identificáveis ao Programa & & \\
\hline (=) Resultado Econômico do Programa "X" & & \\
\hline
\end{tabular}

Fonte: adaptado de Slomski (2007, p. 101).

Tem-se que: a) Receita econômica: é o valor apurado a partir de benefícios gerados a sociedade pela ação pública, multiplicando-se o número de serviços prestados pelo seu custo de oportunidade; b) Os custos diretos identificáveis aos serviços: serão aqueles efetivamente consumidos no período, em função das unidades produzidas, considerando-se o regime de competência; c) A depreciação dos ativos: será calculado em função da vida útil de cada um dos componentes do ativo, utilizado na prestação dos serviços, objeto da receita econômica; d) Os custos indiretos identificáveis aos serviços prestados: são aqueles que não fazem parte da unidade de serviços, contudo, sem eles seria impossível disponibilizá-los, controlá-los e ou administrá-los; e) 0 resultado econômico apurado: pode ser positivo ou negativo, dependendo da eficiência na gestão pública (determinado programa governamental) (SLOMSKI, 2007).

Os CGPPE devem propor a inserção destas informações no SICE-Educação, pois o Resultado Econômico evidencia a eficiência obtida no programa governamental. Esta eficiência é a econômica que pode ser complementada pelos scores de eficiência técnica, obtidos pela modelagem DEA. Devem ser elaboradas tantas DRE quantos forem os programas governamentais da educação do estado. Ao evoluir neste trabalho, os CGPPE estarão proporcionado o devido accountability social e engajamento cidadão (MENEZES; RONCONI, 2019). 
De acordo com os inputs utilizados na mensuração da eficiência nesta pesquisa, modelo DEA, gastos com educação e número de docentes (Despesas correntes), argumenta-se que os CGPPE devam acompanhar as contratações de professores. Devem analisar os aspectos de quantidade necessária e a devida qualidade docente, com vistas de não se ter o limite de gastos com pessoal extrapolado, conforme a LRF, bem como a entrada de pessoal qualificado, visando o desenvolvimento centrado nas pessoas e com liberdade (Atlas Brasil, SEN, 2010), com o devido aperfeiçoamento e constante qualificação.

Santos Filho et al. (2012, p. 87) ao analisar a literatura e pesquisas empíricas sobre gastos públicos e sua relação com o crescimento econômico em países em desenvolvimento, afirmam que, "diferentemente do que se pensa, a pesquisa empírica mostrou que gastos correntes são mais efetivos na alavancagem do crescimento econômico do que os gastos com despesas de capital".

No entanto, também, o conselho de educação deve acompanhar os investimentos (Despesas de capital) para que não se tenha imobilização de recursos em excesso indevido na educação, o que poderia desencadear ineficiências. A Figura 3 mostra essa relação.

gura 3 - Atuação dos CGPPE na eficiência da educação do Estado.

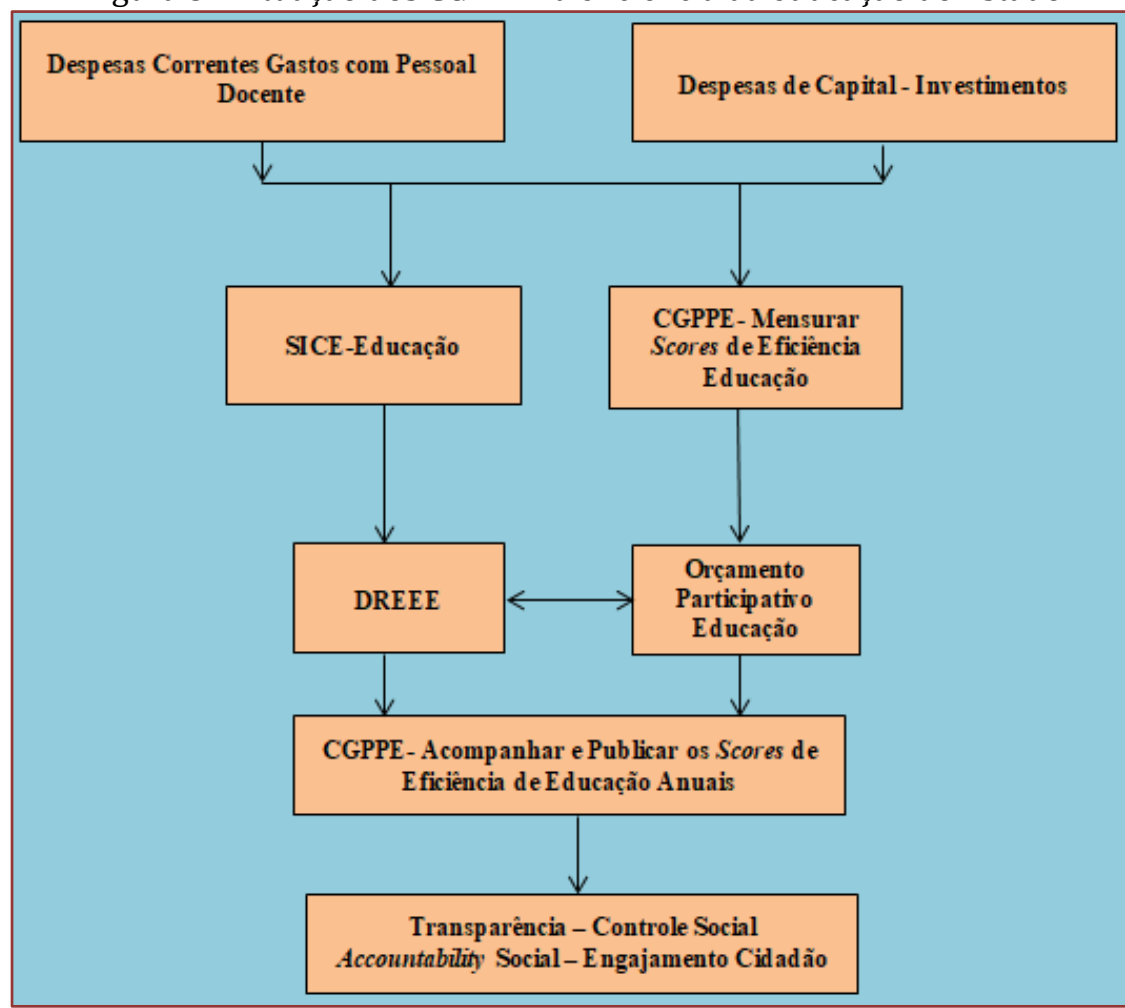

Fonte: elaboração própria, 2019.

Os dados relacionados a pessoal docente, investimentos, e outros, são alimentados no SICE-Educação, que por sua vez tem a DREEE como um dos relatórios como produto, que por sua vez oferecem informações para os Orçamentos Participativos na Educação do Estado. Os CGPPE também mensuram os scores de eficiência ano a ano. A partir destes trabalhos se terá uma efetiva avaliação de políticas públicas educacionais participativas (OLIVEIRA; PASSADOR, 2019).

Os produtos desse trabalho, como relatórios, tabelas, entre outros, deverão ser publicadas, juntamente com os IDH, na home page (que deve ser criada) do Conselho e discutidos em Conferências ou Fóruns criados, organizados e dirigidos por ele.

O ciclo vicioso faz com que a transparência poça melhorar a eficiência nos exercícios financeiros e orçamentários seguintes. E o controle social é fortalecido e os CGPPE terão o devido empoderamento.

De forma complementar, a Figura 4 mostra a aplicação das teorias na atuação dos CGPPE na avaliação de políticas públicas de educação do Estado. 
Figura 4 - Aplicação da teoria na atuação dos CGPPE na eficiência educacional.

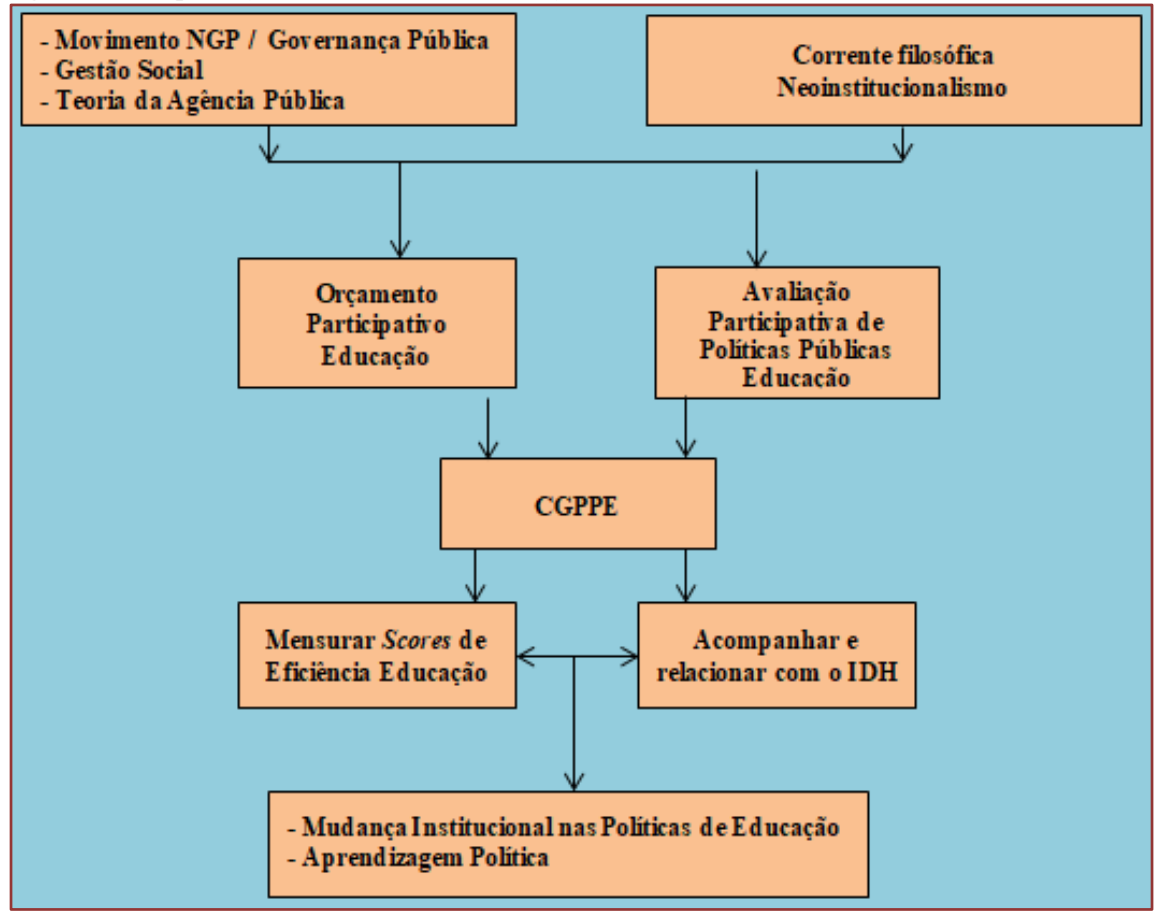

Fonte: elaboração própria, 2019.

\section{CONSIDERAÇÕES FINAIS}

Ao fazer tais trabalhos, estes Conselhos estarão devidamente empoderados e estarão proporcionado a aplicação e aperfeiçoamento da transparência, do controle social, da avaliação participativa, do accountability social, engajamento cidadão, e do desenvolvimento centrado nas pessoas e com liberdade.

Quanto maiores os investimentos em educação, mas atendendo as necessidades humanas; em tese, maiores seriam os níveis de desenvolvimento humano e de eficiência técnica; o que proporcionariam maiores conhecimentos e, por sua vez, melhor transparência. Cidadãos com melhor nível de educação possuiriam melhores condições de cobrar, de seus governantes, via os CGPPE (ciclo vicioso transparência $\mathrm{x}$ controle social).

Por fim, argumenta-se que deva-se criar um mecanismo de responsabilização ao governo estadual que, ao deixar o mandato (depois de 4 anos), obtiver os indicadores de eficiência e/ou do Ideb em queda, ou que apresentarem-se pior do que quando assumiu o seu mandato. Os CGPPE devem participar e acompanhar este processo.

0 conselheiro contador/administrador/economista treinado deve acompanhar as análises destes indicadores, bem como sua relação com o IDH. Deve atualizar a home page do Conselho Estadual de Educação com tais informações e, ainda, apresentar em fóruns ou conferências anuais e, com isso, promover a aprendizagem política (HOWLET et al., (2013).

\section{REFERÊNCIAS}

[1] Avelino, B. C.; Cunha, J. V. A.; Lima, G. A. S. F; Colauto, R. D. Características explicativas do nível de disclosure voluntário de municípios do estado de Minas Gerais. RACE, Unoesc, v. 13, n. 2, p. 571-608, 2014.

[2] Avila-Santos, A. P.; Kaster, D. S.; Baccarin, E.; Negreiros, L. F.; Vieira, S. F. A. Sistema integrado de custo municipal: uma ferramenta de apoio à tomada de decisão pelo gestor público. Anais... Brasilian Symposium on Information System, Goiânia, Brasil, 11, 2015.

[3] Brasil. Constituição (1988). Constituição da República Federativa do Brasil. Brasília: Congresso Nacional, 1988.

[4] Lei Complementar no. 101/2000. LRF. Estabelece normas de finanças públicas voltadas para a responsabilidade na gestão fiscal e dá outras providências. Brasília, 2000. 
[5] Cançado, A. C.; Pereira, J. R.; Tenório, F. G. Gestão social: epistemologia de uma paradigma. 2. ed. Curitiba: Editora CRV, 2015.

[6] Controladoria Geral da União - CGU. Cartilha Olho vivo no dinheiro público: um guia para o cidadão garantir os seus direitos. 2. ed. Brasília: Gráfica Brasil Editora \& Marketing Ltda., 2009.

[7] Crepaldi, S. A.; Crepadi, G. S. Orçamento público: planejamento, elaboração e controle. São Paulo: Saraiva, 2013.

[8] Cruz, C. F. Transparência da gestão pública municipal: referenciais teóricos e a situação dos grandes municípios brasileiros. 140f. Dissertação (Mestrado em Ciências Contábeis). Faculdade de Administração e Ciências Contábeis. Universidade Federal do Rio de Janeiro, Rio de Janeiro, UFRJ, 2010.

[9] Dias, J. C. R.; Vasconcelos, M. T. C. As características qualitativas da informação contábil no desenvolvimento do controle social: uma análise da percepção dos conselheiros municipais do Recife sobre a utilidade das informações contábeis. Revista Contabilidade Vista \& Revista, v. 26, n. 2, p. 15-40, maio/ago. 2015.

[10] Flores, E.; Braunbeck, G.; Carvalho, N. Teoria da contabilidade: em busca dos fundamentos do fenômeno contábil. In: Flores, E.; Braunbeck, G.; Carvalho, N (Org.). Teoria da contabilidade financeira: fundamentos e aplicações. São Paulo: Atlas, 2018.

[11] Galvão, P. R.; Gil, A. de L.; Oliveira Júnior, R. de. Gestão pública municipal de alto desempenho: governança e controladoria municipal. Curitiba: Juruá, 2016

[12] GOHN, M. G. Conselhos gestores e participação sociopolítica. 4. ed. São Paulo: Cortez (Coleção questões de nossa época; v. 32), 2011.

[13] Howlett, M.; Ramesh, M.; PERL, A. Política pública: seus ciclos e subsistemas: uma abordagem integral. Trad. Francisco G. Heidemann. Rio de Janeiro: Elsevier, 2013.

[14] Kleba, M. E.; Wendhausen, A. L. P. Empoderamento e participação social na gestão pública. In: Wendhausen, A. L. P.; Kleba, M. E. (Orgs.). Conselhos gestores e empoderamento: vivências e pontenciais da participação social na gestão pública. Jundiaí: Paco Editorial, 2012.

[15] Matos, F.; DIAS, R. Governança pública: novo arranjo de governo. Campinas: Editora Alínea, 2013.

[16] Menezes, E. C. O.; RONCONI, L. F. A. Accountabilty social e engajamento cidadão em saúde: a experiência de um município brasileiro. Revista Eletrônica Gestão \& Sociedade, v. 13, n. 35, p. 2820-2838, 2019.

[17] Nakagawa, M.; Relvas, T. R. S.; Dias Filho, J. M. Accountability: a razão de ser da contabilidade. Revista de Educação e Pesquisa em Contabilidade, Brasília, v. 1, n. 3, p. 83-100, 2007.

[18] Oliveira, V. C. S.; Keinert, T. M. M. A perspectiva sociocêntrica e a reconfiguração das principais políticas sociais após a Constituição de 1988. Pensamento Contemporâneo em Administração, v. 10, n. 3, p. 1-15, 2016.

[19] Oliveira, L. R.; Passador, C. S. Ensaio teórico sobre avaliações de políticas públicas. Cadernos EBAPE.BR, v. 17, n. 2, p. 324-337, 2019.

[20] Pinho, J. G.; Sacramento, A. R. S. Accountability: já podemos traduzi-la para o português? Revista de Administração Pública, v. 43, n. 6, Rio de Janeiro, nov./dez., 2009.

[21] Rocha, A. C. Accountability na administração pública: modelos teóricos e abordagens, Contabilidade, Gestão e Governança, v. 14, n. 2, p. 82-97, 2011.

[22] Santos Filhi, M. R.; Dias Filhos, J. M.; Fernandes, G. B. Avaliação da capacidade de predição do Índice de Desenvolvimento Humano dos Municípios (IDH-M) a partir das demonstrações contábeis e legais. Revista Ciências Administrativas, Fortaleza, v. 18, n. 1, p. 83-109, 2012.

[23] Scarpi, J. E.; Slomski, V. Estudo dos fatores condicionantes do índice de desenvolvimento humano nos municípios do estado do Paraná: instrumento de controladoria para a tomada de decisões na gestão governamental. Revista de Administração Pública, Rio de Janeiro, v. 45, n . 5, p. 909-933, 2007.

[24] Sen, A. (2010). Desenvolvimento como liberdade. Tradução: Laura Teixeira Motta. 6. reimpr. São Paulo: Companhia das Letras, 2010.

[25] Slomski, V. (2007). Controladoria e governança na gestão pública. São Paulo: Atlas.

[26] Zuccolotto, R.; Teixeira, M. A. C.; Riccio, E. L. Transparência: reposicionando o debate. Revista Contemporânea de Contabilidade, Florianópolis, v. 2, n. 25, p. 137-158, 2015. 


\section{Capítulo 20}

Eficiência em licitações: Um estudo sobre o sistema compras WEB

\section{Larissa Barbosa Ferreira de Souza \\ Flavio Pinheiro Martins \\ Luciana Romano Morilas}

Resumo: Visando maior eficiência e rapidez no processo de contratação pública em licitação, criou-se a modalidade pregão eletrônico, o qual também busca aumentar a competitividade entre os licitantes. Foi feito um estudo de caso no âmbito do campus USP-RP, questionando se o sistema compras web, utilizado para realizar compras centralizadas nas repartições da usp, é eficiente ou não na visão dos usuários. Para averiguar, foram elaboradas questões semi-estruturadas, voltadas às questões práticas dessa ferramenta, e, posteriormente, essas perguntas foram aplicadas em cada unidade do campus USP-RP; os agentes entrevistados foram pregoeiros. Concluiu-se então, que os agentes que utilizam essa ferramenta não têm um conhecimento pleno de sua capacidade; os agentes que utilizam essa ferramenta, não têm um conhecimento pleno de sua capacidade; os agentes que utilizam o sistema o sistema com uma frequência maior afirmam que o treinamento fornecido foi superficial, entre outros treinamentos oferecidos. Para as unidades que mais aderem às compras do que realizam o pregão de fato, o processo de contratação ficou mais ágil.

Palavras-chave: licitação, pregão eletrônico, compra centralizada 


\section{INTRODUÇÃO}

A Constituição de 1988 consagra, em seu Capítulo II, os chamados Direitos Sociais, materializados quando o Estado assume papel ativo e intervém na sociedade fomentando o bem-estar da coletividade e garantindo os patamares mínimos necessários à dignidade humana de seus cidadãos. Para fazer-se presente no alcance desses direitos econômicos, sociais e culturais, o Estado, em suas esferas federal, estadual e municipal, assume funções de prestador de serviços, visando à promoção da igualdade material dos indivíduos.

Na medida em que se compromete com essas prestações positivas presentes no texto constitucional, o Estado de Direito precisa se organizar para o atendimento das necessidades e aspirações da população. É necessário construir escolas, hospitais e rodovias, contratar professores, médicos, pesquisadores, adquirir insumos e equipamentos, defender suas fronteiras, combater o crime, recolher tributos, desenvolver tecnologia, enfim, adequar-se a uma miríade não taxativa de demandas advindas da coletividade para cumprir, principalmente, com as obrigações decorrentes dos direitos de $2^{\underline{a}}$ geração.

No sentido de viabilizar as condições para que a Administração Pública, a representação institucional do Estado, consiga prover serviços públicos de maneira eficiente, ela contrata particulares para o fornecimento de bens e prestação de serviços, podendo assim, a máquina estatal, concentrar seus esforços nas funções típicas e inalienáveis, de Estado. É nesse ponto que se fazem primordiais as modalidades de interface, por assim dizer, entre Estado e particulares.

As compras públicas são engrenagens fundamentais dessa intersecção público-privado, na medida em que regulamentam, sob a égide dos princípios da Administração Pública, os contratos de compra e prestação de serviços que irão permitir à máquina estatal cumprir seus objetivos.

A Lei no 8.666, de 21 de junho de 1993, conhecida como Lei de Licitações e Contratos, é o diploma infraconstitucional que regulamenta o inciso XXI do artigo 37 da Constituição Federal, é a lei geral de normas regulamentadoras licitação. De extrema relevância foi também a Lei no 10.520, de 17 de julho de 2002, a qual instituiu o Pregão, sexta modalidade de licitação, posteriormente regulada em sua forma eletrônica pelo Decreto no 5.450 , de 31 de maio de 2005.

Licitar é, segundo a doutrina, realizar um procedimento formal de natureza pré-contratual, visando eleger o detentor da proposta mais vantajosa para a administração, bem como promover a igualdade material de competição entre os particulares que, atendendo às exigências do instrumento editalício, podem participar. Por consequência, ao cabo do processo, ser elegíveis para a celebração do contrato de fornecimento dos produtos e serviços.

A licitação tem por finalidades expressas: a) o atendimento do interesse público; b) a obtenção da proposta mais vantajosa; c) a garantia da isonomia; d) a promoção do desenvolvimento nacional sustentável.

A legislação prevê um rol taxativo de modalidades licitatórias: concorrência, tomada de preços, convite, concurso, leilão e pregão. A definição da modalidade adequada para cada tipo de aquisição depende das características e do vulto do objeto. Em algumas situaç̧ões, o agente público tem sua decisão vinculada, só podendo licitar em determinada modalidade; em outras, tem poder discricionário, podendo optar entre duas ou mais modalidades, pela qual considere, por critérios objetivos e justificados, mais eficiente para a licitação. Além das modalidades, existe o instrumento do Sistema de Registro de Preços (SRP), que não é uma forma de licitar e sim uma espécie de banco de preços obtido através do procedimento licitatório, com o objetivo de tornar célere a aquisição de objetos frequentes e de difícil planejamento.

No âmbito da USP, tem se realizado os SRP por meio de um sistema centralizado de compras, denominado Compras Web, o qual tem por objetivo a centralização de compras realizadas em diferentes unidades, dentro ou não do mesmo campus.

O sistema, em síntese, procura agregar as demandas das unidades, com o objetivo de promover uma maior eficiência através da celeridade e dos ganhos de escala. A modalidade licitatória utilizada no referido sistema é o pregão eletrônico, realizado no ambiente virtual da Bolsa Eletrônica de Compras do Estado de São Paulo - BEC/SP, um sistema de bolsa de mercadorias utilizado por toda a Administração Pública Paulista.

Os dados da BEC/SP são relevantes quanto ao volume de recursos envolvidos; em 2016, foram mais de 25.000 certames nessa modalidade, totalizando uma soma superior à 10 bilhões em aquisições e economia estimada de 3,7 bilhões de reais (Bolsa Eletrônica de Compras, 2017). 
O que sinaliza que o Estado de São Paulo é detentor de um grande poder de compra, executado em sua maioria, por meio de procedimentos com alto nível de transparência: Pregões Eletrônicos.

A Universidade de São Paulo, unidade integrante da administração pública estadual, tem grande representatividade no cenário de pesquisa científica nacional, sendo responsável por centenas de cursos em todas as áreas do saber, além de controlar hospitais, museus e institutos especializados.

A complexidade da instituição se reflete em uma diversidade muito grande de atividades realizadas dentro do escopo de ensino, pesquisa e extensão, e uma consequente variedade de processos demandantes de produtos e serviços diversos. Ainda, o tamanho da universidade impacta no volume das aquisições que devem ser feitas. Em 2015, existiam 94.000 alunos de graduação e pós-graduação, na USP. Em termos financeiros, para o ano de 2017, as receitas da USP foram estimadas em R \$ 5.052.466.860, sendo $\mathrm{R} \$ 4.806 .950 .350$ oriundos de repasses do tesouro do estado e transferências da União e R \$ 245.516.510 das receitas da instituição (USP, 2018. Boa parte desses recursos é alocada via licitação. Desde 2004, a USP realizou 6.325 pregões presenciais e desde 2011, 5.446 procedimentos eletrônicos (São Paulo, 2017).

As pesquisas sobre pregão eletrônico, em sua maioria, comprovam sua eficiência relativa às demais modalidades licitatórias (Kariyado, 2016; Silveira, \& Ducati, 2014; Faria, Ferreira, Santos, \& Silveira, 2011; Freitas, 2011; Bittencourt, 2010; Souza, 2009; Fernandes, 2005). Todavia, pouco se sabe sobre o procedimento no âmbito da Universidade de São Paulo, bem como sobre o seu uso para o Sistema de Registro de Preços.

Em observações prévias, identificou-se um elevado número de pregões eletrônicos malsucedidos na USP. Na bibliografia, encontram-se registros de níveis de insucesso de até 30\% nessa modalidade de licitação (BRANDÃO, 2016; KARIYADO, 2016).

No que se refere aos Sistemas de Registro de Preços, em maio de 2017 encontravam-se ativos 500 registros de preços na USP, muitos dos quais foram realizados via sistema Compras Web. Foram observadas também repetições dos mesmos itens registrados concomitantemente. Pode-se deduzir que a repetição é indesejada na medida em que prejudica a economia de escala:

A quantidade comprada também se mostrou determinante na redução dos preços pagos em licitações. Por isso, os órgãos públicos devem se planejar para fazer compras conjuntas e evitar a realização de várias licitações para a compra do mesmo produto, pois assim eles terão maior poder de barganha e poderão exigir diminuições mais substanciais de seus fornecedores. (FARIA, FERREIRA, SANTOS, \& SILVEIRA 2010, p.1424)

Procedimentos malsucedidos ou repetidos desnecessariamente impactam em gasto adicional de recursos. Em um ambiente financiado em grande parte pela tributação da sociedade, no caso o ICMS estadual paulista, é imperioso aprimorar os procedimentos licitatórios e, consequentemente, melhorar o uso de recursos dentro da instituição e o atendimento às demandas da coletividade.

Sendo assim, este trabalho concentra-se em avaliar a eficiência do uso dos Sistemas de Registro de Preço (SRP), efetuado mediante o uso da modalidade licitatória Pregão, em sua forma eletrônica, no âmbito do sistema Compras Web da Universidade de São Paulo (USP) e com o auxílio da Bolsa Eletrônica de Compras do Estado de São Paulo (BEC/SP) no ano de 2018.

\section{LICITAÇÕES}

O Estado tem a necessidade de realizar contratos com particulares para que consiga alcançar seus objetivos, decorrentes das contraprestações necessárias ao atendimento da sociedade. A Administração Pública tem discricionariedade para determinar o objeto e as condições que serão tratados no contrato, mas sua execução segue um rito rigoroso e que deve ser constantemente monitorado para não se desviar do interesse público. 0 processo para a contratação pública segue um conjunto estruturado de fases, etapas e atos que permitem à administração, a partir da sua necessidade, definir o valor a ser gasto, reduzindo os riscos e selecionando a melhor pessoa para satisfazer a demanda com a melhor relação custo-benefício (MENDES, 2012). 
As Licitações, maneira usual de referir-se ao processo de contratação, traduzem o interesse público em procedimentos instrumentais que objetivam selecionar a proposta mais vantajosa para a Administração Pública ao encontrar a proposta menos onerosa, com a realização da melhor e mais completa prestação de serviço ou fornecimento de mercadoria (Justen Filho, 2004). A lei 8.666/93 - Lei de Licitações - é o maior referencial para realização de todo o processo licitatório. Essa lei contém normas aplicáveis a todos os tipos de contratos em esfera federativa, e usualmente é entendida para outras esferas na forma de decretos e legislações específicas.

A lei 8.666/93 é regida pelos princípios da isonomia, legalidade, impessoalidade, moralidade, publicidade, probidade administrativa, da vinculação ao instrumento convocatório e do julgamento objetivo e, como descrito no seu artigo 1을 , se aplica às licitações e contratos administrativos relativos às obras, serviços, inclusive de publicidade, compras, alienações e locações compras de bens. Essas licitações e contratos são feitos pelos órgãos da administração direta, os fundos especiais, as autarquias, as fundações públicas, as empresas públicas, as sociedades de economia mista e demais entidades controladas direta ou indiretamente pela União, Estados, Distrito Federal e Municípios.

A Licitação é um ato administrativo organizado, de obrigação do Estado para a contratação de terceiros, no qual se determina a competição entre os fornecedores participantes, que antecede o ato da compra. Para realizar essa contratação, são divulgados editais, abertos a todos os possíveis fornecedores, que permitem que a concorrência seja a maior possível. As entidades interessadas em fornecer o bem ou serviço devem oferecer sua proposta, cumprindo com as regras do edital e, finalizando o processo, o órgão público escolhe a oferta mais vantajosa, ou seja, que atenda às suas necessidades de forma eficiente e eficaz. Para que a eficiência e a eficácia sejam atendidas, os bens ou serviços requeridos devem alcançar a maior qualidade junto ao menor preço. Existe um debate corrente sobre a inserção de critérios de julgamento para além do preço, cujo objetivo final seria o alcance dessa maior qualidade (DIMITRI, 2013), esse conceito é expresso na doutrina sobre licitações como a obtenção da "vantajosidade" nas contratações.

O edital é aberto a todos (universalidade), e claramente a licitação cumpre o princípio da isonomia, pois qualquer empresa que queira participar do processo licitatório, tem a possibilidade, desde que se enquadre nos pré-requisitos de participação em cada modalidade. Para reforçar essa ideia de participação em nível de igualdade, o texto constitucional prevê que às microempresas e empresas de pequeno porte sejam concedidas prerrogativas.

Conforme Pestana (2013), o princípio da igualdade determina que não deve haver discriminação entre os participantes, ou seja, eles devem ser tratados igualmente, de maneira equânime, de modo que o princípio da competitividade prevaleça nos processos licitatórios.

A lei de licitações carrega várias exceções com relação ao princípio da isonomia. Um corolário deste princípio é o princípio da preferência nacional, segundo o qual deve haver preferência às empresas nacionais que fornecem bens e serviços de informática e automação, para que haja desenvolvimento da indústria e aumento da empregabilidade, outro recorrente exemplo é o art. 14, que prevê um tratamento diferenciado às micro e pequenas empresas, regulamentado pela Lei Complementar 123/2006. Tais prerrogativas não devem ser interpretadas como vantagens, e sim uma forma de garantir a igualdade através de incentivos que promovem a igualdade material, sem ferir a isonomia do processo (PESTANA, 2013).

Para executar o processo licitatório, o agente pode se utilizar de seis modalidades, cada uma com sua particularidade e finalidade específicas. São elas: Concorrência, Tomada de preços, Convite, Concurso, Leilão e, o mais recente, o Pregão. Também existe a dispensa da licitação, uma forma de simplificada para aquisições de menor valor, cujo valores foram recentemente ajustados pelo Decreto no 9.412/18; recentemente, os valores habilitados para a dispensa tiveram uma alteração significativa.

Dentre as modalidades de licitação, o pregão figura como a principal inovação do ponto de vista jurídico e administrativo.

\subsection{O PREGÃO E SUA VERTENTE ELETRÔNICA}

O pregão surgiu no contexto da reforma gerencialista do Estado, da década de 90, tendo sido inserido no ordenamento jurídico pela Lei no 9.472 / 97, que dispôs sobre a organização dos serviços de telecomunicações, a criou a Agência Nacional de Telecomunicações - ANATEL. 
O pregão, regido atualmente pela lei 10.520/02, é utilizado para a aquisição de serviços e bens comuns, conforme serão definidos adiante. Essa modalidade também pode ser executada através de recursos tecnológicos, que é o chamado Pregão Eletrônico, criado com o intuito de obter maior eficiência agilidade no processo licitatório.

A modalidade é uma ferramenta especialmente adequada a buscar o equilíbrio entre menor preço e melhor qualidade, a chamada vantajosidade, através da soma dos dois componentes: I) critério de julgamento linear baseado no menor preço e II) objetividade na descrição dos atributos multi-critérios expressos no edital.

A junção dos componentes resultaria em uma licitação com eficiência alocativa, maximizando os benefícios para a sociedade, e atenderia também aos critérios da eficiência de Pareto (KERSTEN, 2014).

Uma das questões existentes no debate sobre a eficiência em licitações, refere-se ao uso do critério de preço, linear, de maneira hierárquica em relação aos demais critérios descritos nos Editais. 0 rigor do rito licitatório não exclui a inserção de especificações nos editais, capazes de conferir uma qualidade mínima necessária para atendimento das necessidades da administração pública. Com base nesse piso de qualidade, o Pregão instrumentaliza o agente público para alcançar o menor preço sem sacrificar a qualidade, obtendo assim o "melhor valor pelo preço pago" (DIMITRI, 2013).

O funcionamento da etapa de lances proporciona esse ajuste da função linear do preço aos critérios de qualidade exigido no Edital. O pregão funciona como um leilão reverso ou "leilão inglês", na medida em que permite o comprador adquirir bens e contratar serviços de um grande número de fornecedores desconhecidos (BOER, HARINK, \& HEIJBOER, 2002). É um modelo que permite a alteração dinâmica dos valores ao longo da sessão de licitação, reduzindo os valores e consequentemente melhorando sua eficiência (MITHAS \& JONES, 2007; SETIA \& SPEIER-PERO, 2015); as empresas efetuam lances subsequentes até que se alcance o preço limite do mercado.

Outra característica relevante do Pregão é a aquisição de bens e serviços comuns, definidos com aqueles cujos padrões de desempenho e qualidade possam ser objetivamente definidos pelo edital, por meio de especificações usuais do mercado (Lei n. 10.520/02, 2002).

Existe um debate e muita confusão sobre a definição de "comum", nesse sentido, Justen filho (2004) afirma que é um conceito indeterminado e que existem três gradações do que seriam os bens comuns: os que são indubitavelmente comuns, os que não são comuns, e os que a configuração é incerta.

Outra característica marcante que difere das outras modalidades, é a inversão das etapas, na qual a fase da análise dos documentos é realizada em momento posterior ao da escolha do vencedor na etapa de lances. Caso o vencedor tiver problemas com sua documentação, o segundo classificado é convocado e assim sucessivamente até o concorrente selecionado atenda aos requisitos de documentação.

Organizações públicas e privadas têm incorporado a Tecnologia da Informação e Comunicação (TIC) em seus processos de compras; a interação com uma grande quantidade de fornecedores, geograficamente dispersos, permite o acesso a propostas em tempo real e impacta profundamente a maneira como são adquiridos bens e contratados serviços (SETIA \& SPEIER-PERO,2015).

A inovação chegou também nos processos de compras públicas nacionais e ao pregão, regulamentado para operar em sua forma eletrônica (Decreto no 5.450/05, 2005).

As experiências positivas no uso do Pregão em sua modalidade eletrônica, fazem com que ela seja considerada obrigatória na maioria dos cenários licitatórios; no âmbito do Estado de São Paulo o Decreto no 51.469/07, define a modalidade como obrigatória para aquisição de bens comuns e ainda orienta os pregoeiros a utilizar também a Bolsa Eletrônica de Compras do Governo do Estado de São Paulo - BEC/SP, sendo necessário justificar o não uso. 
Quadro 1 - Principais características do pregão eletrônico e seu impacto na eficiência

\begin{tabular}{|l|l|l|}
\multicolumn{1}{|c|}{ Característica } & \multicolumn{2}{|c|}{ Descrição } \\
\hline $\begin{array}{l}\text { Inversão da etapa de } \\
\text { lances e etapa de } \\
\text { habilitação }\end{array}$ & $\begin{array}{l}\text { A documentação referente à habilitação } \\
\text { das empresas é avaliada somente após o } \\
\text { conhecimento do detentor da melhor } \\
\text { proposta }\end{array}$ & $\begin{array}{l}\text { Celeridade. Evita-se assim a análise de } \\
\text { documentação das empresas que não seriam } \\
\text { contratadas por não serem detentoras de } \\
\text { propostas exequíveis. }\end{array}$ \\
\hline Etapa de lances & $\begin{array}{l}\text { As empresas ofertam uma proposta } \\
\text { inicial e podem efetuar reduções no valor } \\
\text { ofertado, como em um leilão reverso }\end{array}$ & $\begin{array}{l}\text { Economicidade. Dessa forma, em um ambiente } \\
\text { competitivo, o melhor valor é alcançado. }\end{array}$ \\
\hline $\begin{array}{l}\text { Uso para bens e } \\
\text { serviços comuns }\end{array}$ & $\begin{array}{l}\text { O pregão não se restringe em faixa de } \\
\text { valor para sua utilização, como é o caso } \\
\text { das outras modalidades. }\end{array}$ & $\begin{array}{l}\text { Eficiência. Amplia-se o uso da ferramenta mais } \\
\text { eficiente, não sendo restrito a determinado teto } \\
\text { de valor, como é o caso das demais } \\
\text { modalidades. }\end{array}$ \\
\hline
\end{tabular}

Fonte: Elaborado pelos autores.

\subsection{SISTEMA DE REGISTRO DE PREÇO}

No art. 15 da lei 8.666/93 está previsto, que nas aquisições dos bens ou serviços deve ser feito, sempre que possível, o registro de preço. Ele é utilizado na modalidade Concorrência, do tipo menor preço (Lei 8.666/93), e na modalidade Pregão (Lei 10.520/02).

O decreto no 7.892/13, que regulamenta o Sistema de Registro de Preço, descreve o SRP como um "conjunto de procedimentos para registro formal de preços relativos à prestação de serviços e aquisição de bens, para contratações futuras." Em suma, ele é uma promessa de compra, que não necessariamente será realizada, no qual o fornecedor se compromete a manter o preço durante doze meses, e envia a mercadoria/ serviço quando é solicitado pela administração pública.

A promessa é registrada por meio de um documento chamado Ata de Registro de Preço. Nesta ata, firmada após a licitação, estão contidas todas as obrigações das partes e as condições a serem praticadas.

0 referido decreto define, em seu art. $3^{\circ}$, as seguintes hipóteses para a adoção do SRP:

I - quando, pelas características do bem ou serviço, houver necessidade de contratações frequentes;

II - quando for conveniente a aquisição de bens com previsão de entregas parceladas ou contratação de serviços remunerados por unidade de medida ou em regime de tarefa;

III - quando for conveniente a aquisição de bens ou a contratação de serviços para atendimento a mais de um órgão ou entidade, ou a programas de governo; ou

IV - quando, pela natureza do objeto, não for possível definir previamente o quantitativo a ser demandado pela Administração (Decreto n. 7.892, 2013)

O registro de preços é uma relevante ferramenta para a celeridade das contratações, evitando que sejam replicados procedimentos muito similares ao longo de um lapso temporal relativamente pequeno. Um ponto a ser considerado refere-se à elasticidade do preço dos bens registrados. Em algumas hipóteses, o risco de garantir determinado é elevado, e acaba sendo revertido em um valor registrado mais elevado, acima do mercado. Cabe a administração avaliar objetivamente os aspectos da economia obtida com a celeridade na contratação, contraposta ao custo potencialmente elevado dos itens registrados.

\section{MATERIAIS E MÉTODOS}

Quanto aos procedimentos, a pesquisa pode ser categorizada como um estudo de caso, desenvolvido pela observação dos processos licitatórios e aplicação de questionários semi-estruturados com os agentes envolvidos nos setores de compras.

Os critérios para a definição dos agentes relevantes foi o nível de envolvimento com o objeto, bem como a capacidade e disponibilidade que eles têm para validar a eficiência do sistema ou fornecer uma visão crítica. Nesse ponto, foram utilizados questionários semi-estruturados focalizados, inspirados na metodologia proposta por Aaker, Kumar, \& Day (2001): 1) Planejar o que vai ser mensurado; 2) Dar forma ao questionário; 3) Definir a maneira como as perguntas serão redigidas; 4) Definir a sequência e aparência do questionário; 5) Realizar pré-testes e correções. 
Posteriormente os questionários foram aplicados, pessoalmente aos agentes envolvidos com o processo de licitações da USP. Além da aplicação dos questionários, o processo de licitação também foi acompanhado, com observações feitas in loco.

As perguntas se abordavam os seguintes itens:

1- É oferecido algum treinamento para manipular o Sistema Compras Web?

2- $\quad 0$ treinamento fornecido é satisfatório?

3- $\quad 0$ sistema é amigável, de fácil utilização?

4- $\quad$ O sistema está sempre disponível?

5- Há falhas no sistema?

6- Você identifica algo que possa/deva ser mudado?

7- Você trabalha com as licitações na USP desde antes de implantarem o sistema?

RESPOSTA NEGATIVA: encerra a entrevista

8- Você percebe que o sistema gerou melhoria de preço nas contratações?

9- $\quad$ O processo melhorou com a adoção do sistema?

RESPOSTA AFIRMATIVA: Em que aspecto?

10- As multiplicidades de licitações diminuíram ao utilizar o sistema?

11- Há ganho de escala com o uso do Compras Web?

12- Houve alteração na qualidade de produtos e serviços contratados?

\section{RESULTADOS}

Os indivíduos que realizam todo o processo de compras na USP são servidores públicos, que integram as comissões de licitação das unidades. Todos os entrevistados eram pregoeiros ou servidores envolvidos no processo de licitação: chefes de seção de compras, membros das equipes de apoio em licitações e assistentes financeiros. A definição do servidor como pregoeiro é concedida pela autoridade competente do órgão público, em consonância com alguns requisitos legais do servidor, entre os quais um curso de capacitação de pregoeiros oferecido, usualmente, por entidades ligadas ao treinamento da força de trabalho da administração pública.

\subsection{VISÃO GERAL DO SISTEMA COMPRAS WEB}

O Sistema Compras Web foi desenvolvido com o intuito conferir maior eficiência no processo de licitação dos órgãos e unidades da USP. A implementação do sistema parte dos diagnósticos relacionados ao grande volume de compras pulverizadas em licitações muito similares, em especial nas unidades localizadas dentro de um mesmo Campus.

O sistema parte do pressuposto de que a compra coletiva de materiais de uso comum das unidades impactaria em uma redução do número de licitações e aumento nos percentuais de economicidade, devido aos ganhos de escala advindos da maior quantidade comprada. Freitas (2007) frisa que o desperdício do dinheiro público é uma ação viciada, que resulta em obras inacabadas, compra de produtos e serviços com preços acima do praticado no mercado. Estas ações, inclusive, podem ser indícios, segundo a auditoria contábil, de fraudes no exercício da atividade.

Não obstante as unidades da USP tenham autonomia administrativa e financeira elas podem usufruir do sistema proposto, embora não exista a obrigatoriedade formal para o uso, cabe salientar que o administrador público, tendo opções que diferem em eficiência, não teria outra escolha senão a de trabalhar com a opção mais vantajosa (JUAREZ FREITAZ, 2007).

A partir das entrevistas realizadas, foi possível entender e sistematizar o funcionamento do sistema, que não está documentado de nenhuma forma acessível ao público. 0 funcionamento do sistema pode ser sintetizado em 5 etapas, conforme referenciado na Figura abaixo. 
Figura 1 - Síntese do processo do Compras Web

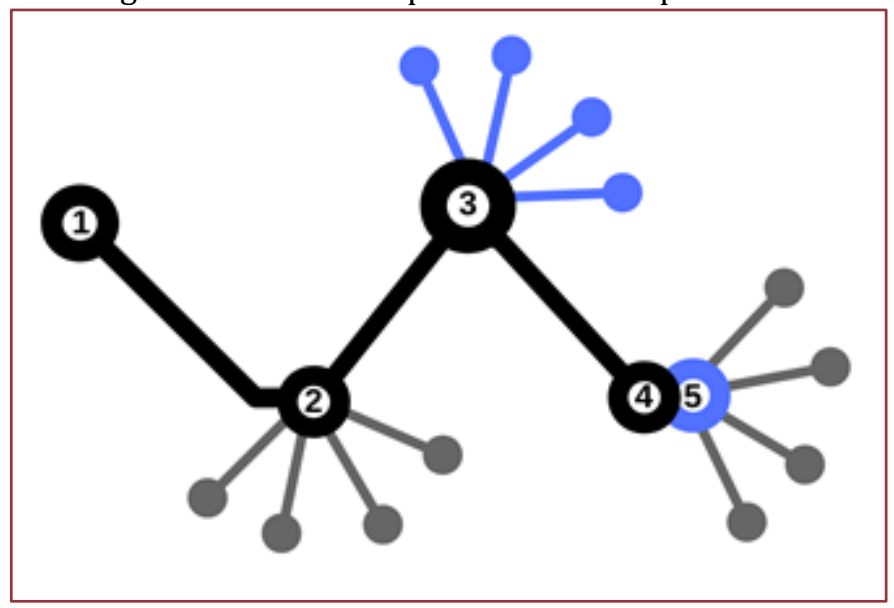

Fonte: Elaborada pelos autores.

Etapa 1 - A Unidade responsável pela aquisição dá início ao processo, define a demanda inicial e divulga para as demais unidades;

Etapa 2 - As Unidades interessadas aderem à compra, indicando a quantidade do produto ou serviço de que necessitam;

Etapa 3 - A Unidade responsável realiza o Pregão, recebendo propostas de diversas empresas;

Etapa 4 - A Ata de Registro de Preços é firmada entre a unidade responsável e a empresa fornecedora;

Etapa 5 - Decorridos os prazos para recursos, a empresa signatária da Ata de Registro de Preços dá início as entregas das unidades participantes do processo.

Um dos principais aspectos positivos relacionados ao sistema refere-se à contratação de serviços de manutenção, em geral, atividades administrativas comuns a maioria dos prédios públicos e que, antes da implementação do sistema, eram realizados por meio da replicação de inúmeras solicitações.

A visão da USP é de ampliação do sistema nos próximos anos, corrigindo erros e estendo o seu escopo as demais modalidades de licitação. Existe também a prerrogativa da transferência de todo o procedimental de licitações para o ambiente virtual e online, reduzindo a quantidade de processos físicos.

\subsection{PONTO DE VISTA DOS ENTREVISTADOS}

Ao avaliarem sobre o treinamento, os respondentes indicam que foi oferecido um treinamento para o uso do sistema, todavia, no que se refere à capacidade de o treinamento ofertado em atender as demandas ocorreram manifestações diversas.

O treinamento foi considerado insuficiente por $45 \%$ dos respondentes. Para os demais respondentes, o treinamento é suficiente, tendo em vista a complexidade atual do trabalho, sinalizando a necessidade de mais treinamento caso o uso do sistema seja ampliado.

As unidades mostraram-se divididas com relação à usabilidade do sistema, o que mostra uma percepção diversa. Enquanto alguns respondentes disseram que o sistema é de fácil utilização, outros apontaram, como melhoria futura, a necessidade de torná-lo mais intuitivo. A disponibilidade do sistema recebeu elogios, em especial quando comparado aos demais sistemas usuais vinculados à intranet, salvo algumas poucas ressalvas relacionadas a uma indisponibilidade pontual em um dia específico da semana. Apenas uma unidade indicou problemas sérios com relação à disponibilidade do sistema.

Com relação às falhas do sistema, foram feitos apontamentos em relação a problemas no momento de adesão das demais unidades. Os usuários também indicaram que não participaram do desenvolvimento do sistema e que consideram isso uma falha.

A redução nos preços foi percebida pelos respondentes, que atribuem isso aos ganhos de escala advindos das maiores quantidades compradas. Outro ponto levantado foi o aumento da celeridade nos processos de aquisição e a redução da multiplicidade de compras realizadas. 
Não obstante, algumas unidades apresentaram uma visão cética com relação aos benefícios do Sistema Compras Web, em especial com sua associação o SRP; tal ceticismo está vinculado à perda na qualidade dos itens e à dificuldade de compra de determinados produtos, em geral os que têm seu preço influenciado por variações cambiais.

As unidades apontaram ainda que o sistema é bastante válido principalmente para unidades que têm problemas de armazenagem, pois permite que o estoque seja mantido no fornecedor.

Algumas unidades indicaram, ainda, problemas que se relacionam com o contexto geral das compras públicas e não necessariamente estão relacionados ao Sistema Compras Web, como, por exemplo, os atrasos nas entregas e a falta de execução dos contratos.

Alguns respondentes indicaram a necessidade de um estímulo maior ao uso, indicando que o sistema ainda é pouco utilizado em decorrência de aspectos da cultura organizacional, associados, em especial, a resistência em abrir mão da autonomia financeira em prol da racionalização dos procedimentos. Algumas unidades sugerem uma ação top-down por parte da reitoria no sentido de promover o uso do sistema, pois, de acordo com os respondentes, as unidades podem beneficiar-se muito da divisão de trabalho que a centralização das compras proporciona.

Figura 2 - Hierarquia dos assuntos abordados

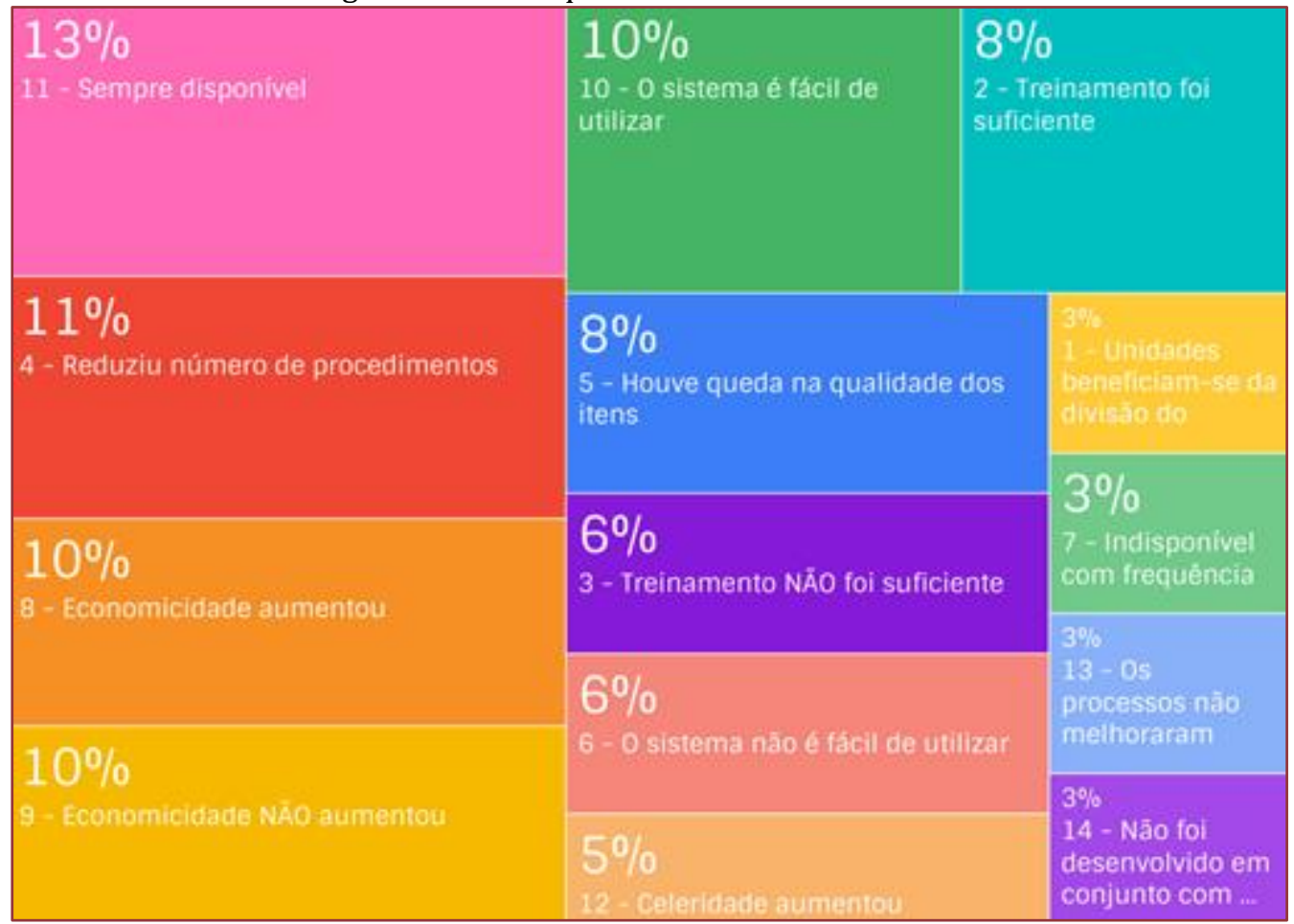

Fonte: Elaborado pelos autores com uso do software Nvivo.

\section{DISCUSSÃo}

Com base nas entrevistas e acompanhamento de alguns processos licitatórios, é possível afirmar que, no processo de contratação pública, há diversos entraves que prejudicam a eficiência nas licitações.

0 primeiro aspecto notado é que o menor preço atrelado à maior qualidade possível é uma questão considerada utópica pelos entrevistados, pois os licitantes usualmente abaixam o preço para ganhar a licitação, sem levarem em consideração as possíveis oscilações de preços de mercado, ou quando o produto é indexado ao dólar, ou se o preço do produto é inelástico, entre outros aspectos que podem impactar no seu custo. Isso leva a uma situação na qual dificilmente entregam o que se comprometeram, com a qualidade requerida no edital. Ou simplesmente desistem da venda, correndo o risco de sofrer punições para não ter prejuízos maiores. Ao final, observando-se que a queda do preço, foi acompanhada de uma queda na qualidade, conclui-se que não houve economia ou vantagens na compra. Em outras 
situações nas quais o preço registrado é maior que o de mercado, o procedimento é abandonado. Em ambos os casos a Administração Pública sai prejudicada.

Uma segunda questão a ser destacada está ligada com a o fator humano. A qualificação do funcionário público desta área, muitas vezes, é insuficiente para a complexidade demandada. Como não há qualificação do funcionário, é impossível que a ferramenta seja utilizada em todo seu potencial. Foi claramente observado isso nas entrevistas, quando algumas unidades (colocaram como ponto determinante que a elaboração do edital impacta diretamente na qualidade da mercadoria recebida. Ou seja, hoje, o pregoeiro atua com seus próprios entendimentos, formação (que não é devidamente oferecida pela instituição) e práticas que afetam diretamente no resultado a licitação. Bergann (ENAP, 2018a) aponta que a questão de "interpretação" deveria ser mitigada, para que toda a estruturação do processo licitatório fosse padronizada.

Essa consideração a respeito da qualificação dos servidores públicos, é corroborada pelas considerações de Fernandes (ENAP, 2018b), conforme afirmou em uma entrevista:

foi observado, numa experiência feita num estado do país, em que as licitações demoravam quatrocentos dias, entre o pedido e a assinatura do contrato. Depois da qualificação (dos servidores), passou a durar apenas cento e trinta dias, pois as pessoas passaram a ficar mais seguras; entenderam o que eram direitos do servidor e o que eram deveres do servidor.

Com relação ao SRP, foi notável que a maioria das unidades concordam que ele é muito efetivo no que se refere à economia de tempo, praticidade e agilidade do pedido. Contudo, também foi perceptível que existe insatisfação dos usuários com relação à instabilidade econômica que causa, em repetidas ocasiões, o cancelamento da compra e a consequente perda do trabalho despendido na sua realização.

A percepção com relação ao Compras Web, no que se refere a seu caráter tecnológico, é a de que o sistema tem muito a melhorar, em especial se comparado com a BEC que, embora não seja um substituto, é um sistema correlato que acaba servindo como patamar comparativo para os funcionários. A grande questão envolve a permanência dos processos físicos, que em geral são muito volumosos e tidos como arcaicos, dada a replicação de toda a informação ser feita no sistema Compras Web.

Outro problema apontado pelas unidades é a falta de uma integração real das unidades. Se o envolvimento entre eles fosse maior, impactaria num uso mais eficiente dessa ferramenta, conforme o propósito para o qual ela foi criada. Na prática, não existe uma grande centralização efetiva, apenas em situações de compras de itens mais comuns, nas quais há uma maior taxa de adesão de outras Unidades.

A troca entre a perda de autonomia e a economicidade advinda da centralização, aparentemente, parece estar mais vinculada a questões culturais que objetivas, do ponto de vista estratégico de cada unidade.

É preciso conscientizar os servidores, assim como a alta direção das unidades, das vantagens da compra centralizada. Ganho de escala, poder de barganha e padronização, melhor uso da capacitação escassa e eliminação de trabalho desnecessário são alguns dos benefícios, identificados pelos agentes do processo, que podem ser alcançados.

Em contrapartida, seria sacrificada em algum nível a celeridade, dado o número maior de agentes decisivos no processo, e algum aspecto de autonomia. Além disso, o grande volume de mercadorias, como de costume, geraria considerações acerca do custo de armazenagem x custo de registro do preço com entregas fracionadas (ENAP, 2018c).

\section{CONCLUSÃO}

Uma das maiores contribuições desta pesquisa é a de foi possível averiguar que o contexto envolvendo as compras públicas no âmbito de uma grande instituição de ensino e pesquisa da rede pública se mostra complexa. Há dois fatores para isso acontecer: o primeiro é pelo grande volume e variedade de compras que as instituições de ensino demandam, que fomentam desde materiais de limpeza, até produtos de laboratório técnicos científicos. O segundo fator que contribui para a complexidade vem a ser a questão central da pesquisa: os resultados desse estudo sugerem que, em muitos casos, os sistemas e os processos usados para realizar a compra podem não ser tão eficientes quanto o esperado. E a unificação do processo de compras dentro da Universidade acentuou esse problema em alguns casos e diminuiu em outros. 
Um fato interessante e relevante ocorrido durante o desenvolvimento da pesquisa, foi a mudança recente nos valores para compras diretas. Para as unidades que mais aderem às licitações em lugar de gerá-las, muitas vezes é mais vantajoso usar a dispensa da licitação que o registro do preço.

No geral, a proposta de unificar as compras na USP foi bem-sucedida quando é vista pela ótica das unidades que aderem mais às compras; contudo, nas unidades que iniciam um número maior de pregões com registro de preços acaba não sendo tão vantajoso, pois eles acabam tendo o mesmo volume de trabalho, caso fizessem um pregão sem registro de preço, e muitas vezes, não é percebida uma melhora nos preços das contratações, justamente pela incerteza da compra.

A figura dos fornecedores especializados em licitações foi abordada por alguns entrevistados durante as entrevistas. Houve críticas quanto à qualidade dos produtos entregues, porém o processo de encerramento do pregão passa a ser mais ágil, justamente por terem a documentação de acordo com os padrões exigidos pela Lei de Licitações.

Outro ponto que merece destaque é o reflexo da capacitação do profissional pregoeiro no resultado do pregão. Outras pesquisas, como discutido, mencionam o mesmo problema, o que foi corroborado pelas entrevistas. Um treinamento ineficiente do pregoeiro provavelmente resultará num edital elaborado com falhas, acarretando a entrega de um produto ou serviço de baixa qualidade.

A questão da comunicação entre as unidades também foi abordada durante as entrevistas. Após analisar os resultados das entrevistas, ficou evidente que há uma grande falha na comunicação entre os pregoeiros do campus da USP-RP que, apesar de suas falhas, também reflete no mau uso da ferramenta em questão, além da questão do treinamento. Caso houvesse maior integração entre os agentes, o compartilhamento de ideias e de visões poderia ajudar o agente a manusear melhor o sistema e aproveitar melhor seus recursos.

Após todas os achados desta pesquisa, é possível considerar que o Sistema Compras Web, apesar de revelar algumas deficiências, é eficiente, na medida em que gerou economicidade e rapidez em alguns processos de compras. São necessários aperfeiçoamentos, mas um sistema centralizado de compras se mostra vantajoso para a administração pública.

Perspectivas futuras de pesquisa podem voltar-se na direção de avaliar os mecanismos de seleção multicritério para a obtenção de contratações mais vantajosas nas licitações.

\section{REFERÊNCIAS}

[1] Aaker, D. A, Kumar, D., Day, G. (2001). Marketing Research (7th Ed.), New York: John Wiley \& Sons, Inc

[2] Araújo, L.M., \& Rodrigues, M. I. A. (2010). A relação entre os princípios da eficiência e da economicidade nos contratos administrativos. Revista do Serviço Público, 63, 46.

[3] Bittencourt, S. (2010). Pregão Eletrônico-revisado e ampliado. Belo Horizonte: Fórum.

[4] Boer, L., Harink, J., \& Heijboer, G. (2002). A conceptual model for assessing the impact of electronic procurement. European Journal of Purchasing \& Supply Management, 8(1), 25-33.

[5] Bolsa Eletrônica de Compras. (2017). Recuperado em https://www.bec.sp.gov.br/FAQ_UI/FAQ.aspx

[6] Brandão, F. T. (2016). Eficiência na gestão das compras públicas: um estudo de caso da modalidade pregão eletrônico nos processos licitatórios do Instituto Federal de Educação, Ciência e Tecnologia do Sertão Pernambucano. Dissertação de Mestrado. UFRN, Natal, RN, Brasil.

[7] Constituição da República Federativa do Brasil de 1988. (1998). Brasília. Recuperado em 17 agosto, 2017, de http://www.planalto.gov.br/ccivil_03/Constituicao/Constituicao.htm

[8] Decreto no 5.450, de 31 de maio de 2005 (2005). Regulamenta o pregão, na forma eletrônica, para aquisição de bens e serviços comuns, e dá outras providências. Recuperado em 25 junho, 2017, de http://www.planalto.gov.br/ccivil_03/_ato2004-2006/2005/decreto/d5450.htm

[9] Decreto $\mathrm{n}^{\circ}$ 7.892, de 23 de janeiro de 2013 (2013). Regulamenta o Sistema de Registro de Preços. Recuperado em janeiro, 2018, de https://www.al.sp.gov.br/repositorio/legislacao/decreto/2007/decreto-51469-02.01.2007.html

[10] Decreto no 9.412/18, de 18 de junho de 2018 (2018). Atualiza os valores das modalidades de licitação de que trata o art. 23 da Lei $\mathrm{n}^{\circ}$ 8.666, de 21 de junho de 1993. Recuperado em 05 novembro, 2018, de https://www2.camara.leg.br/legin/fed/decret/2018/decreto-9412-18-junho-2018-786866-publicacaooriginal155861-pe.html 
[11] Decreto $\mathrm{n}^{\circ}$ 51.469, de 02 de janeiro de 2007 (2007). Dispõe sobre a obrigatoriedade da modalidade de pregão para aquisição de bens e serviços comuns. Recuperado em 25 junho, 2017, de https://www.al.sp.gov.br/repositorio/legislacao/decreto/2007/decreto-51469-02.01.2007.html

[12] Dimitri, N. (2013). "Best value for money" in procurement. Journal of Public Procurement, 13(2), 149-175.

[13] ENAP - Escola Nacional de Administração Pública. (2018a). Sandro Bernardes, Thiago Bergmann e Arthur Pinho discutem o projeto da nova Lei de Licitações. Recuperado em 26 julho, 2018, de https://www.youtube.com/watch?v=mc_yFQaTgDQ\&feature=youtu.be

[14] ENAP - Escola Nacional de Administração Pública. (2018b). Professor Jacoby Fernandes fala sobre os 25 anos da Lei 8.666/93. Recuperado em 26 julho, 2018, de https://www.youtube.com/watch?v=6dzXTDIPuoc

[15] ENAP - Escola Nacional de Administração Pública. (2018c). Leonardo Ferreira fala sobre compras públicas no DF. Recuperado em 26 julho, 2018, de https://www.youtube.com/watch?v=fD5wFBz4WMI

[16] Faria, E. R. de, Ferreira, M. A. M., Santos, L. M. dos, \& Silveira, S. F. R. (2010). Fatores determinantes na variação dos preços dos produtos contratados por pregão eletrônico. Revista de Administração Pública, 44(6), 1405-1428.

[17] Faria, E. R., Ferreira, M. A. M, Santos, L. M, \& Silveira, S. F. R. (2011). Pregão eletrônico versus pregão presencial: estudo comparativo de redução de preços e tempo. Revista de Contabilidade do Mestrado em Ciências Contábeis da UERJ, v. 16, n. 1, p. 47-61.

[18] Fernandes, C. C. C. (2005). Abrangência, inserção e impacto transformador dos sistemas de compras eletrônicas na administração pública - análise do Siasg/Comprasnet. Revista do Serviço Público, 56, 2, 195-216.

[19] Freitas, J. (2007). Discricionariedade administrativa e o direito fundamental à boa administração pública (2a ed.). São Paulo: Malheiros.

[20] Freitas, M. de. (2011). Investigação das causas dos problemas de gestão e execução dos contratos de prestação de serviços contínuos, licitados por pregão eletrônico, pela Diretoria de Administração do CampusDIRAC/FIOCRUZ. Tese de Doutorado, Escola Nacional de Saúde Pública Sergio Arouca, Rio de Janeiro, RJ, Brasil.

[21] Governo Aberto SP. Recuperado em 08 agosto, 2017, de http://www.governoaberto.sp.gov.br/acesso-ainformacao

[22] Justen Filho, M. (2001). Comentários à Lei de Licitações e Contratos Administrativos. São Paulo: Dialética.

[23] Justen Filho, M. (2005). Curso de Direito Administrativo. São Paulo: Saraiva.

[24] Kariyado, M.Y. (2016). Proposta e aplicação de uma sistemática baseada na gestão do conhecimento para a melhoria do processo de compras públicas. Dissertação de mestrado. Universidade Federal de São Carlos, SP, Brasil.

[25] Kersten, G. E. (2014). Multiattribute procurement auctions: Efficiency and social welfare in theory and practice. Decision Analysis, 11(4), 215-232.

[26] Lei Complementar n. 123/2006, de 14 de dezembro de 2006 (2006). Institui o Estatuto Nacional da Microempresa e da Empresa de Pequeno Porte. Recuperado em junho, 2018, de http://www.planalto.gov.br/ccivil_03/Leis/LCP/Lcp123.htm

[27] Lei n. 8.666/93, de 21 de junho de 1993. (1993). Lei de Licitações. Recuperado em fevereiro, 2018, de http://www.planalto.gov.br/ccivil_03/LEIS/L8666cons.htm

[28] Lei n. 9.472/97, de 16 de julho de 1997. (1997). Dispõe sobre a organização dos serviços de telecomunicações, a criação e funcionamento de um órgão regulador e outros aspectos institucionais. Recuperado de http://www.planalto.gov.br/ccivil_03/LEIS/L9472.htm

[29] Lei n. 10.520/02, de 14 de julho de 2002. (2002). Lei da modalidade de licitação denominada Pregão. Recuperado em abril, 2018, de http://www.planalto.gov.br/ccivil_03/Leis/2002/L10520.htm

[30] Mendes, R. G. (2012). O Processo de Contratação pública - fases, etapas e atos. Curitiba: Zênite.

[31] Mithas, S., \& Jones, J. L. (2007). Do auction parameters affect buyer surplus in Eauctions for procurement? Production and Operations Management, 16(4), 455-470.

[32] Niebuhr, J. de M. (2013). Pregão Presencial e Eletrônico. Curitiba: Zênite.

[33] Pestana, M. (2013). Licitações Públicas no Brasil. São Paulo: Atlas.

[34] Setia, P., \& Speier-Pero, C. (2015). Reverse auctions to innovate procurement processes: effects of bid information presentation design on a supplier's bidding outcome. Decision Sciences, 46(2), 333-366.

[35] São Paulo, SP. Portal de Pregões do Governo do Estado: Cadastro de Pregões. Recuperado em 13 julho, 2019, de http://www.pregao.sp.gov.br/

[36] Setia, P., \& Speier-Pero, C. (2015). Reverse auctions to innovate procurement processes: effects of bid information presentation design on a supplier's bidding outcome. Decision Sciences, 46(2), 333-366. 
[37] Silveira, N. G, \& Ducati, E. (2014). O Custo do Pregão Eletrônico e a Aplicação do Princípio da Economicidade - Caso Eletrosul. Congresso UFSC de controladoria e finanças \& iniciação científica em contabilidade (Vol. 5).

[38] Souza, W. de; Teixeira, A. J. C. (2009). Um estudo sobre a viabilidade de implantação do pregão eletrônico e uma contribuição na apuração dos resultados nos processos licitatórios. Revista de Educação e Pesquisa em Contabilidade (REPeC), 2, 2, 75-94.

[39] USP - Universidade de São Paulo. Departamento de Administração - USP, Compras Web. Recuperado em 04 maio, 2017, de http://www.usp.br/da2/?q=node/75

[40] USP - Universidade de São Paulo. (2018). Usp em Números - 2015. Revisitado em 13, 2017, de https://uspdigital.usp.br/anuario 


\section{Capítulo 21}

Crescimento pró-pobre na Amazônia Legal: Uma análise para o decênio 2004-2014 com dados em painel

\section{Luan Gomes de Oliveira}

Abner Vilhena de Carvalho

Rhayza Alves Figueiredo de Carvalho

Jarsen Luis Castro Guimarães

Márcio Júnior Benassuly Barros

Mario Tanaka Filho

Rodolfo Maduro Almeida

Ednéa do Nascimento Carvalho

Resumo: Este artigo procura verificar se no decênio 2004 a 2014 o crescimento econômico experimentado na região da Amazônia Legal pode ser considerado própobre, ou seja, se beneficiou mais os mais pobres. Sob a ótica recente da literatura sobre o crescimento pró-pobre a metodologia empregada foi a elasticidade renda-pobreza, estimada mediante uso de modelos econométricos de dados em painel. Os resultados mostraram que embora a maioria dos estados da região apresentarem desempenho abaixo da média do país na redução do indicador de pobreza, a elasticidade rendapobreza estimada para região se mostrou suficiente para configurar o crescimento como pró-pobre.

Palavras-chave: Crescimento; Desigualdade; Pobreza; Pró-pobre; Amazônia legal. 


\section{INTRODUÇÃO}

Os estados da Amazônia Legal concentram boa parte da proporção total de pobres do Brasil. Segundo dados do IPEA em 2014 do total de 25.888.565 de pessoas consideras pobres no país, mais de 6 milhões viviam nos estados da Amazônia Legal, o que corresponde a quase $24 \%$ do número total de pobres, vale ressaltar que a população total da região representa somente $13,48 \%$ da população brasileira. A Amazônia Legal e o Nordeste correspondem por 70\% do número total de indivíduos considerados pobres no país.

Contrário a esse cenário temos a expansão econômica que tanto o país como a região da Amazônia Legal tem experimentado, em especial no período de 2004 a 2014, onde a partir de 2004 o aumento na demanda internacional de commodities passou a favorecer o desempenho econômico dos países em desenvolvimento dotados de recursos naturais, fazendo com que nesse período o país experimentasse as maiores taxas de crescimento pós Plano Real (BALTAR, 2015). Segundo dados do IPEA (2014) o PIB da região medido a preços corrente ${ }^{2}$ para ano de 2014 correspondia cerca de $8,41 \%$ do PIB nacional, um aumento na participação quando comparado com 2004 onde era de somente $7,79 \%$, a média de crescimento anual do produto corrente dos estados da região nesse período foi de $12 \%$, acima da média nacional que no período que foi de $11 \%$.

Constitui-se um contraste, de um lado a pobreza que segundo Rocha (2003) pode ser entendida como uma situação onde as necessidades não são atendidas de forma satisfatória dada à escassez de renda e do outro, o crescimento econômico, que se traduz justamente em uma maior produção de bens e serviços, e com isso o aumento da renda agregada. Por muito tempo o pensamento dominante na literatura econômica era de que essa equação seria facilmente resolvida, bastava existir crescimento econômico que o problema da pobreza estaria resolvido, mas não foi o que a experiência econômica mostrou, nem sempre o crescimento se traduz em mais benefícios para os mais pobres, ou seja, em desenvolvimento (SOUZA, 2006; VEIGA, 2010; SANTOS, 2011).

Nesse sentido surge dentro da literatura sobre o desenvolvimento a análise pró-pobre, não existe um consenso teórico sobre suas definições e metodologias no que se considera um crescimento como própobre ou não. Mas em suma, a análise pró-pobre busca analisar os benefícios do crescimento econômico para os mais pobres.

Sabendo, que o crescimento econômico constitui-se condição necessária, mas não suficiente para o desenvolvimento (MANSO et al., 2008; SOUZA, 2008; THOMAZ et al., 2002) procuramos saber se no período 2004 a 2014 o crescimento econômico na região da Amazônia Legal foi pró-pobre? Com isso constitui-se objetivo geral desse trabalho estimar as elasticidades renda-pobreza e desigualdade-pobreza para Amazônia Legal para período 2004-2014 e partir dos resultados pode se aferir se o crescimento foi pró-pobre ou não. A escolha do período de análise se deve por duas razões, é o último decênio que se tem dados disponível no IPEADATA, além de ser o período recente em que se registraram as maiores taxas de crescimento do produto agregado.

Seguinte a essa introdução é feita uma breve discussão conceitual acerca do tema, posteriormente é apresentado a metodologia empregada no trabalho onde será detalhado as estimações das elasticidades mediante a utilização de dados em painel. E em seguida os resultados das estimações do modelo econômico, bem como um panorama da evolução dos indicadores de renda, pobreza e desigualdade dos estados da Amazônia Legal.

\footnotetext{
2 O PIB a preços correntes consiste no produto do período calculado a preços do mesmo período. Vale ressaltar com isso, a diferença entre PIB a preços correntes e PIB a preços constantes. PIB a preços constantes é o Produto do período medido a preço do período anterior, a diferença está no efeito inflacionário sobre os resultados, sendo a PIB a preços constantes também chamado de PIB real, por considerar o efeito da inflação sobre o resultado do Produto interno Bruto. O PIB a preços constantes para os estados Brasileiros pode ser encontrado para o período 2002-2012 e PIB a preços correntes para período 2004-2014 através do por portal IPEADATA em: http://www.ipeadata.gov.br/Default.aspx
} 


\section{CRESCIMENTO ECONÔMICO VERSUS DESENVOLVIMENTO ECONÔMICO}

A ciência econômica nasce tendo com foco central o crescimento econômico. Adam Smith um dos precursores do pensamento econômico, em sua obra "A Riqueza das Nações" procurou identificar justamente isso, as causas do crescimento econômico e de como ele contribuía para a elevação do bemestar geral da população. Não só nas obras de Adam Smith, mais outros economistas clássicos como David Ricardo e Malthus a preocupação com crescimento econômico é central (SOUZA, 2008).

Dado a importância que o crescimento econômico possui na teoria econômica desde sua formulação foi natural que logo se assimilasse o processo de crescimento como sinônimo do desenvolvimento econômico, embora hoje tratados como processos distintos, foi por muito tempo dominante essa similaridade dentro da literatura econômica. Tanto que o PIB per capita foi por muito tempo um indicador usado para medir o desenvolvimento e servir de comparações entre os países, até que no final da década de 1990, o PNUD (Programa das Nações Unidas para o Desenvolvimento) lançou o IDH (Índice de Desenvolvimento Humano) como uma alternativa a visão unidimensional da renda (VEIGA, 2010).

Essa visão de similaridade entre crescimento e desenvolvimento parte do pressuposto de que os benefícios do crescimento se espalham automaticamente por todos os segmentos da sociedade, esse pensamento ficou sendo conhecido como teoria do trickle-down. Esse pensamento foi dominantes durante as décadas de 1950 e 1960 e serviram de base para formulação das políticas econômicas a época (PINTO; OLIVEIRA, 2010; SANTOS, 2011).

Segundo Veiga (2010) até o início da década de 1960 não se tinha a necessidade tão clara de distinguir desenvolvimento de crescimento econômico, pois naquela época as poucas nações consideradas desenvolvidas eram justamente aquelas que tinham experimentado um intenso processo de industrialização, o que reforçava a ideia de similaridade entre crescimento e desenvolvimento.

No entanto existe hoje um consenso na literatura empírica sobre desenvolvimento econômico, de que embora o aumento da renda seja condição necessária, não é por si só, condição suficiente para a redução da pobreza (MANSO et al., 2008; SOUZA, 2008; THOMAZ et al., 2002). O que marca essa mudança na literatura, da necessidade de se distinguir crescimento econômico do processo de desenvolvimento econômico, foi justamente a experiência de diversos países semi-industrializados na década de 1950, a exemplo do Brasil, onde os mesmos tiveram nesse período um intenso crescimento econômico, mas esse crescimento não veio acompanhado de melhorias sociais, em especial para as camadas mais pobres da sociedade. E nesse período que surge a economia do desenvolvimento, como um campo de estudos dentro da economia, tendo como foco de análise principal as causas do subdesenvolvimento (VEIGA, 2010; MOREIRA; CRESPO, 2012).

Embora o tema do desenvolvimento venha sendo discutido a décadas dentro da literatura, ainda é um debate em construção, e hoje tratado como problema multidimensional, não havendo uma definição única para o que seja o desenvolvimento econômico, no entanto, existe um consenso teórico de que ele pode ser distinguido do crescimento econômico (VEIGA,2010). Segundo Souza (2008) enquanto o crescimento diz respeito aos efeitos quantitativos no produto, o desenvolvimento é um processo mais amplo de mudanças qualitativas no modo de vida das pessoas.

Segundo Paulani (2007) na mesma linha de pensamento de Souza (2008) enquanto o crescimento econômico diz respeito a elevação do produto agregado do país podendo ser facilmente avaliado e mensurado a partir das contas nacionais o desenvolvimento é um conceito bem mais abrangente, leva em conta a elevação da qualidade de vida da sociedade e a redução das diferenças econômicas e sociais entre seus membros.

\subsection{CRESCIMENTO PRÓ-POBRE}

De acordo com Kakwani, Khander e Son (2004) apud Pinto e Oliveira (2010) os estudos do crescimento pró-pobre tem seu início contemporâneo ao surgimento da economia do desenvolvimento, nasce da crítica à teoria do trickle-down. Mas, o termo pró-pobre só veio ganhar forma a partir da década de 1990 onde passou a ser incluindo no Relatório de Desenvolvimento Humano da ONU (PINTO; OLIVEIRA, 2010). 
Embora o debate sobre o crescimento pró-pobre tenha surgido há algumas décadas, ainda não existe um consenso dentro da literatura quanto a uma definição única do seja um crescimento pró-pobre. Segundo Barreto (2005), as quatro principais definições teóricas são: a de Lopes (2004); Ravallion e Chen (2003): White e Anderson (2000); Kalkwani e Pernia (2000)

As abordagens se dividem em duas vertentes: na análise do crescimento econômico, pobreza e desigualdade apresentam-se Lopes (2004); White e Anderson (2000); Kalkwani e Pernia (2000); Crescimento econômico e pobreza temos Ravallion e Chen, (2003). Na primeira abordagem, para que haja um crescimento pró-pobre é necessária que a renda dos mais pobres cresça além da dos não pobres, havendo assim redução da desigualdade; sendo também considerada definição forte de crescimento própobre; a segunda definição, para que o crescimento seja pró-pobre basta apenas que ocorra uma redução na pobreza com crescimento econômico, considerada definição fraca de crescimento pró-pobre (SANTOS, 2011; PINTO; OLIVEIRA, 2010).

A partir da definição de crescimento pró-pobre escolhida, a análise pode se dividir em duas abordagens: parcial ou completa. A análise parcial não utiliza uma linha de pobreza ou indicador, sendo válido para qualquer linha de pobreza e possibilita classificar o crescimento como pró-pobre e não pró-pobre a partir de uma definição forte, uma de suas limitações é fato de não medir o grau de crescimento pró-pobre e nem permitir se fazer comparações entre duas situações. A abordagem completa, por sua vez, utiliza além de uma linha de pobreza um índice, o que possibilita medir grau de benefícios dos pobres em relação aos demais indivíduos da sociedade, sendo possível classificar o crescimento em pró-pobre a partir das duas definições (forte e fraca), além de se estimar o grau de crescimento pró-pobre e permitir comparações entre duas situações distintas (SANTOS, 2011).

Para mensurar o crescimento pró-pobre diversos autores têm tentado desenvolver metodologias, a utilização de cada metodologia dependerá da abordagem e definição que se dar ao crescimento pró-pobre. São três as principais metodologias utilizadas nos trabalhos: Curva de Incidência do Crescimento (Ravallion e Chen 2003), para uma definição forte de crescimento e uma abordagem parcial; Taxa de Crescimento Pró-pobre (Ravallion e Chen, 2003) e elasticidade-renda da pobreza (Datt e Ravallion, 1992) para uma definição forte ou fraca e uma abordagem completa (PINTO; OLIVEIRA 2010; SANTOS, 2011).

Adotando uma definição forte de crescimento pró-pobre e uma abordagem completa na análise, o crescimento pró-pobre pode ser classificado como: i) pró-pobre quando o aumento da renda do pobre é superior à dos não pobres; ii) não pró-pobre quando a renda dos pobres cresce menos que a dos não pobres; iii) empobrecedor, quando há um crescimento econômico positivo, mas, há uma redução na renda dos mais pobres; iv) inconclusivo quando um padrão de crescimento não se enquadra em nenhum desses anteriores (RESENDE et al., 2007).

\section{METODOLOGIA}

\section{1. ÁREA DE ESTUDO E FONTE DE DADOS}

A Amazônia Legal corresponde a cerca de 59\% do território brasileiro e engloba os sete estados da Região Norte, Acre, Amapá, Amazonas, Pará, Rondônia, Roraima e Tocantins, mais um estado do Centro-Oeste, Mato Grosso, e um do Nordeste, o Estado do Maranhão (considerado integralmente da Amazônia Legal em 2008, anteriormente somente a parte oeste do meridiano de $44^{\circ} \mathrm{W}$ pertencia a Amazônia Legal) (IPEA, 2008). 0 que totalizando nove estados, em uma área 5,0 milhões de $\mathrm{km}^{2}$, onde vivem mais de 27 milhões de pessoas, segundo dados do IPEA em 2014.

O conceito de Amazônia Legal foi instituído em 1953 para fins de planejamento governamental para o desenvolvimento econômico da região, por isso a seus limites territoriais não se resumem ao ecossistema de selva úmida. Os limites da Amazônia Legal foram alterados várias vezes em consequência de mudanças na divisão política do país, a exemplo do Plano Amazônia Sustentável (PAS), que considerou integralmente o Estado do Maranhão como parte da Amazônia Brasileira em 2008 (IPEA, 2008).

Para os objetivos do presente estudo, utilizaram-se os dados da Pesquisa Nacional por Amostra de domicilio (PNAD) sobre: renda per capita domiciliar média (proxy do crescimento econômico); índice de Gini (proxy da desigualdade de renda); proporção de domicílios pobres (proxy da pobreza), para os anos de 2004 a 2014, com exceção do ano de 2010 que foi realizado o censo. 
Para Manso et al. (2006) a discussão sobre o impacto do crescimento da renda sobre o nível de pobreza deve primeiramente iniciar com correta delimitação da dimensão que se queira dar à pobreza, entendida nesse trabalho como um fenômeno monetário, dado pela escassez de renda, o que justifica a escolha das proxy utilizadas neste trabalho.

Todos os dados foram obtidos pelo portal IPEADATA, com isso, a linha de pobreza considerada nesse trabalho é a mesma do IPEA, que corresponde ao dobro da linha de extrema pobreza, sendo uma estimativa do valor de uma cesta de alimentos com o mínimo de calorias necessárias para suprir adequadamente uma pessoa, com base em recomendações da FAO (Organização das Nações Unidas para a Alimentação e a Agricultura) e da OMS (Organização Mundial da Saúde).

\subsection{ELASTICIDADES RENDA-POBREZA E DESIGUALDADE-POBREZA}

Dentro da linha de pesquisa sobre o desenvolvimento econômico, o crescimento pró-pobre pode ser considerado um assunto relativamente novo, pois embora tenha surgido a algumas décadas, só veio ganhar forma a partir do final da década de 1990 (PINTO; OLIVEIRA, 2010). Não havendo com isso um consenso quanto á definições e formas de se calcular o crescimento pró-pobre. A metodologia que vem sendo mais utilizada nos trabalhos sobre o crescimento pró-pobre no Brasil é a elasticidade-renda da pobreza, de Datt e Ravallion (1992). Que será a metodologia adotada nesse trabalho, seguindo os trabalhos de Pinto e Oliveira (2010), Santos (2011), Godoy e Rodrigues (2017).

A metodologia das Elasticidades Renda-Pobreza e Desigualdade-Pobreza, consistem em medir a sensibilidade da pobreza em relação ao aumento da renda, e da redução da pobreza em relação a mudanças na desigualdade. Isso permite se obtenha a elasticidade total a partir de duas elasticidades parciais (SANTOS, 2011).

Com isso temos que: Elasticidade parcial renda-pobreza possibilita medir a sensibilidade da pobreza em relação ao crescimento da renda, também considerado o "efeito crescimento puro", uma vez que considera apenas o impacto da variação da renda sobre a pobreza; Elasticidade parcial desigualdade-pobreza objetiva medir a sensibilidade da pobreza em relação à redução na desigualdade considerando somente o impacto da variação da distribuição de renda sobre a pobreza, e a renda constante, sendo denominado de "efeito distribuição puro" (SANTOS, 2011).

O conceito de elasticidade aqui empregado é similar ao da microeconomia, ou seja, há elasticidade quando uma variação percentual em uma variável causa uma variação percentual em mesma proporção em outra variável. Nesse ponto, reside a principal divergência entre os pesquisadores, em qual magnitude de variação da diminuição da pobreza em relação ao aumento da renda pode ser considerado um crescimento como pró-pobre ou não? Para os defensores da definição fraca, basta apenas que a pobreza reduza com o crescimento econômico, não se importando com a magnitude dessa redução, podendo ser menor que 1 (inelástica). Já para os defensores da definição forte, o crescimento só pode ser considerado pró-pobre se os benefícios para os mais pobres forem maiores, nesse caso, o aumento da renda dos mais pobres deve ser maior do que os dos não pobres, com isso temos uma elasticidade acima de 1 (elástica) (PINTO; OLIVEIRA, 2010; SANTOS, 2011).

\subsection{MODELO ECONOMÉTRICO DE ESTIMAÇÃO COM DADOS EM PAINEL}

0 modelo de regressão com dados em Painel consiste na combinação de séries temporais com observações de corte transversal, sendo com isso, observações sobre as mesmas unidades de corte transversal, ou individuais (nesse caso, os estados da Amazônia Legal) em vários períodos de tempo.

Modelos de dados em painel seguem a seguinte formulação geral:

$$
Y_{i t}=\beta_{0 i}+\beta 1_{1 i t} X_{i t 1}+\beta 2_{2 i t} X_{i t 2}+\ldots+\beta K_{K i t} X_{k t i}+u_{i t}
$$

Os modelos com dados em painel se diferenciam da série temporais ou corte transversal, por apresentarem um índice duplo para cada variável, sendo $i$ a dimensão das unidades estatísticas, que varia de $1, \ldots, \mathrm{N}$, e $t$ sendo a dimensão tempo, variando de $1, \ldots, \mathrm{T}$. 
O número total de observações é obtido pela multiplicação das dimensões temporal e corte transversal , ou seja, $\mathrm{N}$ x T. Naturalmente, Y representa a variável dependente ou aquela a ser explicada em termos de $k$ variáveis independentes $X_{i t 1}, X_{i t 2}, X_{k t i}$. 0 intercepto e os parâmetros de inclinação não são conhecidos. Por fim, tem-se o termo de resíduo $U_{i t}$, não observado e aleatório.

0 modelo construído para o presente estudo possuirá 9 unidades estatísticas (Estados) sendo a dimensão de tempo 10 períodos (2004-2014), com isso $i$ variará de 1,2,3,4,5,6,7,8,9 e $t=1,2,3,4,5,6,7,8,9,10$, sendo o número total de observações do modelo igual a 90 . No modelo será empregado logaritmo natural nas variáveis dependentes e explicativas, o que possibilitará obter as elasticidades, de quanto uma variação percentual de $Y$ corresponde em uma variação percentual em $X$. Modelo terá a seguinte forma:

$$
\ln P_{i t}=\beta_{0}+\beta 1_{i t} \ln Y_{i t}+\beta 2_{i t} \ln \operatorname{Gini}_{i t}+u_{i t}
$$

Onde: $P_{i t}=$ Proporção de domicílios pobres; $Y_{i t}=$ Renda domiciliar per capita; Gini $i t=$ Coeficiente de Gini; $u_{i t}$ =Termo de erro idiossincrático.

O modelo possui a proporção de pobres como variável dependente e a renda familiar per capita como variável explicativa, além da variação do índice de Gini como mais uma variável explicativa no modelo, seguindo a metodologia utilizada por Pinto e Oliveira (2010) e Santos (2011), que justificam a inclusão da variação do índice de Gini no modelo, com intuito de se captar também o efeito da redução da desigualdade para a redução da pobreza.

Os resultados de $\beta_{1}$ e $\beta_{2}$ respectivamente, forneceram os resultados das elasticidades renda-pobreza e desigualdade-pobreza para Amazônia Legal no período de 2004 a 2014, sendo possível se aferi se no período o crescimento foi pró-pobre ou não. Para que o crescimento seja considerado pró-pobre o valor encontrado para $\beta_{1}$ deverá ser negativo e superior à unidade. Indicando que o aumento de $1 \%$ na renda familiar per capita resulta em uma redução superior a $1 \%$ na pobreza. Seguindo com isso uma definição forte de crescimento pró-pobre.

Várias são as vantagens de se usar dados em painel segundo Gujarati (2006), além de aumentar consideravelmente o tamanho da amostra, oferece dados mais informativos, leva em conta a heterogeneidade das unidades (nesse caso, estados), menos colinearidade entre variáveis, mais graus de liberdade e mais eficiência, sendo cada vez mais usados nos trabalhos acadêmicos da área das ciências sociais aplicadas. Além do que, conforme destaca Pinto e Oliveira (2010) não seria possível estimar um modelo para cada estado separadamente, já que para isso seriam necessárias mais de 30 observações para cada unidade de corte transversal.

Apesar de suas vantagens substanciais, a adoção do método de dados em painel impõe vários problemas de estimação e inferência. Uma vez que esses dados envolvem tanto dimensões temporais quanto de corte transversal, os problemas inerentes aos dados de corte transversal (por exemplo, heterocedasticidade) e de séries temporais (por exemplo, autocorrelação) precisam ser tratados. Há também alguns problemas adicionais, como de correlação cruzada de unidades individuais no mesmo ponto no tempo. As técnicas de estimação mais utilizadas para tratar de um ou mais desses problemas são: (1) o Modelo de Efeitos Fixos (MEF) e (2) o modelo de efeitos aleatórios (MEA), ou também chamado de Modelo Componentes dos Erros (MCE) (GUJARATI, 2006).

A diferença fundamental entre o modelo de efeitos fixos e Aleatórios segundo Gujarati (2006) reside que no primeiro, a unidade de corte transversal tem seu próprio valor (fixo) de intercepto em todos esses $N$ valores para $N$ unidades de corte transversal. Já no modelo de efeitos aleatórios, por outro lado, o intercepto (comum) representa o valor médio de todos os interceptos (de corte transversal) e o componente de erro representa o desvio (aleatório) do intercepto individual desse valor médio.

Tem-se que: i) Modelo de efeitos fixos (EF): que supõe, que o termo $\beta_{0}$ é uma variável aleatória não observada e correlacionada com alguma (s) das variáveis explicativas. 
Sendo o intercepto agora composto pelo coeficiente autônomo $\left(\beta_{0}\right)$ mais o termo não observado específico a cada unidade $\left(\delta_{\mathrm{i}}\right)$. Sendo gerando o seguinte modelo:

$$
\ln P_{i t}=\beta_{0 i}+\beta 1_{i t} \ln Y_{i t}+\beta 2_{i t} \operatorname{lnGini}_{i t}+U_{i t}
$$

Onde: o subscrito $i$ no intercepto decorre do fato de que $\beta_{0 \mathrm{i}}=\left(\beta_{0_{+}} \delta_{\mathrm{i}}\right)$.

(II) Modelo de efeitos aleatórios (EA): nesse modelo se supõe que a heterogeneidade não está correlacionada com as variáveis explicativas, o que implica considerar que o erro de composição do modelo, pode ser composto pelo efeito não observado e pelo erro idiossincrático $\delta_{i}+\varepsilon_{i t}=v_{i t}$, o modelo toma a seguinte forma:

$$
\ln P_{i t}=\beta_{0 i}+\beta 1_{i t} \ln Y_{i t}+\beta 2_{i t} \operatorname{lnGini}_{i t}+V_{i t}
$$

A distinção entre os dois modelos consiste que no uso de efeitos fixos supõe-se que $\delta_{i}$ (efeito não observado) apresenta correlação com alguma das variáveis explicativas, enquanto a utilização de efeitos aleatórios requer $\delta_{i}$ não seja correlacionado com nenhuma das variáveis independentes (GUJARATI, 2006; PINTO; OLIVEIRA, 2010).

Assim, para auxiliar na escolha do método mais adequado para presente estudo, foi utilizado o teste de Hausman para verificar a hipótese de endogeneidade do termo não observado, verificando a possível existência de correlação entre $\delta_{i}$ e alguma(s) das variáveis explanatórias (GUJARATI, 2006).

0 teste de Hausman tem como hipótese nula a ausência de diferenças sistemáticas entre os estimadores dos dois métodos (EF e EA). Caso o valor do teste seja suficiente para rejeitar $\mathrm{H}_{0}$, sugere-se o uso do modelo de efeitos fixos (EF) como o modelo mais adequado, do contrário, caso não seja possível rejeitar $\mathrm{H}_{0}$, sugere-se que as estimativas do modelo de efeitos aleatórios sejam além de não viesadas e consistentes as mais eficientes (GUJARATI, 2006).

Além de se testar endogeneidade do termo não observado, será realizado outros testes de adequação do modelo para garantir que os resultados sejam confiáveis. 0 teste de especificação de Chow para auxiliar na decisão quanto ao uso do modelo de efeitos fixos ou pooled, a decisão se dará pela observação do p-valor do Teste F nos resultados da estimação do modelo de efeitos fixos. Nesse teste, a rejeição da hipótese nula indica que o modelo de efeitos fixos é preferível ao modelo pooled; Teste de Breusch-Pagan (BP) para verificar a hipótese de que não há efeitos aleatórios, tendo como hipótese nula $\left(\mathrm{H}_{0}\right)$ de que o modelo MQO (Mínimos Quadrados Ordinários) agrupado (pooled) é adequado, e a hipótese alternativa $\left(\mathrm{H}_{1}\right)$ a existência de efeitos aleatórias.

Além disso, se verificará a possível presença de heterocedasticidade e autocorrelação. Toda a modelagem estatística como a estimação dos parâmetros e os testes de adequação do modelo será realizada através do software livre de estatística Gretl.

\section{RESULTADOS}

\subsection{EVOLUÇÃO DA RENDA PER CAPITA}

O bom desempenho econômico do País no decênio 2004-2014 repercutiu no aumento da renda domiciliar média do país nesse período, conforme mostra a Tabela 1. 
Tabela 1 - Renda Domiciliar Média: Regiões Brasileiras (2004-2014)

\begin{tabular}{|c|c|c|c|}
\hline Região & 2004 & 2014 & $\Delta 2004 / 2014$ \\
\hline Região Centro-oeste & 792,03 & $1.394,4$ & $76,10 \%$ \\
\hline Região Norte & 471,68 & 782,76 & $66,00 \%$ \\
\hline Região Nordeste & 400,04 & 730,24 & $82,50 \%$ \\
\hline Região Sul & 870,68 & $1.413,81$ & $62,40 \%$ \\
\hline Região Sudeste & 849,97 & $1.378,32$ & $62,20 \%$ \\
\hline Amazônia Legal $^{*}$ & 488,42 & 869,31 & $78,00 \%$ \\
\hline Brasil & 691,55 & $1.152,24$ & $66,60 \%$ \\
\hline
\end{tabular}

Fonte: Elaboração do autor (2018) - IPEADATA.

* dados obtidos a partir da média dos valores da renda domiciliar média anual dos nove estados que compõe a Amazônia legal.

Em todas as regiões do país houve aumento na renda domiciliar média, e em termos de crescimento percentual a renda na região da Amazônia Legal cresceu acima da média nacional, região Sul e Sudeste apresentaram o menor crescimento, o que explica o desempenho menor da renda média do país. No entanto, quando comparamos a renda absoluta, a renda domiciliar média da região era em 2014 cerca de quase $25 \%$ menor que a nacional. Comparando com a renda média das regiões mais desenvolvidas do país (Sul e Sudeste) a diferença é ainda maior, a renda da região é menor, aproximadamente $38,51 \%$ em comparação com a da região Sul, e 36,93\% com a região Sudeste. Evidenciando a grande desigualdade regional existente no país.

A tabela 2 mostra a renda domiciliar média per capita no período 2004-2014 para nove estados da região.

Tabela 2 - Renda Domiciliar Média Per Capita: Estados Da Amazônia Legal 2004-2014

\begin{tabular}{|l|c|c|c|}
\multicolumn{1}{c|}{ Estados } & 2004 & 2014 & $\Delta 2004 / 2014$ \\
\hline Acre & 495,28 & 791,68 & $59,8 \%$ \\
\hline Amazonas & 459,84 & 833,68 & $81,3 \%$ \\
\hline Amapá & 471,19 & 911,83 & $93,5 \%$ \\
\hline Maranhão & 352,13 & 614,2 & $74,4 \%$ \\
\hline Mato Grosso & 695,39 & $1.204,76$ & $73,2 \%$ \\
\hline Pará & 449,39 & 676,49 & $50,5 \%$ \\
\hline Rondônia & 588,85 & 950,16 & $61,4 \%$ \\
\hline Roraima & 387,84 & 946,82 & $144,1 \%$ \\
\hline Tocantins & 495,87 & 894,2 & $80,3 \%$ \\
\hline Amazônia Legal* & 488,42 & 869,31 & $78,0 \%$ \\
\hline \multicolumn{1}{|c|}{ Brasil } & 691,55 & $1.152,24$ & $66,6 \%$ \\
\hline
\end{tabular}

Fonte: Elaboração do autor (2018) - IPEADATA.

* dados obtidos a partir da média dos valores, da renda domiciliar média anual dos nove estados que compõe a Amazônia legal.

Percebe-se nesse período um ciclo ascendente na renda domiciliar média dos estados, apresentando um crescimento de: 59,84\% no Acre; Amazonas 81,30\%; Amapá 93,52\%; Maranhão 74,42\%; Mato Grosso 73,25\%; Pará 50,54\%; Rondônia 61,36\%; Roraima 144,13\%; Tocantins 80,33\%. Comparando, em termos percentuais, o comportamento da renda domiciliar média nacional que teve um crescimento $66,62 \%$ no período a maioria dos estados com exceção de Acre e Rondônia, tiveram um crescimento acima da média nacional. No geral, a renda média na região cresceu 77,98\%.

No entanto, embora os estados da região venham experimentando esse ciclo de crescimento na renda domiciliar média, a renda média da região se encontra bem abaixo da média nacional. 0 único estado que possui uma renda absoluta superior à média nacional é o estado de Mato Grosso, os demais no período 2004-2014 seguiram uma trajetória abaixo da renda média do país.

Outra maneira de se avaliar o comportamento da evolução da renda domiciliar média na região é a partir da renda média por décimo da população, que consiste na média de renda domiciliar per capita mensal dos indivíduos da população ordenados a partir da renda crescente, e dividida em dez grupos com o mesmo número de pessoas (IPEA, 2018). 
Sendo o $1^{\text {o }}$ décimo correspondente aos $10 \%$ de indivíduos com a menor renda, e o 10ำ décimo de renda corresponde aos $10 \%$ dos indivíduos com a maior renda, a série é calculada a partir das respostas à Pesquisa Nacional por Amostra de Domicílios (PNAD/IBGE), com valores reais aos preços vigentes na realização da última edição da pesquisa, atualizados conforme o deflator para rendimentos da PNAD apresentado pelo IPEADATA.

A análise da renda a partir dos décimos possibilita comparar a evolução da renda dos mais pobres e dos mais ricos no período de 2004-2014. E os resultados mostram que não só a renda média dos mais pobres cresceu, como cresceu em uma proporção percentual acima ao crescimento da renda dos mais ricos.

Tabela 3- Renda domiciliar média por decimo da população na Amazônia Legal

\begin{tabular}{|c|c|c|c|c|c|c|}
\hline \multirow{2}{*}{ Estados } & \multicolumn{3}{|c|}{$10 \%$ mais pobres } & \multicolumn{3}{|c|}{$10 \%$ mais ricos } \\
\hline & 2004 & 2014 & $\Delta$ 2004-2014 & 2004 & 2014 & $\Delta$ 2004-2014 \\
\hline Acre & 45,68 & 80,42 & $76,10 \%$ & $2.399,09$ & $3.379,24$ & $40,90 \%$ \\
\hline Amazonas & 49 & 104,34 & $112,90 \%$ & $1.936,13$ & $3.534,01$ & $82,50 \%$ \\
\hline Amapá & 50,87 & 166,18 & $226,70 \%$ & $1.991,62$ & $3.200,08$ & $60,70 \%$ \\
\hline Maranhão & 25,3 & 60,51 & $139,10 \%$ & $1.783,23$ & $2.573,44$ & $44,30 \%$ \\
\hline Mato Grosso & 87,19 & 204,84 & $134,90 \%$ & $2.898,66$ & $4.437,08$ & $53,10 \%$ \\
\hline Pará & 60,94 & 94,44 & $55,00 \%$ & $1.956,60$ & $2.569,72$ & $31,30 \%$ \\
\hline Rondônia & 87 & 136,45 & $56,80 \%$ & $2.476,34$ & $3.405,59$ & $37,50 \%$ \\
\hline Roraima & 9,27 & 140,24 & $1413,70 \%$ & $1.721,55$ & $3.742,13$ & $117,40 \%$ \\
\hline Tocantins & 52,68 & 100,73 & $91,20 \%$ & $2.193,78$ & $3.619,92$ & $65,00 \%$ \\
\hline Amazônia legal* & 51,99 & 120,91 & $132,50 \%$ & $2.150,78$ & $3.384,58$ & $57,40 \%$ \\
\hline Brasil & 59,42 & 133,12 & $124,00 \%$ & $3.135,08$ & $4.711,91$ & $50,30 \%$ \\
\hline
\end{tabular}

Fonte: Elaboração do Autor (2018) - IPEADATA

* dados obtidos a partir da média dos valores, da renda domiciliar média anual dos nove estados que compõe a Amazônia legal.

Em todos os estados da Amazônia legal a renda do décimo mais pobres da população, teve um crescimento maior que o décimo de renda dos mais ricos. Em média, na região da Amazônia Legal a renda dos $10 \%$ mais pobres cresceu $132,5 \%$ enquanto dos $10 \%$ mais ricos cresceu $57,4 \%$, com destaque ao estado de Roraima no qual a renda dos $10 \%$ mais pobres obteve um crescimento de mais de $1000 \%$. De modo geral, a renda dos mais pobres e dos mais ricos teve um crescimento percentual maior que a média nacional.

Contudo, para analisarmos o quanto dessa elevação da renda dos mais pobres contribuiu para redução na desigualdade de renda, a tabela 4 mostra a participação percentual da renda dos 10\% e 20\% mais pobres e dos 10\% mais ricos da população, para a formação da renda domiciliar média geral no período 20042014, o que evidencia o quanto da renda geral é apropriada por cada décimo de renda (IPEA, 2018).

Tabela 4 - Participação Na Renda Média Por Décimo Da População Na Amazônia Legal

\begin{tabular}{|c|c|c|c|c|c|c|c|c|c|}
\hline \multirow{2}{*}{ ESTADO } & \multicolumn{3}{|c|}{$10 \%$ MAIS POBRES } & \multicolumn{3}{|c|}{$20 \%$ MAIS POBRES } & \multicolumn{3}{|c|}{ 10\% MAIS RICO } \\
\hline & 2004 & 2014 & $\Delta 2004-2014$ & 2004 & 2014 & $\Delta$ 2004-2014 & 2004 & 2014 & $\Delta 2004-2014$ \\
\hline Acre & 0,92 & 1,02 & $10,10 \%$ & 1,92 & 2,25 & $17,30 \%$ & 48,44 & 42,68 & $-11,90 \%$ \\
\hline Amazonas & 1,07 & 1,25 & $17,40 \%$ & 2,26 & 2,42 & $7,40 \%$ & 42,1 & 42,39 & $0,70 \%$ \\
\hline Amapá & 1,08 & 1,82 & $68,80 \%$ & 2,27 & 2,99 & $31,80 \%$ & 42,27 & 35,1 & $-17,00 \%$ \\
\hline Maranhão & 0,72 & 0,99 & $37,10 \%$ & 1,7 & 2,32 & $36,50 \%$ & 50,64 & 41,9 & $-17,30 \%$ \\
\hline Mato Grosso & 1,25 & 1,7 & $35,60 \%$ & 2,36 & 3,23 & $36,60 \%$ & 41,68 & 36,83 & $-11,60 \%$ \\
\hline Pará & 1,36 & 1,4 & $2,90 \%$ & 2,45 & 2,73 & $11,40 \%$ & 43,54 & 37,99 & $-12,80 \%$ \\
\hline Rondônia & 1,48 & 1,44 & $-2,80 \%$ & 2,7 & 2,92 & $8,20 \%$ & 42,05 & 35,84 & $-14,80 \%$ \\
\hline Roraima & 0,24 & 1,48 & $520,00 \%$ & 1,57 & 2,73 & $73,20 \%$ & 44,39 & 39,52 & $-11,00 \%$ \\
\hline Tocantins & 1,06 & 1,13 & $6,00 \%$ & 2,22 & 2,46 & $11,00 \%$ & 44,24 & 40,48 & $-8,50 \%$ \\
\hline Amazônia Legal* & 1,02 & 1,36 & $33,33 \%$ & 2,16 & 2,67 & $23,65 \%$ & 44,37 & 39,19 & $-11,67 \%$ \\
\hline BRASIL & 0,86 & 1,16 & $34,88 \%$ & 1,89 & 2,4 & $27,16 \%$ & 45,33 & 40,89 & $-9,79 \%$ \\
\hline
\end{tabular}

Fonte: Elaboração do autor (2018) - IPEADATA.

* dados obtidos a partir da média dos valores, da renda domiciliar média anual dos nove estados que compõe a Amazônia legal. 
Na tabela acima, percebe-se um aumento da participação da renda dos mais pobres para formação da renda média geral e uma consequente redução na participação da renda dos 10\% mais ricos, mesmo no estado de Rondônia em que a renda dos $10 \%$ mais pobres apresentou uma redução na participação percentual, a participação da renda dos mais ricos também apresentou uma redução em uma proporção maior, e no Amazonas único estado que participação dos 10\% mais ricos teve uma variação positiva, mas muito menor que a dos $10 \%$ mais pobres, o que de maneira preliminar sinaliza para um crescimento do tipo pró-pobre em todos os estados da região, tendo em vista que há uma apropriação maior da renda geral gerada por parte dos mais pobres.

Em comparação com a média nacional a renda dos mais pobres obteve um desempenho menor, tanto dos $10 \%$ como nos $20 \%$ mais pobres. Já em relação à participação dos mais ricos, na região houve uma maior redução da participação em comparação com a média nacional.

\subsection{EVOLUÇÃO DA PROPORÇÃO DE POBRES}

No período 2004-2014 os estados da Amazônia Legal sem exceção, experimentaram avanços significativos no que diz respeito à redução no nível de pobreza. A proporção de domicílios pobres teve uma redução de mais $50 \%$ na região nesse período. Os dados da tabela 5 mostram a evolução desse índice para os estados da Amazônia Legal.

Tabela 5 - Proporção de Domicílios Pobres: Estados da Amazônia legal 2004-2014

\begin{tabular}{|l|c|c|c|}
\multicolumn{1}{|c|}{ Estados } & 2004 & 2014 & $\Delta 2004-2014$ \\
\hline Acre & 51,11 & 27,74 & $-45,70 \%$ \\
\hline Amazonas & 46,86 & 24,22 & $-48,30 \%$ \\
\hline Amapá & 48,09 & 14,6 & $-69,60 \%$ \\
\hline Maranhão & 63,63 & 33,97 & $-46,60 \%$ \\
\hline Mato Grosso & 20,64 & 4,23 & $-79,50 \%$ \\
\hline Pará & 48,89 & 25,98 & $-46,90 \%$ \\
\hline Rondônia & 33,48 & 13,72 & $-59,00 \%$ \\
\hline Roraima & 56,53 & 17,25 & $-69,50 \%$ \\
\hline Tocantins & 44,57 & 19,61 & $-56,00 \%$ \\
\hline Amazônia Legal* & 45,98 & 20,15 & $-56,20 \%$ \\
\hline \multicolumn{1}{|c|}{ Brasil $^{\prime}$} & 33,71 & 13,29 & $-60,60 \%$ \\
\hline
\end{tabular}

Fonte: Elaboração do autor (2018) - IPEADATA.

* dados obtidos a partir da média dos valores, da renda domiciliar média anual dos nove estados que compõe a Amazônia legal.

O índice de proporção de domicílios pobres evidencia uma trajetória de redução da pobreza em todos os estados. No entanto, apesar dos avanços, este ocorreu em um ritmo menor que a média nacional, a média para Amazônia Legal como um todo foi de uma redução de 56,2\%, abaixo da média nacional onde a variação negativa foi de 60,6\%, somente os estados do Amapá, Mato Grosso e Roraima tiveram desempenho superior ao nacional.

Além de uma menor variação no índice de proporção de domicílios pobres, o único estado que manteve uma trajetória durante todo período de 2004 a 2014 abaixo da média nacional, foi o estado do Mato Grosso, todos os outros demais estados apresentam uma proporção de domicílios pobres superiores à média nacional. Rondônia e Amapá são os que mais se aproximaram da média nacional, em 2004 a média de domicílios pobres em Rondônia chegou a ser menor que a nacional, mas a partir de 2005 a média nacional teve maior redução. De modo geral, a proporção de domicílios pobres é cerca de 34\% maior que a média nacional. Fato este, que evidência a condição de segunda região mais pobre do país.

\subsection{EVOLUÇÃO DO ÍNDICE DE GINI}

Tanto em nível de Brasil como a nível regional a desigualdade de renda medida pela métrica do índice de Gini tem apresentado uma trajetória de redução. Em todos os estados da Amazônia Legal no decênio 2004-2014 houve uma redução no índice de Gini conforme pode ser constatado na tabela 6. 
Tabela 6 - Índice De Gini: Estados Da Amazônia Legal 2004-2014

\begin{tabular}{|l|c|c|c|}
\multicolumn{1}{c|}{ Estados } & 2004 & 2014 & $\Delta 2004-2014$ \\
\hline Acre & 0,594 & 0,542 & $-8,80 \%$ \\
\hline Amazonas & 0,536 & 0,53 & $-1,10 \%$ \\
\hline Amapá & 0,542 & 0,47 & $-13,30 \%$ \\
\hline Maranhão & 0,609 & 0,529 & $-13,10 \%$ \\
\hline Mato Grosso & 0,528 & 0,46 & $-12,90 \%$ \\
\hline Pará & 0,535 & 0,486 & $-9,20 \%$ \\
\hline Rondônia & 0,516 & 0,47 & $-8,90 \%$ \\
\hline Roraima & 0,583 & 0,502 & $-13,90 \%$ \\
\hline Tocantins & 0,551 & 0,515 & $-6,50 \%$ \\
\hline Amazônia legal* & 0,555 & 0,501 & $-9,70 \%$ \\
\hline \multicolumn{1}{|c|}{ Brasil } & 0,572 & 0,518 & $-9,40 \%$ \\
\hline \multicolumn{2}{r|}{ ronte: Elab }
\end{tabular}

Fonte: Elaboração do autor (2018) - IPEADATA.

* dados obtidos a partir da média dos valores, da renda domiciliar média anual dos nove estados que compõe a Amazônia legal.

0 índice de Gini apresentou uma redução de 8,75\% no Acre, 1,12\% no Amazonas, 13,28\% Amapá, 13,14\% no Maranhão, 12,88\% no Mato Grosso, 9,16\% Pará, 8,91\% em Rondônia, 13,89\% em Roraima, 6,53\% Tocantins. Evidenciando uma trajetória de redução no nível de desigualdade de renda na região como um todo, onde a média de redução para os noves estados foi de $9,73 \%$ acima de média nacional que apresentou uma redução de 9,44\% no índice, com destaque para o estado do Amapá, Maranhão, Mato Grosso, Roraima, que tiveram uma redução de mais de $10 \%$ no índice.

Conforme se percebe na tabela acima a maioria dos estados apresenta um índice de Gini abaixo da média nacional. Em 2004 eram somente Acre, Maranhão e Roraima, que apresentavam um índice superior ao nacional, em 2014 foi os estados do Acre, Amazonas e Maranhão.

Comparando o índice de Gini por regiões que está apresentado na tabela 7, percebe-se que a desigualdade de renda medida pelo índice de Gini na Amazônia Legal se apresenta abaixo da média nacional e da maioria das regiões do país. Vale ressaltar que os valores da Amazônia Legal é a média dos noves estados, que inclui os estados da região Norte, que representa a maioria dos estados da Amazônia Legal, além do Mato Grosso do Centro Oeste e o Maranhão do Nordeste.

Tabela 7 - Índice Gini: Regiões do Brasil 2004-2104

\begin{tabular}{|c|c|c|c|}
\hline Região & 2004 & 2014 & $\Delta$ 2004-2014 \\
\hline Região Centro-oeste & 0,572 & 0,511 & $-10,70 \%$ \\
\hline Região Norte & 0,541 & 0,505 & $-6,70 \%$ \\
\hline Região Nordeste & 0,583 & 0,516 & $-11,50 \%$ \\
\hline Região Sul & 0,522 & 0,456 & $-12,60 \%$ \\
\hline Região Sudeste & 0,542 & 0,501 & $-7,60 \%$ \\
\hline Amazônia legal* & 0,555 & 0,501 & $-9,70 \%$ \\
\hline Brasil & 0,572 & 0,518 & $-9,40 \%$ \\
\hline
\end{tabular}

O índice de Gini para a Amazônia Legal é igual da região Sudeste e só fica abaixo da região Sul, e vale ressaltar que os estados do Mato Grosso, Rondônia, Pará, Amapá apresentam um índice abaixo de cinco. No entanto, quando comparamos novamente a renda média, dos $10 \%$ mais pobres com os $10 \%$ mais ricos, podemos encontrar algumas explicações para essas diferenças no índice de Gini da região no que se refere aos valores serem bem abaixo da média nacional em alguns estados. A tabela 8 apresenta a renda média e participação do décimo mais pobre e mais rico para anos 2004 e 2014. 
Tabela 8 - Renda Média E Participação (\%): 10\% Mais Pobres E 10\% Mais Ricos

\begin{tabular}{|c|c|c|c|c|c|c|c|c|}
\hline \multirow{3}{*}{ Estados } & \multicolumn{4}{|c|}{$10 \%$ mais pobres } & \multicolumn{4}{|c|}{$10 \%$ mais ricos } \\
\hline & \multicolumn{2}{|c|}{$\begin{array}{l}\text { Renda domiciliar } \\
\text { média }\end{array}$} & \multicolumn{2}{|c|}{$\begin{array}{l}\text { Participação na } \\
\text { Renda média }\end{array}$} & \multicolumn{2}{|c|}{ Renda domiciliar média } & \multicolumn{2}{|c|}{$\begin{array}{c}\text { Participação na Renda } \\
\text { média }\end{array}$} \\
\hline & 2004 & 2014 & 2004 & 2014 & 2004 & 2014 & 2004 & 2014 \\
\hline Acre & 45,68 & 80,42 & 0,92 & 1,02 & $2.399,09$ & $3.379,24$ & 48,44 & 42,68 \\
\hline Amazonas & 49 & 104,34 & 1,07 & 1,25 & $1.936,13$ & $3.534,01$ & 42,1 & 42,39 \\
\hline Amapá & 50,87 & 166,18 & 1,08 & 1,82 & $1.991,62$ & $3.200,08$ & 42,27 & 35,1 \\
\hline Maranhão & 25,3 & 60,51 & 0,72 & 0,99 & $1.783,23$ & $2.573,44$ & 50,64 & 41,9 \\
\hline Mato Grosso & 87,19 & 204,84 & 1,25 & 1,7 & $2.898,66$ & $4,437,08$ & 41,68 & 36,83 \\
\hline Pará & 60,94 & 94,44 & 1,36 & 1,4 & $1.956,60$ & $2.569,72$ & 43,54 & 37,99 \\
\hline Rondônia & 87 & 136,45 & 1,48 & 1,44 & $2.476,34$ & $3.405,59$ & 42,05 & 35,84 \\
\hline Roraima & 9,27 & 140,24 & 0,24 & 1,48 & $1.721,55$ & $3.742,13$ & 44,39 & 39,52 \\
\hline Tocantins & 52,68 & 100,73 & 1,06 & 1,13 & $2.193,78$ & $3.619,92$ & 44,24 & 40,48 \\
\hline Amazônia legal* & 51,99 & 120,91 & 1,02 & 1,36 & $2.150,78$ & $3.384,58$ & 44,37 & 39,19 \\
\hline Brasil & 59,42 & 133,12 & 0,86 & 1,16 & $3.135,08$ & $4.711,91$ & 45,33 & 40,89 \\
\hline
\end{tabular}

Fonte: Elaboração do autor (2018) - IPEADATA.

* dados obtidos a partir da média dos valores, da renda domiciliar média anual dos nove estados que compõe a Amazônia legal.

Quando comparado a renda dos 10\% mais pobres com a dos 10\% mais ricos, percebemos que a renda dos $10 \%$ mais pobres corresponde cerca 3,57\% da renda dos 10\% mais ricos dos estados da Amazônia Legal, enquanto que no país essa média é de 2,83\%, o que explica o porquê do índice de Gini se apresentar menor na região, tendo em vista essa menor diferença entre a renda dos mais pobres e dos mais ricos, que é evidenciado na participação total dos rendimentos dos mais ricos para a composição da renda média geral, que na região é 39,19\% contra 40,89\% da renda média nacional.

Quando analisado por estado fica claro por que estados como: Mato Grosso, Rondônia, Pará, Amapá, apresentam um índice de Gini menor que cinco bem abaixo da média nacional, nesses estados a diferença entre as renda dos mais pobres e mais ricos é menor, a renda dos mais pobres corresponde em termos percentuais a renda dos mais ricos cerca de: 4,62\% no Mato Grosso, Pará 3,68\%, Rondônia 4,01\%, Amapá 5,19\%, acima da média da região e do país. Nos demais estados essa participação é de 2,95\% no Amazonas, 2,35\% no Maranhão, 2,78\% no Tocantins, 3,75\% em Roraima, 2,38\% no Acre, destes somente nos estados do Acre e Maranhão a renda dos mais pobres apresentou uma diferença percentual abaixo da média nacional.

No entanto, isso não quer dizer que as condições socioeconômicas sejam melhores na região, pelo contrário, mostra que renda em geral na região é mais baixa, a renda domiciliar per capita é cerca de $32,55 \%$ menor que a média nacional, a renda dos $10 \%$ mais pobres é menor, cerca de $10,10 \%$, e a renda dos $10 \%$ mais ricos na região é cerca de $28,17 \%$, menor que a média de renda do mais ricos para o Brasil, mesmo no estado do Mato Grosso único estado com renda acima dos quatro mil e que sempre apresenta um desempenho acima da média nacional, a renda dos mais ricos e cerca de 5,83\% menor que a média nacional. Fatos que evidenciam ainda mais a desigualdade econômica que existe entre a região e as regiões mais desenvolvidas do País.

\subsection{RESULTADOS DAS ELASTICIDADES RENDA-POBREZA E DESIGUALDADE POBREZA}

O diagnóstico de painel do Gretl para o modelo econométrico apontou no teste de Hausman, um $p$-valor de 0,409029. 0 que sugere a utilização do modelo de efeitos aleatórios, uma vez que não se rejeita a hipótese nula. Isso significa que os coeficientes de efeitos aleatórios são, além de não viesados e consistentes, os mais eficientes para estimação do modelo proposto no estudo.

0 resultado é reforçado pelo teste de Breusch-Pagan (BP) com p- valor de 0,0000 validando a hipótese alternativa da existência de efeitos aleatórios. Esse resultado se assemelha aos obtidos nos trabalhos de Pinto e Oliveira (2010) e Godoy e Rodrigues (2017) onde também os resultados apontaram para uma estimação por meio de efeitos aleatórios. Para Pinto e Oliveira (2010) o modelo de efeitos aleatórios pode ser mais consistente nesse caso específico, por considerar uma elasticidade renda-pobreza única, sem levar em conta as diferenças por estado. 
Sendo o modelo de efeitos aleatórios o mais consistente para estudo não se faz necessário à realização do teste de Chow. Quanto a heterocedasticidade e autocorrelação, por propriedade do modelo de efeito aleatórios os termos do erro das unidades de corte transversal apresentarem correlação com período de tempo diferentes. Fazendo com que os estimadores de Mínimos Quadrados Ordinários (MQ0) sejam ineficientes, sendo com isso o método mais adequado para estimação de efeitos aleatórios os mínimos quadrados generalizados (MQG ou GLS na sigla em inglês). As estimativas GLS têm como propriedade corrigir a possível correlação entre os resíduos e a heterocedasticidade (GUJARATI, 2006). Sendo com isso o modelo de efeitos aleatórios estimado seguindo o método GLS, corrigindo com isso a possível a heterocedasticidade e autocorrelação.

Os resultados do modelo com as Elasticidades renda-pobreza e desigualdade-pobreza para Amazônia Legal é apresentado abaixo na tabela 9.

Tabela 9 - Resultados do modelo de efeitos aleatórios (GLS)

\begin{tabular}{|l|c|c|c|c|}
\multicolumn{1}{c}{ Variáveis } & Coeficiente & Erro Padrão* & Teste-T & P-Valor \\
\hline Constante & 12,9701 & 0,946325 & 13,71 & 0,00 \\
\hline In renda per capita & $-1,27307$ & 0,128454 & $-9,911$ & 0,00 \\
\hline In Gini & 2,15257 & 0,281941 & 7,635 & 0,00 \\
\hline Número de observações & 90 & & & \\
\hline $\mathrm{R}^{2}$ & 0,855 & & & \\
\hline Teste $F$ - $p$-valor & 0,000 & & & \\
\hline Teste Hausman & 0,409 & & & \\
\hline Teste BP & 0,000 & & & \\
\hline
\end{tabular}

Fonte: Elaboração própria, com base em resultados obtidos pelo Software Gretl.

*Erros padrão robustos

Todos os coeficientes estimados foram significativos, apresentado uma Elasticidade renda pobreza de $1,27 \%(\beta 1)$, o que significa dizer que um aumento de $1 \%$ na renda resultou numa redução de $1,27 \%$ na pobreza no período 2004-2014, o que nos leva a classificar a partir de uma definição forte e uma análise completa o crescimento como pró-pobre, uma vez que a Elasticidade foi superior a uma unidade indicando segundo Santos (2013) que o benefício monetário da população pobre foi superior ao obtido pela média da população.

No modelo também foi estimada a Elasticidade desigualdade-pobreza de 2,15\% ( $\beta 2)$, nesse caso o valor é positivo pois uma redução da desigualdade também implica numa redução na pobreza. Como se percebe nesse caso, a elasticidade é superior à elasticidade renda-pobreza, muito embora a literatura sobre desenvolvimento aponte para a importância da redução da desigualdade, Pinto e Oliveira (2010) salientam que à primeira vista, pode parecer que a distribuição exerce um papel mais importante do que o crescimento no combate à pobreza, mas chama atenção ao fato que as duas medidas variam em escalas distintas, enquanto o coeficiente de Gini varia apenas entre 0 e 1 , a renda pode assumir qualquer valor positivo. No entanto, não deixa de ser importante o resultado, pois conforme é destacado por Barreto (2005) os efeitos do crescimento para redução da pobreza são potencializados quando são acompanhados por políticas redistributivas.

\section{CONSIDERAÇÕES FINAIS}

A evolução dos indicadores evidência que houve nesse período relativa melhora na renda, pobreza e desigualdade na região. No entanto, essa condição de melhora é relativa, pois quando comparado os valores absolutos da Renda domiciliar média do país, com a média para Amazônia Legal, a renda média da região em valores absolutos é menor 282,93 Reais ao valor da renda domiciliar média para o país, seria necessário um crescimento de 135,91\% nesse período para que a renda média para região fosse igualado a média para o Brasil em 2014. Esse desempenho também foi seguido na renda dos 10\% mais pobres e $10 \%$ mais ricos, onde embora o desempenho no crescimento percentual tenha sido superior ao nacional, em valores absolutos a média de renda para região é menor 12,20 Reais e 1.327,30 Reais para dois décimos de renda respectivamente. 
Quanto ao indicador de pobreza o índice proporção de domicílios pobres se apresenta bem acima da média nacional, e no período obteve um desempenho inferior à média de redução do País. Para que que a região alcança-se a média nacional seria necessário uma redução de 71,10\% nesse período. Maranhão e Acre estados com maior proporção de domicílios pobres em 2004 seria necessária uma redução de $79,11 \%$ e $-74 \%$ respectivamente. Se todos os estados tivessem obtido o desempenho do estado do Mato Grosso (-79,50\%) a proporção de domicílios pobres em 2014 estaria em um patamar semelhante é média nacional.

O indicador de desigualdade é o que apresenta relativa condição mais favorável tanto em termos absolutos como em termos de desempenho foi superior à média nacional. No entanto chama atenção ao fato de a renda em geral na região ser mais baixa, o que pode explicar essa menor diferença entre os rendimentos dos mais ricos e mais pobres, como evidencia o índice de participação nos rendimentos, onde os 10\% mais pobres para média da Amazônia Legal tem uma participação de 1,36\% na renda média, frente $1,16 \%$ da média nacional. Indicando que na região os $10 \%$ mais pobres tem uma maior participação na renda média.

Porém, no que pese as dificuldades e avanços da região, as elasticidades renda-pobreza e desigualdadepobreza auferidas pelo modelo econométrico nos fazem concluir que no período de 2004 a 2014 o crescimento econômico experimentado na região da Amazônia Legal pode ser considerado pró-pobre. Tendo em vista, que um aumento de $1 \%$ na renda nesse período resultou em uma redução superior a 1,27\% no nível de pobreza, ou seja, uma variação maior que a unidade.

\section{REFERÊNCIAS}

[1] Barreto, Flávio Ataliba Flexa Daltro. Crescimento econômico, pobreza e desigualdade de renda: o que sabemos sobre eles? Fortaleza: Laboratório de Estudos da Pobreza/CAEN/UFC, 2005. Ensaio sobre Pobreza, 01. Disponível em:<http://www.repositorio.ufc.br/handle/riufc/1125>. Acesso em: 17 jun. 2017.

[2] Baltar, Paulo. Crescimento da economia e mercado de trabalho no Brasil. Texto para Discussão, Instituto de Pesquisa Econômica Aplicada (IPEA), 2015.

[3] Datt, Gaurav; Ravallion, Martin. Growth and redistribution components of changes in poverty measures: a decomposition with applications to Brazil and India in the 1980s. Journal of Development Economics, n. 38, p. 275295, 1992.

[4] Gujarati, Damodar. Econometria Básica. Rio de Janeiro. Editora Campus, 2006.

[5] Godoy, Karine Rosa; Rodrigues, Rodrigo Vilela. Crescimento pró-pobre no Brasil: uma análise do período 2003-13 para os estados brasileiros. Ensaios FEE, v. 38, n. 1, p. 185-214, 2017.

[6] IPEA. Instituto de Pesquisa Econômica Aplicada. IPEADATA. Disponível em:<http://www.ipeadata.gov.br/> Acesso em: 23 de set 2017.

[7] 0 que é? Amazônia Legal. IPEA Desafios do Desenvolvimento. Disponível em:<http://www.ipea.gov.br/desafios/index.php?option=com_content\&id=2154:catid=28\&Itemid=23 >. Acesso em: 07 set. 2018

[8] Kakwani, Nanak; Khander, Shahid; SON, Hyun H. Pro-poor growth: concepts and measurement with country case studies. Working Paper, Brasília: UNDP, n. 1, 2004. Disponível em:<http:// undp.org/povertycentre>. Acesso em: 20 ago. 2008.

[9] Kakwani, Nanak; Pernia, Ernesto M. What is pro-poor growth. Asian Development Review, v. 18, n. 1, 2000.

[10] Lopez, J. Humberto(2004a). "Pro-Poor-Growth: A Review of What We Know (and of What We Don'T). Mimeo. The World Bank.2004

[11] Lopez, Humberto; Serven, L. The mechanics of growth-poverty inequality relationship. The World Bank, 2004. (Mimeogr.).

[12] Manso, Carlos Alberto; Barreto, Flávio Ataliba; Tebaldi, Edinaldo. O desequilíbrio regional brasileiro: novas perspectivas a partir das fontes de crescimento "pró-pobre". Revista Econômica do Nordeste, v. 37, n. 3, p. 307-328, 2006.

[13] Manso, Carlos Alberto; de Sena Pereira, Dílson José; Barreto, Flávio Ataliba Flexa Daltro. Crescimento própobre: diferenças de intensidade entre rural e urbano no período 2002-2005. Revista Econômica do Nordeste, v. 39, n. 4, p. 365-385, 2008.

[14] Moreira, Sandrina Berthault; Crespo, Nuno. Economia do Desenvolvimento: das abordagens tradicionais aos novos conceitos de desenvolvimento. Revista de economia, v. 38, n. 2 (ano 36), p. 25-50, 2012. 
[15] Paulani, Leda Maria; Braga, Márcio Bobik. A nova contabilidade social. Editora Saraiva, 2007.

[16] Pinto, Mauricio Silveira; Oliveira, Júlio César de. Crescimento pró-pobre: análise dos estados brasileiros entre 1995 e 2007. Revista de Economia Contemporânea. v. 14, n. 2 (maio/ago. 2010), p. 327-358, 2010.

[17] Ravallion, Martin; CHEN, Shaohua. "Measuring Pro-Poor Growth." World Bank, Policy Research Working Paper, 2666, 2003.

[18] Resende, Guilherme Mendes; da Mata, Daniel; Carvalho, Alexandre Xavier Ywata. Crescimento pró-pobre e distribuição de renda das capitais dos estados brasileiros. Ensaios de Economia Regional e Urbano. Brasília: IPEA, p. 21-46, 2007.

[19] Rocha, Sônia. Pobreza no Brasil: afinal, de que se trata? Rio de Janeiro: Fundação Getúlio Vargas, 2003.

[20] Santos, Wesley Oliveira. Crescimento pró-pobre no Brasil (1981-2009). [Maringá]: Pós-Graduação em Economia da Universidade Estadual de Maringá, 2011. Disponível em: <http://www.apec.unesc.net/VI_EEC/sessoes_tematicas/TemaEconomia\%20Social\%20e\%20Politicas\%20Publicas/ Artigo-6-Autoria.pdf>. Acesso em: 12 set. 2017.

[21] Souza, Nali de Jesus de. Desenvolvimento econômico. 5aㅡ ed. São Paulo: Atlas 2008.

[22] Veiga, José Eli da. Desenvolvimento sustentável: o desafio do século XXI. Editora Garamond, 2010.

[23] Thomas, Vinod; Dailami, Mansoor; Dhareshwar, Ashok; Kaufmann, Daniel; Kishor, Nalin; López, Ramón; WANG, Yan. A qualidade do crescimento. Tradução Élcio Fernandes. São Paulo: Editora UNESP, 2002.

[24] White, Howard; Anderson, Edward. "Growth vs. Redistribution: Does the Pattern of Growth Matter?. DFID white paper on Elimination World Poverty; making Globalization Work for the Poor, 2000. 


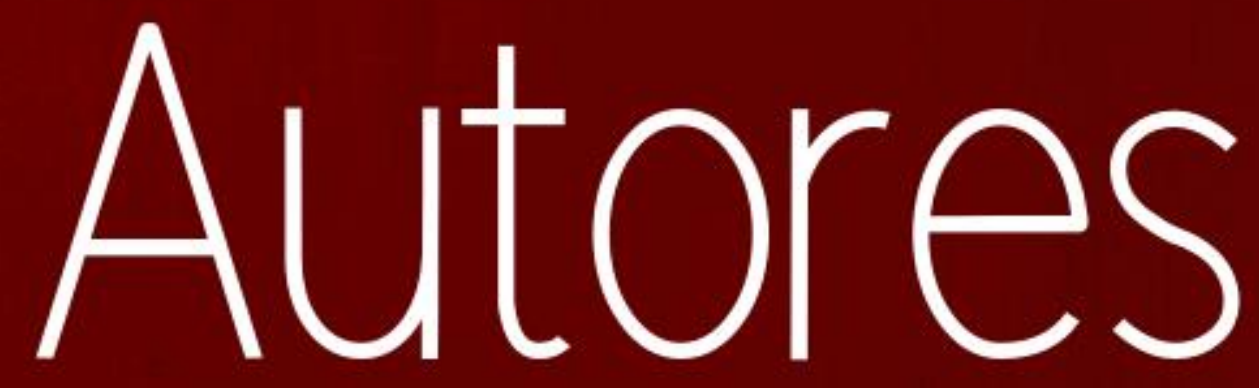




\section{ABNER VILHENA DE CARVALHO}

Doutor em Ciências Ambientais pelo Programa de Pós Graduação Sociedade, Natureza e Desenvolvimento (PPGSND) da Universidade Federal do Oeste do Pará (UFOPA) Instituição: Universidade Federal do Oeste do Pará (UFOPA) Endereço: Avenida Mendonça Furtado no 2946 - Fátima, Santarém-PA, Brasil.

\section{ADÃO MARQUES DOS SANTOS CARDOSO}

Graduado em Direito, Especialização em Docência em Ensino Superior e Direito Civil e Processual Civil, MBA e Mestrado em Engenharia de Produção. Docente nas áreas do Direito tributário, Empresarial e Administrativo. Diretor em Empresas na área de tecnologia e educação.

\section{ALESSANDRA CARLA CEOLIN}

Professora vinculada ao Departamento de Administração (UFRPE). Doutorado e Pós-doutorado em Agronegócios (UFRGS), mestrado em Ciências da Computação (UFRGS) e graduação em Ciência da Computação (UPF), Comércio Exterior e Administração pela (UCB). Recife - Brasil.

\section{ALÉXA LAUREN SOUSA VASCONCELOS}

Graduada em Ciências Contábeis, Graduada em Administração e Especializada em Gestão em Saúde.

\section{ALEXANDRE DA COSTA REIS}

Técnico em Alimentos pelo Instituto Federal de Educação, Ciência e Tecnologia do Maranhão. Graduando do Curso de Tecnologia em Alimentos pelo Instituto Federal de Educação, Ciência e Tecnologia do Maranhão. Atuando como pesquisador no Grupo de Pesquisas em Análises Químicas Sustentáveis (GPAQS), do IFMA - Campus Zé Doca.

\section{ALEXANDRE DE FREITAS CARNEIRO}

Professor da Universidade Federal de Rondônia nos cursos de Administração e Ciências Contábeis. Mestre e doutorando em Administração. Especialização em Contabilidade e Controladoria. Contador. Graduação em Ciências Contábeis pela Universidade Vale do Rio Doce (UNIVALE-MG). Membro pesquisador do ECCONT - Estudos Contemporâneos em Contabilidade e Gestão, coordenador da linha de pesquisa "Contabilidade e Controladoria de Organizações Públicas e do Terceiro Setor". Revisor de periódicos e avaliador de congresso internacional. Artigo premiado na Espanha (GIGAAP, 2015). Foi Contador, Chefe de Contadoria e Assessor Especial do Município de Vilhena/RO; e Diretor Administrativo, Contador e Assessor Especial da Autarquia Municipal SAAE. Já exerceu funções de direção, chefia, vice chefia de departamento e conselho fiscal. Atua nas áreas de Contabilidade e Gestão Pública, Terceiro Setor, Ambiental e Controladoria de Organizações.

\section{ANA CARLA CAVALCANTE DAS CHAGAS}

Professora na Unifamento (Centro Universitário Fametro) nas áreas de gestão, inovação e empreendedorismo, mestranda em Administração e Controladoria pela Universidade Federal do Ceará (UFC), possui um grupo de pesquisa sobre simbiose industrial e um grupo sobre o capital social nos ambientes inovadores do Estado do Ceará, graduada em administração e especialista em inovação e gestão do conhecimento.

\section{ANA CLARA CAVALCANTI DE MIRANDA}

Mestranda em Ensino de Ciências (PPGEC/UFRPE), com especialização em pedagogia empresarial (FJN), graduada em pedagogia (UFPE, 2010) e Graduanda em administração - UFRPE - Recife Brasil 


\section{ANTÔNIA AMANDA ALVES PEREIRA MOREIRA}

MBA em Comércio Exterior pela Faculdade Anhanguera, Camocim-CE.

\section{ARIBERTO DALCHIAVON}

Graduado em Ciências Contábeis pela Universidade Comunitária Regional de Chapecó (2002). Pós graduado em Auditoria e Perícia Contábil (2008) e Mestrado em Ciências Contábeis e Administração (2018). Possui ainda especialização em Gestão de Cooperativas (2017-2019). Perito contador judicial e extrajudicial. Possui experiência na área de Administração, com ênfase em Administração de Pessoal, Gestão e Controladoria, ainda possui conhecimentos relacionados a área do cooperativismo. Atualmente é contador autônomo.

\section{CÉLIA DARK LUZEIRO RIBEIRO}

Graduada em Ciências Contábeis, Graduada em Administração e Especializada em Gestão em Saúde.

\section{CELIA EDI LOBO SILVA}

Graduada em Administração (2018), Atua no mercado de alimento há 35 anos. Realiza pesquisas nas áreas de Marketing, Logística (Reversa/Supply Chain).

\section{CELITO NUERNBERG}

Possui Mestrado em Ensino de Ciências pela Universidade Estadual do Amazonas (2009), Graduação em Teologia pela PUC - PR(1979), graduação em Filosofia Pela Faculdade Dom Bosco de Filosofia Ciências e Letras de São João Del Rei -MG. (1976),Metodologia do Ensino Superior pela Universidade Federal do Amazonas -AM (2002). Foi Coordenador de Pesquisa e Extensão na Faculdade do Amazonas- IAES, Professor do Centro Universitário do Norte (AM), Vice-Coordenador do Comitê de Ética (UNINORTE), Coordenador da CPA junto ao MEC. Tem experiência na área de Educação com ênfase em Filosofia, Antropologia e Sociologia além de Orientações de Trabalhos de Conclusão de Curso, atualmente Diretor Acadêmico da Faculdade Educacional de Francisco Beltrão - FEFB - Pr.

\section{CITANIA AP. PILATTI BORTOLUZZI}

Mestrado Profissional em Administração - Ênfase em Sustentabilidade pela Unoesc - Chapecó; Possui graduação em CIÊNCIAS CONTÁBEIS - FACULDADES REUNIDAS DE ADMINISTRAÇÃO, CIÊNCIAS CONTÁBEIS E CIÊNCIAS ECONÔMICAS DE PALMAS - PARANÁ - FACEPAL (2000). Tem experiência na área de Administração, com ênfase em Ciências Contábeis. Atua como Professora de cursos Técnicos e profissionalizantes no Senac unidade de Xanxerê.Trabalha com as disciplinas de Contabilidade, Legislação Tributaria e Legislação Trabalhista. Também atua como professora de ensino superior na UCEFF - Unidade Central de Educação FAEM - Chapecó. Possui experiência em docência em EAD.

\section{CLAUDELIR CLEIN}

Possui Graduação em Administração pela Universidade Tecnológica Federal do Paraná. Especialização em Gestão de Recursos Humanos pela Universidade Tecnológica Federal do Paraná. Especialização em Métodos de Melhoria da Produtividade (Engenharia de Produção) pela Universidade Tecnológica Federal do Paraná. Mestrado em Gestão e Desenvolvimento Regional pela Universidade Estadual do Oeste do Paraná. Doutorando em Desenvolvimento Regional e Agronegócio pela Universidade Estadual do Oeste do Paraná. Atualmente trabalha na Coordenadoria de Gestão de Recursos Humanos da Universidade Tecnológica Federal do Paraná - Campus Francisco Beltrão. É Docente na União de Ensino do Sudoeste do Paraná - UNISEP. Tem experiência na área de Administração. Temas de interesse em pesquisa: Gestão de agroindústrias, agronegócio, planejamento estratégico, gestão de projetos e liderança. 


\section{DALTON RÉGIS DE OLIVEIRA SOARES}

Bacharel em Administração (Universidade Federal do Piauí - UFPI); especialista em Gestão de Pequenas e Médias Empresas (Universidade Federal do Piauí - UFPI).

\section{DEMÉTRIO DE MENDONÇA JÚNIOR}

Mestrado em Administração na linha de Estratégia de Marketing e Comportamento do Consumidor pela Universidade Federal do Paraná (UFPR). Graduação em Administração pela Pontifícia Universidade Católica de Minas Gerais (Julho/2017). Participante do Grupo de Pesquisa de Estratégia de Marketing na Universidade Federal do Paraná. Os temas de interesse em pesquisas são, principalmente, práticas de implementação de estratégias de marketing nas organizações, como também a influencia das orientações estratégicas nessas atividades, com o foco atual em empresas que atuam com orientação empreendedora e orientação para o mercado de forma simultânea.

\section{DJONATA SCHIESSL}

Doutorando em administração de empresas na Universidade Federal do Paraná na linha de pesquisa de marketing e comportamento do consumidor. Área de pesquisa, comunidade de marca e influências sociais no comportamento do consumidor. Possui graduação em Administração pela Universidade da Região de Joinville (2017). E mestrado em administração de empresas pela Universidade Federal do Paraná (2020). Têm experiência na área de Administração, com ênfase em Marketing.

\section{EDUARDO CODEVILLA SOARES}

Graduado e mestre em administração e doutorando em ciências contábeis.

\section{ELAINE GARCIA DOS SANTOS}

Especialista em Gestão Empresarial - FURG e em Gestão Integral do Capital Intelectual. FATEC -2010. Mestre em Desenvolvimento Territorial e Sistemas Agroindustriais -PPGDTSA /UFPEL. Atualmente é Professora Adjunta da Faculdade de Administração e de Turismo - UFPEL, atuando nas áreas de ensino, pesquisa e extensão.

\section{FLAVIO PINHEIRO MARTINS}

Graduado em Administração de Empresas pela Faculdade de Economia, Administração e Contabilidade de Ribeirão Preto, FEA-RP/USP. Aluno de mestrado pelo Programa de Pós-graduação em Administração de Organizações da FEA-RP/USP na linha: Inovação e Sustentabilidade. Atualmente trabalha Superintendência de Gestão Ambiental da USP (SGA-USP). É membro da Comissão do Principles For Responsible Management Education (PRME) da FEA/RP-USP e dos Grupos de Trabalhos - Sustentabilidade na Administração, Uso e Ocupação do Solo e Educação Ambiental da Comissão Técnica de Gestão Ambiental do Campus USP Ribeirão Preto. Tem experiência na área de licitações e contratos públicos. Pesquisa políticas públicas para o desenvolvimento sustentável e formação de lideranças responsáveis, em especial sob a lente dos Objetivos de Desenvolvimento Sustentável (ODS).

\section{FRANCISCO SOUSA COSTA}

Acadêmico do curso de Licenciatura em Química. Do IFMA campus Ze Doca. Pesquisador na área de linguística com o projeto diagnóstico das dificuldades de produção textual dos alunos das séries iniciais do ensino Médio, pesquisador na área de materias de produção com o projeto de um motor alternativo usando motor de geladeira, e pesquisador na área química com o projeto produção de biocombustíveis a partir de frutas de descartes. 


\section{GESUALDO MENEZES CAVALCANTE}

Graduação em ciências contábeis pela UFAL; Contador do Instituto Federal de Alagoas; Pós graduado em contabilidade pública; Pós graduado em auditoria e controladoria; pós graduado em gestão organizacional (em andamento).

\section{GILSON MUSSI DOS REIS}

Possui graduação em Ciências Econômicas pela Universidade Estadual do Oeste do Paraná (1995), mestrado em Engenharia da Produção pela Universidade Federal de Santa Catarina (2005), MBA em Saneamento Executive pela Fundação Getulio Vargas (2004) e Especialização em Gestão da Qualidade Ambiental pela Universidade Federal de Santa Catarina (2006), Especialização em Administração, Supervisão e Orientação Educacional pela Universidade Norte do Paraná (2000) e Especialização em Metodologia do Ensino da Matemática no Processo Educativo, pela Faculdade de Educação São Luis (SP) (1999).

\section{GUSTAVO SILVA DE FRANÇA}

Especialista em Gestão Pública - UFMA (2019). MBA em Contabilidade Pública e Responsabilidade Fiscal - UNINTER (2017). Bacharel em Ciências Contábeis - FACIMP (2013). Atua como Contador Público no Município de Davinópolis - MA (desde 2016).

\section{HELENA RÖPKE}

Estudante do Curso de Bacharelado em Administração da Faculdade de Administração e de Turismo da Universidade Federal de Pelotas, UFPel.

\section{HÉLIA GERALDA SIQUEIRA}

Bacharel em Direito pela Universidade de Itaúna e Especialização (MBA) em Gestão de Cooperativas de Crédito pelo Centro Universitário Unihorizontes. Ocupou os cargos de Chefe de Departamento de Pessoal na empresa Fundição Aldebarã Ltda; Encarregada de Departamento de Pessoal na Cia Cimetal Siderurgia S/A e na empresa ARG Ltda; Coordenadora do Setor de Administração de Pessoal na Cia Industrial Itaunense. Atualmente é Sócia- Proprietária da empresa Sport Point Ltda.

\section{HELISON BERTOLI ALVES DIAS}

Doutorando em administração na Universidade Federal do Paraná na linha de pesquisa Estratégias de Marketing e Comportamento do Consumidor. Mestre em administração pela Universidade Federal do Paraná - UFPR (2018). Bacharel em Engenharia Mecânica pela Universidade Federal do Paraná - UFPR (2015). Editor e Colaborador do PONTE DO MARKETING (projeto destinado à divulgação de conhecimento científico sobre marketing para estudantes, gestores e professores: pontedomarketing.com.br). Interesses de Pesquisa: Comportamento do Consumidor, Relacionamento Consumidor-marca, Processos de Influência Social.

\section{HELOISA SIQUEIRA LORDELLO}

Formada em Ciências Contábeis e Direito pela Universidade Gama Filho (1988 e 1995), Pós Graduada em Auditoria pela Unigranrio (2000), Mestre em Ciências Contábeis pela Universidade do Estado do Rio de Janeiro - UERJ (2007), Doutora em Contabilidade pela Universidade do Minho (2019), Ex-Coordenadora do Curso de Ciências Contábeis e Professora da Universidade Federal Rural do Rio de Janeiro - UFRRJ, Ex-Professora da PUC/RJ, do Centro Universitário Augusto Motta UNISUAM e do Centro Universitário Moacyr Sreder Bastos - UniMSB, Conselho Regional de Contabilidade do CRC/RJ , Ex-Professora Orientadora do MBA Gestão Financeira da PUC /RJ. Participante em banca de concurso público. Tem experiência na área de Contabilidade, com ênfase em Contabilidade Tributária e Societária. 


\section{HENRIQUE CÉSAR MELO RIBEIRO}

Doutor em Administração pela UNINOVE. Professor DE do Curso de Administração da UFDPar.

\section{HUGO DA COSTA REIS}

Graduando do Curso de Licenciatura em Química pelo Instituto Federal de Educação, Ciência e Tecnologia do Maranhão. Iniciou os trabalhos científicos no terceiro período de graduação, atualmente atua como pesquisador do Grupo de Pesquisas em Análises Químicas Sustentáveis (GPAQS), do IFMA -Campus Zé Doca.

\section{JAIRO DE CARVALHO GUIMARÃES}

Doutor em Educação (UFRJ); mestre em Administração e Controladoria (UFC); especialista em Contabilidade e Planejamento Tributário (UFC); graduado em Administração (FACE); professor permanente do Programa de Pós-Graduação em Políticas Públicas (CCHL/UFPI); professor Adjunto III do Curso de Administração do Campus Amílcar Ferreira Sobral (CAFS); coordenador do Curso de Administração do CAFS (2016-2018), reeleito para um novo mandato (2018-2020); membro representante do CAFS junto ao CONSUN, CEPEX, CAMEN - Câmara de Ensino (PREG) e CAMEX Câmara de Extensão (PREXC).

\section{JARSEN LUIS CASTRO GUIMARÃES}

Doutor em Desenvolvimento Sustentável do Trópico Úmido pelo Núcleo de Altos Estudos Amazônicos (NAEA) da Universidade Federal do Pará (UFPA). Instituição: Universidade Federal do Oeste do Pará (UFOPA) Endereço: Avenida Mendonça Furtado no 2946 - Fátima, Santarém-PA, Brasil

\section{JOÃO VITOR DE OLIVEIRA SOUSA}

Bacharelado em Administração pela Universidade Federal do Piauí (UFPI). Possui MBA em Gestão Empresarial pela Fundação Getúlio Vargas. Mestrando em Desenvolvimento e Meio Ambiente pela Universidade Federal do Piauí (UFPI). Professor em Administração do Instituto Federal do Piauí (IFPI) do Campus Uruçuí/PI.

\section{JORGE GONÇALVES DE SOUZA}

Graduado em Administração (2018), Acadêmico de Língua Japonesa. Atua no mercado de assessoria empresarial em Makerting e Estrutura Organizacional. Realiza pesquisas nas áreas de Marketing, Logística (Reversa/Supply Chain) e administra um projeto nas redes sociais de cunho educativo. Experiência empregatícia nas áreas de Marketing e Fiscal (Tributário).

\section{JULIANO CORREA DALEASTE}

Mestre em Administração pela Universidade do Oeste de Santa Catarina, UNOESC (2017). Especialista em Finanças Corporativas (2013), Gestão da Produção e Logística (2010) e bacharelado em Ciências Econômicas (2008) pela Universidade Comunitária da Região de Chapecó, Unochapecó. Vasta experiência na área administrativa e financeira. Sócio de uma revenda de auto peças e docente universitário. Realizo palestras motivacionais, consultorias empresariais, cursos e treinamentos voltado a área administrativa (Vendas, operador de caixa, logística, desenvolvimento Organizacional, contábeis, logística estrutural entre outros.) 


\section{KARLA DAYANE BEZERRA CRUZ}

Bacharel em administração em empresas pela universidade federal do rio grande do norte - ufrn (2009), pós-graduada em gestão pública municipal - ufrn (2012), possui mba em marketing pela universidade potiguar - unp (2013), curso de aperfeiçoamento em gestão da educação a distância pelo instituto federal do rio grande do norte - ifrn (2014), mestrado em engenharia de produção ufrn (2016); formação pedagógica (em andamento)- ifrn. Atua como professora universitária de graduação e pós-graduação em faculdades particulares da região do seridó desde 2011, professora externa da ufrn e ifrn. Atua no ifrn campus zona leste nas pós-graduações, trabalhando na educação a distância da ufrn desde 2010, já atuando como tutora presencial, tutora a distância, e orientadora de trabalho de conclusão de curso. Atua como assistente à docência da capes (2019) no polo currais novos e na anhanguera como professora/tutora. Consultora e instrutora.

\section{LARISSA BARBOSA FERREIRA DE SOUZA}

Aluna da Faculdade de Economia, Administração e Contabilidade de Ribeirão Preto (FEARP) - USP, nas áreas de Economia e Controladoria.

\section{LEANDRO APARECIDO DA SILVA}

Mestre em Administração com ênfase em Gestão e Estratégia de Negócios pela Universidade Potiguar (2015). Especialista em Gestão Estratégica na modalidade MBA pela Universidade de São Paulo FEA-USP (2015). Graduado em Sistemas de Informação pela Universidade Potiguar (2005). Possui certificação Life Cycle Canvas para atuação em gestão de projetos. Pesquisas e publicações nas áreas de Gestão Estratégica e Competitividade nas MPEs, Logística Empresarial e Cadeia de Suprimentos, Marketing, Modelos de Gestão e Processos de Negócios, Sistemas e Tecnologia da Informação em MPEs e Órgãos Públicos. Membro do NDE (Núcleo Docente Estruturante) dos cursos de Administração e Ciências Contábeis da Faculdade Católica Santa Teresinha.

\section{LEOSSANIA MANFROI}

Mestre em Contabilidade pela Universidade Regional de Blumenau - FURB (2013); Mestre em Auditoria e Gestão Empresarial pela Universidad Politécnica y Artística Del Paraguay - UPAP (2009); Pós Graduada em Qualidade dos Serviços Contábeis pela UNOCHAPECó (2002); Graduada em Ciências Contábeis pela UNOESC (2001); Cursando Administração na modalidade EAD pela Uniasselvi (início em 2018). Contadora; Coordenadora do Centro de Ciências Sociais e Aplicadas da UCEFF Faculdades; Professora de Pós-Graduação e Graduação da UCEFF Faculdades. Membro titular do Comitê de Ética em Pesquisa (CEP) da UCEFF Faculdades. Avaliadora de cursos de Graduação do INEP (BASIS).

\section{LETICIA MONTEIRO PIMENTEL}

Mestre em Administração pela Universidade Federal do Paraná (UFPR) na linha de pesquisa Estratégias de Marketing e Comportamento do Consumidor. MBA em Comunicação Digital pela Unibrasil (2015) e Graduada em Marketing pela Universidade Tuiuti do Paraná (2011). Experiência como professora do curso técnico em Administração para o Estado do Paraná. Com mais de 9 anos na área de Marketing em empresas de diversos setores como Telecom, Educação e Tecnologia.

\section{LUAN GOMES DE OLIVEIRA}

Bacharel em Economia pela Programa de Ciências Econômicas e Desenvolvimento Regional (PCEDR) da Universidade Federal do Oeste do Pará (UFOPA). Instituição: Universidade Federal do Oeste do Pará (UFOPA). 


\section{LUCIANA ROMANO MORILAS}

Possui graduação em Letras pela Universidade Estadual Paulista Júlio de Mesquita Filho (1995), graduação em Direito - Faculdades Integradas de São Carlos (2001), mestrado em Linguística e Língua Portuguesa pela Universidade Estadual Paulista Júlio de Mesquita Filho (1998) e doutorado em Linguística e Língua Portuguesa pela Universidade Estadual Paulista Júlio de Mesquita Filho (2003). Atualmente é professor doutor em RDIDP na Faculdade de Economia e Administração de Ribeirão Preto da Universidade de São Paulo (FEA-RP/USP), onde leciona variadas disciplinas de Direito para o curso de Administração - Direito do Trabalho, Direito Tributário, Direito Empresarial e Direito Internacional. Já teve diferentes interesses de pesquisa durante sua carreira, o que a posiciona com forte viés de pesquisa. Ultimamente, pesquisou programas de sustentabilidade (Projeto Last Minute Market, em conjunto com a Universidade de Bologna e financiado pela FAPESP) e também em Educação Internacional de 2012 a 2015. Atualmente coordena o grupo de pesquisa "Habeas Data - Centro de Estudos e Pesquisa em Jurimetria", que estuda possíveis aplicações do direito ao mundo dos negócios.

\section{LYGIA NATHÁLIA PEREIRA DA SILVA}

Mestre em Ciências Contábeis pela Universidade do Estado do Rio de Janeiro - UERJ (2016) e Graduada em Ciências Contábeis pelo Centro Universitário Augusto Motta - UNISUAM (2009). Na área de docência atualmente sou Professora/Tutora no Centro Universitário Augusto Motta UNISUAM, atuei como Professora de Contabilidade e Finanças na Universidade Federal Rural do Rio de Janeiro - UFRRJ, ministrando disciplinas de Contabilidade, Balanço Social, Avaliação de Atividades Atuariais e Matemática Financeira, além de orientação de alunos de graduação na elaboração de Trabalhos de Conclusão de Curso. No mercado trabalhei em prestadoras de serviço e indústrias de médio e grande porte. Possuo amplo conhecimento em contabilidade societária, controladoria, finanças e informações gerenciais.

\section{MAGNA DA SILVA VILANOVA CASTRO}

Graduanda em Administração pela Universidade Federal do Delta do Parnaíba

\section{MARALI SILVA SANTOS}

Mestranda em Desenvolvimento e Meio Ambiente (UFPI), MBA em Gestão Financeira, Auditoria e Controladoria, pela Fundação Getúlio Vargas - FGV - RJ (2010). E graduada em Bacharelado em Administração de Empresas pela Universidade Estadual do Piauí em 2008, em Ciências Contábeis pela Universidade Estadual do Piauí em 2015. E atualmente, atua como Professora de Ensino Básico, Técnico e Tecnológico no Instituto Federal do Maranhão - IFMA.

\section{MÁRCIO JÚNIOR BENASSULY BARROS}

Doutor em Geografia pela Universidade de Brasília (UNB), Instituição: Universidade Federal do Oeste do Pará (UFOPA).

\section{MARCOS PAULO ANDRADE SILVA}

Especialista em Finanças e Controladoria - UNOPAR (2019). Graduado em Administração pela Faculdade Atenas Maranhense - FAMA (2007). Atualmente exercendo os cargos de professor efetivo da Faculdade Vale do Aço - FAVALE, do Instituto de Ensino Profissionalizante Veneza e da Escola Técnica Imperador. Exerce também, na modalidade a distância, o papel de tutor presencial no Curso de Administração Pública da Universidade Estadual do Maranhão - UEMA (Núcleo de Tecnologias UEMANET). 


\section{MÁRIO TANAKA FILHO}

Doutor pelo Instituto Alberto Luiz Coimbra de Pós-Graduação e Pesquisa em Engenharia (CPPE) da Universidade Federal do Rio de Janeiro (UFRJ). Instituição: Universidade Federal do Oeste do Pará (UFOPA).

\section{MARLENE CATARINA DE OLIVEIRA LOPES MELO}

Bolsista Sênior do CNPq. Professora Titular do Centro Universitário Unihorizontes. Professora Titular aposentada da UFMG. Diretora de Ensino, Pesquisa e Extensão do Instituto Novos Horizontes de Ensino Superior e Pesquisa Ltda. Doutora em Ciências das Organizações pela Université Paris IX - Dauphine - França, mestrado em Administração pela UFMG, especialização - Diploma de Estudos Aprofundados - DEA, pela Université Paris IX - Dauphine - França, e bacharelado em Comunicação Social - Jornalismo pela UFMG. Coordenadora do Núcleo de Relações de Trabalho e Tecnologia de Gestão -NURTEG.

\section{MATHEUS MORAIS BRUNO}

Graduando em Administração pela Universidade Federal do Delta do Parnaíba

\section{MILLENA DE CARVALHO DA CUNHA}

Graduanda em Administração e participante do projeto PIBIC/UFRPE pela Universidade Federal Rural de Pernambuco (UFRPE), atuando no projeto "Concepções dos discentes do curso de Administração UFRPE-SEDE quanto a aceitação e uso de Sistemas de Informação". Atua nas seguintes áreas: sistemas de informação e inovação.

\section{MIRIAM BARBOSA SOARES}

Graduando Gestao PORTUÁRIA. Bacharel em Teologia, Capelã.

\section{NEEMIAS DA SILVA NASCIMENTO}

Técnico em Análises Química e graduando em Licenciatura em Química (sétimo de oito períodos) ambos pelo Instituto de Educação, Ciência e Tecnologia do Maranhão, Campus Zé Doca. Experiente em projetos sobre sustentabilidade, além de integrar o Grupo de Pesquisa em Análises Químicas Sustentáveis - GPAQS e o Grupo de Pesquisa em Gestão, Empreendedorismo, Consumo e Inovação GPGECI.

\section{PABLO PHORLAN PEREIRA DE ARAÚJO}

Especialista em Educação ambiental pelo Instituto Federal de Educação Ciência e Tecnologia - IFRN (2014). Especialista em Gestão de Pessoas pela Faculdade Católica Santa Teresinha - FCST (2013). Graduado em Administração pela Universidade do Estado do Rio Grande do Norte - UERN (2010). Servidor público da Prefeitura Municipal de Caicó-RN. Professor dos cursos de graduação e pósgraduação da Faculdade Católica Santa Teresinha. Coordenador do curso de graduação em administração da Faculdade Católica Santa Teresinha.

\section{PATRÍCIA LACERDA DE CARVALHO}

Professora Temporária no Departamento de Finanças e Contabilidade da Universidade Federal da Paraíba . Doutoranda em administração pela Universidade Federal da Paraíba . 


\section{PAULO RICARDO DE OLIVEIRA RAMOS}

Possui graduação em Humanidades pela Universidade Federal dos Vales do Jequitinhonha e Mucuri - UFVJM (2012) e pós-graduação de Mestre em Psicologia pela Universidade Federal do Amazonas UFAM (2018).

\section{PEDRO HENRIQUE DA SILVA TELES}

Graduado em administração pelo Instituto Federal da Paraíba.

\section{POLIANA KARINA FAUSTINO}

Graduada em Administração pela Faculdade Católica Santa Teresinha

\section{REBECA SÁ DO NASCIMENTO CARRAZZONI}

Professora na Faculdade Três Marias. Doutoranda em administração pela Universidade Federal da Paraíba .

\section{REGIANE ACILÉIA GONÇALVES LOPES}

Bacharel em Administração e atualmente trabalho com Marketing Digital.

\section{RHAYZA ALVES FIGUEIREDO DE CARVALHO}

Mestra em Ciências da Sociedade pelo Programa de Pós Graduação em Ciências da Sociedade (PPGCS) da Universidade Federal do Oeste do Pará (UFOPA), Instituição: Universidade Federal do Oeste do Pará (UFOPA).

\section{ROSANY CORRÊA}

Doutora em Administração pela UNINOVE. Professora TI do curso de Sistema de Informação da UESPI de Parnaíba. Instituição: UESPI e UNINASSAU.

\section{SALMO BATISTA DE ARAÚJO}

Especialista em Contabilidade Pública, Auditoria e Perícia (FCST). Especialista em Gestão Financeira (UFRN). Graduado em Ciências Contábeis pela Universidade Federal do Rio Grande do Norte Campus de Caicó RN. Coordenador e Professor do Curso de Ciências Contábeis da Faculdade Católica Santa Teresinha. Membro do NDE (Núcleo Docente Estruturante) do curso de Ciências Contábeis da Faculdade Católica Santa Teresinha.

\section{SÉRGIO DE OLIVEIRA LIMA}

Graduado em Ciências Contábeis pela Universidade Federal de Pernambuco (1997). Tem experiência na área de Direito, com ênfase em Pós Graduação Lato Sensu em Direito Público. Faculdade INESP. Graduado em Administração (UFRPE- 2019).

\section{SILVANA MARIA DE JESUS VETTER}

Doutora em Ciência da Informação - IBICT/UFRJ (2018). Mestre em Educação - UFMA (2006). Graduação em Biblioteconomia - UFMA (2002). Professora Adjunto I do Departamento de Biblioteconomia, da Universidade Federal do Maranhão (UFMA) (desde 2008). Coordenou o Curso de Especialização em Mídias na Educação, modalidade à distância. 


\section{SIMONE PORTELLA TEIXEIRA DE MELLO}

Doutora em Educação pelo PPGEDU - UFRGS e Pós-Doutora em Administração pelo PPGA - UFSC. Atualmente é professora associada da Faculdade de Administração e de Turismo da Universidade Federal de Pelotas e docente permanente do Programa de Pós-Graduação em Administração Pública em Rede, PROFIAP, na mesma instituição.

\section{SOLANGE CHIOSSI}

Cursando Pós graduação (EAD) em Direito Tributário pela Unoesc; Possui graduação em Ciências Contábeis, pela UNIDADE CENTRAL FAEM FACULDADES - UCEFF (2017). Tem experiência como atendente de caixa em Lotérica ( 2019). E atualmente trabalha como agente de atendimento caixa na Cooperativa Sicoob.

\section{STÊNIO LIMA RODRIGUES}

Mestrando em Desenvolvimento e Meio Ambiente (PRODEMA/UFPI). Exerce a função de Professor efetivo do Ensino Básico, Técnico e Tecnológico(EBTT) no Instituto de Educação, Ciência e Tecnologia do Maranhão(IFMA), Campus Codó. Possui especialização em Gestão Estratégica de Custos e Finanças (Prominas), Logística e Distribuição pela Universidade Federal do Piauí (UFPI) e graduação em Administração também pela UFPI.

\section{TIAGO DOUGLAS CAVALCANTE CARNEIRO}

Possui graduação em Administração pela Faculdade Católica Santa Teresinha (2012), é Especialista em Marketing e Gestão Estratégica pela Universidade Cândido Mendes - EAD (2014), e em Gestão Empresarial pela a Faculdade Católica Santa Teresinha (2015). Desenvolveu atividades de gerenciamento e planejamento como gerente administrativo. Lecionou cursos profissionalizantes no SENAC e atualmente é professor dos cursos de Administração e Ciências Contábeis e Coordenador dos Cursos de Pós-graduaç̧ões da Faculdade Católica Santa Teresinha - FCST.

\section{TIAGO FRANCISCO CAMARGO}

Possui 12 anos de experiência profissional relacionado as áreas: Comercial (vendas internas e externas) com treinamento de equipes para gestão de performance e metas; atuando em empresas como: VIVO TELECOM, CLARO TELECOM e DPASCHOAL (GOODYEAR). Nos aspectos Gerenciais e Administrativos foi durante 3 anos gestor da Empresa NutriFrutas Comercio e Transporte (logística) entre 2007-2010; Entre 2012 e 2013 trabalhou na Secretaria da Fazenda do Rio Grande do Sul (SEFAZ-RS) na agência de Rio Grande/ RS. Possui aptidão para empreender, é sócio da Business Center; está sempre se relacionando com empresas na busca de melhores soluções para problemas relacionados com: dificuldades na organização da Gestão-processos; Comercial (treinamento de equipes e atendimento de metas) em aspectos Contábeis, organiza plano de contas, orçamento base zero e planejamento tributário. Formou-se técnico em informática em 2001 ? Brasil Sul Informática; Entre 2011 e 2014 graduou-se em Ciências Contábeis pela Universidade Federal do Rio Grande; cursou o último semestre de graduação na Universidad de Girona (UDG) em Girona (Es) em 2014. Entre 2012 e 2015 formou tecnólogo em Seguros todos os ramos, Previdência Privada e Vida pela Funenseg- RJ. Entre 2015 e 2017 formou-se no Mestrado em Administração e Ciências Contábeis pela Unochapecó; Foi tutor em Contabilidade de Custos 1,2,3 entre os anos de 2013 e 2014 na Universidade Federal do Rio Grande; Em 2017.2 ingressou como professor na Uceff, para disciplina de Teoria da Contabilidade na modalidade Semipresencial e Orientações; em 2018.1 também ministra a disciplina de Engenharia Econômica e Financeira, além de orientações para projetos de TCC. É autor de 17 artigos publicados em anais de congresso e eventos internacionais, nacionais, regionais e locais. Possui 5 artigos publicados em revistas qualis B3 capes; e 1 artigo em Journal international com qualis A1 capes. 


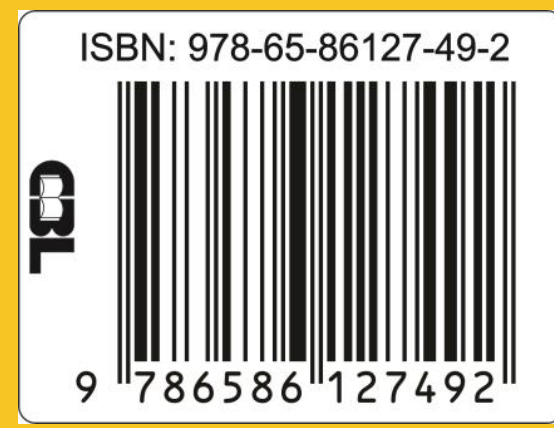

